Ayşe Uygun-Altunbaş

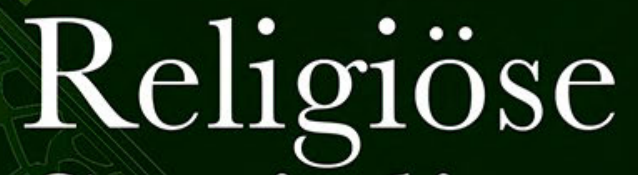

Sozialisation

in muslimischen

Familien

Eine vergleichende Studie 
Ayşe Uygun-Altunbaş

Religiöse Sozialisation in muslimischen Familien 
Ayşe Uygun-Altunbaş, geb. 1977, studierte Erziehungswissenschaften und Soziologie in Heidelberg und promovierte an der Fakultät für Bildungswissenschaften der Universität Duisburg-Essen. 
Ayşe Uygun-Altunbaş

\section{Religiöse Sozialisation \\ in muslimischen Familien}

Eine vergleichende Studie

[transcript] 
Dem Fachbereich Bildungswissenschaften der Universität Duisburg-Essen zur Erlangung des akademischen Grades Dr. phil. vorgelegte Dissertation unter dem Originaltitel

»Religiöse Sozialisation und religiöse Erziehung in muslimischen Familien«

Erschienen im transcript Verlag 20I7

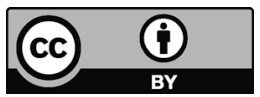

Dieses Werk ist lizenziert unter der Creative Commons Attribution 4.0 (BY). Diese Lizenz erlaubt unter Voraussetzung der Namensnennung des Urhebers die Bearbeitung, Vervielfältigung und Verbreitung des Materials in jedem Format oder Medium für beliebige Zwecke, auch kommerziell.

(Lizenztext: https://creativecommons.org/licenses/by/4.o/deed.de)

Die Bedingungen der Creative Commons Lizenz gelten nur für Originalmaterial. Die Wiederverwendung von Material aus anderen Quellen (gekennzeichnet mit Quellenangabe) wie z.B. Schaubilder, Abbildungen, Fotos und Textauszüge erfordert ggf. weitere Nutzungsgenehmigungen durch den jeweiligen Rechteinhaber.

\section{Bibliografische Information der Deutschen Nationalbibliothek}

Die Deutsche Nationalbibliothek verzeichnet diese Publikation in der Deutschen Nationalbibliografie; detaillierte bibliografische Daten sind im Internet über http://dnb.d-nb.de abrufbar.

(C) Ayşe Uygun-Altunbaş

Umschlaggestaltung: Kordula Röckenhaus, Bielefeld

Umschlagabbildung: Serge Zimniy, fotolia.com

Satz: Justine Buri, Bielefeld

Druck: Majuskel Medienproduktion GmbH, Wetzlar

Print-ISBN 978-3-8376-4047-2

PDF-ISBN 978-3-8394-4047-6

Gedruckt auf alterungsbeständigem Papier mit chlorfrei gebleichtem Zellstoff.

Besuchen Sie uns im Internet: http://www.transcript-verlag.de

Bitte fordern Sie unser Gesamtverzeichnis und andere Broschüren an unter:info@transcript-verlag.de 


\section{Inhalt}

Danksagung | 11

I. Einleitung $\mid 13$

II. Religiöse Sozialisation und religiöse Erziehung in muslimischen Familien | 19

1. Muslime in Deutschland $\mid 19$

1.1 Die Ausgangslage in Zahlen und Fakten $\mid 20$

1.2 Muslimische Familien $\mid 22$

1.3 Die Religiosität von Muslimen 26

1.4 Muslimische Organisationen und Vereine 29

2. Stand der Forschung $\mid 34$

2.1 Religiöse Sozialisation in der Forschung | 34

2.1.1 Religiöse Sozialisation in Familien - Ergebnisse aus Expertisen, Berichten und Untersuchungen $\mid 35$

2.1.2 Das Aufwachsen in muslimischen Familien Ergebnisse aus empirischen Untersuchungen 146

2.1.3 Zusammenfassung $\mid 6_{1}$

2.2 Religiöse Sozialisation in anderen Kontexten | 68

2.2.1 Im Kontext von außerschulischen Bildungseinrichtungen $\mid 68$

a) Außerschulische religiöse Bildungseinrichtungen in Moscheen und Vereinen 169

b) Erfahrungen der Jugendlichen mit religiösen Bildungseinrichtungen $\mid 71$

2.2.2 Muslimische Kinder und Jugendliche im Kontext institutioneller Bildungseinrichtungen $\mid 74$

a) Empirische Ergebnisse zu den Erfahrungen mit dem Islam im schulischen Kontext $\mid 76$

b) Islamischer Religionsunterricht (IRU) an deutschen Schulen $\mid 82$ 
c) Muslimische Kinder in Kindertagesstätten und Kindergärten $\mid 85$

2.2.3 Peergroups, Freundschaften und das Verhältnis zu Andersgläubigen | 88

2.2.4 Die Medien $\mid 93$

2.3 Schlussfolgerungen und Forschungsleitfragen 95

3. Analytischer Bezugsrahmen $\mid 102$

3.1 Was ist religiöse Sozialisation? | 103

3.1.1 Religiöse Sozialisation als eine Dimension der allgemeinen Sozialisation | 103

3.1.2 Sozialisation $\mid 105$

a) Sozialisation: einige Grundannahmen zum Sozialisationsprozess | 105

b) Sozialisation als produktive Verarbeitung der Realität | 108

3.1.3 Religiöse Sozialisation in der Familie $\mid 112$

a) Sozialisation und Erziehung $\mid 113$

b) Was ist Erziehung? Eine Annäherung an die Begriffsbestimmung | 114

c) Was ist religiöse Erziehung? | 117

d) Exkurs: normative Grundüberlegungen zur religiösen Erziehung im Islam | 119

3.1.4 Die Entstehung von Religiosität im Rahmen der Sozialisation | 125

a) Was ist Religiosität? Zur operationalen Definition von Religiosität | 125

b) »Dimensionen der Religiosität« nach Glock als heuristisches Analyseinstrument | 126

3.2 Folgerungen für den Untersuchungszusammenhang | 131

III. Empirische Untersuchung | 135

1. Methodik $\mid 135$

1.1 Die Begründung der Erhebungsmethode | 135

1.2 Das Erkenntnisinteresse/Erläuterungen zum Interviewleitfaden | 136

1.3 Die Auswahl der Probanden und Probandinnen | 141

1.4 Die Beschreibung der Untersuchungsgruppe 143

1.5 Die Datenerhebung (Planung und Durchführung) | 145

2. Auswertung der Interviews 148

2.1 Arbeitsschritte der Auswertung | 148

2.2 Die Auswertungsmethode $\mid 150$

2.3 Die Typenbildung $\mid 153$

3. Typologie religiöser Erziehungsvorstellungen $\mid 155$ 
3.1 Religiöser Erziehungstyp, der nach Sinn und Orientierung strebt »Idealisten « 155

3.2 Religiöser Erziehungstyp, bei dem die Einhaltung von religiösen Vorschriften von zentraler Bedeutung ist - २Ritualisten «| 168

3.3 Religiöser Erziehungstyp, der Identität und Persönlichkeit in den Vordergrund stellt - »Identitätssucher « 176

3.4 Religiöser Erziehungstyp, der sich ethischen Grundsätzen verpflichtet - »Ethiker«| 184

4. Die Religiöse Erziehung in den Familien $\mid 202$

4.1 Religiöse Erziehung in den Familien der »Idealisten « 204

4.1.1 Die Religiosität in den Familien der »Idealisten«| 204

4.1.2 Die Erziehungsmethoden und Erziehungsstile in den Familien der »Idealisten «| 218

4.2 Religiöse Erziehung in den Familien der »Ritualisten « 229

4.2.1 Die Religiosität in den Familien der »Ritualisten «| 229

4.2.2 Die Erziehungsmethoden und Erziehungsstile in den Familien der »Ritualisten $\ll \mid 242$

4.3 Religiöse Erziehung in den Familien der »Identitätssucher« 249

4.3.1 Die Religiosität in den Familien der »Identitätssucher«| 249

4.3.2 Die Erziehungsmethoden und Erziehungsstile in den Familien der »Identitätssucher« $\mid 258$

4.4 Religiöse Erziehung in den Familien der »Ethiker« $\mid 265$

4.4.1 Die Religiosität in den Familien der »Ethiker« $\mid 265$

4.4.2 Die Erziehungsmethoden und Erziehungsstile in den Familien der »Ethiker«| 286

5. Religiöse Sozialisation in anderen Kontexten | 302

5.1 Bedeutung und Stellenwert der Sozialisationsinstanzen | 302

5.1.1 Das Verhältnis der »Idealisten« zu den Sozialisationsinstanzen $\mid 303$

5.1.2 Das Verhältnis der »Ritualisten« zu den Sozialisationsinstanzen $\mid 306$

5.1.3 Das Verhältnis der »Identitätssucher« zu den Sozialisationsinstanzen $\mid 307$

5.1.4 Das Verhältnis der »Ethiker« zu den Sozialisationsinstanzen | 310

5.2 Religiöse Erziehung in außerschulischen

Bildungseinrichtungen $\mid 312$

5.2.1 Religiöse Bildungsangebote und -inhalte, die die Kinder der »Idealisten « wahrnehmen | 314

5.2.2 Religiöse Bildungsangebote und -inhalte, die die Kinder der »Ritualisten« wahrnehmen | 318 
5.2.3 Religiöse Bildungsangebote und -inhalte, die die Kinder der »Identitätssucher« wahrnehmen | 323

5.2.4 Religiöse Bildungsangebote und -inhalte, die die Kinder der »Ethiker« wahrnehmen | 325

5.3 Muslimische Kinder und Jugendliche im Kontext von institutionellen Bildungseinrichtungen | 329

5.3.1 Wahrnehmungen und Erwartungen der »idealistischen« Eltern | 330

5.3.2 Wahrnehmungen und Erwartungen der »ritualistischen« Eltern | 344

5.3.3 Wahrnehmungen und Erwartungen der »Identitätssucher« $\mid 352$

5.3.4 Wahrnehmungen und Erwartungen der »Ethiker« $\mid 360$

5.4 Peers, Freundschaften und deren Einfluss auf die religiöse Sozialisation $\mid 371$

5.4.1 Peers und Freundschaften - die »Idealisten « 372

5.4.2 Peers und Freundschaften - die »Ritualisten « $\mid 375$

5.4.3 Peers und Freundschaften - die »Identitätssucher« $\mid 377$

5.4.4 Peers und Freundschaften - die »Ethiker« $\mid 378$

5.5 Der Einfluss der Medien auf die religiöse Sozialisation | 381

5.5.1 Der Umgang mit den Medien - die »Idealisten« $\mid 382$

5.5.2 Der Umgang mit den Medien - die »Ritualisten « $\mid 386$

5.5.3 Der Umgang mit den Medien - die »Identitätssucher« 1389

5.5.4 Der Umgang mit den Medien - die »Ethiker« $\mid 392$

5.6 Die religiöse Sozialisation in einer pluralistischen

Gesellschaft $\mid 396$

5.6.1 Die religiöse Sozialisation in der Gesellschaft die »Idealisten « | 397

5.6.2 Die religiöse Sozialisation in der Gesellschaft die »Ritualisten $\ll \mid 403$

5.6.3 Die religiöse Sozialisation in der Gesellschaft die »Identitätssucher« $\mid 408$

5.6.4 Die religiöse Sozialisation in der Gesellschaft die »Ethiker« | 412

6. Zusammenfassung der wichtigsten Ergebnisse aus der Untersuchung $\mid 418$

6.1 Die Typen religiöser Erziehung | 419

6.2 Religiöse Erziehung/Religiosität in den Familien | 425

6.3 Religiöse Sozialisation in anderen Kontexten | 434

6.3.1 Religiöse Erziehung in außerschulischen

Bildungseinrichtungen | 434 
6.3.2 Muslimische Kinder im Kontext von institutionellen Bildungseinrichtungen $\mid 437$

6.3.3 Die Peers, Freundschaften und deren Einfluss auf die religiöse Sozialisation $\mid 439$

6.3.4 Der Einfluss der Medien auf die religiöse Sozialisation | 441

6.3.5 Die religiöse Sozialisation in einer pluralistischen Gesellschaft | 443

\section{Schlussfolgerungen 447}

\section{Literatur $\mid 459$}

\section{Anhang $\mid 471$}

Anhang 1: Interviewleitfaden $\mid 471$

Anhang 2: Die Untersuchungsgruppe nach Typenzuordnung/

Angaben über Kinder der Interviewten $\mid 476$

Anhang 3: Tabelle (1) Religiöse Erziehungstypen und die Einflüsse auf die religiöse Sozialisation $\mid 477$

Tabelle (2) Spezifika der religiösen Erziehung in der Familie/ Ausprägungen der Religiosität in der Familie nach religiösen Erziehungstypen $\mid 480$ 



\section{Danksagung}

Ich möchte mich bei allen Personen, die auf vielfältige Art und Weise zur Entstehung dieser Arbeit beigetragen haben, bedanken. Danken möchte ich meiner Doktormutter Prof. Dr. Ursula Boos-Nünning für die engagierte und fachlich fundierte Betreuung dieser Dissertation. Mit der Erforschung der »religiösen Sozialisation « begab ich mich auf ein wissenschaftlich anspruchsvolles interdisziplinäres Forschungsfeld. Ihr breites Wissen und ihr Erfahrungsschatz waren wichtige Wegweiser, um die vorliegende Thematik in einer sehr eigenständigen Weise zu bearbeiten. Nicht zuletzt gilt ihr mein besonderer und aufrichtiger Dank für das Interesse, das sie in mir für das Thema der Erforschung von »Religiosität« geweckt hat. Ohne die Erfassung und Charakterisierung dessen hätte das alleinige Aufzeigen religiöser Sozialisationsvorgänge nicht die notwendige Tiefe erreicht, die jenseits des gestellten wissenschaftlichen Anspruchs zu meiner inneren Zufriedenheit beigetragen hat. Mein herzlicher Dank gilt auch Prof. Dr. Margit Stein für die Begutachtung dieser Arbeit, die doch keinen geringen Umfang aufweist. Danken möchte ich ihr für ihr sorgfältig erarbeitetes Gutachten und das mir entgegengebrachte Vertrauen, um diese Arbeit letztlich »mit Auszeichnung zu versehen. Danken möchte ich auch Prof. Dr. Harry Harun Behr, der mir vor allem zu Beginn meiner Dissertation eine wichtige Stütze hinsichtlich religionspädagogischer Fragestellungen gewesen ist. Dem Forschungszentrum für Religion und Gesellschaft (forege) und der DITIB möchte ich für die nötige finanzielle Unterstützung danken, mittels derer ich auch stets an meine Verantwortung erinnert wurde, diese Arbeit zu einem guten und gelungenen Abschluss zu bringen. Schließlich möchte ich mich vor allem bei den Eltern bzw. den Interviewteilnehmer(inne)n bedanken, die diese Untersuchung mit ihrer freundlichen Unterstützung erst ermöglicht haben.

Meinem Ehemann Ahmet Altunbaş möchte ich für seine Geduld, seine Motivation und die Ermutigungen in den schwierigen Phasen auf dem Weg zu dieser Arbeit danken. Danken möchte ich ihm auch für die Wertschätzung, die er für meinen wissenschaftlichen Werdegang aufbringt. 



\section{Einleitung}

Die seit dem Beginn der Migration einsetzende verstärkte Präsenz der Muslime in Deutschland hat die wissenschaftliche Forschung mit unterschiedlichen Themenstellungen und Schwerpunkten beschäftigt. Hierbei war die Religiosität der Muslime, insbesondere in den letzten zwei Jahrzehnten, Gegenstand vieler Untersuchungen. Die Studien beschreiben hier mit unterschiedlichen wissenschaftlich-theoriegeleiteten Ansätzen und angewandten Methoden Einstellungs- und Verhaltensmuster der muslimischen Bevölkerung, die sich in Deutschland mit einer aktuell geschätzten Zahl von etwa vier Millionen in einer Minderheit befinden und momentan bereits in der vierten Generation in diesem Land leben. Die wissenschaftlichen Untersuchungen konzentrieren sich auf Muslime verschiedenen Alters und Geschlechts und rücken dabei ihren Fokus sowohl auf Jugendliche als auch auf Erwachsene. Die Entstehung von Religiosität, die in Form von religiöser Erziehung oder Sozialisation an sie herangetragen wurde, wird in diesen Untersuchungen jedoch kaum thematisiert bzw. nur am Rande aufgegriffen. Auch kommen die befragten Probanden und Probandinnen nicht in ihren Rollen als Väter oder Mütter zu Wort, die es erlauben würden, Rückschlüsse auf ihre Familienreligiosität als Folge und Resultat religiöser Sozialisationsprozesse zu ziehen. Daher rückt die vorliegende Untersuchung erstmalig »Familien« in den Fokus der Betrachtung, mittels derer die Perspektive muslimischer Eltern aufgegriffen und Aussagen über die religiöse Erziehung und Sozialisation ihrer Kinder getroffen werden sollen.

Damit stellt sich auch die Frage, über welchen »muslimischen« Bevölkerungsteil oder welche »muslimischen Familien« von der Gesamtheit der in Deutschland lebenden Muslime in dieser Untersuchung gesprochen wird. Oder anders gefragt: Was verbirgt sich hinter dem Attribut »muslimisch«, wenn die statistische Erfassbarkeit der Muslimen insgesamt Probleme birgt und damit Aussagen über die zahlenmäßige Präsenz der Muslimen erschwert werden (vgl. Boos-Nünning 2015)? Die begriffliche Verwendung »muslimisch « erweist sich als irreführend, wenn keine angemessene Beschreibung bzw. Bestimmung dessen, über wen oder was gesprochen wird, erfolgt ist (vgl. Spielhaus 2013). Dabei zeigt sich, dass die alleinige Religionszugehörigkeit (»Mus$\mathrm{lim} \ll)$ als Kriterium, ohne Angaben über eindeutige religiöse Bezüge,wie z.B. 
das persönliche Verhältnis des Einzelnen zur Religion und damit zu seiner Religiosität, nicht ausreicht, um generalisierbare Aussagen über »Muslime« insgesamt treffen zu können. ${ }^{1}$ Diese Problematik betrifft nicht zuletzt auch einige Expertisen über »muslimische Familien«, die im Forschungsstand näher betrachtet werden.

Gerade vor diesem Hintergrund ist es wichtig, zu bestimmen, auf welche Gruppe innerhalb der muslimischen Bevölkerung sich die Dissertation konzentriert. Die vorliegende Untersuchung befasst sich mit muslimischen Familien bzw. Eltern mit türkischem Migrationshintergrund. Sie erkundet sowohl die religiöse Erziehung in den Familien, als einen Bestandteil des religiösen Sozialisationsprozesses, als auch den Einfluss weiterer Sozialisationsinstanzen auf die religiöse Entwicklung von muslimischen Kindern und Jugendlichen; sie berücksichtigt dabei mit ihrer qualitativen Vorgehensweise subjektive Deutungsmuster von muslimischen Eltern, die einen türkischen Migrationshintergrund ${ }^{2}$ aufweisen. Es sind Eltern der zweiten Generation ${ }^{3}$, die zum Teil in Deutschland geboren und aufgewachsen sind und dem Islam mit sunnitischer Ausrichtung angehören. Zudem sind unter ihnen Mütter oder Väter, die kürzlich, bedingt durch Heirat, nach Deutschland eingewandert sind. Folglich wurden die Interviews zum Teil auch auf Türkisch geführt. Es befinden sich unter ihnen auch Mütter, die über pädagogische Hochschulabschlüsse verfügen. Als Expertinnen haben sie eine hohe Reflexionsbereitschaft bzgl. der in der Untersuchung angesprochenen Themenbereiche, die sich zugleich in einer hohen Artikulationsfreudigkeit äußert. Die Bereitschaft von Pädagoginnen, an dieser Untersuchung teilzunehmen, war hoch, bildete es doch einen gewissen Reiz, sich wissenschaftlich mit dem vorliegenden Thema zu befassen. Jedoch lag es im Interesse dieser Arbeit, möglicherweise auch weniger wissenschaftlich fundierte Einstellungen zuzulassen, sodass die Zahl der Pädagoginnen niedrig gehalten wurde.

1 | Vgl. Kap. II.1.1.

2 | Die Beschränkung der Untersuchungsgruppe auf Menschen und Muslime mit türkischem Migrationshintergrund erfolgte vor dem Hintergrund, dass sich im Islam - je nach kultureller Prägung - sehr unterschiedliche Formen von Religiosität entwickelt haben (vgl. Karakaşoğlu-Aydın 2000:7). Auch spielte der persönliche Erfahrungshintergrund der Verfasserin dieser Arbeit eine wichtige Rolle, die aufgrund ihrer Zugangsmöglichkeiten (das Beherrschen der türkischen Sprache, das Aufwachsen in religiösen Gemeinden mit türkischer Prägung, Erfahrungen im Umgang mit religiösen Themen) (vgl. hierzu III. 1.3) ein größtmögliches Verständnis für die vorliegende Thematik zu erzielen suchte.

3 | Es ist mir durchaus bewusst, dass der Begriff "Generation" in der Migrationsforschung umstritten ist, da aktuell durch Heirat bedingte Migrantinnen und Migranten auch als Zuwanderer der ersten Generation bezeichnet werden. Folglich sind hier die Kinder der ersten Migrantinnen und Migranten gemeint, die etwa zu Beginn der 1960er-Jahre nach Deutschland eingewandert sind. 
Die Auswahl der Untersuchungsgruppe erfolgte nach verschiedenen vorab festgelegten Kriterien, wie z.B. nach dem Alter eines Elternteils, das zwischen 21-45 Jahren betragen sollte. Stellvertretend für die gesamte Familie wurde jeweils ein Elternteil, entweder Vater oder Mutter, einer Familie befragt. Ein grundsätzliches Interesse für die Weitergabe einer religiösen Erziehung an die eigenen Kinder war die wesentlichste Voraussetzung für die Teilnahme an den Interviews. Damit wollte man gewährleisten, dass sowohl ein breites Spektrum an religiösen Erziehungsvorstellungen mit ihren norm- und handlungsleitenden Prinzipien als auch die Darstellung unterschiedlicher sozialisationsrelevanter Einflüsse, die die Religiosität von muslimischen Kindern und Jugendlichen maßgeblich beeinflussen, aufgezeigt werden. Erst die Erfassung der Zieldimension einer religiösen Erziehung und damit der Bedeutung von religiöser Erziehung für Eltern ermöglicht eine wissenschaftlich fundierte Einordnung religiöser Erziehungsvorstellungen in Form einer Typenbildung. Es gilt daher, zu überprüfen, welche Formen religiöser Erziehung bzw. welche religiösen Erziehungstypen ermittelbar sind und wie sich diese jeweils zu den verschiedenen Sozialisationseinflüssen und Sozialisationsinstanzen verhalten.

Demzufolge ist das Ziel dieser Untersuchung, herauszufinden, welchen fördernden oder hemmenden Einfluss andere zentrale Sozialisationsinstanzen neben der Familie als primärer Sozialisationsinstanz, wie außerschulische Bildungseinrichtungen (Moscheen oder ähnliche Bildungseinrichtungen), Schulen oder Kindertagesstätten, die Peers, Medien und Gesellschaft, auf die religiöse Sozialisation von muslimischen Kindern ausüben. Ausgehend von diesem Erkenntnisinteresse, lassen sich folgende forschungsleitende Fragen bestimmen:

- Welche Erziehungsziele verbinden muslimische Eltern mit ihrer religiösen Erziehung im familiären Rahmen?

- Welche Formen religiöser Erziehung lassen sich hieraus ableiten?

- Wie äußert sich ihre subjektiv vermittelte religiöse Erziehung in ihrer (Familien-)Religiosität?

- Welche Merkmale und Eigenschaften hat ihre Religiosität und in welchen Dimensionen wird diese deutlich und sichtbar?

- In welcher Art und Weise vermitteln sie ihre Religion an ihre Kinder?

- Welche Rolle und welchen Stellenwert nehmen die oben aufgeführten Sozialisationsinstanzen für die religiöse Sozialisation ihrer Kinder ein?

- Welche fördernden oder hemmenden Effekte gehen von ihnen aus?

Die Untersuchung gliedert sich in mehrere Teile:

In Kapitel II wird zunächst ein (Teil 1) Überblick über die Ausgangssituation von Muslimen bzw. muslimischen Familien in Deutschland gegeben. Dieser zeigt die Besonderheiten und Strukturen der Muslime in Deutschland und in spezifischer Weise der Muslime mit türkischem Migrationshintergrund auf. 
Dabei sollen einige sozialstrukturellen Merkmale von Migrationsfamilien dargestellt und ein Bezug zu ihrer Religiosität hergestellt werden. Zudem wird die Bedeutung von muslimischen Organisationen und Vereinen näher erörtert.

Der Forschungsstand (Teil 2) besteht aus einer kritischen Analyse der Sekundärliteratur, die das Thema der religiösen Sozialisation und religiösen Erziehung bei Muslimen und im Speziellen in muslimischen Familien tangiert bzw. in den meisten Fällen nur kurz skizziert. Auch wenn es kaum Untersuchungen zu dieser Thematik gibt, die die religiöse Sozialisation in den Familien aufzeigen, konnten anhand von verschiedenen Quellen die Erziehungswirklichkeit, die Religiosität und einzelne Aspekte der religiösen Sozialisation in muslimischen Familien rekonstruiert werden. Es existieren a) Expertisen, Rezeptionsberichte bzw. Literaturanalysen oder b) Untersuchungen, die - wenn auch in sehr geringem Umfang - die Sicht der Eltern auf religiöse Erziehungsvorstellungen wiedergeben oder c) Untersuchungen über die Religiosität von Jugendlichen, aus denen hervorgeht, wie die elterliche Erziehung von ihnen wahrgenommen wurde und wie sie ihre zukünftige religiöse Erziehung ausrichten wollen. Schließlich konnten damit immer nur Teilaspekte der religiösen Erziehung und Sozialisation in Familien thematisiert werden. Die vorliegende Untersuchung beabsichtigt jedoch eine umfassende, verschiedene Sozialisationskontexte berücksichtigende Darstellung von Ergebnissen, die die religiöse Sozialisation in muslimischen Familien aus der Perspektive von Eltern wiedergibt. Der Forschungsstand zur religiösen Sozialisation in anderen Sozialisationskontexten ${ }^{4}$ (auch: Sozialisationsinstanzen) beinhaltet einen Überblick über den Stellenwert und die Bedeutung dieser Einrichtungen für die religiöse Sozialisation.

Im analytischen Bezugsrahmen (Teil 3) werden die Begrifflichkeiten aufgeführt, die der Bestimmung von Untersuchungsbereichen und den zentralen Untersuchungskategorien dienen. Da theoretische Ansätze zur Erklärung der religiösen Sozialisation von Muslimen noch nicht entwickelt sind, wurde hier insbesondere darauf geachtet, die Begrifflichkeiten und Definitionen von »Sozialisation« oder »religiöser Sozialisation« so allgemein wie möglich wiederzugeben, um sie für eine sozialwissenschaftliche Analyse und Auswertung brauchbar zu machen. Die »religiöse Erziehung « bildet eine weitere zentrale Untersuchungskategorie, deren Erforschung in der vorliegenden Untersu-

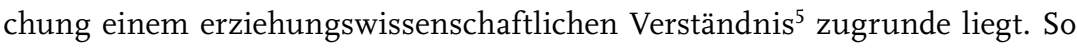

4 | Die Begriffe "Sozialisationsinstanz" und "Sozialisationskontext" werden hier synonym verwendet. Der Begriff "Sozialisationskontext" zielt stärker auf ein Umfeld ab, sodass er im weiteren Verlauf dieser Studie bevorzugt verwendet wird (vgl. Erläuterungen in Kap. II. 3.1.2).

5 | Die Untersuchung der religiösen Erziehung greift schließlich auch in den Fachbereich der islamischen Religionspädagogik über, der einen interdisziplinären Zugang 
werden in dieser Untersuchung auch (deskriptiv) normative Grundüberlegungen zur religiösen Erziehung im Islam wiedergegeben, die zum besseren Verständnis des Forschungsgegenstandes beitragen sollen. Zur Erfassung von Kennzeichen und Merkmalen der (Familien-)Religiosität, als Ausdruck einer subjektiv vermittelten religiösen Erziehung, wird außerdem Glocks mehrdimensionaler Ansatz der Religiosität herangezogen. Dieser hat die Funktion eines heuristischen Analyseinstrumentes.

Kapitel III bildet den Kern der vorliegenden Arbeit. Es umfasst die empirische Untersuchung zur religiösen Sozialisation und religiösen Erziehung in muslimischen Familien. Zu Beginn wird die Methodik der Arbeit vorgestellt, um die Vorgehensweise in der Untersuchung aufzuzeigen. Es wurde zunächst anhand der Zieldimension einer religiösen Erziehung, die als Untersuchungskategorie dem analytischen Bezugsrahmen (Teil 2 im zweiten Kapitel) zu entnehmen ist, eine Typisierung der in der Untersuchungsgruppe vorgefundenen religiösen Erziehungsvorstellungen vorgenommen. Die Ermittlung von religiösen Erziehungstypen ermöglichte in einem weiteren Schritt, vor dem Hintergrund der in Kapitel II aufgeführten Erkenntnisse aus dem Forschungsstand bzw. der Sekundärliteraturanalyse und des analytischen Bezugsrahmens, eine Untersuchung der religiösen Erziehung und Religiosität in den Familien und zu weiteren Untersuchungsbereichen bzw. Sozialisationskontexten. So konnten sowohl Ergebnisse über typspezifische Merkmale und Kennzeichen der Religiosität, über Methoden und Vermittlungsformen der religiösen Erziehung in den Familien, als auch über das Verhältnis und die Einstellungen der religiösen Erziehungstypen zu den anderen Sozialisationskontexten verzeichnet werden. Am Ende der Untersuchung wird schließlich eine typübergreifende Zusammenfassung der Ergebnisse aus der empirischen Untersuchung wiedergegeben.

In Kapitel IV werden Schlussfolgerungen aus den Ergebnissen abgeleitet und es erfolgt ein Ausblick auf mögliche weiterführende Untersuchungen.

zum Forschungsgegenstand nahelegt. So erscheint der Bezug zu den islamischen Wissenschaften oder ein Theologiebezug allein schon aufgrund der Normativität einer religiösen Erziehung folgerichtig. Im Vergleich dazu ist diese Arbeit eher sozialwissenschaftlich ausgerichtet, weist jedoch auch eine religionswissenschaftliche und religionspädagogische Komponente auf. 



\section{Religiöse Sozialisation und religiöse Erziehung in muslimischen Familien}

\section{Muslime in Deutschland}

In diesem Kapitel wird zunächst die Ausgangssituation der Muslime geschildert. Da die vorliegende Studie sich auf die Situation der türkischstämmigen Muslime mit sunnitischer Ausrichtung des Islams konzentriert, wird bei der Beschreibung der Fokus auf diese Gruppe gerichtet. Die Merkmale dieser Gruppe werden nach den für die vorliegende Studie bedeutsamen Kriterien beschrieben.

Es geht zunächst darum, sich einen Überblick über die zahlenmäßige Präsenz von Muslimen und im Speziellen von Muslimen mit türkischem Migrationshintergrund in Deutschland zu verschaffen. Die statistische Erfassbarkeit von muslimischen Familien birgt jedoch einige Probleme, sodass sozialstrukturelle Daten über sie vorwiegend aus Untersuchungen zu türkischen Migrationsfamilien entstammen.

Ein Blick auf die Religiosität der Muslime mit türkischem Migrationshintergrund zeigt, welche Aspekte des Islams für diese von Bedeutung sind. Schließlich werden die Organisationsstrukturen von Muslimen vorgestellt. Neben den religiösen Dachverbänden, die sich im Migrationsverlauf etabliert haben, werden die Rolle und die Funktionen der ihnen zugehörigen religiösen Gemeinden aufgezeigt. Sie gelten als Orte, in denen ein nicht unbedeutender Teil der religiösen Sozialisation von Kindern und Jugendlichen stattfindet und mit denen die Mehrheit der befragten Eltern dieser Untersuchung in Verbindung steht. 


\subsection{Die Ausgangslage in Zahlen und Fakten}

Der Islam in Deutschland lässt sich in der Geschichte ${ }^{1}$ auch schon vor den $1960 e r-J a h r e n$ vereinzelt vorfinden. Jedoch hat die zahlenmäßig bedeutende Präsenz von Muslimen erst in den $1960 e r-J a h r e n$ mit der Arbeitsmigration aus der Türkei, dem ehemaligen Jugoslawien und aus Nordafrika eingesetzt. In späteren Jahren kamen zudem Kriegsflüchtlinge aus unterschiedlichen muslimisch geprägten Ländern, wie bspw. Bosnien, Irak, Iran, Afghanistan und neuerdings aus Syrien u.a., hinzu. Deutschland bietet spätestens seit den Migrationswellen der 1980er-Jahre ein Bild religiöser und multikultureller Vielfalt. Die Muslime in Deutschland bilden eine heterogene Gruppe unterschiedlicher nationaler Herkunft mit einer bunten Mischung muslimischen Lebens. ${ }^{2}$

Die Mehrheit der Muslime in Deutschland hat einen türkischen Migrationshintergrund. Es handelt sich bei den türkischen Muslimen zumeist um Arbeitsmigranten, die - wie oben erwähnt- im Zuge des Anwerbeabkommens in den

$1960 e r-J a h r e n$ nach Deutschland kamen. Arbeit ist unter den muslimischen Türken ein wichtiger Migrationsgrund und die wenigsten von ihnen verfügen über einen hohen Bildungsabschluss. Sie wurden zumeist als Hilfsarbeiter in Fabriken eingesetzt und verfolgten das Ziel, nach einiger Zeit in ihre Heimat zurückzukehren. Der Grund hierfür lag zunächst an lediglich befristeten Arbeitsverträgen. Erst mit der zunehmend längeren Aufenthaltsdauer wurden letztendlich auch die restlichen Familienmitglieder nach Deutschland geholt, wodurch die Zahl der Muslime insgesamt stark zunahm (vgl. Seifert 2012).

Mit dem Nachzug der Familien stieg auch die Bedeutung des Islams. Die erlebte Fremdheit förderte innerhalb der nach Deutschland geholten Familien eine Orientierung nach eigenen kulturellen und religiösen Werthaltungen, die insbesondere der Wahrung der eigenen Identität dienen sollte. Dies erklärt u.a., warum das Leben vieler Muslime hierzulande durch einen besonderen Bezug zur eigenen Religion geprägt ist.

Die Etablierung von muslimischen Gemeinden und entsprechenden religiösen Organisationen kann ebenfalls mit dieser Tatsache in Zusammenhang gebracht werden. Die Vielfalt des muslimischen Lebens hat sich zudem nicht nur

1 | Kaiser Wilhelm II. ließ 1914 eine mit einem Minarett versehene Moschee für Kriegsgefangene bauen. Erste kleinere islamische Gemeinden gab es in Deutschland bereits nach dem Ersten Weltkrieg (z.B. "Islamische Gemeinde zu Berlin", gegründet 1922). Bei einer Volkszählung gehörten 1925 weniger als 3.000 Personen einer anderen Religion als dem Christentum und Judentum an (vgl. Mirbach 2008: 82). Bis dahin galt die Geschichte des Islams in Deutschland eher als eine Randerscheinung (vgl. Schmitz/Seibert 2007: 13f.). 2 | Vgl. Lemmen 2001: 17-34 für eine detaillierte und phasenweise folgende Beschreibung der Geschichte des Islams in Deutschland unter Bezugnahme auf Primärquellen (Vereinsregister, Gerichtsentscheide, Berichte etc.). 
aufgrund der unterschiedlichen nationalen Herkunft der Muslime in Deutschland gesteigert. Auch innerhalb der jeweiligen ethnischen Gruppen muss eine Binnendifferenzierung vorgenommen werden, um ein angemessenes Bild der religiösen Orientierungen, religiösen Einstellungs- und Handlungsmuster wiedergeben zu können.

Heute leben rund vier Millionen Muslime in Deutschland. Die Muslime bilden nach den Christen somit die nächstgrößte Religionsgemeinschaft. Es gibt keine genauen Zahlen darüber, wie viele Muslime tatsächlich in Deutschland leben. Die Gründe hierfür liegen darin, dass genaue Zahlen über eine islamische Religionszugehörigkeit über das Statistische Bundesamt nicht zu ermitteln ${ }^{3}$ sind. Laut der Studie des Bundesamtes ${ }^{4}$ für Migration (2009) variiert diese Zahl immer zwischen 3,8 und 4,3 Millionen Muslimen. In Deutschland leben inzwischen rund 82 Millionen Menschen, sodass der Anteil der Muslime an der Gesamtbevölkerung insgesamt zwischen 4,6 und 5,2 \% beträgt. Dabei wird geschätzt, dass rund $45 \%$ der in Deutschland lebenden Muslime mit Migrationshintergrund aus den berücksichtigten Herkunftsländern deutsche Staatsangehörige sind und rund 55 \% über eine ausländische Nationalität verfügen (vgl. Haug/Müssig/Stichs 2009: 80).

Die in Deutschland lebenden Muslime stellen eine sehr heterogene Bevölkerung dar. Es dominiert die Gruppe der Türkischstämmigen. Etwa 2,5 bis 2,7 Millionen der in Deutschland lebenden Muslime haben somit einen türkischen Migrationshintergrund, d.h., sie stellen rund $63 \%$ der Muslime in Deutschland dar. ${ }^{5}$ Auch was die konfessionelle Zugehörigkeit der Muslime anbelangt, ist eine Vielzahl von Glaubensrichtungen festzustellen. Die Mehrzahl der türkischstämmigen Muslime sind Sunniten (76\%), auf die sich die vorliegende Studie konzentriert. Mit einem Anteil von $17 \%$ stellen die Aleviten die zweitgrößte Glaubensgruppe dar (vgl. Haug/Müssig/Stichs 2009: 303).

Von den etwa 2,5-2,7 Millionen türkischstämmigen Muslimen besitzen rund $40 \%$ die deutsche Staatsbürgerschaft. Im Vergleich zu anderen Herkunftsgruppen ist der Anteil der im Ausland geborenen türkischstämmigen Muslime geringer, d.h., es ist die zweite Generation an türkischstämmigen Muslimen in Deutschland herangewachsen, deren Eltern zumeist Arbeitsmigranten waren (vgl. Haug/Müssig/Stichs 2009: 303f.).

3 | Vgl. für die vorliegende Problematik der statistischen Erfassbarkeit der Muslime Lemmen 2001: 35ff.; vgl. auch Spielhaus 2013 in diesem Kapitel.

4 | Diese Zahlen ergeben sich aus einer standardisierten telefonischen Befragung von insgesamt 6.004 Personen im ersten Halbjahr 2008 (vgl. Haug/Müssig/Stichs 2009: 38).

5 | Die restlichen Muslime stammen aus südeuropäischen Ländern (ca. 14 \%), aus dem Nahen Osten ( $8 \%$ ), aus Nordafrika ( $7 \%$ ) und Zentralasien/GUS, dem Iran sowie Südostasien (insgesamt rund $8 \%$ ). 
Auf die geografische Verteilung bezogen, kann festgehalten werden, dass Muslime vor allem in den alten Bundesländern leben, und zwar meist in Ballungsgebieten. Etwa ein Drittel (35,3\%) der türkischen Muslime lebt in NRW, hier überwiegend im Ruhrgebiet. Der nächstgrößere Anteil an Muslimen lebt in Baden-Württemberg (18,3\%) und Bayern (14,1\%) (vgl. Haug/Müssig/Stichs 2009: 107). Die Probandenauswahl für die vorliegende Untersuchung erfolgte in NRW. Demnach ist sie in einem Gebiet durchgeführt worden, in dem die Mehrheit der Muslime in Deutschland lebt.

Es ist jedoch darauf hinzuweisen, dass diese statistischen Angaben lediglich auf Schätzungen beruhen, die die einfache Zuordnung als »Muslim« infrage stellen lassen. In diesem Zusammenhang zeigt Spielhaus (2013), wie auf der Grundlage von Migrationsstatistiken oder Umfragen unter Menschen aus ausgewählten Herkunftsländern und darauf basierenden Hochrechnungen Schätzungen zur Anzahl von Muslimen gemacht wurden, wobei die Autorin hier schlussfolgernd klarstellt, dass diese Zahlenangaben verbesserungswürdig sind (vgl. Spielhaus 2013: 5-8).

Nach Spielhaus ist die »Kategorie« des Muslims in ihrer inflationären Verwendung kritisch zu hinterfragen. Jene Kategorie könne in Wissenschaft, Politik, Medien etc. lediglich im Kontext religiöser oder identitärer Bezüge eine Aussagekraft erhalten (vgl. Spielhaus 2013: 15). Dabei gelte es, zu unterscheiden, von welcher Kategorie ausgegangen und auf welcher Ebene eine Debatte geführt werde. Die Religionszugehörigkeit erweise sich somit, wenn sich nicht eindeutige religiöse Bezüge (Deutungs- und Handlungsmuster) nachweisen lassen würden, als irreführend.

Die Bezeichnung »muslimisch« oder »Muslim« gibt demnach nur wenig Aufschluss über das persönliche Verhältnis des Einzelnen zur eigenen Religion. Welchen Stellenwert die Religion im eigenen Leben hat, wie sie praktiziert wird, welche Rolle der Islam im Leben des Einzelnen oder gar im Sozialisationsprozess der eigenen Kinder spielt, ist mit der alleinigen Zuschreibung »Muslim« nicht ohne Weiteres identifizierbar. Der Vorteil einer qualitativen Analyse besteht darin, detaillierte Informationen über die zu erfassende Gruppe mit ihren religiösen Bezügen geben zu können. Sicherlich ist dabei der Anspruch auf Repräsentativität nicht gegeben, aber der Blick für eine differenzierte Wahrnehmung und Erfassung verschiedener Bereiche des »Muslim«-Seins und der Lebenswelten kann dadurch geschärft werden.

\subsection{Muslimische Familien}

Muslimische Familien in Deutschland haben, wie bereits erwähnt, die unterschiedlichsten ethnischen Hintergründe, die für die zahlreichen Variationen religiöser Orientierungen verantwortlich sind. Die vermehrte Aufmerksamkeit, die diesen Familien gewidmet wird, hat vielseitige Gründe. Zumeist han- 
delt es sich um politische Debatten, die die vermeintliche Integrationsbereitschaft bzw. -unwilligkeit der Familien in den Blick nehmen. Spätestens im Zusammenhang mit Bildungsdefiziten wird die religiöse Zugehörigkeit der Familien vermehrt in den Vordergrund gerückt. Ehemalige »Ausländerfamilien« oder »Migrantenfamilien« werden so $\mathrm{zu} »$ muslimischen Familien« deklariert (vgl. Spielhaus 2013: 4f.; vgl. auch Spenlen 2012). So ist es eigentlich verwunderlich, warum in der wissenschaftlichen Forschung die Familienreligiosität bislang kaum Berücksichtigung fand.

Es ist schwierig, Aussagen über sozialstrukturelle Merkmale und Besonderheiten von Muslimen und speziell von muslimischen Familien zu treffen, zumal, wie schon weiter oben beschrieben, bei Muslimen nicht von einer homogenen Gruppe ausgegangen werden kann und der Islam sehr unterschiedlich ausgelegt und gelebt wird. Auch die statistische Erfassbarkeit birgt einige Probleme. Ergebnisse in der sozialwissenschaftlichen Literatur zielen zumeist auf die türkische Population oder auf Migrationsfamilien ohne Rücksicht auf ihre Religion, religiöse Zugehörigkeit, den Grad ihrer Religiosität und damit auch auf die religiöse Lebensweise, Alltagspraktiken in verschiedenen Lebenswelten und Werthaltungen ab. ${ }^{6}$

Bedeutsam ist in diesem Zusammenhang demnach, dass unter Migrationsfamilien die Lebensbedingungen und religiösen Orientierungen erheblich variieren können. Diese Differenzen beziehen sich sowohl auf herkunftsspezifische Aspekte, wonach zwischen einer eher ländlichen und einer städtischen Herkunft (in der Türkei) unterschieden wird, als auch auf differente Formen von traditionellen Werten, die in der Lebensweise und Familienstruktur z.T. stark voneinander abweichen (vgl. Seiser 2006: 56).

Es wurden bislang vereinzelt mehrere groß angelegte repräsentative Studien über Muslime in Deutschland veröffentlicht, aus denen einige sozial-

6 I Thiessen (2008) verweist hier auf ein analytisches Problem, das nicht allein auf die islamische Religionszugehörigkeit reduziert werden kann. Sie stellt thesenhaft fest, dass islamische Rituale, Werthaltungen und Alltagspraktiken in vielfältigen regionalen Traditionen wurzeln und je nach Schicht und ethnischer Herkunft sehr unterschiedlich sein können. Entsprechend schwierig gestalte sich die Analyse muslimischer Alltagspraktiken und Werthaltungen (vgl. Thiessen 2008: 5). Gerade in der wissenschaftlichen Literatur, die vor allem in Form von Expertisen über "muslimische" Familien hervorgebracht wurde, ist diese Schwierigkeit besonders deutlich zu sehen (vgl. Kap. I. 2.1). Zu beachten ist hier zudem der historisch-gesellschaftliche Kontext der Herkunftsländer und ihre regional unterschiedlichen Formen religiöser Praktiken und Einstellungen, die oft mit traditionellen Vorstellungen vermischt werden. Da es keine institutionalisierte "Clearingstelle" gibt, die die ganze Breite des Alltagslebens abbildet, d.h., man nicht präzise sagt, was nun spezifisch "islamisch" ist und was den lokalen Traditionen entstammt, ist der Islam nicht ohne Weiteres identifizierbar (vgl. Bukow 2007: 214). 
strukturelle Grunddaten gewonnen werden konnten und Aussagen über die Muslime im Allgemeinen getätigt wurden. Einige Studien und Ergebnisse beziehen sich auch auf türkische Migrationsfamilien, über die weitere Aspekte des Familienlebens dargelegt werden, die hier im Folgenden näher erläutert und analysiert werden sollen.

\section{Sozialstrukturelle Merkmale von Familien mit türkischem Migrationshintergrund}

Dem Ergebnis des Mikrozensus 2009 zufolge machen 28,4 \% (2,3 Mio. von insgesamt 8,2 Mio.) aller Familien in Deutschland den Anteil an Migrationsfamilien aus. Dabei stellen Familien, in denen jeweils ein Familienmitglied einen türkischen Migrationshintergrund aufweist, mit $21 \%$ den höchsten Anteil dar ${ }^{7}$ (Prognos AG 2010: 16-19).

Migrationsfamilien haben im Vergleich zu einheimischen Familien traditionelle Familienbindungen, in der die Ehe mit Kindern (Mutter-Vater-Kind-Familie) die dominierende Form des familiären Zusammenlebens darstellt. Alternative Lebensformen mit Kindern sind eher selten (vgl. BFMSFJ 2009: 57). Gerade Familien mit einem türkischen Migrationshintergrund und aus dem mittleren Osten weisen »in hohem Maße ein an der typischen bürgerlichen $>$ Normalfamilie< orientiertes familiäres Gefüge auf« (BFMSFJ 2009: 57). Es wird geschätzt, dass etwa zwei Drittel der Migrationsfamilien mit einem oder zwei Kindern leben, worin sie sich von deutschen Familien nicht unterscheiden. Allerdings liegt die Zahl der Familien mit drei oder vier Kindern bei $20 \%$, während dieser Anteil der Familien bei der Bevölkerung ohne Migrationshintergrund nur bei $12 \%$ liegt. Nach der Herkunft der Migrationsfamilien unterschieden, ist die Quote bei türkischen Ehepaaren, die drei oder vier Kindern haben, mit etwa $32 \%$ im Vergleich zu anderen Migrantengruppen überdurchschnittlich hoch. Auch unverheiratete Partner mit Kind gibt es unter Familien mit Migrationshintergrund deutlich seltener (6\%) als bei einheimischen deutschen Familien (13\%) (Sonderauswertung des Mikrozensus 2009 in Prognos AG 2010: 20f.). Ebenso bestätigt der Religionsmonitor (2008b) diesen Befund, wonach die Bedeutung von Familie und Kindern für die überwiegende Mehrheit der Muslime groß bis sehr groß ist (vgl. Bertelsmann 2008b: 30 und 45).

7 | Laut Boos-Nünning unterschätzt diese Zahl den Anteil der Migrationsfamilien, weil die ihr zugrunde liegende Definition verlangt, dass mindestens ein Familienmitglied außerhalb Deutschlands geboren ist oder eine ausländische Staatsangehörigkeit besitzt. Dabei wird jedoch die steigende Anzahl an Familien, in denen beide Elternteile in Deutschland geboren sind und die deutsche Staatsangehörigkeit besitzen, nicht berücksichtigt. Untersuchungen belegen hierbei, dass diese Familien durch die kulturellen oder religiösen Werte der ethnischen Gemeinschaften (mit)geprägt sein könnten (vgl. Boos-Nünning 2011a: 9; vgl. auch ders. 2015). 
Dass die Familienorientierung und -bindung eine wichtige Rolle im Leben von muslimischen Migrationsfamilien einnimmt, spiegelt sich auch in der Haushaltsgröße und Kinderanzahl wider. Muslime leben in signifikant größeren Haushalten als Angehörige anderer Religionsgemeinschaften sowie weitere Migranten in Deutschland insgesamt. Bezeichnend ist zudem, dass etwa $5 \%$ der Muslime in Einpersonenhaushalten leben. Daran lässt sich ein geringeres $\mathrm{Ma}$ an Individualisierung und eine höhere Familienorientierung ablesen. Im Durchschnitt leben 3,8 Personen in einem Haushalt mit Bewohnern türkischer Herkunft. Im Vergleich dazu sind die Haushalte deutlich größer als bei der Gesamtbevölkerung bei einer durchschnittlichen Größe von 2,1 Personen im Jahr 2006 (vgl. Haug/Müssig/Stichs 2009: 13; vgl. auch BMFSJ 2009: 61-64).

Gemäß der Sonderauswertung des Mikrozensus 2009 liegt die durchschnittliche Zahl in den Familien mit Migrationshintergrund mit 1,96 Kindern etwas über dem Durchschnitt der Familien ohne Migrationshintergrund $(1,74)$. Bei türkischen Familien wird sogar ein Mittelwert von 2,27 Kindern festgestellt (Sonderauswertung des Mikrozensus 2009 in Prognos AG 2010: 22). Auch die Zahlen (der sekundäranalytischen Untersuchung) des BMFSFJ (2009) zeigen, dass in Migrationshaushalten mehr Kinder leben als in einheimischen Haushalten. Insgesamt zeichnet sich die Bevölkerung mit Migrationshintergrund somit durch eine deutlich höhere Anzahl an Familien mit Kindern und zum anderen durch einen höheren Anteil an kinderreichen Familien aus (vgl. BMFSFJ 2009: 52-61; vgl. auch Bertelsmann 2008b: 22).

Die Partnerwahl und die Heiratsneigung können als Indikator für die Orientierung an traditionellen Familienmustern gesehen werden. Eheschließungen erfolgen tendenziell häufiger im Migrationskontext. Die Ehe wird überdurchschnittlich häufig insbesondere von Personen mit türkischen Wurzeln als Lebensform bevorzugt. Drei Viertel $(74,9 \%)$ der Befragten mit aktueller oder ehemals türkischer Staatsangehörigkeit leben in einer Ehe und etwa lediglich ein Fünftel (18,8 \%) gibt an, ledig zu sein, wohingegen die Zahl der Eheschließungen bei einheimisch Deutschen 56,2 \% beträgt (vgl. BMFSFJ 2009: 48).

Auch das Heiratsalter ist im Vergleich zur deutschen Bevölkerung jünger ${ }^{8}$ (vgl. BMFSFJ 2009: 49-52). Ebenso lässt sich daraus das generative Verhalten der Mütter ableiten, denn im Vergleich zu einheimischen Müttern (28 Jahre) ist das Durchschnittsalter der Mütter mit türkischem Migrationshintergrund bei der Geburt des ersten Kindes 24 Jahre (vgl. Boos-Nünning 2011: 16).

Die Wahl der Ehepartner und Eheschließungen finden vorwiegend im monoethnischen Kontext statt: dabei heiraten 95 \% der Frauen mit türkischem

8 | Das junge Heiratsalter ist jedoch nicht auf traditionelle Geschlechterrollen oder kulturelle Traditionen zurückzuführen. Vielmehr sei dieser Einflussfaktor dem durchschnittlich geringeren formellen Bildungsniveau geschuldet (vgl. BFMFSJ 2009: 51). 
Migrationshintergrund jeweils innerethnisch. Die Zahl ist bei den Männern mit $87 \%$ etwas geringer (vgl. BMFSFJ 2009: 81-83). Auch transnationale Ehen, in der eine innerethnische Ehe mit einem Partner oder einer Partnerin im Herkunftsland der Eltern oder Großeltern geschlossen wird, sind verbreitet. Es wird geschätzt, dass von den Ehen in der türkischen Gemeinschaft mehr als ein Viertel einem transnationalen Muster folgt (Boos-Nünning 2011a: 17). Für die Migrationsfamilien in Deutschland bedeutet dies, dass ein nicht geringer Anteil an Kindern einen Elternteil hat, der im Rahmen der Heiratsmigration nach Deutschland eingewandert ist (vgl. Boos-Nünning 2011a: 17f.).

Ehescheidungen sind, auch wenn die Zahlen zunehmen, im Vergleich zu einheimischen Familien seltener. Die Quote der Alleinerziehenden beträgt $14 \%$, wohingegen die Anzahl der Alleinerziehenden in den deutschen Haushalten mit 21 \% etwas höher ausfällt (vgl. Prognos AG 2010: 20ff.).

Folgt man diesen Ergebnissen, so ist bei Migrationsfamilien mit türkischer Herkunft ein ausgeprägter sog. Familialismus zu beobachten, der durchaus religiös begründbar ist (vgl. Bertelsmann 2008b: 30 und 45) und zugleich bei ausgeprägt religiösen Menschen etwas stärker sein dürfte. Er beinhaltet eine stärkere familiäre Verankerung und eine entsprechende Orientierung an traditionellen Familienmustern. Obgleich der Tatsache, dass auch hier Tendenzen der Pluralisierung der Lebensformen im Zuge sozialer Wandlungsprozesse zu beobachten sind, erreicht diese nicht das Ausmaß, das in der Bevölkerung ohne Migrationshintergrund vorzufinden ist (vgl. BFMSJ 2009: 45).

Interessant wären hier auch noch weitere Aspekte der Lebenssituation, wie das räumliche Umfeld, die Wohngegend und die sozialen Rahmenbedingungen von Migrationsfamilien. Die Bildungssituation sowie die Erwerbsbeteiligung geben letztlich Auskunft über den sozialen Status in der Gesellschaft und bestimmen Faktoren wie Armut oder das Armutsrisiko. Sie sind nicht zuletzt auch im Zusammenhang mit Fragen nach der Integration in die deutsche Gesellschaft wichtige Indikatoren, die das Familienleben von Migrantinnen und Migranten erheblich beeinflussen und mitbestimmen. Da die vorliegende Studie jedoch nicht ihren Fokus darauf richtet, in welcher Form diese Faktoren einen Einfluss auf die religiöse Sozialisation bzw. religiöse Erziehung ausüben, wurde hier auf deren Ausführung verzichtet.

\subsection{Die Religiosität von Muslimen}

Religion bzw. Religiosität spielt unter den muslimischen Türken eine große Rolle. Bezogen auf die Situation der Muslime, gibt es eine Vielzahl von Studien, in denen anhand von bestimmten Merkmalen und Variablen Aussagen über die Religiosität von Muslimen im Allgemeinen getroffen werden. Die meisten Studien stimmen darin überein, dass Religiosität bzw. der Bezug zur Religion und die individuelle Gläubigkeit unter den Muslimen auch heute 
noch sehr stark ausgeprägt sind. Diese Studien sollen im Folgenden näher beleuchtet werden, um die Bedeutung und die alltägliche Relevanz aufzuzeigen, welche die Religion für die Muslime insbesondere in der Diasporasituation spielt. Die nachfolgend erwähnte Forschungsliteratur nimmt die muslimische Bevölkerung ohne Differenzierungen nach Geschlecht und/oder Altersgruppe in den Blick.

In der Studie Muslimisches Leben in Deutschland, die im Auftrag der Deutschen Islamkonferenz über das BAMF durchgeführt wurde, sehen sich 41,4\% der Muslime (mit türkischem Migrationshintergrund) als sehr gläubig und $47,1 \%$ als eher gläubig an, sodass der Anteil mit 80 bis $90 \%$ der religiösen Muslimen im weltweiten Normalbereich der subjektiven Einschätzung liegt. Auch die täglichen Gebete spielen hier eine besondere Rolle. Der Anteil der täglich bzw. mehrmals in der Woche Betenden liegt bei über $45 \%$. Auf die Einhaltung des Fastengebotes legen über $70 \%$ Wert. Religiöse Feste und Feiertage sind immerhin für ca. $80 \%$ von großer Bedeutung (Haug/Müssig/Stichs 2009: 142ff.).

In der Ergänzungsstudie Muslimische Religiosität in Deutschland der Bertelsmann Stiftung wird ein Anteil von $41 \%$ an hochreligiösen und $49 \%$ an religiösen Menschen benannt (mit $44 \%$ der Hochreligiösen nimmt hier die Gruppe der »Türkischsprachigen« den höchsten Anteil ein). Es lasse sich ein Diaspora-Effekt feststellen, wonach laut »Religionsmonitor « (vgl. Bertelsmann 2008a) $85 \%$ der Menschen in der Türkei religiös sind. In Deutschland liege der Wert um 6 \% höher. Die Studie veranschaulicht somit, dass im Vergleich zur deutschen Bevölkerung Muslime in Deutschland deutlich religiöser leben. Ein wichtiges Ergebnis ist hier entgegen der gängigen Meinung innerhalb der Medienlandschaften, dass mit einer »hohen Zentralität« der Religiosität kein rigider Dogmatismus oder Fundamentalismus verbunden ist. Hochreligiöse Menschen in Deutschland sind laut Studie durch eine kritisch-reflektierende Haltung und durch eine hohe Akzeptanz von religiösem Pluralismus gekennzeichnet (vgl. Bertelsmann 2008b: 29).

Auch die Studie Muslime in Deutschland ${ }^{9}$, die im Auftrag des Bundesministeriums des Innern durchgeführt wurde, gibt Auskunft über die Bedeutung des Islams in der alltäglichen Lebensführung von Muslimen: Es wird eine große persönliche Gläubigkeit (87\%) festgestellt. Es beschreiben sich hier lediglich 4,5\% als »absolut ungläubig « und weitere $8,1 \%$ als »eher nicht gläubig«.

9 | Das Design der Gesamtstudie ist komplex aufgebaut: Es fanden eine standardisierte telefonische Befragung der muslimischen Bevölkerung von ca. 1.000 Personen aus der Zielgruppe der erwachsenen Personen, eine standardisierte Befragung von ca. 500 Schülerinnen und Schülern, eine standardisierte Befragung von ca. 150 Studierenden und qualitative Befragungen im Umfeld islamischer Organisationen statt (vgl. Brettfeld/Wetzels 2007: 60-65). 
Die hohe Bedeutung der individuellen Religiosität überschneidet sich jedoch nur zum Teil mit der tatsächlichen Religionsausübung (wie z.B. Häufigkeit des Betens, des Besuchs von Moscheen und Gebetshäusern): 31,4 \% der befragten Muslime beten täglich und etwa $19 \%$ mehrmals bis einmal die Woche. Als Ergebnis lässt sich festhalten, dass, je ausgeprägter die individuelle Religiosität ist, desto häufiger auch auf die täglichen Gebete und auf den Moscheebesuch Wert gelegt wird (vgl. Brettfeld/Wetzels 2007: 11of.). Die individuelle Bedeutung religiöser Ge- und Verbote zeigt sich z.B. im Schweinefleischverzicht (86,7 \%), bei der Einhaltung des Fastengebots (etwa $75 \%$ ) und in der Bejahung der zentralen Aussagen des Glaubensbekenntnisses, dass der Koran die wahre Offenbarung Gottes sei (79,6\%). Für einen Großteil der befragten Muslime (52,1\%) fand die religiöse Unterweisung somit durch den Koranschulbesuch statt. Etwas über $30 \%$ der Befragten haben für mehr als zwei Jahre eine Koranschule besucht. Die Quote derer, die eine Koranschule besucht haben, liegt bei den jüngeren Muslimen deutlich höher als bei den älteren Muslimen (etwa $60 \%$ vs. $50 \%$ ). Am höchsten ist diese Quote bei den in Deutschland geborenen Muslimen (60,2 \%). Der Koranschulbesuch der jüngeren Generationen bzw. derer, die ihre Kindheit in Deutschland verbracht haben, ist eine weit verbreitete Praxis und mit einem größeren Ausmaß an Religiosität verlängert sich auch der Besuch einer Koranschule. Brettfeld/Wetzels deuten dies neben dem religiösen Bedürfnis, in Ermangelung schulischer Möglichkeiten einer religiösen Unterweisung der islamischen Religion, als einen möglichen Weg der »Bewahrung kulturell-religiöser Traditionen«. Daneben wird festgestellt, dass mit rund $70 \%$ auch ein großes Interesse an der Einführung eines islamischen Religionsunterrichts in deutscher Sprache an einer deutschen Schule für muslimische Kinder besteht (vgl. Brettfeld/Wetzels 2007: 112ff.).

Auch die Ergebnisse der Studie Islam in Deutschland. Einstellungen der türkeistämmigen Muslime ${ }^{10}$ des ZfT (Zentrum für Türkeistudien) in Essen unterstützen die zentrale Bedeutung von Religiosität für die Muslime in der Diaspora. Die Mehrheit der türkischstämmigen Muslime definiert sich als eher religiös $(55 \%)$, ein Viertel $(28 \%)$ sieht sich als sehr religiös an. Im Vergleich zu den Ergebnissen im Jahr 2000 ist eine Zunahme der subjektiven Religiosität festzustellen. Dies könnte als eine Folge der Geschehnisse vom 11. September 2001 gedeutet werden, aber auch die Kriege in Afghanistan oder dem Irak könnten zu einer verstärkten Auseinandersetzung mit dem und zu einer bestimmten Positionierung dem Islam gegenüber geführt haben. Es könnte zudem auch denkbar sein, dass positive und konstruktive Diskussionen mit deutschen Bekannten, Nachbarn, Kollegen und Freunden zu einer verstärkten Religiosität geführt hätten (Şen/Sauer 2006: 2of.). Bei der Einhaltung der re-

10 | Im Jahr 2005 wurden mithilfe eines computergestützten Zufallsprinzips telefonisch insgesamt 1.019 Interviews geführt (vgl. Şen/Sauer 2006). 
ligiösen Praxis spielen für die Muslime allen voran das Fasten (74 \%) und die Almosenabgabe, Zakat, (77\%) eine zentrale Rolle. Diejenigen, die das tägliche Gebet verrichten, stellen eine Gruppe von 35 \% dar. Auch darin ist eine Erhöhung im Vergleich zur Befragung im Jahre 2000 feststellbar. Somit zeige sich, dass die gestiegene Religiosität sich auch in der religiösen Praxis niederschlage (vgl. Şen/Sauer 2006: 23).

Es wurden hier die Ergebnisse von quantitativen Repräsentativbefragungen dargestellt. Es ging dabei vor allem darum, die enorme Bedeutung von Religion im Alltagsleben muslimisch-türkischer Migranten ohne Altersbeschränkung aufzuzeigen. Eine detailliertere Analyse, die die Religiosität und ihre vielfältigen Ausdrucksformen unter der Perspektive der religiösen Sozialisation in muslimischen Familien besonders berücksichtigt, wird im nächsten Kapitel vorgenommen (vgl. Kap. II. 2.1).

\subsection{Muslimische Organisationen und Vereine}

Religiöse Organisationen und Gemeinden stellen die häufigsten Vergemeinschaftungsformen von muslimischen Migranten und Migrantinnen dar. Die religiöse Landschaft der Muslime in Deutschland ist vielfältig gewachsen. Sie hat sich seit dem Beginn der Migrationsgeschichte gemäß den Bedürfnissen der Muslime entwickelt. Es finden sich zahlreiche religiöse Organisationen mit einer breiten Angebotsvielfalt, in der nicht ausschließlich der Gebetsverrichtung Raum gegeben wird.

Einhergehend mit dem Familiennachzug nach Deutschland und dem daraus resultierenden Bedürfnis, die Kinder religiös $\mathrm{zu}$ erziehen, sind religiöse Gemeinden und Vereine als Orte entstanden, an denen schon immer die Vermittlung von religiösen Inhalten bzw. die religiöse Unterweisung von Kindern, Jugendlichen und auch Erwachsenen im Vordergrund stand. Als untersuchungsleitendes Kriterium wird in der vorliegenden Studie der Bezug der Eltern und ihrer Kinder zur Moschee bzw. zu ähnlichen Einrichtungen als Sozialisationskontext vorgestellt. So erscheint es hier interessant, sich einen Überblick über die Angebotsstrukturen der Moscheegemeinden und ihrer Dachorganisationen zu verschaffen, zu denen die interviewten Eltern in fast allen Fällen Verbindungen haben.

Eine bundesweit einheitliche Erhebung, die Ergebnisse über Gemeindestrukturen bzw. -angebote und die Organisationslandschaft anbietet, wurde jüngst vom BAMF in Auftrag gegeben und durch das ZfTI durchgeführt" ${ }^{11}$ (vgl.

11 | Im ersten Halbjahr 2011 wurde eine telefonische, computergestützte, standardisierte Befragung von Moscheegemeinden durchgeführt. Die Grundlage der Befragung war die Datenbank, die das ZfTI im Jahr 2009 bearbeitet hatte. Es wurden insgesamt 1.141 Interviews vollständig durchgeführt (vgl. Halm/Sauer 2012: 46-57). 
Halm et al. 2012). Der Bezug zur letztgenannten Studie ermöglicht eine aktuelle Bestandsaufnahme muslimischer Gruppierungen und Organisationen mit ihren jeweiligen Funktionen und Angebotsstrukturen.

Heute existieren in Deutschland 2.342 religiöse Vereine bzw. Moscheegemeinden, einschließlich der alevitischen Gemeinden mit Gebetsräumlichkeiten. Angesichts der zahlenmäßigen Überlegenheit der türkischstämmigen Muslime ist ein Großteil der Gemeinden türkisch geprägt. Gleichzeitig werden diese von weiteren Herkunftsgruppen besucht (vgl. Halm et al. 2012: 7).

Muslimische Gemeinden sind in vielen (Dach-)Verbänden organisiert. Die größten Dachverbände wurden vonseiten der Muslime türkischer Herkunft etabliert. Dabei ist die DITIB - Türkisch-Islamische Union der Anstalt für Religion e. V. - die größte Dachorganisation. Sie wurde vonseiten des Präsidiums für Religionsangelegenheiten der Türkei (Diyanet Işleri Başkanlığı) gegründet. Mit etwa 870 Moscheegemeinden ist die DITIB der größte muslimische Dachverband. Daneben ist die IGMG (Islamische Gemeinschaft Millî Görüş e. V.) der zweitgrößte sunnitische Verband. Sie stand und steht in enger Verbindung zu der von Necmettin Erbakan gegründeten Millî-Görüş-Bewegung in der Türkei, ${ }^{12}$ die vor allem politische Leitziele verfolgt. Der Verband der Islamischen Kulturzentren (VIKZ) knüpft an die Lehren Süleyman Hilmi Tunahans an und vertritt einen mystisch geprägten sunnitischen Islam. Dieser islamische Gelehrte engagierte sich stark für die religiöse Bildung der Mitglieder und war orthodox-konservativ ausgerichtet. Ferner existieren zwei mehrheitlich sunnitisch geprägte größere »Dachverbände« auf Bundesebene; zum einen der Islamrat, dem die IGMG angehört, sowie der Zentralrat der Muslime (ZMD). VIKZ und DITIB sind beide keine Mitglieder dieser Dachverbände. Im Kontext der DIK (Deutsche Islamkonferenz) hat sich der »Koordinierungsrat der Muslime« (KRM) konstituiert, der sich aus DITIB, Islamrat, VIKZ und ZMD zusammensetzt. Der KRM entstand als Reaktion der Verbände auf die Forderung nach einem einheitlichen Ansprechpartner für den deutschen Staat (vgl. Halm/Sauer 2012: 36f. vgl. Lemmen 2001: 62-92). Neben den großen Dachverbänden existieren diverse kleinere Organisationen und Gemeinden, wie z.B. die ATIB, ADÜTF, Jamat' un Nur, die Gülen-Gemeinde und sufistische Orden. Nicht $\mathrm{zu}$ vergessen ist die Alevitische Gemeinde Deutschland (AABF), die ihr Hauptziel in der Etablierung und Förderung des Alevitentums sieht $^{13}$ (vgl. Lemmen 2001; Wunn 2007).

12 | Vgl. Schiffauer (2010) zu einer detaillierten Beschreibung.

13 | Es wurden hier die türkischstämmigen muslimischen Organisationen benannt. Eine umfassendere Bestandsaufnahme mit unterschiedlichen nationalen Hintergründen einschließlich der Beschreibung von rechtlichen Voraussetzungen, der Selbstdarstellung und Organisationsstrukturen findet sich in Lemmen 2001: 52-127. Wunn 
Vielfach wird die Vertretungsleistung der Dachverbände und ihr Anspruch auf die Repräsentation der Muslime im Zusammenhang mit vielen (sozial-) politischen Fragen, wie z.B. in der Debatte um die Einführung des islamischen Religionsunterrichts, kritisiert. Dies geschieht nicht zuletzt deshalb, weil die Mitgliedszahlen eine geringere Beteiligung der Muslime in den Gemeinden vermuten lassen, als es tatsächlich der Fall ist.

Es wird konstatiert, dass, trotz der hohen Religiosität und der starken religiösen Praxis, die Mitgliedschaft in einer religiösen Gemeinde niedriger als bei Angehörigen anderer Religionen ist. Laut der Studie des BAMF geben etwa 23,7\% der Muslime an, Mitglied in einem religiösen Verein oder einer Gemeinde zu sein. Die aktive Beteiligung in religiösen Gruppen macht laut Studie eine Zahl von 14 \% aus (vgl. Haug/Müssig/Stichs 2009: 168). Zu ähnlichen Ergebnissen kommen auch andere Studien. Die Autoren weisen daraufhin, dass etwa knapp ein Fünftel der Muslime Mitglied im Verein oder aktiv in einem solchen engagiert ist (vgl. Brettfeld/Wetzels 2007: 193; Şen/Sauer 2006: 16; Thielmann 2008: 14).

Şen und Sauer (2006) verweisen in diesem Zusammenhang darauf, dass eine formale Mitgliedschaft für die Teilnahme an kulturellen, gesellschaftlichen, religiösen und sozialen Angeboten der Moscheegemeinden und Moscheevereine nicht zwingend notwendig sei, da ca. $40 \%$ der Muslime diese regelmäßig besuchen würden (vgl. Şen/Sauer 2006: 16). Folglich scheint die Zahl der involvierten Muslime in Gemeinden bzw. deren Teilnahme am Gemeindeleben größer zu sein, als dies statistisch genau erfassbar wäre. Der Grund hierfür liegt darin, dass sich die islamischen Vereine mit ihrem religiösen Angebot in der Regel an alle Muslime in ihrem Einzugsbereich richten (vgl. Lemmen 2001: ${ }_{56} 6$ ).

Wichtig ist hier, festzuhalten, dass Gemeindemitgliedszahlen keine klare Auskunft darüber geben, ob auch tatsächlich die Angebote der religiösen Gemeinden wahrgenommen werden. Vielfach ist zu beobachten, dass auch ohne offizielle Mitgliedschaft in einer bestimmten Gemeinde religiöse Dienstleistungen derselben in Anspruch genommen werden. Zum einen liegt das daran, dass keine feste Einordnung vonseiten der Muslime in eine bestimmte Gemeinschaft (bzw. einen religiösen Verband, Verein) gewünscht wird ${ }^{14}$, und

(2007) gibt zudem in inrem Handbuch ein detailliertes Bild der muslimischen Gruppierungen in Deutschland wieder.

14 | Anhand der Interviews wurde deutlich, dass muslimische Eltern, wenn sie nicht ausschließlich in einem Verein aktiv waren, verschiedene Angebote der religiösen Organisationen und Vereine wahrnahmen. Man muss nicht Mitglied in einem Verein sein, um auch das Angebot für die religiöse Unterweisung seiner Kinder nutzen zu können. Oftmals wurde hier deutlich, dass im Lauf der Entwicklung der Kinder mehrere Vereine durchlaufen worden sind, um das "Bestmögliche" an religiöser Erziehung für die eigenen 
zum anderen, dass es qualitative Unterschiede hinsichtlich der Bildungsangebote gibt. Vielfach wird versucht, den eigenen Bedürfnissen und Ansprüchen entsprechend vorzugehen, um eine bestmögliche Versorgung an Bildungsmöglichkeiten für die Kinder und Jugendlichen zu finden. Schiffauer spricht in diesem Zusammenhang gar von einem »religiösen Markt«, auf dem Anbieter versuchen, der muslimischen Klientel entsprechende religiöse Angebote zu machen. Dies habe dazu geführt, dass es zu einer Differenzierung des religiösen Angebots, je nach Zielgruppe, die man gewinnen wollte, gekommen sei (vgl. Schiffauer 2010: 55f.).

\section{Religiöse Angebote der Gemeinden}

Unter den türkisch geprägten religiösen Einrichtungen ist ein durchaus differenziertes Angebotsspektrum entstanden. Die vielfältigen Nutzungsmöglichkeiten gehen somit in den meisten Fällen über den Gottesdienst und die Gebetsverrichtung hinaus. Im Vordergrund stehen die religiöse Unterweisung und Korankurse für Kinder und Jugendliche. Schaut man in die Anfänge ihrer Gründungszeit, so wird die besondere Bedeutung der Moscheegemeinden für die gläubigen Muslime noch deutlicher. So fungierten diese als Selbsthilfeorganisationen und dienten als Anlaufstelle für diverse soziale Handlungsoptionen - Versorgungskasse für Notfälle, Informationsbörsen, soziale Clubs/ Teestuben, Vermittlung von Wohnungen und Arbeitsplätzen, vielfach mit einem kleinen Supermarkt ausgestattet (vgl. Schiffauer 2010: 45).

Daneben haben religiöse Gemeinden noch zahlreiche andere Funktionen, die von engagierten Gemeindemitgliedern vorangetrieben und aufrechterhalten werden. Die religiösen Vereine bieten neben Korankursen und einer religiösen Unterweisung für Kinder zudem in Einzelfällen auch geistlichen Beistand an, begleiten und organisieren Beisetzungen, Hochzeiten, Beschneidungen und Pilgerfahrten. Sie offerieren zudem Fortbildungskurse, Freizeitund Sportangebote, eine Beratung in sozialen Fragen, kulturelle Angebote sowie Informationsveranstaltungen zu unterschiedlichen Themen (vgl. Şen/ Sauer 2006: 8).

In der jüngst erschienenen Studie des BAMF (2012) erscheinen die befragten Gemeinden mehrheitlich recht differenziert, zumal angesichts des

Kinder zu gewährleisten. Die Vereine, deren Angebote genutzt wurden, gehören dabei unterschiedlichen Dachverbänden an. Wunn stellt in diesem Zusammenhang fest, dass die unterschiedlichen religiösen Angebote (z.B. Gebet, Freizeitgestaltung, Koranschulbesuch) einmal in dieser, ein anderes Mal in jener Moschee wahrgenommen werden können. Auch ein Interessenwandel im Lebenszyklus lasse sich beobachten: Während man in der Jugend vielleicht mit einer eher mystischen oder politisch aktiven Richtung sympathisiert und sich dort aktiv engagiert habe, nähere man sich in späteren Jahren einer anderen muslimischen Gruppierung an (vgl. Wunn 2007: 250f.). 
grundsätzlich ehrenamtlichen Charakters der Tätigkeiten. Die meisten Gemeinden (93\%) verfügen über einen Imam. Im Falle der DITIB werden die Imame vom türkischen Staat gestellt. Die Ressourcen der Gemeinden gehen über das Angebot religiöser Aufgaben hinaus, ${ }^{15}$ es werden hierbei mehrheitlich Frauen- (84\%), Jugend- (83\%), Dialog- (79\%) sowie Öffentlichkeitsarbeit (78\%) und Bildungsbeauftragte (74 \%) bzw. Sportabteilungen (52 \%) benannt. Immerhin $46 \%$ der Gemeinden verfügen über eine Abteilung für Senioren, die angesichts der Migrationsgeschichte erst in jüngster Zeit entstanden ist. Die Gemeindeausstattung ist unmittelbar mit der Gemeindegröße verbunden, denn je größer die Gemeinde ausfällt, desto besser ist auch deren Ausstattung zu erwarten. Sunnitische Gemeinden, die von Türkischstämmigen dominiert werden, haben eine überdurchschnittliche Ressourcenausstattung. Je länger die Gemeinden bestehen, desto vielfältiger ist auch ihr religiöses Angebot. Dabei konnte auch festgestellt werden, dass die Gemeinden von DITIB und IGMG überdurchschnittlich differenzierte Organisationsstrukturen besitzen (vgl. Halm/Sauer 2012: 72f.).

Über die religiösen Angebote, wie z.B. die Gebete und die Feier von Gottesdiensten, hinaus bieten die Gemeinden Korankurse bzw. Islamunterricht für Kinder und Jugendliche an (95,8 \%). Daneben werden interne Iftar-Essen, Fastenbrechen (91,8\%), ausgerichtet und es finden Feiern zu besonderen religiösen Festtagen, Wallfahrten und Begräbnisfeiern statt (85,1\%). Jeweils mehr als die Hälfte der Gemeinden bieten Spendensammlungen (Zakat) (79,9\%), Feiern anlässlich von Beschneidungen (69,7\%) und Eheschließungen (68,5\%), die Vermittlung von Tieropfern anlässlich des Opferfestes (66\%) und Geburtsfeiern (50\%) an (vgl. Halm/Sauer 2012: 74).

Die Angebotsvielfalt der religiösen Gemeinden und Vereine wurde in diesem Kapitel vorgestellt. Dabei konnte festgestellt werden, dass neben der Gebetsverrichtung die Korankurse und der Islamunterricht für Kinder den wichtigsten Platz einnehmen. Um ein differenziertes Bild des Islamunterrichts und der religiösen Unterweisung in Moscheegemeinden und ähnlichen Bildungseinrichtungen zu erhalten, ist es notwendig, einen Blick auf die ihnen zugrundeliegenden Bildungskonzepte und die dort vorzufindenden Erziehungspraktiken zu werfen. Die Forschungslage ist in diesem Zusammenhang dürftig.

15 | Aufgrund der integrationspolitischen Erwartungen des Aufnahmelandes, aber auch des intergenerationalen Wandels der Klientel machen die Gemeinden weit über religiöse Dienstleistungen hinausgehende Angebote. Dazu gehören Veranstaltungen zum interreligiösen Dialog und zur Gesellschaftskunde, Sprachkurse, Ausflüge sowie Erziehungs- und Sozialberatung. Für Jugendliche sind nichtreligiöse Angebote verbreiteter. Sportkurse und Orientierungshilfen (Sozial-, Erziehungs- und Gesundheitsberatung, Hausaufgabenhilfe, interreligiöser Dialog) sind in der deutschen Gesellschaft verbreiteter als die Traditionspflege der Herkunftskultur (vgl. Halm/Sauer 2012: 75ff.). 
Doch auf diese Problematik soll an anderer Stelle noch einmal ausführlicher eingegangen werden (vgl. Kap. II. 2.2.1 Religiöse Sozialisation im Kontext von außerschulischen Bildungseinrichtungen).

\section{Stand der Forschung}

Abgesehen von zahlreichen Veröffentlichungen, die sich vor allem mit den gesellschaftspolitischen Aspekten des Islams und der Religiosität von Muslimen im Allgemeinen befassen, sind Forschungsbeiträge zur religiösen Sozialisation von muslimischen Kindern und Jugendlichen kaum existent. Eine für die Forschungsfrage adäquate Auflistung der Literatur, die insbesondere die Themen religiöser Sozialisation von muslimischen Kindern und religiöser Erziehung im Islam berührt, brachte einige Herausforderungen mit sich, die im Folgenden näher erläutert werden.

\subsection{Religiöse Sozialisation in der Forschung}

Auch wenn im Bereich der Familienforschung Beiträge zur Situation von Familien mit Migrationshintergrund, insbesondere der türkischen, vorhanden sind und seit einigen Jahrzehnten insbesondere Kinder und Jugendliche im Fokus der interkulturellen Bildungsforschung stehen, ist die Thematik der religiösen Sozialisation von muslimischen Kindern und Jugendlichen bzw. selbige in muslimischen Familien bis dato wenig erforscht worden. Dies liegt vor allem daran, dass bislang keine Betrachtung der Gruppe der Muslime mit ihrer Eigenschaft als Angehörige der Religion erfolgt ist, sondern vor allem türkische Familien nach ihren Erziehungsvorstellungen und -praktiken befragt wurden, die dann auch Vorstellungen über religiöse Erziehung beinhalteten (vgl. Karakaşoğlu/Öztürk 2007: 157).

Die Elternperspektive hinsichtlich religiöser Erziehungsvorstellungen mit ihren norm- und handlungsleitenden Prinzipien findet in kaum einer Untersuchung Berücksichtigung. Die vorliegende Studie beabsichtigt vor diesem Hintergrund, eine umfassende Darstellung unterschiedlicher sozialisationsrelevanter Einflüsse, die die Religiosität von muslimischen Kindern und Jugendlichen maßgeblich beeinflussen, aus dem Blickwinkel muslimischer Eltern.

Die im Folgenden aufgeführten Beiträge bieten ansatzweise Ergebnisse (mit unterschiedlichen Schwerpunkten), die im Zusammenhang mit der religiösen Sozialisation bzw. der religiösen Erziehung in muslimischen Familien mit türkischem Migrationshintergrund stehen. Aus diesen Quellen bzw. Beiträgen lässt sich eine Erziehungswirklichkeit in muslimischen Familien rekonstruieren, die auch Rückschlüsse auf den Stellenwert der Religion bei der Erziehung erlaubt. Es existieren folgende Arten an Quellen: 
a. Expertisen, Rezeptionsberichte bzw. Literaturanalysen

b. Untersuchungen, die, wenn auch in sehr geringem Maße, die Sicht der Eltern auf religiöse Erziehungsvorstellungen wiedergeben

c. Untersuchungen über Jugendliche, aus denen hervorgeht, wie die elterliche religiöse Erziehung wahrgenommen wird und welche Vorstellungen von religiöser Erziehung sie, bezogen auf die Gegenwart und Zukunft, entwickelt haben.

Schließlich konnten immer nur Teilaspekte der religiösen Sozialisation von Kindern und Jugendlichen in muslimischen Familien dargelegt werden. Im Rahmen der vorliegenden Untersuchung wird daher beabsichtigt, eine umfassende Darstellung unterschiedlicher sozialisationsrelevanter Einflüsse aus dem Blickwinkel muslimischer Eltern abzubilden.

\subsubsection{Religiöse Sozialisation in Familien - Ergebnisse aus Expertisen, Berichten und Untersuchungen}

Zunächst wird die Literatur, die aus (a) Expertisen, Beiträgen, Literaturanalysen und einigen (b) wenigen empirischen Ergebnissen besteht, rezipiert wiedergegeben. Die Literaturanalysen beziehen sich auf die Ergebnisse aus Studien (zu Migrationsfamilien), die weit zurück in die 1980er-Jahre reichen. Vielfach handelt es sich dabei um Untersuchungen, die durch die Migration bedingte Veränderungsprozesse in türkischen Familien aufzeigen. Der Faktor der Religiosität und der Einfluss der Religion auf das Erziehungsverhalten von türkischen Eltern ${ }^{16}$ werden innerhalb dieser Studien jedoch größtenteils nur am Rande erwähnt bzw. unzureichend thematisiert.

Stöbe (I998) setzt sich in seiner Literaturanalyse mit empirischen Untersuchungen zum Einfluss des Islams auf muslimische Familien mit türkischem Migrationshintergrund auseinander. Die von ihm analysierten quantitativ und qualitativ angelegten Untersuchungen reichen weit zurück in die 1980er-Jahre. Sie liefern Aussagen über Lebensbedingungen muslimischer Familien und Auswirkungen auf den Sozialisationsprozess ihrer Kinder, woraus auch ein »Bild « über diese im Hinblick auf die forschungsrelevante Frage abgeleitet werden soll. Die Analyse zeigt des Weiteren auf, wie elterlich angewandte Erziehungsmuster auf undifferenzierte Weise mit dem Islam gleichgesetzt wurden, ohne hierbei darauf zu achten, welche traditionellen und kulturellen Faktoren für ihr Erziehungsverhalten tatsächlich maßgeblich waren.

Stöbe kritisiert bei den Aussagen über Wertorientierungen die pauschale Herangehensweise bei der Identifikation »des Islams« (vgl. Stöbe 1998: 94). Die Undifferenziertheit, die frühere Untersuchungen und auch heutige Expertisen (vgl. auch in diesem Kapitel) aufweisen, veranlasste Stöbe dazu, die

16 | Einen diesbezüglichen Überblick bietet Karakaşoğlu-Aydın (2000: 79-97). 
Ergebnisse der Untersuchungen unter den Aspekten Kultur, Islam und Familie/ Sozialisation zusammenzufassen.

Hinsichtlich der Kultur wird anfangs für die quantitativen Untersuchungen festgestellt, dass Unterschiede zwischen der Kultur der Migranten und der Kultur der Aufnahmegesellschaft existieren. Es bestehe somit eine »kulturelle Distanz«, insbesondere hinsichtlich Erziehungsfragen und der Familienstruktur. Diese Distanz beziehe sich nicht auf Leistungsorientierung, sondern auf religiöse Bindungen und familiale Sozialisationseinflüsse. In der Aufnahmegesellschaft wirke Religion »als letzte Zufluchtsstätte« (vgl. Stöbe 1998: 132).

Unter dem Aspekt Islam wird einerseits konstatiert, dass der Islam als wesentliche Grundlage für Wertorientierungen betrachtet wird. Die Erziehung zum gläubigen Muslim sei für türkische Familien wichtig und der Islam biete den in Deutschland lebenden Muslimen einen Bezugsrahmen und damit auch eine Bezugsgruppe (vgl. Verweis auf verschiedene Autoren in: Stöbe 1998: 132f.).

Bei den qualitativ angelegten Untersuchungen handelt es sich weitgehend um biografische Fallstudien, ethnografische Studien und Niederschriften längerfristiger Beobachtungen. Hierbei wird deutlich, dass die Frage nach dem Einfluss des Islams in den Sozialisationsprozess türkischer Kinder manchmal am Rande, eher nebenbei, aufgegriffen wird (vgl. in: Stöbe 1998: 145-187; Lebensweltgeschichten: Mihçıyazgan 1986; Ethnologische Studien: Schiffauer 1991; Pfluger-Schindlbeck 1989; u.a.). So stellt Stöbe zusammenfassend fest, dass der Einflussfaktor »Islam« in künftigen Studien in Bezug auf das familiäre Interaktionsgeschehen wesentlich differenzierter betrachtet und gesondert nach religiösen und kulturell bedingten Wirkfaktoren analysiert werden muss (vgl. Stöbe 1998: 189f.).

Insgesamt schlussfolgert Stöbe, dass Migration die türkische Familienstruktur ändert. Sie führe häufig dazu, das Gegebene kritisch zu reflektieren. Die Frage nach der eigenen Identität sei dabei ein wesentliches Kriterium, das die Migranten und Migrantinnen besonders beschäftige (vgl. Stöbe 1998: 189). Eine Differenzierung von kulturellen und religiösen Einflüssen sei hierbei besonders wichtig. Des Weiteren könne nicht von »dem Islam« als solchem gesprochen werden. Zudem müsse vor zu einfachen Deutungen und vor einer zu schnellen Gleichsetzung von Aussagen des Korans mit der Alltagswirklichkeit gewarnt werden (vgl. Stöbe 1998: 195).

Neben der eingeschränkten Repräsentativität, die ihre Ursachen in der methodischen Durchführung der Untersuchungen und der fehlenden Aktualität habe, können die Ergebnisse laut Stöbe als Basis für Hypothesen angesehen werden (vgl. Stöbe 1998: 131).

Die Ergebnisse, zu denen Stöbe aufgrund seiner Literaturanalyse kommt, lassen die Frage nach dem Spezifischen an der religiösen Sozialisation von Muslimen und ihren Kindern in einer pluralistischen Gesellschaft offen. Hier- 
bei ist es wichtig, kulturelle, soziale und sozioökonomische Einflüsse nicht mit den Einflussfaktoren der Religion zu vermischen und eine differenzierte analytische Vorgehensweise auszuwählen, um herausstellen zu können, was unter »religiöser Erziehung « verstanden wird und an welche normativen, orientierungs- und handlungsleitenden Prinzipien diese angekoppelt werden. Wie der Grad der Religiosität bzw. des »Religiösen « an der Erziehung gemessen werden kann, ist daher für die vorliegende Untersuchung von zentraler Bedeutung.

Yalçın-Heckmann (1998) untersucht in ihrer zwischen 1990 und 1993 in Nürnberg durchgeführten Feldstudie ${ }^{17}$ die religiösen Entwicklungen in der türkischen Migrationsgruppe. Sie legt dabei ihren Schwerpunkt auf die »religiöse Sozialisation in Migrantenfamilien «. Ziel war hier die Erfassung der Rolle (»Zentralität oder Marginalität«) der Religion im Alltagsleben der türkischen Migrationsfamilien, der Prozesse religiöser Sozialisation, religiöser Praxis und die jeweiligen Einstellungen in den Familien.

Nach einer Beschreibung der sozialen und familiären Situation von Migrationsfamilien, fasst Yalçın-Heckmann (1998) die wichtigsten Ergebnisse zusammen. Zunächst wird das Verhältnis der Eltern zu ihren Kindern in einen Zusammenhang mit der religiösen Erziehung im Elternhaus, in der Schule und in der Moschee gesetzt. Der überwiegende Anteil der Eltern (44 von 49) befürwortet den Korankursbesuch, der durch verschiedene religiöse Organisationen angeboten wird. Es gibt zwar eine breite Zustimmung (für den Korankursbesuch), jedoch scheint dies eher prinzipieller Natur zu sein und die Vorstellung als solche findet Anklang, denn in der Tat besucht (16 von 34) gerade mal die Hälfte der Kinder einen Korankurs in der Moschee. Viele Eltern begründen ihre Unzufriedenheit mit der politischen Ausrichtung der religiösen Organisationen. Dabei wird auch die fachliche Qualifikation der Imame kritisiert, was ein Grund für das fehlende Interesse darstellt, ihre Kinder in die Moschee bzw. Korankurse zu schicken. Zahlreiche Eltern befürworten die besondere

17 | Die von inr vorgestellte Studie liegt in Form eines Rezeptionsberichtes vor und bezieht sich auf eine fallanalytische Darstellung von vier Familien mit türkischem Migrationshintergrund. Die Untersuchung beschränkt sich auf die Erfassung der sunnitischmuslimischen Religiosität. Die ursprüngliche Datenbasis setzt sich aus 82 qualitativen Interviews mit Mitgliedern verschiedener Generationen (Interviews mit 8- bis 9-jährigen Kindern, 14- bis 15-jährigen Jugendlichen und Elternteilen beiden Geschlechts) aus 30 türkischen Familien in Nürnberg sowie einer nicht bezifferten Anzahl von Multiplikatoreninterviews mit türkischen Lehrern und Imamen zusammen. Zur Vertiefung wurden teilnehmende Beobachtungen in Schulen und Moscheen Nürnbergs einbezogen. Der Anspruch auf Repräsentativität ist hier zwar nicht gegeben, doch aufgrund der Tatsache, dass hier ein Forschungsdesiderat existiert, wurden die Ergebnisse trotz ihrer fehlenden Aktualität aufgeführt, um wenigstens für den Forschungszusammenhang einige ableitbare Hypothesen bzw. Fragestellungen zu bilden. 
Bedeutung des Koranunterrichts, in dem religiöses Wissen über die islamische Religion und Kultur vermittelt wird. Dieses Wissen ist für einige Eltern innerhalb der eigenen Gemeinschaft identitätsfördernd und man erlerne auch soziale Fertigkeiten. Wieder andere betonen denbesonderen Stellenwert des Erlernens von grundlegenden moralischen Werten. Schließlich stelle für einige andere dieses Wissen die Voraussetzung für den Glauben dar und ein Leben ohne Glauben sei für die meisten letztlich undenkbar (vgl. Yalçın-Heckmann 1998: 167).

Die Wissensaneignung stellt für die Eltern ein wichtiges Kriterium dar. Das »technische« Erlernen der Glaubensgrundlagen und der fünf Säulen des Islams, womit auch auf das Auswendiglernen Bezug genommen wird, erfüllt hier eine wichtige Funktion, nicht zuletzt vor dem Hintergrund, dass dieses einen wichtigen Einfluss auf verschiedene andere Lebensbereiche ausübt. Damit würden Grundlagen für eine moralische Erziehung gelegt, durch die die Kinder sich $\mathrm{zu}$ ausgeglichenen verantwortungsbewussten Persönlichkeiten entwickeln sollen (vgl. Yalçın-Heckmann 1998: 167f.).

Obgleich das Erlernen von religiösen Inhalten als eine Voraussetzung für die Bewahrung des eigenen Glaubens gilt, stellt die Beziehung zwischen Glauben und religiöser Praxis, die sich in der Befolgung der rituellen Handlungen und Vorschriften äußert, ein komplexes Phänomen dar. Viele Eltern (mehr Frauen als Männer) wünschen für sich und ihre Kinder eine religiöse Lebensführung, die der wichtigste Aspekt in ihrem Leben sein sollte. Sie stimmen darin überein, dass ihre Kinder die Vorschriften ihrer Religion einhalten lernen sollen, doch ist es wichtig, dass dies von »innen« (türk. >içinden geldi<) kommt, d.h., dass man die religiösen Pflichten freiwillig und ohne Zwang befolgt (vgl. Yalçın-Heckmann 1998: 168). Die religiöse Erziehung ist im Hinblick auf die soziale Kompetenz, die religiöse Handlungskompetenz und als moralische Richtschnur für die Eltern bedeutsam.

Was die religiöse Praxis angeht, gibt es große Unterschiede bei den einzelnen Familien. Generell konnte festgestellt werden, dass Kinder in ihrer religiösen Praxis weitgehend derjenigen der Eltern folgen. Dabei spiele der Grad der Beziehungen zur deutschen Umwelt keine besondere Rolle. Jedoch würden sie dazu neigen, die Umstände des Lebens in der Migration als Gründe anzugeben, die es ihnen nicht möglich machen würden, die religiösen Pflichten angemessen zu befolgen (vgl. ebd.).

Die Auswertung ergab ferner, dass von den nach Deutschland eingewanderten Familien und deren Kindern, die hier geboren wurden, die religiöse Erziehung nicht auf einen bestimmten Elternteil festgelegt ist.

Des Weiteren wurde festgestellt, dass die Haltung der Jugendlichen zu ihrer Religion, $z u$ ihrem Glauben eng in Zusammenhang mit der Haltung und dem Glauben der Eltern steht (vgl. Yalçın-Heckmann 1998: 170). 
In ihrer fallanalytischen Darstellung der Untersuchungsergebnisse von vier Familien konstatiert Yalçın-Heckmann, dass sich die Familien im Hinblick auf die religiöse Orientierung ihrer Mitglieder sowie die religiöse Erziehung der Kinder deutlich voneinander unterscheiden. Sie schließt daraus, dass sich die religiöse Sozialisation von türkischen Kindern und Jugendlichen auf sehr unterschiedlichen Ebenen, je nach Familie, überaus differenziert vollzieht. Ähnlich wie es bereits der oben ausgeführten Feststellung von Stöbe aus demselben Jahr zu entnehmen ist, kann somit laut Yalçın-Heckmann weder von einem einheitlichen kulturellen Hintergrund noch von einheitlichen religiösen Traditionen innerhalb einer Familie, geschweige denn jedoch innerhalb der türkischen Community insgesamt ausgegangen werden.

Kanacher (200I) geht in ihrer Literaturanalyse ${ }^{18}$ auf der Basis von theoretischer und empirischer Literatur der Frage nach, inwiefern sich potenzielle Kultur- und Identitätskonflikte muslimischer Migranten, die sich im Kontext ihrer religiösen Sozialisation ergeben, präsentieren können. Sie nähert sich ihrem »Problemfeld « anhand sozialisationstheoretischer und religionssoziologischer Vorüberlegungen und entwickelt schließlich das theoretische Konzept von einem »idealtypischen« Identitätsverständnis. Dabei geht sie von einem Antagonismus zwischen der christlich geprägten westlichen Moderne und dem Islam aus, woraus eine antagonistische Gesellschaftssituation resultiere (vgl. auch Kanacher 2003).

Dem konfliktorientierten und auf Dichotomien basierendem Blickwinkel Kanachers kann jedoch nur bedingt zugestimmt werden. Dabei ist zu berücksichtigen, dass nicht nur die fehlende Aktualität ihrer dargestellten empirischen Bezüge, sondern vor allem auch der von ihr ausgewählte theoretische Bezugshorizont, der seit Beginn der Migration einigen zentralen Entwicklungen unterworfen war, es erschwert, Kanachers Sichtweise zu folgen. Die Ergebnisse der empirischen Literatur spiegeln die Grundgedanken früherer Veröffentlichungen wider, deren Aktualität jedoch aufgrund von Veränderungsprozessen ${ }^{19}$ und nicht zuletzt auch aufgrund mangelnder Studien im Bereich der religiösen Erziehung kritisch zu hinterfragen ist. Die unreflektierte Übernahme veralteter Untersuchungsergebnisse führt bis heute zu widersprüchlichen und verwirrenden Ergebnissen (vgl. auch oben Stöbe 1998).

In ihrem Beitrag (Rezeptionsbericht) stellen Karakaşoğlu/Öztürk (2007) die Erziehung und das Aufwachsen junger Muslime in Deutschland dar. Dabei berücksichtigen sie sowohl das islamische Erziehungsideal, das sich primär auf die Quellen des Islams, des Korans und die Überlieferungen des Propheten

18 | Vgl. Kanacher, Britta (2001): Religiöse Sozialisation und Individualisierung - Zum religiösen Kultur- und Identitätskonflikt muslimischer Migranten.

19 | Die neuere Forschung deutet auf einen Wandel der Familien unter Migrationsbedingungen hin (vgl. Boos-Nünning/Karakaşoğlu 2006: 97-103). 
stützt, als auch die empirische Erziehungswirklichkeit ${ }^{20}$ in der Migrationsgesellschaft.

Im Folgenden soll jedoch auf die ausführliche Beschreibung idealer Erziehungsvorstellungen und einem entsprechenden Aufwachsen nach islamischer Auffassung verzichtet werden. Vielmehr werden die Ergebnisse dargestellt, zudenen Karakaşoğlu/Öztürk (2007) aufgrund der von ihnen veranschaulichten Datenlage kommen.

Die Ausführungen zum islamischen Erziehungsideal machen deutlich, dass die Religion selbst einen hohen Anspruch an die religiöse Mündigkeit und den allgemeinen Bildungsstatus der Eltern stellt. Das Erziehungshandeln in muslimischen Familien ist demzufolge die Erziehung zu einem gläubigen, kenntnisreichen und mündigen Menschen, der nützlich für die Gesellschaft ist. Dabei stellt sich die Erziehungswirklichkeit vielfach anders dar, nicht zuletzt aufgrund der überwiegend geringen Bildungsvoraussetzungen sowohl im Hinblick auf weltliches Wissen wie auch religiöses Wissen bei der muslimischtürkischen Elterngeneration in der Migration (Karakaşoğlu/Öztürk 2007: 161).

Es stellt sich grundsätzlich heraus, dass Religion für ältere wie jüngere Muslime in Deutschland einen hohen identifikatorischen Wert besitzt. Der religiösen Erziehung und dem Aufwachsen in Familien mit türkischem Migrationshintergrund wird in der Regel generationsübergreifend ein hoher Stellenwert zugesprochen.

Muslimische Eltern mit türkischem Migrationshintergrund erachten es als wichtig, dass ihre Kinder den Koran auf Arabisch rezitieren und bestimmte religiöse und kulturelle Normen und Werte kennenlernen (Gebete, rituelle Waschung, Feiertage, Respekt vor Älteren). Noch bevor ein Kind am Koranunterricht teilnimmt, findet eine allgemeine religiöse Erziehung innerhalb der Familie statt. Die Intensität und wohl auch die Qualität der religiösen Erziehung kann, je nachdem, wie religiös versiert die Eltern oder andere Verwandte (Großeltern, Onkel oder Tanten) im näheren Umfeld sind, unterschiedliche Ausprägungen haben. Die Kinder werden einerseits durch familiäre Vorbilder (»Vorleben«, »Imitation«), andererseits durch eine kindgerechte Vermittlung religiöser Inhalte in einer altersgemäßen Sprache an die Religion herangeführt. Nur in seltenen Fällen unterrichten Eltern oder andere Verwandte die Kinder ausdrücklich im familiären Rahmen. Bei der Vermittlung von Grundfertigkeiten für die religiöse Praxis werden insbesondere Angebote der Moscheevereine und -gemeinden wahrgenommen. Dies geschieht vor dem Hintergrund, dass viele Eltern ihr eigenes Wissen über die Religion sowie ihre religiöse Praxis nicht als ausreichend betrachten, um ihren Kindern das vom Islam geforderte

20 | Diese werden methodisch unter Einbezug verschiedener Untersuchungen über Migrationsfamilien und über Jugendreligiosität von jungen muslimischen Frauen und Männern erschlossen. 
Vorbild zu sein. Diese Tatsache verweise auf ein Auseinanderdriften bzgl. der Erfüllung diesbezüglicher Ansprüche bzw. deren Weitergabe an die nächste Generation (vgl. Karakaşoğlu/Öztürk 2007: 166).

Die nächste Studie bestätigt den hohen Stellenwert der Erziehung der eigenen Kinder. Die religiöse Erziehung stellt für einen hohen Anteil an Muslimen einen wichtigen Bezugshorizont dar. Im Religionsmonitor der Bertelsmann Stiftung (2008b), einer quantitativ durchgeführten Repräsentativbefragung in Deutschland, wird die zentrale Bedeutung der Familie und der Religiosität bestätigt: Dabei ist für Muslime in Deutschland der Bereich Familie und Bildung (94\%) von enormer Wichtigkeit. Die religiöse Erziehung spielt für die meisten Muslime eine große Rolle. Es geben 66 \% der Befragten an, selbst religiös erzogen worden zu sein, und für $51 \%$, also rund die Hälfte aller befragten Muslime, hat die persönliche Religiosität auch einen großen Einfluss hinsichtlich der Erziehung der eigenen Kinder. Insgesamt macht die Studie deutlich, dass Religiosität viel stärker alltags- und lebensbezogen wahrgenommen wird (vgl. Bertelsmann 2008b: 8 und 22).

In der Expertise, die Uslucan (2008) im Auftrag des Bundesministeriums für Familie, Senioren, Frauen und Jugend (BMFSFJ) erstellte, bietet er einen Überblick über zentrale Aspekte islamischer Erziehung und ihrer Implikationen für die kindliche Entwicklung. Dabei stehen muslimische Migrationsfamilien und ihre erzieherischen Kontexte im Vordergrund. Aufgrund der fehlenden Forschung, die in diesem Bereich zu vermerken ist, wurden für die Expertise Quellen unterschiedlichen Wissenschaftsgrades herangezogen. Es werden »islamische Erziehungsmanuale« hierbei angeführt, die einerseits normative Ansprüche einer religiösen Erziehung aufzeigen, die »ideale« Erziehungsvorstellungen markieren und dabei sowohl auf den Koran wie auf Vorbilder islamischer Geschichte, beginnend mit dem Propheten, rekurrieren (vgl. Uslucan 2008: 2). In diesen Erziehungsmanualen wird jedoch die Übersetzbarkeit dieser Ideale in die Lebenswirklichkeit der Moderne nur selten thematisiert, sie spiegeln somit letztlich konzeptionelle normativ begründete Erziehungsvorstellungen verschiedener Autoren wider (vgl. ebd.).

Uslucan (2008) bezieht sich andererseits sowohl auf allgemeine erziehungswissenschaftliche Erkenntnisse als auch auf Befunde aus der Migrationsforschung und der Religionspsychologie (vgl. ebd.: 2-9). Auch psychologische und kulturvergleichende Forschungen zu Themen wie Akkulturationsbelastungen in Migrationsfamilien sowie Werteauffassungen im interkulturellen Vergleich werden als weitere Quellengrundlage integriert (vgl. ebd.: 9-12).

Gerade innerhalb dieser Quellen findet die Religion oder Religiosität als Einflussfaktor auf das elterliche Erziehungsverhalten in muslimischen Familien in empirisch nachweisbarer Form kaum Berücksichtigung. Die Ergebnisse, zu denen Uslucan (2008) auf der Basis der von ihm angeführten Literatur kommt, bilden vielmehr eine Informationsgrundlage, woraus Hypothesen für 
die religiöse Erziehung in muslimischen Familien gezogen werden können. Sein Fokus richtet sich dabei insbesondere auf eine psychologische Betrachtungsweise. Erschwerend kommt hinzu, dass mit den empirischen Untersuchungen zu Migrationsfamilien eher auf ihre Religionszugehörigkeit (vgl. Kap. II.1.1 und II.1.2) als auf ihre religiösen Einstellungen und ihre religiöse Lebensweise abgezielt wird. Dessen ungeachtet, beinhalten die von ihm abgeleiteten Erkenntnisse mögliche Deutungspotenziale im Hinblick auf die Erklärung von religiöser Sozialisation in einer nichtmuslimischen Umwelt bzw. in der Diasporasituation. Diese Aspekte greift er auch in einem weiteren aktuelleren Beitrag unter dem Blickwinkel der Integration muslimischer Kinder in die Gesellschaft wieder auf (vgl. Uslucan 2015).

El-Mafaalani und Toprak (20II) analysieren in der von der Konrad-Adenauer-Stiftung herausgegebenen Expertise die Sozialisationsbedingungen der in Deutschland geborenen Migrantenkinder. Sie beziehen sich hierbei besonders auf frühere Studien (vgl. El-Mafaalani/Toprak 2011: 42 ff.), deren Aktualität jedoch inzwischen nicht mehr gegeben ist. Die unreflektierte Übernahme dieser Ergebnisse wirkt eher verwirrend, als dass sie zur Aufklärung der Situation »muslimischer« Familien beitragen könnte.

Gemäß El-Mafaalani und Toprak handelt es sich um einen selektiven Ausschnitt, in dem Muslime in Deutschland thematisiert und Kindheit und Jugend in »traditionell-muslimischen« Milieus beleuchtet würden (vgl. El-Mafaalani/ Toprak 2011: 9). Sie differenzieren zwischen den Sozialisationsinstanzen Familie, Schule und Peers. Ihre analytischen Betrachtungen, die auf der Basis von Sekundärliteratur und Untersuchungen analysiert werden, weisen auf differente Lebenswelten von »muslimischen« Jugendlichen hin.

Jedoch muss hier, wie schon in den vorangegangenen Expertisen, darauf hingewiesen werden, dass die rezipierte Literatur nicht immer deutlich macht, welche Rolle die Religion tatsächlich in den Lebenswelten der Jugendlichen spielt. Folglich stellt sich auch hier die Frage, wieso implizit immer direkt von »muslimischen « Familien ausgegangen wird und nicht von Familien und Jugendlichen, die zwar einen eindeutigen Migrationshintergrund aufweisen, aber anhand derer das Ausmaß bzw. ihre Selbsteinschätzung im Hinblick auf ihre Religiosität kaum deutlich wird. ${ }^{21}$

In ihrer Expertise Migrationsfamilien als Partner von Erziehung und Bildung analysiert Boos-Nünning (2011a) differenziert die Lebenssituation und die Familienstrukturen von Migrationsfamilien. Dabei richtet sie ihr besonderes Augenmerk auf die in den Familien wirksamen Werte und Erziehungsziele, zu denen auch Religiosität gehöre. Sie konstatiert, dass im Vergleich zwischen Migrationsfamilien und einheimischen Familien hinsichtlich der Wertorien-

21 Auch die Expertise von Thiessen (2008) kann in diesem Zusammenhang erwähnt werden. 
tierungen Unterschiede bestehen. Für Migrationsfamilien sei neben dem $\mathrm{Fa}$ milialismus, hohen Bildungsaspirationen ${ }^{22}$ vonseiten der Eltern für ihre Kinder, Respekt ${ }^{23}$ und Achtung vor Älteren, Zwei(Mehr)sprachigkeit, einer konventionellen Sexualmoral, die religiöse Erziehung bzw. die Religiosität von zentraler Bedeutung. ${ }^{24}$ Des Weiteren wird angemerkt, dass innerhalb dieser Bereiche die Vorstellungen zwischen Migrationsfamilien stark variieren würden. Während ein Teil der Untersuchungen von einer wert- und traditionsgebundenen Erziehung ausgeht, betonen andere Untersuchungen, dass in den Familien, unabhängig von Migrationshintergrund, Geschlecht und Bildungsniveau, ein ähnliches Spektrum an Erziehungsvorstellungen vorhanden sei. Dabei gilt es als unstrittig, dass die in den Familien vertretenen Werte einen großen Einfluss auf die Erziehung und Bildung haben.

Aufgrund der Tatsache, dass es bei den Eltern keine Untersuchungen für alle Wertebereiche gibt, müsse man hier methodisch auf Vorstellungen junger Männer und Frauen oder auf die erlebten Erziehungswerte zurückgreifen (vgl. Boos-Nünning 2011a: 23-32).

Die Beschäftigung mit den Werten und mit Erziehungsstilen fordere zum Nachdenken und zur Auseinandersetzung mit stereotypisierenden Vorstellungen über Migrationsfamilien in der (einheimischen) deutschen Gesellschaft auf (vgl. Boos-Nünning 2011a: 23-32; vgl. auch Seiser 2006: 355-359).

Die folgenden Ergebnisse der Shell Jugendstudie (2000) spiegeln den von Boos-Nünning in ihrer Expertise ausgeführten Vergleich der Werthaltungen zwischen Migrationsfamilien und deutschen Familien wider.

Die Zusatzstudie (2000) der »Shell Jugendstudie«, die qualitativ ausgerichtet ist, zeigt anhand der biografischen Methode Porträts von 32 Jugendlichen in Deutschland.

Für die türkischen Jugendlichen lassen sich folgende Ergebnisse ableiten: Die Eltern und die Wertschätzung von Familie und Freunden sind für deutsche wie für türkische Jugendliche von besonderer Bedeutung. Dies gilt, obwohl die Erziehung in türkischen Elternhäusern als streng oder zu streng bemängelt wird. Auch Respekt spielt neben der starken Familienbezogenheit eine wichtige Rolle. Über Eltern wurde mit Achtung und Respekt gesprochen, selbst wenn kritische Worte für ihr Verhalten gefunden wurden. Auch um der sozial geprägten Wahrung der Ehre (auch Sexualmoral) willen sehen türkische Jugend-

22 | Vgl. auch Boos-Nünning 2013 und Boos-Nünning 2011b.

23 | Vgl. auch Hunner-Kreisel 2010: 180-189.

24 | Seiser kommt in ihrer Studie zum Wertewandel und der Tradierung von Werthaltungen in türkischen Migrationsfamilien zu ähnlichen Ergebnissen. Besonders deutlich trete eine hohe Bedeutsamkeit der Werte Respekt, soziale Anerkennung und Zusammengehörigkeit in sozialen Beziehungen hervor (vgl. Seiser 2006: 355). Auch die Erfüllung religiöser Pflichten sei für Migrationsfamilien sehr wichtig (vgl. ebd.: 320ff.). 
liche, vor allem Mädchen, große Unterschiede zu ihren deutschen Freunden und Freundinnen. Ehre und Zusammenhalt sind hier zentrale Werte. Ängste, die Familie durch falsches Verhalten in Verruf zu bringen, würden sowohl türkische Mädchen als auch Jungen teilen (vgl. Blank 2000: 9-18).

Ein wichtiges Erziehungsziel, das mit großer Wahrscheinlichkeit auch im vorliegenden Untersuchungszusammenhang bei der Befragung der Eltern Erwähnung finden wird, ist die Sexualmoral2 ${ }^{25}$. Es ist womöglich davon auszugehen, dass Eltern mit dieser Thematik Befürchtungen und normativ bedingte Grenzverletzungen (außerehelichen Geschlechtsverkehr; im sozialen Kontext etwa die »Achtung der Ehre«) verbinden (vgl. Schiffauer 1991), was sie tendenziell zu einer religiöseren Erziehungseinstellung und zu einem entsprechenden Erziehungshandeln tendieren lässt.

Schließlich werden in der aktuelleren qualitativ angelegten Untersuchung von Ceylan (20I4) Experten und Expertinnen ${ }^{26}$ befragt, die Auskunft über die Entwicklungen zur Moscheekatechese (vgl. auch Kap. II. 2.2.1) und zum islamischen Religionsunterricht im Kontext von Säkularsierung geben. Da sich diese auch zur religiösen Erziehung in muslimischen Familien und ihrem Bedeutungswandel im Zuge von Individualisierungs- und Säkularisierungsprozessen geäußert haben, können, unabhängig von den letzten beiden Aspekten, einige wichtige Ergebnisse zusammenfassend aufgezeigt werden. Die Erkenntnisse und Erfahrungen der Experten und Expertinnen basieren auf der Grundlage der von ihnen geleisteten Bildungsarbeit in den Moscheen. Hierbei verweisen sie auf mehrere Aspekte der religiösen Erziehung in den Familien. Sie gehen davon aus, dass der Großteil der befragten Eltern über ein niedriges religiöses Bildungsniveau verfügt und nur ein geringer Anteil von ihnen imstande ist, eine bewusst religiöse Erziehung an ihre Kinder weiterzuvermitteln. So wird schon im Anmeldeverfahren zum Moscheeunterricht bzw. für die »Gemeindekatechese« (vgl. Ceylan 2014: 333) von Kindern und Jugendlichen ausgegangen, die in unterschiedlichem Maße religiös sozialisiert sind. Diese können in zwei Kategorien unterteilt werden:

"Kinder, deren Eltern die Religion zu Hause praktizieren und religiöse Normen nicht nur oral, sondern auch mithilfe von Materialien vermitteln und Kinder, die aus nicht-praktizierenden Familien kommen und eine muslimische Identität - als Bewusstsein, der isla-

25 | Vgl. in Boos-Nünning 2011a: 28-31 „Erziehungsziel: Sexualmoral und Geschlechtertrennung"; vgl. auch Schäfer/Schwarz 2007: 251-281: "Zwischen Tabu und Liberalisierung - Zur Sexualität junger Muslime".

26 | Es wurden insgesamt 29 Experten und Expertinnen (Imame, Vorstand, Prediger/innen, die der DITIB und der Schura Niedersachsen angehören, interviewt (vgl. Ceylan 2014: 234f.). 
mischen Gemeinschaft anzugehören - besitzen, Glaubensinhalte aber bis zum Eintritt in die Moscheekatechese weitgehend oral vermittelt bekamen." (Ceylan 2014: 333)

Die erste Gruppe von Eltern erzieht ihre Kinder auf der Basis von »idealen« Erziehungsvorstellungen, denen normative Überzeugungen (Glaubenselemente und religiöse Praxis) zugrunde liegen (vgl. für die Beschreibung religiöser Erziehung in muslimischen Familien aus der Perspektive von Experten und Expertinnen Ceylan 2014: 324-332). Die Kinder der Eltern, die der zweiten Kategorie zugeordnet werden, haben etwa bis zum sechsten Lebensjahr keinen Bezug zur Moschee. Jedoch werden in diesen Familien bestimmte religiöse Rituale oder zentrale Glaubenselemente vermittelt, um eine »muslimische Identität« aufzubauen (vgl. ebd.: 333). Hierbei sei ein Formalismus zu beobachten, bei dem in einer unreflektierten Art und Weise zentrale Glaubensinhalte, vermengt mit traditionellen Elementen an die Kinder weitergegeben würden. Im Gegensatz zu den Eltern, die ihre religiöse Erziehungsverantwortung bewusst und autonom angehen würden, sei das Verhalten dieser Eltern durch die Delegation ihrer Erziehungsaufgabe an Moscheegemeinden und an weitere Autoritäten im Bekanntennetzwerk und Verwandtschaftskreis bestimmt. Kritisiert wird an ihnen sowohl ihre fehlende Vorbildfunktion, der Einsatz einer Angstpädagogik oder die Vermittlung eines strafenden Gottesbildes, was infolge von Überforderung geschehe (vgl. ebd.: 334-338). Ceylan folgert insgesamt, dass religiös gebildete Familien mit Gemeindegebundenheit eine bessere religiöse Erziehung anbieten könnten (vgl. ebd.: 338).

Sowohl die Delegation der elterlichen religiösen Erziehungsverantwortung an die Moscheegmeinden als auch die hohen Erwartungen an einen guten qualifizierten Unterricht würden auf eine Divergenz zwischen Anspruch und Realität verweisen. So verdeutlicht Ceylan, dass die Moscheegemeinden mit den hohen und vielfältigen Erwartungen, die muslimische Familien an sie stellen würden, überfordert seien. Weder könnten sie dem idealisierten Bild der Moscheen entsprechen, weil dies nicht die realen Bedingungen widerspiegele, noch würden die vorhandenen Ressourcen ausreichen, um einen qualifizierten Unterricht anbieten zu können (vgl. Ceylan 2014: 340ff.). Ceylan analysiert im weiteren Verlauf der Studie sowohl die Rahmenbedingungen als auch die Inhalte, Methoden, Lehrpläne, Materialien, Freizeitangebote usw. der Moscheekatechese, die er als solche bezeichnet.

Schließlich verweist Ceylan auf die erforderliche Kooperation zwischen Elternhaus und Moscheegemeinde, um die jeweiligen Bedürfnisse (der Eltern) zu ermitteln und abzugleichen. Hieraus könne nicht zuletzt eine gegenseitige Wertschätzung und ein Vertrauensverhältnis zwischen allen Beteiligten erwachsen (vgl. Ceylan 2014: 379-385). 


\subsubsection{Das Aufwachsen in muslimischen Familien - Ergebnisse aus empirischen Untersuchungen}

Im Folgenden sollen (c) Untersuchungen (vgl. oben) vorgestellt werden, in denen die Erfahrungen der Jugendlichen mit einer familiären Erziehung beschrieben werden. Diese geben Hinweise darauf, wie das elterliche Erziehungsverhalten im Hinblick auf die religiöse Erziehung von den Jugendlichen erlebt wurde und welche Vorstellungen sie selbst entwickelt haben. Es werden zunächst qualitative Untersuchungen und im Anschluss quantitativ angelegte Untersuchungen vorgestellt.

In ihrer Untersuchung Muslimische Religiosität und Erziehungsvorstellungen geht Karakaşoğlu-Aydın (2000) der Frage nach, welche Bedeutung die Religiosität für das Selbstverständnis der zweiten Generation muslimischer Migrantinnen ${ }^{27}$ hat und inwiefern spezifisch islamisch-religiöse Orientierungen mit religiös-normativen Erziehungsvorstellungen verbunden sind. Die Erhebung eines möglichst breiten Spektrums religiöser Orientierungen unter muslimisch sozialisierten Migrantinnen mit türkischem Migrationshintergrund ermöglicht es ihr, eine Typologie der Probandinnen vorzunehmen, um die umfassenden und miteinander zu vergleichenden Erscheinungsformen ihrer Religiosität/religiösen Orientierungen und ihre damit im Zusammenhang stehenden Erziehungsvorstellungen wiederzugeben (vgl. Karakaşoğlu-Aydın 2000: 160-167). Die Bezugnahme auf den Glock'schen Ansatz der »Dimensionen der Religiosität« hilft, die im Sample vorkommenden verschiedenen Formen der Religiosität durch eine differenzierte Typenbildung zu erfassen. Es werden sechs Typen religiöser Orientierung identifiziert: Atheistinnen, Spiritualistinnen, sunnitische Laizistinnen, alevitische Laizistinnen, pragmatische Ritualistinnen und idealistische Ritualistinnen (vgl. ebd.: 178-182). Ausgehend von diesen Typologien, werden jeweils die religiöse Einstellung und die jeweiligen familiären und religiösen Erziehungsvorstellungen abgebildet (vgl. ebd.: 183412).

Anhand der Studie wird deutlich, dass für die Gruppe der Hochschulstudierenden die Kognition und Wissensaneignung ein identitätsbestimmendes Merkmal darstellt und dies eine Abwendung von dem traditionalistischen Religiositätsverständnis der Eltern zur Folge hat. Es wird von den Probandinnen ein intellektueller Zugang zu ihrer religiösen Orientierung befürwortet, der sich mit ihrem gehobenen Bildungsstatus erklären lässt. Nach Karakaşoğlu-Aydın

27 | Die Untersuchungsgruppe von Pädagogik- und Lehramtsstudentinnen, der sich Karakaşoğlu-Aydın (2000) widmete, ist eine Gruppe weiblicher Studierender türkischmuslimischer Herkunft. Hierunter befanden sich neun Studentinnen der Diplom-Pädagogik, eine Sozialpädagogikstudentin und 16 Lehramtsstudentinnen im Alter zwischen 20 und 26 Jahren. Die Untersuchung wurde zwischen Mai 1996 und Januar 1997 durchgeführt. 
manifestiert sich ihr modernes religiöses Selbstverständnis in der Hinterfragung der von den Eltern als religiöse Dogmen vermittelten Verhaltensnormen und somit in der Ablehnung von Traditionalismus (vgl. Karakaşoğlu-Aydın 2000: 414f. und Karakaşoğlu-Aydın 2001: 26). Kritik sowohl gegenüber elterlicher religiöser Erziehung als auch elterlicher Erziehungsmaßnahmen deuten im Bereich der Erziehungsvorstellungen auf einen zentralen Wandel hin.

Es ist ein breites Spektrum an religösen und familiären Erziehungsvorstellungen unter den Probandinnen zu verzeichnen. Diese Vorstellungen sind allerdings nicht auf konkrete Erziehungssituationen bezogen und stellen somit Antizipationen dar.

Karakaşoğlu-Aydın (2000) unterscheidet innerhalb der Gruppen zwischen zwei verschiedenen Ebenen. Demnach betrifft die erste Ebene die Frage, ob die Probandinnen a) religiöse Vorstellungen in ihre allgemeinen Erziehungsvorstellungen einbinden oder ob sie b) religiöse getrennt von allgemeinen Erziehungsvorstellungen betrachten. Es wird festgestellt, dass nur eine bestimmte Probandinnengruppe (Ritualistinnen) eine islamisch fundierte Basiserziehung befürworten, während die restlichen Typen zwischen einer allgemeinen und einer religiösen Erziehung trennen. Auch im Zusammenhang mit perzipierten Erziehungsstilen kommt die Autorin zu differenzierten Ergebnissen (vgl. Karakaşoğlu-Aydın 2000: 425ff.).

Es lassen sich sehr unterschiedliche Vorstellungen von religiöser Erziehung feststellen. Dabei besteht ein eindeutiger Zusammenhang zwischen der eigenen Religiosität und der für die Kinder gewünschten Intensität religiöser Erziehung (vgl. Karakaşoğlu-Aydın 2000: 431f.).

Die meisten Probandinnen würden sich bzgl. der religiösen Erziehung durch ihnen bekannte Einrichtungen, wie die Korankurse oder einen einzurichtenden islamischen Religionsunterricht an Schulen, unterstützen lassen, auch wenn bei einigen negative Erfahrungen damit verbunden sind (vgl. Karakaşoğlu-Aydın 2000: 433).

Diese Studie weist eine Spannbreite an religiösen Erziehungsvorstellungen und perzipierten Erziehungsstilen auf, die zu einer differenzierten Wahrnehmung hinsichtlich der Variabilität von (religiösen) Erziehungsvorstellungen führt. Auch konnte anhand dieser Studie gezeigt werden, welche Rolle der Islam im Sozialisationsprozess im Vergleich zu den vorher vorgestellten Expertisen usw. tatsächlich spielt bzw. spielen »soll«, ohne dabei verschwommen zu wirken. Dennoch muss hier angemerkt werden, dass es sich primär um Erziehungsvorstellungen handelt. Es werden bzw. können keine Angaben darüber gemacht werden, wie die befragten jungen Frauen ihre Vorstellungen in die Erziehungspraxis umsetzen (wollen/konnten).

Gerade hierauf liegt für den vorliegenden Zusammenhang ein besonderes Augenmerk. Zudem muss in Betracht gezogen werden, dass die hohe Reflexionsbereitschaft der befragten jungen Frauen im Hinblick auf pädagogische 
Fragen ihren Studiengängen entsprechend sehr hoch ist und demgemäß differenzierte Analysen vorgenommen werden konnten. Es stellt sich also die Frage, inwieweit die befragten Eltern bei dieser vorliegenden Untersuchung zu derart differenzierten Aussagen bereit sind und welche »Typen« sich hinsichtlich ihrer religiösen Erziehungsvorstellungen herausbilden lassen.

Auch Klinkhammer (2000) geht anhand ihrer qualitativ-empirischen Untersuchung zur Religiosität sunnitisch geprägter Türkinnen in Deutschland »modernen Formen islamischer Lebensführung « nach. Dabei stellt sich für sie auch die Frage, wie junge Frauen ${ }^{28}$ sich die Religion ihrer Eltern aneignen, d.h., wie sie ihr Verhältnis zum Islam und zur Tradition ihrer Eltern selbst verstehen und sinnhaft für sich umsetzen. Klinkhammer entwickelt auf der Grundlage ihrer Ergebnisse und anhand von Einzelfalldarstellungen drei Typen moderner islamischer Lebensführung: »traditionalisierende«, »exklusivistische«, »universalisierende« islamische Lebensführung.

Die religiöse Erziehung im Elternhaus wird unter den befragten jungen Frauen sehr unterschiedlich erlebt und findet dementsprechend Eingang in die eigene Biografie. Ohne auf die von Klinkhammer (2000) vorgeschlagenen Typisierungen religiöser Lebensführung näher einzugehen, soll hierauf im Folgenden Bezug genommen werden, da es vielmehr darum geht, die erlebte Wirklichkeit unter verschiedenen Aspekten (Wie wurde Religion gelebt? Wie wurde sie weitergegeben? Worauf wurde besonders viel Wert gelegt?) zu beschreiben.

\section{Religiöse Erziehung im Elternhaus}

Die Tendenz, sich von der nicht aufgeklärten unreflektierten Übernahme islamischer Inhalte im Vergleich zur Elterngeneration zu lösen, ist auch bei den von Klinkhammer befragten jungen Frauen (vgl. Zusammenfassung) zu beobachten. Die Frauen richten ihre »Aktivitäten auf die Institutionalisierung einer neuen, unterweisenden und reflektierenden Vermittlung islamischer Inhalte und damit auf die Förderung einer islamischen Religiosität insgesamt« (Klinkhammer 2000: 283) und distanzieren sich dabei vom Religiositätsverständnis der Eltern. Die Aneignung des Islams vollzieht sich dabei nicht als eine einfache Verknüpfung der Religion und ethnischer Zugehörigkeit. Die Entwicklung einer islamischen Religiosität ist somit als eine Folge der »Thematisierung der familiären Herkunft und der biographischen Selbstverortung im Rahmen des Sozialisationshintergrundes« (Klinkhammer 2000: 284) zu verstehen.

28 | Von den 19 aufgezeichneten problemzentrierten Interviews wurden sieben für die vorliegende Arbeit berücksichtigt. Die befragten jungen Frauen waren im Alter von 20 und 31 Jahren. Sie hatten entweder ein Studium oder eine Ausbildung abgeschlossen oder waren zum Zeitpunkt des Interviews gerade damit beschäftigt, eine Ausbildung zu absolvieren. 
Die religiöse Erziehung war bei einem Teil der befragten jungen Frauen ein selbstverständlicher fester Bestandteil des familiären Lebens. Die rituelle Praxis (Fasten, Beten, das Auswendiglernen von Suren, das Aufsagen der basma$1 \mathrm{a}^{29}$ ) wurde durch die Nachahmung der Eltern entsprechend angeeignet, was zudem durch kleinere Belohnungen angeregt wurde (vgl. Klinkhammer 2000: 142 und 216f.). Das Familienleben war teilweise durch einen starken Gemeinschaftsbezug und das gemeinsame Feiern von religiösen Festen bestimmt. Sie besuchten häufig, durch die Eltern angeregt, eine Koranschule oder Sommerschule (Ferienkurse, in denen religiöse Inhalte vermittelt werden) (vgl. ebd.: 123; 127; 162; 181 und 142). In einem Fall wurde der Besuch als »unsinnig« beschrieben (vgl. ebd.: 123), da im Korankurs wenige Erklärungen und Begründungen bzgl. der Religion stattgefunden hätten; in einem anderen Fall wurde auf Prügel vonseiten des Lehrers verwiesen (in diesem Fall übernahm dann der Vater den Koranunterricht) (vgl. ebd.: 142).

Kritisiert werden an der Erziehung der Eltern die »traditionelle« unreflektierte Weitergabe von »falschem« Wissen über den Islam und die oberflächliche religiöse Praxis. Diese Kritik an der religiösen Erziehung bezieht sich auf die fehlende Bereitschaft der Eltern, eine plausible religiöse Begründung für ihre Erziehungspraxis aufzuführen - religiöses Wissen wurde nicht angeboten und gedeutet. Hierbei wurden von einer der Befragten der fehlende Jenseitsbezug (ein interner Aspekt der Religion) und die fehlende Unterstützung der Eltern bei der Aufklärung im Umgang mit der nichtmuslimischen Umwelt, wie sie bspw. in der Schule vorzufinden ist, benannt. Gerade das Tragen des Kopftuches rief Probleme hervor, was natürlich einer Aufklärung bedurfte (vgl. Klinkhammer 2000: 143-147).

Diejenigen Mädchen, die eher in einem türkisch-laizistischen Umfeld aufgewachsen sind, kritisieren die Religionspraxis der Eltern weniger und wurden kaum religiös erzogen, auch wenn im Verwandtenkreis religiös engagierte Personen vorzufinden waren. Die religiöse Praxis beschränkte sich hier auf die mehr oder weniger wichtige Einhaltung des Fastengebots im Ramadan, das Auswendiglernen von Koranversen oder die Rezitation aus dem Koran (vgl. Klinkhammer 2000: 198 und 230), das Feiern der religiösen Festtage und das Aufsagen von Bittgebeten (vgl.ebd.: 214).

Eine weitere, für alle Mädchen einzuhaltende Regel ist die von allen Eltern vertretene Sexualmoral. Insbesondere berichten alle Befragten über Konflikte mit den Eltern hinsichtlich der von ihnen vertretenen Sexualmoral bzw. des Keuschheitsgebots, mit dem in der Regel auch ein Ausgehverbot verbunden war. Dieser Konflikt trete besonders in der Minderheitensituation deutlich her-

29 | Die basmala (arabisches Wort) ist eine Anrufungsformel. Sie spielt eine wichtige Rolle im Gottesdienst und Alltag der Muslime. 
vor, da die Differenz zwischen den Ansprüchen der Eltern und der deutschen Alltagsrealität relativ groß sei (Klinkhammer 2000: 246).

Diese Untersuchung zeigt, dass eine bewusst tradierte religiöse Erziehung auch zu einer entsprechenden religiösen Lebensweise bei den Kindern und Jugendlichen führt. Auch wenn es Ausnahmesituationen gebe, in denen der Bezug zur Religion durch erlebte Lebenskrisen (vgl. ebd.: 165) und nicht durch die Tradierung in der Familie hergestellt werde, lässt sich anhand der Ergebnisse die These aufstellen, dass eine religiöse Erziehung zu einer ähnlich ausgeprägten Religiosität in der nächsten Generation führt.

Des Weiteren wird deutlich, dass innerhalb der Familien, in denen eine religiöse Erziehung und Praxis weniger im Vordergrund steht, eher auf die Einhaltung einer traditionell geprägten religiösen Praxis, die einen Zusammengehörigkeitssinn vermittelt (Fasten, Koranlesen, Feiern von religiösen Festen), und den Respekt vor der Religion geachtet wird. Daran zeigt sich, dass unterschiedliche Formen gelebter Religiosität innerhalb verschiedener Familien vorhanden sind, die es im Folgenden näher zu untersuchen und entsprechend voneinander $\mathrm{zu}$ unterscheiden gilt

Tietze (200I) stellt in ihrer Vergleichsstudie Formen muslimischer Religiosität bei jungen Männern in Deutschland und Frankreich vor. Anhand von Einzelporträts werden Islamische Identitäten in ihren vielfältigen Formen veranschaulicht.

Ähnlich wie die Untersuchungen von Karakaşoğlu-Aydın und Klinkhammer veranschaulicht auch Tietze anhand der Lebensgeschichte von Mourad (vgl. Tietze 2000: 71), wie das »Gefühl« für den Islam durch die Eltern vermittelt wurde. Ausgeführt werden hier u.a. die Pflichten der Eltern, die sie ihrem Kind gegenüber vor Gott zu erfüllen haben: Hierzu gehören die Vergabe eines muslimischen Namens, die richtige islamische Erziehung und die Verheiratung. ${ }^{30}$ Unzufrieden ist Mourad jedoch mit seiner Sozialisation, bei der es die Eltern versäumt hätten, ihm den »wahren Glauben« zu vermitteln. Der »wahre Glauben« beinhalte die Entscheidung und das ureigene Gefühl, die Wahrheit gefunden zu haben. Diese Entdeckung, die das Erleben des Spirituellen auf der Ebene der religiösen Erfahrung unterstreiche, sei mit Worten nicht zu beschreiben. Sie verhelfe zur Autonomie und einer »echten« Identifikation mit dem Islam. Durch kritisch-reflektierendes Hinterfragen werde die Religion eigenständig angeeignet, wobei der Beitrag der Eltern hier kaum zu gewichten sei (vgl. Tietze 2001: 73).

An diesem Beispiel wird somit deutlich, dass traditionelle Muster religiöser Erziehung zugunsten einer Autonomie im Selbstverständnis als Muslim

30 | Diese sind die in der klassisch-islamischen Literatur aufgeführten normativ gesetzten Pflichten bzw. Rechte der Kinder, die muslimischen Eltern mit der Geburt ihrer Kinder auferlegt werden (vgl. z.B. Ibn Kayyim El-Cezviyye 1998). 
in den Vordergrund getreten sind. Nicht das fraglose Übernehmen ritueller Handlungsvorschriften und die blinde Nachahmung traditioneller Vorstellungen (der Eltern) würden die individuelle Religiosität bestimmen, sondern der Islam selbst werde als Prinzip verstanden, woraus sich neue Handlungsmöglichkeiten erschließen lassen würden (vgl. Tietze 2001: $76 f$.).

Die von Nökel (2002) $)^{31}$ sehr eindrücklich durchgeführte qualitative Studie lässt sich in eine Reihe mit den vorangegangenen und noch folgenden Studien setzen, da die Vorstellungen der befragten jungen Frauen auf einen Wandel im Vergleich zur Elterngeneration hinsichtlich ihrer Religiosität und dem Selbstverständnis als muslimische Frau hindeuten. Die Elterngeneration konnte mit ihrem »traditionellen « Verständnis des Islams, das »volksreligiöse « (vgl. ebd.: 74) Züge trägt, keine für ihr heutiges Selbstverständnis adäquate religiöse Erziehung weitergeben. Dessen ungeachtet würden die jungen Frauen unter dem Regime eines modernen Islams durch eine »Rückkehr zu den Wurzeln« ein »authentisches Selbst« entwickeln (vgl. ebd.: 263).

Nökel zeigt auf, dass alle 18 Erzählerinnen »den Islam für sich entdeckt« haben, und zwar unabhängig vom religiösen Hintergrund der Familie. Die meisten Frauen betrachten sich dabei nicht als systematisch religiös erzogen. Wie auch schon bei Klinkhammer (2000) für einen Teil der jungen Frauen dargelegt, haben die Eltern keine oder kaum Bezüge zum Islam, zum Teil war oder ist der Islam »irgendwie da« (vgl. Nökel 2002: 19; vgl. oben Tietze 2001), ohne jedoch greifbar zu sein. Lediglich fünf der befragten jungen Frauen berichten von einer nachhaltigen religiösen Erziehung, wobei drei von ihnen diese als gelungen im Sinne einer profunden Wissensvermittlung betrachten. Bei diesen dreien verfügen die Eltern über eine akademische Ausbildung. Bei den anderen beiden findet hingegen ein »Prozess der »Enttraditionalisierung«, der von wachsenden Ressentiments gegenüber »allem Türkischen« begleitet sei (vgl. Nökel 2002: 19), statt. In den Familien, in denen eine religiöse Erziehung im Vordergrund gestanden habe, seien die Kinder nicht repressiv, sondern mit einer umsichtigen Pädagogik der Belohnung und Anerkennung (vgl. ebd.: 289), mit Diskussionen über Religion und Kultur auf der Basis einer freiwillig durchgeführten religiösen Praxis (vgl. ebd.: 290), offen (vgl.ebd.: 291), aber

31 | Befragt wurden 18 junge Frauen im Alter von 18-28 Jahren im Zeitraum von 1994 und 1996 im Bielefelder Raum sowie im Hessischen, d.h. im Frankfurter Einzugsgebiet. Die Mädchen haben einen unterschiedlichen nationalen Hintergrund (Türkei, Marokko u.a.). Über narrativ-biografische Erzählungen werden konkrete soziale Handlungsfelder und kulturelle Bezugsfelder der einzelnen Akteurinnen nachvollziehbar. Nökel beschränkt sich hier jedoch nicht auf Einzelschicksale, "auf einzelne begrenzte Modi der Entwicklung von Identität und Integration", sondern auf die "Rekonstruktion und Präsentation der sich aus dem weiblichen Islamdiskurs ergebenden Handlungs- und Dialogfelder" (Nökel 2002: 12). 
auch traditionell (vgl. ebd.: 294) sowie streng-traditionell (vgl.ebd.: 293) mit Religion in Berührung gekommen.

Die Beweggründe der jungen Frauen, die schließlich mit und ohne familiäre Anstöße zum Islam finden, sind in der Studie aufschlussreich beschrieben. Im vorliegenden Zusammenhang erschien es bedeutsam, was sich aus der Sicht der Frauen als »traditionalistisch« und was sich als »Rückkehr zu den Wurzeln« erwiesen hat.

Der »richtige Islam« unterscheidet sich von jenem der Elterngeneration dahingehend, dass ein intellektuelles Verständnis vom Islam entwickelt wird, das zumeist nicht auf sozialisiertem religiösen Wissen aufgebaut werden kann. Die Elterngeneration leitete ihr Wissen von Gebräuchen und Autoritäten, Imamen, selbsternannten Experten ab, ohne zu hinterfragen, ohne sich selbst mit den Quellen auseinanderzusetzen. Die sog. »Neo-Muslimas« erleben sich hingegen, so Nökel, infolge der selbstreflexiven und kritischen Auseinandersetzung mit ihrer Religion und den religiösen Quellen als religiös handelnde Subjekte und nicht als gehorsame Objekte ihres Glaubens. Für die jungen Frauen sei es neben der Aneignung von religiösem Wissen von Bedeutung, (vgl. Nökel 2002: 69; Nökel 2007: 142f.), dass sie im Vergleich zu ihren Eltern eine disziplinierte und systematische Lebensweise nach den Prinzipien des Islams führen würden (vgl. ebd.: 74).

Nökel stellt fest, dass, je nachdem, ob eine islamische Erziehung vorliegt und in welcher Weise diese erfolgt ist, verschiedene Ausprägungen »islamischer Hyperkorrektheit« hervorgehen. Die Rückkehr zu den Wurzeln als Metapher bezieht sich auf eine ideale Kultur, die in dieser Form nicht wiedererlebbar ist, sondern eine Projektion von Steuerung, Ordnung und Identität. Sie stelle keine Versöhnung mit der Lebensweise der Eltern bzw. mit einer wahrgenommenen oder bestehenden traditionellen Ordnung dar, sondern erfordere eine disziplinierte und kontinuierliche Reflexionsbereitschaft, die über den alltagsweltlichen Dialog und derartige Interaktionen hinaus nachhaltige praktische Handlungen nach sich ziehe (vgl. ebd.: 264).

Nökel bietet hier eine Möglichkeit der theoretischen Einbettung. Sie zeigt in ihrer Studie, wie die Unterscheidung eines Volksislams vs. der Rückkehr zu den Wurzeln bestimmend für die Einwandergeneration und ihre Töchter ist. Dabei kann von einem religiösen Wandel gesprochen werden, der annehmen lässt, dass religiöse Erziehung heute und in Zukunft bewusster und gezielter an die nächste Generation weitergegeben wird. $\mathrm{Zu}$ erwarten ist demgemäß auch eine Professionalisierung in diesem Bereich.

Leider kommen in dieser Studie die Inhalte und die Art und Weise bzw. die Frage, welche religiösen Erziehungsvorstellungen die Jugendlichen selbst entwickelt haben, viel zu kurz. Wünschenswert wäre daher eine Darstellung gewesen, die veranschaulicht hätte, welche eigenen Vorstellungen sie, entgegen 
der lautstark hervorgebrachten Kritik gegenüber den Eltern, selbst entwickelt haben.

Die Ergebnisse zeigen des Weiteren, dass eine fehlende religiöse Erziehung nicht zwangsläufig zu einer nicht religiösen Lebensweise führt. Im Gegenteil. Offensichtlich gibt es vielerlei andere Gründe, warum die Religion gerade in der Migrationssituation an Bedeutung gewinnt, ohne dass dabei ein Anstoß von der eigenen Familie kommt.

Frese (2002) ergründet in seiner Studie Den Islam ausleben Konzepte authentischer Lebensführung junger türkischer Muslime. ${ }^{32}$ Seine zentralen Fragestellungen teilen sich in zwei Bereiche: Zum einen (a) wird danach gefragt, wie in religiösen Gemeinden geglaubt wird, und zum anderen geht es darum, (b) wie die spezifischen Situationsbedingungen der in den Migrantengemeinden aufgewachsenen und sozialisierten Jugendlichen sind.

Da nach Sozialisationsfaktoren, wie bspw. Familie, religiöser Community, Freundschaftsbeziehungen, religiöser Erziehung und Bildung, gefragt wird, spielen für den vorliegenden Forschungszusammenhang vor allem die im zweiten Bereich aufgestellten Fragen eine wichtige Rolle. Es wird aufgedeckt, welche Strategien muslimische Jugendliche entwickeln, um sich mit unterschiedlichen Ansprüchen ihrer Eltern und der Aufnahmegesellschaft auseinanderzusetzen, und welche Rolle diese u.a. bei der Gemeindebildung einnehmen (vgl. Frese 2002: 11).

\section{Religiöse Erziehung im Elternhaus}

Die religiöse Sozialisation vollzieht sich den Jugendlichen zufolge durch das Nachleben der Verhaltensmuster der Eltern. Der Koranunterricht in den Gemeinden könne auf diese Grundlagen aufbauen. Dieser wird im Vergleich zu den Eltern oft als weniger wichtige Quelle religiöser Erfahrungen angesehen. Vielen befragten Jugendlichen ist es wichtig, dass die entsprechenden Kenntnisse altersgerecht vermittelt werden. Kinder sollten daher nicht überfordert,

32 | Frese interviewte für seine qualitativ angelegte Studie in Bremen insgesamt 29 Jugendliche männlichen Geschlechts im Alter zwischen 14 und 26 Jahren im Zeitraum von 1998-1999. Er stellte dabei fest, dass sich die Bildungsaspirationen der Befragtengruppe nicht mit dem Niveau der Gesamtgruppe von Schülern in Bremen deckten. Allein 20 der befragten Jugendlichen sind Absolventen von Gymnasien oder Fachoberschulen, neun von innen studieren an Fachhochschulen und Universitäten. Anders als in vielen anderen Untersuchungen, geht Frese von Bildern aus, die Denk- und Handlungsmuster als authentisches Zeugnis der Jugendlichen darstellen. Statt Typologien und aus ihnen gebildeten Matrizes wird eine Wiedergabe der Interviewaussagen anhand von Bildern gezeigt. Nicht die abstrahierte Kategorie, sondern das authentische Zeugnis konkreter Denk- und Handlungsmuster steht für inn im Vordergrund (vgl. zur detaillierten Vorgehensweise Frese 2002: 76). 
sondern altersgerecht gefördert werden (vgl. Frese 2002: 216). Der Bezug zur Moscheegemeinde wird über den Vater hergestellt. Das »Reinwachsen in den Islam«, wie es vonseiten einiger Jugendlichen benannt wird, sei damit verbunden, dass der Vater die Kinder zur Moschee mitnehme. Bevor man am Koranunterricht teilnehme, finde eine religiöse Erziehung innerhalb der Familie statt. Die Qualität selbiger hänge dabei von der Ausprägung der Religiosität der Eltern oder anderer Verwandter ab. Einerseits lernen die Kinder somit durch die Vorbildfunktion der Eltern und andererseits durch die Vermittlung von religiösen Inhalten innerhalb der Familie. In den seltensten Fällen würden sie ihre Religion ausschließlich zu Hause erlernen. Gerade die Vermittlung von ritueller Kompetenz geschehe in den Moscheen (vgl. Frese 2002: 217f.).

Als eine problematische Phase wird aus Sicht der Jugendlichen die Pubertätsphase benannt. Die beginnende Autonomisierung der Jugendlichen, innerhalb derer religiöse Inhalte nicht einfach als gegeben angenommen würden, und die elterlichen Forderungen und Befürchtungen könnten in dieser Phase zu Auseinandersetzungen führen. Die Regeln, die ihnen auferlegt würden, müssten auf ihren islamischen Sinngehalt überprüft werden (vgl. Frese 2002: 219).

Nicht zuletzt sehen sie in der fehlenden Auseinandersetzung der Eltern mit den eigenen Wurzeln und ihren geistigen Grundlagen zusätzlich die Isolation und ihre von der hiesigen Gesellschaft abgeschottete Existenz. Deshalb ist die Aneignung der religiösen Bildung für diese Jugendlichen besonders wichtig. Diese erfolge somit nicht nur, um die Erwartungen und Forderungen der Eltern zu erfüllen, sondern um sich diese eigenständig zu erarbeiten und sie in die (religiöse) Praxis umzusetzen. Frese fügt hinzu, dass dieses Wissen nicht in einem intellektuellen Vakuum erarbeitet werde, sondern in einem prozesshaften Sichabgrenzen, Zustimmen, Weiterentwickeln von Meinungen erfolge, die seitens der Eltern und der hocas (Hodschas=türk. für Lehrer) sowie der religiösen Dachverbände in Deutschland vertreten und z.B. durch Lektüre überprüft würden. Ebenso geht Frese davon aus, dass der Bildungsauftrag individuell ist (vgl. Frese 2002: 22of und 281).

Schließlich kann noch auf die komplizierten Anforderungen der Mehrheitsgesellschaft, denen sich Migrationsfamilien $\mathrm{zu}$ stellen haben, verwiesen werden. Es wird festgestellt, dass hier unterschiedliche Erziehungsziele häufig aufeinanderprallen. Sowohl die Jugendlichen als auch die Eltern seien sich den durchaus komplizierten Anforderungen, die sich den Familien in der Migrationssituation stellen, bewusst. Viele Eltern würden somit einen Spagat zwischen den »[...] - wie auch immer - kulturell, traditionell und religiös hergeleiteten erzieherischen Konzepten« (Frese 2002: 97) vollziehen. Sie würden versuchen, die gesellschaftliche Realität mitzuberücksichtigen.

In seiner Studie Wege zur Integration untersuchte Öztürk im Jahre 2007 die Lebenswelten muslimischer Jugendlicher in Deutschland. Diese analy- 
siert die Einstellungen und Verhaltensweisen muslimischer Jugendlicher mit unterschiedlichsten nationalen Hintergründen (z.B. aus der Türkei, Indien, Deutschland u.a. stammend) hinsichtlich ihres Verständnisses von Religiosität und Integration. Der Fokus wird dabei auf die Beziehung ihrer Religiosität zur Integration in die deutsche Gesellschaft gelegt. ${ }^{33}$

\section{Religiöse Bildung und Erziehung im Elternhaus}

Ähnlich wie in den vorausgegangenen Studien empfinden junge Muslime und Musliminnen die religiöse Erziehung in ihren Familien nicht als befriedigend. Das Wissen der Eltern über die eigene Religion sei bescheiden gewesen und es wird berichtet, dass ihr Wissen nicht gesichert und tiefgehend wäre. Zumeist wirke die islamische Bildung zu Hause auf sie »intuitiv und floskelhaft « (vgl. ebd.: 224). Problematisch werde diese schlechte Informiertheit insbesondere dann, wenn sie von ihrem nichtislamischen Umfeld häufiger mit Fragen zum Islam konfrontiert würden, die sie nicht beantworten könnten (z.B. Fragen nach dem Sinn religiöser Ge- und Verbote) (vgl. Öztürk 2007: 224-229).

Vermisst wird auch ein konsistentes, kindgerechtes Erziehungskonzept nach religiösen Grundsätzen. Es wird kritisiert, dass die Ziele und Inhalte der von den Eltern vermittelten Erziehung und Bildung nicht immer eindeutig nachvollziehbar gewesen seien. Zudem seien die Eltern nicht imstande gewesen, ihnen den Ursprung und die Bedeutung religiöser Vorschriften ${ }^{34}$ nachvollziehbar zu erklären (vgl. Öztürk 2007: 229).

\section{Religiöse Erziehungsvorstellungen der Jugendlichen}

Die Jugendlichen legen besonders viel Wert auf eine Erziehung nach islamischen Grundsätzen. Sie geben unterschiedliche Beweggründe an, die letztlich dazu führen könnten, zukünftig auch ihre eigenen Kinder nach den Maßstäben des Islams zu erziehen. Es sei letztlich der Mangel an religiöser Erziehung im eigenen Elternhaus, der die Jugendlichen dazu bewege, ihren Kindern zukünftig eine kontinuierliche religiöse Erziehung weiterzugeben. Zudem sähen

33 | Auf der Grundlage einer qualitativen Befragung anhand von Leitfadeninterviews werden zwölf Jugendliche aus Berlin zwischen 2004 und 2005 hinsichtlich der subjektiven Deutung ihrer Handlungen, der Strukturierung ihres Lebensraumes sowie ihrer Wünsche analysiert. Die Themen, die hierbei zur Sprache kommen, sehen folgendermaßen aus: ihre Freizeitgestaltung, die Beziehung zu den Eltern, Rückkehrwünsche in ihre Heimatländer, ihre gegenwärtige Situation, das Leben als Muslime in Deutschland und ihr eigenes Verständnis von Religiosität.

34 | Die Befolgung der islamischen Regeln bewahre die Jugendlichen vor Sünden, wie bspw. Alkohol- und Drogenkonsum und strafbarem Verhalten. Der Glaube stelle für die Jugendlichen eine Schutzmauer dar, der sie vor kriminellen und unsittlichen Verhaltensweisen schütze (vgl. Öztürk 2007: 226). 
sie sich in der »Pflicht«, ihren Kindern »eine gute allgemeine und religiöse Erziehung und Bildung « zu ermöglichen, da im Jenseits darüber Rechenschaft abgelegt werden müsse. Die religiöse Erziehung lasse zudem eine solide Wertevermittlung zu und die Gottesliebe wachsen, was Hilfsbereitschaft und respektvolles Verhalten hervorrufen solle. Hingegen würde das Fehlen einer religiösen Erziehung die regelmäßige religiöse Pflichterfüllung erschweren (vgl. Öztürk 2007: 230).

Die im Zusammenhang mit der religiösen Erziehung stehende Haltung zur Sexualmoral äußert sich bei den Jugendlichen darin, dass außerehelicher Geschlechtsverkehr verneint und die Religion somit als Prävention gegen Ehebruch und Prostitution angesehen wird. Eine Heirat mit einer nicht muslimischen Frau oder mit einem nicht muslimischen Mann wird zwar nicht gänzlich abgelehnt, aber es werden Bedenken geäußert. Die Diskrepanz bzgl. der jeweilig kulturell bedingten Einstellungen und Vorstellungen könne hinsichtlich der Erziehung von Kindern zu Problemen führen. Kulturelle und religiöse Unterschiede könnten zudem die Stabilität einer Ehe erheblich gefährden (vgl. Öztürk 2007: 231)

Öztürk stellt resümierend fest, dass die befragten Jugendlichen Fragen zur Kindererziehung, Ehe- und Sexualmoral sowie zur Wahl des Ehepartners eine nicht unerhebliche Bedeutung zuweisen. Alle, auch diejenigen, die lediglich einen geringen Moscheekontakt pflegen würden, möchten ihre Kinder nach den islamischen Grundsätzen des Korans und der Sunna erziehen (Öztürk 2007: 232).

Aygün (20I0) analysiert unter Bezugnahme auf den protestantisch ausgerichteten, strukturgenetischen Ansatz nach Fowler die Glaubensentwicklung Jugendlicher mit türkischem Migrationshintergrund in Deutschland im Vergleich mit türkischen Jugendlichen aus der Türkei. ${ }^{35}$ Auch wenn die Übertragbarkeit dieses theoretischen Ansatzes auf »muslimische« Jugendliche und auf den Islam bei Aygün (2010) nicht eindeutig nachvollziehbar ${ }^{36}$ ist, bietet sie Ergebnisse an, die in einem engen Zusammenhang mit der Sozialisation in Familie, Schule, Korankursen und Moscheevereinen stehen. Neben den re-

35 | Befragt wurden (im Jahr 2006) 29 deutsche und etwa 41 türkische Jugendliche im Alter zwischen 15 und 25 Jahren. Allerdings wurden 35 der Probanden und Probandinnen für die Typisierung ausgewählt.

36 | Unter Verweis auf theologische Grundpositionen im Islam oder beispielsweise die "sufistische Erziehungspraxis des Selbst" wird versucht, die Glaubensentwicklung nach Fowler mit islamischen Quellen in einen Zusammenhang zu setzen. Dem Argumentationsstrang kann nicht eindeutig gefolgt werden, da er dies rekurrierend auf bestimmte antagonistische Grundpositionen des Islams ("spiritualistisch" vs. "rationalistisch") vornimmt. Auch wirkt die begriffliche Verwendung, wohl aus Gründen der Übersetzbarkeit aus dem Türkischen und Arabischen, verschwommen und nicht eindeutig. 
ligiösen Orientierungen in unterschiedlichen kulturellen Kontexten werden diverse Glaubensstile, Sozialisationsbedingungen, Zukunftsperspektiven und Bewältigungsstrategien aufgezeigt. Aygün (2010) hält als Ergebnis seiner Untersuchung schließlich vier »Glaubensstile« fest: den »traditionellen «, den »ideologischen«, den »laizistischen (säkularen)« und den »individuellen« Typ.

Die Familie, die Beziehung zu den Eltern und die Freundschaften im Rahmen von Korankursen spielen für Jugendliche mit Migrationshintergrund eine deutlich wichtigere Rolle, als es für Jugendliche in der Türkei der Fall ist. Die Rolle der Eltern wird gerade im Zusammenhang mit religiöser Erziehung thematisiert. Nicht selten stehen diese in einer engen Verbindung zu religiösen Gruppen und Vereinen, die als religiöse Erziehungseinrichtungen eine bedeutsame Rolle im Leben von muslimischen Jugendlichen spielen. Die eher dem »individuellen « Typ zugeordneten Probanden und Probandinnen haben ein distanziertes Verhältnis zur Religion und sind auch nicht religiös erzogen worden. Aygün kommt zu dem Schluss, dass eine religiöse Erziehung im Elternhaus einen eindeutigen Einfluss auf die spätere Religiosität der Jugendlichen hat. Bei allen Befragten sei demnach ein auffälliger familiärer Einfluss bzgl. der »Perspektivenübernahme« der religiösen Einstellungen zu beobachten (vgl. Aygün 2010: 9off.). Deutsch-türkische Jugendliche benennten insbesondere die Beziehung zu Gott und zu ihren Eltern bzw. der Familie als die für sie wichtigsten Werte (vgl. ebd.: 102).

Die Religion habe im familiären Rahmen zudem eine identitätsstiftende Funktion inne. Sie sichere nicht zuletzt die »Gehorsamkeit gegenüber den Eltern«, was wiederum Respekt gegenüber den Eltern hervorrufe. Damit sei die Autorität der Eltern gewahrt, die in einer nichtislamischen Umwelt versuchen würden, ihren Kindern die Religion zu vermitteln. Aygün folgt hier jedoch einemgängigen »Stereotyp«, ohne einen empirischen Nachweis für diese Behauptung zu erbringen (vgl. ebd.: 94).

Als religiöses Vorbild diente den in Deutschland aufgewachsenen Jugendlichen z.B. eine Lehrerin, die den Religionsunterricht vermittelt hat, der Großvater u.a. Die Vorbilder treten vor allem im familiären Rahmen hervor. Daneben werden zudem historische und religiöse Persönlichkeiten wie der Prophet Muhammad (s) benannt (vgl. Aygün 2010: 103).

Vor allem die im Elternhaus religiös aufgewachsenen Jugendlichen betonen die Einhaltung der ritualistischen Dimension des Islams. Die fünf Säulen, innerhalb derer vor allem der Gebetsverrichtung als alltäglichem Ritual und einem wichtigen Pfeiler der Religion eine zentrale Bedeutung zukommt, da diese das Verhalten diszipliniere und die Menschen von dem »Bösen und Schädlichen« fernhalte (vgl. Aygün 2010: 99), spielen für die Jugendlichen eine besondere Rolle. Aygün führt dies auf die katechismuszentrierte (die fünf Säulen des Islams, die Glaubensgrundlagen) Bildung der Jugendlichen in religiösen außerschulischen Einrichtungen zurück. Dort werde ein besonderer 
Schwerpunkt auf die Rezitation des Korans, das Auswendiglernen der Verse und die fünf Säulen des Islams gelegt (vgl. ebd.). Da die Jugendlichen zudem die Hingabe zu Gott und die Erfüllung von religiösen Pflichten als Kennzeichnen eines fortgeschrittenen Glaubens betrachten, schließt Aygün daraus, dass die Inhalte im religiösen Unterricht sehr »autoritätsorientiert « aufgenommen werden und sich eine kritisch-religiöse Lernkultur in der Praxis kaum finden lässt. Kritisch-rationale Neuinterpretationen würden sich somit weitestgehend bei älteren und gebildeten Jugendlichen feststellen lassen (vgl. ebd.: 103f.).

Aygün belegt mit seiner Studie den Einfluss der Familie und der außerschulischen Bildungseinrichtungen (vgl. auch Kap. II. 2.2.1) auf die religiöse Sozialisation von muslimischen Jugendlichen. Die Familien und Moscheevereine treten dabei in der Migrations- bzw. Diasporasituation stärker in den Vordergrund, als dies für muslimische Jugendliche in der Türkei der Fall ist. Ungeachtet dessen, dass die Studie aufgrund ihres strukturgenetischen Ansatzes, die eine hierarchische Normierung der religiösen Entwicklung voraussetzt und damit stärker kategorisiert und folglich eine wertende Haltung einnimmt (Stufe zwei ist nicht fortgeschritten/entwickelt wie drei oder vier), konnten Ergebnisse aufgezeigt werden, die im Zusammenhang mit der religiösen Sozialisation stehen.

Schließlich ist an dieser Stelle noch auf die qualitativ angelegte Studie von Wensierski und Lübcke (20I2) zu verweisen. Unter Verwendung der biografischen Methode werden Porträts von Jugendlichen ${ }^{37}$, in denen Prozesse der Selbstfindung, Alltagskulturen und Lebenswelten junger Muslime im Vordergrund stehen, gezeichnet. Die Studie präsentiert die Pluralität der Lebensentwürfe auch in den muslimischen Migrantenmilieus. Mittels eines »komplexen analytischen Rasters « wird die Prozessstruktur der Jugendphase erfasst. Diese sollte (in der Auswertungsphase) wiederum so sensibel sein, dass sie

"[...] die Bedeutung und Vielschichtigkeit des islamischen Herkunftsmilieus sowie für die potentielle Bedeutung des Islam als religiöses Leitbild, dass sie offen sein sollte für die Bedeutungen von Sozialisationsprozessen im Kontext von Migrantenmilieus und schließlich, dass sie potentielle Wandlungsprozesse im Spannungsfeld zwischen islamischer Religiosität und Säkularisierung sowie zwischen ethnischem Herkunftsmilieu und deutscher Mehrheitskultur fassen sollte." (Wensierski/Lübcke 2012: 357)

37 | Es wurden insgesamt 107 Interviews mit Jugendlichen verschiedener ethnischer Zugehörigkeit im Alter zwischen 20 und 30 Jahren in Deutschland durchgeführt, bei 55 von innen erfolgte eine anschließende Auswertung. Die Erhebung fand zwischen 2006 und 2008 statt und wurde in westdeutschen Großstädten bzw. Ballungsräumen (Hamburg, Berlin, Hannover, Ruhrgebiet) durchgeführt. 
Auf dieser Basis der Prozesshaftigkeit werden vier Typen (mit jeweils vier Untertypen) festgelegt: »Säkularisierter jugendbiographischer Verselbständigungsprozess« (1), »Bikulturelle Identitätsproblematik« (2), »Re-Islamisierung im Gefolge der Adoleszenz« (3), »Islamisch-selektiv modernisierte Jugendbiographie« (4). Die Typen 1 (säkular) und 4 (religiös) bilden hierbei die maximalen Pole. Laut Wensierski/Lübcke tragen diese Jugendbiografien das Spannungsfeld zwischen Mehrheitsgesellschaft und Migrantencommunity als biografisches Problem zwischen säkularer Mehrheitskultur und islamischer Herkunftskultur in sich (vgl. Wensierski/Lübcke 2012: 358).

Im vorliegenden Zusammenhang ist vor allem die Bedeutung des religiösen Sozialisationsprozesses interessant, der im familiären Rahmen eine zentrale Rolle spielte. Die dargestellten Typen verhalten sich jeweils sehr unterschiedlich zur Religion und haben in den Elternhäusern diesbezüglich eine Variationsbreite an sozialisatorischen Einflüssen erlebt. Aufgrund der sehr differenzierten Beschreibungen der jeweiligen Typen und ihren kulturellen bzw. religiösen Bezügen werden diese hier nicht näher analysiert (vgl. für eine ausführliche Typenbeschreibung entsprechend Wensierski/Lübcke 2012: 357406). Für die vorliegende Untersuchung, die sich auf religiöse Menschen mit einem eindeutigen Bezug zu religiösen Wert- und Handlungsmustern konzentriert, sind insbesondere die letztgenannten beiden Typbeschreibungen (die Typen 3 und 4) von Bedeutung.

Die Vielfalt der religiösen Orientierungen wurde schon in anderen Studien (vgl. u.a. die oben erwähnten Studien) veranschaulicht. In der Studie von Wensierski/Lübcke werden Sozialisationsprozesse von Jugendlichen, analytisch differenziert wiedergegeben. Sicherlich liegt hierbei der Fokus auf der Sozialisation in der Jugendphase, die wiederum in einem engen Zusammenhang mit familiären Sozialisationsprozessen zu betrachten ist. Berücksichtigt werden hier auch unterschiedliche Sozialisationsfelder (vgl. nachfolgendes Kap. II. 2.2.), die Aufschluss darüber geben, wie die religiöse Sozialisation von Muslimen in dieser Gesellschaft verläuft. Die Stärke dieser Untersuchung besteht darin, dass sie analytisch differenziert vorgeht und nach kulturellen und religiösen Deutungs- und Handlungsmustern der Jugendlichen trennt. Für die ersten beiden Gruppen spielt Religion eine eher untergeordnete Rolle, folglich ist das, was sie als »muslimische« Jugendliche auszeichnet, einzig ihre Religionszugehörigkeit (1) und (2). Für die anderen beiden trifft das, was unter »muslimisch « verstanden und entsprechend gelebt wird, wiederum auf einen anderen Deutungshorizont. Die Religion wird in einem Fall als identitätsbestimmend (3), im anderen Fall als handlungs- und orientierungsleitendes Prinzip (4) verstanden. Dies berücksichtigt die Pluralität dessen, was unter dem Prädikat »muslimisch « (hier in der Jugendphase) zum Vorschein kommt.

Die Ergebnisse können als möglicher theoretischer Bezugshorizont zur Deutung der religiösen Sozialisation in einer pluralistischen Gesellschaft an- 
gesehen werden, selbst wenn sich mit ihnen keine eindeutig benennbare religiöse Erziehungspraxis in Familien nachzeichnen lässt.

Die Shell Jugendstudie (2000) $)^{38}$ vermag einige Aussagen darüber geben, welchen großen Stellenwert die religiöse Erziehung für junge Muslime einnimmt.

Auf die Frage, ob sie ihre Kinder religiös erziehen wollen, antworten $64 \%$ der männlichen jungen Muslime und $74 \%$ der weiblichen Muslime mit »a«. Also knapp drei Viertel der Befragten befürworten eine religiöse Erziehung (vgl. Fuchs-Heinritz 2000: 171f.). Dies zeigt die zentrale Bedeutung der religiösen Erziehung, trotz der Kritik, die immer wieder an den elterlichen Erziehungsmaßnahmen geübt wird.

Zur religiösen Praxis, fälschlicherweise als »Koran-beten« bezeichnet, richtig heißt es jedoch »Koranlesen«, verhalten sich die muslimischen Jugendlichen folgendermaßen: $11 \%$ lesen sehr oft den Koran, $30 \%$ oft, $32 \%$ sehr selten, $27 \%$ nie. Die muslimischen Mädchen führen diese Praxis häufiger aus (vgl. Fuchs-Heinritz 2000: 167).

Auch die nächste Studie verweist auf den Stellenwert, den die religiöse Erziehung bei weiblichen Jugendlichen im Hinblick für die familiale Sozialisation einnimmt.

In ihrer quantitativ angelegten repräsentativen Mehrthemenbefragung ${ }^{39}$, die im Auftrag des Bundesministeriums für Familie, Senioren, Frauen und Jugend durchgeführt wurde, zeigen, Boos-Nünning/Karakaşoğlu (2006) den Stellenwert der religiösen Erziehung im Rahmen der familialen Sozialisation auf. Befragt wurden ausschließlich Mädchen und junge Frauen verschiedener nationaler Herkunft. Die meisten Mädchen stufen ihre Erziehung als religiös ein, doch bestehen hier Unterschiede bzgl. des Migrationshintergrundes. ${ }^{40}$

38 | Insgesamt umfasste die quantitativ (Befragungszeitraum April 1998-August 1999) als auch die qualitativ angelegte Studie (Mai 1999-August 1999) eine Stichprobe von bundesweit 4.546 Jugendlichen im Alter zwischen 15 und 24 Jahren. Befragt wurden deutsche, türkische und italienische Jugendliche hinsichtlich ihrer Religion. Bedeutsam waren dabei bestimmte Merkmalsausprägungen, wie u.a. das Feiern von religiösen Festen oder die Lektüre von heiligen Schriften.

39 | Befragt wurden insgesamt 950 junge Frauen und Mädchen verschiedener nationaler Herkunft (deutsche, türkische, griechische, italienische, jugoslawische, Aussiedler, z.B. aus der GUS). Die Datenerhebung fand zwischen November 2001 und März 2002 statt.

40 | Mädchen aus Aussiedlerfamilien fühlen sich deutlich weniger religiös erzogen, sind aber auch mit der familialen Erziehung weniger einverstanden. Mädchen mit griechischen Wurzeln geben im Vergleich am häufigsten an, religiös erzogen worden zu sein und diese Erziehung auch gut zu finden. Die Befragten mit jugoslawischer und italienischer Herkunft folgen ähnlichen Mustern wie die türkischen. 
Über die Hälfte der Mädchen mit türkischem Migrationshintergrund wurden im Elternhaus religiös erzogen und etwa drei Viertel bewerten die elterliche Erziehung als positiv. Der Glaube ist in türkischen Familien - wie auch in griechischen - weniger eine Privatsache jedes Einzelnen als in den übrigen Familien. Es wird im Ganzen geschlussfolgert, dass eine mittlere religiöse Erziehung kennzeichnend für die Praxis in allen Migrationsfamilien (mit Ausnahme der Aussiedlerfamilien) ist (vgl. Boos-Nünning/Karakaşoğlu 2006: 115ff.). Die religiöse Erziehung bildet nach Boos-Nünning/Karakaşoğlu (2006) den Bereich, in dem sich Migrationsfamilien am ehesten wertkonservativ darstellen können.

Der Wunsch, die eigene religiöse Orientierung an die nächste Generation weiterzugeben, wurde anhand der Bedeutung eines religiösen Vornamens für das Kind und der religiösen Initiationsriten (Beschneidung des Sohnes) sowie der Vorstellung bezüglich der religiösen Erziehung befragt. Etwa ein Drittel (32\%) der befragten Musliminnen wünschen sich einen religiösen Namen für ihre Kinder. Die Beschneidung des Sohnes wird von den meisten befürwortet $(84 \%)$. Etwa zwei Drittel der muslimischen Mädchen und jungen Frauen möchten die eigenen Kinder religiös erziehen. Dieses Ergebnis zeigt wiederum den hohen Stellenwert der religiösen Erziehung (vgl. Boos-Nünning/Karakaşoğlu 2006: 402f.).

\subsubsection{Zusammenfassung}

Insgesamt wurden für die Darstellung des Forschungsstandes verschiedene Quellen herangezogen, aus denen wiederum eine Erziehungswirklichkeit in muslimisch-türkischen Familien abgeleitet werden konnte. Alle Untersuchungen, einschließlich früherer Untersuchungen, belegen, dass die Religion grundsätzlich für ältere wie auch jüngere Muslime in hohem Maße identitätsstiftend ist und der religiösen Erziehung generationsübergreifend ein besonderer Stellenwert beigemessen wird.

Die Literaturanalysen (vgl. Stöbe 1998; vgl. Kanacher 2001) beziehen sich auf frühere empirische Untersuchungen, deren Aktualität jedoch nicht mehr gegeben ist. Dabei ist vor allem der Einfluss des Islams auf die religiöse Sozialisation in fast keiner Studie eindeutig nachweisbar. Es wird in diesen lediglich der hohe Stellenwert, den die Erziehung zum islamischen Glauben, die religiöse Pflichterfüllung und der Bezug zu Moscheegemeinden für die Eltern mit Migrationshintergrund einnahm, erwähnt. Religion war identitätsbestimmend und erfüllte in der Fremde eine Orientierungsfunktion. Eine Durchmischung von kulturell und religiös bedingten Faktoren ist kennzeichnend für die früheren Studien, in denen bzgl. des Islams, wenn auch nur am Rande, dessen Rolle im Sozialisationsprozess von Kindern in Migrationsfamilien thematisiert und undifferenziert mit kulturellen Praktiken gleichgesetzt wurde. Schließlich wurde dieser als zentrales Hemmniss bzgl. der Integration in die 
deutsche Gesellschaft erklärt und es wurden nicht selten dichotome Ausgangssituationen produziert, die den Eltern von Migrantenkindern und deutschen Eltern antagonistische Werthaltungen bescheinigten. Erst Stöbe bildet 1998 unter den »Islam«, »Kultur« und »Sozialisation und Familie« analytisch differenzierende Kategorien heraus, um die Ergebnisse in ihren jeweiligen Bezügen darzustellen. Er ist der Auffassung, dass es nicht »den Islam« gebe und der Einflussfaktor »Islam« in Bezug auf das familiäre Interaktionsgeschehen wesentlich differenzierter betrachtet werden müsse.

Daraus lässt sich die Frage ableiten, was nun das Spezifische an der religiösen Sozialisation von muslimischen Kindern darstellt, ohne dabei kulturelle, soziale und sozioökonomische Einflüsse mit den Einflussfaktoren der Religion zu vermischen. Hierbei ist es notwendig, eine Vorgehensweise zu wählen, die eine differenzierte analytische Operationalisierung der Religiosität ermöglicht. An welche normativen, orientierungs- und handlungsweisenden Prinzipien die »religiöse« Erziehung durch Eltern gekoppelt wird, ist folglich eine der zentralen Forschungsfragen der vorliegenden Untersuchung.

Die Beiträge von Yalçın-Heckmann (1998) und Karakaşoğlu/Öztürk (2007) verdeutlichen, welche Einflussfaktoren für die religiöse Sozialisation bestimmend sind. Der religiösen Erziehung innerhalb der Familie wird ein hoher Stellenwert beigemessen (vgl.auch Bertelsmann Stiftung 2008b). Zunächst findet eine allgemeine religiöse Erziehung in der Familie statt. Die Kinder erlernen die religiöse Lebensweise der Eltern durch »Imitation« und »Nachahmung« sowie durch eine altersgemäße Vermittlung religiöser Inhalte. Die Qualität und die Intensität variiert unter den Familien und ihren Mitgliedern, je nachdem, wie religiös versiert sie sind. Nur in seltenen Fällen wird ausdrücklich im familiären Rahmen unterrichtet, da viele Eltern ihr Wissen und ihre religiöse Praxis als nicht ausreichend betrachten (vgl. Karakaşoğlu/ Öztürk 2007; vgl. auch Uslucan 2008: 35; vgl. Ceylan 2014). Dabei wird auch der Stellenwert der Moscheegemeinden und Korankurse bei der Vermittlung von religiösen Grundfertigkeiten deutlich. Sie gelten als Orte, an denen die Wissensaneignung über den Islam, das Einüben von sozialen Fertigkeiten, das Erlernen von moralischen Werthaltungen und die Rezitation des Korans auf Arabisch im Vordergrund steht. Zudem wird ihre identitätsfördernde und -bestimmende Funktion betont. Die Wissensaneignung und die praktische Umsetzung, gerade im Zusammenhang mit den fünf Säulen des Islams und der moralischen Erziehung, stellen wesentliche Eckpfeiler dar, um den Jugendlichen dabei zu helfen, sich zu verantwortungsbewussten und ausgeglichenen Persönlichkeiten zu entwickeln. Die religiöse Erziehung hat für Eltern folglich eine mehrdimensionale Funktion: Sie soll soziale Fertigkeiten und eine religiöse Handlungskompetenz vermitteln, aber auch als moralische Richtschnur orientierungsweisend wirken. Zwang und Restriktionen werden innerhalb der 
religiösen Lebensführung hingegen abgelehnt (vgl. Yalçın-Heckmann 1998; Karakaşoğlu/Öztürk 2007; Ceylan 2014).

Vor diesem Hintergrund gilt es, im vorliegenden Kontext zu überprüfen, welche Rolle neben der Familie als der zentralen Sozialisationsinstanz den Moscheegemeinden $u$. ä. außerschulischen Bildungseinrichtungen in der religiösen Sozialisation und Erziehung zukommt.

Die Expertise von Uslucan (2008) und sein aktueller Beitrag (vgl. Uslucan 2015) bieten auf der Grundlage verschiedener Quellen die Möglichkeit, Deutungspotenziale für die religiöse Erziehung und Sozialisation in muslimischen Familien zu erschließen. El-Mafaalani und Toprak (2011) ${ }^{41}$ gehen zwar von muslimischen Familien aus, jedoch bezieht sich bei ihnen die Attribuierung »muslimisch « eher auf die Religionszugehörigkeit (vgl. Kap. II.1.1. und II.1.2) als auf empirisch eindeutig belegbare religiöse Einstellungen und eine entsprechende Ausübung der religiösen Praxis in muslimischen Familien.

Schließlich weist Boos-Nünning (2011a) auf Wertebereiche hin, die in Migrationsfamilien vorherrschend sind. Diese betreffen den Familialismus, hohe Bildungsaspirationen der Eltern für ihre Kinder (vgl. auch Boos-Nünning 2013), Respekt und Achtung vor den Älteren (vgl. auch Stöbe 1998; Blank 2000; Hunner-Kreisel 2010 u.a.), Zwei(Mehr)sprachigkeit, einer konventionellen Sexualmoral (vgl. auch Schiffauer 1991; Stöbe 1998; Blank 2000 u.a.) und die religiöse Erziehung bzw. die Religiosität (vgl. Boos-Nünning 2011a). Dabei ist von einer großen Variationsbreite der Erziehungsvorstellungen in Migrationsfamilien auszugehen, die durch zahlreiche Studien belegt wurde.

Was die religiösen Orientierungen und die religiöse Praxis oder die religiöse Erziehung angeht, weisen die Familien ebenfalls eine hohe Variabilität auf. Weder kann von einem einheitlichen kulturellen Hintergrund noch von religiösen Orientierungen innerhalb einer einzigen Familie (vgl. YalçınHeckmann 1998), geschweige denn einer ethnischen Community ausgegangen werden (vgl. Stöbe 1998). Die Untersuchung von Ceylan (2014) bescheinigt eine grobe Einteilung von muslimischen Eltern in zwei Kategorien, wonach die eine Gruppe über religiöse Bildungsvoraussetzungen verfügt, um ihren Kindern eine bewusst islamische Erziehung zukommen zu lassen. Die andere wiederum, die die Mehrheit der muslimischen Eltern bildet, delegiert diese Aufgabe aufgrund ihrer Überforderung und geringer Bildungsvoraussetzungen an Moscheegemeinden (vgl. auch oben).

Diese Ergebnisse führen gerade im Zusammenhang mit einer religiösen Erziehung zur Frage, welche konkrete greif- und benennbare religiös fundierte Erziehungspraxis in muslimischen Familien vorzufinden ist und wie diese sich in den unterschiedlichen Familien voneinander unterscheiden lässt.

41 | Vgl. auch Thiessen (2008). 


\section{Ergebnisse der Untersuchungen über Jugendliche}

Fast alle Untersuchungen über muslimische Jugendliche belegen einen $\mathrm{Zu}$ sammenhang zwischen religiöser Erziehung in der Familie als wichtigste Bedingung einer späteren Religiosität. Auch wenn hier Ausnahmen zu verzeichnen sind, so hängen die Stärke und die Intensität der religiösen Orientierung entscheidend von der Erziehung in der Familie ab.

Die Zusammenfassung der Ergebnisse über muslimische Jugendliche deutet im Vergleich zur Elterngeneration auf eine bewusstere religiöse Lebensführung als auch auf höhere Ansprüche und Erwartungen hinsichtlich einer religiösen Erziehung, was an den eigenen perzipierten religiösen Erziehungsvorstellungen abzulesen ist. Hier scheint sich eindeutig der Wunsch nach einer »Professionalisierung « der religiösen Erziehung innerhalb der Familie abzuzeichnen. Dies bezieht sich sowohl auf die Wissensaneignung als auch auf die religiöse Praxis, die reflektiert und im Vergleich zu den Eltern systematisch ausgeübt werden sollte. Sowohl die Ziel- als auch die Inhaltsdimension soll unter Bezugnahme auf islamische Quellen für die Kinder reflexiv nachvollziehbar sein. Es zeigen sich, wenn auch nur sehr selten, Wünsche nach einer Verbesserung der didaktischen Möglichkeiten. Die gestiegenen Ansprüche finden auch in der religiösen Mündigkeit ihren Niederschlag. Nicht mehr das unreflektierte Nachahmen, sondern die bewusste Auseinandersetzung mit der eigenen Religion wird angestrebt, um den »wahren « universalistisch geprägten Islam auszuleben. Dies schließt auch eine Abwendung vom kulturell geprägten »traditionalistisch-türkischen« Islam mit ein. Den besonderen Stellenwert, den die religiöse Erziehung für die Jugendlichen, trotz der vielfach ausgedrückten Unzufriedenheit mit der religiösen Erziehung der Eltern, hat, veranschaulicht die Bedeutung und die identitätsstiftende Funktion der Religion.

Die Studien weisen ferner darauf hin, wie unterschiedlich Religiosität im familiären Rahmen erlebt wurde und welche Konsequenzen sowohl auf kognitiver als auch auf alltagspraktischer Ebene daraus gezogen wurden. Die unterschiedlichen Einflüsse, die im Zusammenhang der religiösen Sozialisation erlebt wurden, deuten auf differente Muster religiöser Sozialisationsprozesse. Auch hier spielt bei religiösen Jugendlichen, häufig angeregt durch die Eltern, der Bezug zu Moscheegemeinden eine große Rolle.

Um die unterschiedlichen religiösen Sozialisationseinflüsse nachzeichnen zu können, sollen die qualitativen und quantitativen Studien über muslimische Jugendliche entlang der folgenden Schwerpunkte noch einmal zusammengefasst werden:

- Wie wird die religiöse Erziehung im Elternhaus erlebt?

- Welche eigenen Vorstellungen von Religiosität haben die Jugendlichen selbst entwickelt? 


\section{Die religiöse Erziehung im Elternhaus}

Fast alle Studien veranschaulichen, dass die im Elternhaus erfahrene religiöse Erziehung Auswirkungen auf die spätere Religiosität der Jugendlichen hat (Boos-Nünning/Karakaşoğlu 2006; Karakaşoğlu-Aydın 2000; Klinkhammer 2000; Frese 2002; Aygün 2010; Wensierski/Lübcke 2012). Somit stellt die Familie im religiösen Sozialisationsprozess einen bedeuten Einflussfaktor dar und spielt eine zentrale Rolle bei der Vermittlung von religiösen Inhalten. Es gibt aber auch Beispiele, bei denen Jugendliche angeregt durch Freundeskreis, Schule und Moscheegemeinde zum Islam finden, ohne dass die Eltern einen wesentlichen Einfluss auf ihre religiöse Sozialisation ausgeübt hätten (vgl. Klinkhammer 2000; Nökel 2002; Wensierski/Lübcke 2012). Diese sind in ihren Fallzahlen geringer und erleben ihre familiäre Situation häufig konflikthaft.

Die religiöse Erziehung im Elternhaus wurde durch die Jugendlichen unterschiedlich wahrgenommen. Dabei wird einerseits Kritik am elterlichen Erziehungsverhalten geübt, andererseits hat man jedoch auch Verständnis für die Eltern.

Die religiöse Erziehung wurde als ein fester Bestandteil des familiären Lebens erlebt. Die Aneignung der rituellen Praxis erfolgte durch die Nachahmung der Eltern und wurde zudem durch kleinere Belohnungen verstärkt (vgl. Klinkhammer 2000; Frese 2002). Das Familienleben war teilweise durch den gemeinsamen Bezug zur Gemeinschaft/religiösen Gemeinde sowie gemeinsames Feiern religiöser Feste bestimmt. Die Jugendlichen besuchten, häufig durch die Eltern angeregt, eine Koran- oder Sommerschule (vgl. Klinkhammer 2000; Frese 2002; vgl. Öztürk 2007; vgl. Aygün 2010; vgl. Wensierski/Lübcke 2012). Im Vergleich zu den Eltern wird dem Koranunterricht von einigen Jugendlichen weniger Bedeutung beigemessen (vgl. Frese 2002). Im Zusammenhang mit den Peers stellt dieser jedoch einen wichtigen religiösen Erfahrungshintergrund dar (vgl. Frese 2002; vgl. Aygün 2010; vgl. Wensierski/ Lübcke 2012).

Der religiöse Erfahrungshintergrund im familiären Rahmen war nicht konkret benennbar, jedoch prägend; d.h., es gab »Gefühle«, die im Zusammenhang mit der religiösen Erziehung in der Familie standen (»[...] der Islam war irgendwie da«) (vgl. Tietze 2001; Nökel 2002). Einige Jugendliche betrachteten die familiäre religiöse Erziehung im Sinne einer »profunden Wissensvermittlung« als erfolgreich (vgl. Nökel 2002). In den Familien, in denen die religiöse Erziehung im Vordergrund stand, kamen die Kinder nicht repressiv, sondern mit einer umsichtigen Pädagogik der Belohnung und Anerkennung (vgl. ebd.: 289), mit Diskussionen über Religion und Kultur auf der Basis einer freiwillig durchgeführten religiösen Praxis (vgl. ebd.: 290), offen (vgl.ebd.: 
291), traditionell (vgl. ebd.: 294), aber auch streng-traditionell ${ }^{42}$ (vgl.ebd.: 293; vgl. Wensierski/Lübcke 2012; vgl. Karakaşoğlu-Aydın 2000) mit Religion in Berührung. Auch eine »negativ erfahrene soziale Kontrolle«, die Auswirkungen auf das Verhältnis zu Gott hatte, wird benannt (vgl. Karakaşoğlu-Aydın 2000).

Die traditionelle unreflektierte Weitergabe von »falschem« Wissen über den Islam wird dem Elternhaus vorgeworfen. Es wurden wenig plausible Erklärungen für die Erziehungspraxis aufgeführt, religiöses Wissen wurde nicht angeboten (vgl. Klinkhammer 2000; Tietze 2001; Frese 2002; Aygün 2010). Die religiöse Erziehung habe auf die Jugendlichen »floskelhaft und intuitiv« gewirkt; Ziele und Inhalte der von den Eltern vermittelten religiösen Erziehung seien nicht immer nachvollziehbar gewesen (vgl. Öztürk 2007). Ebenso wird den Eltern die fehlende Selbstdisziplin bei der Befolgung der religiösen Gebote vorgeworfen (vgl. Nökel 2002). Nicht zuletzt lasse sich die Isolation der Eltern von der Mehrheitsgesellschaft durch die fehlende Bereitschaft, sich mit den eigenen Wurzeln und geistigen Grundlagen zu beschäftigen, erklären (vgl. Frese 2002).

Zudem wird die fehlende Unterstützung der Eltern im Umgang mit der nichtmuslimischen Umwelt wie der Schule bemängelt, was gerade mit dem Tragen des Kopftuches oder einem Mangel an Informationen über den Islam bei Fragen aus dem nichtislamischen Umfeld einhergeht (vgl. Klinkhammer 2000; Frese 2002; Öztürk 2007).

Die von den Eltern vertretene Sexualmoral führt des Weiteren zu Differenzen zwischen den Eltern und ihren Kindern. Diese Thematik wird ab dem Beginn der Pubertät von den Jugendlichen zum Teil als sehr problematisch empfunden (vgl. Klinkhammer 2000; vgl. Frese 2002; Wensierski/Lübcke 2012) und größtenteils in ihrer normweisenden Funktion wahrgenommen (vgl. Öztürk 2007; Klinkhammer 2000; Blank 2000; Frese 2002; Wensierski/Lübcke 2012; vgl. auch Kap. 3.1.3 d) für die normweisende Funktion der Sexualmoral).

Als positive Einflussfaktoren der religiösen Erziehung werden Eltern, Personen aus dem Verwandtenkreis, Kursleiter/-innen sowie Korankursleiter/-innen benannt (vgl. Karakaşoğlu-Aydın 2000; Klinkhammer 2000; Aygün 2010; Wensierski/Lübcke 2012).

42 | Eine Gruppe von muslimischen Jugendlichen hat eine "strenge" religiöse Erziehung im Elternhaus erlebt (vgl. z.B. Wensierski/Lübcke 2012: 320). Hierbei gilt es, zu unterscheiden, worauf sich "streng" bezieht. Bezieht es sich auf einen repressiven Stil, der Zwang einschließt, oder wird "Strenge" im Sinne einer strikten Befolgung religiöser Gebote gesehen? 


\section{Religiöse Erziehungsvorstellungen der Jugendlichen}

Die eigene religiöse Bildung bzw. ihre Weitergabe an die zukünftigen Kinder steht, wenn auch mit unterschiedlicher Intensität, für alle Jugendlichen im Vordergrund (vgl. alle vorgestellten Studien). Der hohe Stellenwert, den die religiöse Erziehung für sie in Zukunft einnimmt, wurde insbesondere durch die quantitativ angelegten Studien, wie z.B. die Shell Jugendstudie (2000), und durch Boos-Nünning/Karakaşoğlu (2006) näher erläutert.

Im Vergleich zur Elterngeneration entwickeln sie ein modernes religiöses Selbstverständnis, bei dem die Hinterfragung der elterlich vermittelten Verhaltensnormen und Dogmen im Vordergrund steht, was wiederum eine Abwendung von dem traditionalistischen Religiositätsverständnis der Eltern mit sich bringt. Dabei beziehen sich die Jugendlichen auf den »wahren« Islam, was sich aus der intellektuellen Auseinandersetzung mit islamischen Quellen ergibt (vgl. Karakaşoğlu-Aydın 2000; vgl. Klinkhammer 2000; vgl. Nökel 2002; vgl. Tietze 2001; vgl. Frese 2002; vgl. Öztürk 2007).

Bei den von Karakaşoğlu-Aydın (2000) befragten jungen Frauen ist eine Spannbreite an Erziehungsvorstellungen und perzipierten Erziehungsstilen vorhanden. Interessant ist dabei, ob religiöse Vorstellungen in allgemeine Erziehungseinstellungen eingebunden wurden oder nicht, also ob zwischen allgemeiner und religiöser Erziehung unterschieden wird, d.h. hier getrennte Vorstellungen entwickelt wurden. Die religiöse Erziehung soll durch Korankursbesuche und schulischen Religionsunterricht unterstützt werden. Der Schule als Erziehungsinstanz wird hierbei eine besondere Bedeutung beigemessen (vgl. Karakaşoğlu-Aydın 2000).

Die Jugendlichen betrachten es als ihre Pflicht, die Kinder nach den islamischen Grundsätzen zu erziehen (vgl. Tietze 2001; vgl. Öztürk 2007). Die Einhaltung der Gebote und Verbote stellt ein wesentliches Kriterium der religiösen Erziehung dar. Die Verantwortung bzw. religiöse Mündigkeit setzt ab dem Pubertätsalter ein. Eine fundierte Erziehung und Bildung im Islam wird vermisst. Ein konsistentes, kindgerechtes und altersgemäßes Erziehungskonzept nach religiösen Grundsätzen erscheint für die Jugendlichen wünschenswert (vgl. Frese 2002; Öztürk 2007). Die von Öztürk (2007) und Karakaşoğlu-Aydın (2000) befragten Jugendlichen geben einige Hinweise, welchen Aspekten sie in der religiösen Erziehung eine besondere Bedeutung beimessen wollen.

Zwang und Restriktionen im Glauben werden grundsätzlich abgelehnt, die religiöse Mündigkeit des Kindes soll immer gewahrt und die elterliche Autorität darf nicht missbräuchlich verwendet werden (vgl. Karakaşoğlu-Aydın 2000; Nökel 2002).

Insgesamt stellt sich folglich die Frage, wie sich der veränderte Zugang zur Religion auf den Inhalt der religiösen Erziehung und deren Vermittlungsform auswirkt und welches Erziehungshandeln sich demnach in heutigen Familien abzeichnet. 


\subsection{Religiöse Sozialisation in anderen Kontexten}

\subsubsection{Im Kontext von außerschulischen Bildungseinrichtungen}

Wie oben schon dargestellt wurde, nehmen außerschulische Bildungseinrichtungen wie Moscheen, in welche die Koranschulen ${ }^{43}$ bzw. Korankurse integriert sind, und ähnliche religiöse Bildungseinrichtungen ${ }^{44}$ einen wichtigen Stellenwert in der religiösen Erziehung und Sozialisation von Kindern und Jugendlichen ein (vgl. Brettfeld/Wetzels 2007 in Kap. II.1.3 und II.1.4; vgl. Kap. II. 2.1). Die meisten muslimischen Eltern fühlen sich auch aufgrund ihrer geringen Bildungsvoraussetzungen und ihrer Uninformiertheit über den Islam (vgl. Alacacıoğlu 1999; Ceylan 2008; Ceylan 2014; Karakaşoğlu/Öztürk 2007 und vgl. Kritik an Eltern in den vorgestellten Studien) nicht dazu in der Lage, ihre Kinder ausschließlich innerhalb des familiären Rahmens religiös zu erziehen, sodass sie sich von diesen Einrichtungen unterstützen lassen. Diese religiösen Bildungseinrichtungen gelten als Orte, an denen a) Wissensaneignung über den Islam, b) das Einüben von sozialen Fertigkeiten einschließlich religiöser Rituale, c) das Erlernen von moralischen Werthaltungen und d) die Rezitation des Korans auf Arabisch im Vordergrund steht. Auch bieten diese e) Freizeitmöglichkeiten, die für Kinder und Jugendliche einen wichtigen Erfahrungsraum darstellen.

Die außerschulische religiöse Unterweisung, in welcher Form diese auch stattfindet, ist mit einigen wenigen Ausnahmen bislang kaum erforscht worden, sodass entsprechende Bezüge zum Thema der vorliegenden Studie mittels einiger Beiträge und einiger weniger Untersuchungen hergestellt werden können.

Die vorgestellten Untersuchungen zur Jugendreligiosität geben einige Hinweise, wie die Korankurse u.ä. Einrichtungen erlebt wurden. Die Korankurse werden als außerfamiliäre Sozialisationsinstanz in ihrer Nutzung grundsätzlich nicht infrage gestellt. Die Jugendlichen nehmen die Korankurse bzw. die Moscheegemeinden, in denen diese zumeist stattfinden, als wichtige Eckpfeiler hinsichtlich ihres religiösen Sozialisationsprozesses wahr, weil sie positive Erfahrungen mit Freunden, die sie dort kennengelernt haben, und besonderen Vorbildern gemacht haben. Jedoch werden durch die Jugendlichen auch Er-

43 | Vgl. Behr 2009 zur historischen Einordung der Koranschulen sowie ihrer Funktion und inren Aufgaben.

Die Bezeichnung "Koranschule" bzw. "Korankurs" unterscheidet sich lediglich in der Begriffsverwendung. Jedoch können die Bildungsangebote der jeweiligen Moscheegemeinden in den Korankursen deutlich voneinander abweichen (vgl. auch Kap. 1.3). Deshalb wird hier der gängigere Begriff "Korankurs" verwendet.

44 | Diese existieren in Form von unabhängigen Vereinen oder sind sozialen Bildungseinrichtungen angegliedert. 
wartungen und Wünsche an den Moscheeunterricht formuliert, die zukünftig weitere Verbesserungsmöglichkeiten ermöglichen sollen.

So geht es im Folgenden darum, die Ergebnisse der Untersuchungen nach zwei wesentlichen Kriterien zusammenzufassen:

a. nachdem, was die wenigen Untersuchungen bzw. Beiträge über Korankurse u.ä. Einrichtungen aussagen;

b. und wie Jugendliche den Korankursbesuch bzw. religiöse Bildungseinrichtungen erlebt haben und welche Forderungen und Wünsche sie dabei an eine religiöse Unterweisung (innerhalb der Moschee) usw. stellen.

Zunächst erfolgt die Darstellung der Ergebnisse hinsichtlich außerschulischer religiöser Bildungseinrichtungen in Moscheen und Vereinen.

\section{a) Außerschulische religiöse Bildungseinrichtungen in Moscheen und Vereinen}

Auch wenn in einer neueren Studie Angebote der Moscheegemeinden (vgl. Halm/Sauer 2012 in Kap. II. 1.4) je nach zugehörigem Dachverband differenziert dargestellt werden können, gibt es keine verlässlichen Statistiken über das Koranschulwesen in Deutschland. Lediglich anhand einzelner Analysen, die sich auf der Basis exemplarischer qualitativer Fallstudien zu Unterrichtskonzepten in türkisch-islamischen Gemeinden in NRW (vgl. Alacacıŏlu 1999) sowie mit den Erziehungsvorstellungen, religiösen Orientierungen und Unterrichtskonzepten von Imamen auseinandersetzen, können Aussagen über diese Einrichtungen getroffen werden (vgl. Ceylan 2008; vgl. Ceylan 2010a; Ceylan 2010b, Ceylan 2014).

Die Untersuchung von Alacacioğlu (1999) zeigt die Bedeutung der Korankurse für die religiöse Erziehung in türkisch-muslimischen Gemeinden unter Berücksichtigung ihrer Erziehungskonzeptionen und dem in diesen aktiven Lehrpersonal. Dabei werden sowohl die Ziele, die Inhalte, die Unterrichtsstrukturen und -methoden, die Auswahl und Qualifikation der Vorbeter und die Einstellung zum schulischen Religionsunterricht einer Analyse unterzogen (vgl. überblicksweise Alacacığlu 1999: 245-256). Insgesamt lässt sich konstatieren, dass die Moscheegemeinden mit unterschiedlichen Schwerpunktsetzungen, den weltanschaulichen Ideologien der jeweiligen muslimischen Dachverbände folgen.

Ceylan (2008) untersuchte angewandte Formen islamischer Religionspädagogik in Moscheen und Schulen. Der Vergleich stellt die Ausgangslage, die Lehre und Ziele der in den Moscheen und Schulen vermittelten religiösen Erziehung dar. Dabei ist die didaktisch-methodische Orientierung von Bedeutung und die Frage entscheidend, welche pädagogischen und religiösen Ziele durch die von ihm interviewten Imame in ihrer einflussreichen Rolle verfolgt werden. Es werden Grundrisse und elementare Inhalte erläutert. Des Weiteren wird der Frage nachgegangen, ob Moscheen in Bezug auf den islamischen 
Religionsunterricht als Kooperationspartner von Schulen gelten. Außerschulische Einrichtungen bilden für Ceylan neben dem Elternhaus die zweite Säule in der religiösen Erziehung und Sozialisation der muslimischen Kinder. Die Erwartungen der Eltern, ihre besonderen Sichtweisen, Forderungen und Bedenken werden ebenso beachtet wie jene der muslimischen Organisationen (vgl. Ceylan 2008: 11-17).

Religiöse Bildung in den Moscheen ${ }^{45}$, welche die Grundbildung vieler muslimischer Kinder sichert, wird in Deutschland seit den 1970er-Jahren angeboten. Auch wenn jahrzehntelange Erfahrungen vorhanden sind, konnte keine systematisch ausgearbeitete didaktische Konzeption einer islamischen Religionspädagogik auf der Basis wissenschaftlicher Kenntnisse entwickelt werden. Inhaltlich sowie in ihren Zielsetzungen weicht die religiöse Unterweisung in den Moscheen von der eines islamischen Religionsunterrichts in den Schulen ab. Die zentralen Elemente sind hier das Erlernen der arabischen Schriftsprache, die Rezitation des Korans, das Auswendiglernen von Koransuren/-passagen, Prophetengeschichten, Glaubensgrundlagen, die Ausbildung zum Muezzin (Gebetsruf)/zum (Teilzeit-)Imam und das Erlernen der arabischen Sprache. Daneben ist die religiöse Praxis, die auf Formalismus angelegt ist, ein wesentlicher Bestandteil der religiösen Erziehung in den Moscheen. Bei der Unterweisung durch Imame sind didaktisch-methodische Defizite feststellbar, die sich in der Unfähigkeit einer kritischen Selbstreflexion äußern, da man weder von schriftlich ausgearbeiteten Lehrplänen noch von schriftlichen Erfahrungsberichten ausgehen kann. Zudem wird häufig die Nichtbeachtung der Lebenswirklichkeit der Kinder und Jugendlichen kritisiert. Es werden soziokulturelle Faktoren ausgeblendet. Auch methodische Defizite erschweren einen pädagogisch sinnvollen Verlauf (Frontalunterricht, Unterricht ohne Einsatz von Medien, hohe Schülerzahlen, autoritärer Erziehungsstil, sprachlich bedingte Kommunikationsschwierigkeiten) (vgl. Ceylan 2010a: 68 und 176). Ferner werde die Erziehung zur Selbstständigkeit und zur kritischen Reflexion durch eine inhaltlich-systematische Auseinandersetzung mit islamischen Quellen wenig gefördert. Dafür stünden Nachahmung und Imitation im Vordergrund. Nicht der Intellekt werde angeregt, sondern die Emotionalität (vgl. Ceylan 2008: 138-144). ${ }^{46}$ Trotz der Defizite nehmen die Moscheen dennoch eine zentrale Rolle in der religiösen Sozialisation von Kindern ein. Die Bedeutung der Einrichtungen wird nicht nur in ihrer identitätsstiftenden Funktion

45 | Dieser kurze geschichtliche Abriss folgt Ceylan 2008.

46 | In diesem Zusammenhang spielen die Einstellungen und religiösen Orientierungen der Imame eine besondere Rolle, nicht zuletzt deshalb, weil der Erfolg einer religiösen Erziehung von ihren Einstellungen und Kompetenzen abhängt. Ceylan unterscheidet zwischen drei Typen von Imamen, neo-salafistisch, traditionell-defensiv, intellektuelloffensiv (vgl. Ceylan 2008: 144ff.; vgl. auch: Ceylan 2010a). 
gesehen, denn diese erscheinen auch als Orte, an denen soziale, kulturelle und sportliche Aktivitäten stattfinden.

Auch in seiner aktuelleren Untersuchung aus dem Jahr 2014 widmet sich Ceylan der Moscheekatechese, allerdings unter Berücksichtigung von Säkularisierungsprozessen, die voraussichtlich eintreten würden. Es werden hier die Rahmenbedingungen der religiösen Erziehung in den Moscheegemeinden aufgegriffen und die aktuelle Situation, Strukturen und Entwicklungen näher analysiert. Hierunter fallen, angefangen von Anmeldungsverfahren der Schüler für den Moscheeunterricht, auch das Selbstverständnis und die Ziele der Moschee, die Situation der Lehrkräfte bis hin zu Lehrplänen, Materialien, Inhalten, Methoden und religionspädagogischen Herausforderungen u.a. (vgl. Ceylan 2014 in Kap. II. 2.1.1 und Ceylan 2014: 343-379).

\section{b) Erfahrungen der Jugendlichen mit religiösen Bildungseinrichtungen}

Der bedeutsame Kontext religiöser Einrichtungen wird durch Wensierski/Lübcke (2012) anhand der von ihnen porträtierten Jugendlichen herausgestellt. Moscheen und Moscheevereine sichern ihren Ergebnissen zufolge die »Kontinuität wie auch die kollektive Identität des eigenen Islamisierungsprozesses « (Wensierski/Lübcke 2012: 388). Sie ermöglichen es, biografisch bedeutsame und orientierungs Bezugspersonen oder auch besondere Vorbilder wie die Peergroup zu finden. Zudem hätten die Jugendlichen hier die Möglichkeit, aktiv soziale Rollen zu übernehmen und unterschiedliche Funktionen zu erfüllen. Vor allem für die Ausübung alltagspraktischer, religiöser Rituale sei die Bedeutung der Moscheen hervorzuheben. In der Gemeinschaft mit anderen verlören diese Rituale den Charakter des »Fremden«, der ihnen innerhalb der deutschen Mehrheitskultur zugeschrieben werde. Diese Gemeinschaften würden somit die soziale Anerkennung des religiösen Lebensstils sichern (vgl. ebd.: $388 f$.).

Die besondere Bedeutung der religiösen Bildungseinrichtungen (in der Migrationssituation) wird auch von Aygün (2010) verdeutlicht. In einem Vergleich zwischen Jugendlichen aus der Türkei und (türkischen) Jugendlichen aus Deutschland beziehen sich alle muslimischen Jugendlichen darauf, welche Beziehungen sie als wertvoll empfinden und auf Einrichtungen, in denen sie eine religiöse Erziehung genossen haben. Vor allem die in Deutschland lebenden jungen Muslime betonen die Bedeutung von Moscheen, Vereinen und religiösen Gruppen und auch die Bedeutung der Freundschaften, die in diesem Kontext entstünden (vgl. auch Frese 2002; Tietze 2001; vgl. oben Wensierski/Lübcke 2012). Die Freizeit wird gerne im Rahmen der Moschee und mit den Freunden verbracht (vgl. auch Frese 2002; Öztürk 2007; Alacacioğlu 2000). Im Vergleich dazu nehmen Moscheen usw. für die in der Türkei lebenden muslimischen Jugendlichen einen geringeren Stellenwert ein, hingegen 
unterstreichen sie die Beziehungen zu Professoren, Lehrern, Gruppen, Schulfreunden und historischen Persönlichkeiten (vgl. Aygün 2010: 89-93).

Des Weiteren können anhand der Untersuchungen Aussagen über die in den religiösen Bildungseinrichtungen bzw. Moscheen vermittelten Inhalte und Methoden gemacht werden. Hierbei erscheint der Unterricht, der in den Moscheen angeboten wird, als verbesserungswürdig. Vielfach wird hier auch die Vermittlungsform kritisiert.

In der von Tietze (2001) untersuchten Biografie zeigt sie u.a. auf, wie Jugendliche mit dem ansozialisierten Wissen umgehen möchten. Interessant ist dabei, welcher Methodik sie folgen möchten, also welche Mittel von Jugendlichen gewählt werden, um sich die Religion anzueignen. Wichtig sei hierbei der Austausch mit Freunden, gerade im Rahmen einer Moscheegemeinde. Daneben würden die Vorträge des Imams und das Lesen von Büchern zur Wissensaneignung dienen. Doch viel wichtiger sei dabei, anhand praktischer Beispiele zu lernen. Der Lernprozess solle auf Erlebtem basieren, d.h. ein Praxisbezug sei unabdingbar. Religion werde als ein Prozess verstanden, in dessen Verlauf der Gläubige Gefühl, Wissen und Praxis immer enger miteinander verbinden solle (vgl. Tietze 2001: 74).

Auch Frese (2002) liefert Anhaltspunkte dafür, wie sich Jugendliche innerhalb des Moscheeunterrichts religiöses Wissen aneignen. Indem sie sich dieses eigenständig erarbeiten, erfüllen sie nicht nur die Erwartungen der Eltern, sondern bilden sich selbstständig fort und setzen somit ihre eigenen Überzeugungen in die religiöse Praxis um. Frese fügt hinzu, dass dieses Wissen nicht in einem intellektuellen Vakuum erarbeitet werde, sondern in einem prozesshaften Sichabgrenzen, Zustimmen, Weiterentwickeln von Meinungen, die seitens der Eltern und der hocas (Imame ${ }^{47}$, Religionsbedienstete) sowie der religiösen Dachverbände in Deutschland vertreten und z.B. durch Lektüre überprüft würden. Ebenso ist der Bildungsauftrag laut Frese individuell (vgl. Frese 2002: 220 und 281).

Der Wunsch nach Erklärungen und Begründungen bzgl. der Religion drückt sich nicht nur gegenüber den Eltern, sondern auch gegenüber Lehrern und Imamen in der Moschee aus. Vielfach zeigt sich, dass eine Verbesserung auf didaktischer und methodischer Ebene jenseits eines autoritären Erziehungsstils und frontal geleiteten Unterrichts als wünschenswert erachtet wird. Die Jugendlichen kritisieren das einseitige Auswendiglernen, bei dem den Unterrichteten weder Information über die Bedeutung des »Gelernten« noch islamische Geschichte vermittelt wird. Im Grunde würden sie sich dennoch zufrieden mit dem Unterricht äußern, sofern kein Zwang vonseiten der Eltern und Geistlichen zu befürchten sei (vgl. Alacacioğlu 2000: 62; Frese 2002:

47 | Geistlicher Vorbeter in einer Gemeinde, vgl. Ceylan 2010a zur Begriffsdefinition und Funktion eines Imams. 
285f. vgl. Klinkhammer 2000: 123 und 142). Die altersgerechte Vermittlung von Kenntnissen soll Überforderungen vermeiden (vgl. Frese 2002: 216). Zudem wird der Wunsch geäußert, dass der Unterricht »unterhaltsamer« verlaufen sollte, um motiviert am Unterricht teilnehmen zu können. Des Weiteren kommt es zur Forderung nach dem Deutschen als Vermittlungssprache, damit man auch außerhalb der Moschee, wie z.B. in der Schule, über die eigene Religion sprechen könne (vgl. Öztürk 2007: 128f.). In diesem Zusammenhang ist auf die Qualifikation bzw. Kompetenz der Imame bzw. hocas zu verweisen. Diese sollten somit die komplizierte Lebensrealität der Jugendlichen in Deutschland aufgrund ihres Migrationshintergrundes erkennen. Dabei seien die coolen hocas, denen es gelinge, bei einigen Jugendlichen einen islamisch orientierten Lebenswandel zu bewirken, besonders beliebt (vgl. Frese 2002: 219f. und 2002: 284; vgl. auch Öztürk 2007: 235).

Den Eltern wird im Rahmen des Moschee- bzw. Korankursbesuchs vorgeworfen, dass die »religiöse Vermittlungsinstanz« nicht bewusst und unkritisch in Kenntnis des pädagogischen Programms gewählt worden sei. Daneben habe die religiöse Komponente keine große Rolle gespielt; viel wichtiger sei den Eltern hingegen die gesellschaftliche Zielsetzung gewesen, die Kinder »gut versorgt« und »betreut« zu sehen bzw. diese von der Straße fernzuhalten $^{48}$ (vgl. Öztürk 2007: 239).

Anhand einer weiteren Studie wird deutlich, dass für Jugendliche nicht primär religiöse Angebote (18 von 56 befragten Jugendlichen, also etwa ein Drittel), wie bspw. »Informationen über Religion«, »Koranunterricht« im Vordergrund stehen, sondern soziale, kulturelle und sportliche (»geselliger Kontakt«, »sportliche Aktivitäten«, »kulturelle Aktivitäten«, »soziale Aktivitäten«, »Bildungsangebote «) Aktionen. 32 von 56 der befragten Jugendlichen (also mehr als die Hälfte) wünschen sich noch umfangreichere Freizeitmöglichkeiten, als jene, die ihnen bereits im Rahmen ihrer Moscheegemeinden angeboten werden (vgl. Alacacıŏ̆lu 2000: 55f.).

Die Anforderungen, die an Moscheegemeinden gestellt werden, sind im Laufe der Zeit gestiegen. Die Moschee müsse eine intensive Bildungsarbeit für Kinder, Jugendliche und Erwachsene anbieten. Bezahlbare Weiterbildungsangebote und die interne Kommunikation zwischen den Gläubigen sollten gefördert und auch verstärkt Angebote in deutscher Sprache organsiert werden (vgl.

48 So wird auch festgestellt, dass die Einhaltung von religiösen Pflichten, der Moscheebesuch und der Islamunterricht die Jugendlichen vor Kriminalität, Drogen und Respektlosigkeit schützen und als Schutzmauer für ein konsequent gesetzestreues Leben dienen sollen. Es wird zudem in einigen Fällen eine totale Abwendung vom gewaltfreien Leben beobachtet. Eine frühzeitige religiöse Bindung ermögliche somit dauerhaft, eine respektvolle und hilfsbereite (Lebens-)Einstellung einzunehmen (vgl. Öztürk 2007: 239). 
Öztürk 2007: 235; vgl. Alacacioğlu 2000: 56f.). Moscheegemeinden sollten nicht nur zur Verrichtung des Gemeinschaftsgebetes zur Verfügung stehen, sondern auch über den Koranunterricht hinausgehende soziale Funktionen erfüllen. Niedrigschwellige Angebote für Jugendliche und Familien sowie Freizeitangebote und Kurse, die eine vertiefende Bildung zum bereits Gelernten ermöglichen würden, seien wünschenswerte Veränderungen (vgl. Frese 2002: 226; vgl. Alacacioğlu 2000: 56).

Insgesamt verdeutlichen die Erfahrungen der Jugendlichen, dass auch im Bereich der Moscheen die Erwartungen und Wünsche hinsichtlich ihrer religiösen Bildung gewachsen sind und hier eine »Professionalität« erwartet wird, um den eigenen Ansprüchen an eine religiöse Bildung sowohl auf individueller Ebene als auch gegenüber einer nichtislamischen Umwelt besser gerecht werden zu können.

\subsubsection{Muslimische Kinder und Jugendliche im Kontext institutioneller Bildungseinrichtungen}

Die Bildungssituation und Bildungsprozesse spezifisch junger Muslime werden nicht oder nur wenig gesondert erforscht. Vielmehr wird in diesem Zusammenhang von Schüler/-innen »mit Migrationshintergrund«, von »ausländischen«, hauptsächlich jedoch von türkischen Schüler/-innen ausgegangen und entsprechend gesprochen. Zudem fällt, wie oben bereits erklärt (vgl. Kap. II.1.1 und II.1.2) wurde, auf, dass »türkische« Schüler in der Regel unter der Kategorie »muslimisch « erfasst werden, ohne ein differenziertes Bild über deren Bezug zur Religion herzustellen (vgl. Bukow 2007; Wensierski 2007). Der Anspruch auf eine repräsentative Darstellung zur Erklärung der Bildungssituation von muslimischen Jugendlichen kann hier demzufolge nur bedingt erfüllt werden.

Einige Studien, in denen Bezüge zur Schule im Zusammenhang mit der Religiosität von Jugendlichen hergestellt werden, verweisen auf hohe Bildungsaspirationen der Eltern. Die meisten Eltern wünschen sich hohe Bildungsabschlüsse für ihre Kinder, die diesen im Vergleich zu ihrer Situation bessere Zukunftschancen ermöglichen sollen. Die Eltern erhoffen für ihre Kinder somit einen gesellschaftlichen Status, den sie selbst niemals erreichen konnten (vgl. z.B. Boos-Nünning/Karakaşoğlu 2006; Öztürk 2007; Schröter 2002; Schiffauer 2010; Wensierski 2007) ${ }^{49}$. Inwieweit der Islam einen zentralen Einfluss auf ihre Bildungsverläufe nimmt, kann jedoch anhand der einzelnen Biografien nur ansatzweise herausgelesen werden.

49 | Die Jugendlichen nähmen zwar häufig den Bildungsauftrag der Eltern auf, bekämen aber durch die Eltern oftmals kaum Unterstützung und Hilfe bei der Umsetzung des Auftrags (vgl. Boos-Nünning/Karakaşoğlu 2006: 125ff. und 134f.). 
Öztürk, der im Rahmen seiner Studie Religiositätsprofile von muslimischen Schülerinnen und Schülern nachzeichnete, stellte fest, dass Eltern schulische und berufliche Erfolge sowie ein gesetzestreues Leben höher bewerten als die Frömmigkeit ihrer Kinder. Die Eltern erwarten von ihren Kindern hauptsächlich, dass diese ein konfliktfreies Leben in dieser Gesellschaft führen. Dass schulische und berufliche Misserfolge sowie Konflikte innerhalb der Gesellschaft die Hauptursachen für verbale Auseinandersetzungen zwischen Eltern und ihren Kindern seien, zeige den hohen Stellenwert, den die Eltern der Bildung beimäßen (vgl. Öztürk 2007: 239). Vor diesem Hintergrund erscheint es ferner interessant, dass ein Jugendlicher davon berichtete, wie der Glaube seinen Wandel hin zu einem geduldigen und frommen Menschen bewirkt habe. Seine schulischen und beruflichen Erfolge verdanke er dem Islam, weil erst dieser ihn auf die zentrale Bedeutung von Bildung, Ehrlichkeit, Hilfsbereitschaft, Großzügigkeit und vorbildlichen zwischenmenschlichen Beziehungen aufmerksam gemacht habe (vgl. Öztürk 2007: 225ff.).

Das Thema »Islam in der Schule oder Kindertagesstätten« bringt Herausforderungen mit sich, die sowohl seitens der Schülerinnen und Schüler als auch insgesamt von den am Bildungssystem Beteiligten dargelegt werden. Zudem ist zu berücksichtigen, dass muslimische Eltern ihre Kinder in der Minderheitensituation bzw. Diasporasituation aufziehen. Religiös bedingte Lebens- und Verhaltensweisen, insbesondere in der Kleidung und dem Umgang mit dem anderen Geschlecht, führen hier zu erheblichen Diskrepanzen, nicht selten sogar zu Konflikten, vor allem in deutschen Bildungseinrichtungen (vgl. Boos-Nünning 2011a: 28).

Es lassen sich dabei nachfolgende Bereiche bestimmen, aus denen sich potenzielle Konfliktlinien abzeichnen könnten ${ }^{50}$ :

- Das Tragen des Kopftuches, was die muslimischen Mädchen und jungen Frauen betrifft.

- Diskriminierungserfahrungen, die sich aus der Zuschreibung als Muslim oder der ethnischen Zugehörigkeit ergeben.

- Die Teilnahme an Sport- und Schwimmunterricht, am Sexualkundeunterricht und an Klassenfahrten. Wenn dieser Bereich oft auch überschätzt wird, so bestimmt dieser doch häufig die öffentliche Diskussion.

- Die Einhaltung von religiösen Ritualen, wie bspw. dem Fastengebot, oder das Verrichten der Gebete.

50 | In den einzelnen Bundesländern (Berlin, Hessen, NRW u.a.) sind Handreichungen, Faltblätter und Informationsmaterialien entstanden, mittels derer auf die angeführten Aspekte mit unterschiedlicher Intensität Bezug genommen wird; vgl. hierzu auch Turhan/Turhan 2011. 
Die Einführung des islamischen Religionsunterrichts, der vielerorts in Form von verschiedenen Modellen eingeführt wurde, steht schließlich auch sehr eng mit dem Thema »Islam in der Schule« in Verbindung. Die damit verbundenen Ziele, die inhaltliche wie auch die praktische Dimension, sollen im weiteren Verlauf der Studie aufgezeigt werden.

Zunächst soll jedoch die Suche nach empirischen Zugängen im Vordergrund stehen, die die Lebenswelt der Schule aus der Sicht von jungen muslimischen Schülerinnen und Schülern darstellt. Dabei werden auch die oben aufgeführten Konfliktlinien und die positiven Erfahrungen von muslimischen Schülerinnen und Schülern einbezogen.

\section{a) Empirische Ergebnisse zu den Erfahrungen mit dem Islam im schulischen Kontext}

Forschungsergebnisse, die den Umgang mit muslimischen Schülern, d.h. diejenigen Einflüsse, die einen Zusammenhang mit der Institution der Schule und der muslimischen Familie ${ }^{51}$ darstellen, sind bis dato noch kaum vorhanden. Empirische Studien, deren Schwerpunkt auf der Darstellung von Religiositätsformen bei Jugendlichen liegt, bieten entsprechende Ergebnisse über die in der Schule gemachten Erfahrungen.

Der Religion kommt hierbei eine Orientierungsfunktion zu, die den Jugendlichen und den Kindern bei der Bewältigung ihres Lebens einen wichtigen Halt bzw. Rahmen gibt. Religion werde des Weiteren auch als eine Ressource wahrgenommen, die ihnen im Hinblick auf ihren Identitätsbildungsprozess hilfreich erscheine (vgl. Boos-Nünning/Karakaşoğlu 2006; Klinkhammer 2000; vgl. Weniserski/Lübcke 2012).

Die Schulerfahrungen von Jugendlichen und Kindern erweisen sich als überaus ambivalent. Es werden zum einen die Benachteiligungen und Diskriminierungen beklagt, die insbesondere die ungerechte Bildungsempfehlung der Lehrer beinhaltet, zum anderen erweist sich die Schule als Ort der vielfältigen Entfaltungsmöglichkeiten und Nutzung von Ressourcen. Vielfach lässt sich die Perspektive der Schüler und Schülerinnen nachzeichnen, die Sichtweise der Eltern findet in der Forschung jedoch kaum oder nur wenig Berücksichtigung.

Die von Klinkhammer befragten Jugendlichen erlebten das schulische Umfeld im Zusammenhang mit ihrer Religiosität oder religiösen Zugehörigkeit, die ihnen entweder durch Mitschüler und Lehrer zugeschrieben oder durch das Tragen des Kopftuches deutlich wurde, zum einen als eine besondere Ressource und zum anderen auch als sehr problematisch. Als schwierig erwies sich in diesem Kontext insbesondere die fehlende Unterstützung vonseiten der

51 | Dies bezieht sich hier nicht auf die alleinige Religionszugehörigkeit. Hier wird auch auf die Religiosität abgezielt. 
Eltern, was letztendlich zu einem Legitimationsdefizit gegenüber den nichtmuslimischen Mitschülern in der Schule führte. Hinzu kamen des Weiteren noch Motivationsschwierigkeiten bei der Durchführung von Ritualen (vgl. Klinkhammer 2000: 146).

Die religiöse Einstellung zu erklären, diese zu begründen und sich vielfach auch rechtfertigen $\mathrm{zu}$ müssen, stellte die Jugendlichen vor große Herausforderungen, die aus Sicht der befragten Jugendlichen auch zu positiven Effekten führten. Gerade in der Auseinandersetzung mit dem Islam im schulischen Kontext fand somit eine Bewusstwerdung im Hinblick auf die eigene Religion statt, welche die inneren Widersprüche, hervorgerufen durch unterschiedlich erlebte Sozialisationsfelder, das muslimische Elternhaus und den deutschen schulischen Alltag, aufhob (vgl. Klinkhammer 2000: 125 und139). In der Zuschreibung als Kompetenzperson in Sachen Islam finde im schulischen Rahmen eine »Auseinandersetzung mit dem Islam« statt, die zu einem neuen intellektuell angeregten muslimischen Selbstverständnis der Jugendlichen beitrage (vgl. ebd.: 127 und 181ff.; vgl. Bukow 2007: 224; vgl. auch unten: Wensierski/Lübcke 2012).

\section{Das Kopftuch an Schulen}

Das Tragen des Kopftuches als ein Bestandteil der religiösen Pflichterfüllung wird von muslimischen Schülerinnen im Schulalltag häufig als problematisch erlebt. Auch wenn rechtlich keine Einschränkungen vorhanden sind, die das Kopftuch im Unterricht verbieten, bestimmen stereotypisierende Verhaltensweisen gegenüber kopftuchtragenden Mädchen den Schulalltag, da mit dem Tragen des Kopftuches vielfach auch eine Unterdrückung der Frau im Islam postuliert wird. Schülerinnen würden so unwillentlich in eine Verteidigungsposition gedrängt, die sie zu einer Auseinandersetzung mit ihrer Religion veranlasse und in vielen Fällen auch in ein reflektiertes muslimisches Selbstverständnis münde (vgl. Boos-Nünning/Karakaşoğlu 2005; Boos-Nünning 2007; Karakaşoğlu-Aydın 2000; Klinkhammer 2000; Nökel 2002; Nökel 2007; Haug/Müssig/Stichs 2009 u.a.). Die hier angeführten Untersuchungen verweisen auf die Notwendigkeit einer differenzierten Betrachtung, die die individuellen Motive der Betroffenen in ihrer Vielschichtigkeit wahrnimmt. Dies kann jedoch im begrenzten Rahmen der vorliegenden Dissertation nicht geleistet werden.

Das Kopftuchtragen in Schulen wird vielerorts unterschiedlich gehandhabt. Pädagogik und Schule reagieren auf die zunehmende Zahl kopftuchtragender Mädchen an Schulen und es wird häufig versucht, »Überzeugungsarbeit« bei Eltern und Schülerinnen zu leisten oder durch Interventionsmaßnahmen die Zahl kopftuchtragender Mädchen zu verringern. Vielfach geschieht dies unter der Annahme, dass die Mädchen zu einer solchen Bekleidung gezwungen worden seien. Die Schule, so Boos-Nünning (2007), sah sich offensichtlich in 
Fragen des Islams daher als ein notwendiger Gegenpol zu den muslimischen Elternhäusern. Auch wenn vielfach belegt wurde, dass türkische Familien nicht durch vorwiegend autoritär-rigides, sondern durch ein liebevoll-behütendes Erziehungsverhalten gekennzeichnet sind, bestimmen diejenigen Fälle, in denen familiäre Repressionen zu unerträglichen Lebensverhältnissen von Mädchen und jungen Frauen führten, das Bild von türkischen und damit auch muslimischen Familien in der Öffentlichkeit (vgl. Boos-Nünning 2007: 127f.).

Mit diesem Thema stehen auch Diskriminierungserfahrungen in einem engen Zusammenhang, sodass im Folgenden näher auf diese eingegangen werden soll.

\section{Diskriminierungserfahrungen in der Schule}

Muslimische Kinder und Jugendliche machen immer wieder Diskriminierungserfahrungen, die sich in vielfältiger Weise ausdrücken. Hierbei sind sowohl ethnisierende als auch auf die Religion bezogene Diskriminierungs- und Rassismuserfahrungen keine Seltenheit.

In der Forschung zur muslimischen Jugendreligiosität lassen sich hierzu zahlreiche Hinweise finden. Oft werden stigmatisierende und ethnisierende Erfahrungen im mehrheitskulturellen Kontext gemacht. Die Schule erweist sich als ein Ort, an dem die eigene kulturelle Identität zugespitzt reflexiv erlebt wird. Diskriminierungserfahrungen, aber auch Erfahrungen mit Lehrern, bei denen sie zur Auseinandersetzung mit ihrer eigenen Kultur und Religion oder Ethnie hervorgerufen werden, sind für manche muslimische Jugendliche typisch (vgl. Wensierski/Lübcke 2012: 388). Sie werden durch diese Erfahrungen von außen zu einer »kulturellen und religiösen Selbstvergewisserung « angeregt und geraten jedoch in keinen gravierenden »Identitätskonflikt« (vgl. ebd.: 395, vgl. oben).

In diesem Zusammenhang stellt Bukow fest, dass der Umgang mit der Religion im schulischen Alltag an Deutungsinteressen geknüpft ist:

"Es ist klar, dass das Thema Religion im Kontext der unsichtbaren Schulrealität durchaus virulent sein kann, weil es hier um Konstruktion und Pflege von Beziehungen, Hierarchien usw. geht, die unter Umständen in der primären Sozialisation durch das ,Einschalten von religiösen Konnotationen gesichert wurden." (Bukow 2007: 223)

Die Schüler positionieren sich selbst, so Bukow, anhand kommunikativer Selbstregulierung und praktischer Aushandlung. Die Differenzlinien (Geschlecht, sozialer Status, Herkunft, Religion und Körper ${ }^{52}$ ) böten hierzu das notwendige Material. Für Bukow steht fest, dass »in einer Gesellschaft, in der

52 | In diesen Bereich gehört auch das Tragen des Kopftuches. Vgl. auch der Beitrag "Geschlechter- und Identitätskonstruktionen" in: Turhan/Turhan 2011: 94-100. 
bestimmte Differenzlinien dogmatisiert und gegen Dekonstruktionsversuche immunisiert werden« (Bukow 2007: 223), Unrechtserfahrungen keine Seltenheit sind. Er stellt in Anlehnung an Weber (2003) und Schulze/Spindler (2006) fest, dass viele Schülerinnen und Schüler türkischer Herkunft in der Schule die Erfahrungen zuerst als Türk(inn)en machen und dann als »muslimische« Schüler/-innen eingestuft werden, um dann im Anschluss die ihnen zugeschriebene Religiosität in einer Art selbsterfüllenden Prophezeiung zum Bildungshemmnis zu stilisieren (vgl. in Bukow 2007: 223). Von solchen Zuschreibungen könnten sich Schüler/-innen nur sehr schwer distanzieren, da sie ja einen Migrationshintergrund aufweisen würden und sie unter Umständen tatsächlich religiös sozialisiert worden seien. Hier greife somit der klassische rassistische Mechanismus (vgl. ebd.). Die Zuordnung erfolge bisweilen aus einem nichtigen Anlass. Gezielt oder beiläufig würden Schüler/-innen durch Fragen zur Herkunft, Religion oder an der Hautfarbe festgemachter virtueller Differenz kategorisiert und es werde eine Differenzlinie gezogen, an der man sich in der Folge tagtäglich abzuarbeiten habe. Zudem würden Schüler/-innen in Fragen zum Islam häufig als Experten herangezogen, was zu Überforderungen bei den Schüler/-innen führe und sie in die Ecke der Islamverteidiger stelle: »Hier handelt es sich um eine symbolische Antwort, auf die ebenfalls symbolisch gestellte Statusfrage, die freilich oft in einer Herkunftsfrage verborgen wird« (Bukow 2007: 224).

Die im Kontext Schule und Arbeitsplatzsuche erfahrenen Ausgrenzungen führen zu einer erheblichen Demoralisierung der Jugendlichen. Die Frustration verschärft sich, wenn die Jugendlichen weder ausreichende Bildungserfolge vorweisen können noch bei der Ausbildungs- und Arbeitsplatzsuche Erfolg haben. Wird den Jugendlichen laut Öztürk keine Alternative geboten, verlieren sie ihr Vertrauen in die staatlichen Instanzen, was häufig eine Selbstisolation $\mathrm{zu}$ Folge hat. Eine erfolgreiche schulische und berufliche Eingliederung aller Jugendlichen ist daher unverzichtbar. Bei einer islamischen Lebensführung wäre man fleißiger und man könnte bessere Ergebnisse vorweisen, folglich sei die Einhaltung der islamischen Vorschriften für die schulische und berufliche Integration empfehlenswert und als wichtige Ressource zur Identitätsbildung zu nutzen (vgl. Öztürk 2007: 240 und 243; vgl. auch Tietze 2001: 77).

Die Perspektive der Lehrer und Lehrerinnen; der Schulsozialarbeiter und der Eltern greifen Turhan/Turhan (2011) auf und gehen der Frage nach, mit welchen Problemen muslimische Kinder sich im Schulalltag auseinandersetzen müssen. ${ }^{53}$ In ihrer Arbeit verdeutlichen sich, auch entlang der oben genannten Konfliktlinien, die differenten Problemsituationen und Erfahrungen, die sich in den Schulen und Klassenzimmern abspielen.

53 | Befragt wurden insgesamt acht Lehrer/-innen und Sozialpädagog(inn)en sowie sechs Eltern im Zeitraum von November 2006 bis März 2007. 
Als ein wesentliches Ergebnis stellen Turhan/Turhan heraus, dass es nicht immer einfach ist, religiöse und/oder ethnisch-kulturelle Zuschreibungen auf der individuellen wie gesellschaftlichen Ebene präzise zu differenzieren. Hier gebe es Fälle, in denen das Verhalten der Jugendlichen der Religiosität zugeschrieben werde, obwohl es im Grunde ethnisch-kulturell bedingt sei. Zudem würden auch Fälle existieren, bei denen Handlungsweisen von Eltern als ethnisch-kulturell wahrgenommen würden, im Grunde aber religiöse Motive hinter dem Verhalten stünden. Noch schwieriger gestalte sich die Analyse, wenn man bedenke, dass in vielen Fällen religiöse und ethnisch-kulturelle Aspekte in der Alltagspraxis miteinander verbunden seien (vgl. Turhan/Turhan 2011: 119). Hierbei ist $\mathrm{zu}$ beachten und allgemein festzuhalten, dass gerade diese Undifferenziertheit im Alltag zu vielfältigen Missverständnissen und stereotypisierenden Vorurteilen führt, was von muslimischen Eltern und auch von Kindern und Jugendlichen immer wieder leidvoll erfahren werden muss.

Hinsichtlich der Diskriminierungserfahrungen und der Vorurteile, denen Eltern im schulischen Kontext begegnen, stellen Turhan/Turhan (2011) fest, dass fast alle Eltern (fünf von sechs Befragten) diese thematisieren. Vor allem die Religionszugehörigkeit oder die ethnische Zugehörigkeit würden als ausgrenzende Zuschreibungsprozesse erlebt. Hier greife der »antiislamische Rassismus« (vgl. ebd. 109f.). Die Fallbeispiele beziehen sich auf Aspekte und Themen, die sich auf mehreren Ebenen abspielen ${ }^{54}$ (vgl. für die Fallbeispiele ebd.: 109-112).

Zusammenfassend lässt sich an dieser Stelle konstatieren, dass muslimische Eltern mit Migrationshintergrund auf mehreren Ebenen Diskriminierungserfahrungen ausgesetzt sind. Einerseits gibt es Phänomene von Alltagsrassismus, bei denen Kinder/Jugendliche und Eltern als Fremde bezeichnet und ausgegrenzt werden. Andererseits wird auch auf institutionelle Diskriminierungen, die sich auf das Schulsystem beziehen, verwiesen. In den präsentierten Einzelfällen wurde nochmals deutlich, dass zwischen religionsbezoge-

54 | Es wird beklagt, dass Lehrpersonen sich vor der Klasse lustig über fremde Namen machen und in der Klasse darüber gelacht wird, worunter die Kinder mehrfach zu leiden hätten. Auch interreligiöse Projekte, bei denen über den Ramadan gesprochen und im Anschluss eine Moschee besucht werden sollte, wurden aufgrund des Widerstands einer nichtmuslimischen Mutter letztlich abgebrochen. Gerade die Reaktion der Lehrerin auf diese Situation wurde durch eine Mutter als kränkend erlebt (vgl. Turhan/ Turhan 2011: 109f.). Stereotypisierende Vorurteile und Etikettierungen zum Thema des Geschlechterverhältnisses, wie z.B., wenn Männer als "Machos" hingestellt werden, werden ferner als diskriminierend erlebt (vgl. ebd.: 110f.; vgl. ebd.: 94-100). Ungleiche Behandlungen und Benachteiligungen aufgrund der ethnischen Zugehörigkeit würden sich des Weiteren an Elternabenden, an der Bewertung von schulischen Leistungen usw. zeigen (vgl. ebd.: 112). 
nen und ethnischen Diskriminierungen differenziert werden muss. Gerade im Bezug auf religionsbezogene Rassismus- und Diskriminierungseffekte zeigt sich jedoch noch ein großer Forschungsbedarf ${ }^{55}$ (vgl. Turhan/Turhan 2011: 113).

\section{Die Teilnahme an Sport- und Schwimmunterricht, am Sexualkundeunterricht und an Klassenfahrten}

Ein weiteres vermeintliches Konfliktfeld in öffentlichen Bildungseinrichtungen wird in der Teilnahme am Sport- und Schwimmunterricht oder am Sexualkundeunterricht gesehen. Gerade in der öffentlichen Diskussion, welche in Form von journalistischen Beiträgen und Aufsätzen weiterverfolgt werden kann, wird die Teilnahme an schulischen Aktivitätenn thematisiert. Sexualkunde, Sport- und Schwimmunterricht tangieren sowohl die islamische Sexualmoral als auch die muslimische Bekleidungsweise, in der die Präsentation der weiblichen Körperlichkeit im öffentlichen Raum verhindert werden soll. Dabei wird auf die Einhaltung eines religiösen Gebots abgezielt, das beinhaltet, dass Mädchen und junge Frauen einen potenziell erotisierenden Blick fremder Männer vermeiden sollten.

Was statistische Werte anbelangt, so bietet die Studie Muslimisches Leben in Deutschland (Haug/Müssig/Stichs 2009) ${ }^{56}$ einige wichtige Informationen. ${ }^{57}$ Ein relativ hoher Anteil (88\%) der befragten Schülerinnen und Schüler nehmen am Sexualkundeunterricht teil. $87 \%$ besuchen den gemischtgeschlechtlichen Sportunterricht. Religiöse Gründe und Motive werden hier nicht benannt, sodass die fehlende Teilnahmebereitschaft von Muslim(inn)en bzgl. sportlicher Aktivitäten an Schulen usw. in der öffentlichen Diskussion offensichtlich übertrieben wird (vgl. Haug/Müssig/Stichs 2009: 182f.). Die Teilnahme am gemischtgeschlechtlichen Schwimmunterricht sowie am Sexualkundeunterricht stellt sich somit etwas anders dar: 53-58 \% der Schülerinnen nahmen am Schwimm- und Sexualkundeunterricht teil. Demgegenüber nahmen $70 \%$ der weiblichen und männlichen Muslime an Klassenfahrten teil (vgl. ebd.: 188). Es wird hier lediglich ein Anteil von etwa 7-10 \% bzgl. der muslimischen Mäd-

55 | Hierbei ist klar, dass das Thema Rassismus bzw. Diskriminierungserfahrungen im schulischen Kontext ein komplexes und vielschichtiges Thema darstellt, bei dem alle beteiligten Akteure zu Wort kommen sollten. Vergleichende Analysen zwischen den Aussagen von Schülerinnen und Schülern, Eltern und Lehrpersonen könnten diesem Anliegen Rechnung tragen. Auch stellt dies insgesamt einen eigenständigen Bereich dar, welcher in der Kürze nicht angemessen behandelt werden kann.

56 | Befragt wurden hier insgesamt 3.283 Schülerinnen und Schüler im Alter von sechs bis 22 Jahren aller Glaubensrichtungen.

57 | Vgl. auch: "Muslimisches Leben in Nordrhein-Westfalen" (2010), die im Auftrag des Ministeriums für Arbeit, Integration und Soziales des Landes durchgeführt wurde. 
chen festgehalten, die die Teilnahme am Schwimm- und Sexualkundeunterricht verweigern (vgl. ebd.: 191).

Insgesamt stellen sich die wenigen empirischen Ergebnisse somit als nicht verlässlich heraus, da sich mit ihnen nicht eindeutig aussagen lässt, worin die Ursachen für eine Nichtteilnahme liegen. Die journalistischen Berichte rund um die vorliegende Thematik beschreiben in der Regel Einzelfälle, bei denen Lehrer die Abwesenheit in den entsprechenden Fächern sogar tolerieren. Hier ist folglich nicht von einem Massenphänomen zu sprechen, sondern lediglich von Einzelfällen.

Es wurde bisher auf die Erfahrungen von Jugendlichen und Schülerinnen und Schülern hingewiesen, die sie mit ihrer Religionszugehörigkeit und ihrer Religiosität in ihren individuell verschiedenen Ausprägungen gemacht haben. Dargestellt wurden zudem potenzielle Konfliktfelder, die sich, auch aus der öffentlichen Diskussion hervorgehend, im Umgang mit dem Islam im schulischen Kontext ergeben können. Diese Darstellungen sollen jedoch die positiven Erfahrungen, die die muslimischen Schülerinnen und Schüler mit der Institution Schule machen konnten, keineswegs minimieren.

Die vorliegende Untersuchung widmet sich der Frage, wie die religiöse Sozialisation von muslimischen Kindern abläuft, und berücksichtigt dabei auch den möglichen Einfluss der Schule auf diesen Prozess. Sicherlich wird hier nicht davon ausgegangen, dass die Schule religiös sozialisiert. Von einem solchen Auftrag ist sie weit entfernt. Diese Frage könnte sich höchstens im Rahmen eines (bekenntnisorientierenden) islamischen Religionsunterrichts stellen (vgl. nächstes Teilkapitel).

In dieser Studie sollen auch Eltern zu Wort kommen, um ihre Eindrücke der Bildungsinstitutionen Schule und Kindertagesstätten im Umgang mit dem Islam zu schildern, und zu erläutern, welchen Herausforderungen sie sich stellen müssen, wenn sie ihre religiöse Lebensweise und die damit verbundenen religiösen Werthaltungen an ihre Kinder weitergeben möchten.

Insgesamt veranlassen die Ergebnisse im vorliegenden Zusammenhang somit dazu, zu fragen, welche Erfahrungen Eltern und deren Kinder in Bezug auf ihre Religionszugehörigkeit und ihre religiöse Praxis im schulischen Kontext machen/bereits gemacht haben. Es soll daher anhand der Meinung der Lehrer/-innen bzgl. ihrer (muslimischen) Religion erforscht werden, ob religiöse bzw. kulturelle Elemente im Schulalltag überhaupt Platz haben oder ob es möglicherweise Konfliktsituationen und Benachteiligungen gibt, die auf die Religion der Befragten zurückgeführt werden.

\section{b) Islamischer Religionsunterricht (IRU) an deutschen Schulen}

Mit dem Thema »Islam in der Schule« ist auch die Frage nach der Einführung des islamischen Religionsunterrichts an deutschen Schulen verbunden. 
Schon Brettfeld/Wetzels (2007) (vgl. Kap. II. 1.3.) konnten im Zuge ihrer Repräsentativbefragung aufzeigen, dass ein hoher Anteil an Muslimen (70 \%) ein Interesse an der Einführung eines islamischen Religionsunterrichts hat.

Die bisherigen empirischen Ergebnisse über muslimische Jugendliche weisen auf den Wunsch einer adäquaten Unterstützung bzgl. der religiösen Bildung hin. Sie sehen sich bislang nicht angemessen unterstützt und möchten auch im schulischen Rahmen mehr über ihre eigene Religion und andere Religionen erfahren. Die Einführung des islamischen Religionsunterrichtes als ein Regelfach an deutschen Schulen ist für die meisten der von Öztürk befragten Jugendlichen wünschenswert. Eine inadäquate Behandlung der islamischen Religion in Schulbüchern wird als herabwürdigend angesehen (vgl. Karakaşoğlu/Öztürk 2007; Öztürk 2007: 229).

Ferner deuten die Ergebnisse der Mehrthemenbefragung auf ein Defizit hin, das es aufzuholen gilt. Konnte bei den von Boos-Nünning/Karakaşoğlu (2006) befragten jungen Frauen und Mädchen hinsichtlich der familiären religiösen Erziehung noch von einer großen Zufriedenheit ausgegangen (vgl. oben) werden, so ist diese Zufriedenheit auf den schulischen Kontext nicht übertragbar. Musliminnen (58 \%) (und auch Orthodoxe jugoslawischer Herkunft) sind eher unzufrieden mit der schulischen Religionserziehung. Sie hätten gerne mehr über ihre Religion in der Schule erfahren. $61 \%$ der türkischen Musliminnen geben an, Religionsunterricht/religiöse Unterweisungen überwiegend im Rahmen des muttersprachlichen Ergänzungsunterrichts erfahren $\mathrm{zu}$ haben. In den Bundesländern sind diese in unterschiedlich intensiver Abstimmung organisiert. Besonders gut versorgt waren hingegen die protestantischen und katholischen Befragten, da diese den christlich-konfessionellen Religionsunterricht besuchten, der als ein reguläres Angebot im Stundenplan der meisten Schulen im Bundesgebiet vorzufinden ist (vgl. Boos-Nünning/Karakaşoğlu 2006: 414).

Diese Ergebnisse verweisen auf das Anliegen und Bedürfnis der Jugendlichen, sich mit der eigenen Religion im Kontext der Schule auseinanderzusetzen. Die vorhandenen Angebote scheinen diesem Bedarf bisher noch nicht gerecht zu werden. Daher interessiert im vorliegenden Zusammenhang, welche Haltungen muslimische Eltern gegenüber einer Einführung eines islamischen Religionsunterrichts einnehmen und welche potenziellen (auch) sozialisationsrelevanten Erwartungen sie an diesen knüpfen.

\section{Die Einführung des IRU}

Die Debatten um die Einführung eines IRU finden schon seit vier Jahrzehnten statt. Die diversen Realisierungsbemühungen begannen Ende der 1970er-Jahre und dauern bis heute an. Sowohl politische als auch organisatorische Gründe stellten Hindernisse dar, die immer noch Lösungen seitens der beteiligten Akteure erfordern. Nicht zuletzt berührt(e) eine solche Einführung verfas- 
sungsrechtliche Fragen, wie bspw. die Mitwirkung einer oder mehrerer Religionsgemeinschaften. Angestrebt wurde ein bekenntnisorientierter Religionsunterricht nach Art. 7 III GG, der aufgrund der heterogenen muslimischen Organisationslandschaft und den daraus resultierenden fehlenden muslimischen Ansprechpartnern im Sinne von anerkannten Religionsgemeinschaften nicht erfolgreich implementiert werden konnte. Dennoch gab es infolge von Diskussionen in mehreren Bundesländern Schulversuche anhand verschiedener Unterrichtsmodelle. Sie erscheinen als vorübergehende Alternativen für einen bekenntnisorientierten Religionsunterricht nach Art. 7 III GG (vgl. DIK 2011: 6-14 und 60-63; vgl. Darwisch 2013).

Bildungspolitisch wird von einem integrationsfördernden Effekt einer islamischen Unterweisung in deutscher Sprache ausgegangen, womit der Gleichstellungsprozess muslimischer Schüler/-innen vorangetrieben werden solle. Neben der Stärkung einer religiösen Identität der Schüler/-innen trage der IRU ferner dazu bei, Respekt gegenüber anderen Religionen aufzubauen, was ein friedliches und respektvolles Zusammenleben von Menschen mit unterschiedlichen Traditionen, Kulturen und religiösen Bindungen auf der Grundlage des GG fördere (vgl. DIK 2011: 21).

Von der Einführung eines IRU sind bundesweit mehr als 700.000 Schüler/-innen betroffen. Angesichts dieser Situation werden in den Bundesländern mit den größten muslimischen Schülerzahlen, wie z.B. Bayern, Baden-Württemberg, Niedersachsen, Nordrhein-Westfalen und Rheinland-Pfalz, Berlin und Hamburg, islamische Unterrichtsangebote gemacht, die sich in ihrer Ausgestaltung jedoch voneinander unterscheiden. Auf Länderebene finden institutionalisierte Gespräche oder sog. »Runde Tische« statt, die den Dialog zwischen Kultusverwaltung und islamischen Vereinen vorantreiben. Mithilfe einer solchen Kooperation wird angestrebt, Arbeitsgruppen von muslimischen Theologen und Pädagogen zu bilden, die die Modellversuche begleiten und an ihnen mitwirken.

Der Beschreibung der Unterrichtsmodelle, die sowohl einen (a) religionskundlichen als auch religionsunterweisenden (b) Charakter vorweisen, haben sich mehrere Autoren gewidmet (vgl. Alacacioğlu 2006; Ceylan 2008; Darwisch 2013; DIK 2011; Kiefer 2005; Khorchide 2009 u.a.). In diesen Studien findet sich die inhaltlich-curriculare Ausgestaltung des Religionsunterrichts sowie die dazugehörige pädagogische Konzeption. Die Arbeiten von Behr (2005) und Mohr (2006) befassen sich anhand unterschiedlicher Fragestellungen mit Lehrplananalysen zum IRU.

Mit der Einführung des islamischen Religionsunterrichts an Schulen sind auch die Frage nach einer Lehrerausbildung und der Etablierung von Lehrstühlen verbunden. In Osnabrück, Münster und Nürnberg wird islamische Religionspädagogik als reguläres Studienfach angeboten. Die Qualifikation und 
Anforderungen an das Lehrerprofil sind vieldiskutierte Themen, die in diesem Zusammenhang ebenfalls zu berücksichtigen sind.

\section{c) Muslimische Kinder in Kindertagesstätten und Kindergärten}

Im Rahmen der vorschulischen Erziehung können lediglich Handreichungen und einige wenige Forschungsberichte Hinweise darauf geben, welchen Herausforderungen sich muslimische Familien in der vorschulischen Sozialisationsphase im Zusammenhang mit ihrer Religion stellen müssen.

Ausgehend von den Fragen, wie es muslimischen Kindern in deutschen Kindertagesstätten geht und was die Tatsache bedeutet, dass muslimische Kinder Einrichtungen besuchen, die von einer »christlich-abendländischen Pädagogik« geprägt sind, werden von Thiersch (2009) Chancen und Herausforderungen aufgezeigt, die hier zusammengefasst dargestellt werden.

Dabei soll der Fokus auf muslimischen Familien und ihren Kindern liegen. Sowohl die pädagogischen Konzeptionen, die auf Ansätzen wie der interkulturellen Bildung und dem interreligiösen Dialog beruhen und darlegen, welchem Bildungsauftrag Kindertagesstätten folgen (sollten), als auch Kompetenzen, die von Erziehern und Erzieherinnen erwartet werden, sind sehr interessante Aspekte, die sich im Rahmen dieser Fragestellungen auch ergeben, aber im Rahmen der vorliegenden Dissertation nicht umfassend dargestellt werden können.

Anhand von drei Fallbeispielen, die nach Thiersch nicht die Vielfalt der muslimischen Lebensweisen, ihre religiöse Praxis und ihre unterschiedlichen sozialen Bedingungen widerspiegeln können, wird der Umgang mit religiösen Differenzen in Bezug auf muslimische Kinder und ihre Familien beschrieben. Hiervon sind Gebote und Regeln betroffen, die freilich nur bestimmte Aspekte des Islams betreffen, die aber nicht zu einer verkürzten Sicht des Islams führen sollten (vgl. Thiersch 2009: 56).

Die Praxisbeispiele beziehen sich auf den Umgang mit

- Speisegeboten,

- religiösen Festen,

- Kleidungs- und Schamgeboten.

Die Anforderungen an Offenheit und Toleranz im Umgang mit kulturellen Unterschieden sind jedoch nicht in allen Kindergärten gegeben. Muslimische Kinder machen in deutschen Kindergärten somit durchaus negative Erfahrungen. Abwertende Kommentare, die sich auf die Sprachfähigkeit, Anpassungsleistungen und um einen möglichen »Terrorverdacht« und die negative Bewertung des Kopftuches beziehen, können Verletzungen hervorrufen. Hier wird jedoch nicht nur vonseiten der Erzieher/-innen, so Thiersch, die Erziehungspflicht verletzt, auch würden häufig negative Bemerkungen von anderen Kindern und Eltern gemacht. Thiersch stellt dabei Folgendes fest: 
"Kinder, die in der frühen Kindheit Erfahrungen mit solchen Äußerungen gemacht haben, sind in ihrem Selbstbewusstsein und Selbstwertgefühl beschädigt, sie und ihre Eltern werden es schwer haben, Zutrauen zu deutschen Bildungseinrichtungen zu fassen." (Thiersch 2009: 56f. und 65)

Aber die Praxis zeigt auch gelungene Beispiele. Schon bei der Aufnahme in die Kindergärten werde darauf geachtet, welche praktischen Dinge zu berücksichtigen seien. Hier wird u.a. das Schweinefleischverbot genannt. Zur muslimischen Speisevorschrift gehört auch das Nichtverzehren von gelatinehaltigen Produkten. Auf diese Regeln wurde besonders eingegangen, indem auch nichtmuslimische Eltern gebeten wurden, in ihren mitgebrachten Speisen darauf zu verzichten (vgl. ebd. 57f.). Des Weiteren wurde eine Mutter gefragt, ob sie sich mit ihrem Kulturkreis einbringen wolle, und sie hat daraufhin etwas Türkisches zubereitet und zu ihrem religiösen Fest Süßigkeiten mitgebracht. Islamische Feste - werden neben christlichen und weltlichen Festen - gefeiert und die Kinder erhalten hierbei Geschenke (vgl. ebd.: 58). Die Eltern werden zum Mitfeiern angeregt und die Inhalte der Feste sollen jeweils besprochen werden. Es erfolgt außerdem eine Erläuterung bestimmter Geschichten aus der Bibel und ähnliche Koranstellen. Zudem wird erklärt, warum muslimische Familien nicht so viel Wert auf Geburtstagsfeiern legen (vgl. ebd.). Unter muslimischen Familien wird die unterschiedliche Handhabung hinsichtlich des Feierns religiöser Feste festgestellt. Einige Eltern wollen z.B. keine Weihnachtsfeier abhalten (vgl. auch Biesinger/Edelbrock/Patak/Schweitzer 2009: 165-170).

Aufgrund der Kleidervorschriften bei Muslimen und der Bedeutung von Scham fanden entsprechende Elternabende zur Benutzung des Planschbeckens statt. Muslimische Eltern wollten bspw. nicht, dass ihre Kinder nackt im Badebecken planschten. Es fand somit z.B. eine Einigung statt, die besagt, dass die Kinder mit einem Badeanzug erscheinen können oder dass jeder es so handhaben soll, wie er es möchte und vertreten kann (vgl. Thiersch 2009: 58). Wenig thematisiert, aber immer kontrovers diskutiert wurde auch der Bereich der Sexualerziehung (vgl. ebd.: 59).

Die Ergebnisse aus den drei Einrichtungen haben letztlich gezeigt, dass in Kindertagesstätten auf unterschiedliche Art und Weise auf die Gebote und Bedürfnisse der muslimischen Familien eingegangen wird. Je nach den Wünschen der Eltern und der Sensibilität der Erzieher/-innen gibt es hier ganz unterschiedliche Lösungen. Dabei werde vonseiten der Erzieher/-innen vor allem nach der Praktikabilität im Umgang mit Geboten, Festen und Bräuchen gefragt (vgl. ebd.: 6o). Thiersch betont dabei Folgendes: So wichtig die pragmatischen Fragen im alltäglichen Umgang auch seien, so könne ihre Klärung nicht die Beschäftigung mit weiteren Dimensionen/Ausprägungen des Islams ersetzen. Diese Auseinandersetzung sei notwendig, wenn man Eltern wirklich 
verstehen möchte und um sich auf Gespräche mit den Kindern einlassen zu können (vgl. ebd.; vgl. z.B. auch Huber-Rudolf 2002).

Hinsichtlich der Thematisierung der Sorgen und der Erwartungen der Eltern fehlt es bis dato an Forschungsergebnissen. Da die vorliegende Dissertation an diesem Desiderat anknüpfen möchte und sich explizit mit der Fragestellung auseinandersetzt, ob Kindertagesstätten einen (fördernden oder hemmenden) Einfluss auf die religiöse Sozialisation ausüben und in welcher Form mit der Religion von muslimischen Familien umgegangen wird, sollen hier erstmals auch insbesondere die Wünsche und Erwartungen der Eltern Berücksichtigung finden.

Thiersch (2009) stellt die Übertretung religiöser Gebote, wie bspw. den Verzehr von Schweinefleisch, als eine wichtige Sorge heraus. Ein weiteres Problem bestehe darin, dass Kinder von ihrem Glauben, ihrer Familie und ihrer Herkunftskultur entfremdet würden. Neben der Erwartung, dass die Kinder erfolgreich am deutschen Bildungssystem teilnähmen, sei die Religiosität ein wichtiges Erziehungsziel. Muslimische Eltern befänden sich in der Diaspora jedoch in einer Minderheitensituation, in der sie in einer Umwelt leben würden, die in ihnen Ängste in Bezug auf die Entwicklung der Kinder schüre. In ihren Herkunftsländern, wo die Mehrheit der Bevölkerung muslimisch gesprägt sei, stelle sich dieses Problem nicht (vgl. Thiersch 2009: 60; vgl. auch oben Boos-Nünning 2011a).

So wachsen muslimische Kinder in unterschiedlichen Lebenswelten auf. Sie erleben zu Hause häufig eine andere Form von Familie, andere Kleidung, einen anderen Sprachgebrauch und andere Regeln. Hier stellt sich die Frage, ob diese divergenten Orientierungen der verschiedenen Lebenswelten letztendlich miteinander zu vereinbaren sind. Diese existiert schon seit Beginn der Migration in der Migrationsforschung und wird vor allem in formellen Bildungseinrichtungen immer wieder aufgeworfen.

Thiersch (2009) plädiert, um die Vereinbarkeit der Lebenswelten zu gewährleisten, für einen gegenseitig respektvollen und wertschätzenden Umgang. Gerade hier sei eine enge Zusammenarbeit zwischen Erzieherinen und Erziehern sowie den Eltern umso wichtiger (vgl. ebd.: 62) Diese gegenseitige Wertschätzung erfordere Begegnungen auch zwischen muslimischen und nichtmuslimischen Eltern, die von gegenseitigem Zuhören und einer großen Achtung vor der Verschiedenheit der Lebensentwürfe geprägt sein sollten (vgl. ebd.: 64).

Auch die Erfüllung des Wunsches muslimischer Eltern nach einem muslimischen Kindergarten für ihren Nachwuchs befindet sich mit bundesweit erst vereinzelten Projekten noch in ihren Anfängen (z.B. Halima-Kindergarten in Karlsruhe; vgl. in Yölek-Cantay 2010: 93-96).

Einen weiteren wichtigen Bereich stellt die interreligiöse Bildung in diesen Einrichtungen dar. Auch hier sind die Forschungsbefunde rar. In der Praxis 
wird davon ausgegangen, dass interreligiöse Bildungsangebote überwiegend in christlich orientierten Kindertagesstätten, die auch von muslimischen Kindern besucht werden, stattfinden. Doch hängt dies, wie Biesinger/Edelbrock/ Schweitzer (2009) zeigen, am stärksten vom Träger ab, da auch städtische Einrichtungen eine interreligiöse Erziehung in ihre Arbeit integrieren und christlich orientierte dies womöglich vernachlässigen (vgl. Biesinger/Schweitzer/Edelbrock 2009: 19). Die Ergebnisse der von den Autoren durchgeführten Studie Interkulturelle und interreligiöse Bildung in Kindertagesstätten geben Einblicke, in welchen Bereichen interreligiöses Lernen erfolgt (vgl. ebd.: 15-30). Die interreligiösen Bildungsangebote drehen sich v.a. um das gemeinsame Feiern von religiösen Festen (vgl. Biesinger/Edelbrock/Patak/Schweitzer 2009: 165170), das gemeinsame Essen in Kitas (vgl. ebd.: 156-161), das gemeinsame Beten sowie das Singen, jeweils mit Inhalten, die von beiden Religionen gleichermaßen vertreten werden (vgl. ebd.: 161-164).

Auch die interreligiöse Bildung ist mit vielfältigen Herausforderungen und Chancen verknüpft und sollte im Sinne eines erfolgreichen Gelingens ebenso die Perspektive der muslimischen Eltern berücksichtigen, obgleich diese laut den empirischen Befunden von Biesinger/Edelbrock/Patak/Schweitzer (vgl. ebd.: 222) hier bislang eine eher geringere Rolle spielen.

In der vorliegenden Untersuchung soll deshalb im Folgenden ausführlicher darauf eingegangen werden, inwiefern ein Interesse an interreligiösen Bildungsangeboten seitens der Eltern muslimischer Kinder/Jugendlicher besteht, in welcher Form sich Eltern für diese engagieren möchten und ob darin ein sozialisationsrelevanter Effekt gesehen wird.

\subsubsection{Peergroups, Freundschaften und das Verhältnis zu Andersgläubigen}

Die Peers als Netzwerke Gleichaltriger oder Freundschaftsgruppen werden als die zentralen Orte für die Suche nach Milieuzugehörigkeit und Lebensorientierung angesehen. Kinder und Jugendliche mit ähnlichen Bedürfnissen und Orientierungen kommen zusammen, um ihr Verlangen nach Gemeinschaft und Beteiligung zu erfüllen. Diese Gruppen dienen zum Erfahrungsaustausch unter Gleichaltrigen, in denen entwicklungsbedingte Probleme beoder verarbeitet werden können. Mit Verständnis und Solidarität unterstützen sie sich gegenseitig bei der Gestaltung von Sozialräumen (vgl. Hurrelmann 2012: 164). Peergroups könnten folglich für die eigene Biografie orientierungsweisend und identitätsbestimmend sein und vor allem gemeinschaftfördernd wirken. Sie seien jedoch auch dazu in der Lage, einen negativen Einfluss ausüben, was zu Verhaltensauffälligkeiten und einem abweichendem Verhalten bei den Jugendlichen führe (vgl. Oswald 2008: 325f.).

Dabei sei auch zu berücksichtigen, dass kulturelle Differenzen bei der Wahl der Peergroups mitentscheidend sein könnten (vgl. Oswald 2008: 321). 
Im Rahmen der religiösen Sozialisation ergibt sich des Weiteren die Frage, welchen Einfluss die Peergroup oder Freundschaftsbeziehungen bei der Entwicklung von Religiosität ausüben. Hier soll im Folgenden aus der Perspektive der Eltern dargestellt werden, welchen religiösen Sozialisationseffekt sie mit der jeweiligen Freundschaftswahl ihrer Kinder verbinden.

Freundschaften spielen eine wichtige Rolle im Leben der Jugendlichen. Die Ergebnisse der bisher angeführten Studien geben keine einheitliche Auskunft darüber, inwiefern die Religion bzw. der religiöse Kontext, wie z.B. die Moscheegemeinde oder andere religiöse Netzwerke, die Wahl der Freundschaften bestimmt. Allerdings verdeutlichen diese die besondere Bedeutung und den hohen Stellenwert der Freundschaftsbeziehungen.

Bei den von Frese (2002) befragten Jugendlichen kommt der Freundschaft neben der Familie eine wesentliche Bedeutung zu: »Nicht zuletzt hier entscheidet sich, ob die in der Beziehung von Eltern und Kindern angelegten positiven Impulse tragfähig sind, ob die Jugendlichen, um mit ihren Worten zu sprechen, auf dem richtigen Pfad gehen « (Frese 2002: 83). Mit dem Passus »auf dem richtigen Pfad gehen « wird auf das Risiko von Gefahren, die sozial auffälliges Verhalten und möglicherweise ein kriminelles Verhalten hervorrufen könnten, verwiesen. Der Freundeskreis, d.h. die Tatsache, ob man gute oder schlechte Freunde hat, spielt hierbei eine wichtige Rolle.

Für die befragten Jugendlichen ist es von zentralem Wert, Freundschaften $\mathrm{zu}$ haben und zu pflegen. Diese werden als Garanten für das Bewahren der eigenen Traditionen angesehen. Des Weiteren sind den Jugendlichen deutsche Freunde wichtig, wobei es hier Unterschiede in der Intensität der Beziehungen gibt. Die emotionale und solidarische Nähe wird als eine besondere Qualität der Türken begriffen, was erklärt, warum die Beziehungen zu gleichaltrigen Türken enger und intensiver gepflegt werden. Religionszugehörigkeit, d.h. die Zugehörigkeit zum Islam, scheint dabei nicht das entscheidende Kriterium zu sein. Tatsächlich seien der Charakter und die Gedanken eines potenziellen Freundes von Bedeutung (vgl. Frese 2002: 105-112).

Der türkische Freundeskreis der Jugendlichen übe zudem einen erheblichen Einfluss auf die Verbundenheit zur islamischen Gemeinde aus. Die Anwesenheit der Freunde spiele gerade in der Wahrnehmung des Koranunterrichts oder auch anderen Angeboten der Moscheegemeinden eine besondere Rolle (Frese 2002: 102ff.).

Religiöse Einrichtungen scheinen für die von Boos-Nünning/Karakaşoğlu (2006) befragten jungen Frauen hingegen eine nur geringfügige Bedeutung zu haben, wenn es um die Freunde und Freundinnen geht. Nur die Zugehörigkeit zu einer bestimmten Religionsgemeinschaft ist bei einigen Gruppen stark ausgeprägt, nicht aber das Bedürfnis, sich in einem von der identischen religiösen Orientierung geprägten Milieu zu bewegen. Zudem zeigen die Daten, dass unabhängig davon, wie stark sich die Angehörigen der Herkunfts- und 
Religionsgruppen mit ihrer eigenen Religionsgruppe identifizieren, ihnen die Religion der Freunde und der Freundinnen mehrheitlich unwichtig ist (vgl. Boos-Nünning/Karakaşoğlu 2006: 406).

Bei der Wahl des Freundeskreises spiele für die von Öztürk (2007) befragten Jugendlichen die Religion keine dominante Rolle. Die Jugendlichen würden ihre Beziehungen zu nichtmuslimischen Jugendlichen wie selbstverständlich pflegen. Dabei sei es auch nicht wichtig, ob sie selbst Moscheegänger seien oder nicht. Die Moschee als Ort des Austausches solle ihnen, ohne die Überbetonung der eigenen Ethnie und Kultur voranzutreiben, lediglich eine Plattform zum gegenseitigen Austausch anbieten (vgl. Öztürk 2007: 242).

Wensierski/Lübcke (2012) veranschaulichen, dass muslimische Jugendliche, für die der Islam eine wichtige Rolle im Leben spielt, die sozialen Kontakte sowohl in den Familien als auch in der Peergroup in innerethnischen Beziehungsnetzwerken durchlaufen. Gleichzeitig zeigten sich die befragten Jugendlichen offen gegenüber der Mehrheitskultur. Es wurden in einigen Fällen auch Freundschaften zu Deutschen aufgebaut und gepflegt. Die Beziehungspflege im eigenen ethnisch-kulturellen Milieu gehe somit eher mit »sozialen Integrationsprozessen « als mit »Segregation mit einer Mehrheitsgesellschaft« einher, wobei hier auf unterschiedliche Nuancen, von hochgradig bis hin zu weniger stark integriert, zu achten sei (vgl. Wensierski/Lübcke 2012: 394). Die Schnittstellen mit der Mehrheitsgesellschaft ergeben sich für die Jugendlichen durch Bildungseinrichtungen, Sportvereine, Freizeitangebote und andere Sozialräume und werden grundsätzlich als positiv bewertet, obgleich auch immer wieder Stigmatisierungs- und Ethnisierungserfahrungen (Bildungsbenachteiligungen, islamische Lebensführung, Kopftuch) gemacht werden.

Die Ergebnisse der Studie Viele Welten leben (vgl. oben) zeigen, dass Mädchen und junge Frauen mit Migrationshintergrund mehrheitlich beste Freundinnen und Freunde haben, die aus derselben Herkunftsgruppe stammen wie die Befragten selbst. So schließen $79 \%$ der Mädchen mit türkischem Migrationshintergrund (51 \% ausschließlich bzw. $28 \%$ überwiegend) und $84 \%$ der Mädchen aus Aussiedlerfamilien ethnisch homogene Freundschaften. Drei Prozent der Mädchen mit türkischem Migrationshintergrund haben ausschließlich einheimische, d.h. deutsche Freunde (vgl. Boos-Nünning/Karakaşoğlu 2006: 156f.). Die Distanz zwischen den Zugewanderten und den Angehörigen der Mehrheitsgesellschaft wird, so das Ergebnis der Studie, somit dadurch deutlich, dass innerethnische Freundschaftenüberwiegen und Beziehungen zu deutschen Freund(inn)en fehlen (vgl. Boos-Nünning/Karakaşoğlu 2006: 157).

Die Ergebnisse führen vor Augen, dass innerethnische Freundschaften unter Migranten letztendlich überwiegen. Über die Rolle der Religion, der religiösen Einrichtungen bzw. der Religiosität bei der Wahl von Freundschaften 
liegen zum Teil widersprüchliche Ergebnisse vor. So spielen religiöse Einrichtungen im Hinblick auf die Freundschaftsbeziehungen in manchen Studien eine wichtige (vgl. Frese 2002) und in anderen wiederum nur eine geringe Rolle (vgl. Boos-Nünning/Karakaşoğlu 2006; Öztürk 2007). Es scheint, zumindest den Ergebnissen zufolge, letztlich so, dass die Religiosität bzw. religiöse Zugehörigkeit bei der Wahl von Freundschaften keine Rolle spielt, die ethnische Zugehörigkeit hingegen hierfür schon von Bedeutung ist.

\section{Das Verhältnis zu Andersgläubigen}

Auch im Verhältnis zu Andersgläubigen werden unterschiedliche Positionen deutlich. Es ist zum einen ein Interesse für die Religion des anderen vorhanden, was sich z.B. durch die Integration christlicher Elemente in den eigenen Familienalltag äußert. Zum anderen werden jedoch große Herausforderungen im Umgang mit Andersgläubigen sichtbar und diese entsprechend auch beschrieben.

Ein Teil der von Klinkhammer (2000) befragten Jugendlichen gibt an, beide religiöse Kulturen erlebt zu haben. Dabei habe in einigen Familien die Integration von christlichen Elementen stattgefunden: Man habe sich bspw. zur Weihnachtszeit beschenkt und es sei sogar Silvester gefeiert worden. Die Kirche sei ferner als Gebetsort verstanden worden, in der man auch auf Arabisch habe beten können (vgl. Klinkhammer 2000: 198). Die Eltern hätten somit kein Problem darin gesehen, mit christlichen Werten und Riten in Berührung zu kommen. Es sei beispielsweise anstelle des ausgefallenen türkischen Landeskundeunterrichts der christliche Religionsunterricht besucht worden und auch der Gottesdienstbesuch habekein Problem dargestellt. Man habe sogar Weihnachten gefeiert und Geschenke verteilt. Als Grund für diese kulturelle/ religiöse Anpassung gaben die Eltern an, dass die Kinder »unter Deutschen« diesen in nichts nachstehen, sondern mitreden können sollen, wenn es bspw. um Weihnachtsgeschenke ging (vgl. ebd.: 215f.). Diese Jugendlichen würden sich in ihrem Selbstverständnis somit als »moderne und aufgeklärte« Muslime betrachten, die den Islam nur bedingt praktizieren.

Auch die Ergebnisse von Boos-Nünning/Karakaşoğlu (2006) zeigen das große Interesse vonseiten der Migrant(inn)en an der Religion der Mehrheitsgesellschaft. Immerhin $8 \%$ der Musliminnen benannten Weihnachten und $2 \%$ Ostern als die für sie persönlich wichtigsten religiösen Feste. 18 \% bezeichneten Neujahr als wichtigstes religiöses Fest. Dies wiederum könne als Interesse am öffentlichen Leben der Bundesrepublik gedeutet werden, was die Mädchen dazu veranlasse, an einem gesellschaftlich und geschäftlich vermittelten Brauchtum teilzunehmen, das über seine rein religiöse Bedeutung hinaus verankert sei. Gerade das Aufstellen des Weihnachtsbaums (von $19 \%$ der Musliminnen angegeben) könne als ein Indiz für das Wahrnehmen dieses Brauchtums gedeutet werden (vgl. Boos-Nünning/Karakaşoğlu 2006: 407). 
Die von Frese (2002) befragten Jugendlichen hatten keinen Kontakt zu Angehörigen anderer nichtchristlicher Religionen. Es werden, wenn auch nur oberflächlich, Schwierigkeiten im persönlichen Umgang mit Christen und Atheisten angedeutet. Dabei sind die Jugendlichen gleichzeitig bemüht, eine Nähe zu den Christen herzustellen. Es werden Gemeinsamkeiten zwischen Muslimen und Christen, die sie von Atheisten trennt, hervorgehoben. Auch wird einerseits ein interreligiöser Dialog angestrebt, andererseits fühlen sich die Jugendlichen im Vergleich zu den Christen, wenn es um solche Begegnungen geht, schlechter ausgerüstet. Oftmals fühlen sie sich von ihnen in die Rolle der Unterlegenen gedrängt, was laut Frese mit dem öffentlichen Islambild im Westen zu tun hat. Dennoch solle hier der Kontakt gehalten werden, da es auch um ein konstruktives Miteinander im Zusammenleben gehe (vgl. Frese 2002: 262-265).

Was den interreligiösen Dialog betrifft, zeigt sich hingegen bei den von Öztürk (2007) befragten Jugendlichen, dass diese allesamt dazu bereit sind, andere Kulturen und Religionen kennenzulernen. Wichtig sei dabei auch, um eine harmonische und kooperative Zusammenarbeit $\mathrm{zu}$ gewährleisten, eine gemeinsame Sprache für die Repräsentation des Islams in dieser Gesellschaft zu entwickeln. Der Austausch zwischen Muslimen und Nichtmuslimen sollte verbessert werden, indem aktive Informationsarbeit betrieben werde, damit gesellschaftliche Vorurteile gegenüber dem Islam und den Muslimen abgeschwächt werden könnten. In diesem Zusammenhang wird z.B. die Arbeit der Moscheen als unzureichend und unprofessionell bewertet (Öztürk 2007: 233f.; vgl. auch Karakaşoğlu 2006: 25).

Anhand der obigen Darstellung wird deutlich, dass mit dem Kontakt zu Andersgläubigen unterschiedliche Ziele und Ideen verknüpft sind und diese in einer differenten Intensität wahrgenommen werden. Auch der interreligiöse Dialog wird angestrebt, um das Miteinander zu stärken, wobei hier auch weiterhin Herausforderungen bestehen, die bewältigt werden müssen.

In der vorliegenden Arbeit soll im weiteren Verlauf ermittelt werden, ob ein Austausch bzgl. der Religionen angestrebt wird und in welcher Form die interreligiösen Begegnungen stattfinden sollen. Dabei könnten interreligiöse Begegnungen in unterschiedlichen Kontexten (in Schulen, Kindertageseinrichtungen, Nachbarschaft, Peers) erfolgen. Es soll im Folgenden somit auch herausgefunden werden, ob generell überhaupt ein Interesse für einen solchen Austausch vorhanden ist und welche Vorstellungen und Erwartungen die Eltern mit diesem verbinden. 


\subsubsection{Die Medien}

Die in den Medien verbreiteten Inhalte stellen aufgrund der »Dominanz der alltäglichen Medienexposition« wichtige Umwelterfahrungen dar. Sie gelten als »bedeutsame Sozialisationsfaktoren im Geflecht der Erlebnisse, die Kinder und Jugendliche in ihren Familien, mit ihren Peers, mit der wichtigen Institution der Schule oder anderen lebensweltlichen Gegebenheiten machen « (Lukesch 2008: 386). Manche Befunde deuten darauf hin, dass Medien einen stärkeren Einfluss auf das Verhalten ausüben als z.B. die Familien oder die Peers.

Nach Lukesch handelt es sich bei Sozialisationsprozessen im Kern um ein ständig ablaufendes inzidentelles Lernen. Im Unterschied zu beabsichtigten häuslichen Erziehungshandlungen oder didaktisch arrangierter schulischer Lehre sei das Lernen durch die Medien nicht geplant, sondern erfolge zufällig, aber keinesfalls regellos. Man könne von einem »heimlichen Lehrplan der Massenmedien « ausgehen, der mit inhaltsanalytischen Methoden zu untersuchen sei (vgl. Lukesch 2008: 386ff.).

Sozialisationstheoretisch ist es von Bedeutung, aus der Fülle an Informationen, den eigenen Bedürfnissen entsprechend, die richtige Auswahl und die Bewertung der Inhalte zu treffen. Dies erfordert eine zunehmend höhere Medienkompetenz, da bei der Suche nach Informationen die Relevanz und Glaubwürdigkeit der Inhalte eingeschätzt werden muss. Schließlich stelle diese Fähigkeit auch das entscheidende Kriterium dar, ob Medien einen positiven Einfluss auf die Persönlichkeitsentwicklung, d.h. auf die Bewältigung von Entwicklungsaufgaben, ausüben könnten oder nicht (vgl. Hurrelmann 2012: 166).

Die Massenmedien, wie bspw. Radio, Fernsehen und Internet, sind konstitutive Bestandteile der heutigen Kultur. Sie stellen eine Plattform des gesellschaftlichen Austausches dar und sind für den Informationsfluss unverzichtbar. Sie können neben vielfältigen positiven Effekten jedoch auch Konsequenzen nach sich ziehen, die die Chancen auf eine gesellschaftliche und kulturelle Teilhabe beeinträchtigen. Zu diesem Aspekt haben sich eine Vielzahl an Fragestellungen und dazugehörigen Befunden angesammelt. Hierzu zählen Stereotypen und eine entsprechende Vorurteilsbildung (wie z.B. zu Geschlechterrollen, Berufen, psychisch Kranken, Behinderten, gegen rassische, ethnische oder religiöse Minderheiten), die Beeinträchtigung von Schulleistungen (durch einen erhöhten Medienkonsum, gesundheitliche Auswirkungen u.a.), eine gewisse Verbrauchersozialisation (Werbung usw.) sowie politische Sozialisation und auch der Erwerb gewalthaltiger und delinquenter Verhaltensmuster (vgl. Lukesch 2008: 39off.).

Da gerade in den vergangenen Jahren die Stereotypisierung von Muslimen in den Medien (DIK 2009: 282-289) eine große Rolle gespielt und aufgrund der Tatsache, dass das von den Medien transportierte Islambild nicht zuletzt auch bestimmte Effekte bei Kindern und Jugendlichen bewirkt hat, liegt hier die Frage nahe, ob dieses nicht auch einen Einfluss auf die religiöse Sozialisation 
von muslimischen Kindern und Jugendlichen haben könnte. Welche Einstellungen und Meinungen muslimische Eltern dazu einnehmen bzw. haben und wie sie damit umgehen, soll daher im Folgenden genauer beleuchtet werden.

Die bisherige Forschungslandschaft liefert in Bezug auf die Gruppe der Kinder und Jugendlichen schon einige Befunde. ${ }^{58}$

Die Untersuchung von Turhan/Turhan (2011) verdeutlicht, dass die negative Darstellung des Islams vonseiten der Medien bei Kindern und Jugendlichen erhebliche Belastungen hervorruft, da sie nicht selten aufgrund ihrer Religionszugehörigkeit unter einen allgemeinen Terrorismusverdacht gestellt werden. Gemäß den befragten Lehrern führen die produzierten Feindbilder $\mathrm{zu}$ Auseinandersetzungen und Gruppenbildungen. Gestritten werde unter den Jugendlichen über Länder, Glauben und Herkunft. Ein anderer Lehrer mit Migrationshintergrund betont zudem, dass eine allgemeine Islamophobie für die verzerrte Darstellung des Islams in den Medien verantwortlich sei. Auch wenn Christen ähnliche Probleme hätten, erscheine nichts über deren Probleme in den Medien. Die Kinder erführen Ausgrenzung und Ablehnung durch die negative Berichterstattung in den Medien, wodurch ein friedliches Zusammenleben gefährdet sei (vgl. Turhan/Turhan 2011: 91ff.).

Die Rolle der Medien wurde auch in einer Mehrgenerationenfallstudie ${ }^{59}$, für die muslimische Familien und ihre Mitglieder befragt wurden, als negativ bewertet. Es werde ihnen (den Familien) in der Beziehung zwischen Muslimen und Nichtmuslimen immer eine negative Rolle zugeschrieben. Dabei kritisierten die Interviewten, dass es häufig zu einer selektiven, undifferenzierten Darstellung komme, die Muslime zu sehr mit Terrorismus in Verbindung bringe und muslimische Akteure durchweg in ein negatives Licht stelle. Die Berichterstattung wird somit weniger als sachlich und aufklärend, sondern eher als manipulativ und emotionsschürend erlebt. Eine sachlich umfassende Darstellung der Probleme, die verschiedene Perspektiven berücksichtigt, wird ebenso vermisst. Ferner verschärfe sich das konflikthafte Verhältnis zwischen westlicher und islamischer Welt, wodurch ein Aufbau von positiven Beziehungen verhindert werde und bereits bestehende Ängste in der Bevölkerung noch verstärkt würden (vgl. Möllering/Schiefer 2011: 64). Daher müsse zukünftig verstärkt auf die mediale Berichterstattung geachtet und diese kritisch hinter-

58 | In den vergangenen letzten Jahren wurden einige repräsentative Studien zur Mediennutzung der türkischen Bevölkerung, einschließlich der Jugendlichen ab 14 Jahre durchgeführt (vgl. eine Übersicht in DIK 2009: 298f.; vgl. auch Teilstudien in: Boehnke et al. 2011).

59 | Befragt wurden insgesamt sechs Familien mit jeweils drei Teilnehmerinnen und Teilnehmern dreier Generationen in den Altersgruppen von 14-24, 25-44 und 65-84 Jahren. 
fragt werden, um der pauschalen Etikettierung bzw. Verurteilung von Muslimen als Terroristen entgegenzuwirken (vgl. ebd.: 65).

\section{Medien als didaktisches Mittel}

Die Frage zur Nutzung von Medien (Bücher, PC-Programme, Radio, Zeitschriften, religiöse Sendungen, religiös geprägte Zeichentrickfilme) als didaktische Mittel, d.h. als von den Eltern gezielt eingesetzte Mittel zur Weitergabe von religiösen Inhalten, erscheint hier zudem als sinnvoll, da wie bereits oben ausgeführt wurde, diese erhebliche Auswirkungen auf die Sozialisation haben können. Besonders im vergangenen Jahrzehnt haben sich diesbezüglich enorme Entwicklungen abgezeichnet. Gerade hinsichtlich der Veröffentlichung von religiös geprägten (türkischsprachigen) Büchern ist diese Entwicklung als bemerkenswert zu bezeichnen. Es haben sich zudem türkischsprachige Sender etabliert, die religiöse Inhalte vermitteln und die auch Kinderprogramme zur religiösen Bildung zur Verfügung stellen. Die Nutzung und die Reflexion der Inhalte sind in den meisten Fällen erforderlich, wenn sie auch sozialisationsrelevante Funktionen erfüllen sollen. Es soll daher die Frage gestellt werden, welche Haltung die Eltern gegenüber der Nutzung von Medien als didaktische Mittel einnehmen.

Auch hierzu gibt es bis dato nur unzureichende Forschungsergebnisse. Lediglich in einer Untersuchung wird der Mangel an deutschsprachigen Büchern über den Islam als Defizit anerkannt. Die Jugendlichen fühlen sich in dem Erlernen der eigenen Religion somit alleingelassen. Sie versuchen sich, damit zu behelfen, dass sie sich durch ein Selbststudium und die Teilnahme an Gesprächskreisen und gemeinsamen Lesungen untereinander austauschen. Es wird auch erwähnt, dass einige von ihnen ein Studium in der theologischen Fakultät in Istanbul aufnehmen möchten, um sich ein fundiertes und tiefergehendes Wissen anzueignen. Ebenso werden die Berichterstattungen über den Islam in den Medien kritisiert und entsprechend beanstandet (vgl. Öztürk 2007: 229).

\subsection{Schlussfolgerungen und Forschungsleitfragen}

In der Zusammenfassung am Ende des ersten Teilkapitels (vgl. Kap. II. 2.1.3) konnten die zentralen Ergebnisse, die die Studien und andere relevanten Quellen zur Erziehungswirklichkeit in muslimischen Familien ausformuliert haben, aufgezeigt werden. Es soll an dieser Stelle somit nicht noch einmal ausführlich darauf eingegangen werden.

Als wichtigste Einflussfaktoren für die religiöse Sozialisation spielen allen Ergebnissen zufolge sowohl die erlebte und gelebte Religiosität in der Familie und die mehr oder weniger intentional tradierte religiöse Erziehung als auch 
der Bezug zu Moscheegemeinden und ähnlichen Einrichtungen in Form von Koranschul- oder -kursbesuchen eine Rolle.

Wichtig ist, dass die Religion eine zentrale Bedeutung im Leben von muslimischen Familien einnimmt und der religiösen Erziehung generationsübergreifend ein hoher Stellenwert beigemessen wird. Die Studien belegen, auch wenn hier einige Ausnahmen zu verzeichnen sind, einen engen Zusammenhang zwischen der religiösen Erziehung in der Familie als die wichtigste Bedingung für eine spätere Religiosität. Dabei wird gerade durch die befragten Jugendlichen religiöse Erziehung im familiären Rahmen unterschiedlich erlebt. Sowohl das Erziehungshandeln als auch die Ziele, die mit einer religiösen Erziehung verbunden werden, variieren von Familie zu Familie. Auch in der Art und Weise, wie religiöse Erziehung vermittelt wird, sind Unterschiede zu vermerken. Gerade im Zusammenhang mit den Erziehungsstilen lassen sich möglicherweise Formen oder Typen herausarbeiten, die unterschiedliche Vorgehensweisen im erzieherischen Handeln nachzeichnen lassen.

Ein weiteres wichtiges Ergebnis stellt gerade auch im Zusammenhang mit früheren Studien die Durchmischung von kulturellen (diese reichen bis heute in viele Studien hinein) und anderen Einflussfaktoren, wie den ökonomischen Bedingungen und anderen familiären Voraussetzungen, mit den Faktoren, die die religiöse Sozialisation insgesamt betreffen. Da nicht von dem Islam ausgegangen werden kann und die Religion sehr unterschiedlich verstanden und gelebt wird, ist hier auf die Pluralität innerhalb der muslimischen Migrantencommunity zu verweisen. Der Islam als Einflussfaktor auf das familiäre Interaktionsgeschehen muss daher wesentlich differenzierter betrachtet werden. Das erfordert eine Operationalisierung der Religiosität, mit der sich möglichst viele Dimensionen und Aspekte der religiösen Sozialisation bzw. der religiösen Erziehung innerhalb der Familie erfassen lassen.

Schaut man sich die Ergebnisse der Jugendreligiosität an, so ist zu vermerken, dass im Vergleich zur Elterngeneration die Ansprüche und die Erwartungen an eine religiöse Erziehung gestiegen sind und eine höhere »Professionalität« erwartet wird. Diese betreffen sowohl die Wissensaneignung, die religiöse Praxis als auch die Verbesserung der didaktischen Möglichkeiten. Auch hinsichtlich einer religiösen Mündigkeit findet dieser Anspruch seinen Niederschlag, sodass Zwang und Restriktionen abgelehnt werden und der freie Wille in der Religionsausübung entscheidend sein muss. Letztendlich findet innerhalb der jüngeren Generation somit eine Abwendung von einem kulturell geprägten Islam der Elterngeneration statt, innerhalb dessen man auf den »wahren Islam« rekurriert. Die Jugendlichen vertreten in den von ihnen perzipierten Erziehungsvorstellungen ein modernes Selbstverständnis, in dem das traditionelle Religiositätsverständnis der Eltern von einem intellektuell geprägten Religiositätsverständnis abgelöst und der »wahre« Islam gelebt wird. Interessant ist in diesem Zusammenhang, inwiefern auch die perzipierten 
religiösen Erziehungsvorstellungen in eine allgemeine Erziehung eingebunden oder von dieser getrennt werden. Insgesamt stellt sich folglich die Frage, wie sich der veränderte Zugang zur Religion auf den Inhalt der religiösen Erziehung und die Vermittlungsform auswirkt und welches Erziehungshandeln sich demnach in heutigen Familien abzeichnet.

Jedoch kann man schlussfolgern, dass keine einzige Studie sich der religiösen Sozialisation in muslimischen Familien aus Sicht der Eltern widmet. Die vorgestellten Studien bieten ansatzweise Ergebnisse, die aufzeigen, welche Einflüsse bei der religiösen Sozialisation maßgeblich sind, doch keine Studie widmet sich in umfassender Weise einer solchen Frage. Auch die religiöse Erziehung und die Erziehungswirklichkeit in muslimischen Familien konnte zunächst anhand der Ergebnisse und Aussagen muslimischer Jugendlicher $\mathrm{zu}$ dieser Thematik rekonstruiert werden. Diese Forschungsliteratur gibt somit Auskünfte darüber, was von einer religiösen Erziehung erwartet wird, doch über die aktuell tatsächlich gelebte Erziehungspraxis konnten kaum Erkenntnisse aus der Forschung gewonnen werden, da die religiöse Erziehung auch vielfach als ein Hineinwachsen und als ein unreflektierter Bestandteil des familiären Lebens wahrgenommen wird. Kaum eine Untersuchung hat sich bislang dem normativen Bezugshorizont der religiösen Erziehung gewidmet. Gerade dieser bildet jedoch eine wichtige Grundlage im Hinblick darauf, was eine religiöse Erziehung kennzeichnet. Eine differenziert-analytische Operationalisierung der religiösen Erziehung, in der der normative und praktische (Ziele und Inhalte) Bezugshorizont einbezogen wird, fehlt bis heute.

Wie bereits erwähnt wurde, bescheinigen die Studien ferner, dass die Moscheegemeinden bzw. die außerschulischen religiösen Bildungseinrichtungen einen wichtigen Einfluss auf die religiöse Sozialisation ausüben. Als zentrale außerfamiliäre Sozialisationsinstanzen nehmen die Bildungsangebote der Moscheegemeinden einen wichtigen Stellenwert in der religiösen Erziehung ein (vgl. Kap. II. 2.2.1a). Eltern delegieren die Aufgabe einer religiösen Erziehung vielfach an die religiösen außerschulischen Bildungseinrichtungen (Korankurse oder Koranschulen u.ä.), mit der sie auch unterschiedliche Zielsetzungen verfolgen. Die Studien zeigen zudem, dass häufig Kritik an der Bildungsarbeit geübt wird. Auch hier sind gestiegene Erwartungen hinsichtlich einer religiöse Bildung bzw. Erziehung zu vermerken. In der Forschung wurden die Moscheen $u$.ä. Bildungseinrichtungen als außerfamiliäre Sozialisationsinstanzen kaum berücksichtigt. Die wenigen Ergebnisse deuten zudem auf das Fehlen systematisch ausgearbeiteter Erziehungskonzepte hin, obwohl die Bildungsarbeit der Moscheegemeinden immer wieder als verbesserungswürdig charakterisiert wurde und noch wird und die religiöse Erziehung seit dem Beginn der Migration nicht an ihrem zentralen Stellenwert eingebüßt hat. Die Elternperspektive könnte somit dezidiert aufzeigen, wie bspw. der Korankursbesuch u.ä. 
Bildungsangebote heute wahrgenommen und welche Ziele damit verbunden werden.

Die staatlich-institutionellen Einrichtungen wie Kindertagesstätten und Schulen sind, was ihren Bildungsauftrag angeht, im Grunde für die religiöse Sozialisation nicht relevant. Trotzdem erscheint die Auseinandersetzung (vielfach auch durch negative Zuschreibungen) mit der eigenen religiösen Identität gerade im schulischen Kontext zu einer religiösen Selbstvergewisserung bei den Schülerinnen und Schülern beizutragen (vgl. Kap. II. 2.2.2). Folglich lässt sich vorsichtig formulieren, dass die Schule in manchen Fällen einen nichtintendierten religiösen Sozialisationseffekt ausübt.

Die Studien führen des Weiteren vor Augen, dass muslimische Kinder und ihre Eltern in den staatlichen Bildungseinrichtungen aufgrund ihrer Religionszugehörigkeit und ihrer religiösen Praxis häufig Benachteiligungen, Ausgrenzungen und weitere Konflikte erleben. Doch es gibt kaum eine veröffentlichte Studie, die die Elternperspektive in diesem Zusammenhang aufzeigt.

Muslimische Eltern müssen sich, was ihre religiöse Praxis angeht, vielen Herausforderungen stellen, mit denen in Schulen und Kindertagesstätten in unterschiedlicher Weise umgegangen wird. Häufig machen muslimische Kinder ausgrenzende Erfahrungen, die ihnen das Vertrauen in die staatlichen Bildungseinrichtungen rauben. Doch es bestehen auch Chancen, wie bspw. eine erfolgreiche Integration in den Alltag der Schule oder Kindertagesstätte und das Lernen voneinander, im Sinne von Toleranz, Austausch und einem friedlichen Zusammenleben. Auch hier ist die Elternperspektive bis heute kaum erforscht. Die Sorgen und Erwartungen, die Eltern mit dem Besuch ihrer Kinder in staatlichen Bildungseinrichtungen verbinden, und die Fragen, welche fördernden oder hemmenden (religiösen) Sozialisationseffekte sie diesen zuschreiben, sollen daher im Folgenden analysiert, beantwortet und entsprechend erläutert werden.

Der islamische Religionsunterricht, der im Rahmen der Schule in Form von diversen Schulmodellen bereits angeboten wird, könnte möglicherweise einen Einfluss auf die religiöse Sozialisation ausüben. Bislang wurde dieser jedoch nicht flächendeckend eingeführt und es fehlen empirische Ergebnisse, die auf einen entsprechenden Sozialisationseffekt hinweisen. Vor diesem Hintergrund erscheint es für den vorliegenden Zusammenhang als interessante Fragestellung, welche Haltung muslimische Eltern zur Einführung eines islamischen Religionsunterrichts einnehmen und welche potenziellen (möglicherweise auch) sozialisationsrelevanten Erwartungen sie an einen solchen knüpfen.

Die Peers üben gemäß vielen Studien einen wichtigen Sozialisationseffekt aus (vgl. Kap. II. 2.2.3). Einige Studien deuten gerade in religiösen Netzwerken auf deren zentrale Bedeutung hin, was vermuten lässt, dass dies für die religiöse Sozialisation relevant ist. Andere wiederum erörtern zwar die Wichtig- 
keit von Freundschaften, aber ihr Effekt auf die religiöse Sozialisation scheint diesen zufolge nicht gegeben. Im Rahmen der religiösen Sozialisation ergibt sich somit die Frage, welchen Einfluss die Peergroup oder Freundschaftsbeziehungen letztendlich auf die Entwicklung von Religiosität ausüben. Die elterliche Sichtweise hinsichtlich des Schließens von Freundschaften könnte hier Aufschluss darüber geben, ob diesem Aspekt eine Bedeutung für die religiöse Sozialisation zugemessen werden muss und inwiefern ihre Kinder durch solche eine entsprechende Beeinflussung erfahren.

Der Kontakt zu Andersgläubigen wird in einer unterschiedlichen Intensität wahrgenommen und es bestehen hier große Herausforderungen. Der interreligiöse Dialog wird von einem Teil der muslimischen Jugendlichen angestrebt, um ein friedliches Miteinander zu gewährleisten. Interreligiöse Begegnungen können in unterschiedlichen Kontexten (in Schulen, Kindertageseinrichtungen, in der Nachbarschaft und in Peergroups) stattfinden. Ob ein Interesse für einen solchen Austausch vorhanden ist, und welche Vorstellungen und Erwartungen Eltern damit verbinden, blieb in der Forschung bisher ein Randthema. Deshalb soll untersucht werden, inwiefern ein Interesse an interreligiösen Bildungsangeboten seitens der Eltern besteht, in welcher Form sich Eltern dafür engagieren möchten und ob darin ein sozialisationsrelevanter Effekt gesehen wird.

Schließlich ist noch nach dem Einfluss der Medien (vgl. Kap. II. 2.2.4) zu fragen. Das von den Medien vermittelte Islambild führt häufig zu Stereotypisierungen von Muslimen, die sich negativ und belastend auf die Kinder auswirken können. Ob hier ein fördernder oder behindernder Sozialisationseffekt gesehen wird, wie muslimische Eltern dazu stehen und wie sie damit umgehen, sind demzufolge Fragestellungen, denen sich die Untersuchung im weiteren Verlauf widmet. Auch der Einsatz von Medien als didaktisches Mittel kann sozialisationsrelevant sein. Es soll daher im Folgenden zudem die Frage beantwortet werden, welche Haltung Eltern zur Nutzung von Medien einnehmen.

Muslimische Eltern, die mit ihren Kindern in Deutschland in einer Minderheitensituation leben und sich in manchen grundlegenden Wertebereichen gegenüber der deutschen Gesellschaft unterscheiden, stehen auch hier vor der Herausforderung, ihre Kinder religiös zu erziehen. Nicht selten ergeben sich aus dieser Situation mögliche Konfliktlinien, aber auch Chancen, die sie nutzbringend einsetzen. So soll demnach gefragt werden, wie sie ihr »Gegenüber«, d.h. die nichtmuslimischen Deutschen erleben und welche Vorstellungen einheimisch Deutsche ihrer Meinung nach über den Islam haben bzw. welche Perspektive sie diesem gegenüber einnehmen. Auch die Intensität, wie sehr sie ihre Religion ausleben können, stellt ein weiteres Kriterium für ein gelungenes Miteinander bzw. Zusammenleben in dieser Gesellschaft dar. Nicht zuletzt drückt sich darin auch die individuelle Religionsfreiheit aus, die in diesem Land den Muslimen zuerkannt wird. Schließlich wird mit der Frage, was eine 
religiöse Erziehung in dieser Gesellschaft bewirken soll, nochmals die Position muslimischer Eltern zur deutschen Gesellschaft verdeutlicht.

Insgesamt lassen sich daraus die nachfolgenden zentralen Forschungsfragen ableiten und ausformulieren:

- Ziel dieser Untersuchung ist es, herauszufinden, welchen (fördernden oder hemmenden) Einfluss, neben der Familie als der primären Sozialisationsinstanz, andere zentrale Sozialisationsinstanzen, wie z.B. Schulen oder Kindertagesstätten, außerschulische Bildungseinrichtungen (Moscheegemeinden, Korankurse oder ähnliche Einrichtungen), der Freundeskreis der Kinder (Peers), Medien und Gesellschaft, auf die religiöse Sozialisation von muslimischen Kindern ausüben.

- Die Studien deuten auf die Pluralität von religiösen Orientierungen und auf die Notwendigkeit einer wesentlich differenzierteren Wahrnehmung des Islams als Einflussfaktor auf das familiäre Interaktionsgeschehen hin. Dies veranlasst gerade im Zusammenhang mit religiöser Erziehung dazu, $\mathrm{zu}$ fragen, welche konkrete greif- und benennbare religiös fundierte Erziehungspraxis in muslimischen Familien vorzufinden ist und wie sich die einzelnen Erziehungspraktiken der Familien voneinander unterscheiden.

- Die religiöse Erziehung ist ein wesentlicher Aspekt der (allgemeinen und) religiösen Sozialisation. Es stellt sich die Frage, an welche normativen, orientierungs- und handlungsleitenden Prinzipien die »religiöse« Erziehung durch Eltern in muslimischen Familien anknüpft und wie die inhaltliche Füllung des Begriffs anhand subjektiver Deutungsmuster vorgenommen wird, ohne dabei kulturelle oder andere Faktoren bzw. Einflüsse zu vermischen.

- Hierbei ist es notwendig, eine Vorgehensweise zu wählen, die eine differenzierte analytische Operationalisierung der Religiosität als das Resultat der religiösen Sozialisation ermöglicht. Dabei sollen möglichst viele Dimensionen der Religiosität berücksichtigt werden. Da nicht zuletzt die gelebte Religiosität innerhalb des familiären Rahmens Aufschluss darüber geben kann, welchen Stellenwert die Religion und damit die religiöse Sozialisation hier hat, sollen die verschiedenen Ausprägungen der Religiosität ausführlich untersucht werden.

- Die benannte Forschungsliteratur zu dieser Thematik gibt nur wenige Hinweise darauf, wie die Religion methodisch im Rahmen der religiösen Erziehung weitergegeben wurde. Es soll daher im Folgenden gefragt werden, wie die Art und Weise, d.h. die Vermittlungsform von religiösen Werthaltungen in der Familie geschieht. Auch sollen mögliche Erziehungsstile ergründet werden. Dazu sollen Eltern gefragt werden, wie sie mit Konflikten und der Einhaltung von Regeln umgehen und welche Belohnungen oder Strafen sie in ihrer Erziehung einsetzen. 
- Die Studien/Expertisen belegen, dass die außerschulischen Bildungseinrichtungen (Moscheegemeinden, in denen Koranschulen/Korankurse integriert sind usw.) einen wichtigen Einfluss auf den religiösen Sozialisationsprozess ausüben. Vor diesem Hintergrund soll erkundet werden, welchen fördernden oder hemmenden Beitrag diese zur religiösen Sozialisation/Erziehung leisten und wie die Eltern die Angebote der Moscheen insgesamt bewerten.

- Der Umgang mit dem Islam in öffentlichen Bildungseinrichtungen, wie bspw. Schulen, Kindergärten und Kindertagesstätten sowie offenen Ganztageseinrichtungen, ist ein Thema, welches Spannungs- und Konfliktpotenzial enthält. Möglicherweise ist davon auszugehen, dass öffentliche Bildungseinrichtungen einen hemmenden Einfluss auf die religiöse Sozialisation haben. Gefragt wird daher nach der Haltung der Lehrer/-innen sowie Erzieher/-innen zur eigenen Religion und danach, ob religiöse bzw. kulturelle Elemente im Schul- und Kindertagesstättenalltag Platz haben oder ob es hier Konfliktsituationen und Benachteiligungen gibt, die auf die Religionszugehörigkeit und auf die religiöse Praxis zurückzuführen sind.

- Der islamische Religionsunterricht, der bereits an einigen Schulen eingeführt wurde, ist ein aktuell viel diskutiertes Thema, das dazu einlädt, die Positionen der Eltern zu bestimmen. Daher interessiert im vorliegenden Zusammenhang, welche Perspektive muslimische Eltern zur Einführung eines islamischen Religionsunterrichts einnehmen und welche potenziellen (auch) sozialisationsrelevanten Erwartungen sie an diesen knüpfen.

- Interreligiöse Begegnungen können in unterschiedlichen Kontexten (u.a. in Schulen, Kindertageseinrichtungen, in der Nachbarschaft usw.) stattfinden. Es soll erörtert werden, ob grundsätzlich ein Interesse an einem solchen Austausch besteht, und wenn dies bejaht wird, welche Vorstellungen und Erwartungen die Eltern im Einzelnen damit verbinden.

- Der Freundeskreis oder die Peers der Kinder und Jugendlichen spielen eine wichtige Rolle bzgl. ihrer Sozialisation. Im Rahmen der religiösen Sozialisation ergibt sich die Frage, welchen konkreten Einfluss die Peergroup oder Freundschaftsbeziehungen auf die Entwicklung der Religiosität von Kindern und Jugendlichen ausüben. Die Elternperspektive gibt Aufschluss darüber, welche Bedeutung den Peers und den Freundschaften ihrer Kinder für die religiöse Sozialisation beigemessen wird und inwiefern sie ihre Kinder bei der Wahl ihrer Freunde beeinflussen.

- Es wird ein Islambild vonseiten der Medien übermittelt, das vielfach auf die Muslime projiziert wird. So erscheint es im Hinblick darauf interessant, herauszufinden, welchen (fördernden oder behindernden) Sozialisationseffekt dieses Image auf muslimische Kinder oder Jugendliche ausübt und welchen Umgang sie mit diesem pflegen. 
- Die Medien als didaktisches Mittel zur Unterstützung von religiöser Erziehung kommen möglicherweise vielfältig zum Einsatz. So soll erforscht werden, welche Relevanz diese für die religiöse Erziehung der Kinder besitzen.

- Auf der gesellschaftlichen Ebene soll schließlich analysiert werden, welche Vorstellungen Eltern bzgl. der Haltung einheimisch Deutscher ihrer islamischen Kultur/muslimischen Religion gegenüber haben. Die Antworten sollen dokumentieren, welchen Herausforderungen sie sich stellen müssen bzw. welche potenziellen Chancen sie für ein friedliches Zusammenleben sehen. In diesem Zusammenhang kann zudem die Frage gestellt werden, inwiefern die eigene Religion in dieser Gesellschaft (in einer Minderheitensituation) überhaupt ausgelebt werden kann.

- Mit der Frage, was religiöse Erziehung in dieser Gesellschaft bewirken soll, geht es nochmals darum, die Position muslimischer Eltern zur deutschen Gesellschaft zu veranschaulichen.

\section{Analytischer Bezugstahmen}

Der analytische Bezugsrahmen soll helfen, den Forschungsgegenstand, auf den sich diese Untersuchung bezieht, theoretisch zu verorten. Ausgehend von den Forschungsleitfragen wird hier ein theoretischer Bezugshorizont vorgestellt, mithilfe dessen die religiöse Sozialisation und die religiöse Erziehung in muslimischen Familien besser verstanden werden kann. Es sind hierbei jedoch Herausforderungen zu berücksichtigen, die im Rahmen der vorliegenden Dissertation nicht bearbeitet werden können und im Rahmen eines anderen Forschungsprojekts noch einmal gesondert betrachtet werden müssten. Diese betreffen zum einen die Sozialisationsforschung, die sich ausgehend von ihrer theoriegeschichtlichen Disposition und ihrer Weiterentwicklung auf die modernen westlichen Gesellschaften bezieht und sich nicht in genügendem Maße zur Erklärung der Sozialisation von Menschen mit Migrationshintergrund eignet. Dabei müsste ein Sozialisationsmodell, das sich auf diese Gruppe bezöge, die Minderheitensituation der Sozialisanden ebenso beachten wie auch die subkulturellen Besonderheiten der unterschiedlichen Gruppen, die für ihre Sozialisation in der Mehrheitsgesellschaft maßgeblich mitbestimmend sind. ${ }^{60}$ Zielt man zudem noch auf die religiöse Sozialisation als eine Dimension der allgemeinen Sozialisation von Muslimen ab, so verstärkt sich

60 | An dieser Stelle ist darauf hinzuweisen, dass die Ansätze der Interkulturellen Pädagogik (vgl. für eine Übersicht z.B. Badawia 2002: 29-33) und der Migrationssoziologie sozialisationsbedingende Faktoren zumeist unter der Fragestellung des Assimilations- bzw. des Integrationsgrades der Migrant(inn)en und deren Kinder darzustellen 
die Suche nach einem geeigneten Modell umso mehr. Hier stößt man auf Probleme, die im vorliegenden Zusammenhang gelöst werden konnten, indem die Begrifflichkeiten und Grundannahmen zur Sozialisation, über die in der Sozialisationsforschung breiter Konsens herrscht, so allgemein wie möglich dargelegt wurden. Auch ist die religiöse Sozialisation von Muslimen in der Diasporasituation mit unterschiedlichen Herausforderungen gekennzeichnet. Gegenwärtig existieren kaum metatheoretische Erklärungsmuster, die die Besonderheiten einer muslimischen Religiosität in der Diasporasituation berücksichtigen (vgl. Klinkhammer 2000: 51-57). Lediglich die empirische Forschung (vgl. Kap. II. 2.) bietet Anhaltspunkte, welche Aspekte für die religiöse Sozialisation von Muslimen relevant sind. Daher kann die folgende Ausarbeitung als ein Deutungsrahmen verstanden werden, der jedoch nicht auf Endgültigkeit bzw. Ausschließlichkeit abzielt.

Um nochmals die zentralen Fragestellungen in Erinnerung zu rufen: Es soll analysiert werden, welchen Einfluss, neben der Familie als primärer Sozialisationsinstanz, die nichtinstitutionellen religiösen Bildungseinrichtungen (in Moscheegemeinden, Korankurse usw.), die staatlichen Bildungseinrichtungen, der Freundeskreis der Kinder, Medien und die Gesellschaft auf die religiöse Sozialisation von muslimischen Kindern ausüben.

Des Weiteren möchte die vorliegende Arbeit der Frage nachgehen, wie im Rahmen der Familie religiöse Werthaltungen im Sozialisationsprozess auf die Kinder übertragen werden. Die religiösen Erziehungsvorstellungen und die konkrete religiöse Erziehungspraxis als die Folge normativer Beeinflussung sollen dabei genauso einer Untersuchung unterzogen werden wie die verschiedenen Ausprägungen der Religiosität, die aus einer solchen resultieren. Bezogen auf mögliche andere Einflussfaktoren der religiösen Sozialisation außerhalb der Familie, wurde im empirischen Teil (Kap. II. 2.) bereits Bezug genommen. In diesem Kapitel werden diese daher nur kurz skizziert.

Zunächst soll im Folgenden eine Bestimmung erfolgen, was unter einer religiösen Sozialisation überhaupt zu verstehen ist.

\subsection{Was ist religiöse Sozialisation?}

\subsubsection{Religiöse Sozialisation als eine Dimension der allgemeinen Sozialisation}

Die religiöse Sozialisation kann im Grunde als eine Ausprägung der allgemeinen Sozialisation verstanden werden. Sie stellt keinen Sonderbereich dar, sondern eine Dimension des allgemeinen Sozialisationsprozesses, »[...] der seinerseits nicht zwangsläufig religiös verstanden werden muss, wohl aber die

versuchten. Auch wurden die religiöse Praxis und die Religiosität von Migrant(inn)en in der wissenschaftlichen Literatur vorwiegend unter diesem Gesichtspunkt betrachtet. 
religiöse Thematik betrifft« (vgl. Fraas 1990: 76). Als eine wesentliche Komponente der gesellschaftlichen Sozialisation kann sie »als motivkräftige Übermittlung religiöser Inhalte, Einstellungen und Verhaltensweisen an nachfolgende Generationen, die sich diesen Sinnkomplex des Glaubens und seiner Lebenspraxis aneignen [...]« definiert werden (Drehsen/Mette 2000: 2011).

Im Kontext der allgemeinen Sozialisation beschreibt religiöse Sozialisation die Entwicklung von religiösen Überzeugungen, Haltungen und Handlungen. Inhalte und Ziele können hierbei 1) das Interesse und eine grundsätzlich positive Haltung gegenüber religiösen Fragen und Themen, 2) eine positive Grundhaltung gegenüber einem bestimmten religiösen Glaubenssystem oder einer Glaubensgemeinschaft, 3) den Erwerb von Wissen und die kognitive Akzeptanz von inhaltlichen Annahmen und Glaubensüberzeugungen beinhalten. Die religiöse Sozialisation ist ein interaktiver Prozess, bei dem die Entwicklungsaufgaben durch angeborene Dispositionen und Möglichkeiten einerseits und durch die Lernbedingungen mit ihren Sozialisationsangeboten andererseits bedingt sind. Sie basiert auf einer aktiven, kognitiven und emotionalen Verarbeitung und (Re-)Konstruktion von religiösen Angeboten und persönlichen Erfahrungen. ${ }^{61}$

Die Sozialisation ist ein Sammelbegriff für unterschiedliche Prozesse und die Sozialisationsforschung umfasst unterschiedliche Theorieansätze, die wiederum unterschiedlichen wissenschaftlichen Disziplinen zugeordnet werden können. ${ }^{62}$ Es handelt sich bei den verschiedenen Sozialisationsmodellen um unterschiedliche Paradigmen, die das interaktive Verhältnis des Individuums zu seiner Umwelt darstellen (vgl. Bukow 1974; Fraas 1987; Fraas 1990: 73ff.). Im Zusammenhang mit der religiösen Sozialisation blenden diese Denkansätze theologische Sachverhalte aus, die für die Entwicklung von religiösen Überzeugungen, Haltungen und Handlungen die Grundlage bilden.

An dieser Stelle muss festgehalten werden, dass Sozialisationsmodelle zentrale Fragen, wie bspw. die Entwicklung der Persönlichkeit und parallel dazu die Übernahme eines Repertoires an Einstellungsmustern, Kompetenzen, Handlungsbefähigungen, die für das spezifische Umfeld kennzeichnend sind, zu klären versuchen (vgl. Bauer/Hurrelmann 2007: 674). Im Rahmen der religiösen Sozialisation bedeutet das konkret die Frage, wie religiöse norm-, orientierungs- und handlungsleitende Inhalte in Interaktion mit der Umwelt die Entwicklung einer (religiösen) Persönlichkeit bzw. die Religiosität eines Menschen bedingen. Hier ist zudem auf die oben vorgeschlagene Definition zu verweisen, die auf die Entwicklung von religiösen Überzeugungen, Haltungen und Handlungen eines Individuums hindeutet.

61 | Vgl. Lexikon der Psychologie. URL: www.psychology48.com/deu/d/religioese-so zialisation/religioese-sozialisation.htm [Stand: 30.12 .2016 ].

62 | Vgl. für eine Übersicht aller Sozialisationsmodelle Veith 2008: 17. 
Wie bereits erörtert wurde, ist die religiöse Sozialisation ein zentraler Bestandteil der allgemeinen Sozialisation und methodisch im Rahmen der allgemeinen Sozialisationstheorien einzuordnen (vgl. Fraas 1990: 73-76 und Bukow 1974: 213ff.). Vor diesem Hintergrund werden im Folgenden zunächst eine begriffliche Definition sowie die Grundannahmen, die dem Begriff Sozialisation zugrunde liegen, formuliert.

\subsubsection{Sozialisation}

Da allein mit dem Begriff Sozialisation nicht von einer allgemeingültigen, alles umfassenden Theorie der Sozialisation ausgegangen werden kann, ist zunächst eine Verständigung darüber notwendig, was im Zusammenhang mit Sozialisation alles assoziiert bzw. was darunter jeweils verstanden wird. Zunächst geht es vorrangig um eine begriffliche Abgrenzung und um das, was zum Gegenstandsbereich von Sozialisation gehört.

Mit Sozialisation wird auf den »Prozess der Entstehung und Entwicklung der Persönlichkeit in wechselseitiger Abhängigkeit von der gesellschaftlich vermittelten sozialen und materiellen Umwelt« abgezielt (vgl. Hurrelmann 2012: 46 in Anlehnung an: Geulen/Hurrelmann 1980: 51). Es gab in der Folgezeit Modifizierungen und Variationen dieses Begriffs, doch gilt dieseDefinition in ihrem Grundsatz in der Sozialisationsforschung als weitestgehend akzeptiert.

Mit dieser begrifflichen Definition wird die Gesamtheit aller Umweltbedingungen, die auf die Subjektbildung Einfluss nehmen hervorgehoben. Die sozialen und materiellen Umweltfaktoren sind gesellschaftlich beeinflusst und können als Bedingungen des Sozialisationsprozesses für die Persönlichkeitsentwicklung von entscheidender Bedeutung sein (vgl. Tillmann 2010: 14f.).

\section{a) Sozialisation: einige Grundannahmen zum Sozialisationsprozess}

Im Zentrum der Sozialisationsforschung stehen die Entwicklung und die Veränderung der Persönlichkeit. Mit dem Begriff der Persönlichkeit lässt sich ein spezifisches Gefüge von Merkmalen, Eigenschaften, Einstellungen und Handlungskompetenzen, die den einzelnen Menschen kennzeichnet, bestimmen. Diese sind durch biologische Lebensgrundlagen und Erfahrungen, die der Einzelne im Laufe seiner Lebensgeschichte gemacht hat, entstanden (vgl. Tillmann 2010: 16).

Mit dem Begriff >Persönlichkeit< lässt sich somit die Vorstellung über ein Gefüge von psychischen Strukturen und Merkmalen bei einem Individuum in Verbindung bringen. Dabei geht es jedoch nicht nur um von außen beobachtbare Verhaltensweisen, sondern auch um innerpsychische Prozesse und Zustände, Gefühle und Motivationen. Dazu gehören ebenso Wissen, Sprache und Werthaltungen. Sozialisationsforschung und -theorie hat, so Tillmann, aufzuzeigen, in welchem Verhältnis diese Aspekte der inneren Realität zu den Bedingungen der äußeren Realität stehen (vgl. Tillman 2010: 16). Ein solches Ver- 
ständnis von Persönlichkeit weist zudem auf Ausprägungen des psychischen Gefüges hin, das bei jedem einzelnen Menschen unterschiedlich angelegt ist. Dieses spezifische Gefüge des Einzelnen lasse sich demnach als >Individualität< bezeichnen. Dabei gehöre zur Persönlichkeit sowohl diese Individualität, die den Einzelnen von den anderen unterscheidet, als auch der Sozialcharakter, den die Mitglieder einer Gesellschaft teilen würden (vgl. ebd.: 16). Hiermit ist der Teil der Persönlichkeit gemeint, der signifikanten sozialen Gruppen gemeinsam ist und das Resultat der gemeinsamen Erfahrungen dieser Gruppen darstellt. Der soziale Charakter, der so verstanden wird, erlaubt es damit, vom Charakter der Klassen, Gruppen, Völker und Nationen zu sprechen (vgl. ebd.). Auch innerhalb einer Gesellschaft lassen sich unterschiedliche Sozialcharaktere voneinander abgrenzen. Ethnische Minderheiten können unterschiedliche kulturelle »Selbstverständlichkeiten« ausleben, die sich von denen der »Mehrheitskultur« unterscheiden. Diese Selbstverständlichkeiten können sich auf kulturelle Eigenarten (wie Höflichkeitsformen, Essgewohnheiten, Rollenbilder) und Lebensgewohnheiten der ethnischen Minderheiten innerhalb der deutschen Mehrheitsgesellschaft beziehen. Ein Heranwachsender erwerbe in jedem Fall die »Selbstverständlichkeiten« seiner Gruppe - und damit auch die entsprechenden Anteile des Sozialcharakters (vgl. ebd.: 17). Tillmann folgert daraus, dass damit die Genese der Persönlichkeit zugleich auf Vergesellschaftung und Individualisierung hinausläuft. Er sieht es dabei dezidiert als Aufgabe einer Sozialisationstheorie an, diese beiden Dimensionen der Persönlichkeitsentwicklung systematisch zu erfassen (vgl. ebd.). ${ }^{63}$

Das Verhältnis des Individuums zu den Bedingungen seiner Umwelt ist von der Grundannahme geprägt, dass der heranwachsende Mensch auf seine Lebens- und Lernprozesse aktiv Einfluss nehmen kann. Dieser wirke auf sich und seine Umwelt selbst ein und entwickele sich zu einem handlungsfähigen Subjekt (vgl. Tillmann 2010: 17).

Eine weitere Grundannahme besteht darin, dass das Sozialisationsfeld in gesellschaftliche Ebenen gegliedert ist: »Aus der Bestimmung, dass die Persönlichkeitsentwicklung ein Austauschprozess zwischen dem Subjekt und seiner gesellschaftlich vermittelten Umwelt ist, ergibt sich eine Gliederung des Sozialisationsprozesses in gesellschaftliche Ebenen« (Tillmann 2010: 21). Diese Ebenen betreffen die Ebene des Subjekts bis hin zur Gesamtgesellschaft.

63 | Hinsichtlich der religiösen Sozialisation können sich diese "Selbstverständlichkeiten " auf religiöse Inhalte, Einstellungen, Haltungen und Verhaltensweisen beziehen, die für Muslime typisch sind und damit ihren Sozialcharakter ausmachen. 
Im Sozialisationsprozess trete dem Einzelnen die Gesellschaft (d.h. die äußere Realität) nicht in ihrer Totalität oder Komplexität gegenüber, sondern das Individuum bewege sich im Laufe seiner Entwicklung in konkreten sozialen Umwelten, die wiederum in weitere Zusammenhänge eingebunden seien (vgl. Tillmann 2010: 21).

Um diese Ebenen zu verdeutlichen bzw. eine grobe Einordnung der Sozialisationsbedingungen vornehmen zu können, verweist Tillmann auf das »Strukturmodell der Sozialisationsbedingungen«. Darin kommt zum Ausdruck, in welchen systematischen Beziehungen die einzelnen Faktoren zueinander stehen und in welcher Weise sie auf die Persönlichkeitsentwicklung einwirken. Die Gliederung der Ebenen strukturiert den Gegenstandsbereich der Sozialisationsforschung, die sich wiederum dem Anspruch stellen muss, zum einen die Frage zu klären, wie sich Subjekte ihre unmittelbare soziale Umwelt aneignen und dabei ihre Persönlichkeitsstrukturen ausbilden. Zum anderen sollte sie die Zusammenhänge aufzeigen, die zwischen den Umweltbedingungen und umfassenderen gesamtgesellschaftlichen Strukturen bestehen.

Auf diese auch kritisierte, vereinfachte und mechanisch anmutende Schematisierung des Mehrebenenmodells ist hinzuweisen, sodass der Ertrag letztlich darin liegt, eine ordnende Funktion zu erfüllen. Es soll ein gestaltgebender Rahmen zur Verfügung gestellt werden, dessen inhaltliche Füllung und empirische Anwendung vom jeweiligen Erkenntnisinteresse zu systematisieren bleibt (vgl. Tillmann 2010: 24).

\begin{tabular}{|c|c|}
\hline Ebene & Komponenten (beispielhaft) \\
\hline (4) Gesamtgesellschaft & $\begin{array}{l}\text { ökonomische, soziale, politische, kulturelle } \\
\text { Struktur }\end{array}$ \\
\hline (3) Institutionen & $\begin{array}{l}\text { Betriebe, Massenmedien, Schulen, } \\
\text { Universitäten, Militär, Kirchen }\end{array}$ \\
\hline $\begin{array}{l}\text { (2) Interaktionen und } \\
\text { Tätigkeiten }\end{array}$ & $\begin{array}{l}\text { Eltern-Kind-Beziehungen; } \\
\text { schulischer Unterricht; } \\
\text { Kommunikation zwischen Gleichaltrigen, } \\
\text { Freunden, Verwandten }\end{array}$ \\
\hline (1) Subjekt & $\begin{array}{l}\text { Erfahrungsmuster, Einstellungen, Wissen, } \\
\text { emotionale Strukturen, kognitive Fähigkeiten }\end{array}$ \\
\hline
\end{tabular}

Abbildung 1: Struktur der Sozialisationsbedingungen

(Quelle: Tillmann 2010:23) 
Die Pfeile, die in beide Richtungen verweisen, deuten auf das Wechselwirkungsprinzip zwischen den Ebenen hin.

Auf der ersten Ebene geht es um die Entwicklung der Individuen, um Erfahrungsmuster, Einstellungen, Wissen und emotionale Strukturen. Die Entwicklung der Persönlichkeitsmerkmale geschieht in Interaktion mit anderen Menschen und im gemeinschaftlichen gesellschaftlichen Austausch. Entsprechend lässt sich die zweite Ebene der sozialisatorischen Umwelt als Ebene von »Interaktionen und Tätigkeiten« bezeichnen. Diese Aktionen sind überwiegend an Institutionen, wie bspw. Kindergärten, Schulen und Betriebe, gebunden, die wiederum die dritte Ebene bilden. Dabei ist z.B. die Schule zum Zweck der Sozialisation eingerichtet worden. All das hier Aufgeführte bzw. die Institutionen sind wiederum Teil eines gesamtgesellschaftlichen Systems mit ihren ökonomischen, sozialen und kulturellen Strukturen, aus denen heraus sich die Institutionen entwickelt haben und in denen sie verankert sind (vgl. Tillmann 2010: 23f.).

\section{b) Sozialisation als produktive Verarbeitung der Realität}

Hurrelmann entwickelt ein umfassendes Modell der Sozialisation, das psychologische und soziologische Einzeltheorien miteinander verbindet, um die Wechselwirkung zwischen Individuum und Gesellschaft darzustellen. Damit stellt er ein Repertoire zur Verfügung, das die Analyse der Sozialisation als ein Wechselspiel von gesellschaftlichen und individuellen Einflüssen ermöglicht.

Den Ausführungen zu diesem Modell liegt die folgende Definition von »Sozialisation« zugrunde:

"Sozialisation bezeichnet die Persönlichkeitsentwicklung eines Menschen, die sich aus der produktiven Verarbeitung der inneren und äußeren Realität ergibt. Die körperlichen und psychischen Dispositionen und Eigenschaften bilden für einen Menschen die innere، Realität, die Gegebenheiten der sozialen und physischen Umwelt die ‘äußere، Realität. Die Realitätsverarbeitung ist ’produktiv،, weil ein Mensch sich stets aktiv mit seinem Leben auseinandersetzt und die damit einhergehenden Entwicklungsaufgaben zu bewältigen versucht. Ob die Bewältigung gelingt oder nicht, hängt von den zur Verfügung stehenden personalen und sozialen Ressourcen ab. Durch alle Entwicklungsaufgaben zieht sich die Anforderung, die persönliche Individuation mit der gesellschaftlichen Integration in Einklang zu bringen, um die Ich-Identität zu sichern." (Hurrelmann 2012: 52)

Das Modell ${ }^{64}$, das als eine Sozialisationstheorie betrachtet wird, kann hier nicht im Detail ausgeführt werden. Daher sollen die wichtigsten Aussagen, die für

64 | Hier ist wohl anzumerken, dass sich Hurrelmanns Konzept auf die allgemeine Sozialisation bezieht, die auch von unterschiedlichen Seiten Kritik erfahren hat. Beer/Bittlingmayer (2008) stellen hierzu fest, dass für eine gelingende individuelle Sozialisation 
die vorliegende Untersuchung relevant sind, nochmals in verkürzter Weise dargelegt werden. Damit ist auch verbunden, dass der Blick nur einen bestimmten Ausschnitt der Sozialisation fokussiert. Im Zentrum stehen innerhalb dieser Untersuchung Eltern bzw. Familien, deren Perspektive auf bestimmte Aspekte der (religiösen) Sozialisation ihrer Kinder gerichtet ist. Familien fungieren gemäß diesem Modell als die wichtigsten Vermittler der äußeren Realität. Sie gelten als »zentrale« Koordinationsort, an dem Erziehungsprozesse angeregt und bestimmte Entwicklungseffekte ausgeübt werden, die es zu untersuchen gilt. Damit wird vor allem im Rahmen dieser Sozialisationstheorie das Verhältnis von innerer und äußerer Realität sowie neben der Familie als der primären Sozialisationsinstanz die Bedeutung weiterer Sozialisationsinstanzen angesprochen.

Mit Sozialisation wird der oben angeführten Definition zufolge auf den »Prozess der Entwicklung der Persönlichkeit in produktiver Auseinandersetzung mit den natürlichen Anlagen, insbesondere den körperlichen und psychischen Grundmerkmalen (der sinneren Realitäts) und mit der sozialen physikalischen Umwelt (der >äußeren Realitäts) « (Hurrelmann 2002a: 15) abgezielt. Dabei gehören zur »inneren Realität« bestimmte Einflussgrößen, wie bspw. die genetische Veranlagung, die körperliche Konstitution, die Intelligenz, das psychische Temperament, Grundstrukturen der Persönlichkeit, und zur »äußeren Realität« spezifische Lebenskontexte, wie z.B. Familie, Freundesgruppen, Erziehungs- und Bildungseinrichtungen, Arbeitsstätten, Massenmedien, Wohnbedingungen sowie die physikalische Umwelt.

Das folgende Schaubild (Abb. 1) verdeutlicht diesen Zusammenhang folgendermaßen:

zwar eine ganze Reihe von Kompetenzen erworben werden müssen, diese Kompetenzen aber nicht weiter begründet werden. Trotz der Betonung der Eigenaktivität des Subjekts bedeute dies nach Hurrelmanns Konzept die Hinnahme gegebener gesellschaftlicher Strukturen (vgl. Beer/Bittlingmayer 2008: 64). Hurrelmann selbst gibt keine ausgewiesene normative Perspektive an. Es fehlen auch normative Maßstäbe, an denen sich die Subjekte/Individuen ihre eigene Realität erarbeiten. Im Rahmen der religiösen Sozialisation nimmt der normative Bezugshorizont einen wichtigen Stellenwert ein. Die im weiteren Verlauf ausformulierten Folgerungen offenbaren eine eigene diesbezügliche Wahrnehmung, die wiederum mit den Grundannahmen zur Sozialisation, mit dem Sozialisationskonzept Hurrelmanns und mit der Definition zur religiösen Sozialisation in Verbindung gebracht werden kann. Mit dieser Vorgehensweise ging es primär darum, den Forschungsgegenstand in einem überschaubaren Rahmen zu präsentieren. 


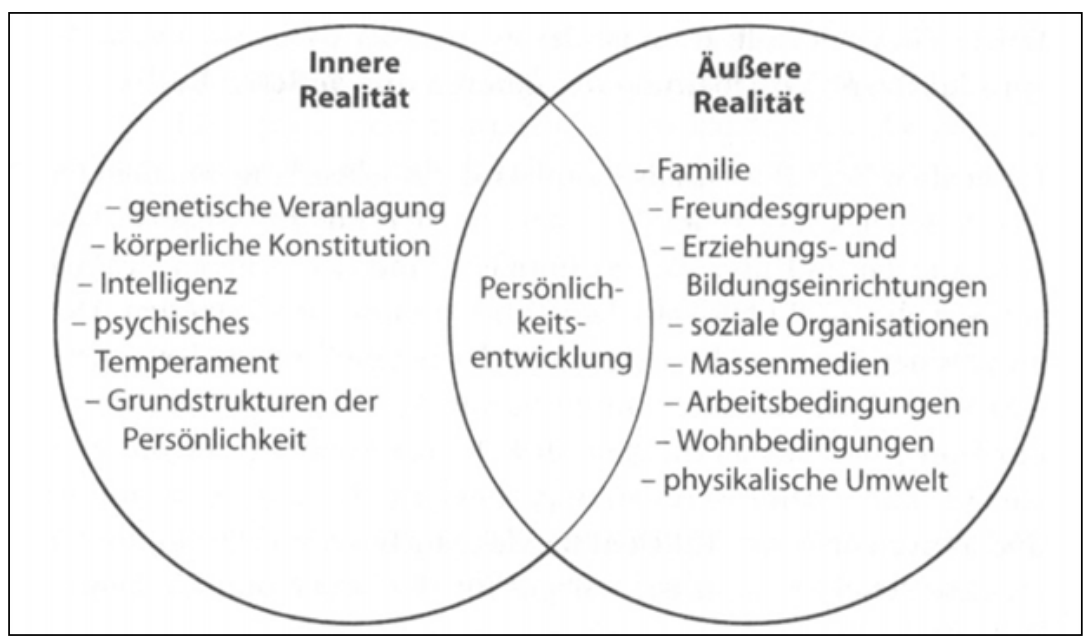

Abbildung 2: Das Verhältnis von innerer und äußerer Realität (Quelle: Hurrelmann 2002a: 27)

Das Verhältnis von »innerer« und »äußerer« Realität wird im Laufe der Persönlichkeitsentwicklung ständig neu reguliert, es entsteht ein lebenslang anhaltender dynamischer Prozess der Verarbeitung der inneren und äußeren Realität. Dieser Prozess wird als »produktiv« im Sinne von »prozesshaft« bezeichnet und ist jeweils abhängig von der individuell spezifischen Verarbeitung/der kreativen Anpassung des Individuums an die Realität (vgl. Hurrelman 2002a: 26 und 2002b: 504f.). Sozialisation wird hier demnach als ein interaktiver Prozess verstanden, bei dem die Persönlichkeitsentwicklung in der Auseinandersetzung zwischen Mensch und Umwelt stattfindet. Die Vermittlung der inneren Realität im Vergleich zur äußeren Realität geschieht durch Interaktion und Kommunikation. Die inneren und die äußeren Realitäten sind immer durch die eigene subjektive Wahrnehmung beeinflusst. Daher kann jede Vorstellung der inneren und äußeren Realität nur eine individuell eingefärbte sein (vgl. Hurrelmann 2012: 55).

Dies bedeutet schließlich, dass Sozialisation ein Prozess ist, »durch den in wechselseitiger Interdependenz zwischen der biopsychischen Grundstruktur individueller Akteure und ihrer sozialen und physischen Umwelt relativ dauerhafte Wahrnehmungs-, Bewertungs- und Handlungsdispositionen auf persönlicher ebenso wie auf kollektiver Ebene ${ }^{65}$ entstehen « (Grundmann/Hurrelmann/Walper 2008: 24).

65 | Auf kollektiver Ebene bezieht sich hier auf die "soziale Identität" (vgl. Hurrelmann 2012: 61ff.) bzw. auf den "Sozialcharakter" (vgl. Tillmann 2010: 17). 
Die Sozialisationsinstanzen sind für eine gelingende Persönlichkeitsentwicklung von zentraler Bedeutung. Diese hängt wiederum von adäquaten körperlichen, psychischen und äußeren Lebensbedingungen ab. Dabei funktionieren Familien, Gleichaltrigengruppen (Peergroups), Erziehungs- und Bildungseinrichtungen, wie bspw. Kindertagesstätten, Schulen und sozialpädagogische Institutionen, sowie Hochschulen als Vermittler und Erschließer der äußeren Realität. Sie werden auch als Sozialisationsinstanzen ${ }^{66}$ bezeichnet. Weitere soziale Systeme, die nicht zum Zweck von Erziehung und Ausbildung etabliert wurden, sind, neben dem beruflichen Erwerbssektor, die Partnerschaft, der Freundes- und Bekanntenkreis, der Konsumsektor, die Freizeiteinrichtungen, die Medien, die Institutionen der Politik, die religiösen Einrichtungen und die sozialökologische Lebenswelt (vgl. Hurrelmann 2012: 66).

Die Rolle der Sozialisationsinstanzen besteht darin, Wahrnehmungs- und Problemlösungsstrategien für die Verarbeitung der inneren und äußeren Realität zur Verfügung zu stellen, die von ihren Mitgliedern in individuell modifizierter Weise übernommen werden. Sie beziehen sich in erster Linie auf Kinder und Jugendliche, um die Grundstrukturen der Persönlichkeitsentwicklung zu stabilisieren.

Die Familien spielen als wichtigste Vermittler der äußeren Realität eine wesentliche Rolle im Sozialisationsprozess. Sie werden auch »als primäreSozialisationsinstanz bezeichnet, da sie gezielt auf die Art und Weise der Aneignung und Verarbeitung der Realität einwirken, vor allem über die Einflüsse der Eltern auf die Persönlichkeitsentwicklung der Kinder« (Hurrelmann 2012: 66). Als dem »zentralen Koordinationsort«, der vor allem in den ersten Lebensjahren eines Menschen einen prägenden Einfluss ausübt, spiegeln sich, wie in einem Mikrokosmos, in der Familie von frühester Kindheit an kulturelle, ökonomische und normative Lebensbedingungen wider, die im wechselseitigen Umgang von Eltern und Kindern aufgenommen und verarbeitet werden. Die soziale Lebenslage von Vätern und Müttern und insbesondere ihr Bildungsgrad entscheiden dabei über die Vielfalt und Angemessenheit der Entwicklungsimpulse und der Erziehungsstile, mit denen Eltern auf ihre Kinder Einfluss ausüben (vgl. Hurrelmann 2002a: 31; Hurrelmann 2012: 66).

66 | Oftmals werden im allgemeinen Sprachgebrauch für diesen Begriff auch Termini wie "Sozialisationsfeld ", "Sozialisationsbereich", "Lebensbereich" u.ä. verwendet. Dabei spielt der bevorzugte theoretische Ansatz aus den Sozialisationstheorien eine Rolle. Nach dem sozialökologischen Ansatz von Bronfenbrenner findet hierfür der Begriff "Kontext" bzw. "System" Verwendung. Aber auch der Begriff "Sozialisationsumwelt" (vgl. Dippelhofer-Stiem 2008) wird in Bezug auf Bronfenbrenner angewandt. 


\subsubsection{Religiöse Sozialisation in der Familie}

Die Bedeutung der Familie im Sozialisationsprozess wurde bereits oben erwähnt. Im religiösen Sozialisationsprozess spielt die Familie als primäre Sozialisationsinstanz bei der Weitergabe von Normen und Werthaltungen die wichtigste Rolle. Die religiöse Erziehung gilt als ein wesentlicher Bestandteil der religiösen Sozialisation und soll im Anschluss an dieses Kapitel (vgl. Kap. 3.1.3 c) näher ausgeführt werden.

Auch die empirische Forschung liefert Ergebnisse, wie sich die Erziehungswirklichkeit in muslimischen Familien darstellt und welche Aspekte der religiösen Sozialisation in muslimischen Familien von Bedeutung sind (vgl. Kap. II. 2.1 und Kap. II. 2.2). Methodisch wurde hierbei die Perspektive der Jugendlichen berücksichtigt, um deren Wirklichkeit darzustellen, während die Sicht der Eltern bislang in der Regel vernachlässigt wurde.

Im Hinblick auf die Sozialisation bzgl. der muslimischen Religiosität kann im deutschsprachigen Raum ${ }^{67}$ nicht auf theoretische Ansätze zurückgegriffen werden. Nun erscheint es interessant, welche allgemeinen Fragen die religiöse Sozialisation in Familien aufwirft. Diese Thematik soll zunächst im Vordergrund stehen, ohne dabei die normative Dimension zu berücksichtigen.

Unter der Voraussetzung, dass Sozialisation die Wechselbeziehungen zwischen Individuum und Gesellschaft ausmacht, nimmt das Kind von Geburt an aktiv am Lebensmodell, an der Lebenswelt seiner Bezugsgruppe durch ständige Interaktionen, wechselseitige Rollenerwartungen, Nachahmung, Identifikation und Verstärkung teil. Die Sozialisationsforschung gibt mit unterschiedlichen Erklärungsmodellen Antworten auf diese Einzelaspekte (vgl. Fraas 1990: 73). In allen Fällen wird der familiäre Einfluss auf den persönlichen Glauben bzw. die religiöse Orientierung hervorgehoben.

Die Theorien zur religiösen Sozialisation führen dementsprechend auch die Religiosität auf soziale Lernprozesse zurück. Bzgl. der Frage nach der religiösen Sozialisation besteht der Ansatzpunkt darin, dass das Kind in die Lebenswelt seiner Bezugspersonen hineinwächst und im Wechselprozess mit dieser seine eigene Lebensgeschichte entwirft. Religiöse Sozialisation könne demnach als »Übernahme der in einer bestimmten Gruppe geltenden Vorstellungs- und Lebensformen« (Fraas 1990: 74) interpretiert werden. Die Weltorientierung wird durch die Haltung der Bezugspersonen an das Kind herangetragen. Es ist der Lebensglaube der Eltern bzw. Bezugspersonen, »die Weltdeutung oder die Quintessenz der elterlichen Lebensgeschichte, die die Weichen für die neue Lebensdeutung stellt« (Fraas 1990: 164). Dies bedeutet,

67 | Ansätze und Konzepte zur religiösen Erziehung unter Bezug auf normative Grundannahmen aus Quellen des Islams sind in der Regel vonseiten türkischsprachiger Autoren verfasst worden. Im deutschsprachigen Raum beschränken sich diese Ansätze auf den schulischen Kontext, d.h. auf den islamischen Religionsunterricht. 
dass über die soziale bzw. gesellschaftliche Vermittlung immer auch bestimmte Wert- und Sinnkonzepte den Rahmen des kindlichen Lebenswegs abstecken (vgl. Fraas 1990: 164). Religiöse Sozialisation könne demzufolge auch unter dem »Aspekt des Aufbaus von Werthaltungen « gesehen werden (vgl. Fraas 1987: 114), die als Rollenerwartungen vermittelt und durch Sanktionen gesichert würden.

Die Frühphase ist für den Erwerb handlungsrelevanter Grundstrukturen von erheblicher Bedeutung. Dabei ist die Familie der Ort, an dem diese Grundstrukturen aufgebaut werden. Kulturelle Werte werden innerhalb der Familie im Kindesalter internalisiert und mit der Bildung eines Gewissens übernommen. Diese verinnerlichten Grundwerte sind für spätere Verhaltensorientierungen als Dispositionen von entscheidender Bedeutung. Laut Vaskovics (1967) gehören zu diesen kulturellen Werten auch religiöse Werte, die a) durch einen dominierenden Geltungsanspruch ausgezeichnet sind, b) einen moralischen Charakter haben, c) in Verhaltensmustern definiert sein müssen, die wiederum häufig wiederkehrende Handlungen verlangen, und d) von sozialer Bedeutung sein müssen (vgl. Vaskovics in: Boos-Nünning/Golomb 1974: 66).

Als entscheidend ist die Sozialisation religiöser Orientierungen in der $\mathrm{Fa}$ milie anzusehen. Die Eltern vermitteln im Zuge des Sozialisationsprozesses religiöse Werthaltungen und Normen und daraus abgeleitete ethische Verhaltensmaximen als Sozialisationsinhalte an ihre Kinder. Die Familie ist der wichtigste Ort der Religionsausübung. Die religiöse Praxis im Elternhaus bestimmt die religiöse Haltung bzw. die spätere Religiosität im Erwachsenenalter (vgl. auch Kap. II. 2.1). Von zentraler Bedeutung sei dabei auch die Atmosphäre, die in der Familie vorherrsche (vgl. Boos-Nünning/Golomb 1974: 78). Religiöse Bezüge des familiären Alltags würden wiederum einen wichtigen Einfluss auf die kindlichen Lernerfahrungen ausüben:

"Noch vor der ausdrücklichen Artikulation entwickelt das Kind ein Lebensgefühl, das durch die Qualität der familiären Beziehung, deren Symbole und Gewohnheiten und durch die inhärenten religiösen Normen und Motive bestimmt wird" (0tt 1986: 64).

Demzufolge ist die Weitergabe von religiösen Werthaltungen auch durch die in der Familie gemachten religiösen Erfahrungen bestimmt. Im Zusammenspiel mit anderen Sozialisationsinstanzen wie Moscheegemeinden u.ä. werden die anfänglich gemachten Lernerfahrungen gestärkt (vgl. hierzu auch Kap. II. 2.2.1).

\section{a) Sozialisation und Erziehung}

In diesem Zusammenhang kommt der religiösen Erziehung als einer intentionalen Weitergabe von Werthaltungen eine besondere Bedeutung zu. Die Sozialisation eines Menschen, geplant oder unbeabsichtigt, vollzieht sich unabhängig 
davon, welche Dimensionen der Persönlichkeitsentwicklung (religiöse Erfahrungsmuster, Handlungsmuster, Einstellungen, Werthaltungen) beeinflusst werden. Die (religiöse) Erziehung hingegen führt beabsichtigte Handlungen aus und hat somit einen gezielten und bewussten Einfluss auf den Bildungsprozess eines Menschen. Ebenso wie die »Bildung« sei die »Erziehung« ein Unterbegriff der Sozialisation (vgl. Hurrelmann 2002a: 17 und 2002b: 502). Émile Durkheim (1858-1917) verwendete das Wort »Sozialisation« in einem sozialpädagogischen Sinn. Von ihm wurde Erziehung als socialisation méthodique, d.h. als »planmäßige Sozialisation« der heranwachsenden Generation bezeichnet. Die Unterscheidung der beiden Begriffe nimmt auch Friedhelm Neidhardt vor und differenziert diese folgendermaßen: Der Sozialisationsbegriff beziehe sich auf alle faktischen Bedingungen des Hereinwachsens in die Gesellschaft, wohingegen die Erziehung ein normatives Konzept darstelle, bei dem bestimmte Ideale pädagogischer Vorstellungen umgesetzt, gelenkt und kontrolliert würden. Erziehung spiele sich immer zwischen einem Erzieher und einem Zögling ab (vgl. Neidhardt in: Drinck 2008: 73).

Demnach ist das, was unter Sozialisation verstanden wird, breiter angelegt. Die Erziehung stellt somit lediglich einen Ausschnitt bzw. einen Bestandteil des gesamten Sozialisationsprozesses dar und verläuft intentional und zielgerichtet. Die präzise Abgrenzung beider Begriffe ist nicht immer gegeben bzw. gelingt häufig nicht. Die Sozialisation beinhaltet im Gegensatz zur zielgerichteten Erziehung jedoch auch die nichtintendierten Einflüsse im Prozess der menschlichen Entwicklung.

Die religiöse Erziehung ist damit ein wesentlicher Bestandteil des religiösen Sozialisationsprozesses, der auch eine Dimension des allgemeinen Sozialisationsprozesses darstellt. Es soll im Folgenden zunächst erklärt werden, was unter Erziehung allgemein verstanden wird, um im Anschluss daran auf die religiöse Erziehung überzugehen. Hier wird für deren Beschreibung ein erziehungswissenschaftlicher Zugang gewählt, mithilfe dessen der allgemeine Erziehungsbegriff, die Religion, bzw. die Religiosität als ein individueller Ausdruck der angeeigneten Religion miteinander in Beziehung gesetzt werden sollen.

\section{b) Was ist Erziehung? Eine Annäherung an die Begriffsbestimmung}

Nachfolgend wird die Definition von Erziehung nach ihrer allgemeinen Struktur und ihrem Begriff bestimmt.

Erziehung ist aus erziehungswissenschaftlicher Sicht ein Grundbegriff, der auf die Veränderung des menschlichen Individuums bezogen ist und der als ein Prozess bezeichnet wird, der lebensweltlich (z.B. durch die Eltern) oder beruflich (bspw. durch Pädagogen) gesteuert wird (vgl. Miller-Kipp/Oelkers 2007: 204). Es existiert keine einheitliche und allseits anerkannte Theorie der Erziehung, wohingegen unterschiedliche Akzentuierungen in der Be- 
stimmung von Erziehung vorhanden sind. Dabei würden der im Erziehungsgeschehen hervorgehobene Aspekt und der perspektivische Zugang eine bedeutende Rolle spielen (vgl. Mette 1986: 54; Miller-Kipp/Oelkers 2007: 205).

Die begriffliche Definition lässt sich folgendermaßen ableiten:

"Erziehung [...] meint zentral diejenigen Akte, die sich auf das heranwachsende Individuum richten und dessen Entwicklung fördern wollen. Träger und Subjekte dieser Akte, deren Dauer und Ort, Mittel und Ziele samt ihrer Legitimation sowie die gesellschaftliche Funktion von Erziehung nicht festliegen, unterliegen vielmehr historischem Wandel. [...] Streng genommen lässt sich Erziehung nicht definieren, Praktiker und Theoretiker der Erziehung legen sich je nach eigener Sicht auf einen Erziehungsbegriff fest. Die Erziehungstatsache selbst kann beschrieben, verstanden, geplant, organisiert oder konstruiert werden. Der Komplexität der Erziehungstatsache entspricht der Umfang des Erziehungsbegriffs. Sie verbürgt zudem auch dessen interdisziplinäre Funktion: mit dem Erziehungsbegriff knüpft Erziehungswissenschaft an Soziologie, Psychologie und Anthropologie und deren Thematisierung von Aufwachsen in einer Gesellschaft." (Miller-Kipp/Oelkers 2007: 204)

Mittels einer interdisziplinären Herangehensweise kann Erziehung (oder Bildung) im Verhältnis zur Religion betrachtet werden. Schweitzer (2003) erläutert, welche systematischen und theoretischen Zusammenhänge zwischen Religion und Erziehung hergestellt werden können (vgl. Schweitzer 2003: 103-133). Er stellt fest, dass bei einer religiösen Erziehung die Religion ${ }^{68}$ der ausdrückliche Inhalt und das Ziel ist, so wie dies am deutlichsten bei der direkten religiösen Unterweisung der Fall sei. In jeder Form von Erziehung spielen Normen und Werthaltungen eine wichtige Rolle. So kann gefragt werden, in welchem Verhältnis diese Normen und Werthaltungen zu religiösen Begründungen stehen (vgl. ebd.: 108).

Eine weitere umfassende Definition von Erziehung beschreibt Erziehung als Handeln, bei dem von Erziehern im Rahmen gewisser Lebensvorstellungen (Normen und Werthaltungen) und unter konkreten Umständen (Erziehungsbedingungen) sowie mit bestimmten Aufgaben (Erziehungsinhalten) und Maßnahmen (Methoden) in der Absicht einer erzieherischen Einflussnahme den zu Erziehenden zur Lebensführung verholfen wird (vgl. Bokelmann in: Mette 1986: 54). Zudem würden die Einstellung des Erziehers zu den Heranwachsenden/Edukanden, die von ihm bevorzugten Mittel sowie die von ihm beanspruchte Autorität seine Erziehung ausmachen (vgl. Miller-Kipp/Oelkers 2007: 205). Diese können somit auch als Maßnahmen und Methoden im obigen Sinne verstanden werden.

68 | Hierbei ist es wichtig, welches Religionsverständnis gewählt wird. 
Auf die normative Dimension der Erziehung bezogen, stellt sich die Frage nach den Erziehungszielen. Diese stellen normative Vorgriffe dar, die einer Begründung bedürfen. In der vorliegenden Untersuchung sollen diese im weiteren Verlauf durch eine Befragung der Eltern empirisch-deskriptiv erfasst werden:

"Erziehungsziele werden im Blick auf den Zögling oder im Blick auf Kultur und Gesellschaft vorgetragen. Personal gesehen, zielt Erziehung auf den Zögling insgesamt oder auf Entwicklungsbereiche der Person, etwa Motivation oder Emotion oder Kognition. Erziehungsziele bezeichnen Tugenden, soziale Einstellungen, moralisches Verhalten oder körperliche oder geistige Fähigkeiten. Systembezogen handelt es sich um die Übertragung oder Erhaltung von Normen und Werten, kollektiven Einstellungen, Tüchtigkeiten usw. Ein eigenes Problem ist die Realisierung oder Durchsetzung von Erziehungszielen." (Miller-Kipp/Oelkers 2007: 205f.)

Auch die Definition von Erziehungsmitteln ist wichtig. Als Erziehungsmittel (Maßnahmen, Methoden, Erziehungsformen) gelten neben personalen Handlungen alle Formen und Medien des intentionalen Einwirkens auf den Zögling, also Worte und Taten, Mienen und Gesten (verbale und nonverbale Handlungen), Rituale und arrangierte Situationen mit Aufgabencharakter (vgl. Miller-Kipp/Oelkers 2007: 206).

Nach Neidhardt lassen sich drei Formen von Erziehungsmitteln (Methoden), wie Werthaltungen und Verhaltensmuster, die von Eltern an ihre Kinder übertragen werden, unterscheiden: (1) Erstens, indem Eltern eine bestimmte Normfunktion durch direkte bzw. unmittelbare Erziehung ausüben. In Abhängigkeit von manifesten Erziehungsleitbildern wenden sie sich mit spezifischen Techniken der Belohnung und Bestrafung ihren Kindern zu und geben gewünschtes und unerwünschtes Verhalten vor. (2) Zweitens können Eltern durch Vorbildcharakter ohne spezifisch pädagogische Absichten auf ihre Kinder einwirken. Auf von den Eltern oft unterschätzte Weise nehmen Kinder an deren Existenz teil. Sie erfahren Vorlieben und Abneigungen, Affekte, Form und Ausmaß ihrer Rationalität, ihrer Sehnsüchte und Widersprüche. Schließlich übernehmen sie wesentliche Teile des elterlichen Verhaltens durch Imitation oder durch einen tiefergehenden Vorgang der Identifikation. Drittens (3) können sich weitere - vielmehr indirekte - Erziehungseinflüsse dadurch ergeben, dass Eltern ihre Kinder in außerfamiliäre Sozialisationsträger vermitteln. Mittels der Platzierungsfunktion der Familie werden die Kinder in bestimmte Nachbarschaften und Freundeskreise gebracht und Kindergärten, Schulen, religiösen Einrichtungen und Vereinen anvertraut (vgl. Neidhardt 1968: 181 in: Boos-Nünning/Golomb 1974: 78f.). Der erzieherische Einfluss durch Anwendung dieser Sozialisationstechniken weise auch auf die zentrale Bedeutung der Familie bei der Übertragung von religiösen Werthaltungen hin, denn El- 
tern könnten gebieten und verbieten, sie können als Beispiel vorangehen oder dafür sorgen, dass ihre Kinder religiöse Bildungseinrichtungen besuchen (vgl. Boos-Nünning/Golomb 1974: 79f.).

Ein weiterer Aspekt, der bezogen auf Erziehung untersuchbar ist und als Fragestellung in dieser Untersuchung behandelt wird, betrifft die Charakterisierung des Eltern-Kind-Verhältnisses, das der Erziehungsstilforschung zugeordnet wird. Die Erziehungsstile von Migrationseltern sind schon seit Beginn der Migrationsforschung ein wichtiger Untersuchungsgegenstand der Erziehungsstilforschung (vgl. Alamdar-Niemann 1992; Merkens/Schmidt 1997; vgl. Nauck: verschiedene Jahrgänge; Uslucan 2008, 2009a und 2009b; Boos-Nünning 2011a u.a.).

Mit dem Begriff Erziehungsstil wird die »Charakterisierung von interindividuell verschiedenen, aber individuell stabilen Verhaltensweisen (Erziehungspraktiken), Erziehungszielen und -einstellungen von Erziehern (Eltern, Lehrern), von denen angenommen wird, dass sie einen unterschiedlichen Einfluss auf die Persönlichkeit und Leistung der zu Erziehenden haben« (Tenorth/Tippelt 2007: 213), vorgenommen. Es sind Modelle vorhanden, die die Erziehungsstile in übergeordneten Dimensionen (bspw. aus lerntheoretischer Sicht in Strenge und Unterstützung) zu erfassen versuchen (vgl. z.B. Schneewind 1980; Schneewind 2010, 175-193 für die Erziehungsstilforschung).

\section{c) Was ist religiöse Erziehung?}

Die Auseinandersetzung mit dem Erziehungsbegriff hat gezeigt, dass diese im Zuge ihrer historischen Entwicklung gemäß den epochalen gesellschaftlichen Rahmenbedingungen unterschiedliche Konzepte und Inhalte voraussetzt. Erziehungs- und Bildungskonzepte sind stark normativ bestimmt und bedürfen einer Begründung. Dies gilt vornehmlich für den Bereich der religiösen Erziehung.

Festzuhalten gilt, dass die religiöse Erziehung ein Bestandteil der allgemeinen Erziehung überhaupt ist (vgl. Stachel 1976: 85). Mit religiöser Erziehung soll der Schritt zum Glauben in einer für die Heranwachsenden nachvollziehbaren Weise vermittelt werden. Religiöse Einstellungen werden durch Lebensformen affektiv weitergegeben (vgl. oben Kap. II. 3.1.3, vgl. Ay 2001b: 126; vgl. Dodurgal1 1998: 134-141; vgl. Sauter 2006: 462). Dabei wird die religiöse Erziehung der Prämisse eines ganzheitlichen Menschenverständnisses untergeordnet, in der die folgenden drei Komponenten des Menschseins berücksichtigt werden $^{69}$ : Erfahrungen (Affekte, Emotionen), Einstellungen (übertragen durch Wissensvermittlung) und religiöse Handlungen (Verhaltensmuster, religiöses Leben) (vgl. Dodurgalı 1998: 134-141; vgl. Çamdibi 2003: 47-76 für eine aus-

69 | Die Einheit von Herz, Hand und Verstand. 
führliche Betrachtungsweise des ganzheitlichen Menschenverständnisses und der religiösen Erziehung im Islam).

Wenn Erziehung allgemein als normatives Konzept beschrieben wird, innerhalb dessen bestimmte Erziehungsziele und -ideale bzw. Erziehungsvorstellungen umgesetzt, gelenkt und kontrolliert werden, so gilt das vornehmlich für das, was unter religiöser Erziehung verstanden wird. Im vorliegenden Zusammenhang stellt sich somit die Frage, auf welche Weise die religiöse Erziehung empirisch erfassbar ist. Dies erfordert eine Vorgehensweise und ein Verständnis von religiöser Erziehung, die eine Offenheit für subjektive Deutungsmuster zulässt. Daher ist es von entscheidender Bedeutung, wie die eigene Religion verstanden, gedeutet und gelebt wird, um Aussagen über religiöse Erziehungsvorstellungen treffen zu können.

Wie oben bereits beschrieben wurde, wird in der religiösen Erziehung Religion, je nachdem, wie sie verstanden und gelebt wird, als Ziel und Inhalt aufgefasst (vgl. Schweitzer 2003). Die Religion kann sich individuell gedeutet bzw. angeeignet in Form von Religiosität ausdrücken. Sie kann als ein normatives Deutungssystem bzw. religiöses Symbolsystem verstanden werden, zu demder Mensch jeweils ein individuelles Verhältnis entwickelt. Traditionelle religiöse Bildung orientiert sich am Katechismus, am Ilmihal (= islamischer Begriff für den Katechismus) oder ähnlichen Sammelwerken. Diese gehen davon aus, dass sich Religiosität unmittelbar aus den Inhalten der Religion ergibt: Der Katechismus gebe die entsprechenden Glaubensinhalte, Verhaltensmodelle usw. vor und die Religiosität des Einzelnen werde daran gemessen, ob und wie intensiv er sich an diese halte ${ }^{70}$ (vgl. Bochinger 2010: 110f.).

In dieser Untersuchung wird die Religiosität als ein Erziehungsziel verstanden. Dieser Überlegung zufolge kann religiöse Erziehung als die intentionale Weitergabe von Religiosität verstanden werden. Ziele und Inhalte religiöser Erziehung sind demnach individuell bestimmt, deren Begründung sich letztendlich auf ein religiöses Symbolsystem stützt.

70 | Für Bochinger (2010) ist empirisch gesehen das Verhältnis zwischen religiösen Vorgaben (kodifiziert im Katechismus und in ähnlichen Werken) und individueller Aneignung komplizierter: "Der einzelne Mensch, zumal in modernen Gesellschaften, nutzt die Ressourcen der religiösen Tradition in sehr eigenständiger Weise [...]. Er macht sich, so gut es geht, sein eigenes Bild von der Religion und handelt danach. Religion und Religiosität sind damit nicht einfach identisch. In der Religionswissenschaft hat sich für die objektive Seite der Religion, d.h. die ,Tradition`, Theologie und Geschichte inkl. dessen, was im Katechismus darüber zu lesen ist, die Bezeichnung religiöses Symbolsystem، eingebürgert [...]. Für die subjektive Seite, die Aneignung dieser Bestände in der eigenen Lebenswelt, steht das Wort ,Religiositätı. Religion ist in diesem Verständnis der Oberbegriff, der beides miteinander verbindet [...]" (Bochinger 2010: 111). 
Um Kenntnis darüber zu erlangen, wie religiöse Erziehung im Islam verstanden wird, sollen hierzu einige normative Grundüberlegungen erfolgen. Die für diesen Zweck herangezogenen Quellen beziehen sich zum Teil auf Gelehrte in der Türkei, die in theologischen Fakultäten im Fachbereich Religionspädagogik tätig sind.

\section{d) Exkurs: normative Grundüberlegungen zur religiösen Erziehung im Islam}

Die Auseinandersetzung mit dem Thema der religiösen Erziehung im Islam ergab, dass eine Vielzahl an Vorstellungen zur religiösen Erziehung sowohl in ihrer normativen Grundlegung als auch hinsichtlich ihrer methodischen Ausgestaltung vorhanden ist. Diese Vorstellungen sollen hier in aller Kürze beispielhaft angeführt werden.

In Anlehnung an die Hauptquellen des Islams, den Koran und die Sunna ${ }^{71}$, in denen sich Verweise auf das Leben des Propheten Muhammad (s) ${ }^{72}$ finden lassen, werden durch muslimische Autoren Bezüge zur Erziehung und Bildung des Menschen hergestellt. In den meisten Fällen sind diese konzeptionell ausgerichtet, sodass nicht von allgemein anerkannten Theorien im Hinblick auf die muslimische Religionspädagogik ${ }^{73}$ ausgegangen werden kann. Ausgehend vom Menschenbild bzw. der Anthropologie im Koran, werden Bildungsund Erziehungsziele ausgearbeitet, aus denen Erziehungsprinzipien bzw. Leitvorstellungen hinsichtlich einer religiösen Erziehung geschlossen werden. Die Auseinandersetzung mit den Konzepten der islamisch-religiösen Erziehung ergab ein vielfältiges und pluralistisches Bild. Diese Konzepte weisen in ihren zentralen Aussagen sowohl Gemeinsamkeiten als auch Unterschiede auf. ${ }^{74}$

Mit diesem Anliegen mögliche Konzeptionen islamisch-religiöser Erziehung zu ergründen, wurde von der Verfasserin dieser Arbeit eine Erhebung durchgeführt (vgl. Uygun-Altunbas 2010). Als Ergebnis konnte hinsichtlich

71 | Die Tradition des Propheten Muhammad (s) in Worten und Taten. Diese werden als Überlieferungen in Form von Hadithen nachgewiesen.

72 I Im Türkischen wird vorwiegend Muhammed (s) verwendet. Das nach Muhammad angefügte (s) bildet die Abkürzung von "salla-llahu'alaihi wa sallam" (arab. für "Allahs Gnade und Friede seien mit inm ") (vgl. Zaidan 1999: 265). Der Segenswunsch wird ausschließlich für den Propheten selbst verwendet.

73 | Diese steht in Deutschland noch ganz am Anfang, steckt quasi noch in den Kinderschuhen.

74 | Diese können in Kürze nicht angemessen abgebildet werden, sodass vorwiegend diejenigen Aspekte der religiösen Erziehung aufgeführt sind, über die ein breiter Konsens unter den sunnitischen Gelehrten herrscht und die für die Untersuchung relevant erschienen. Die zunächst vorgestellten Bildungs- und Erziehungsziele für die religiöse Unterweisung entstammen der eigenen Abschlussarbeit zum Thema: Konzepte islamischer Religonspädagogik anhand von Experteninterviews aus dem Jahre 2010. 
der Erziehungsziele im Islam festgestellt werden, dass diese an die Erwartungshaltungen eines Kontextes angepasst werden können. Unter Erziehungszielen versteht man, wie bereits beschrieben, Fertigkeiten, Kompetenzen und Verhaltensmerkmale. Insbesondere unter Berücksichtigung des Lebens in einer nichtmuslimischen Gesellschaft ist es wichtig, dass das Erziehungsziel einer islamischen Erziehung nicht darin besteht, einen besseren Menschen zu kreieren, der religiös und kulturell der ungläubigen Gesellschaft überlegen ist. Religion soll Sinn stiften und Positives bewirken, nicht nur für ihre Anhängerinnen und Anhänger, sondern für alle Menschen und diverse weitere Bereiche: Theologie, Pädagogik, Bildungs- und Erziehungsziele seien dieser Prämisse unterworfen (vgl. Behr in: Uygun-Altunbas 2010: 69). Im Zusammenhang mit dem Wertediskurs haben Erziehungsziele sehr viel mit dem Verhalten zu tun. Dieses soll Ausdruck für eine bestimmte Werthaltung, die diesem zugrunde liegt, sein. Diese Werthaltungen können auf der Grundlage von islamischen Quellen beschrieben werden. Laut Behr (einem der befragten Experten) werden in diesem Sinne drei Werthaltungen genannt: a) Erziehung zu einer Haltung der Achtsamkeit: Leben und Handeln, im Bewusstsein, dass Gott Mitwisser ist; b) Vertrauen (arab. tawakkul) in Gott und der Glaube daran, dass man etwas erreichen kann; c) Nachsichtigkeit im Sinne von Milde und Güte (arab. rahma), d.h. gnädig zu sein im Umgang miteinander (vgl. ebd.: 69).

Die Erziehungs- und Bildungsziele im Islam sind nach Polat (einem weiteren Experten) durch a) Monotheismus, b) Jenseits- und Diesseitsbezogenheit und c) eine soziale und ethische Orientierung der Religion bestimmt. Als soziales Erziehungsziel in der pluralen Gesellschaft ist die Mitgestaltung eines friedlichen Miteinanders, des Zusammenlebens von religiös, sozial und politisch unterschiedlichen Menschen zu benennen (vgl. Polat in: Uygun-Altunbas 2010: 69f.). Anders als im zuvor genannten Konzept, ist die Erziehung zum Islam hier dadurch geprägt, dass der Mensch als Statthalter Gottes auf der Erde (arab. khalifat-ul amana) gegenüber sich und den anderen Geschöpfen Gottes Verantwortung trägt. Wichtig ist dabei die Ehrfurcht vor Gott (arab. taq$w a$ ), was bedeutet, das höchste religiöse und ethische Verantwortungsbewusstsein zu erlangen. Der Mensch soll durch Erziehung und Bildung schließlich dazu befähigt werden, sich zu einer menschenmöglichen Vollkommenheit zu entwickeln (arab. al-insan al kamil). Dazu sollen ihm zuerst das Bewusstsein, die Kompetenzen und die Instrumentarien verliehen werden. Dieses Werden beginne in der »Wiege« und dauere bis zum »Grab« an (vgl. ebd.: 70).

Auch die Befähigung zum Umgang mit islamischen Quellen wird unter den Experten als wichtiges Erziehungsziel benannt (vgl. Uygun-Altunbas 2010: 79). Erziehung und Bildung werden im Islam als zentrale Anliegen betrachtet, was eine lebenslange Auseinandersetzung mit der Botschaft des Korans beinhaltet. Die enge Interdependenz zwischen Wissenserwerb und der Stärkung des Glaubens wird hierbei besonders betont: Dies zeigt sich schon 
durch die Ableitung des arabischen Wortes »Koran « vom Imperativ des Verbes »lesen«: Iqra = Lies! (vgl. Sure 96: 1-4, erster Befehl Gottes an den Propheten Muhammad (s)) (vgl. Karakaşoğlu/Öztürk 2007: 158).

Die Aufgabe islamischer Erziehung wird durch andere muslimische Autoren in ähnlicher Weise beantwortet: Die islamische Erziehung zielt zum einen darauf ab, den Glauben zu stärken und die Glaubenspflichten (die religiöse Praxis) einzuhalten, und zum anderen geht es darum, die persönliche moralische Entwicklung zu unterstützen, der Werthaltungen aus dem Koran und der Sunna zugrundeliegen. Der Mensch soll in seiner Persönlichkeitsentwicklung unterstützt werden, indem in diesem Sinne seine Potenziale erweckt werden, welche ihn wiederum dazu befähigen, das Verhältnis zu seinem Schöpfer zu verstehen. Die religiöse Erziehung beschäftigt sich demnach mit dem Verhältnis des Menschen zu Gott und davon ausgehend mit dem Verhältnis der Menschen zueinander (vgl. Bayrakl1 2002: 306).

Die Glaubensvermittlung im Islam basiert auf dem Monotheismus (arab. tauhid) und dem Jenseitsbezug. Neben der Vorstellung, dass Gott (Allah), der Einzige, als die letztgültige transzendente Wahrheit eine wesentliche Voraussetzung für die Ausgestaltung erzieherischer Prinzipien, auf die sich die islamische Erziehung stützen muss, darstellt, wird mit dem Jenseitsbezug auf die Verpflichtung des Menschen abgezielt, über seine Handlungen und Taten im diesseitigen Leben im Jenseits Rechenschaft abzulegen. Die essenzielle Aufgabe einer islamischen Erziehung besteht darin, diese Glaubensinhalte, vor allem aber die Beziehung des Kindes zu Gott, seinem alleinigen Schöpfer, seinem Entwicklungsstand entsprechend zu vermitteln (vgl. Bayrakl1 2002; Bilgin 2001; Behr 1998; Dodurgalı 1998; Karakaşoğlu/Öztürk 2007).

Da sich die Persönlichkeit des Kindes primär innerhalb des familiären Rahmens herausbildet, haben Eltern die besondere Aufgabe bzw. religiöse Pflicht gegenüber Gott, ihre Kinder zum Glauben zu erziehen (vgl. Ay 2001b: 125135). Den Eltern wird das Kind durch Gott anvertraut, worüber sie im Jenseits Rechenschaft ablegen müssen. Nach islamischer Auffassung ist der Mensch von Grund auf mit reiner Seele geboren, gleich einem unbeschriebenen Blatt, jedoch mit positiven und negativen Anlagen ausgestattet (vgl. Ay 2001b: 77-82; vgl. Karakaşoğlu/Öztürk 2007: 159; vgl. Sarıkaya 2008: 98). Es ist ein den muslimischen Elternteilen auferlegtes Gebot, die positiven Anlagen ihrer Kinder zu fördern und sie vor den Versuchungen des Bösen zu schützen. Im Koran wird der Mensch aufgefordert, die (Familien-)Angehörigen vor der Hölle zu bewahren (vgl. Koran 66: 675; vgl. Dodurgal1 1998: 128f. für die Deutung dieses

75 | Es sind weitere Koranverse vorhanden, die auf die Verantwortung der Eltern hinweisen. Dieser Vers wurde hier genannt, weil er in den Büchern zur religiösen Erziehung am häufigsten zitiert wird. Für die Übersetzungen der Verse ins Deutsche vgl. z.B. Asad 2009. 
Verses; vgl. auch Bayrakl1 2002: 146 ffৎ.). Es ist also eine religiöse Pflicht, die Grundlagen für die Ausformung der positiven Anlagen zu legen (vgl. Sarıkaya 2008: 98), um auch im Diesseits durch Bezugnahme zu Gott inneren Frieden zu finden und eine Balance zwischen dem eigenen Selbst und der Umwelt zu entwickeln.

Die wichtigsten Erziehungsinhalte, die sich aus den oben dargelegten Gedanken ableiten lassen, sind, dass dem Individuum seine Bestimmung als Muslim, der Sinn und Zweck seines irdischen Daseins vermittelt und erläutert wird. Dem Heranwachsenden soll durch seine Eltern die Verantwortung verdeutlicht werden, die er gegenüber seinem Schöpfer, sich selbst, der Menschheit und der gesamten Umwelt trägt (vgl. Karakaşoğlu/Öztürk 2007: 159). Um dies zu verwirklichen, sollen zumindestens die Glaubensgrundlagen und die Hauptpflichten (die fünf Säulen des Islams) erlernt werden ${ }^{76}$. Um dem sozialen Aspekt der Religion gerecht zu werden, sollten ebenso Normen und Werthaltungen, die die zwischenmenschlichen Beziehungen klären, durch Eltern und weitere relevante Personen vorgelebt und übermittelt werden (vgl. ebd.).

Die religiöse Erziehung in der Familie hängt von vielen Faktoren ab, die sowohl theoretisierend als auch von der praktischen Seite her darstellbar sind.

Eltern haben die Aufgabe, durch religiöse Erfahrungen und Wissensvermittlung die religiösen Einstellungs- und Verhaltensmuster ihrer Kinder zu fördern (vgl. Dodurgal1 1998: 134). Dodurgalı verweist hier darauf, dass beide Aspekte miteinander verwoben sind, sodass ohne religiöse Erfahrungen eine Wissensvermittlung bzw. das gemeinsame Ausleben der Religion nicht möglich sein wird. Diese sollen motivierend mit einer liebevollen und gütigen Haltung gegenüber dem Kind an dieses herangetragen werden (vgl. Dodurgalı 1998: 136; vgl. auch Ay 2001a: 27-35; vgl. Ay 2001b: 77-81; vgl. Bilgiz 2006: 139-144; vgl. Öcal 2001: 59ff.; vgl. Sarıkaya 2008: 107). Barmherzigkeit (arab. rahman und rahim) ist die wichtigste Eigenschaft Gottes/Allahs, welche die Eltern in ihrer Beziehung zu Gott erfahren, bewusst wahrnehmen und die diese als ihre wichtigste erzieherische Grundhaltung gegenüber ihrem Kind einnehmen sollen..$^{77}$ Der Einsatz von Druck, Zwang, Kritik und Strafen ist folglich kontraproduktiv und mit den Grundprinzipien der islamischen Quellen nicht vereinbar.

Neben der allmählichen Ausrichtung auf eine islamisch geprägte Lebensweise stellt der kognitive Bereich, der die Verinnerlichung der Grundlagen

76 | Diese stellen sozusagen die in der Katechese formulierten Grundlagen der Religion dar, über die unter den Muslimen Konsens herrscht (vgl. z.B. Hamidullah 2003; Bilmen 2004).

77 | In diesem Zusammenhang ist zudem von Bedeutung, wie die Beziehung des Kindes zu Gott hergestellt wird und worauf dabei geachtet werden sollte. Ay (2001b) hat sich in seinem Buch ausführlich diesem Thema gewidmet. 
des Islams betrifft, für Eltern eine besondere Herausforderung dar (vgl. auch Kap. II. 2.1). Eltern selbst fehlt häufig die religiöse Bildung, sodass dieses Defizit durch verschiedene Bildungsmöglichkeiten behoben werden soll (vgl. Dodurgal1 1998: 138; vgl. Karaman 2012: 299). Die Aneignung von religiösem Wissen setzt zuvor beim Kind altersgerechte kognitive Anregungen, wie bspw. u.a. das Stellen von Fragen, Erläuterungen, das Erzählen von Geschichten, voraus (vgl. Dodurgal1: 138-142; vgl. Ay 2001a: 14-18; vgl. Bayrakl1 2002: 201-247 für eine detaillierte Beschreibung der kognitiven Methoden der religiösen Erziehung; vgl. Dodurgal1 1998: 197-204; vgl. Öcal 2001: 56-59). Auch die Befolgung der rituellen Praxis, zu diesen Praktiken gehören u.a. das Beten, die rituelle Waschung, Moscheebesuche, das Fasten, das Koranlesen, das Erlernen von Bittgebeten, das Auswendiglernen von Suren, übt das Kind im Alltag mithilfe und durch die Nachahmung der Eltern und weiterer Bezugspersonen wie z.B. der Großeltern ein (vgl. Ay 2001a: 19-23; vgl. Bilgili 2005: 137ff.).

Das gemeinsame Ausleben der Religion entsteht zumeist auf der Basis von Kommunikation und einer gemeinsam durchgeführten rituellen Praxis, die ausschließlich auf der Grundlage einer Affektbildung im Zusammenhang mit religiösen Themen förderlich erscheint, denn schließlich ist die religiöse Atmosphäre im Elternhaus als Erfahrungshintergrund prägend für die spätere Religiosität (vgl. oben, vgl. auch Kap. II. 2.1, vgl. Hökelekli 2003: 257ff.).

Hinsichtlich der Methoden der religiösen Erziehung sind vielfältige Vorstellungen unter Bezugnahme auf islamische Quellen vorgestellt worden. Das Vorleben der Religion im Sinne eines Vorbildes ist die zumeist zitierte Methode, die Eltern zu beachten haben. Aber auch das Reflektieren und die Auseinandersetzung mit sich selbst werden angeregt, um eine Persönlichkeit zu entwickeln, die den Vorstellungen im Koran und der Sunna entspricht (vgl. Ay 2001a: 19-42; Ay 2001b; Bayrakl1 2002: 201-285; Dodurgal1 1998: 57-70). Die Familie bietet den wichtigsten Rahmen für eine islamische Lebensweise. Als Vorbilder sind die Eltern sowohl für die Einhaltung von ethischen Prinzipien als auch für das kontinuierlich altersgemäße Einüben von religiöser Praxis verantwortlich (vgl. Dodurgal1 1998). Das Lernen am Modell ist gerade hinsichtlich des Aufbaus von Werthaltungen und moralischen Tugenden sehr bedeutsam. Diese Methoden soll das Kind von klein auf, dem Alter entsprechend, in sich aufnehmen bzw. internalisieren und praktisch einüben, um diese im religiös mündigen Alter (d.h. ab der Geschlechtsreife) einzuhalten (vgl. Behr 1995 für Grundlagen in der Charakterbildung; vgl. Behr 1998: 71-86).

Hat das Kind die mit der Pubertät einsetzende Geschlechtsreife erlangt, soll es nach islamischem Verständnis die Verantwortung für die Einhaltung der Gebote und Verbote der Religion selbst übernehmen. Es ist dann sozusagen im mündigen Alter und kann somit vor Gott im Jenseits zur Rechenschaft gezogen werden (vgl. Bilmen 2004: 59; Karaman 2012: 328ff.). Im religiösen Alltag spielt im Jugendalter vor allem das Verhältnis zum Gegengeschlecht, 
das bestimmten Regeln unterworfen ist, eine besondere Rolle. Die Geschlechtertrennung, das Tragen eines Kopftuches, die Einhaltung der Keuschheit stellt die Jugendlichen vor besondere Herausforderungen, mit denen sie sich in einer nichtislamischen Umwelt auseinandersetzen müssen (vgl. Kap. II. 2.1; vgl. auch Dodurgal1 1998: 239-268). Die Weiterbildung im Islam ist wichtig, um den tieferen Sinn des bereits Gelernten zu erfassen. Da mit der Pubertät die Entwicklung der Persönlichkeit und somit die Selbstständigkeit und Unabhängigkeit von den Eltern voranschreitet, übernimmt der Jugendliche für sich als Individuum selbst die Verantwortung vor Gott. Ab diesem Zeitpunkt sind Eltern nicht mehr für die religiöse Erziehung ihrer Kinder verantwortlich, sondern stehen diesen als Wegweiser und »Berater« in allen Lebensfragen zur Seite. Sie sollen ihre Kinder begleiten, »indem sie die kritische Beurteilung eigener Verhaltensweisen und Einstellungen sowie die selbständige Urteilskraft ihrer Kinder fördern« (vgl. Karakaşoğlu/Öztürk 2007: 161). Den modernen Erziehungszielen, wie bspw. Mündigkeit, Autonomie, Freiheit oder Konfliktfähigkeit wird nach islamischem Verständnis in der Beziehung zum Schöpfer Rechnung getragen (vgl. Behr 1998: 117-136; vgl. auch Karaman 2012: 327-330).

Wichtig ist auch das Erlernen eines Gemeinschaftssinns im engeren familiären Kreis (vgl. Hökelekli 2003: 257ff.) und in der religiösen Gemeinde (z.B. in der Moschee), um einen Rahmen für die religiöse Lebensweise zu schaffen. Die religiöse Erziehung zielt neben dem Aufbau des Verhältnisses zu Gott auch auf das Verhältnis des Menschen zu seinen Mitmenschen ab. Der Moschee als Lernort kommt dabei eine wichtige Rolle zu (vgl. Bilgin 2001: 22ff.). Gerade das Rezitieren des Korans, das Erlernen der arabischen Buchstaben, das Auswendiglernen von Suren und Bittgebeten, das Singen von religiös geprägten Liedern sowie die Einübung und Befolgung der rituellen Praxis sind wichtige Bestandteile der religiösen Unterweisung, die nicht nur innerhalb der Familie, sondern unterstützend auch in der Moschee erfolgt (vgl. Kap. II. 2.2.1). Die Moschee bietet zum Austausch über die Religion einen wichtigen Erfahrungsraum an, der die Kinder auch dazu befähige, ein Gemeinschaftsgefühl aufzubauen (vgl. Bilgin 2001: 22ff.; vgl. Dodurgal1 1998: 201-206). Der Freundeskreis, der in diesem Rahmen gebildet wird, stellt eine wichtige Voraussetzung für das Erlernen des sozialen Verhaltens und für die Persönlichkeitsbildung dar (vgl. Kap. II. 2.2.3).

In Moscheegemeinden und im familiären Kreis zudem durch gegenseitige Unterstützung und Kommunikation, Spiel- und Freizeitangebote eine wichtige Basis für das religiöse Selbstverständnis gelegt (vgl. Dodurgal1 1998: 200205, vgl. auch Kap. II. 2.2.1).

Nicht zuletzt sind Feste und religiöse Feiertage wichtig, um das Gemeinschaftsgefühl innerhalb der Familie und unter den Muslimen zu stärken. Die Kinder sollen durch Geschenke und Belohnungen dazu motiviert werden, an 
religiösen Fest- und Feiertagen und am religiösen Leben teilzunehmen (vgl. Dodurgal1 1998: 204f.; vgl. Hökelekli 2003: 245f.).

\subsubsection{Die Entstehung von Religiosität im Rahmen der Sozialisation}

Der Zusammenhang zwischen religiöser Sozialisation und der religiösen Erziehung wurde bereits erörtert. Die Entstehung von religiösen Orientierungen ist das Resultat eines religiösen Sozialisationsprozesses, den der Mensch hauptsächlich in seiner Familie erfährt. Es sollte verdeutlicht werden, dass die Entstehung von Religiosität auf unterschiedliche Weise beobachtbar ist und in einem jeweils spezifischen Sinn, gemäß den angewandten theoretischen Grundüberlegungen zur religiösen Sozialisation, zu beschreiben ist.

In dieser Untersuchung soll der mehrdimensionale Religiositätsbegriff nach Glock zur Anwendung kommen, der im Kontext der bislang festgelegten Forschungskategorien der religiösen Sozialisation zu betrachten ist. Hierzu zeigt Fraas (1990), Glocks Ansatz der Vieldimensionalität von Religion in Bezug zur Sozialisation des Menschen setzend, dass die Religiosität des Menschen sich in unterschiedlichen Formen religiösen Lebens ausdrückt:

"Religiöses Leben kann in der Kenntnis und Gegenwärtigkeit religiöser Texte bestehen, in der inneren Verfügbarkeit religiöser Riten, in an bestimmte Situationen gebundenen Gefühlshaltungen, in oder sozialen oder rituellen Verhaltensformen und der Bereitschaft zu sozialen Aktivitäten, in Wertvorstellungen und in der Imaginationsfähigkeit." (vgl. Fraas 1990: 81)

\section{a) Was ist Religiosität? Zur operationalen Definition von Religiosität}

Eine begriffliche Annäherung an das Thema lässt die Religiosität als individuellen Ausdruck von Religion bestimmen. Religiosität sei die subjektive Aneignung von Religion in der gelebten Lebenswelt (vgl. Bochinger 2010: 110). In der Religiosität des Menschen zeige sich die Beziehung des Menschen zum Transzendenten als dem Letztgültigen, dem Höchsten oder Wahrsten. Individuelle Religiosität lasse sich allgemein in drei wesentliche Komponenten des Glaubens ausdifferenzieren: die affektive, kognitive und handlungsorientierte. Somit sollten die wesentlichen Komponenten der Religiosität (wie des Menschseins überhaupt) berücksichtigt werden (vgl. Boos-Nünning 1972: 23). Selbst wenn im Lebensalltag eine innere Einheit zwischen diesen Komponenten besteht, kann die Gewichtung der einzelnen Elemente von Person zu Person variieren.

Demgemäß sollen mit diesem Instrument, die im religiösen Sozialisationsprozess vermittelten Einstellungen (Grundorientierungen) und Verhaltensmuster, die auf der Grundlage von religiösen Normen und Werthaltungen der Eltern entstanden sind, bestimmt werden. Schließlich deuten diese zu erfassenden Kategorien auf unterschiedliche religiöse Orientierungen mit den da- 
zugehörigen Erziehungsvorstellungen und der Erziehungspraxis in Familien, die hier untersucht werden sollen. Damit wird der Bezug zur Übermittlung von religiösen Inhalten, Einstellungen und Verhaltensweisen an nachfolgende Generationen, die sich den Sinnkomplex des Glaubens und seiner Lebenspraxis aneignen, hergestellt (vgl. Drehsen/Mette 2000: 2011).

Vor diesem Hintergrund muss der Begriff »religiös« so bestimmt werden, dass er für die vorliegende sozialwissenschaftliche Untersuchung »fruchtbar« gemacht werden kann. Die Kategorie »Religiosität« muss so operationalisiert werden, dass sie in empirisch beobachtbare oder erfragbare Sachverhalte übersetzt wird, um Aussagen über religiöse Orientierungen treffen zu können.

\section{b) »Dimensionen der Religiosität« nach Glock}

als heuristisches Analyseinstrument

Zunächst stellt sich die Frage, ob sich dieses Analyseinstrument zur Beschreibung von muslimischer Religiosität als brauchbar erweist. Mit dieser Frage haben sich bereits diverse muslimische Autoren befasst.

Das Ende der 196oer-Jahre von Glock entwickelte Verfahren ist ein schon vielfach zur Darstellung der muslimischen Religiosität in sozialwissenschaftlichen Studien eingesetztes Instrument, sodass sich die Autoren dieser Studien schon mit der Frage auseinandergesetzt haben, ob dieses zur Beschreibung der muslimischen Religiosität als geeignet erscheint (vgl. z.B. Karakaşoğlu-Aydın 2000; Öztürk 2007).

Köse und Ayten (2012) zeigen in ihrem (türkischsprachigen) einführenden Werk über »Religionspsychologie« (»Din psikolojisi«), wie der Glock'sche Ansatz hinsichtlich der Beschreibung der muslimischen Religiosität Verwendung findet. Dabei werden die Inhalte der islamischen Religion letztlich ins Verhältnis zu den Dimensionen der Religiosität gesetzt (vgl. Köse/Ayten 2012: 110-114).

Die Studie von Karakaşoğlu-Aydın (2000) kann als Beitrag verstanden werden, in dem die religiösen Orientierungen von Musliminnen auf differenzierte Weise dargelegt wurden. In ihrer Untersuchung zeigt sie auch, wie die Erscheinungsformen muslimischer Religiosität in die jeweiligen Untersuchungskategorien eingeordnet werden können (vgl. Karakaşoğlu-Aydın 2000: 123-126).

Auch Öztürk (2007), der in seiner Studie die Religiosität von muslimischen Jugendlichen anhand des Glock'schen Analyseinstruments beschreibt, stellt eine Beziehung zwischen dem Analyseinstrument und den islamischen Grundlagen her. Er erläutert, wie Religion und Religiosität nach islamischem Verständnis mit den dazugehörigen normativen Implikationen anhand von islamischen Quellen aufgefasst werden können, um im Anschluss die Verbindungslinien zwischen diesen und den Dimensionen zur Erhebung von Religiosität herzustellen (vgl. Öztürk 2007: 66-72). Öztürk kommt schließlich zum Ergebnis, dass die zentralen Gesichtspunkte der islamischen Religiosität 
problemlos in die Dimensionen der Religiosität von Glock überführbar seien (vgl. Öztürk 2007: 74).

Glock selbst ist der Überzeugung, dass sein Ansatz zur Erhebung von Religiosität, trotz einiger Unterschiede in den religiösen Ausdrucksformen der jeweiligen Religion, für alle großen Weltreligionen Gültigkeit besitzt. Dabei geht er von fünf Dimensionen aus. Die vielfältigen Manifestationen der Religiosität, wie sie von den verschiedenen Religionen vorgeschrieben würden, könnten jeweils der einen oder anderen dieser Dimensionen zugeordnet werden (vgl. Glock 1969: 151).

Religiöse Orientierungen lassen sich Glock (1969) zufolge nach den folgenden Dimensionen erheben:

- Dimension der religiösen Erfahrung (ausgedrückt in religiösen Gemütsbewegungen)

- Dimension des religiösen Glaubens (ideologische Dimension: ausgedrückt in der Zustimmung zu Glaubensaussagen der eigenen Religion)

- Dimension der religiösen Praxis (rituelle Dimension: ausgedrückt im religiösen rituellen Verhalten)

- Dimension der Konsequenzen aus der religiösen Überzeugungen (ausgedrückt in religiös motiviertem sozialen Handeln)

- Dimension des religiösen Wissens (Rezeption des eigenen Wissens) (vgl. Glock 1969: 151).

Als weitere Dimension hat Boos-Nünning (1972) hier zudem noch die folgende vorgeschlagen:

- die Untersuchung der Bindung an religiöse Gemeinden, die auf die soziale Dimension der Religiosität hinweist (vgl. Boos-Nünning 1972: 108).

Mit diesen Dimensionen, die eine differenzierte und gegenstandsbezogene Kategorisierung der religiösen Orientierung ermöglichen bzw. für unseren Zusammenhang der religiösen Erziehungsvorstellungen von entscheidender Bedeutung sind, wird ein kategorialer Bezugsrahmen für die Erforschung der Religion und für die Abschätzung der Religiosität vorgeschlagen. Gemessen wird hier die Bedeutung des Glaubens für den Einzelnen, wie sie sich in den verschiedenen Dimensionen äußert, wobei diese nicht scharf voneinander getrennt zu betrachten sind. ${ }^{78}$

78 | Boos-Nünning (1972) stellt in ihrer Untersuchung fest, dass das theoretische Konzept ohne jede empirische Überprüfung übernommen worden ist (vgl. ebd.: 148). In ihrer Studie zu Katholiken in einer Ruhrgebietsstadt zeigt sie erstmals eine solche Überprüfung mittels statistischer Verfahren auf. Anhand der Interkorrelationsmatrix aller Items der verschiedenen Dimensionen folgert sie, dass "die theoretischen Dimensionen Glocks nicht der empirischen Wirklichkeit» entsprächen, diese würden »nicht die 
Die Zuordnung der Glock'schen Dimensionen zu den zentralen Aspekten bzw. den Erscheinungsformen der islamischen Religiosität folgt der Perspektive, die die hier angeführten Autoren veranschaulichen. Auch stellen die normativen Grundüberlegungen zur religiösen Erziehung im Islam (vgl. Kap. II3.1.3 d) den theoretischen Hintergrund dessen dar, wie die muslimische Religiosität in dieser Untersuchung verstanden wird.

*Die Dimension des Glaubens, die auch als die ideologische Dimension bezeichnet wird, beinhaltet die zentralen Glaubensüberzeugungen der Anhänger einer Religion. Demnach gibt diese Dimension Antworten auf die Glaubensstruktur. Diese Glaubensstruktur setzt sich nach Glock wiederum aus drei Subdimensionen zusammen:

- Jede Religion enthält Glaubengrundlagen, deren primäre Aufgabe darin besteht, die Existenz eines göttlichen Wesens und die Bestimmung seiner Natur und die Inhalte und Ziele des göttlichen Willens zu erläutern;

- die Definition der Rolle des Menschen in Bezug auf den göttlichen Willen;

- das Aufstellen von Glaubensaussagen, die das rechte Verhalten des Menschen gegenüber Gott und gegenüber seinen Mitmenschen festlegen (vgl. Glock 1969: 155f.).

Hinsichtlich des Islams drückt sich die Religiosität in der Zustimmung den zentralen Glaubensgrundlagen gegenüber aus, die sich auf die primären Quellen des Islams stützen. Die Vorstellung von Gott, die Rolle seines Gesandten Muhammad (s) und der Koran, als Offenbarungswerk Gottes, sowie der Glaube an die Auferstehung und an das Jenseits (ein Leben nach dem Tode) u.a. sind Aspekte, die dieser Dimension zugeordnet werden (vgl. Interviewleitfaden: 2. Religiöse Erziehung in der Familie).

*Die Dimension der religiösen Erfahrung. Die religiöse Erfahrung beinhaltet die unmittelbare subjektive Erfahrung, die mehr mit dem Gefühl als mit dem Verstand erfasst wird, und ist jeweils sehr individuell. Das religiöse Erlebnis fixiert den emotionalen Charakter, die affektive Komponente religiöser Phänomene und kann sich in den Formen Sinnerfüllung, seelischer Frieden, Bedürfnis, Erkennen, Vertrauen (auf Gott), Zuversicht, Gemeinschaftserlebnis oder Furcht ausdrücken. Religiöse Empfindungen und Erlebnisse könnten in mehr als einer Form ausgedrückt werden (vgl. Glock 1967: 161f.).

Wie bereits hinreichend erläutert wurde (vgl. Kap. II. 2.1 und vgl. Kap. II. 3.1.3), wird der Bereich der religiösen Erfahrungen, die innerhalb der

vorgegebene Sozialform der Religiosität" abbilden, sonders seien "nur taxonomische Einteilungen“ (vgl. Boos-Nünning 1972: 148; vgl. ebd.: 147 das Kapitel "Kritik des dimensionalen Ansatzes"). Die Verwobenheit mehrerer Dimensionen ist anzunehmen, daher finden die Glock'schen Dimensionen in der vorliegenden Untersuchung in dieser Eigenschaft Berücksichtigung. 
Familie gemacht werden, als wesentlich für die Übertragung der Religiosität gesehen. Die emotionale Atmosphäre bzw. die affektive Grundhaltung der Eltern zu religiösen Themen ist gerade dann bedeutsam, wenn es um das gemeinsame Ausleben der Religion innerhalb der Familie geht (in Form von u.a. gemeinsamen Gebeten, dem Koranlesen, Bittgebeten). Folglich wurde danach gefragt, in welcher Situation erste gemeinsame religiöse Erfahrungen gemacht wurden. Da dieser Bereich häufig schwierig zu beschreiben ist, wurden auch Vorgaben gemacht und Erläuterungen vorgenommen (vgl. Interviewleitfaden: 2. Religiöse Erziehung in der Familie).

*Die rituelle Dimension. In der rituellen Dimension richtet sich das Interesse darauf, welche religiösen Praktiken die Anhänger einer Religion einhalten. Zu dieser können sowohl die in den fünf Säulen des Islams enthaltenen Praktiken, wie die Pflichtgebete, das Fasten und die Wallfahrt, als auch das Koranlesen, das Vollziehen von Bittgebeten, das Abhalten täglicher oder wöchentlicher Sitzungen, um religiöse Inhalte (auch in der Moschee) zu besprechen, gezählt werden. Auch Rituale wie das gemeinschaftliche Freitagsgebet in der Moschee, das Feiern von religiösen Festen, die Abgabe von Spenden, die ihren Schwerpunkt in der Stärkung des Gemeinschaftsgefühls haben, können der rituellen Dimension zugeordnet werden.

*Die Dimension des religiösen Wissens. Im Bereich der intellektuellen Dimension wird erfasst, wie gut die Anhänger der Religion über ihren Glauben informiert sind. Dabei soll herausgefunden werden, wie gut sie mit den grundlegenden Lehrsätzen ihres Glaubens und ihrer Heiligen Schrift, den Quellen der Religion und dem argumentativen Umgang damit vertraut sind (vgl. Glock 1967: 163). Bezogen auf den Islam bedeutet das etwa das Kennen der wesentlichen Glaubensgrundlagen, Wissen über Aussagen aus dem Koran, über das Leben des Propheten Muhammad (s) (Sira).

Nach Glock macht die große Variationsbreite darüber, was der religiöse Mensch wissen und wie die Qualität seines religiösen Wissens beschaffen sein sollte, es schwierig, zu bestimmen, welche Wissensarten als Indikatoren religiöser Bindung anzusehen sind. Vor diesem Hintergrund sei es wichtig, die Beziehungen zwischen Umfang und Art des individuellen religiösen Wissens einerseits und den Mustern religiösen Glaubens, religiöser Praxis und religiösen Erlebens andererseits zu ergründen (vgl. Glock 1967: 163).

Für unseren Zusammenhang erschien es interessant, welches Wissen die Eltern ihren Kindern in jedem Fall vermitteln wollen. Darin kommt auch zum Ausdruck, welchen Umgang sie selbst mit den islamischen Quellen pflegen. Und umgekehrt, geben die Fragen, welche Themen die Kinder interessieren und ob sie Fragen zu religiösen Themen stellen, Auskunft darüber, inwieweit sie an religiösem Wissen und entsprechenden Themen interessiert sind (vgl. Interviewleitfaden: 2. Religiöse Erziehung in der Familie). 
*Die Dimension der Konsequenzen aus den religiösen Überzeugungen. Die Dimension der Konsequenzen aus religiösen Überzeugungen soll Effekte religiösen Glaubens, religiöser Praxis, religiöser Erfahrungen und religiösen Wissens auf die Alltagsgestaltung des einzelnen Menschen zusammenfassen und zielt damit auf die Konsequenzen der religiösen Überzeugung auf zwischenmenschliche Beziehungen ab (vgl. Glock 1967: 164), in unserem Falle auf die Beziehung der Eltern zu ihren Kindern und die weitreichenderen religiösen Netzwerken bzw. Peers der Kinder. Sie drückt sich dementsprechend auch im sozialen Handeln aus.

Es soll in dieser Dimension der Frage nachgegangen werden, was ein Mensch als Konsequenz seiner Religiosität tut oder lässt, d.h., es soll erforscht werden, inwiefern die Gläubigen aus ihren religiösen Überzeugungen und Erfahrungen Konsequenzen für ihr Alltagsleben bzw. ihr Erziehungshandeln ziehen. Diese Dimension beziehe sich somit auf Normen und Werthaltungen, die sich aus der Religion ergäben und sich in Handlungen äußern würden (vgl. Glock 1967: 164).

Nun zeigen sich die Konsequenzen aus den religiösen Überzeugungen im sozialen Handeln in verschiedenen Lebensbereichen. Diese sind in der vorliegenden Untersuchung bestimmt durch den eigenen familiären Rahmen, die außerschulischen Bildungseinrichtungen (Moscheen, religiöse Vereinigungen, Gemeinden), Religion in öffentlichen Bildungseinrichtungen (Schule/ Kiga/Kita/OGS), Peers der Kinder, Bekanntenkreis, interreligiöse Begegnungen, Medien und die Gesellschaft. Die Konstruktion des Leitfadens fand unter Berücksichtigung dieser Lebenskontexte statt (vgl. Interviewleitfaden, alle Themenbereiche).

Es wurde bereits erwähnt, dass die Einbindung in religiöse Netzwerke (Anbindung an eine religiöse Gemeinde) durch Boos-Nünning (1972) als Erweiterung des Glock'schen Ansatzes nachweislich untersucht wurde. ${ }^{79}$ Die vorliegende Untersuchung befasst sich mit diesem Thema anhand der Frage, wie die Einbindung der Kinder in die religiösen Netzwerke der Eltern (Moschee, Bildungseinrichtungen u.ä. Einrichtungen) erfolgt bzw. wie diese zur Unterstützung der religiösen Unterweisung ihrer Kinder genutzt werden. Dabei wird kein konkreter Bezug auf spezifische politische und religiöse Ausrichtungen von Vereinen und Verbänden genommen, vielmehr steht das Interesse der Eltern, ihre Kinder gemäß ihren religiösen Vorstellungen zu erziehen und sich entsprechend in einem religiös organisierten Rahmen zu bewegen, im Vorder-

79 | Boos-Nünning/Karakaşoğlu verweisen darauf, dass die Untersuchung zur Einbindung in religiöse Netzwerke von Migrant(inn)en unter Migrationsbedingungen im Hinblick auf die Muslime und Musliminnen einen Schwerpunkt der Untersuchung von muslimischer Religiosität in der Migrationssituation bildet (vgl. Boos-Nünning/Karakaşoğlu 2005: 403). 
grund und Fokus des Interesses (vgl. Interviewleitfaden: 3. Außerschulische Bildungseinrichtungen).

\subsection{Folgerungen für den Untersuchungszusammenhang}

Es wurde zunächst geklärt, was unter religiöser Sozialisation als einer Dimension der allgemeinen Sozialisation verstanden wird. Es wurden Grundannahmen zur allgemeinen Sozialisation ausgeführt, um im Anschluss daran einige Aspekte des Sozialisationsprozesses anhand des von Hurrelmann vorgestellten Modells der Sozialisation als produktive Verarbeitung der Realität dargelegt (vgl. Kap. II. 3.1.2). Diese theoretischen Ausführungen bilden den analytischen Rahmen des zu untersuchenden Forschungsgegenstandes.

Wie schon erwähnt, ist es erforderlich, Vorstellungen über Konturen und das Erscheinungsbild dieses Gebildes einzuholen, um »Sozialisationsbedingungen « (vgl. Tillmann 2010: 21) theoretisch strukturieren und empirisch erfassen zu können. Hier ist es notwendig, die Gestalt der Sozialisationsumwelten bzw. der Sozialisationsinstanzen klar einzugrenzen. Dies unterliegt der Entscheidung, welchen Aspekten bzw. Indikatoren das Forschungsinteresse gelten soll. Sie ist auch davon abhängig, welche Instanzen fokussiert werden - wie Familie, Bildungsinstitutionen usw. - und welchen inhaltlichen Feldern das Interesse gilt: beispielsweise der Sozialisation von Normen und Werthaltungen. Dabei wird ein kriteriengeleitetes Vorgehen vorgeschlagen, das sich an theoretischen Begründungen empirischer Erwägungen orientiert (vgl. Dippelhofer-Stiem 2008: 119ff.).

Entsprechend der eingangs formulierten Fragestellung (vgl. auch Kap. II. 2.3), welchen Einfluss neben der Familie als der primären Sozialisationsinstanz die nichtinstitutionellen religiösen Bildungseinrichtungen (Moscheen, Korankurse usw.), die staatlichen Bildungseinrichtungen, der Freundeskreis der Kinder, Medien und Gesellschaft auf die religiöse Sozialisation von muslimischen Kindern ausüben, sollen diese Sozialisationsinstanzen im Folgenden näher bestimmt werden.

Ausgangspunkt ist hier zunächst die Familie, die als »äußere Realität« auf die Entwicklung der »inneren Realität« (der Kinder) Einfluss nimmt. Als die »innere Realität«, die sich im Zuge der Sozialisation herausbildet, können die religiösen Überzeugungen, Haltungen, Handlungen beschrieben werden; bzw. um es mit Hurrelmanns Worten zu umschreiben, umfasst diese das gesamte Repertoire an Einstellungsmustern, Kompetenzen und Handlungsbefähigungen. Infolge der Auseinandersetzung mit religiösen Inhalten im Rahmen der Familie ergeben sich Wahrnehmungs-, Bewertungs- und Handlungsdispositionen, die kennzeichnend für das familiäre Umfeld sind. Diese erscheinen individuell unterschiedlich ausgeprägt. Die Erfassung bzw. Erhebung dieser Aspekte erfordert einen Religiositätsbegriff, der all diese Kernaspekte in sich vereint 
(vgl. Kap. II. 3.1.4). Hier wird auch die religiöse Erziehung im Rahmen der Familie angesprochen (vgl. Kap. II. 3.1.3). Die intentionale und interaktive Weitergabe von religiösen Inhalten und Normen stellt einen Ausschnitt der religiösen Sozialisation dar. Eltern können mit ihrer Erziehung die Dimensionen der Persönlichkeitsentwicklung (Wissen, Motive, Gefühle, Bedürfnisse, Handlungskompetenzen) beeinflussen, um religiöse Einstellungen, Wissen, emotionale Strukturen und kognitive Fähigkeiten bei ihren Kindern hervorzurufen (in Anlehnung an Hurrelmann 2012 und die Kap. II. 3.1.1 bzw. Kap. II. 3.1.2).

Gemäß der Abbildung »Struktur der Sozialisationsbedingungen« (vgl. Tillmann 2010: 23; vgl. Tab. 1 in der vorliegenden Arbeit), der vier Ebenen zugeordnet werden und den eben aufgeführten Grundüberlegungen, sind folgende Untersuchungskriterien von Bedeutung.

Auf der ersten Ebene des Subjekts: Religiöse Inhalte, Einstellungen, Verhaltensweisen, die im Rahmen der religiösen Sozialisation und der religiösen Erziehung innerhalb der Familie übertragen werden, rufen religiöse Überzeugungen, Erfahrungsmuster, Wissen, Handlungen, Haltungen, emotionale Strukturen und kognitive Fähigkeiten hervor. Diese werden anhand des Religiositätsbegriffs nach Glock operationalisiert (vgl. Kap. II. 3.1.4). Es ist dabei von verschiedenen individuellen religiösen Erziehungsvorstellungen innerhalb der Familien auszugehen.

Die religiöse Erziehung als intentional und »planmäßig« durchgeführte Sozialisation (vgl. Drinck 2008) stellt eine wichtige Säule dar. In diesem Zusammenhang wurde Erziehung aus erziehungswissenschaftlicher Sicht bestimmt. Diese wird in der vorliegenden Untersuchung in einer interdisziplinären Herangehensweise ins Verhältnis zur Religion bzw. zur Religiosität gesetzt, d.h., es soll nach Normen und Werthaltungen gefragt werden, die auch religiöse Begründungen beinhalten können (Grundorientierungen, Einstellungen). Die Bestimmung der Erziehungsziele dient eben diesem Interesse.

Die verschiedenen Einstellungen und Grundorientierungen, die im Zuge des religiösen Sozialisationsprozesses und mit der religiösen Erziehung an die Kinder herangetragen werden, fördern, neben unterschiedlichen Einstellungen, eine Erziehungspraxis zutage, die als Verhaltensmuster operationalisierbar ist.

Demnach kristallisieren sich zwei Untersuchungskriterien heraus. Um eine differenzierte Analyse zu ermöglichen, sollen die im Sozialisationsprozess vermittelten Einstellungen nach a) Grundorientierungen (Werthaltungen, Motive, Erfahrungsmuster, Bedürfnisse, normleitende Prinzipien, Wahrnehmungs- und Bewertungsdispositionen, Erziehungsziele usw.) und b) Verhaltensmustern (Tätigkeiten, Interaktionen, religiöse Praxis, handlungsleitende Prinzipien, Handlungsdispositionen usw.) erforscht werden. Eine differenziertere Beschreibung der »Religiosität«, die die verschiedenen Aspekte bzw. Di- 
mensionen religiöser Erziehungsvorstellungen und der Religiosität innerhalb der Familien beschreibt, dient diesem Interesse.

Auf der zweiten Ebene sind folgende religiös geprägten Interaktionen und Tätigkeiten von entscheidender Bedeutung:

- die Eltern-Kind-Beziehungen;

- in diesem Zusammenhang sollen auch Aussagen über das Eltern-KindVerhältnis (vgl. »Erziehungsstile«) und die von Eltern angewandten Erziehungsmethoden (»Erziehungsmittel«, »Sozialisationstechniken«) getroffen werden.

- die Beziehung der Eltern und ihrer Kinder zu den nichtinstitutionellen religiösen Bildungseinrichtungen;

- das Verhältnis zu den staatlichen Bildungseinrichtungen im Umgang mit der Religion;

- Interreligiöse Begegnungen;

- die Kommunikation zwischen gleichaltrigen Freunden der Kinder und Nachbarn.

Auf der dritten Ebene der Institutionen soll der fördernde oder hemmende Einfluss der folgenden Sozialisationsinstanzen bzw. -kontexte im Hinblick auf die religiöse Sozialisation untersucht werden:

- die religiösen Organisationen und ihnen angegliedert die Moscheegemeinden, in die die religiösen Bildungseinrichtungen mit ihren für sie spezifischen Gefüge und Eigenschaften eingebettet sind;

die Schulen und Kindertagesstätten;

- die Medien

Schließlich interessiert auf der vierten Ebene der Gesamtgesellschaft, in welchem Verhältnis sich muslimische Eltern mit ihren religiösen Erziehungsvorstellungen in der deutschen Gesellschaft unter Berücksichtigung der Diasporasituation sehen. Gefragt wird dabei, welche Möglichkeiten eine muslimisch-religiöse Erziehung für ein gesellschaftliches Miteinander eröffnen kann. 



\section{Empirische Untersuchung}

\section{Methodik}

\subsection{Die Begründung der Erhebungsmethode}

Die religiöse Sozialisation in muslimischen Familien ist ein bisher kaum untersuchtes (Forschungs-)Feld. Insbesondere die Darstellung des Forschungsgegenstandes anhand der bisher durchgeführten Untersuchungen beinhaltete große Herausforderungen. Es konnten mit ihnen immer nur einige wenige Teilaspekte der religiösen Sozialisation aufgezeigt werden. In diesem Zusammenhang wird beabsichtigt, im Zuge dieser Studie eine umfassende Analyse der religiösen Sozialisation durchzuführen, die verschiedene Sozialisationskontexte berücksichtigt. Im Blickpunkt stehen hierbei muslimische Migrant(inn)en, d.h. muslimische Eltern mit ihren Erziehungsvorstellungen, Einstellungen/Grundorientierungen und ihrer Religiosität. Durch eine qualitative Analyse lassen sich tiefgreifendere Erkenntisse gewinnen, in denen sich subjektive Wahrnehmungen, Einstellungsmuster und religiöse Erziehungsvorstellungen widerspiegeln und somit konkret nachzeichnen lassen.

Nun handelt es sich bei Sozialisationsvorgängen um komplexe Interaktionsverläufe, mit denen in einer qualitativen Analyse je nach Fragestellung immer nur Ausschnitte aus diesen Interaktionen dargestellt werden können. Die Komplexität dieser Vorgänge dürfte in den bisher vorgestellten Ausführungen deutlich geworden sein (vgl. Kap. II. 3). Gerade diese Tatsache führte zur entsprechenden Auswahl des qualitativen Verfahrens, um hier ein tieferes Verständnis für die aus den Interaktionen entstehenden Handlungs- und Deutungsmuster erlangen zu können.

Somit sollen innerhalb dieser Forschungsarbeit zum ersten Mal Eltern zu Wort kommen, die ihre Erziehungsvorstellungen und ihre Grundorientierungen sowie ihre religiöse Praxis innerhalb des eigenen familiären Rahmens wiedergeben. Die Familie ist ein Lebensbereich, der durch Intimität gekennzeichnet ist. Durch das qualitativ erhobene Material besteht die Möglichkeit, Einblicke in die familiäre Religiosität bzw. in die damit zusammenhängenden religiösen Erziehungsvorstellungen zu gewinnen, wie sie bisher noch nicht 
gewährt wurden; plausibel und nachvollziehbar bzw. transparent sind diese nur mittels einer qualitativ durchgeführten Methode $\mathrm{zu}$ veranschaulichen. Nicht zuletzt stellen Erfahrungen mit Religiosität einen emotional besetzten, biografisch verankerten Lebensbereich dar, der mit einer qualitativen Analyse tiefergehend dargelegt werden kann und mittels derer Interpretationen, Sichtweisen und Einstellungen des Befragten selbst in den Vordergrund gestellt werden.

In den meisten Interviews wurden die Befragten zumeist erstmalig mit Fragen konfrontiert, die sie zur Reflexion über das eigene Verhältnis zur Religion anregten. Die Interviewsituationen waren häufig davon gekennzeichnet, dass sie gerade im Zusammenhang mit religiösen Erziehungsvorstellungen auch zum ersten Mal dazu bewogen wurden, darüber nachzudenken, welchen erzieherischen Prinzipien sie grundsätzlich folgen. Daraus ergaben sich während der Interviews möglicherweise sogar Neudefinitionen bzw. Transformationen ihrer ursprünglichen Standpunkte.

\subsection{Das Erkenntnisinteresse/ Erläuterungen zum Interviewleitfaden}

Um eine klare und zusammenfassende Übersicht zu gewährleisten, sollen das Erkenntnisinteresse bzw. die zentralen Fragestellungen hier nochmals genauer beschrieben werden. Diese wurden bislang schon in den Kapiteln II. 2.3, II. 3.1.4b) sowie in II. 3.2 ausführlich diskutiert und theoretisch verortet.

Es geht im Folgenden darum, herauszufinden, welchen Einfluss neben der Familie als primärer Sozialisationsinstanz andere Sozialisationsinstanzen auf die religiöse Sozialisation von muslimischen Kindern ausüben.

Es wurden hierfür nachfolgende Untersuchungskriterien bestimmt:

Auf der Ebene des Subjekts bzw. der befragten Eltern wurden die im Sozialisationsprozess vermittelten Einstellungen nach a) Grundorientierungen/Einstellungen und b) Verhaltensmustern befragt. Hierbei geht es darum, an welche normativen, orientierungs- und handlungsleitenden Prinzipien die religiöse Erziehung als wesentlicher Aspekt der religiösen Sozialisation gebunden ist. Diese wurden anhand des Religiositätsbegriffs nach Glock operationalisiert, vgl. Kap. II. 3.1.4b).

In diesem Zusammenhang erfolgten auch Aussagen über das Eltern-KindVerhältnis und die von Eltern angewandten Erziehungsmethoden.

Es ist von verschiedenen religiösen Orientierungen sowie Erziehungsvorstellungen und -mustern innerhalb der Familien auszugehen, was wiederum eine Typenbildung ermöglichen sollte.

Als weitere Sozialisationsinstanzen, die Einfluss auf die religiöse Sozialisation ausüben, sind die außerschulischen Bildungseinrichtungen zu nennen. Es sollte erkundet werden, welchen Beitrag sie im Hinblick auf die religiöse 
Sozialisation leisten und wie Eltern die wahrgenommenen Angebote bewerten. Es wurde demnach gefragt, was in diesen Einrichtungen für die religiöse Erziehung geleistet wird $(\rightarrow$ Inhalte) sowie in welcher Art und Weise die Vermittlung stattfindet ( $\rightarrow$ Methode).

Der Umgang mit dem Islam in öffentlichen Bildungseinrichtungen stellt Eltern vor besondere Herausforderungen. Hier wurde auch erfragt, wie die Lehrpersonen selbst mit dem Islam umgehen würden, ob religiösen Elementen im Schulalltag/Kindergarten ein Platz eingeräumt werde oder ob es bereits Konfliktsituationen und Benachteiligungen gegeben habe, die auf die Religionszugehörigkeit und die religiöse Praxis zurückzuführen seien. Zudem wurde erkundet, welchen Stellenwert für Eltern der IRU (islamische Religionsunterricht) sowie interreligiöse Begegnungen in den öffentlichen Bildungseinrichtungen einnehmen.

Der Einfluss der Peers oder des Freundeskreises auf die religiöse Sozialisation sollte des Weiteren aus der Perspektive der Eltern untersucht werden. Dabei wurde erfragt, welche Freunde die Kinder und Jugendlichen haben und ob sie sich über Religionen austauschen.

Gerade im Zusammenhang mit Beziehungen zu Außenstehenden war es zudem interessant, zu analysieren, welche Beziehungen zur Nachbarschaft gepflegt werden und ein weiteres Thema war, ob auch hier ein Austausch über die Religion stattfindet.

Der Einfluss der Medien als ein möglicher Sozialisationseffekt und die Medien als didaktische Mittel zur Unterstützung von religiöser Erziehung sowie der Umgang mit dem Islambild in den Medien stellten weitere Untersuchungskriterien dar.

Schließlich beeinflusst das Leben in dieser Gesellschaft das Ausleben der eigenen Religion. Hierzu wurden die Eltern befragt, welche Vorstellungen gegenüber Muslimen es vonseiten der (einheimisch) Deutschen gebe und inwiefern die eigene Religion in diesem Land überhaupt ausgelebt werden könne. Auch die Frage, was die religiöse Erziehung in dieser Gesellschaft grundsätzlich bewirken solle, ist in diesem Kontext von zentraler Bedeutung.

\section{Erläuterungen zum Interviewleitfaden}

Für diese Untersuchung wurde das halbstandardisierte Erhebungsverfahren ausgewählt, das mittels eines konstruierten Leitfadens durchgeführt wurde. Es erfolgte die Befragung jeweils eines Elternteils, d.h. entweder des Vaters oder der Mutter stellvertretend für die ganze Familie.

Mittlerweile existieren für die Organisation von Leitfadeninterviews verschiedene Methoden. Das halbstandardisierte Interview, das 1988 von Scheele und Groeben entwickelt wurde, zielt auf die Rekonstruktion subjektiver Theorien ab. Dabei wird davon ausgegangen, dass der Interviewpartner über einen um- 
fangreichen Wissensbestand zum Thema (als subjektive Theorie) der Untersuchung verfügt (vgl. in Flick 2007: 203). Flick führt hierzu Folgendes aus:

"Dieser Wissensbestand enthält explizit verfügbare Annahmen, die der Interviewpartner auf offene Fragen äußern kann, und implizite Annahmen, für deren Artikulation er durch methodische Hilfen unterstützt werden sollte, weshalb hier verschiedene Typen von Fragen verwendet werden." (Flick 2007: 203)

Damit werden mittels Leitfadeninterviews die subjektiven Theorien des Befragten über den Untersuchungsgegenstand rekonstruiert.

Im Interview werden die Inhalte der subjektiven Theorie rekonstruiert. Der Leitfaden ist nach thematischen Bereichen strukturiert, die jeweils von einer offenen Frage eingeleitet werden. Ergänzend hierzu werden theoriegeleitete Fragen gestellt, die an der wissenschaftlichen Literatur zum Thema orientiert sind. Die darin formulierten Annahmen sollten dem Interviewpartner gegenüber als Angebote formuliert werden, die er aufgreifen oder ablehnen könne (vgl. Flick 2007: 203f.). Die Interviewführung sei durch die Vorgabe von inhaltlichen Bereichen und durch die gezielte Formulierung von Fragen entlang wissenschaftlicher Theorien gekennzeichnet (vgl. ebd.).

Ähnlich verläuft auch das von Witzel (vgl. in Lamnek 2005: 365, vgl. auch in Flick 2007: 210-214) vorgeschlagene problemzentrierte Interview aus dem Jahre 1982. Im Vergleich zum narrativen Interview, bei dem kein theoretisch ausgearbeiteter Entwurf vorhanden ist und bei dem der Forscher sein wissenschaftliches Konzept auf den Äußerungen des Befragten nachträglich aufbaut, orientiert sich das problemzentrierte Interview deutlich an bestimmten Fragestellungen und enthält - wie in dieser Untersuchung vorgenommen - vorformulierte, teilweise in ihrer Abfolge festgelegte Fragen, von denen die Interviewenden- so auch die Autorin der vorliegenden Studie - nach eigenem Ermessen unter Berücksichtigung des theoretischen Anliegens der Forschungsarbeit abweichen können, indem weitere aufklärende Fragen und andere zentrale Gesichtspunkte aufgegriffen werden:

„Im problemzentrierten Interview [...] steht die Konzeptgenerierung durch den Befragten zwar immer noch im Vordergrund, doch wird ein bereits bestehendes wissenschaftliches Konzept durch die Äußerungen des Erzählenden evtentuell modifiziert. Methodologisch gesehen wird also die streng induktive Vorgehensweise [ohne Prädetermination durch den Forscher im narrativen Interview beim problemzentrierten Interview mittels einer Kombination aus Induktion und Deduktion mit der Chance auf Modifikation der theoretischen Konzepte des Forschers abgelöst." (Lamnek 2005: 364)

Der Forscher bereitet sich durch ein Literaturstudium, eigene Erkundungen im Untersuchungsfeld, durch die Ermittlung des Fachwissens von Experten 
usw. auf seine Studie vor. Aus den gesammelten Informationen werden die relevant erscheinenden Aspekte des Problembereichs der sozialen Realität herausgefiltert und zu einem theoretischen Konzept verknüpft und verdichtet (vgl. Lamnek 2005: 364).

Entsprechend dem Erzählprinzip bleibt die Bedeutungsstrukturierung dem Befragten allein überlassen. Das theoretische Konzept des Forschers soll gegenüber den Bedeutungsstrukturierungen des Befragten offen bleiben. Stelle sich im Forschungsverlauf heraus, dass sich das theoretische Konzept des Forschers als unzureichend oder gar falsch erweise, so werde es modifiziert, revidiert und erneut an der Wirklichkeit gemessen (vgl. Lamnek 2005: 364 ).

Ziel war es, gemäß den oben vorgestellten Prinzipien, eine angemessene Balance zwischen einer größtmöglichen Vergleichbarkeit der Interviewergebnisse bei einer gleichzeitig größtmöglichenr Offenheit für die Erzählungen und eigenen Standpunkte der Befragten zu halte. ${ }^{1}$ Bevor der Leitfaden in der Untersuchung schließlich zur Anwendung kam, waren Probeinterviews durchgeführt und diese immer wieder modifiziert worden, bis eine Festlegung auf eine endgültige Fassung des Leitfadens erfolgte. Des Weiteren wurde hierzu der Rat von Expert(inn)en, die im Bereich der Erwachsenenbildung für die religiöse Bildungsarbeit zuständig und zudem im Fachbereich Religionspädagogik $^{2}$ tätig sind, eingeholt, um sowohl fachlich als auch fragetechnisch für die Untersuchung angemessene Ergebnisse erzielen zu können.

Der Interviewleitfaden (vgl. Anhang) ist in folgende Themenbereiche gegliedert:

- Eröffnungsfrage

- Religiöse Erziehung in der Familie/Religiöse Erziehungsvorstellungen

- Außerschulische Bildungseinrichtungen (Moscheen, religiöse Vereinigungen, Gemeinden, religiöse Vorbilder)

- Religion in öffentlichen Bildungseinrichtungen (Schule, Kiga, Kita, OGS)/ Islamischer Religionsunterricht

- Peers (Freunde, Kontakte zu Andersgläubigen)

- Nachbarschaftsbeziehungen

- Medien

- Gesellschaft

- Islam in der Diasporasituation

1 | Die Interviewdurchführung erfolgte gemäß den Empfehlungen von Hermanns und Hopf (vgl. Hermanns 2009: 360-368 und vgl. Hopf 2009: 353-360). Hinsichtlich der Besonderheiten, die in der Fragebogenkonstruktion und in den Fragenstellungen zu beachten sind, wurden die Empfehlungen von Scheuch (vgl. Scheuch 1967: 136-162) befolgt.

2 | Für die hilfreichen Hinweise aus diesem Fachbereich sei insbesondere Prof. Harry Harun Behr gedankt. 
- Ergänzungen/fehlende Aspekte

- Rahmendaten

Die Eröffnungsfrage, bei der die Proband(inn)en dazu angeregt werden, die Rolle oder Bedeutung, die die Religion in ihrer Ursprungsfamilie spielte bzw. hatte, darzulegen, hat eine Einführung in die Thematik zum Ziel und soll die Befragten entsprechend stimulieren, einen persönlichen Bezug zur Thematik herzustellen und einen Erzählrhythmus zu entwickeln.

Die thematischen Bereiche wurden theoriegleitet festgelegt und es erfolgte die Formulierung von Fragen, die dem Erkenntnisinteresse entsprechen. Die bei Bedarf eingesetzten Nachfragen sollten der Vertiefung und Intensivierung der jeweiligen Thematik dienen. Durch Nachfragen, Zusammenfassen und Zurückspiegeln des Gesagten konnten die Aussagen der Befragten systematisierend eingeordnet werden. Die Befragten hatten dadurch jeweils auch die Möglichkeit, die Äußerungen der Forscherin zu kontrollieren, zu modifizieren oder zu korrigieren.

Im Anschluss an die jeweiligen Themenbereiche hatten die Interviewpartner die Möglichkeit, noch Ergänzungen vorzunehmen und Aussagen darüber zu machen, was ihnen noch wichtig erschien.

Die Rahmendaten, die im Anschluss eines jeden Interviews mithilfe eines standardisieren Fragebogens erhoben wurden, geben Auskunft über die sozialstrukturellen Merkmale der Proband(inn)en und ihrer Kinder. Die Daten geben Auskunft über die Anzahl der Kinder, die besuchte Schule oder Kindertagesstätte der Kinder bzw. das Alter der Kinder. Zudem wurden weitere wichtige Lebensdaten (das Alter, die Bildungs- bzw. berufliche Situation, die Staatsangehörigkeit) der Interviewpartner erfasst, die einen weiteren wichtigen Eindruck über die familiäre Situation der Interviewten vermitteln sollten (vgl. Anhang: Untersuchungsgruppe).

\section{Das Postskriptum}

Im Anschluss an die Interviews wurden Beobachtungsprotokolle verfasst, worin die Eindrücke über die Kommunikation, die Person des Interviewpartners, über sich und sein Verhalten in der Situation, äußere Einflüsse und den Raum, in dem das Interview stattgefunden hat, notiert wurden (vgl. Flick 2007: 213). Außerdem wird in diesen Protokollen deutlich gemacht, wie der Zugang zum Interviewpartner stattfand und es werden wichtige Kontextinformationen notiert. Die festgehaltenen Informationen konnten Hinweise für die spätere Interpretation der Ergebnisse und wichtige Daten zum Verständnis einzelner Passagen geben. 


\subsection{Die Auswahl der Probanden und Probandinnen}

Bei der Auswahl der Proband(inn)en spielen in qualitativen Untersuchungen stichprobentheoretische Überlegungen und damit die Repräsentativität der Studie eine untergeordnete Rolle. Vielmehr geht es in der qualitativen Methodologie darum, Typisierungen bzw. Typologien zu bestimmen. Wichtig ist daher eine realitätsgerechte Rekonstruktion von Typen von Bedeutungsstrukturierungen zu einem speziellen Themenbereich. Ziel ist folglich, mögliche Formen an relevanten Handlungsmustern herauszufinden (vgl. Lamnek 2005: 384).

Gemäß dieser Logik und dem Erkenntnisinteresse, ein möglichst breites Spektrum an religiösen Erziehungsvorstellungen und subjektiven Deutungsmustern zu erfassen, wurde darauf geachtet, religiöse Menschen zu befragen, bei denen die religiöse Erziehung ihrer Kinder von zentraler Bedeutung ist. Es wurde insbesondere darauf Wert gelegt, dass die Mehrzahl der Befragten aktiv darum bemüht ist, eine religiöse Erziehung an ihre Kinder weiterzugeben.

Um religiöse Deutungs- und Handlungsmuster in ihrer sinngemäßen Bedeutung zu erfassen, wurde vornehmlich die qualitative Erhebungsmethode ausgewählt. Das dabei entstehende umfangreiche Datenmaterial, das ein tieferes Verständnis von religiösen Einstellungen und religiösen Handlungsmustern ermöglicht, machte es erforderlich, die Stichprobe eher klein zu halten. Demgemäß wurden insgesamt nicht mehr als 16 Personen interviewt.

Die Probandenauswahl richtete sich zunächst nach vorab festgelegten Kriterien (vgl. Flick 2007: 155). Um eine größtmögliche Vergleichbarkeit der Ergebnisse zu erreichen, war es wichtig, sich auf eine bestimmte soziale Gruppe zu beschränken. Die Eingrenzung auf die muslimisch-türkische Migrantengruppe mit der sunnitischen Ausrichtung des Islams hatte ihre Ursache nicht darin, eine bestimmte ethnische Gruppe zu bevorzugen und wiederum andere muslimische Gruppierungen auszuschließen. Vielmehr waren hierfür die Zugangsmöglichkeiten der Forscherin (das Beherrschen der türkischen Sprache, das Aufwachsen in religiösen Gemeinden mit türkischer Prägung, Erfahrungen im Umgang mit religiösen Themen) ausschlaggebend.

Die Auswahl wurde also nach vorab bestimmten Kriterien getroffen. Damit sollten die ethnische Herkunft, das Alter, die religiöse Ausrichtung, Eltern von mindestens einem Kind zu sein (Kinderanzahl) als abstrakte Entscheidungskriterien gelten. Diese sind insofern abstrakt, als sie unabhängig vom konkret untersuchten Material und vor dessen Erhebung und Analyse entwickelt wurden (vgl. Flick 2007: 156). Die Religiosität der Befragten und ein ausgeprägtes Interesse für die religiöse Erziehung sind, wie bereits angeführt, weitere Kriterien, die für die Fallauswahl relevant gewesen sind. Bei der ausgewählten Gruppe der befragten Eltern drückt sich ihre Religiosität in der Praxis aus. Folglich wird hier von einer spezifischen Gruppe von Muslimen ausgegangen, 
die versucht, besonders viele Aspekte des Islams in ihr Leben zu integrieren (vgl. auch Kap. II. 1.3). Mit dieser Vorabfestlegung konnte erreicht werden, dass die Gesamtheit der infrage kommenden Fälle eingeschränkt wurde, sodass diese möglichst vollständig in der Untersuchung berücksichtigt werden konnten (vgl. Flick 2007: 157).

Zusammengefasst sollten die Proband(inn)en folgende Merkmale besitzen:

- Die Proband(inn)en sollen einen türkischen Migrationshintergrund haben.

- Die Religionsgruppenzugehörigkeit sollte muslimisch-sunnitisch sein.

- Es sollten Mütter und Väter befragt werden, die zwischen 21 und 45 Jahren sind und Kinder im Alter von o bis 18 Jahren haben.

- Es wird nur ein Elternteil, entweder Vater oder Mutter, stellvertretend für die ganze Familie interviewt. ${ }^{3}$

- Sie sollen religiös leben und ein Interesse für religiöse Erziehung haben.

Die Auswahl der Interviewpartner/-innen erfolgte über verschiedene Wege. Zum einen wurden die großen muslimischen Dachverbände, wie die IGMG, DITIB oder die VIKZ, bzw. kleinere Verbände, wie die Jama'at-un Nur, ein religiös unabhängiger Verein in Neuss usw. angefragt. Es wurden Vorabgespräche mit Vertretern und Vertreterinnen der jeweiligen Verbände geführt und das Anliegen der Untersuchung vorgestellt, sodass sie Informationen an potenzielle Interviewpartner/-innen weitergeben konnten. Mit Ausnahme der VIKZ und einigen Mitgliedern der Gülen-Gemeinde hat sich aus diesen Kontakten der Zugang zu mehr als der Hälfte der Proband(inn)en der vorliegenden Untersuchung ergeben.

Zum anderen spielten auch persönliche Kontakte bei der Probandenauswahl eine wichtige Rolle, da doch ein gewisses Vertrauensverhältnis die Voraussetzung dafür war, die Interviewpartner/-innen von dem Forschungsanliegen zu überzeugen. So ergaben sich einige Interviews aus Kontakten zum Bekanntenkreis der Bekannten der Forscherin. Wiederum andere Kontakte sind gemäß dem »Schneeballprinzip« durch die Proband(inn)en selbst entstanden, welche die Autorin der vorliegenden Dissertation an ihre Bekannten und Freunde weitervermittelten.

Die meisten Befragten nahmen die religiösen Bildungsangebote der verschiedenen Dachverbände wahr, ohne gleichzeitig Mitglieder in diesen Dachverbänden zu sein. Es gab unter ihnen aber auch Personen, die engagierte Mitglieder in ihren jeweiligen religiösen Gemeinden sind (dies wurde insbesondere im Anschluss der Tonbandaufzeichnung deutlich, aber auch die Art

3 | Die Berücksichtigung der gesamten Familie (Vater, Mutter und Kinder) würde ein Gruppendiskussionsverfahren erforderlich machen, welches anders aufgebaut werden müsste. 
und Weise, wie sie ihre Argumente in einem selbstbewussten, sich repräsentierenden Stil hervorbrachten, ließ diesen Rückschluss zu).

Die meisten Proband(inn)en leben im Großraum Köln. Doch es gibt unter ihnen auch einige Interviewpartner/-innen, die im weiteren Umkreis von Köln zu Hause sind, wie z.B. in Krefeld, Duisburg oder Monheim.

\subsection{Die Beschreibung der Untersuchungsgruppe}

Insgesamt wurden 16 Interviews für die Auswertung herangezogen. Die Beschreibung der Untersuchungsgruppe ergibt sich aus den Rahmendaten, die im Anschluss der Interviews durch die Befragten ausgefüllt wurden.

Insgesamt stellte sich heraus, dass Frauen eher dazu bereit waren, an den Interviews teilzunehmen als Männer. Dadurch ergeben sich unterschiedliche Fallzahlen. Es wurden insgesamt elf Frauen, d.h. Mütter, und fünf Männer, das bedeutet Väter, in die Untersuchung einbezogen.

Neun der Befragten sind in der Türkei geboren, die restlichen sieben in Deutschland. Ungefähr genauso viele besitzen die deutsche Staatsbürgerschaft, folglich bedeutet dies, dass mehr als die Hälfte der Proband(inn)en türkische Staatsbürger sind. Von den in der Türkei geborenen sind, bis auf zwei Probandinnen und einen Probanden, alle im Kleinkindalter nach Deutschland eingereist und haben somit das deutsche Bildungssystem kennengelernt und absolviert, sodass sie als Bildungsinländer/-innen gelten. Sie haben mindestens einen Hauptschulabschluss und unter ihnen sind sowohl Hausfrauen bzw. Arbeiter als auch Akademiker/-innen mit und ohne Berufstätigkeit. Zwei der Probandinnen sind bedingt durch ihre Heirat nach Deutschland ausgewandert. Ein männlicher Befragter ist zwecks Studiums nach Deutschland gekommen und heiratete in diesem Land (mit den letzten drei erwähnten Befragten wurden die Interviews auf Türkisch geführt). Eine Ausnahme bildet eine Probandin, die in Deutschland geboren wurde und hier studierte, aber nach ihrem Studium in die Türkei zurückging. Sie ist jedoch mit dem Ziel der Absolvierung einer Weiterbildung kurzfristig nach Deutschland zurückgekommen.

Die Proband(inn)en waren zum Zeitpunkt der Erhebung (zwischen Dezember 2012 und Februar 2013) im Alter von 28 und 41 Jahren. Die jüngste Probandin ist zum damaligen Zeitpunkt 28 Jahre alt gewesen. Zwei weitere Befragte waren im Alter von 32 und 33 Jahren. Eine war 35, drei waren 36 , vier 37, eine 38 , eine 39 , eine 40 und der älteste Befragte war 41 Jahre alt. Von einem Probanden liegt das Alter nicht vor, er ist aber ungefähr im Alter der anderen an der Untersuchung Beteiligten. 


\section{Die Kinder der befragten Eltern}

Die befragten Eltern haben mindestens ein Kind bis fünf Kinder im Alter von sechs Monaten bis 21 Jahren, die sowohl männlichen als auch weiblichen Geschlechter sind. Die Mehrheit der Interviewteilnehmenden bzw. Eltern $(\mathrm{n}=9)$, d.h. Hülya, Feride, Dilek, Belkıs, Rabia, Melek, Mecelle, Ethem und Adem haben zwei Kinder. Zwei $(n=2)$ der Befragten, Lema und Ali, haben jeweils nur ein Kind. Vier $(\mathrm{n}=4)$ der befragten Frauen haben drei oder mehr Kinder: Selma und Nisa haben jeweils drei Kinder, Zehra vier und Nermin fünf Kinder.

Von den insgesamt 37 Kindern sind drei $(n=3)$ im Säuglingsalter, sieben $(n=7)$ im Kleinkindalter. Fünf der Kleinkinder besuchen eine Kindertagesstätte. Elf $(\mathrm{n}=11)$ von den insgesamt 37 Kindern besuchen eine Grundschule, davon gehen fünf auf konfessionell (katholisch und evangelisch) gebundene Grundschulen. Als weiterführende Schulen wurden das Gymnasium und die Gesamtschule angegeben. Zwölf $(n=12)$ von den 37 Kindern besuchen das Gymnasium, davon gehen zwei auf ein Wirtschaftsgymnasium. Zwei $(\mathrm{n}=2)$ der Kinder gehen auf eine Gesamtschule. Eine Ausnahme bilden die zwei Söhne $(n=2)$ von Lale, von denen einer ein Internat (=Lise) in der Türkei besucht und der andere ein Studium in der Türkei absolviert. Alles in allem dominieren die Zahlen der Grundschulkinder ( $\mathrm{n}=11)$ und die Kinder und Jugendlichen, die ein Gymnasium ( $\mathrm{n}=13$ ) besuchen. Dies zeigt, dass es sich um Eltern handelt, die nicht nur im religiösen Bereich engagiert sind, sondern auch hohe Bildungsansprüche haben.

\section{Bildungsstand/Berufliche Qualifikation}

Der Bildungsstand und die berufliche Qualifikation bzw. Tätigkeit variierte unter den Befragten insgesamt stark. Auffallend viele Teilnehmer/-innen haben einen akademischen Bildungsabschluss $(n=6)$ oder haben den Weg eingeschlagen, einen zu erwerben $(n=3)$. Diese hohe Fallzahl ist wohl auch damit zu begründen, dass diese Eltern dazu in der Lage sein wollten, auch im Rahmen dieses Forschungsbereiches entsprechend argumentieren und sich angemessen artikulieren zu können. Auffällig war zudem, dass fünf der Mütter sogar einen pädagogischen Bildungsabschluss vorweisen konnten, lediglich zwei von ihnen waren jedoch beruflich bzw. ehrenamtlich tätig.

Zwei Mütter und ein Vater haben das Abitur (Lise-Abschluss) in der Türkei abgeschlossen. Die Mütter sind Haufrauen und sind zudem in ihren religiösen Gemeinden ehrenamtlich tätig. Ein in der Türkei sozialisierter Vater ist ein selbstständiger Unternehmer. Einer von den fünf befragten Vätern, der in Deutschland geboren ist, hat seine berufliche Ausbildung abgeschlossen und war zum Zeitpunkt der Befragung damit beschäftigt, das Abitur nachzuholen, um im Anschluss daran Sozialpädagogik zu studieren. Auch war er in der religiösen Bildungsarbeit einer Gemeinde aktiv engagiert. Aufgrund der höheren Bereitschaft der Akademiker/-innen, an den Interviews teilzunehmen, 
wurde zudem darauf geachtet, auch Mütter und Väter zu befragen, die einen geringeren Bildungsabschluss vorzuweisen hatten. So ergab es sich, dass zwei der Mütter eine Berufsausbildung abgeschlossen hatten, wobei die eine inzwischen einen anderweitigen Beruf als ihren eigentlich erlernten Beruf ausübt und die andere Mutter aufgrund ihrer vier Kinder Hausfrau ist. Zwei weitere Probandinnen verfügen über einen Hauptschulabschluss. Eine von ihnen hat eine Medrese-Ausbildung abgeschlossen (religiöse Bildung) und ist in der religiösen Bildungsarbeit einer Moscheegemeinde tätig, die andere ist Hausfrau und war zum Zeitpunkt des Interviews gerade dabei, eine religiöse Grundausbildung (einer religiösen Organisation) zu absolvieren.

\section{Merkmale der Ehepartner}

Die Ehemänner und die Ehefrauen der Befragten sind zum Erhebungszeitpunkt im Alter zwischen 29 und 43 Jahren. Neun der Ehepartner/-innen verfügen über einen Hochschulabschluss. Zwei Ehemänner haben einen Hauptschulabschluss mit einer Berufsausbildung. Drei Ehemänner und eine Ehefrau haben das Abitur in der Türkei abgeschlossen, einer von den Männern ist Arbeiter und zwei weitere sind als selbstständige Unternehmer tätig, eine der befragten Frauen ist Hausfrau. Fünf der Ehepartner/-innen sind als Heiratsmigranten nach Deutschland gekommen. Eine Ausnahme bildet hierbei ein Proband, der von seiner Frau geschieden lebt.

Insgesamt handelt es sich in dieser Untersuchung um Männer und Frauen, bildungserfolgreiche Migrant(inn)en sowie Deutsche mit türkischem Migrationshintergrund. Sie sind sowohl an weltlicher als auch an religiöser Weiterbildung interessiert. Fast ein Drittel der an den Interviews Beteiligten sind auch engagierte aktive Personen in ihren jeweiligen religiösen Gemeinden. Die Auswahl dieser Gruppe war kein beabsichtigter Effekt, sondern ist eher als ein Begleitumstand anzusehen.

\subsection{Die Datenerhebung (Planung und Durchführung)}

\section{Erhebungsort und Rahmenbedingungen der Erhebung}

Die Interviews wurden alle von der Verfasserin der vorliegenden Dissertation im Erhebungszeitraum von Dezember 2012 bis Februar 2013 durchgeführt. Von besonderer Bedeutung war es dabei, ein Vertrauensverhältnis zu den befragten Proband(inn)en aufzubauen, was möglichst schon vor dem vereinbarten Termin geschehen sollte. In den Vorabgesprächen wurde die Forschungsabsicht mitgeteilt, um die potenziellen Teilnehmer für die Forschungsarbeit zu gewinnen. Zudem wurde darauf geachtet, den Eltern die Möglichkeit einer Erziehungsberatung einzuräumen, falls diese erwünscht wäre. So hatten sie neben einem Interview zudem unverbindlich die Möglichkeit, einer für sie unbekannten Person ihr Anliegen mitzuteilen und darüber hinaus konnte damit 
erst das Klima geschaffen werden, das es den Interviewpartnern erlaubte, sich $\mathrm{zu}$ den jeweiligen Themenbereichen gegenüber der Interviewerin zu öffnen. In den meisten Fällen, auch bei den Befragten, die, ohne dieses Angebot zu kennen, bereits eingewilligt hatten, folgten im Anschluss, aber auch vor den Interviews Beratungsgespräche zu Erziehungsthemen, familiären Angelegenheiten, bis hin zu beruflichen Themen. In einigen wenigen Fällen traten auch persönliche Konflikte zutage, die den Interviewablauf störten. Diese Interviews wurden für die vorliegende Arbeit nicht verwendet. ${ }^{4}$

Die Interviews fanden an unterschiedlichen Orten statt. Den Befragten war es selbst überlassen, darüber zu entscheiden, wo die Interviews stattfinden sollten. Gerade bei Proband(inn)en, die über die muslimischen Dachverbände rekrutiert wurden, fanden die Interviews sowohl an ihren Arbeitsplätzen als auch in den Räumlichkeiten der Gemeinden, zu denen sie in Verbindung standen, statt. In sechs Fällen fanden die Interviews bei den Proband(inn)en zu Hause statt. In drei weiteren Fällen war es schwieriger, einen Ort zu finden, an dem ungestört kommuniziert werden konnte. Hier hat in einem Fall ein regional bekannter muslimischer Verein seine Räumlichkeiten zur Verfügung gestellt. In einem anderen Fall handelte es sich um einen Vater, der sich einen neutralen Ort für die Interviewdurchführung wünschte, sodass das Interview schließlich im Beisein einer weiblichen Bekannten in einem Café stattfand. ${ }^{5}$ Im letzten Fall wurde das Interview bei mir zu Hause durchgeführt, da die Mutter aufgrund ihrer fünf Kinder keinen ungestörten Ablauf gewährleisten konnte. Die detaillierten Umstände wurden jeweils in Forschungsprotokollen zu den betreffenden Elternteilen festgehalten.

Insgesamt fiel auf, dass die Interviews, die an den Arbeitsplätzen durchgeführt wurden, etwas förmlicher und sachlicher verliefen als die Interviews bei den Proband(inn)en zu Hause. Jedoch war die Reaktion auf die Interviewsituation bei allen Proband(inn)en jeweils eine andere und von Fall zu Fall sehr individuell, sodass hier nicht von einer eindeutigen Tendenz gesprochen werden kann. Auch die Gesprächsatmosphäre war so unterschiedlich, wie es die Interviewpartner selbst waren, sodass diese Eindrücke und Beobachtungen jeweils im eigenen Kontext gewertet werden müssen.

4 | Rerrich (1995) verweist auf ethische Probleme, die im Zusammenhang mit einer qualitativen Familienforschung existieren würden. Mit der Analyse dringe die qualitative Forschung in einen Lebensbereich vor, der von Intimität gekennzeichnet sei. Daneben könnten sich qualitative Interviews in Familien in quasi-therapeutische Interaktionen verwandeln, wenn hier bislang unbearbeitete Konflikte thematisiert würden (vgl. Rerrich 1995: 351).

5 | In diesem Fall war es dem Probanden wichtig, auf das Prinzip der Geschlechtertrennung zu achten. 
Auffällig war des Weiteren auch, dass das Aufnahmegerät bei einem Großteil der Befragten für Irritationen und Verunsicherungen sorgte. Die Gewährleistung einer Anonymität durch die Veränderung des Namens und die Gespräche, die vor den Interviews durchgeführt wurden, konnten diese Verunsicherungen jedoch beheben. Zudem muss berücksichtigt werden, dass mit der Erforschung von Familien in einen Lebensbereich vorgedrungen wird, der von Intimität gekennzeichnet ist, sodass es hier besonders wichtig war, zunächst ein Vertrauensverhältnis zu schaffen. Hier erwies es sich, so ein Befund dieser Studie, als ein großer Vorteil, dass ich als Verfasserin der vorliegenden Dissertation und selbst kopftuchtragende muslimische Forscherin wichtige Voraussetzungen zur Erforschung der vorliegenden Thematik mitbrachte. Gerade die eigenen religiösen Bezüge, die über den Umgang mit religiösen Themen bis hin zur religiösen Praxis und der Kenntnis der muslimischen Binnenstrukturen reichen, waren wichtig, um zu Beginn der Interviewsituation und im Anschluss der Interviews mit den Interviewpartnern im Gespräch zu bleiben. Als ein gewisser Vorteil erwies es sich zudem, wenn die Proband(inn) en über Bekannte vermittelt wurden. In diesen Fällen konnte man mehr Offenheit und ein großes Vertrauen aufseiten der Befragten spüren.

\section{Die Bedeutung der Sprache}

Zunächst sollten die Gesprächspartner deutschsprachig an den Interviews teilnehmen. Dies hatte einen praktischen Hintergrund. Es sollte sowohl die aufwendige Transkription erleichtern, als auch den Aufwand, den die Forscherin mit der Übersetzung in die deutsche Sprache hätte, minimieren. Jedoch sollte die Möglichkeit eingeräumt werden, in den verschiedenen Interviewpassagen auch die türkische Sprache verwenden zu können, da bestimmte Inhalte, wie bspw. der religiös-emotionale Bereich oder innerfamiliäre Aspekte, möglicherweise in ihrer Erlebnisqualität nur in der Muttersprache, d.h. auf Türkisch, entsprechend wiederzugeben wären. Zudem wäre es auch denkbar, dass es bestimmte religiöse Begrifflichkeiten bzw. Deutungen nur in der türkischen Sprache gibt. Mit »Religion« wird ein türkisch als auch arabisch geprägtes Wortfeld aktiviert. Für viele Begriffe der religiösen Praxis, rituelle Handlungen und zur Beschreibung von religiösen Glaubensinhalten würden den Interviewpartnern häufig die adäquaten deutschen Übersetzungen fehlen bzw. behindere die Suche nach den >richtigen Begriffen $>$ den Redefluss (vgl. auch Karakaşoğlu-Aydın 2000: 169). So kam es vor, dass etliche arabische bzw. türkische Begriffe im Redefluss verwendet wurden, auch wenn in den meisten Fällen vorwiegend in deutscher Sprache kommuniziert wurde. In der Transkription der Interviews wurde darauf geachtet, diese Begriffe bzw. Sätze kursiv wiederzugeben; die Übersetzungen bzw. ungefähren Bedeutungen wurden in Klammern angeführt. 
In manchen Fällen war es notwendig, wenn einige Proband(inn)en, die eigentlich vornehmlich deutsch sprechen wollten, sich aber in einigen Passagen nicht in der deutschen Sprache äußern konnten, während der Interviews als Stütze beim Übersetzen der Begrifflichkeiten einzugreifen (so z.B. bei Lale, Rabia, Selma oder Melek und Adem). Bei diesen Proband(inn)en konnte ich mich nicht des Eindrucks erwehren, dass die Qualität und Intensität ihrer Aussagen, wenn sie ausschließlich türkisch gesprochen hätten, viel höher gewesen wäre, weil schlichtweg wichtige Inhalte in einer vereinfachten deutschen, weniger differenzierten Sprache wiedergegeben wurden. Hierzu vermerken auch Boos-Nünning/Neumann/Reich/Yakut (1986) in ihrer zweisprachig durchgeführten Untersuchung über türkische Jugendliche und ihre Familien, dass differenzierte Diskussionen nicht in beiden Sprachen in gleicher Art und Weise möglich seien. Oftmals könnten hierbei komplizierte Sachverhalte in einer der beiden Sprachen nicht in der nötigen Nuancierung vermittelt werden (vgl. ebd.: 57).

Im Laufe der Forschungsarbeit ergab es sich, auch wenn zunächst angegeben wurde, die Interviews auf Deutsch durchzuführen, dass in drei der Fälle die Interviews ausschließlich in türkischer Sprache durchgeführt werden mussten, da die Artikulationsfähigkeit durch die Verwendung der deutschen Sprache sehr eingeschränkt worden wäre. So wurden diese Interviews zunächst in deutscher Sprache begonnen und in türkischer Sprache fortgesetzt. Diese Interviews wurden nicht vollständig transkribiert, da der Aufwand hier sehr hoch gewesen wäre. So wurden diese von mir protokolliert und zusammengefasst auf Deutsch wiedergegeben. Lediglich sehr wichtige Aussagen, die der näheren Auswertung hinzugezogen werden könnten, wurden abschnittsweise auf Türkisch transkribiert. Diese werden im Auswertungsschritt von der Forscherin selbst übersetzt wiedergegeben (diese sind unterstrichen und entsprechend als Übersetzungen gekennzeichnet).

\section{AusWertung Der Interviews}

\subsection{Arbeitsschritte der Auswertung}

\section{Vorbereitung der Interviews für die Auswertung (Datenaufbereitung)}

Die Gespräche wurden mit einem Aufnahmegerät, das sichtbar vor der Interviewerin und den jeweiligen Gesprächspartnern und -partnerinnen auf dem Tisch platziert wurde, aufgezeichnet.

In einem weiteren Schritt wurden die Gespräche bis auf drei, die auf Türkisch (vgl. oben) stattfanden, vollständig wortwörtlich literarisch transkribiert. Auffälligkeiten der Sprache, wie bspw. Betonung, Pausen, Lachen, Unterbrechungen usw., wurden im Wortprotokoll notiert. Türkische (türk.) bzw. ara- 
bische (arab.) Begriffe und Interviewpassagen in türkischer Sprache wurden kursiv gesetzt und die deutsche Übersetzung in Klammern angegeben.

Es wurden bei der Texterschließung die nachfolgenden Transkriptionszeichen verwendet:

$\begin{array}{ll}\text { Wort ... Wort } & \text { Auslassungen in den Interviewzeiten; Pausen; Denkpausen } \\ \text { Satz ... Satz } & \begin{array}{l}\text { Abbruch des Satzes } \\ \text { Unterbrechungen }\end{array} \\ \text { (überlegt) } & \text { Pause des Nachdenkens } \\ \text { (lacht) } & \text { Befragte(r) oder Interviewerin lacht } \\ \text { (lachen) } & \text { beide lachen } \\ \text { (unv.) } & \text { unverständlich gesprochene Worte }\end{array}$

Der Großteil der Interviews wurde durch zwei Schreibkräfte fremdtranskribiert. Es handelt sich hierbei um eine deutsch-türkische Sozialpädagogin und eine Fremdsprachenkorrespondentin, denen die Textaufbereitung bekannt gewesen ist. Die Interviews (Transkriptionen) wurden von der Verfasserin der vorliegenden Arbeit in einem weiteren Kontrollgang durch ein erneutes Abhören des Tondokuments noch einmal nachgebessert. ${ }^{6}$

Insgesamt variierte die Interviewzeit zwischen den Befragten. Sie betrug für jedes einzelne Interview etwa zwischen einer Stunde und zwei Stunden. Daraus ergaben sich insgesamt über 22 Stunden Gesprächszeit und ca. 430 Seiten Material, das schließlich zur Auswertung hinzugezogen wurde.

\section{Nachbereitung der Daten}

Im Rahmen der Auswertung wurde auf wörtliche Aussagen aus der Befragung zurückgegriffen. Die angegebenen Interviewpassagen orientieren sich an den verschriftlichten bzw. protokollierten und übersetzten Interviews. Dabei werden die abgeänderten Namen der Befragten mit der Zeile, in der sich die zitierten Interviewabschnitte befinden, wiedergegeben. Dies setzt sich beispielhaft folgendermaßen zusammen: Selma, Z.: xy (Name, Zeilennummerierung: xy) ${ }^{7}$.

6 | Die türkischen und arabischen Begriffe wurden im Textdokument kursiv wiedergegeben, im Auswertungsschritt werden diese übersetzt und unterstrichen dargelegt, bzw. es werden hierfür Synonyme in Klammern verwendet.

7 | Da mit dem MAXQDA-Programm gearbeitet wurde, erfolgte eine automatische Wiedergabe der Zeilennummerierung. So konnte eine nummerierte Zeile oder vielmehr ein Abschnitt aus einer oder mehreren Zeilen bestehen (siehe entsprechend Abb. 2 oben). 
Im verwendeten Programm ist dies folgendermaßen ausgeführt:

\begin{tabular}{|c|c|c|c|}
\hline 34 & I & Mhm. Also insgesamt? & - \\
\hline 35 & $\mathrm{~N}$ & Genau. & $\square$ \\
\hline 36 & 1 & $\begin{array}{l}\text { Die, die Erziehung, die Sie genossen haben? Können Sie was dazu sagen, also wie es, welche } \\
\text { Auswirkungen diese Erziehung auf Sie hatte? }\end{array}$ & \\
\hline 37 & $\mathrm{~N}$ & $\begin{array}{l}\text { Mhm. Ja eigentlich war die Erziehung eine Einheit. Ich habe es relativ, sehr positiv empfunden...Religion } \\
\text { war für mich...hat immer für mich dazu gehört, so dass ich...ja im...ja Ende des dritten Schuljahres, Anfang } \\
\text { des vierten Schuljahres gesagt habe: So ich möchte jetzt ein Kopftuch tragen. Da waren meine Eltern } \\
\text { erstaunt und erschrocken und haben gesagt: "Kind, du bist noch zu klein!" Und ich habe gesagt: Nee, ich } \\
\text { möchte das jetzt tragen und ich mach das auch." Und...ne, wahrscheinlich war meine religiöse } \\
\text { Erziehung...ja hat mir das so mit gegeben. }\end{array}$ & \\
\hline 38 & I & So überzeugend für Sie? & \\
\hline 39 & $\mathrm{~N}$ & $\begin{array}{l}\text { So überzeugend. Auf jeden Fall! Also meine...ich bin immer mit meiner Mutter in die Moschee gegangen. } \\
\text { Dort musste ich halt neben ihr sitzen und habe dann immer nebenbei dem Hoca zugehört und das hat } \\
\text { mich sehr geprägt. Der hat ja eigentlich den Älteren was gepredigt, wo die Kinder dann halt, einige } \\
\text { gespielt haben und so....aber ich habe ihm gerne zugehört und das hat mir schon sehr viel gebracht. }\end{array}$ & \\
\hline 40 & I & Und was waren das für Themen, die er dann so neben den Predigten...also was hat...was hat dazu & $*$ \\
\hline
\end{tabular}

Abbildung 3: Ausschnitt aus dem MAXQDA-Programm (Quelle: MAXQDA)

Die Interviewpassagen, die im Interviewverlauf als Beispiele dienten, sind, um hier eine bessere Lesbarkeit zu gewährleisten, sprachlich bereinigt wiedergegeben worden. Hierbei wurden zudem Wort- und Formulierungswiederholungen sowie Füllwörter herausgenommen, insofern dadurch der Satzbau nicht verändert wurde. Es ist darauf hinzuweisen, dass einigen Proband(inn)en die grammatische korrekte Wiedergabe von deutschsprachigen Sätzen schwerfiel und daher Fehler unvermeidlich waren. Aus diesem Grund wurden durch die Verfasserin Angaben in eckigen Klammern gemacht. Diese sollen dem besseren Verständnis dienen.

\subsection{Die Auswertungsmethode}

Die Auswertung der transkribierten Interviews erfolgte nach den Kriterien der strukturierenden qualitativen Inhaltsanalyse nach Mayring (vgl. Mayring 2010: 92ff.). Da es für diese Studie wichtig war, aus den erhobenen Interviews Typen von religiösen Erziehungsvorstellungen bzw. -mustern zu bilden, wurde hier eine Methodenkombination ausgewählt, sodass schließlich Elemente der typisierenden und strukturierenden Inhaltsanalyse integriert wurden. Die konkrete Umsetzung der Methode orientierte sich an der Gegenstandsangemessenheit, sodass einzelne Analyseschritte entsprechend der spezifischen Beschaffenheit des vorliegenden Materials und den forschungsleitenden Fragen modifiziert werden mussten (vgl. ebd.: 48 ff.). Kombiniert erfolgte zudem eine vollständig computergestützte Auswertung sämtlicher Transkripte mithilfe des Programms MAXQDA. Dieses ermöglichte eine Systematisierung des Datenmaterials und die Entwicklung eines Kodiersystems bzw. -leitfadens. Diese Variante der Auswertung stellte gegenüber einem manuellen Vorgehen eine erhebliche Vereinfachung dar. 


\section{Erläuterungen zur themenzentrierten Auswertung (nach Mayring)}

Die inhaltsanalytische Vorgehensweise nach Mayring ermöglicht ein systematisches regelgeleitetes Vorgehen, das eine Orientierung an vorab festgelegten Regeln der Textanalyse erforderlich macht. Am zentralsten ist dabei die Festlegung eines konkreten Ablaufmodells, das konkret am Forschungsgegenstand, dem Material und der spezifischen Fragestellung konstruiert wird. Hierbei werden die einzelnen Analyseschritte definiert und ihre Reihenfolge festgelegt. Die Systematik zeigt sich auch in ihrem zergliedernden Vorgehen in inhaltsanalytische Einheiten (Kodiereinheit, Kontexteinheit, Auswertungseinheit) (vgl. Mayring 2010: 48f.). Das bedeutet konkret, dass man sich vorab zu entscheiden hat, »wie das Material angegangen wird, welche Teile nacheinander analysiert werden, welche Bedingungen erfüllt sein müssen, um zu einer Kodierung zu gelangen« (Mayring 2010: 49). Zudem könne es im Prozess der induktiven Kategorienbildung von Vorteil sein, solche inhaltsanalytischen Einheiten sehr offen zu halten (vgl.ebd.).

Dieses Verfahren tendiert dazu, Sachverhalte, Einstellungen bzw. Deutungen aufzuzeigen, die einen über den Einzelfall hinaus zu generellen Aussagen führen.

Die Auswertung der Erhebungen zum Textverstehen erfolgte in zwei Stufen:

a. Die Einstellungen, Deutungen der Eltern werden Inhaltspunkt um Inhaltspunkt analysiert und in ein Schema eingeordnet, wobei auch die Offenheit gewahrt wurde, um induktive Kategorien zu bilden.

b. Auf der zweiten Stufe wurde, je nach Bearbeitungszweck, eine text- oder personenbezogene Zusammenfassung vorgenommen.

\section{Die Entwicklung eines Kategoriensystems (Kodiersystem)}

Auf der Basis des Interviewmaterials galt es, ein Kategorienschema zu entwickeln, das für alle Interviews angewandt werden konnte.

So ergaben sich gemäß den methodischen Empfehlungen von Mayring zunächst folgende Analyseschritte:

- Festlegung der Dimensionen für die Auswertung und Entwicklung eines Kategoriensystems anhand theoretischer Vorüberlegungen

- Bestimmung der Analyseeinheiten und Erstellung eines Kodierleitfadens (gemäß dem Ablaufmodell nach Mayring 2010: G1ff.).

Dieser Vorgang erfolgte sowohl induktiv als auch deduktiv.

In einem ersten Schritt wurden die Dimensionen der Auswertung deduktiv anhand theoretischer Vorüberlegungen und forschungsleitenden Fragen festgelegt (vgl. thematisches Kodieren bei Mayring 2010: 61ff.). So ergaben sich insgesamt neun Themenfelder (vgl. Interviewleitfaden), zu denen entsprechende Kodiereinheiten (Codes), wie z.B. die Glock'schen Dimensionen zur 
Erfassung von Religiosität, Methoden, Erziehungszielen, -methoden, -stilen usw., festgelegt wurden.

Neben der deduktiven spielte auch die induktive Kategoriengewinnung (aus dem Text heraus), wie sie z.B. von Strauss/Glaser (vgl. z.B. Böhm 2003: 475ff.) vorgeschlagen wurde, eine wichtige Rolle. So erfolgte bspw. die Ermittlung der Erziehungsziele nur anhand der Aussagen der Eltern (siehe unten). Zudem konnten den übergeordneten Kodiereinheiten aus den Texten heraus, d.h. induktiv, nochmals Untereinheiten (Subcodes) zugeordnet werden (so konnte z.B. der Methode innerhalb der Familie als Subcode bzw. Untereinheit das Vorbildsein oder die Kommunikation untergeordnet werden).

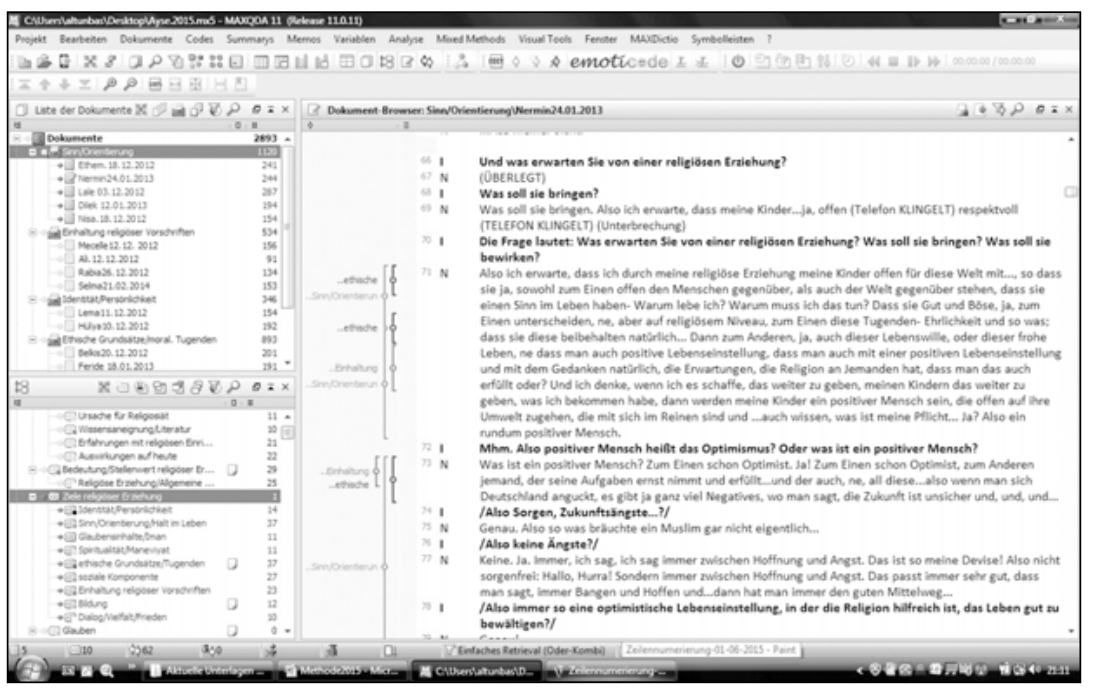

Abbildung 4: Ausschnitt aus dem MAXQDA-Programm (Quelle: MAXQDA)

Die Kodierung der Texteinheiten wurde mit dem Programm MAXQDA vorgenommen. Es wurde mit vorab definierten und aus dem Text gewonnenen Kategorien ein Klassifikationssystem entwickelt, das zunächst auf die ersten Interviews angewandt und ggf. modifiziert und dem Material angepasst wurde. Mithilfe dieses Kodiersystems wurden in einem ersten Durchgang kategorienbezogene Einzelfallanalysen erarbeitet. Die Anwendbarkeit des Kategoriensystems wurde solange überprüft und korrigiert, bis alle Interviews analytisch aufbereitet werden konnten, sodass eine endgültige Festlegung bis zum letzten Interview nicht gegeben war. Dies geschah, weil auch immer Vergleiche zu den Aussagen aller anderen Eltern gezogen wurden und damit einer größtmöglichen Offenheit Rechnung getragen wurde. Schließlich entstanden somit ein Kategoriensystem und ein Kodierleitfaden, durch die das Programm einfacher handhabbar wurde. 
Im nächsten Schritt wurde eine (auch für die Typenbildung wichtige) am Thema der Untersuchung orientierte kurze Zusammenfassung der Befunde für jeden einzelnen Fall erstellt, die wichtige Hinweise auf besondere Schwerpunkte der einzelnen Interviews in einem übersichtlichen Fazit anbot. Die Fallzusammenfassungen ermöglichten einen inhaltlichen Überblick über das gesamte Material und es konnte somit der Blick für Gemeinsamkeiten und Unterschiede zwischen den Befragten geschärft werden.

\subsection{Die Typenbildung}

Bevor die verschiedenen Sozialisationseinflüsse untersucht werden, erschien es sinnvoll, eine Typenbildung vorzunehmen, um das umfangreiche Material systematisch zu ordnen.

Typisierende Strukturierungen ermöglichen es, besondere Bedeutungsgegenstände herauszuziehen und genauer zu beschreiben. Es kann sich bei diesen Typen sowohl um Personen handeln als auch um typische Merkmale, d.h. »allgemein markante Ausprägungen auf einer Typisierungsdimension« (Mayring 2010: 98). Bedeutsam ist, dass diese Dimension zunächst definiert, einzelne Ausprägungen dazu formuliert werden müssen, um dann mit diesen Kategorien das Material durchzuarbeiten (vgl. ebd.). Nach Mayring muss aufgrund des Materials bestimmt werden, welche Ausprägungen als besonders markant, als typisch bezeichnet werden sollten. Dabei seien mindestens drei verschiedene Kriterien denkbar:

- »Besonders extreme Ausprägung sollen beschrieben werden.

- Ausprägungen von besonderem theoretischem Interesse sollen beschrieben werden.

- Ausprägungen, die im Material besonders häufig vorkommen, sollen beschrieben werden.« (Mayring 2010: 98).

Demnach spielte für die Typenbildung die Identifizierung von Kategorien, denen die Interviews zugeordnet werden konnten und die sich im Hinblick auf eine Merkmalskombination untereinander möglichst ähnlich waren, eine zentrale Rolle. Als Gruppe oder Merkmalskombination sollten sich die Fälle jedoch weitestgehend voneinander unterscheiden.

Diese Kategorien wurden im Zusammenhang mit den Erziehungszielen, die als »Ausprägung[en] von besonderem theoretisches Interesse « in der vorliegenden Untersuchung gelten, induktiv aus den Interviewtexten ermittelt. Dies erfolgte nach dem Verfahren der »offenen Kodierung«. Dabei wurde, wie bereits oben beschrieben, in mehreren Schritten vorgegangen. Die Interviewpassagen zu den Erziehungszielen wurden ohne festes Kategorienschema kodiert, wobei sich Zeile für Zeile einzelfallanalytisch induktiv entwickelte Kategorien ergaben, die den Inhalt in repräsentativen Begriffen darstellen und 
dabei den Zugang zur subjektiven Deutung der Interviewten wiedergeben. So konnten verschiedene Zielrichtungen und perspektivische Zugänge zur Thematik herausdestilliert werden. Die Auswertung und Strukturierung des Datenmaterials erfolgte theoriegeleitet (vgl. Kap. II. 3.1.3: Was ist Erziehung?). In der Erziehung, die als ein Aspekt der Sozialisation gilt, ist es von Bedeutung, welche Aspekte hervorgehoben werden und welcher perspektivische Zugang letztlich gewählt wird. Dabei hat jeder Elternteil eine eigene Sicht zum Thema der Erziehung, die dieser »beschreibt, plant, organisiert, konstruiert« (vgl. ebd. $\rightarrow$ Einstellungen, Grundorientierungen/Verhaltensmuster). Auch dem Stellenwert, den der religiösen Erziehung beimisst, wird in den Interviews Ausdruck verliehen. Erfahrungen, die in der Kindheit mit dem Thema der Religion gemacht wurden, haben vielfach Konsequenzen auf die heutige erzieherische Einstellung bzw. -praxis. Diese Zusammenhänge werden in der Typologie eingehend beschrieben.

Zudem wurde bei der Typenbildung darauf geachtet, die Glaubensdimension (Aspekt der Glock'schen Dimensionen) und daraus abgeleitete erzieherische Konsequenzen als Vergleichskriterium heranzuziehen, da sich darin in den meisten Fällen der perspektivische Zugang manifestierte bzw. die von den Eltern zuvor benannten Aspekte der Erziehungsvorstellungen widerspiegelten. Schließlich wurden auch auf der gesellschaftlichen Ebene Ziele und Vorstellungen zur religiösen Erziehung formuliert, die im Grunde die eingangs formulierte Grundeinstellung zur religiösen Erziehung wiedergeben. Die Berücksichtigung dieser Ebene sollte der Überprüfung der zu Beginn formulierten Einstellungen dienen und womöglich ergänzend zur Fallkontrastierung bzw. -übereinstimmung beitragen.

Im letzten Schritt wurden die Interviews mit ihrer jeweiligen Kategorisierung fallübergreifend verglichen und es wurden alle Fälle abschließend anhand von Merkmalskombinationen gruppiert und auf empirische Regelmäßigkeiten hin überprüft. Entscheidend war hierbei zunächst, entsprechend dem theoretischen Interesse vorzugehen und den zu Beginn formulierten perspektivischen Zugang zu berücksichtigen. Demnach konnten Erziehungsziele in anderen Zusammenhängen, wie z.B. auf der Ebene der religiösen Bildungseinrichtungen, zwar auch formuliert werden, wichtig war jedoch vielmehr die Berücksichtigung primärer Aussagen. Auch das Kriterium der Häufigkeit einer Nennung bzw. Bedeutungszuweisung gelte als richtungsweisend für die Typenbildung. Besonders »extreme« (vgl. Mayring 2010: 98) Ausprägungen seien in den jeweiligen Typenbeschreibungen wiedergegeben.

Die aus dem Datenmaterial induktiv gewonnenen Typen religiöser Erziehung stellen somit ein als Konstrukt zu bezeichnendes Hilfsmittel zur Systematisierung des umfangreichen Materials dar, das subjektive Deutungsmuster wiedergibt. Das heißt konkret, dass zum einen die individuelle und biografische Einzigartigkeit eines jeden Interviewpartners unterstrichen wer- 
den muss, auch wenn diese aufgrund einiger besonderer Ausprägungen und Merkmale einem bestimmten religiösen Erziehungstyp zugeordnet wurden. Zum anderen bedeutet dies jedoch, dass sich Überschneidungen zwischen den einzelnen Gruppen nicht vermeiden ließen und bestimmte Merkmale eines religiösen Erziehungstyps somit auch unter einem anderen Typ mit einem anderen Stellenwert ${ }^{8}$ vorgefunden werden konnten. In jedem Fall kann daraus geschlussfolgert werden, dass die Übergänge zwischen den verschiedenen Typen als fließend anzusehen sind und sich hier keine eindeutigen Abgrenzungen vornehmen lassen.

\section{Typologie religiöSer ERZiehungsvorstellungen}

Insgesamt wurden aus dem empirischen Material vier religiöse Erziehungstypen erarbeitet, deren gemeinsame charakteristische Merkmale zusammenfasend unter dem jeweiligen Kapitel wiedergegeben wurden.

Bei der Darstellung wurde vor allem auch darauf geachtet, auf die jeweiligen individuellen Unterschiede der Proband(inn)en hinzuweisen, die einem bestimmten religiösen Erziehungstyp zugeordnet wurden, um den Blickwinkel für eine höhere Differenzierung auch innerhalb der jeweiligen Gruppen zu schärfen. Zudem wurden die Sozialisationsverläufe der jeweiligen Proband(inn)en in den Ursprungsfamilien abgebildet, um den heutigen Stellenwert der religiösen Erziehung zu charakterisieren. Folglich erschien es umso sinnvoller, jeden Elternteil (des jeweiligen Typs) mit seinen charakteristischen Eigenschaften individuell vorzustellen, um dessen Einzigartigkeit, trotz der sich darbietenden gemeinsamen Merkmale, entsprechend zu unterstreichen.

\subsection{Religiöser Erziehungstyp, der nach Sinn und Orientierung strebt - "Idealisten "}

Charakteristisch ist für diesen religiösen Erziehungstyp, dass alle Eltern (Ethem, Nermin, Lale, Dilek und Nisa) nach übergeordneten Prinzipien bzw. einem Sinn streben, der diesen eine Orientierung im diesseitigen Leben geben sollen.

8 | Dies kann exemplarisch an folgendem Beispiel veranschaulicht werden: Ethische Grundsätze spielen uneingeschränkt für alle Eltern, d.h. für alle religiöse Erziehungstypen, eine zentrale Rolle. Sie unterscheiden sich aber darin, welche Bedeutung sie diesen jeweils beimessen. D.h. für jene Eltern, für die ethische Prinzipien im Mittelpunkt stehen ("Ethiker"), nehmen diese einen herausragenden Stellenwert ein. Für idealistische, ritualistische Eltern hingegen spielen diese eine eher untergeordnete Rolle. Wichtig ist demnach, welchen Zugang bzw. welche Ziele die Eltern bzgl. ihrer religiösen Erziehung in den Vordergrund stellen. 
Die Religion stellt für diese Gruppe den (Deutungs-)Rahmen für ihre erzieherischen Vorstellungen und Handlungen dar. Es fällt bei diesem Typus zudem auf, dass sich Begründungen auf religiös fundierte Begrifflichkeiten und etwas vorsichtig ausgedrückt auf »Erziehungskonzeptionen« unter Bezugnahme auf islamische Quellen stützen (vgl. hierzu u.a. Dodurgal1 1998). Alle Eltern haben sich intensiv mit der Religion auseinandergesetzt, sodass ihnen ihre Suche nach dem Sinn viele Vorteile in ihrem Leben bescherte. In diesem Zusammenhang werden gerne sinnhaft spirituelle Aspekte benannt. Diese Eltern wünschen sich für ihre Kinder ein hohes Maß an Selbstverantwortung, das sie dazu befähigen soll, ihre eigene Wahrheit zu finden, indem sie sich verantwortungs- und pflichtbewusst mit ihrer Religion auseinandersetzen, danach leben und handeln. Dies beinhaltet sowohl die Einhaltung von (rituellen) religiösen Vorschriften als auch die Befolgung von ethischen Grundsätzen und Tugenden, ob diese einen sozialen Charakter haben oder ob sie sich auf persönliche Lebenseinstellungen beziehen. Diese nehmen aber im Vergleich z.B. zu den »Ethikern« für die Eltern dieser Gruppe eine eher untergeordnete Stellung ein und sind sozusagen ein wichtiger Teil ihrer religiösen Lebensweise.

Ethem entstammt einer religiösen Familie, in der er auch religiös erzogen wurde. Seine Eltern sind »regelmäßige Moscheegänger«, wie er sie selbst bezeichnet. Beide Eltern waren/sind engagierte Mitglieder in ihrer Gemeinde, in der sein Vater auch Vorstandstätigkeiten übernahm. Im Gegensatz zur Verwandtschaft war die »Kleinfamilie« religiös, in der die Gebete ernst genommen und vor allem viel Wert auf religiöse Literatur gelegt wurde. Die Familienatmosphäre, in der er aufgewachsen ist, und der intensive Gemeindebezug der Familie haben Ethem besonders geprägt. Die Religiosität der »Kleinfamilie« war gegenüber der Verwandtschaft in der Türkei eher eine Ausnahme, was Ethem mit der Migrationserfahrung seiner Familie begründet (vgl. Ethem, Z.: 25). Die positiven Auswirkungen, die die religiöse Erziehung in seinem Elternhaus auf Ethem hatte, beschreibt er folgendermaßen:

"Also für mich gesehen eine positive Auswirkung, also ich habe die Ansätze, die ich aus der Familie mitbekommen habe wie gesagt, wir hatten ... ich hatte die Möglichkeit, auf Bücher zurückzugreifen. Meine Eltern haben auch relativ früh Wert darauf gelegt, dass zum Beispiel mein Türkisch aufrechterhalten bleibt. Also ich habe zum Beispiel in der Grundschulzeit auch Grundschulbücher aus der Türkei bekommen, mit denen ich dann auch mein Türkisch pflegen konnte. Wie gesagt, sie waren auch sehr sozial veranlagt, dahingehend, dass sie halt in einer Moscheegemeinde gewesen sind und auch ein starkes soziales Umfeld gehabt haben. Das hat dazu geführt, dass ich letztendlich die Möglichkeit gehabt hatte, was ich dann auch genutzt habe, sehr viel an religiösem Wissen zu erlangen und auch ein ich sage mal ein ordentliches religiöses Fundament aufzubauen, was mir dann zum Beispiel auch in der Schule letztendlich nie in die Schwierigkeit gebracht hat, dass ich sprachlos geworden bin, sondern selbst bei Fragen, die ich halt 
nicht wusste, wusste ich zumindest, wo ich nachfragen, wo ich nachschauen konnte. Also für mich war es sicherlich sehr identitätsstiftend religiös zu sein ... in einem religiösen Umfeld zu leben und auch letztendlich die Umwelt durch eine religiöse Brille zu betrachten." (Ethem, Z.: 29)

Durch das Aufwachsen in einem religiösen Umfeld, das sehr identitätsstiftend auf ihn einwirkte, wurde Ethem dazu veranlasst, die Welt mit einer »religiösen Brille« zu betrachten. Das Engagement der Familie durchzieht das Leben von Ethem wie ein roter Faden, sodass er noch heute in einer religiösen Organisation arbeitet. Religion war für Ethem hinsichtlich der Sinngebung im Leben auch ein wesentlicher Antrieb, der seine Einstellungen und Weltanschauung geprägt hat. Für seine Kinder erhofft er sich hidayet, d.h. Rechtleitung durch Allah, womit sie letztendlich ein aufrichtiges Leben führen sollen:

"Ich arbeite bei einer (lacht) islamischen Religionsgemeinschaft. Für meine Kinder ist es natürlich ein sehr wichtiger Aspekt, dass sie eine religiöse Erziehung genießen. Ich habe Religion immer als etwas Positives erlebt auch etwas, was hinsichtlich der Sinnsetzung des Lebens, auch Antrieb im Leben ... auch meine Einstellung, die ich oder auch überhaupt meine Weltanschauung ist sehr von meiner Religion geprägt. Da habe ich natürlich ... da lege ich natürlich sehr großen Wert darauf, dass auch meine Kinder Anteil daran haben und letztendlich ist das auch für mich eine Frage der hidayet [türk. für Rechtleitung, Anm. d. Verf.], also dass sie Anteil an diesem ... an dieser Rechtleitung bekommen und auch ein aufrichtiges gutes Leben führen können." (Ethem, Z.: 31f.)

Eine religiöse Erziehung soll die Kinder dazu befähigen, eigenständig mit einem »Kompass«, d.h. mit einen Wegweiser, womit man zwischen Gut und Böse unterscheiden kann, in die Welt hinauszugehen, um das Gelernte in die Tat umzusetzen. Hierbei ist es Ethem vor allem wichtig, dass die Kinder die Ideen bzw. das Prinzip, d.h. auch mit einem anderen Wort ausgedrückt den Sinn hinter ihren eigenen Handlungen verstehen:

"Dass sie die Kinder in die Lage versetzt, auch eigenständig in die Welt hinauszugehen mit einem guten Kompass, der ihnen nicht nur eine Anleitung gibt, was gut und böse ist, sondern innen auch die Möglichkeit gibt, das umzusetzen. Dass sie auch, also ich für mich spielt zum Beispiel in dem Zusammenhang die Eigenschaft des Korans, furkan zu sein, also die Möglichkeit zu geben, zwischen Gutem und Schlechtem zu unterscheiden, eine sehr zentrale Rolle. Das ist zum Beispiel für mich auch ein sehr wichtiger Aspekt in der Erziehung, dass die Kinder auch selbstständig in die Lage versetzt werden, zu unterscheiden, was gut und was schlecht ist, und dass man innen nicht jedes Mal einzeln aufzählen muss, das ist jetzt gut und das ist schlecht, sondern, dass sie das grundsätzliche Prinzip dahinter verstehen, die Idee dahinter verstehen und sich diese Ideen und 
diese Prinzipien dann auch als Wegweiser für das eigene Leben aufgreifen." (Ethem, Z.: 35-38)

In der Eigenschaft des furkan, d.h. der Unterscheidung zwischen Gut und Böse, ist der Koran als Kompass, Orientierung und Anleitung im Leben wegweisend für Ethem. Hierbei ist die Selbstständigkeit bzw. die Religionsmündigkeit, die sich Ethem von seinen Kindern wünscht, als eine Abkehr von sinnloser Nachahmung zu verstehen, welche eine immer wiederkehrende Erklärung von Verhaltensweisen unnötig macht. Das grundsätzliche Prinzip ist zu verstehen, um letztendlich vor dem Schöpfer »Rechenschaft « über das eigene »Tun und Handeln« abzulegen. So sollten die Kinder die Möglichkeit bekommen, ihr Leben entsprechend auszurichten (Ethem, Z.: 44).

Des Weiteren betont Ethem den sozialen Charakter, den die Kinder sich im Alltagsleben aneignen sollten. Angefangen von Fragen, die den Umweltschutz betreffen, bis hin zum Umgang mit Mitschülern innerhalb des Klassenverbandes zielt Ethem auf die moralischen Aspekte einer religiösen Erziehung ab. Neben der Gebetsverrichtung, wozu sich die Kinder gegenseitig »selbstständig« motivieren, spielt für ihn auch das »selbstverständliche« soziale Verhalten der Kinder insbesondere im Alltag eine große Rolle:

"Was für mich natürlich auch sehr wichtig ist, dass diese religiöse Erziehung auch für ihr Alltagsleben einen sehr großen Einfluss hat. Für meine Kinder ist es zum Beispiel eine Selbstverständlichkeit, dass man halt draußen nichts wegwirft, also nur in die Mülltonne wirft, weil, nicht, weil es verboten ist, sondern, weil es halt nicht etwas Gutes ist, die Umwelt zu verdrecken und anderen [...]. Und auch zum Beispiel die Fragen beim Umgang mit Mitschülern, dass es dann zum Beispiel, da erwarte ich dann von meinen Kindern, dass die sich an Mobbing zwischen Schülern dann halt nicht beteiligen. [...]." (Ethem, Z.: 62)

Eine große Ähnlichkeit zu Ethem besteht auch bei Nermin. Sie geht auch von einem orientierungsgebenden Charakter der Religion aus. Für sie spielt die Frage nach dem Sinn der Handlungen und der Lebensweise eine vordergründige Rolle und nicht zuletzt ist es für sie auch entscheidend, zwischen Gut und Böse zu unterscheiden, um verantwortungsbewusst mit den Konsequenzen, die sich aus dieser Entscheidung ergeben, umzugehen. Die Ähnlichkeit zwischen den beiden Elternteilen fällt auch in ihrer Sozialisation in den Ursprungsfamilien auf. Für Nermin war Religion ein selbstverständlicher Bestandteil in ihrem Familienleben. Sie lernte mit dem Vater das Koranlesen und Suren auswendig. Gleichermaßen war der Koranschulbesuch ein wichtiger Aspekt ihrer Religiosität (vgl. Nermin, Z.: 26-30). Die religiöse Erziehung war nicht »ein Extrathema«, sondern ein Bestandteil des alltäglichen Familienlebens, den sie als positiv empfand und der sie dazu brachte, selbstständig im Jugendalter das 
Kopftuch anzulegen. Wie auch schon bei Selma (vgl. Kap. III. 3.2) deutlich wurde, zeigt sich durch das Tragen des Kopftuches eine bewusste Hinwendung zum Islam, was in den meisten Fällen mit dem Beginn eines neuen bewussteren Lebensabschnittes in der Religion einhergeht. Angeregt durch den Moscheebesuch und die Predigten der hocas, stellt sie fest, wie »überzeugend « die religiöse Lebensweise der Eltern auf sie wirkt und wie sie diese geprägt hat:

"Ja, eigentlich war die Erziehung eine Einheit. Ich habe es relativ, sehr positiv empfunden. Religion hat immer für mich dazu gehört, sodass ich Ende des dritten Schuljahres, Anfang des vierten Schuljahres gesagt habe: 'So ich möchte jetzt ein Kopftuch tragen.' Da waren meine Eltern erstaunt und erschrocken und haben gesagt: 'Kind, du bist noch zu klein!، Und ich habe gesagt: ,Nee, ich möchte das jetzt tragen und ich mach das auch. Und ne, wahrscheinlich war meine religiöse Erziehung ... ja, hat mir das so mitgegeben. [...]. So überzeugend. Auf jeden Fall! Also [...] ich bin immer mit meiner Mutter in die Moschee gegangen. Dort musste ich halt neben ihr sitzen und habe dann immer nebenbei dem hoca zugehört und das hat mich sehr geprägt. Der hat ja eigentlich den Älteren was gepredigt, wo die Kinder dann halt, einige gespielt haben und so, aber ich habe inm gerne zugehört und das hat mir schon sehr viel gebracht." (Nermin, Z.: 37)

Gerade die Fragen nach dem Sinn des Lebens waren für Nermin besonders entscheidend, um sich bereits in sehr jungem Alter für eine religiöse Lebensweise, zugleich ausgedrückt durch das Kopftuchtragen, zu entscheiden:

"Ja. Wahrscheinlich, warum leben wir? Warum sind wir erschaffen? Ne, all diese Dinge und diese Sinnfragen wurden mir gegeben, dass Allahu teala [arab. für Allah der Erhabene, Anm. d. Vef.] uns erschaffen hat, damit wir inm dienen, damit wir Gutes tun. Also ich war schon immer davon überzeugt, dass der Mensch gut ist und dass Allahu teala uns deshalb erschaffen hat, um auch Gutes zu tun. Dass wir schon einen positiven Sinn in diesem Leben haben und ja, ich war sehr interessiert. "(Nermin, Z.: 41-45)

Auch heute hat die religiöse Erziehung ihren Stellenwert nicht eingebüßt. Sie ist für Nermin ein wesentlicher Bestandteil der allgemeinen Erziehung überhaupt. Trotz der Tatsache, dass diese Trennung in der Moderne vollzogen wird, stellt die Implementierung von modernen Erziehungsmethoden in die religiöse Erziehung für Nermin keinen Widerspruch dar, auch wenn im Vergleich zu früher einige Brüche zu verzeichnen seien (vgl. Nermin, Z.: 51-61; vgl. auch Karakaşoğlu-Aydın 2000). Diese Brüche, wie das Fehlen von adäquaten religiös geprägten deutschsprachigen Kinderbüchern und die Auseinandersetzung mit einer nichtmuslimischen Umwelt, wie bspw. in der Schule, oder die Einflüsse, die von den Medien ausgehen, versucht Nermin durch religiöse Deutungsmuster auszugleichen (vgl.ebd.: Z.: 55 ff.). Die Religion stellt für Ner- 
min somit einen Lebensmittelpunkt zu Bewältigung des Alltags dar. Beispielhaft sei hier die folgende Interviewpassage angeführt:

"[...] Also zum Beispiel, kann ich ein Beispiel: Mein Sohn ist Star-Wars-Fan und dann heißt es immer: 'Möge die Macht mit Dir sein. Und dann sage ich immer: Ja, wer ist die Macht? Ja, Allahu teala [arab. für Allah der Erhabene, Anm. d. Verf.] ist die Macht. Also eigentlich ist das ja schon religiös, sodass ich versuche, die Welt auch mit der Religion zu, auch zu begründen und zu durchleuchten. Es ist ja auch so aus meiner Sicht." (Ner$\min$, Z.: $63 \mathrm{ff}$.

Hier kann eine Parallele zu Ethem, der die Welt durch eine »religiöse Brille« betrachtet, gezogen werden. Bei Nermin wird die Welt mit der Religion »begründet« und »durchleuchtet«, sodass beide Elternteile im Endeffekt auf das Gleiche abzielen. Auch die Zielrichtung, die sie sich durch eine religiöse Erziehung für ihre Kinder erhoffen, ist sehr ähnlich.

Ihre religiösen Erziehungsziele spiegeln die Gedanken und Erfahrungen, die Nermin in ihrer eigenen Sozialisation erfahren hat, wider. Sowohl das Streben nach einer Sinnorientierung als auch das Einhalten von ethischen Grundsätzen sind für sie von besonderer Relevanz. So sollen die Kinder neben einer Offenheit, die sie gegenüber ihren Mitmenschen haben, auch einen Sinn in ihrem Leben finden. In ihren Handlungen sollen sie zwischen »Gut und Böse« unterscheiden können, um auch mit einer positiven Lebensgrundeinstellung, die von einem religiösen Optimismus geprägt ist, durchs Leben zu gehen:

"Also ich erwarte, dass ich durch meine religiöse Erziehung meine Kinder offen für diese Welt mit ..., so dass sie ja, sowohl zum einen offen den Menschen gegenüber, als auch der Welt gegenüberstehen, dass sie einen Sinn im Leben haben -Warum lebe ich? Warum muss ich das tun?- Dass sie Gut und Böse, ja, zum einen unterscheiden, aber auf religiösem Niveau, zum einen diese Tugenden Ehrlichkeit und so was; dass sie diese beibehalten natürlich. Dann zum anderen, ja, auch dieser Lebenswille, oder dieses frohe Leben, ne, dass man auch eine positive Lebenseinstellung, dass man auch mit einer positiven Lebenseinstellung und mit dem Gedanken natürlich, die Erwartungen, die Religion an jemanden hat, dass man das auch erfüllt, oder? Und ich denke, wenn ich es schaffe, meinen Kindern das weiterzugeben, was ich bekommen habe, dann werden meine Kinder ein positive Menschen sein, die offen auf ihre Umwelt zugehen, die mit sich im Reinen sind und auch wissen, was ist meine Pflicht. Ja? Also ein rundum positiver Mensch." (Nermin, Z.: 71)

Nermin verweist hier zudem auch auf die Entwicklung einer Persönlichkeit, die ihre Pflichten mit einer positiven Grundeinstellung, in Frieden mit sich selbst und ihrer Umwelt wahrnimmt. Dieser »positive Lebenseinstellung«, die auf die Entwicklung eines »positiven Menschen« abzielt, wie dies bereits schon 
in Form von »guten Menschen« in mehreren Interviews angeklungen ist, entgegnet Nermin folgendermaßen:

"Was ist ein positiver Mensch? Zum einen schon Optimist. Ja! Zum einen schon Optimist, zum anderen jemand, der seine Aufgaben ernst nimmt und erfüllt und der auch, ne, all diese ... also wenn man sich Deutschland anguckt, es gibt ja ganz viel Negatives, wo man sagt, die Zukunft ist unsicher und, und, und ..." (Nermin, Z.: 73)

Deshalb solle sich ein Optimismus bei den Kindern entwickeln, der für die Kinder orientierungsweisend sei. Zukunftsängsten solle jedoch nicht völlig sorgenfrei, sondern mit einer optimistischen Grundeinstellung zwischen »Hoffnung und Angst« begegnet werden. Diese Konzeption bezieht sich in der religiösen Literatur auch auf die Glaubensgrundlagen des Islams. Sorgen und Ängste »bräuchte ein Muslim gar nicht«, sondern er soll sich immer zwischen »Hoffnung und Angst « bewegen. Dies heißt, man solle immer zwischen »Bangen und Hoffen« leben, um »den guten Mittelweg« zu erreichen (vgl. Nermin Z.: 75ff.). In diesem Zusammenhang sei die Religion hilfreich, um das Leben in allen möglichen Lebensphasen, angefangen von der Kindheit bis zum Alter, gerade auch im Zusammenleben mit anderen Menschen gut und ohne große Schwierigkeiten bewältigen zu können:

"In der man auch seine Probleme gut meistern könnte und auch seine Probleme mit Mitmenschen, es gibt ja immer ganz vielfältige Probleme, sowohl als Kind als auch als Erwachsener, in der Partnerschaft oder auch mit den Eltern, auch wenn man dann älter wird. Ne, es gibt ja immer ganz, ganz viele Fragen im Laufe des Lebens, die sie dann mithilfe der Religion auch im Positiven, im besten Sinne bewältigen könnten." (Nermin, Z.: 83)

Lale legt ebenso viel Wert auf die Entwicklung einer selbstbewussten Persönlichkeit, der die Einhaltung von religiösen Geboten und Pflichten von Bedeutung ist. Doch auch bei ihr ist die Suche nach einem Sinn und die Orientierung nach religiösen Einstellungsmustern, die der Bewältigung des Lebens dienen, vordergründig. Im Gegensatz zu Ethem und Nermin, wuchs Lale in einer Familie auf, in der »Religion gar kein Thema« war. Es handelt sich um eine Migrationsfamilie, die, »um Geld zu verdienen«, nach Deutschland kam (vgl. Lale, Z.: 24). Lale beschreibt, angeregt durch den Moscheekontakt, wie für sie mit 16 Jahren die Suche nach ihrer Wahrheit begann:

"Das ist mein Herz ... ne Lücke, also, dass mein Herz, irgendetwas hat gefehlt, ne, Zufriedenheit, das kann ich ... wie soll ich es erklären? Also das ... wieso, warum, weshalb, was bin ich? [...] Sinnfragen waren da." (Lale, Z.: 30ff.) 
Lale begann schließlich, Antworten auf ihre Fragen zu finden. Diese bezogen sich darauf, wer sie war und was der Sinn ihres Daseins bedeutete: »Also, was bin ich? Was für einen Sinn habe ich? Das war es ...«(Lale, Z.: 40).

Die religiöse Erziehung spielte in ihrer Ursprungsfamilie kaum eine Rolle. Im Gegensatz zu Ethem waren die Verwandten von Lale (Oma, Opa) in der Türkei religiös, sodass sie einen Bezug zur Religion hatten. Ihr Anderssein gab Lale Anlass zu fragen »Warum sind wir so? Warum sind wir anders?« (Lale, Z.: 45) und bestärkten sie in ihrer Suche nach dem Sinn des Lebens und ihrer persönlichen Wahrheit.

Heute erklärt sie, wie wichtig ihr ihre Religion und demzufolge die religiöse Erziehung sei. Sie empfinde ein solch tiefes »Glück«, dass sie die von ihr ersehnte Wahrheit und den »Sinn« des Daseins nicht nur ihre eigenen Kinder, sondern allen Menschen weitergeben möchte':

"Natürlich bin ich, ja ab bestimmtem Alter da reingekommen, ich hab selber auch sehr viel dafür getan und sehr viel gelernt, ich hab mich mit der islamischen Religion sehrviel befasst und da hab ich auch gemerkt, das ist das, was gefehlt hat, das ist der Sinn des Lebens und ich hab dafür auch Glück empfunden. Ich empfinde immer noch Glück, dass ich mit sowas konfrontiert bin und und das wollte ich immer wieder, nicht nur meinen eigenen Kindern, auch anderen Kindern, auch anderen Menschen, die nicht damit, also zusammengekommen sind, auch das weitergeben, das war immer mein Sinn und mein Zweck und mein Lebenswerk, das zu machen [...] nicht nur, dass ich glücklich bin, auch andere Menschen [...] was bei denen auch fehlt, das zu finden." (Lale, Z.: 56-62)

Lale sieht den Sinn ihres Daseins darin, sich in den Dienst der anderen zu stellen. Sie möchte ihren Daseinszweck damit erfüllen, indem sie das Gelernte allen Menschen, nicht nur ihren Kindern zur Verfügung stellt, um auch letztendlich ihr »Lebenswerk« zu vollenden. Sie will die Menschen in ihrer Selbst- bzw. Wahrheitsfindung unterstützen, damit sie, wie sie selbst, der inneren Leere entgehen und ihr »Glück« finden können.

Demzufolge soll religiöse Erziehung auch »Stärkung« hervorbringen:

"Stärkung für mein Kind, soll bewusst die Religion, erst mal sehr gut wissen [kennen, Anm. d. Verf.] und mit der Religion auch sein Selbstbewusstsein erlangen, auch sich nicht dafür schämen und ein Person als mit der Religion [hier wird auf ein Identitätsbewusstsein angespielt, Anm. d. Verf.], das bin ich: 'Ben buyum ' (=) 'Ich bin dası und brauche mich gar nicht zu schämen dafür und diese Erziehung soll auch dem Kind geben,

9 | Hier ist anzumerken, dass Lale eine Medrese-Ausbildung, eine Form von religiöser Bildung, abgeschlossen hat, um in ihrer Gemeinde als Lehrerin tätig zu werden. Sie ist seit etwa 20 Jahren in der Jugend- und Erwachsenenbildung einer religiösen Gemeinde tätig. 
Persönlichkeit, Stärke, Selbstbewusstsein, all das. [...]. Identität, in guten, in schlechten Zeiten, diese Stärkung soll da sein." (Lale, Z.: 69)

Mit Stärkung bezieht sich Lale, neben der Aneignung von religiöser Bildung, auf einen selbstbewussten Umgang mit der Religion, die einen identitätsfördernden Effekt nach sich ziehen soll. Demnach sollten sich die Kinder »nicht schämen«, sich bewusst zum Islam zu bekennen. Die eher negative Formulierung »nicht schämen« lässt Zweifel vermuten, die durch ein selbstbewusstes Bekenntnis zur Religion behoben werden sollen. Die religiöse Erziehung soll daher die Persönlichkeit, innere Stärke und das Selbstbewusstsein fördern.

Wie auch Nermin möchte Lale bei ihren Kindern durch die religiöse Erziehung, die Entwicklung einer positiven Grundeinstellung erreichen, indem sowohl »in guten « als auch in »schlechten Zeiten« die Rückbesinnung auf die Religion erhalten bleibe. Die Religion solle gerade dann, wenn schwierige Lebensumstände eintreten, Orientierung und inneren Halt bieten. Doch auch in »positiven Situationen« sei es wichtig, bedacht zu sein und das Maß nicht zu verlieren, indem auf die Gebote der Religion geachtet wird:

"Das Leben wird nicht immer rosig sein, das wissen wir und auch in schlechten Zeiten, wie Armut, wie Todesfall, egal, da zu sagen, so ist das Leben, das ist das Leben ... so ist es, so muss es sein; und damit zurechtzukommen, nicht [...] in ein Loch zu fallen und nicht mehr rauszukommen, und viele Menschen haben das und da sage ich, diese Religion ist dafür da, einen Halt zu geben [...]. Ja, auch in positiven Situationen, auch nicht zu übertreiben. Wenn man z.B. viel Glück hat im Leben und viel Geld hat und das auch da zu wissen, nicht alles zu verschwenden, auch diese Religion sagt, hier ist ... so kannst du mit Geld umgehen, so lebst du auch so, dass du auch abgibst und so ... auch dieses im Guten und im Schlechten, [...]." (Lale, Z.: 73-79)

In dem türkischsprachig durchgeführten Interview schildert Dilek, welche religiösen Erziehungsvorstellungen, beeinflusst durch gemeinsame religiöse Erfahrungen mit ihrem Mann, für sie bedeutsam sind. Wie für alle anderen Eltern dieses Typs, denen der sinnhafte Bezug zur Religion wichtig ist, erscheint es für Dilek wichtig, ihr Leben nach dem Prinzip der »Rechtleitung« (arab. sirata-al mustaqim; vgl. Dilek, Z.: 36) zu formen. Auch Dilek ist die Gewissensbildung, die darauf abzielt, dass die Kinder eigenverantwortlich die Pflichten und Gebote der Religion einhalten, von großer Bedeutung.

Dilek wuchs in einer eher traditionell-religiösen Familie auf, in der der Vater zwar linksorientiert war, aber einen großen Spielraum für eine traditionelle religiöse Lebensweise zuließ. Den Bezug zur Religion erhielt Dilek zunächst vonseiten der Mutter, die Rituale wie das Beten und Fasten ernst nahm. Der Mutter war es vor allem wichtig, auf die Bekleidung und das äußere Erscheinungsbild der Töchter zu achten. Ein respektvoller Umgang und 
Gehorsamkeit gegenüber den Älteren, wie es heutzutage nicht mehr selbstverständlich ist, waren wichtige Aspekte des Familienalltags. Der Mutter waren die wesentlichen katechetischen Grundlagen der Religion (»32 Farz« = türk. für die 32 Pflichten des Islams) und der Korankursbesuch, um das Rezitieren des Korans zu erlernen, von Bedeutung. Wie Dilek später erläutert, waren diese Praktiken »traditionell« geprägt und entsprachen nicht ihrem heutigen Verständnis einer religiösen Lebensweise. Der bewusste Umgang mit islamischen Quellen und ein hoher Gemeinschaftsbezug sind heute für Dilek und ihre Kinder essenzielle Aspekte ihrer Religiosität (Dilek, Z.: 12ff.).

Dilek nahm die Auseinandersetzung mit dem Koran zum Anlass, um ihre Lebensweise, die sie ungefähr bis zum 21. Lebensjahr verfolgte, zu verändern. Der hohe Stellenwert, den die religiöse Erziehung in ihrem Leben einnimmt, ist als das Resultat dieser Auseinandersetzung zu sehen. Gerade bestimmte Verse aus dem Koran haben sie besonders beeinflusst und sie wünscht sich für ihre Kinder eine religiöse Erziehung, die durch ein Gottesbewusstsein und die Liebe zu Gott und dem Propheten (s) geprägt sind. Dabei sollen die Kinder Sensibilität und Eigenverantwortung gegenüber den Pflichten und Geboten der Religion entwickeln:

"I.... Ich ${ }^{10}$ habe Koran gelesen, ich habe die Übersetzung des Korans gelesen, ich habe gesehen, dass Allah uns all die Gebote, die wir einhalten sollen, offenbart hat. Ja, und Bücher, wie gesagt, weiterbildende Bücher usw. ... man lernt viel. Ja und ich weiß und ich will, dass meine Kinder ... Es steht ja geschrieben: 0 ihr, die ihr glaubt, nehmt euch in Acht, euch und eure Angehörigen vor einem Feuer, dessen Brennstoff Menschen und Steine sind [ [Koran 66: 6, Anm. d. Verf.]. Dieser Vers beeinflusst mich beispielsweise sehr. Schau, ich habe gerade eine Gänsehaut. Wenn ich Fehler oder Schwächen bei meinem Kind sehe, beeinflusst mich dieser Vers, weil ich für mich und meine Kinder keine Garantie habe. Ich weiß, dass wir Menschen sind, wir können Fehler machen, unser Ego [türk. nefs, Anm. d. Verf.] ist vielen Versuchungen ausgesetzt. Ich wünsche mir, dass meine Kinder gut erzogen werden. Sie sollen eine Liebe zum Islam, die Liebe zu Gott, zum Propheten, die Angst vor dem Höllenfeuer, die Liebe zum Paradies, gleich welchen Namen man dem gibt in ihren Seelen und Herzen spüren. Wenn sie zum Beispiel eine Tat vollbringen oder eine Sünde begehen, werde ich vielleicht nicht an ihrer Seite stehen. Niemand kann den anderen kontrollieren, wir können nur vertrauen. Wenn sie beeinflusst durch Freunde oder anderen Faktoren eine Sünde begehen wollen, dann werde ich vielleicht nicht zugegen sein. Ich wünsche mir, dass meine Kinder ein Bewusstsein entwickeln, dass , Allah innen näher ist, als ihre Halsschlagader [Koran 50: 16, Anm. d. Verf.] und dementsprechend diese Sünde ablehnen.u (Dilek, Z.: 24)

10 | Die unterstrichenen Passagen geben Übersetzungen aus dem Türkischen wieder. 
Wie man hier herauszulesen kann, ist das Gottesbewusstsein, das die Kinder entwickeln sollen, eng an die Einhaltung von religiösen Vorschriften gebunden. Bei Dilek liegt die Betonung, im Vergleich zu den anderen Eltern dieses Typs, etwas stärker auf der Befolgung religiöser Gebote, d.h. auch dem Ritualismus, ausgedrückt z.B. durch die Einhaltung der Bekleidungsvorschriften, das Tragen des Kopftuches, die Einhaltung der vorgeschriebenen Sexualmoral (keine Flirts, keine gegengeschlechtlichen Freunde, kein Ausgehen) oder die Einhaltung der Gebetsvorschrift (vgl. Dilek, Z.: 26-30). Zudem nimmt die Spiritualität, ähnlich wie bei Lale, eine wichtige Rolle im Leben von Dilek ein. Die Nähe Gottes und die Gottesbindung sollen wie eine Schutzmauer vor sündhaften Versuchungen aufgebaut werden. Die Erwartungen, die sie an eine religiöse Erziehung knüpft, werden von ihr bildhaft (»Funken« oder »Feuer«, »Wasser«) wiedergegeben und können daher mehrdeutig aufgefasst werden. Deutlich wird vor allem der spirituelle Bezug zu Gott, der in den Kindern oder den Jugendlichen geweckt werden soll. Hierin ist auch das rechtleitende Prinzip enthalten:

"Ja ehrlich, wenn wir die religiöse Erziehung bei Seite stellen, sollte meiner Meinung nach jeder in seiner Seele einen Funken, ein Feuer aufspüren, das sollte etwas sein. Es ist egal, ob es nun ein Kind, ein Älterer oder sonst jemand ist. Wenn es nicht im Kind vorhanden ist, kannst du es noch so viel erziehen, es kann den Koran auswendig lernen, egal was auch ist. Nein, ich glaube nicht, dass man zu keinem Ergebnis kommen wird. Ja dieser Funken, ich sehe zum Beispiel in meinem Umfeld Kinder und Jugendliche, denen ich nacheifere, ich weiß nicht, wie ihr Innenleben aussieht, ich weiß nicht, wie sie sich zu Hause verhalten, aber, wenn ich diesen Jugendlichen sei es ein Mädchen oder Junge, meistens sind die Jungen reiner [türk. saf, Anm. d. Verf.], ins Gesicht blicke, haben sie eine reine, aufrichtige Haltung. Ja, ich sage, o mein Allah, sieh inn/sie dir an, mașAllah [arab./türk für "Gott schütze dich, sei mit Dir", Anm. d. Verf.]. Da ist was in seinem/ ihrem Inneren, was sich in seinem/ihrem Gesicht, in der Kommunikation und dem Verhalten äußert [...]. Wie soll ich sagen?» (Dilek, Z.: 32ff.)

Es fällt Dilek sichtlich schwer die richtigen Worte ${ }^{11}$ für die von ihr durch die religiöse Erziehung erstrebten Grundhaltungen zu finden. Hier wird gleichermaßen der Kernpunkt des Problems verdeutlicht. Die Kinder sollen diesen »Funken« in sich spüren, indem die Eltern eine Hilfestellung hierfür anbieten. Aber grundsätzlich erwartet Dilek, wie oben herauszulesen ist, die Stärkung von Eigenverantwortung, um dem »rechten Weg« zu folgen:

11 | Dies wurde ja schon in anderen Interviews deutlich, bei denen spirituelle Aspekte, wie religiöse Erfahrungen, Emotionen, zur Sprache kamen. 
"Es kann der iman [arab. für Glauben, Anm. d. Verf.] sein. Ja, ein Verlangen, das eigene Leben nach dem Prinzip des sirata- al mustaqim [arab. für der rechte Weg, vgl. auch Koransure Fatiha 1: 6; Anm. d. Verf.] zu führen. Also, ich möchte das Leben nach diesem Orientierungsprinzip führen und ich muss mich dafür anstrengen. Was muss ich tun? Ja, ich muss mir solche Freunde suchen, zum Beispiel, ja." (Dilek, Z.: 36)

Es ist für Dilek wichtig, ihren Töchtern den »richtigen« Weg aufzuzeigen, folgen müssten sie diesem jedoch selbst. Der Wille hierfür muss »von innen« kommen und »fließen«, gerade wie sie es nochmals bildhaft mit dem Element des Wassers wiedergibt:

"I.... Ja, wie ich es schon sagte, es muss von innen kommen. Wenn es im Inneren vorhanden ist, wird es die Umgebung ohnehin [...] wird das Wasser entsprechend in die Richtung fließen. Man sagt ja, dass das Wasser fließt und seinen Weg finden wird, aber wenn es im Inneren nicht vorhanden ist ... meine Freunde haben auch Kinder. Die Eltern sind reiner Absicht, sind sehr aufmerksam, aber sie können sich gegen ihre Kinder weder durchsetzen noch irgendein Wort sagen. Ich habe zum Beispiel Freunde, die dankbar sind, weil die Kinder zumindest gesund sind ... das ist auch schwer." (Dilek, Z.: 40)

Schließlich verbindet Nisa, als letzter Elternteil dieses Typs, wie auch vor ihr Lale und Dilek, besonders sinnhaft spirituelle Aspekte des Glaubens mit ihrer religiösen Erziehung. In dem türkischsprachig durchgeführten Interview erläutert sie zudem, welche positiven Folgen eine religiöse Erziehung habe, wenn ein Gottesbezug zentral für das eigene Leben sei. Es entwickeln sich durch diesen Fähigkeiten, die sowohl von der Orientierung an den Prinzipien der Religion, d.h. durch ein Gottesbewusstsein, als auch von ethischen Konsequenzen im Zusammenleben mit anderen Menschen geprägt sind.

Nisa wuchs, ähnlich wie Dilek, in der Türkei auf. Sie entstammt einer linksorientierten Familie, innerhalb derer die Mutter ihre religiösen Grundkenntnisse vermittelte. Die Einhaltung der Gebetsvorschriften stellte zum damaligen Zeitpunkt einen wichtigen Aspekt ihrer Religiosität dar, sodass sie ihre Erinnerungen bzgl. ihrer eigenen religiösen Sozialisation besonders damit in Verbindung bringt. Die Mutter betete fünfmal am Tag und Werte wie Ehrlichkeit und Aufrichtigkeit, die sich auf die Charaktererziehung beziehen, waren für sie sehr bedeutsam. Auch ein Onkel mütterlicherseits übte einen entscheidenden Einfluss auf Nisa aus. Im Vergleich zu ihrem Vater nahm dieser die Gebetsvorschriften ernst. Die Religion wurde in ihrer Familie zwar nicht besonders stark ausgelebt und sie genoss keine religiöse Erziehung, aber sie bestand im Herzen »irgendwo in einer Ecke« (vgl. Nisa, Z.: 6f.).

Erst nach ihrer Heirat und ihrer Migration nach Deutschland habe die Religion ihr Leben tiefgreifend bestimmt. Ähnlich wie bei Dilek und Ethem, ist ihre Religiosität durch einen hohen und intensiven Gemeinschaftsbezug ge- 
kennzeichnet, sodass die religiöse Erziehung heute eine sehr wichtige Rolle spiele, überhaupt die höchste Priorität in ihrem Leben habe (vgl. Nisa, Z.: 11).

Die religiöse Erziehung bringe viele Vorteile für das Leben der Kinder. Die Ziele, die sich Nisa durch eine religiöse Erziehung erhofft, deuten auf ein hohes Gottesbewusstsein, in der die Präsenz Gottes mit den ihm zugeschriebenen Eigenschaften des Allwissenden und Sehenden im Vordergrund steht. Aufgrund dieser Eigenschaften Gottes sei der Mensch aufgefordert bzw. dazu motiviert, sein Verhalten und sein Leben entsprechend zu gestalten. Dabei bringe gerade die religiöse Erziehung Menschen hervor, die sowohl im eigenen persönlichen Leben als auch im Leben in der Gesellschaft vielseitige positive Eigenschaften entwickeln und ihre Aufgaben entsprechend erfüllen würden:

"Im ganzen Leben eines Menschen, in seinem sozialen Leben, seinem persönlichen Leben, in seinem Leben in der Gesellschaft, [ist die religiöse Erziehung, Anm. d. Verf.] von Bedeutung. Vor allem, wenn ein Mensch in seinem persönlichen Leben sinnhaft [türk. manevi $=\mathrm{dt}$. auch geistig, seelisch, innerlich; Anm. d. Verf.] ausgerichtete grundlegende religiöse Erziehung bekommt, dann kann er meiner Meinung nach ein Selbstvertrauen an den Tag legen, um alles zu schaffen, er kann gute Beziehungen zu den Menschen aufbauen, weil wie soll ich sagen ... zum Beispiel auch bei der Einhaltung von Regeln im sozialen Leben, können solche Menschen viel genauer sein, weil er weiß, dass jemand da ist, der alles sieht, der alles mitschreibt, da ist eine Hoheit [türk. zat, Anm. d. Verf.] Cenab-ı Hak [türk. für der Allmächtige, der Schöpfer; Anm. d. Verf.], ja so ist das." (Nisa, Z.: 13).

Die positiven Eigenschaften, die sich aus dem Gottesbewusstsein ergeben, beziehen sich hier auf der persönlichen Ebene auf das Selbstvertrauen, das in allen möglichen Lebenssituationen hilfreich sein soll. Von einer solchen stärkenden Eigenschaft gingen auch Lale, Nermin und Dilek aus, wenn sie von ihrer Religion einen orientierungsleitenden Effekt für ihre Kinder erwarteten. Mit einer »sinnhaft« ausgerichteten religiösen Erziehung betont Nisa zudem auf der gesellschaftlichen Ebene den sozial-ethischen Charakter einer religiösen Erziehung, womit ein Miteinander gestaltet werden solle, was einen »viel genauer « und regelgeleitet auf die Beziehungen zu anderen Menschen achten lasse, weil eben die Aufmerksamkeit auf die Präsenz Gottes ausgerichtet sei.

Auch für ihre Familie sieht sie einen hohen Nutzen in der religiösen Erziehung. Die Religion biete Ressourcen, die für die Bewältigung des Familienalltags von besonderer Bedeutung seien. Als ordnungsbringende Kraft bedeute die Religion hierbei Orientierung und Sinn. Nisa verweist dabei besonders stark auf die spirituellen Aspekte der von ihr erwünschten und ausgelebten Religiosität. So seien »innere Ruhe« bzw. »Frieden«, »Segen«, »Herzlichkeit/ Aufrichtigkeit« als Folgen ihrer religiösen Lebensweise bzw. religiösen Erzie- 
hung zu bezeichnen ${ }^{12}$. Gerade in der Pubertätsphase (sie hat zwei Söhne im Alter von 18 und 15 Jahren) und damit verbundenen Problemen beispielsweise in der Schule helfe eine religiöse Erziehung bzw. eine »Glaubenserziehung « dabei, diesen Problemen standzuhalten und diese »viel schöner, viel leichter« zu bewältigen:

„Innerhalb der Familie [ist die religiöse Erziehung, Anm. d. Verf.] natürlich auch sehr von Bedeutung. Das Leben eines Menschen bekommt meiner Meinung nach eine Ordnung, wenn in einer Familie die Religion ausgelebt wird. Es kommt Segen, eine Ruhe [türk. huzur, Anm. d. Verf.] kehrt ein, man hat eine innere Ruhe [türk. manevi iç huzur, Anm. d. Verf.] und es herrscht eine Herzlichkeit/Aufrichtigkeit, sei es mit dem Ehepartner, sei es mit den Kindern oder innerhalb und ... Ein Jugendlicher verbringt seine Jugendzeit [Pubertät, Anm. d. Verf.] meiner Meinung nach viel einfacher, wenn er eine religiöse Erziehung, eine Glaubenserziehung [türk. iman dersi, Anm. d. Verf.] bekommt. Es sieht so aus, dass die Probleme viel einfacher gelöst werden können. Ja, es entstehen ja Probleme, jeden Tag weltliche Unannehmlichkeiten/Unruhen, manchmal gibt es Probleme mit der Schule oder andere Probleme. Diese können damit [mit dem Glauben, mit der religiösen Erziehung, Anm. d. Verf.] viel schöner, viel leichter bewältigt werden." (Nisa, Z.: 15)

\subsection{Religiöser Erziehungstyp, bei dem die Einhaltung von religiösen Vorschriften von zentraler Bedeutung ist - "Ritualisten"}

Eltern (Mecelle, Rabia, Selma, Ali), die diesen Typus kennzeichnen, heben insbesondere die Einhaltung von religiösen Vorschriften hervor. Die Kernaspekte des Islams, wie bspw. das Kennen von Glaubensgrundlagen und die Einhaltung der fünf Säulen, stellen für diese Eltern eine wesentliche Voraussetzung ihrer Erziehung dar. Es wird darauf geachtet, das Gebotene (türk. helal, arab. halal) einzuhalten und das Verworfene (türk./arab. haram) zu umgehen. Charakteristisch für diese Gruppe ist zudem, dass besonders viel Wert auf eine religiöse Bildung gelegt wird, die das Wissen der islamischen Quellen, wie z.B. der Sunna des Propheten (s) oder des Korans, und die Beherrschung der wesentlichen Grundlagen des Islams voraussetzt. Dies ist umso mehr von Bedeutung, wenn handlungsleitende Prinzipien insbesondere in die Praxis umgesetzt werden sollen. Die Erziehungsvorstellungen dieser Eltern korrespondieren sehr stark mit einer klassisch-islamischen Vorstellung (die Glaubensgrundlagen und die

12 | Bei keinem der Interviewpartner war dies während der durchgeführten Interviewzeit fühlbar so stark wahrzunehmen wie bei Nisa. Ihre Überzeugungen übertrugen sich so auf die Interviewatmosphäre, sodass auch laut Nisa ein sehr ausgeglichenes und "sehr schönes" Interview zustande kam (Nisa; Z.: 196). 
fünf Säulen des Islams beherrschen) einer religiösen Erziehung. Es könnte hier auch von praxis- oder handlungsorientierten Eltern gesprochen werden, jedoch könnte dies den Blick auf das, was diesen Typus ausmacht, zu sehr in eine Richtung einschränken, nicht zuletzt vor dem Hintergrund, dass für alle Eltern hier auch ethische Grundsätze von besonderer Bedeutung sind. Im Vergleich zu der Gruppe Eltern, für die die ethischen Grundsätze im Vordergrund stehen (die »Ethiker«), spielen diese für den vorgestellten Erziehungstyp, die Ritualisten, eine eher untergeordnete Rolle.

Bei Mecelle, der vom Alevitentum (eine Denomination des Islams) zum Islam sunnitischer Ausrichtung wechselte, wird besonders deutlich, wie stark seine erzieherischen Vorstellungen von einer bewussten Auseinandersetzung mit dem Islam und einer Aneignung von religiöser Bildung geprägt sind. In seinem Elternhaus stand die Religion nicht im Vordergrund. Er bezeichnet das Finden seiner Wahrheit, was mit der Freundschaft aus der Universitätszeit und der Heirat einer sunnitischen Frau einherging, als »etwas Schönes« (Mecelle, Z.: 33), das nicht mit Worten beschrieben werden könne. Bei der Beschreibung werden die Emotionalität und die berührenden Momente zum Ausdruck gebracht (ebd., Z.: 23-35).

Heute fühle er sich, im Vergleich zu früher, in seinem Glauben gestärkt und es gehe für ihn weiter. Die religiöse Erziehung spiele eine wichtige Rolle in seinem Leben und die Kinder sollten durch die Vorbildfunktion beider Eltern den Islam kennenlernen und seine Lehre umsetzen. Hier weist Mecelle sowohl auf einen kognitiven als auch auf einen praktischen Zugang hin:

"Wir versuchen, die Kinder schon religiös zu erziehen, sind in Vorbildfunktion beide Elternteile und wir leben den Islam vor und (überlegt) die Kinder sollen das auch lernen und (überlegt) umsetzen. Gut, die sind jetzt noch recht jung, aber wir versuchen, schon vieles zu erklären: die Feierlichkeiten, was das Gebet heißt, wer der Prophet ist, alles, was mit dem Islam zu tun hat." (Mecelle, Z.: 40ff.)

Die religiöse Praxis spielt somit für alle Eltern dieser Gruppe eine wichtige Rolle. Mecelle erwähnt Feierlichkeiten, das Gebet, das eindeutig die praktische Dimension der Religion berührt. Mit dem Kennen des Propheten und »alle[m], was mit dem Islam zu tun hat« spielt er auf die religiöse Bildung und auf Grundlagen an, worauf sich die religiöse Praxis stützt. Für ihn steht die religiöse Bildung im Vordergrund. Gerade das Praktische, wie die Gebete, würden sich nur durch plausible Begründungen, d.h. nur durch Wissen erklären lassen (Mecelle, Z.: 49-58).

Für ihn ist das Ziel religiöser Erziehung, »Gott zu erkennen«, somit der ersten Glaubensgrundlage zu folgen und ein »guter Mensch« zu werden (Mecelle, Z.: 44). Auf die Frage, was er unter einem »guten« Menschen verstehe, geht Mecelle folgendermaßen ein: 
"Der tut Gutes, [...] islamische Vorschriften hält er ein: sein Gebet, sein Fasten, diese Sachen; hilft anderen Menschen und auch, natürlich ist [steht, Anm. d. Verf.] die Bildung im Vordergrund. Ohne Bildung kommt man nicht weit. Das gibt [bietet, Anm. d. Verf.] der Islam ja auch durch Koranlernen, Arabischlernen und die Islamwissenschaften, wenn man darein kommt, wird viel Wissen angeeignet." (Mecelle, Z.: 48)

In dieser Interviewpassage sind alle Merkmale dieses Erziehungstyps benannt, wie die Einhaltung islamischer Vorschriften, die sich auf die fünf Säulen des Islams beziehen, das Aneignen von religiöser Bildung, die wiederum auf klassische Inhalte wie das Erlernen des Koranlesen, das Arabischlernen und die islamischen Grundlagen verweist sowie auf die ethische Komponente abzielt.

Eine Parallele könnte man hier zu Rabia herstellen, da sie wie Mecelle großen Wert auf eine religiöse Bildung legt. Auch für Rabia ist Religion inzwischen viel wichtiger geworden, als sie das noch damals in ihrem Elternhaus war. Die religiöse Bildung sei eine wesentliche Voraussetzung, um am Glauben festzuhalten und die Gebote, die der Islam auferlege, einzuhalten. Im Vergleich zu Mecelle hat Rabia in ihrem Elternhaus die »wichtigen Säulen des Islams«, die »Pflichten«, das »Wesentliche«, ohne extrem oder streng zu sein, d.h. »ein bisschen lockerer« kennengelernt und befolgt. Jedoch empfindet sie die Vorgehensweise des Vaters im Nachhinein als eher oberflächlich (Rabia, Z.: 19-32). Die Erziehung im Elternhaus beschränkte sich auf die Einhaltung von religiösen Geboten:

"Von meinen Eltern die Erziehung? Also das war, weil wir waren halt mehrere Kinder und ich finde, die Erziehung ... dass wir halt gläubig erzogen worden sind, war wichtig, dass wir halt gewisse Wege nicht gegangen sind, wie zum Beispiel abends rausgehen, in die Disco gehen und Freund haben, das war bei uns Tabu, also das, das ..." (Rabia, Z.: 38)

Rabia findet das »super« und sie befolgt diese Regeln auch selbst, ohne die Vorgehensweise der Eltern als zu streng zu empfinden:

"Finde ich super, also ich finde, es hat seine Zeit. Man muss nicht sehr früh seinen Freund haben, man muss nicht alleine auf der Straße sein und ... also ich kann jetzt sagen, ich mach jetzt das Gleiche. Ich finde das schon richtig. Also ich kann jetzt nicht sagen, unsere Eltern waren da jetzt streng." (Rabia, Z.: 40)

Der Stellenwert, den die Religion bzw. die religiöse Erziehung für Rabia einnimmt, ist für sie »viel wichtiger« und »viel ernster«, als es noch für ihre Eltern der Fall war. Die Voraussetzung für die Einhaltung religiöser Gebote sei die religiöse Bildung. Für sie ist ihre Religion so wichtig, dass das Leben der Kinder auch darauf basieren soll. Sie schränkt jedoch ihre Erfolgschancen damit ein, 
dass ihr das nötige Wissen über die Religion fehle. Das Wissen solle so aufbereitet werden, dass es »von Herzen« komme, um am Glauben festzuhalten:

"Ich muss sagen, Religion ist mir jetzt viel wichtiger, wie ... also ich nehme es jetzt viel ernster, wie meine Eltern das gemacht haben. Ich muss sagen, ich bin da strenger. Mir ist es sehr wichtig, das ist für mich eigentlich mein Ein und Alles; ich möchte, dass das Leben meiner Kinder eigentlich darauf basiert, also, dass die inwiefern man da halt Erfolg hat, ist ja eine andere Sache, vor allem, weil man [...] das Wissen ist nicht da. Das Wissen über die Religion ist nicht da, wo man den Kindern das auch gut erzählen kann und dass die Kinder das richtig beeindruckt. Das soll von Herzen kommen. Die sollen also richtig festhalten an dem Glauben. Das ist halt ... wie soll ich das sagen? Ich möchte das einfach, dass das so ist. Das ist mein Wunsch! Das ist mein Ziel!" (Rabia, Z.: 48-52)

Hier wird deutlich, was die Aneignung von religiöser Bildung (vgl. auch Rabia, Z.: 637 und Z.: 695) für Rabia sowohl hinsichtlich der Einhaltung religiöser Vorschriften als auch für die Entwicklung einer spirituellen Beziehung zu Gott für eine zentrale Rolle spielt. Auch wenn das Wissen fehle, gebe ihr dieses Gefühl, das sie als »inneres Kribbeln« und »Liebe« bezeichnet, ihr »innerlichen Frieden« und »Glück«, das sie auch ihren Kindern erfahrbar machen möchte (Rabia, Z.: 136-142).

Die Einhaltung des Keuschheitsgebotes bzw. die Berücksichtigung der Sexualmoral (vgl. auch Boos-Nünning 2011a) und das Nichtausgehen am Abend stellen wichtige Aspekt ihrer Erziehung dar. Rabia sieht darin ein Gebot des Islams und es wäre nicht helal (türk. Verworfenes/nicht Gebotenes), d.h. eine Sünde, diesem Gebot nicht zu folgen. Die religiöse Erziehung und das Festhalten am Glauben bieten hier Schutz vor »Fehlern«, die die Kinder vor einer Eheschließung machen könnten:

"Ich finde, alles hat seine Zeit, und vor allem im Islam ist das verboten, dass man, bevor man heiratet, halt einen Freund hat. Das ist bei uns halt im Islam nicht ... wie soll ich das sagen: Das ist nicht helal [türk. für nicht Gebotenes/Verworfenes, Anm. d. Verf.] (Leise) Genau. Das ist eine Sünde für uns und ich stehe dahinter. Also ich finde das richtig, dass man alles, nachdem man verheiratet ist, macht. Also ... und das schützt einen auch gegen Fehler, die man machen kann." (Rabia, Z.: 42-48)

Ziel ist es für Rabia, dass die religiöse Erziehung vor Fehlern und »schlechten Wegen«, wie bspw. auch Drogen, schützen soll (vgl. auch Öztürk 2007). Die Kinder sollten aber auch die Erfahrung machen, was das Ausgehen am Abend, »Disco und das Ganze«, im Vergleich zur »schönen« Seite des Islams ausmache: 
"Ich glaube, dass die Kinder vor Fehlern schützt ... vor schlechten Wegen [...], vor Drogen, vor schlechten Wegen. Schlechte Wege sind wie schlechte Freundschaften, also wenn die nicht gut erzogen worden sind, die zum Beispiel anders erzogen worden sind, die andere Meinungen haben, die meinen, man müsste alles machen dürfen, man darf abends rausgehen bis in die späte Nacht und in Discos. Ich bin da eigentlich ... man kann rausgehen, man kann mit Freunden und Eltern, ich hab auch nichts dagegen, wenn man mit Freunden, mit Eltern einfach ausgeht. Obwohl, auch Disco, sag ich mal. Die Kinder sollen das sehen, die sollen sehen, den Unterschied zwischen abends rausgehen, abends Disco und das Ganze. Aber auch auf der anderen Seite, wie schön der Islam ist, wie schön man auch anders leben kann, dass man nicht nur in Discos geht und das ..." (Rabia, Z.: 55ff.)

Des Weiteren wünscht sich Rabia, dass der extremen Konsumorientierung Einhalt geboten wird, indem auch hier »das Schöne« im Islam hervorgehoben wird. Die Religion und eine religiöse Erziehung sollen neben dem Schutz vor Außeneinflüssen, wie den oben bereits angeführten Gefahren oder auch jenen Gefahren, die z.B. durch die Medien (Fernsehen, Handys und dem Internet) ausgehen, »Frieden«, »Harmonie«, Halt, Sicherheit und Geborgenheit vermitteln (Rabia, Z.: 59-84). Rabia verknüpft mit dem »Schönen« spirituelle Aspekte, die auf der emotionalen Ebene erfahrbar sind. In diesem Zusammenhang betont sie ebenso die Bedeutung des Respekts vor den Eltern:

"Respekt vor Älteren und dass die einfach hören und sehen, dass das, was Eltern sagen, [...] hören und sehen, dass das, was Eltern sagen, eigentlich auch für die Zukunft was zu bedeuten hat." (Rabia, Z.: 94)

Hier wird deutlich, wie sehr sie auch auf ethische Grundsätze Wert legt. Gerade der Respekt vor den Älteren wird auch von Ali unterstrichen (Ali, Z.: 16).

Der spirituelle Aspekt wird, wenn auch in abgeschwächter Form, durch Selma ebenfalls betont. Selma stellt wie Mecelle und Rabia den Glauben an Gott und die Befolgung von islamischen Regeln als Eckpfeiler ihrer religiösen Erziehung dar. Ethische Grundsätze sind als eine Folge dieser von ihnen intendierten religiösen Erziehung zu betrachten. Selma verbindet ihre Beziehung zur Religion mit ihrem Elternhaus, das sie als traditionell muslimisch wahrnimmt und in dem sie »frei erzogen« (Selma, Z.: 14) wurde, zunächst bzgl. des Tragens des Kopftuches, d.h. hinsichtlich der Einhaltung eines religiösen Gebots. Erst das Tragen des Kopftuches, angeregt durch eine Freundin, bewegt Selma schließlich dazu, sich mit dem Islam auseinanderzusetzen (Selma, Z.: 14).

Die religiöse Erziehung spielte beim Aufwachsen in ihrem Elternhaus eine eher untergeordnete Rolle. Sie sieht darin eher »traditionelle« Elemente, wie bspw. den Moscheebesuch, das Koranlesen oder das Kopftuchtragen integriert, 
welche jedoch frei und ungezwungen umgesetzt wurden. Auch wusste sie nicht die Gründe für die Einhaltung verschiedener Gebote im Islam. Die Begründungen für die Ausführung der religiösen Praxis, die auch Mecelle unterstreicht, fehlten in der religiösen Erziehung von Selma. So wie Rabia wuchs sie in einer Atmosphäre, die sie zwar als »frei« bezeichnet, die jedoch eher von Nachahmung traditioneller Praktiken geprägt war:

"... eigentlich jetzt nur das Traditionelle. Also wir sind zwar in die Moschee geschickt worden, aber wir haben dann nur den Koran gelesen, wussten aber nicht, warum, wieso und weshalb wir das machen mussten und wussten auch nicht, warum wir das Kopftuch tragen mussten und das war auch dieses ganze Traditionelle und später ... also wir sind eigentlich ganz frei aufgewachsen, also ohne religiöse Regeln [...]. Also wir konnten selbst entscheiden, ob wir jetzt das machen wollen oder nicht." (Selma, Z.: 16 und 22)

Sie begründet diese unreflektierte Vorgehensweise damit, dass zur damaligen Zeit die Religion nicht praktiziert wurde und erst in ihrer Generation an Bedeutung gewann:

"Zu unserer Zeit war das auch gar nicht so, da waren auch gar nicht so viele muslimische Familien, die das auch praktiziert haben einfach. $\mathrm{Ne}$, also das kam ja alles später, ne? Unsere Generation war das eigentlich mehr, dass es auch mehr ausgelebt worden ist. [...]. Also wir sind da, damit viel bewusster aufgewachsen, mit der Religion." (Selma, Z.: 26-30)

Heute nimmt die religiöse Erziehung für Selma einen hohen Stellenwert ein. Der Glaube an Gott und die Einhaltung der religiös konnotierten Regeln und ein im Vergleich zu ihrer Elterngeneration deutlich hergestellter Sinnbezug mit nachvollziehbaren Begründungen, sind wesentliche Grundpfeiler ihrer Erziehung:

"Ich möchte eigentlich von Anfang an meinen Kindern also beibringen, was unsere Religion ist, warum wir an Gott glauben müssen, warum wir uns an bestimmte Regeln halten müssen. Das ist einfach wichtig, dass das Kind schon von klein auf das also lernt und nicht ... Und ich habe das nicht gehabt in meiner Kindheit und ich wusste nicht, warum, wieso, weshalb; und wenn meine Kinder mich fragen, dann erzähle ich das also, soweit ich das kann eigentlich, so gut wie ich das kann oder mein Mann." (Selma, Z.: 34)

Die Einhaltung religiöser Gebote, die charakteristisch für diesen Typus ist, erscheint auch Selma essenziell. Die Begründung für eine Regelbefolgung macht Selma an einem besonders praktischen Beispiel, dem Verzehrverbot von gelatinehaltigen Lebensmitteln, deutlich: 
"Also wenn man ... es ist einfach so, wenn man zum Beispiel im Kindergarten, wenn jetzt Kinder im Kindergarten sind und die Muslime dürfen ja keine Gelatine essen; und wenn ich dann den Kindern sage, wenn die jetzt Süßigkeiten essen, Haribo essen, [...], Ihr dürft das nicht essen!‘, sagt sie: 'Warum denn? ' Ja, da ist Gelatine doch drin. ' Ja, was ist denn Gelatine?، Das wird dann erst mal erklärt, ja Gelatine ist aus Rind- oder aus Schweinefleisch, es ist nicht geschlachtet nach unseren religiösen Regeln und wir dürfen es einfach dann nicht essen; und das, das bringt man dem Kind von klein auf bei und das erklärt man auch dem Kind und das akzeptiert es und, wenn sie da im Kindergarten ist: 'Eh, ich darf das nicht essen! Weil wir halt Muslime sind und wir dürfen das nicht!، Und das ist schon was Bewusstes, was das Kind dann so vor sich hat! (Selma, Z.: 38)

Anhand dieser Interviewpassage wird auch aufgezeigt, wie der Umgang mit der nichtmuslimischen Umwelt gepflegt wird. Die Regelbefolgung, die sich im Kontext einer Kindertagesstätte auch als ein Anderssein darbietet, ermöglicht es dem Kind, sich in seiner Religiosität als Muslim zu präsentieren. Hier ist der Mutter gerade der bewusste Umgang, der sich aus den Begründungen für die Einhaltung von Regeln ergibt, wodurch auch die Argumentationsfähigkeit des Kindes gegenüber den anderen Kindern gestützt wird, wichtig. Es wisse dann genau, warum es gerade diese Praxis befolge.

Vorrangiges Ziel der religiösen Erziehung ist für Selma demnach die Befolgung von religiösen Regeln, die sie zunächst mit »Disziplin« in Verbindung bringt (Selma, Z.: 42). Die Regelbefolgung soll einen strukturierenden Effekt im Alltag ausüben, die Sicherheit, Halt und Geborgenheit im Leben bietet:

"... genau, dass man eine, eine Struktur in dem Alltag im Leben hat, also eine Sicherheit! Ist das, also für mich ist das auch eine Sicherheit! Also die Religion ist ein Halt für mich." (Selma, Z.: 48)

Wie auch Rabia erhofft sich Selma durch die religiöse Erziehung einen stützenden, Halt und Orientierung bietenden Effekt im Leben und dies »in jeder Hinsicht einfach« (Selma, Z.: 52). Des Weiteren fällt es Selma nicht leicht, über emotionale und spirituelle Aspekte zu sprechen, die die religiöse Erziehung für sie beinhalten sollte. Sie verbindet mit der religiösen Erziehung eine »Wärme«, »eine Geschwisterliebe«, die durch den Islam herbeigeführt werde sowie Respekt und Toleranz gegenüber anderen Menschen erzeuge:

"Ja, dass das einfach ... diese Wärme auch, was auch diese Geschwisterliebe. Das, das auch, ne? Und auch dieser Respekt vor anderen Leuten, dass man toleranter ist, das ist ja alles so etwas, was der Islam uns so gibt." (Selma, Z.: 58)

Die ethische Komponente der religiösen Erziehung, die gerade im türkischen Wortgebrauch durch ahlak (türk. für Moral, Sitte, ethische Grundhaltung, 
Charakter) und edeb (türk. für Anstand, gutes Benehmen, sittliches Verhalten) zum Ausdruck gebracht wird, und die sich im Verhalten gegenüber den Mitmenschen äußert, ist für Selma besonders wichtig: »Genau! Also ahlak und edeb! Also das, was für mich ganz wichtig ist, dieses edeb.« (Selma, Z.: 62ff.)

Auch Ali betont die Bedeutung der Vermittlung eines guten Benehmens. Neben der Regelbefolgung und der Aneignung von religiösem Wissen ist die Entwicklung zu einem "guten Menschen « das wichtigste Ziel seiner religiösen Erziehung. Aufgewachsen in einer religiösen Familie, in der er die Religion als einen selbstverständlichen »Teil des Lebens« (Ali, Z.: 9) begriff, sieht er die Weitergabe von religiöser Erziehung als eine Selbstverständlichkeit an: »Ja, das muss ja auch so sein « (Ali, Z.: 7). Die Religion bietet »inneren Frieden « (türk. huzur) innerhalb der Familie, was das Leben erleichtert. Durch die religiöse Erziehung sollen für ihn mehrere Aspekte, wie bspw. die Weitergabe von ethisch-moralischen Grundhaltungen (türk. ahlak, vgl. oben), die Aneignung von religiöser Bildung und religiösen Erfahrungen, die Einhaltung von grundlegenden religiösen Geboten, wie u.a. die täglichen Gebete, erzielt werden. Er unterstreicht vor allem eine altersgerechte und fundierte religiöse Erziehung, die dem Kind möglichst zu frühen Erfahrungen mit der Religion verhilft. Bei Ali liegt die Betonung in erster Linie auf der Regelbefolgung, die Konsequenzen wie Belohnungen oder Bestrafungen im Jenseits nach sich zieht. Zunächst beginnt er damit, zu erörtern, welche ethischen Grundsätze für ihn wichtig sind:

„Die Weitergabe von religiöser Erziehung, ich fange mal mit dem ahlak an (übelegt). Wenn die Kinder geboren werden, gibt man dies dem Kind sowieso weiter. Es muss wissen, wie es sich gegenüber Älteren zu verhalten hat, zusätzlich wie es gegenüber seinen Mitmenschen, wie auch vor Freunden nicht zu lügen, die Wahrheit zu sagen, immer einen guten Umgang mit seinen Mitmenschen zu pflegen, Gutes zu tun. Dies ist alles in unserer Religion enthalten ..." (Ali, Z.: 18)

Doch die ethischen Grundsätze stehen für Ali nicht im Vordergrund, sie sind lediglich ein wesentlicher Aspekt seiner religiösen Erziehung. Wichtig ist ihm die Fähigkeit, über die eigene Religion kommunizieren zu können, wobei dies nur durch die Aneignung von religiöser Bildung und religiösen Erfahrungen möglich sei. Im Vergleich zu den anderen Eltern spricht hier Ali auch über das »Wie«, d.h. den Weg, wie man die Kinder dazu befähigen kann, die von den Eltern beabsichtigten Ziele zu erreichen, und stellt damit zugleich einen praktischen Bezug her:

Wa, ich würde nicht sagen, dass ahlak für mich im Vordergrund steht, aber es ist einer der wichtigen Punkte. Daneben soll religiöse Erziehung einen Jugendlichen dazu brin- 
gen, über sich, über das Wissen unserer Religion zu kommunizieren, und natürlich in jungem Alter lernen und religiöse Erfahrungen machen, d.h. die Regeln der Religion einhalten, wissen, in welchem Alter, was er einzuhalten hat. Daneben soll er, wenn das Alter für die Einhaltung der Gebetsvorschrift gekommen ist, alles darüber frühzeitig kennenlernen. Er muss, bevor die Zeit zur Gebetspflicht kommt, praktische Erfahrungen damit machen, damit, wenn die Zeit kommt, er dies auf eine sehr gute Weise einhalten kann und natürlich sollen diese Regeln in seinem späteren Leben eine Selbstverständlichkeit darstellen. Es sollen die wichtigsten Themen seines Lebens werden, das ist das, was wir ihm weitergeben müssen." (Vgl. Ali, Z.: 18ff.)

An einer anderen Stelle, weist Ali auf Konsequenzen hin, die durch die Regelbefolgung oder Nichtbefolgung folgen können. Hier wird durch den Jenseitsbezug auf Belohnungen oder Strafen für die Taten im diesseitigen Leben hingewiesen. Es sei deshalb wichtig, Ehrfurcht und Liebe zu entwickeln, um die Fähigkeit der Regelbefolgung zu fördern. In der religiösen Erziehung sei es daher wichtig, Ehrfurcht und Liebe »in einer ausgewogenen« (vgl. Ali, Z.: 32) Weise weiterzugeben.

\subsection{Religiöser Erziehungstyp, der Identität und Persönlichkeit in den Vordergrund stellt - "Identitätssucher"}

Eine geringere Anzahl von Eltern stellt die Entwicklung einer Identität und Persönlichkeit in der religiösen Erziehung in den Vordergrund. Lediglich zwei Probandinnen, namentlich Lema und Hülya, verfolgen dieses Ziel. Als Expertinnen verfügen beide über eine universitäre pädagogische Ausbildung und nehmen daher eine Sonderrolle ein. Dennoch kommen sie in dieser Untersuchung als Mütter zu Wort. Gemeinsam ist ihnen zum einen die Betonung des Aspekts der Identität und der Persönlichkeitsentwicklung in der religiösen Erziehung und zum anderen eine hohe Bereitschaft und Engagement, sich für Dialog und Vielfalt in allen in dieser Untersuchung angesprochenen Bereichen einzusetzen. Daneben stellen für beide Elternteile die Einhaltung von religiösen Vorschriften und die Befolgung von ethischen Grundsätzen einen nicht zu unterschätzenden Aspekt ihrer religiösen Erziehung dar. Bei diesem Typus äußert sich durch deren Befolgung der identitätsbildende Charakter der religiösen Erziehung, der wiederum dazu dienen soll, eine Persönlichkeit zu entwickeln, die verschiedene Anforderungen und Erwartungen erfüllt. In der Bildung einer Identität wird daher auch die Erfüllung eines Zugehörigkeitsbedürfnisses gesehen. Beiden Probandinnen ist überdies gemeinsam, dass sie besonders ausführlich auf alle gestellten Fragen eingingen und viele reflektierte Angaben über ihre eigene religiöse Sozialisation machten.

Lema ist in einer »recht« muslimischen Familie aufgewachsen. Sie schildert ihre Erlebnisse als eine in Deutschland aufgewachsene Muslimin und 
stellt mittels ihrer Erfahrungen bzgl. der Religion in der Kindheit einen Bezug zu ihrer Schulzeit her. Es war ihr zufolge für sie »ganz normal«, in die Schule $\mathrm{zu}$ gehen oder den Kindergarten zu besuchen, wo sie mit der deutschen Sprache »konfrontiert« wurde. $\mathrm{Zu}$ Hause wurde zwar gelegentlich auch deutsch gesprochen, aber türkisch war ihre Alltagssprache. Der Gemeinschaftsbezug der Eltern war ausschlaggebend, sich von klein auf intensiv und »vielfältig« mit der Religion zu befassen und ihren Daseinszweck zu verstehen:

"Ja, also es ist so, dass ich, also meine Eltern muslimisch waren und wir auch in einer recht muslimischen Familie aufgewachsen sind, sodass, zum Beispiel, wir auch ganz normal in die Schule gegangen sind, auch Kindergarten [...] mit der deutschen Sprache konfrontiert waren, gelegentlich deutsch und türkisch gesprochen haben; und dass wir z.B. an den Wochenenden auch mal in die Moschee gingen und aus dem Koran gelernt haben. Und ja, auch mal so Camping gemacht haben, viel so mit Mädchengruppen haben wir auch viel gemacht mit unserer Gemeinde [...]. Und ja, da haben wir auch sehr viel gelernt. Und also es ist so, dass man gelernt hat, dass man auch auf die Erde geschickt ist, aber auch mit bestimmten Aufgaben und so. Dass man, ja, das war auch sehr vielfältig." (Lema, Z.: 14)

Außerdem wuchs sie in einer Familie auf, die das Beten und Fasten ernst nahm sowie die Feierlichkeiten und den Bezug zur Verwandtschaft pflegte. Auch für Lema, wie für viele weitere Probandinnen, war das Kopftuchtragen ein entscheidender Schritt, sich schließlich bewusst zu ihrer eigenen Religiosität zu bekennen. Sie entschied sich hierfür in der Pubertätsphase, d.h. während ihrer Schulzeit:

"Und ja, auch das, das Kopftuch war auch natürlich ... Ich habe also in der Grundschule noch kein Kopftuch getragen. Aber so ab der fünften Klasse, so hingegen in der Pubertät, dann fing es halt an und dass die Frau, das Mädchen auch versucht, bisschen ne. Ja, das fand ich dann halt auch positiv. Also natürlich wurde uns die Entscheidung überlassen, ne? Es war jetzt kein Zwang oder so, was jetzt so sehr viel behauptet wird. Also, ich hab das geliebt und gemocht." (Lema, Z.: 16)

Entscheidend seien für sie zudem das »Lesen« und die Beschäftigung mit dem Koran gewesen; und es sei auch darum gegangen, »wie sich ein Muslim « verhalten solle, ähnlich wie bei der Einhaltung der Zehn Gebote im Christentum (vgl. Lema, Z.: 20). Jedoch betont sie erneut, dass sie ganz »normale« Kinder gewesen wären, die sich nicht nur »24 Stunden « damit auseinandergesetzt, sondern "ganz normal « mit anderen Kindern, z.B. aus der Nachbarschaft, gespielt hätten. Mit der Normalität, die Lema an mehreren Stellen unterstreicht, drückt sie eine Selbstverständlichkeit aus, die sie im Grunde nicht von anderen Kindern unterschied. Hier wird deutlich, dass religiöse Erziehung nicht in 
einem Vakuum unter strengen oder exklusiven Bedingungen stattfand, sondern dass diese ein Bestandteil des »normalen« alltäglichen Lebens überhaupt ist (vgl. Lema, Z.: 16; vgl. Kap. II. 3.1.1 Religiöse Sozialisation als Dimension der allgemeinen Sozialisation).

Die Zugehörigkeit zu einer religiösen Gemeinde und die Peergroup, die sich innerhalb der Gemeinde herausbildete, stärkten Lema hinsichtlich ihres Bedürfnisses nach Zugehörigkeit und des Austausches, gerade in jenen Situationen, bei denen es um Probleme und Konflikte in verschiedenen Entwicklungsphasen ging. So waren auch immer Bezugspersonen in ihrer Gemeinde präsent, die einen positiven Umgang mit der Situation der Jugendlichen pflegten:

"[...] Dann möchten die andere Beispielpersonen oder eine andere Person eine erwachsene andere Person haben, so eine Vertrauensperson, der sie sich auch anvertrauen wollen. Und das hatte ich zum Beispiel in meiner Kindheit ja auch so gehabt, dass ich dann eine ältere Schwester hatte, die sich um uns gekümmert hat, auch bei Problemen. Sei es jetzt schulisch, außerschulisch, auch familiäre Probleme und das war dann halt sozusagen ... schön fand ich, weil dann dem Jugendlichen auch rausgeholfen wird also, wenn man ähnliche Konflikte hat. So wie ich zum Beispiel darauf gekommen bin, dass ich unbedingt mein Abi machen wollte, weil die eine Schwester, also die ältere Schwester mich dann dazu animiert hat, 'mach auf jeden Fall dein Abis, also meine Eltern hatten das zum Beispiel auch, aber das von außen Input kommt, das wirkt dann natürlich auch anders." (Lema, Z.: 22)

Die religiöse Erziehung nimmt heute für Lema einen wichtigen Stellenwert ein. Dabei ist es für sie wichtig, eine gut durchdachte zeitgemäße Vorgehensweise zu entwickeln, wie man mit Kindern und Jugendlichen »heutzutage« umgehen sollte, da sich auch »sehr vieles geändert« habe (vgl. Lema, Z.: 24). Weil sie ja jetzt auch ein Kind hat, stellt sich für sie als Pädagogin die Frage, wie sie später das Kind den Institutionen anvertrauen soll (Lema hat ein Baby). Hier spielt insbesondere die Frage nach der Identität des Kindes eine besondere Rolle. In diesem Zusammenhang thematisiert sie auch den Umgang mit der Religion der »anderen«:

"[...] Man sieht ja, auch z.B. vorher, als ich kein Kind hatte, war es ja anders. Jetzt [sieht, Anm. d. Verf.] man ja die Welt mit anderen Augen. Seien es diese ganzen Institutionen, man muss denen ja später das Kind anvertrauen, ja dann denkt man sich ja auch selber, ich bin ja auch eine Pädagogin, ob und inwiefern ich es anvertrauen soll. Jetzt nicht im negativen Sinne, sondern auch für mich ist es ja auch wichtig, in erster Linie, dass mein Kind ja auch mit seiner Identität, auch aufwächst, dass es jetzt nicht irgendwie sich verstellt oder so, später in der Schule, im Kindergarten. Da fängt das ja auch an. Für mich ist es ja kein Problem, dass das Kind im Kindergarten auch mal Weihnachten mitfeiert, 
aber für mich ist es auch wichtig, dass das Kind seine eigenen religiösen Feste, z.B. sei es im Ramadan oder Opferfest, oder auch die anderen Feste mitfeiern kann, dass es auch die Gelegenheit dazu hat, dass es jetzt nicht nur mit Weihnachten und mit Ostern aufwächst, sondern auch, dass es ..." (Lema, Z.: 26)

Es scheint zunächst so, als ob Lema noch keine endgültige Lösung für ihr Anliegen, dass »das Kind mit seiner Identität« aufwachsen solle, gefunden hat. Es sei wichtig, offen z.B. gegenüber Festlichkeiten wie Weihnachten oder Ostern zu sein, aber sie wünscht sich mindestens genauso viel Anerkennung für die eigenen religiösen Feste, sei es im Ramadan oder für das Opferfest. Hier sieht sie zu Hause kein Problem, aber problematisch könne dies in der Schule werden. So sieht sie das Aufwachsen mit einer Dialogbereitschaft und der Hervorhebung von Vielfalt als eine mögliche Lösung:

"[...] Das ist ja auch insofern wichtig, dass man versucht, anderen zu helfen, was z.B. ein Problemfall ist, dass die Menschen sich immer mehr abkapseln und immer nur mit sich selbst beschäftigt sind, auch nicht ihre Hilfe anbieten und ja, dass das Kind auch möglichst vielfältig aufwächst [...] es kann ja auch mit anderen Religionen konfrontiert werden, z.B. dem Christentum. Es ist ja kein Problem. Es ist ja auch, die haben ja auch christliche Regeln und Normen. Das ist ja ... [Das soll einiges Gutes bewirken?, Anm. d. Verf.]. Bewirken. Ja, auf jeden Fall." (Lema, Z.: 30ff.)

In dieser Interviewpassage macht Lema kenntlich, dass die Wahrung der Identität zu Hause kein Problem darstelle, sondern, dass das Kind lediglich in staatlichen Bildungseinrichtungen, wie bspw. in der Schule, auf eine andere Religion, z.B. das Christentum, treffe. Hier knüpft ihre Erwartung an, dass es möglichst vielfältig aufwächst und sich bei gleichzeitiger Wahrung der eigenen Identität mit anderen Religionen auseinandersetzen kann. Nicht zuletzt beinhalten diese ja nach ihrer Vorstellung ähnliche ethische Grundsätze (die Zehn Gebote im Christentum) wie im Islam.

$\mathrm{Zu}$ Hause ist für Lema z.B. neben der Einhaltung der Gebetsvorschrift auch die Entwicklung zu einer »vollkommenen« Persönlichkeit wichtig. Aus der religiösen Erziehung solle ein »guter Mensch« hervorgehen, der sich ethischen Grundsätzen, wie den Zehn Geboten oder einer Hilfsbereitschaft, die den sozialen Charakter hervorhebt, verpflichte. Gerade darin sieht Lema ein Problem dieser Zeit, nämlich den Individualismus, der immer mehr zu Abkapselung und Egoismus führe. Hier sei es wichtig, sich auf die muslimischen und christlichen Werte zu besinnen, um eben »Gutes« bewirken zu können. An einer anderen Stelle bezieht sich Lema eben auf diese Vervollkommnung, d.h. auf die Reifung eines Menschen, die der Glauben als »Lebensweise « oder »Lebensart« bewirken solle, der dem Einzelnen wiederum tugendhaftes Verhalten auferlege. Diese beiden Aspekte gehören für Lema zusammen: 
"Ja, so eine Art Vervollkommnung. Das ist ja so, der Mensch wird ja, sagen ja auch die meisten Theoretiker, ist wie ein unbeschriebenes Blatt, kommt ja auf die Welt, das muss ja irgendwie beschrieben werden. Das war Arthur Schopenhauer, wenn ich mich nicht falsch erinnere, die Behavioristen auf jeden Fall. Das ist ja so, das Kind wird durch diese Erziehung, durch diese religiöse Erziehung dann, zu einem Menschen gemacht. Also das gehört auf jeden Fall zusammen z.B. die Disziplin, dass das heutzutage immer mehr untergeht, das sieht man ja auch. Das ist ja bei den Jugendlichen, das ist ja auch mal ein Problemfall, dass das Kind auch mal zu Hause lernt, Respekt gegenüber anderen Kindern, auch Disziplin ... ja, das fließt [ineinander, Anm. d. Verf.], denke ich mal." (Lema, Z.: 40ff.)

Des Weiteren würden durch die Religion bzw. eine religiöse Erziehung die Anlagen, die beim Kind zur Vollkommenheit vorhanden seien, erst zur Entfaltung gebracht:

"Also, ich finde, meine Religion ... in der Religion ist es so, dass der Mensch so geboren wird, vollkommen eigentlich. Und durch die Erziehung, durch die religiöse Erziehung, je nachdem, auch dann zu einer Form gestaltet wird. Das ist ja ..." (Lema, Z.: 45)

Auch für Hülya stehen die Identitätsentwicklung und eine »dialogische Orientierung« an erster Stelle. Hülya ist in der Türkei im Schwarzmeergebiet geboren und hat ihre frühe Kindheit bis zu ihrem neunten Lebensjahr in der Türkei verbracht. Die Religion war etwas Selbstverständliches, da sie in eine Umgebung hineingeboren wurde, von der man auch weiß, dass sie als besonders religiös ist. So erkläre sich für sie auch, dass dadurch die Frage nach dem »anderen « gar nicht existiert habe, wie es z.B. heute für ihre Kinder infrage komme. Ihr Umfeld, insbesondere ihre Oma, die sich um sie gekümmert habe, und der Moscheebesuch zum Erlernen des Korans seien für ihre religiöse Sozialisation und Erziehung wesentlich gewesen:

"Also, ich bin in der Türkei geboren, war dort in einem kleinen Dorf von Trabzon geboren und da war nichts anderes als das, da nur Muslime dort waren. Also ich bin in einem nur muslimischen Ort aufgewachsen, sodass das für mich überhaupt keine Frage war, das andere überhaupt zu hinterfragen. Oder ich bin einfach automatisch religiös aufgewachsen bis zu meinem neunten Lebensjahr und ja, also das war für mich jetzt nichts, wo ich mich irgendwie entscheiden konnte oder wo ich sagen konnte, oh, es gibt ja auch was anderes, außer das (lacht). [...]. Wir hatten halt im Dorf, aber die Moschee, wo wir dann ... ja an Wochenenden immer dahingegangen sind und auch die Suren und auch den Koran geübt haben, gelernt haben. [...] Ich hatte eine Oma, also meine Mutter hat immer gearbeitet und meine 0 ma hat sich sehr um mich gekümmert. Die hat mir nachts immer auch die Suren beigebracht [...]." (Hülya, Z.: 12-16) 
Die religiöse Erziehung wurde einfach selbstverständlich vermittelt, da die Menschen an ihrem Herkunftsort sehr auf die religiöse Praxis achteten und so war hier beispielsweise der Gebetsruf mehrmals am Tag zu vernehmen. Ihren Kindern könne dies möglicherweise seltsam vorkommen, wenn sie in der Türkei den Gebetsruf hören würden. Hülya deutet an dieser Stelle auf die »Kirchenglocken«, die die Kinder mitbekämen. Hier wird aufgezeigt, dass im Vernehmen der Kirchenglocken und der Erklärung, die daraufhin folge, die Frage nach dem »Eigenen« aufgeworfen werde. Die Religion des »anderen« bzw. ein religiöses Symbol des »anderen« regt Hülya dazu an, in dem Moment über das »Eigene« bzw. über die eigenen Erfahrungen mit einem äquivalenten religiösen Symbol nachzudenken und das ihren Kindern entsprechend zu vermitteln. An dieser Stelle fällt die »dialogische« Herangehensweise, die zugleich charakteristisch für diesen Typ ist, auf:

"[...] ja, das war, vor allem im Schwarzmeergebiet ist Religion ... auch höchste Priorität ... allgemein. Also da sind die Menschen sehr religiös und auch mit dem Beten, also, dass man fünfmal am Tag betet, das ist einfach sehr wichtig und als kleines Kind, wenn man im Dorf aufwächst, wächst man ja automatisch mit dem ezan [türk. für Gebetsruf, Anm. d. Verf.] auf. Also es ist hier nicht möglich, ich war noch nicht in der Türkei mit meinen Kindern. Wenn ich mal in der Türkei mit denen wäre, wäre das für die ganz komisch, das zu hören, so auf der Straße mal den muezzin [türk. für jemand, der den Gebetsruf verrichtet; Anm. d. Verf.] zu hören, die würden sich auf jeden Fall fragen, was es ist. Umgekehrt fragen sich meine Kinder ... haben das gefragt, z.B., wenn die Kirche, wenn die Glocke an der Kirche geläutet hat, dann haben die gefragt, was das ist dann habe ich das auch erzählt, was es ist, ja ..." (Hülya, Z.: 18)

Religion bedeutet für Hülya, das Leben danach auszurichten und es entsprechend zu gestalten, sodass sie sich selbst in ihrer Vorbildfunktion als ein solches wahrnimmt und es den Kindern vorlebt und »thematisiert«. Dass Hülya ein sehr praktisch orientierter, tatkräftiger Mensch ist, lässt sich anhand des folgenden Interviewabschnitts ablesen. Sie bietet zunächst Beispiele an, wie sie in der religiösen Erziehung vorgeht, und veranschaulicht dann, wie sehr sich diese um die Frage nach der eigenen Identität dreht:

"Also, Religion bedeutet für mich, dass ich dadurch mein Leben orientiere, also, dass sich dadurch mein Leben orientiert und dementsprechend formt, wie soll ich das sagen, ich thematisiere das mit meinen Kindern, ich lebe es innen auch vor. Und, aber allgemein von klein an habe ich damit angefangen, schon im Bauch, dass ich z.B. aus dem Koran vorgelesen habe oder auch gehört und das dann auch meine Kinder habe hören lassen. [...], also man beginnt immer darüber zu sprechen: 'Was ist Gott, ne? Was heißt denn wir überhaupt? Wer bin ich? Also diese Fragen; und das vermittelt man z.B. auch, 
ja, manchmal in kleineren Gesprächen mit dem Kind, ob das jetzt am Tisch ist [...]." (Hülya, Z.: 24)

Zu den Beispielen, die auch als eine Beschreibung ihrer Religiosität aufgefasst werden können, fügt sie hinzu, was diese Praktiken und Rituale letztendlich bewirken sollen. Es geht ihr vor allem darum, über Gott nachzudenken und über ihn zu sprechen. Gleichzeitig möchte sie die Frage nach einer kollektiven Identität (»wir«) bzw. der eigenen Identität (»Wer bin ich?«) klären, so dass sie aktiv wurde und sich mit ihren Kindern zunächst einer »deutschen« Krabbelgruppe anschloss, in der sie merkte, dass viel Wert auf die Religion gelegt wurde. Nach dieser Erfahrung entschloss sie sich dazu, mit einer Freundin eine »eigene« Krabbelgruppe zu gründen, in die sie muslimisch-religiöse Elemente integrierte:

"[...] Ich hab dann irgendwie durch diese Idee, wo meine beiden Kinder dann auf der Welt waren, habe ich die in die Krabbelgruppen gebracht und hab ich dann gesehen, dass auch in den Krabbelgruppen, in den deutschen Krabbelgruppen, doch viel Wert auch auf die Religion gelegt wird. Zum Beispiel: Was ist Nikolaus? Und was ist der Weihnachtsmann? So dass man sich z.B. die Bilderbücher angeschaut und das dann erklärt hat; und für mich war dann entscheidend, was in meiner Religion sehr wichtig ist, sodass ich dann mit einer Freundin zusammen, eine eigene Krabbelgruppe gegründet habe, für Drei- bis Fünfjährige; und wir sind dann, also daraus hat sich dann ein Konzept entwickelt, das wir dann in meiner Stadt durchgeführt haben, sodass z.B. in jeder Krabbelgruppe eine Moschee in Krefeld besucht wurde und vor Ort die Krabbelgruppen eingeführt worden sind, und z.B. so Essgewohnheiten, dass wir z.B., wenn wir jetzt anfangen zu essen, Bismillah sagen; und das haben wir dann auch spielerisch dargestellt, haben dann z.B. statt ıpiep piep، Bismillahirrahmanirrahim [arab. für "Im Namen Allahs des Barmherzigen des Allerbarmers", Anm. d. Verf.] in derselben Melodie dann dargestellt [gesagt, Anm. d. Verf.]. Haben dann auch zu den Festen, zu den religiösen Festen gebastelt usw. [...]." (Hülya, Z.: 24)

Mit Religion verbindet Hülya somit, dass sich mit deren Hilfe später ein »guter Mensch« entwickelt, d.h. die Entwicklung einer Persönlichkeit, die verschiedenen Anforderungen, wie z.B. der Befolgung von bestimmten Werthaltungen gerecht wird, steht hierbei im Vordergrund und soll das Resultat einer religiösen Erziehung sein. Für die Identitätsentwicklung sei es erforderlich, religiöse Werte oder ethische Grundsätze, wie bspw. Respekt, Vertrauen oder Liebe, innerhalb der eigenen »kleinen Familie« weiterzugeben. Dies war für Hülya letztendlich schon, als die Kinder noch im Bauch waren, ein zentrales Thema:

"[...] also für mich ist Religion sehr wichtig, weil damit ein guter Mensch später daraus sich entwickelt und deshalb gibt es auch die Religion meiner Meinung. Die ganzen reli- 
giösen Werte, wie Respekt oder ja Vertrauen oder Liebe, die findet man in der Religion und die lernt man durch Religion; deshalb habe ich es so weitervermittelt, vermittle ich immer noch weiter (lacht). Aber so habe ich angefangen das in meiner Familie, eigenen kleinen Familie, zu thematisieren; also so nachdem meine nicht mal auf der Welt waren, sondern, sogar schon im Bauch waren, war das für mich schon ein Thema [...]." (Hülya, Z.: 24)

Mit der religiösen Erziehung zielt Hülya auf die Identitätsentwicklung ab, sodass Kinder und Jugendliche mit Werten aufwachsen könnten. Gleichzeitig betont sie, wie wichtig es sei, ein Bewusstsein für die eigene Religion, gleich welcher man angehört, zu entwickeln und über diese Bescheid zu wissen. Für den Frieden in der Zukunft wäre dies ein bedeutsamer Weg. Wie auch Lema sorgt sich Hülya (wohl auch aus ihrer professionellen Rolle heraus) um Jugendliche, die sich wenig mit ihrer eigenen Religion befasst haben oder ihre Religion nur vom Hörensagen kennen. Das alleinige Kopftuchtragen und Koranlesen genüge beispielsweise nicht, sondern es solle unter Jugendlichen auf ein vertiefendes Verständnis der eigenen Religion geachtet werden. Dies sei besonders wichtig, damit die Jugendlichen vor möglichen Identitätskonflikten bewahrt werden könnten. Die Bewusstwerdung der eigenen Identität sorge zudem für ein Zugehörigkeitsgefühl. Ebenso wie für Lema ist es auch für Hülya von Bedeutung, zu wissen, wo man hingehört, damit man Respekt vor sich selbst haben und gegenüber anderen aufbringen kann. Das Ergebnis sei dabei die Entwicklung einer »gesunden Identität«, womit Hülya die Erkenntnis darüber, »wer« man ist und »wo« man hingehört, d.h. die Zugehörigkeit zu einer Religion, verknüpft. Diese Erkenntnis sei letztlich ausschlaggebend, um Respekt vor sich selbst und ein entsprechendes Selbstvertrauen zu entwickeln. Nur so könne man auch den »anderen« respektieren und ihm Vertrauen entgegenbringen. Daher sollten die Kinder mit bestimmten universalen Werten, »die auch 100 Jahre später noch vermittelt« würden, aufwachsen, auch wenn neue »gesellschaftliche« oder andere »Orientierungen« hinzu kämen:

"[...] dadurch sehe ich, dass es bei vielen Jugendlichen, zu Identitätskonflikten kommt, dass die gar nicht mehr wissen, was die eigentlich tun; und je mehr sich die Jugendlichen mit der eigenen Religion befassen, [desto eher, Anm. d. Verf.] entsteht eine gesunde Identität; und deshalb finde ich, dass, also bei mir war es so, dass ich mindestens wusste, wer ich bin, wo ich hingehöre, sodass ich dann anderen gegenüber mehr Respekt hatte. Weil, wenn ich weiß, wer ich bin, dann weiß ich, wer mein Gegenüber ist, und so habe ich automatisch Respekt und Vertrauen gegenüber mir und dem anderen, deshalb ist das sehr wichtig, also dazu mache ich es. Ich möchte dann, dass auch meine Kinder so aufwachsen; und mit diesen Grundwerten aufzuwachsen, das heißt nicht, dass da immer wieder neue Sachen aus der Gesellschaft hinzukommen werden, also gesellschaftliche Werte, neue Orientierungen, [...] die Kinder werden automatisch 
sozialisiert in der Gesellschaft. Aber es gibt Grundwerte, die kann man einfach immer mittragen, die man auch 100 Jahre später noch weitervermittelt, deshalb finde ich es sehr wichtig." (Hülya, Z.: 26)

Darüber, auf welche Werte sie sich letztendlich bezieht, gibt sie folgende Antwort:

"Also, dass man erst mal zu sich selbst Respekt hat, dass man einfach weiß, dass ein Mensch, also, dass überhaupt alle Lebewesen von Gott erschaffen sind und dass man, wenn man Gott liebt, automatisch alle Lebewesen liebt, das ist ja der berühmte YunusEmre-Satz [...]."(Lema, Z.: 28)

In diesem Interviewausschnitt wiederholt sich Hülya zunächst. Der Respekt vor sich selbst sei besonders wichtig. Sich auf den berühmten türkischen Mystiker Yunus Emre beziehend, sollten alle Menschen als Geschöpfe Gottes geliebt werden, weil die Liebe zum Schöpfer dies bezwecke (türk. »Yaratılanı sev, yaratan da ötürü«-Yunus Emre). Dabei stehe der Mensch im Mittelpunkt und es sei dabei unerheblich, wen man vor sich habe. Selbsterkenntnis führe bei einem Menschen dazu, sich selbst als Geschöpf Gottes wertzuschätzen. Diese Wertschätzung führe zu einer Offenheit und Toleranz gegenüber anderen. Diese Grundhaltung sei es, die es Hülya erleichtert habe, sich in Deutschland zurechtzufinden. Hingegen habe sie diese Toleranz vom »Gegenüber« nicht selbstverständlich erhalten. Es habe seine Zeit gedauert, bis sie Akzeptanz von ihrem Gegenüber erfahren konnte. Zusammengefasst sind es universale Werte, wie die Liebe zu Gott und zu den eigenen Mitmenschen, Toleranz, Akzeptanz, Dialogbereitschaft und die Wertschätzung von Vielfalt, die zu einer Persönlichkeitsentwicklung beitragen und letztendlich eine solche Identität hervorbringen.

\subsection{Religiöser Erziehungstyp, der sich ethischen Grundsätzen verpflichtet - "Ethiker»}

Eltern (Belkıs, Melek, Feride, Birol, Adem), die sich ethischen Grundsätzen verpflichten, stellen den ethisch-moralischen Aspekt der religiösen Erziehung in den Vordergrund. Allen Eltern dieses Typs ist es von besonderer Bedeutung, dass die Kinder sich zu »guten Menschen« entwickeln, die für ihre Umwelt und sich selbst Gutes und Nützliches tun. Die Entwicklung eines guten Charakters (türk. ahlak) soll dazu dienen, sich auf den Glauben zu beziehen, um die religiösen Pflichten und Gebote gewissenhaft zu erfüllen. Ein gemeinsames Merkmal aller Eltern ist, dass sie zunächst zwischen »religiöser Erziehung « und »allgemeiner Erziehung « unterscheiden. Dies bedeutet, dass beide Erziehungsformen zunächst keine natürliche Einheit bilden und voneinander 
getrennt wahrgenommen werden. Interessant ist vor diesem Hintergrund die Tatsache, dass Eltern dieses Typs diese Erziehungsmodelle jeweils gesondert betrachten und diese erst in einen Zusammenhang miteinander bringen und diese zugleich nicht voneinander getrennt denken und verstehen. ${ }^{13}$ Hier scheint letztlich der Interaktionsrahmen dafür bestimmend zu sein, auf welche »Erziehung« man sich jeweils bezieht.

Des Weiteren muss auch hervorgehoben werden, dass bis auf eine Mutter (Feride), die einen Typ mit »besonderer Ausprägung« (vgl. Mayring 2010) darstellt, alle Mütter neben der ethischen Perspektive als der primären Zugangsform $\mathrm{zu}$ ihrer religiösen Erziehung auch unterschiedlichen Aspekten, wie bspw. dem Glauben, der Sinnorientierung oder der Spiritualität, eine zentrale Bedeutung beimessen. Diese Differenzen werden im Folgenden gleichermaßen thematisiert. Es wird darin auch ein individueller Zugang der befragten Eltern zur Religion deutlich, die ebenfalls typische Elemente und Merkmale von Ritualisten oder Idealisten aufgreifen (wie z.B. Sinnorientierung, Einhaltung von religiösen Geboten).

Belkıs ist in einer eher traditionell-religiösen Familie aufgewachsen, in der das fünfmalige Beten am Tag, das Fasten und das Koranlesen selbstverständliche Bestandteile des Familienalltags darstellten. Sie hat die Religiosität der eigenen Familie mehr »so im Hintergrund « erfahren, innerhalb derer nicht viel reflektiert oder über den Sinn eines Gebots nachgedacht wurde. Ihr Dasein als Muslimin habe sie beispielsweise dadurch erfahren, dass sie keinen Weihnachtsbaum zu Hause aufgestellt oder Karneval gefeiert hätten. Hier habe sie diese Elemente dezidiert als Abgrenzungskriterien gegenüber den Nichtmuslimen wahrgenommen. So kritisiert sie an ihrer Familie, dass ihr nichts »erklärt« worden sei:

"[...] Meine Eltern haben gebetet, fünfmal am Tag, und gefastet natürlich, ab und zu den Koran gelesen, aber sehr bewusst habe ich das in meiner Kindheit nicht erlebt. [...]. Ja, in der Familie [...] lief das immer so beiläufig, so im Hintergrund. Da habe ich es eher so wahrgenommen, dass ich (überlegt) im negativen Sinne so, dass wir zum Beispiel keinen Weihnachtsbaum hatten und dass wir keinen, weiß ich nicht, Karneval gefeiert haben, obwohl das natürlich nicht vorwiegend christlich ist; oder, dass wir halt anders waren als die Nichtmuslime. [...]. Aber im positiven Sinne, dass da irgendwie uns irgendetwas erklärt wurde, so habe ich das nicht wahrgenommen in der Familie." (Belkıs, Z.: 17ff.)

13 | Im Vergleich zu den anderen Eltern, für die die religiöse und allgemeine Erziehung eine selbstverständliche Einheit bilden, findet hier immer wieder eine gesonderte Darstellung beider Erziehungsformen statt. Lediglich in einigen wenigen praktischen Aspekten, wie z.B. in der Befolgung von Regeln oder im Zusammenhang von Erziehungsstilen lässt sich bei den anderen Typen eine solche Differenzierung vorfinden. 
Der Kontakt zu einer Mädchengruppe, die sie ab ihrem 14. Lebensjahr besuchte, war für Belkıs besonders prägend. Dort nahm sie auch zum ersten Mal ihr Dasein als Muslimin bewusst wahr:

"[...]. In meiner Jugend gab es eine Mädchengruppe, da bin ich ab 14 Jahren hingegangen. Ich weiß sehr gut, dass es in meinem 14. Lebensjahr war, und das hat mich schon sehr stark geprägt. Das war sehr prägend für mich und da habe ich eigentlich dieses bewusste Muslimsein, das habe ich dort erst so richtig wahrgenommen." (Belkıs, Z.: 17)

Auch die religiöse Erziehung innerhalb ihrer Familie bewertet sie als eine »traditionelle« Erziehung, in der sie religiöse Motive integriert sah. Bezogen auf ein Beispiel äußerte sich dies in der Haltung der Eltern gegenüber dem Verhalten der Tochter zum Gegengeschlecht. Hier kommt die Sexualmoral zum Tragen, die schon für Rabia (vgl. Kap. III. 3.2.) von Bedeutung war. Belk1s sieht darin aber eher ein »traditionelles Anliegen« der Eltern:

"Ja eher eigentlich traditionelle Erziehung. Da überschneiden sich natürlich auch einige Motive: religiöse und traditionelle. Aber eher traditionell als religiös." (Belkıs, Z.: 21)

"Ja, was zum Beispiel die Haltung zum anderen Geschlecht angeht. Dass sowohl in der Religion, dass so eine gewisse Distanz da ist, eine vorsichtige Distanz, als auch in der Familie, dass man gesagt hat, 'So jetzt pass auf und guck wie du da halt mit Jugendlichen, männlichen Jugendlichen redest mit den Klassenkameraden und so weiter. Es war aber eher so bei meiner Familie, also im Nachhinein denke ich, dass es eher ein traditionelles Anliegen war." (Belkıs, Z.: 25)

Heute nimmt die religiöse Erziehung für Belkıs eine wichtige Rolle ein. Dabei stellt die religiöse Erziehung eine »Grundlage« ihrer allgemeinen Erziehung oder Erziehungsziele überhaupt dar (vgl. hierzu auch Karakaşoğlu-Aydın 2000), aber im Grunde gibt es da für sie Überschneidungen. Nach Belkıs sind z.B. Ehrlichkeit oder Fairness Werte bzw. ethische Grundsätze, die sowohl religiös begründet sein können, als auch universell gelten. Diese Perspektive ist typisch für alle Eltern dieser Gruppe. Die religiöse Erziehung erscheint Belk1s als »sehr wichtig«:

"Ja, das ist für mich sehr wichtig! Das ist so die Grundlage meiner Erziehung oder meiner Erziehungsziele, wobei für mich da religiöse Erziehung und (überlegt), ja, wie soll man das sagen?, Erziehung eigentlich sich überschneiden, also meine religiösen Werte und die universellen Werte, die man halt Kindern beibringt, wie weiß ich nicht, Ehrlichkeit, Fairness und so weiter. [...] Hilfsbereitschaft und so weiter, die überschneiden sich ja, insofern ist das für mich das Wichtige." (Belkıs, Z.: 29ff.) 
Als das zentrale Ziel ihrer religiösen Erziehung betrachtet Belkıs also, dass sie ein Kind dahingehend beeinflussen möchte, dass es zum einen positiv auf seine Umwelt und auf die Gesellschaft einwirkt und daneben ein Mensch wird, der unter Bezugnahme auf sein Gewissen selbstständig denken und entscheiden kann. Dabei spielen die rituellen Aspekte für sie eine eher untergeordnete Rolle, obwohl diese gleichermaßen »auch total wichtig« für sie seien:

"[...] Das ist eigentlich ... für mich ist mein Erziehungsziel, dass ich ein Kind beeinflusse, soweit es geht, zu einem Menschen, der erstens positiv auf die Gesellschaft einwirkt, positiv in seinem Umfeld wirkt, zweitens zu einem Menschen, der selbstständig denkt und entscheidet, aber das auch mit seinem Gewissen vereint, in Bezugnahme auf sein Gewissen quasi. Es kommt mir weniger darauf an, bestimmte rituelle Sachen ... das ist natürlich auch total wichtig für mich. Das fünfmalige Beten und so weiter und so weiter, aber in erster Linie wirklich, selbstständig denken und entscheiden zu können. Das ist für mich sehr wichtig! Für meine Kinder." (Belkıs, Z.: 33)

Auf die Frage, ob für sie damit das Thema ausgeschöpft sei, antwortet sie folgendermaßen:

"Und der Glaube natürlich! Das zu manifestieren, im Charakter, in der Seele des Kindes. Das ist sehr wichtig!“ (Belkıs, Z.: 35)

Der Glaube stellt für Belkıs den Sinn des Lebens dar. Er solle den Charakter und die Seelen der Kinder formen und bestimmte charakterliche Eigenschaften, die den Kindern nahegelegt werden, würden sich eben aus dem Glauben ableiten lassen:

"Ja, das ist so ein Ganzes eben! Ja, heutzutage fragen sich ja viele Menschen, auch also erwachsene Menschen: 'Was ist es für mich, was ist der Sinn?، Für die einen ist es die Familie, für die anderen ist es der Ehepartner. Die anderen sehen überhaupt keinen Sinn. Für mich ist es der Glaube an Gott. Das ist für mich der Sinn des Lebens und ich möchte das, diesen Sinn, auch an meine Kinder weitergeben!« (Belkıs, Z.: 39)

Der Glaube stellt für Belkıs gewissermaßen die Grundlage überhaupt dar. Im konkreten Erziehungsalltag hieße das, dass sie bestimmte Werthaltungen nicht unabhängig von Gott entwickelt und immer einen Bezug zum Glauben herstellt:

"Ja, die Grundlage eigentlich, wie eben schon gesagt, dass halt diese Grundlage, zum Beispiel bestimmte charakterliche Eigenschaften, dem Kind nahezubringen sind. Wie eben gesagt ne, Ehrlichkeit und so weiter. Das bildet so die Basis. [...] Also, dass wir bestimmte Werte nicht unabhängig von Gott machen. Dass ich meinem Kind nicht sage: 
'So, wenn du ehrlich bist, ist das halt gut für dich und für deine Umgebung und für die Menschen, wenn du denen nicht schadest, sondern ich sage: 'Das ist gut für deine Umgebung für dein Miteinander, aber es ist gleichzeitig auch ein religiöses Gut.“" (Belkıs, Z.: 45-49)

Auch bei Melek findet sich die charakteristische Hervorhebung von ethischen Grundsätzen wieder, die kennzeichnend für diesen Typus sind. Sie betont ebenfalls an mehreren Stellen, dass für sie die allgemeine und religiöse Erziehung zusammengehören würden und beiden zugleich eine angemessene Beachtung geschenkt werden müsse. Allerdings bezieht sie sich hierbei auch vermehrt auf den Schulerfolg, den die »allgemeine Erziehung« beinhalten solle.

Die Erfahrungen mit der Religion in ihrer Ursprungsfamilie verbindet Melek stark mit dem Kopftuchtragen. Das Kopftuch scheint für sie das Symbol für die Religiosität schlechthin zu sein. Sie nimmt die Familienatmosphäre in ihrer Kindheit im Vergleich zu anderen Familien als »viel zu locker« wahr:

"Also wir standen nicht so unter Druck. Okay. Wir waren Moslems, aber wir mussten nicht beten, ich habe damals noch kein Kopftuch getragen. Wir haben alles sehr locker gesehen, viel zu locker vielleicht auch." (Melek, Z.: 21)

Auch die religiöse Erziehung, die in der Familie erlebt wurde, koppelt sie an die Erfahrung, das Kopftuch »freiwillig« gewählt zu haben. Das Tragen des Kopftuches, das nicht unter Druck stattfand, sondern »mit Liebe« getragen werden sollte, ist ein wesentliches Element für die erlebte Religiosität innerhalb der Ursprungsfamilie. ${ }^{14}$ Vielmehr war es für sie wichtig, den »Sinn« dahinter zu verstehen:

"Also wir mussten keine Kopftücher tragen. [...] Auf jeden Fall! Denn damals haben wir auch gesehen, unsere Freunde sind von zu Hause aus mit einem Kopftuch rausgegangen, aber auf dem Weg haben die das sofort wieder ausgezogen. Wir haben gedacht: Nee, so möchten wir nicht sein! [...] Auf jeden Fall freiwillig entscheiden! Nicht unter Druck. Denn wir wussten, das hat keinen Sinn!“ (Melek, Z.: 33-41)

Die Eltern überließen die Entscheidung somit den Töchtern, sodass sie schließlich »selbst damit klarkommen« müssten. Hier habe vor allem Meleks Vater viel Wert auf die Entscheidungsfreiheit, die sinnlose Befehle ausschloss, ge-

14 | Wie schon in den vorangegangenen Interviews erläutert wurde (z.B. bei Selma, Nermin, Lema usw.), markiert das Tragen des Kopftuches in den meisten Fällen einen neuen Lebensabschnitt mit der Religion, in der die Religion je nach Bewusstseinsgrad ausgelebt wird. 
legt. Es sollte vielmehr ein liebevoller Umgang im Hinblick auf diese Thematik gepflegt werden:

"Also, die haben schon erwartet, mein Vater vor allem, eine Zeitlang; ab einem bestimmten Alter sollten wir Kopftücher tragen, aber wir sollten es aus Liebe machen, also nicht, weil sie es uns befehlen, sondern weil wir es selber möchten. Also wir müssten selber damit klarkommen. [...] So war er drauf. Unsere Mutter auch." (Melek, Z.: 49ff.)

Das Kopftuch symbolisiert für Melek somit den Ausgangspunkt ihrer Religiosität, sodass sie dem damaligen Wunsch des (zukünftigen) Ehemannes schließlich entsprochen und mit dem Tragen des Kopftuches begonnen habe. Erst in der Ehe habe sie sich dazu bereit gefühlt, diesbezüglich »einen Anfang« zu machen, sodass sie sich heute »viel, viel mehr für ihre Religion « interessiere und »viel mehr« über ihre Religion Bescheid wisse (vgl. Melek, Z.: 53ff.)

Auf die Frage, welche Ziele sie mit einer religiösen Erziehung verbinde, gibt sie folgende Antwort: »Ein guter Mensch zu sein! Vor allem!« (Melek, Z.: 57).

Mit einem "guten Menschen « brachten bisher schon andere Eltern verschiedene (auch ethische) Aspekte bzw. Tugenden, die ein Mensch durch die religiöse Erziehung erlangen sollte, in Verbindung. Für Melek, die diese Frage zum Teil auf Türkisch beantwortete, wohl auch deshalb, weil ihr in dem Moment die richtigen Begriffe (vgl. III. 1.5 »Zur Bedeutung der Sprache«) fehlten, bedeutet dies, dass ihre Kinder »nützlich « (türk. faydalı) für die Gesellschaft werden könnten. Sie sollten sich zu Menschen entwickeln, die der Menschheit, Allah und dem Gesandten Muhammad (s) dienlich seien. Sowie alle anderen Mütter dieses Typs erläutert sie hierbei, dass dies nicht ausschließlich mit der religiösen Erziehung zu erreichen sei, sondern betont zudem, dass hierfür auch die Notwendigkeit einer allgemeinen Erziehung überhaupt bestehe:

"[...]. Sie sollen der Gesellschaft nützlich sein. Ich will, dass sie zu Menschen werden, die der Menschheit, Allah und dem Gesandten von Nutzen sind. Das kann nur, also da muss die religiöse Erziehung da sein! Die Notwendigkeit zur Erziehung ist auch da. Das weiß ich! Also das muss auch dazu, das gehört dazu! Das muss sein! Ich merke an meiner Tochter, sie hat mehr, sie hat viel mehr Spaß an der religiösen Erziehung, wie jetzt in der Schule, aber wir versuchen inr immer klarzumachen: Alle beide Sachen müssen gleichzeitig laufen! Das ist ein Muss! Also nicht sagen: religiöse Erziehung, ja, aber ich möchte dumm bleiben. Das geht nicht! Also passt nicht! (Melek, Z.: 59)

Allgemeine Bildung und religiöse Erziehung sind für Melek nicht voneinander trennbar und müssen miteinander Hand in Hand gehen, trotz der Tatsache, dass sich die Tochter (12 Jahre) im Vergleich zur schulischen Bildung vielmehr für ihre Religion interessiert und sich dieser viel näher fühlt. Aufgrund ihrer 
ruhigen Persönlichkeit erfahre sie eine Geborgenheit in der Religion und reagiere auf alles, was mit dieser zu tun hat ruhiger als auf die Schule. Die Tochter besuche ein Gymnasium, das von einer religiös geprägten Organisation gegründet worden sei (vgl. Melek, Z.: 61-65). Für die Mutter ist das zwar erfreulich, aber sie unterstreicht an dieser Stelle noch einmal die Bedeutung der Schule und des Bildungserfolges:

"Ja. Ja. Das merken wir auch zu Hause. Ne, Schule, da reagiert sie ganz anders. Aber Religion, da reagiert sie ganz ruhig. [...]. Ja. Das freut mich sehr! Aber ich, ich weiß auch, Schule gehört dazu! [...] Auf jeden Fall!» (Melek, Z.: 67-71)

Der Glauben spielt für die religiöse Erziehung von Melek eine ähnlich bedeutsame Rolle wie für Belkıs. Melek ist davon überzeugt, dass nur mit dem Glauben eine »innere Ruhe« bzw. »Überzeugung « im Herzen einkehrt und spricht damit die spirituelle Dimension ihres Glaubens an. Die Gotteskenntnis und die Befolgung des Weges des Propheten Muhammad (s) sind für sie notwendige Schritte, um eine »friedliche« (türk. huzur = dt. auch »ruhig«) Atmosphäre in ihrem Heim und ihrer Familie zu schaffen. Als Vorbild übernimmt der Prophet dabei eine wichtige Stellung in ihrem Leben ein. Interessant ist dabei, dass sie hier zugleich eine bedeutende Parallele zwischen beiden Aspekten herstellt und, ähnlich wie Belkıs, die Notwendigkeit einer Verbindung zwischen Bildung und Glauben sieht. Diese gehören für sie zusammen und ergänzen sich:

"Die Gewissheit bzw. die Überzeugung [türk. mutmain, Anm. d. Verf.] im Herzen kann nur mit dem Glauben entstehen. Das weiß ich. Indem ich Gott erkenne, dem Weg des Propheten folge, kann sie entstehen. Dessen bin ich mir bewusst. Wir versuchen, unser Heim auf diese Weise aufzubauen. Wie haben sie es gemacht und haben ihre Ruhe [türk. huzur, Anm. d. Verf.) gefunden? Wenn wir diese Gewissheit/Überzeugung im Herzen suchen, dann bin ich überzeugt davon, dass dies so sein muss [und wir innen folgen, Anm. d. Verf.]. Die ergänzen sich irgendwo, also iman [arab. für Glauben, Anm. d. Verf.] und Bildung, das ergänzt sich." (Melek, Z.: 77)

Zur Erläuterung dieser Vorstellung, die die Vorbildfunktion des Propheten (s) besonders unterstreicht, konkretisiert sie dies zunächst anhand der Kopftuchfrage, die sich für die Tochter stellte. Dabei spielte gerade die religiöse Erziehung und die daraus folgende Konsequenz der Einhaltung religiöser Gebote für die gesamte Familie eine große Rolle:

"Eine große Rolle! Eine sehr sehr große Rolle! Also ich habe was anderes im Kopf, aber ich weiß, meine Religion verbietet es mir. Das gehört nicht zu der Familie. Dann versuchen wir, es rauszuhalten, auch wenn es uns schwerfällt [...]. Zum Beispiel ... wie soll 
ich sagen jetzt? Was ist jetzt das Populärste? (überlegt) Kleidung vielleicht. Kleidung könnte man sagen. Meine Tochter zieht sich mittlerweile, versucht sich, so wie ich anzuziehen, aber ich weiß, die hat mich als, also ich merke, dass sie mich als Vorbild genommen hat. Ich sage: ‘Büsra, du bist jetzt in dem Alter. Du kannst das ruhig noch anziehen!، ,Nein, Mama, möchte ich aber nicht! ‘ Also sie hat mich da als Vorbild genommen. Sie weiß: Das passt nicht zu meiner Religion, diese Kleidung. Sie hat es selber aus ihrem Leben rausgehalten. $0 b$ das jetzt weiterhin so bleibt, weiß ich natürlich nicht. [...]." (Melek, Z.: 83ff.)

Hier wird nochmals verdeutlicht, dass die Mutter für die Tochter als Vorbild fungiert und diese hinsichtlich der Bekleidungsvorschrift von dieser nachgeahmt wird. Trotz der Einwände der Mutter folgt die Tochter der Überzeugung der Familie und versucht, ihr Leben nach den Geboten der Religion auszurichten, obwohl sie sich gemäß ihrer Mutter »ruhig« noch anders »anziehen« könnte $^{15}$ (vgl. hierzu Kap. II. 3.1.3d) »Normative Grundüberlegungen«).

Schließlich nimmt Melek ihre Ansicht, dass der Glaube (arab. iman) und die Bildung eben zusammengehören würden, nochmals auf. Gerade der Glaube ermögliche bei zu erduldenden Schwierigkeiten für sie und ihre Familie, »Ruhe« und »Geduld « ${ }^{16}$ im Umgang mit diesen zu bewahren, was die Vergangenheit gezeigt habe. Der Bildungserfolg spielt für die Mutter eine große Rolle. Trotz der Tatsache, dass die Tochter den Erfolg im Moscheeunterricht als eine Kompensation ihres »Misserfolg[es]« in der allgemeinen Schule ansieht, erwartet die Mutter bessere, d.h. den Fähigkeiten der Tochter entsprechende Leistungen. Der Glaube bedeutet daher im Hinblick auf die Erziehung einen positiven Einfluss, beeinflusst die Umgangsformen und motiviert auch zu mehr Leistungserfolg in der Schule:

"Wie soll ich sagen. Es kehrt Ruhe und Frieden ein, sodass, die Atmosphäre zu Hause ganz anders ist. Also wenn man weiß: Das gehört nicht dazu. Man reagiert auch ganz anders. Man flippt nicht sofort aus. Man weiß, man muss die Sache ganz anders angehen. Es entsteht eine besondere ruhige Atmosphäre, elhamdulillah [arab. für "Allah sei Dank", Anm. d. Verf.]. Und manche Schwierigkeiten geht man [...] zum Beispiel das Zeugnis war da (lacht), gestern, unsere Tochter war letzte Woche krank. Sie hat ihr Zeugnis erst gestern bekommen. Wir wussten, das ist nicht so gut, wie die vorherigen Zeugnisse, aber das hat sie auch selber gesehen. Sie hat gesagt: 'Mama, das wird vielleicht mein schlechtestes Zeugnis. Sie hat einen Durchschnitt von 2,8. Aber sie weiß, sie muss das verbessern. Ilch habe aber nicht so viel Spaß in der Schule. Du weißt doch, wie ich in der Moschee bin, Mamar. Ich sage: ıB̈sra, ja, aber das reicht nicht. Du weißt,

15 | Das Alter für die Religionsmündigkeit beginnt ab der Pubertätsphase bzw. ab der Menstruation.

16 | Melek spricht die gefühlsbetonten Aspekte auf Türkisch an. 
diese Bildung gehört dazu. Das reicht einfach nicht.` Wir könnten auch ganz anders zu Hause reagieren. Auch mein Mann. Aber, nein. Sie hat gesagt: 'Mama, ich werde mich bemühen.` Wir haben das besprochen. [...]." (Melek, Z.: 87)

Für die nächste Mutter dieses Typs, Feride, steht die Befolgung von ethischen Grundsätzen dermaßen im Vordergrund, dass zunächst der Eindruck entsteht, der Glaube spiele bei ihr eine eher untergeordnete Rolle und diene lediglich zur Ableitung von Werthaltungen, die die charakterliche Entwicklung ihrer Kinder unterstützen. Ihre religiöse Erziehung ist stark durch eine Sichtweise bestimmt, die hauptsächlich zur Entwicklung eines charakterlich »guten « Menschen dienen soll. Es scheint so, als ob dies für Feride das wichtigste Anliegen schlechthin darstellt.

Feride wuchs in einer Familie auf, in der ungefähr bis zu ihrem achten/ neunten Lebensjahr die Religion kaum eine Rolle spielte. Aufgrund der Krankheit der Schwester verbrachte sie die ersten fünfeinhalb Jahre ihres Lebens in der Obhut ihrer Tante in der Türkei. Dort wurde zwar das Gebet verrichtet, aber ein Thema sei die Religion dort »nicht unbedingt« gewesen. Erst nachdem die Familie in Deutschland vereint gewesen sei, habe sich durch den Kontakt mir der Moschee, die sich in der Nähe des Wohnortes befunden habe, ein Zugang zur Religion ergeben:

"[...] also ich war bis zu meinem achten Lebensjahr fünfeinhalb Jahre bei meiner Tante und die haben zwar das tägliche Gebet verrichtet, aber so als Thema war das nie überhaupt angesprochen oder etwas zu lernen oder zu machen, das war nicht unbedingt [nötig, Anm. d. Verf.]. Nachdem meine Schwester und ich dann bei meinen Eltern zurück waren in Deutschland und die Krankheit meiner Schwester sich auch mehr oder weniger schon, ich sag mal jetzt, ausgeheilt hatte, und wir auch, meine Eltern sich eher konzentrieren konnten auf unsere Erziehung, und es sich auch ergab, dass unter anderem ja in Fußnähe auch eine Moschee da war, war Religion doch ein Thema, also so ab dem neunten, neuneinhalbten Lebensjahr, würde ich sagen. [...] Meine Eltern haben täglich gebetet, aber die haben das halt nie thematisiert, das war selbstverständlich, die haben gebetet. Wir haben das auch nie thematisiert und einfach nur registriert: Fertig. Ab dem neunten Lebensjahr, wie gesagt ungefähr, wir waren dann auch nach Monheim umgezogen, da war in der Nähe eine Moschee, da haben wir dann an den Wochenenden, hat mein Vater uns eingeschrieben, an die ... wie sagt man, Moscheekurse, damit wir den Koran lernen konnten und auch die wichtigen Suren und auch das tägliche Gebet verrichten lernen und so weiter. Das war dann ab dem Datum praktisch mehr oder weniger ein Thema, was für uns anstand, und wo gewollt wurde, dass wir uns das aneignen. Also ..." (Feride, Z.: 16ff.)

Wie bei vielen Elternteilen, so z.B. bei Belk1s, die diesem Typus angehört, tritt die Religion als ein selbstverständlicher Bestandteil des alltäglichen Lebens 
auf. So nimmt dies auch Feride in ihrer Familie rückblickend entsprechend wahr. $\mathrm{Zu}$ Hause wurde zwar gebetet, aber nie darüber gesprochen. Erst der Korankursbesuch ermöglichte eine »mehr oder weniger« (?!) Auseinandersetzung mit der Religion. Im Nachhinein betrachtet sie das »Vorleben« der Eltern als eine Form der »religiöse[n] Erziehung« in ihrer Ursprungsfamilie:

"Das religiöse Vorleben war wohl da, aber es wurde nie thematisiert, also nur das einfache Vorleben war da, als religiöse Erziehung praktisch." (Feride, Z.: 22)

Heute fasst Feride die Religion als ein »Medium « auf, das es ihr ermögliche, ihre Kinder religiös zu erziehen, um ihnen einen »besseren Charakter« anerziehen zu können. Dabei spielt für sie die religiöse Erziehung eine sehr bedeutsame Rolle:

"Ich finde sie sehr bedeutsam! Ich finde sie sehr bedeutsam, weil, ich finde (überlegt) durch die Religion als, wie sagt man jetzt, Medium, bin ich in der Lage, meine Kinder noch besser zu erziehen, innen einen besseren Charakter einzuflößen, als wenn ich ohne religiöse Medien arbeiten würde, würde ich sagen ohne das Medium Religion arbeiten würde." (Feride, Z.: 24)

Zur Erläuterung dieser Sichtweise weist Feride auch auf die wesentlichen Inhalte der Religion hin, die wegweisend für ihre Erziehung seien. Doch vorher bezieht sie sich, auf ähnliche Weise wie Belkıs, auf die Vermittlung von Werthaltungen, die sie zunächst allgemein formuliert an ihren Sohn heranträgt:

"[...] Ich würde sagen mit den Inhalten, mit den Weisheiten, indem ich eine gewisse Sache mache oder von meinem Sohn, der jetzt achteinhalb ist, wenn ich inm sage , Komm, lass uns das lieber so und so entscheiden, weil das ist ja dann irgendwie gerechter oder das ist dann halt ..., das kann ich so natürlich erklären und der versteht das auch mit seinen achteinhalb Jahren. Wenn ich zudem auch noch, als Ergänzung noch die Begründung gebe, so würde es, auch von unserer Religion her betrachtet, besser ankommen, weil damals hat ja unser Prophet das so und so gemacht oder Allahu teala [arab. für Allah der Erhabene, Anm. d. Verf.] würde sicher wissen, was in unseren Herzen vorgeht, wenn wir das anders formulieren oder anders machen würden, würde er es, andere würden das nicht wissen, aber inm würde das ja sicher auffallen oder halt als Wissen da ..." (Feride, Z.: 26)

In dieser Interviewpassage werden somit mehrere Aspekte angesprochen. Feride deutet hier darauf hin, warum eine Werthaltung handlungsweisend für sie selbst und ihr Kind sein sollte, und trägt dies zunächst unabhängig von einem religiösen Deutungsmuster vor. Die religiösen Begründungen und Deutungsmuster werden von ihr als »Ergänzung« betrachtet. Hier kristalli- 
siert sich der typische Charakter der ethisch orientierten Eltern heraus, d.h., es wird zwischen allgemeinen und religiösen Erziehungsprinzipien differenzierend argumentiert. Das, was als »Ergänzung«, d.h. »Wissen« (die Hauptquellen des Islams: das Vorbildsein des Propheten/ein Gottesbewusstsein) an das Kind weitervermittelt wird, dient nicht als primärer Ausgangspunkt, sondern wird vielmehr als eine Ergänzung verstanden.

Zudem unterstreicht Feride, dass Gott bzw. Allahu teala allwissend wie er ist, weiß, was im Herzen vorgeht und hierin seiner Beobachterrolle als eine Gewissensinstanz ausgelegt wird. So könne sich das Kind selbst »lieber so und so entscheiden, weil ...« (vgl. Feride oben).

Schließlich erläutert Feride noch, mit welchen Mitteln sie arbeitet, d.h., welche Art und Weise sie auswählt, um ihr Kind von ihrer Grundhaltung (hier: Gerechtigkeit) zu überzeugen. Doch darauf wird im Folgenden noch detaillierter eingegangen.

So erscheint es nicht verwunderlich, dass Feride die »Entwicklung eines besseren Charakters « (Feride, Z.: 28) zum eigentlichen Ziel ihrer religiösen Erziehung erklärt und sich wünscht, dass sich ihre Kinder zu »guten« Menschen entwickeln. Hierbei ist der Islam das »Medium«, welche »gebraucht« werde, um die Kinder zu erziehen:

"Ja, ich finde auf jeden Fall, also mein Erziehungsziel ist, meine Kinder zu guten Menschen zu erziehen, und damit ich sie zu guten Menschen erziehen kann, brauche ich den Islam." (Feride, Z.: 34)

Da ja schon in anderen Interviews deutlich wurde, dass sich hinter dem Attribut »gut« unterschiedliche Auffassungen verbergen, wurde auch Feride hierzu befragt und nahm dazu folgendermaßen Stellung:

"Gute Menschen heißt: gutes Herz, gutes Verhalten, gutes Leben, gutes Vorleben des Islam! Das heißt der ... wie soll ich sagen, der ahlak-Vorschriften [türk. für Moral, Sitte, Verhalten, Anm. d. Verf.] [...]. Der Tugenden, einfach das Internalisieren der verschiedenen islamischen Werte, sei es, wie gesagt, Ehrlichkeit, sei es Wahrhaftigkeit, sei es Treue in jeglicher Hinsicht, ob das jetzt Achtung gegenüber den anderen, ob das jetzt das Ziel ist oder die Umwelt oder der Mensch an sich oder seine Familienangehörigen oder seine Kinder oder seine Mitschüler oder was auch immer in die Richtung, das kann ich natürlich noch weiter ausführen in 50.000 andere [...]. Also zu guten, prosozialen, empathiefähigen, demokratischen, mitfühlenden und helfenden, guten Menschen halt, das alles, was einen guten Menschen ausmacht. Nächstenliebe, wobei die Nächstenliebe, also ich sag, wenn mein Sohn zum Beispiel meckert in der Schule und sagt: Ja, der und der hat das und das gesagt, der mag mich gar nicht!ı, dann sage ich dazu: 'Also lieben muss dich nicht jeder, aber eine gewisse Achtung und einen gewissen Respekt, weil du ein Geschöpf bist, weil du ein Mensch bist, das sollte er dir entgegenbringen. 
Genauso wie du es auch manchmal bei einem Menschen, den du nicht unbedingt magst, auch entgegenbringen musst. Also Liebe ist kein Muss, aber eine gewisse Achtung auf jeden Fall!‘ (Feride, Z.: 36-42)

Hier zählt Feride alle möglichen Werthaltungen auf, die für sie von Bedeutung sind. Sie verknüpft hierbei universale mit religiös fundierten (»ahlak-Vorschriften«, »verschiedene islamische Werte«) Werthaltungen und Tugenden. Auch wird dabei der soziale Charakter (»prosozial«, »empathiefähig«, »mitfühlend « und »helfend«) dieser Werthaltungen unterstrichen. Der Mensch oder die Kinder sollten diese nicht nur innerhalb der Familie gegenüber Familienangehörigen zeigen, sondern genauso gegenüber den Mitschülern und in jeglicher Weise überhaupt in alle »Richtungen « ausleben. Daneben bezieht sie sich auch auf den Wert der Demokratie, der auch eine politische Komponente beinhaltet. Mit einer gewissen Einschränkung erwähnt Feride schließlich noch den Wert der »Nächstenliebe«, die vom Wortgebrauch der christlichen Religion zugeordnet wird.

Feride benennt somit Werthaltungen, die sowohl universalen als auch religiösen Charakter besitzen. Dabei sollen diese durch ihre Kinder nicht nur auf der individuellen Ebene internalisiert werden, sondern auch auf der kollektiven (Schule, Gesellschaft) Ebene den anderen vorgelebt werden.

Ähnlich argumentieren auch die Väter Birol und Adem, die in der religiösen Erziehung die Möglichkeit sehen, die Kinder zu sozialen und ethisch verantwortlichen Menschen zu erziehen. Im Vergleich zu den drei beschriebenen Müttern (Belkıs, Melek, Feride) heben Birol und Adem stärker die sozialen Eigenschaften und Tugenden hervor, die durch eine religiöse Erziehung gefördert werden sollen. Da sich diese Eigenschaften auch unter »ethische Grundsätze« einordnen lassen, erschien es hier als passend, diese unter demselben Typus zusammenzufassen.

Gerade die Vereinbarkeit von modernen Erziehungszielen bzw. -werten mit religiösen Erziehungszielen ist für Birol ein wesentliches Kriterium seines Erziehungsverständnisses. Hier kann durchaus insbesondere eine Parallele zu Feride ${ }^{17}$ gezogen werden, da bei ihnen die Betonung im Vergleich zu (allen anderen Eltern und) den Eltern dieses Typs (Melek, Adem, Belkıs) auf

17 | Aber auch in etwas abgeschwächter Form zu Belkıs. Der Unterschied zwischen Belkıs und Feride besteht darin, dass Belkıs dem Glauben eine ähnliche Bedeutung wie den ethischen Aspekten der religiösen Erziehung zuerkennt. Ihr Ziel ist zwar der Bezug zu universalen und religiösen Werten, doch sie benutzt inren Glauben als "wesentliche Grundlage" für die Ableitung von Werthaltungen. Diese Abstufungen immer vergleichend darzustellen, ist kein einfaches Unterfangen, sodass dies an manchen Stellen möglicherweise nicht angemessen berücksichtigt werden konnte (vgl. hierzu auch die Methode der Typenbildung III. 2.3). Nicht zu vergessen ist, dass jeder Elternteil in seiner 
die Entwicklung eines »aufgeklärt-modernen« Menschens liegt. Dieser solle sich sowohl zu universalen und menschlichen als auch zu religiös-ethischen Grundsätzen bekennen und verpflichten, wobei die Religion keinen Hauptbezugspunkt darstellt. Auch bei Birol findet sich die charakteristische Differenzierung von allgemeiner Erziehung und religiöser Erziehung wieder. Dabei sticht gerade insbesondere bei Birol die Entfaltung eines religiös mündigen Kindes bzw. Menschen hervor, dem ein hohes Maß an Entscheidungsfreiheit hinsichtlich des Auslebens der Religion gewährt werden solle.

Birol wuchs in einer Familie auf, in der die Religion nur eine »sekundäre Rolle« spielte (vgl. Birol, Z.: 24). Die Religion wurde eher in einer kulturell-traditionellen Form aufgefasst und stand nicht »im Vordergrund«:

"Ja. Also es stand nicht so derart im Vordergrund, dass, also meine Eltern zumindest, es ist nicht so, dass sie jetzt so praktizierende Muslime sind, sondern ja eher wahrscheinlich so eher der kulturelle Background." (Birol, Z.: 26)

Den Zugang zur Religion fand Birol schließlich mithilfe seines Umfeldes und durch den Freundeskreis, mit dem er »freiwillig« eine Koranschule besuchte. Die Eltern hätten nicht gerade begeistert reagiert, da sie befürchteten, dass der Schulerfolg durch den Koranschulbesuch nachlasse. Er sollte sich damals mehr um die Hausaufgaben kümmern. Dennoch konnte sich Birol durchsetzen und nahm etwa bis kurz vor dem Abitur am Korankurs an einer Koranschule teil:

"Also ich habe durch meinen Freundeskreis im Umfeld den Zugang eigentlich eher gefunden zur Religion. Ich war beispielsweise freiwillig in der Koranschule. [...] Ja. Von mir aus! Meine Eltern waren sogar nicht so begeistert, weil meine Schulnoten nicht so gut waren, ich sollte lieber meine Hausaufgaben machen, anstatt in die Koranschule zu gehen, aber ich habe mich da so ein bisschen durchgesetzt, ja, so hat sich das entwickelt. Irgendwann so ja, vielleicht mit sechzehn, siebzehn vielleicht ist das auch noch mal wieder ein bisschen abgeebbt bei mir, da stand dann wieder die Schule im Vordergrund, gerade da als Abitur und so anstand, da habe ich mich dann doch ein bisschen mehr auf die Schule konzentrieren müssen, und später hat sich das eigentlich auch nicht mehr so geändert. Also heute würde ich mich auch nicht unbedingt als jemanden bezeichnen, der seine Religion so praktiziert, wie er es eigentlich tun sollte, das Fasten und so, das macht man, aber das Beten, das könnte ich mir noch ein bisschen ..." (Birol, Z.: 30ff.)

Einzigartigkeit von den anderen immer unterschieden werden muss, auch wenn gemeinsame Merkmale benannt werden. 
Deutlich wird hier, dass die Eltern nicht viel Wert auf die religiöse Erziehung von Birol gelegt haben. Auch fällt die Ähnlichkeit zu Melek auf, für die der Schulerfolg eine erhebliche Rolle spielt. Birol deutet den Koranschulbesuch rückblickend zum einen als eine Folge des Einflusses seiner Peergroup, mit der $\mathrm{man}$ »Spaß« hat und seine »Freizeit« verbringt, und zum anderen als Trotzreaktion auf die Eltern, weil diese einen Koranschulbesuch ablehnten. Zudem schien der Einfluss des Opas, der ein seine Religion praktizierender Mensch war, bei Birol einen bleibenden Eindruck hinterlassen zu haben, sodass er sich trotz der Gegenreaktion der Eltern für seine Religion interessierte:

"Also zum einen ist es natürlich: Ja, man ist halt noch klein, jung und die Freunde sind natürlich ein wichtiger Aspekt, dass man da gemeinsam hingeht, dort auch Spaß hat, das waren so wahrscheinlich ein bisschen von mir die Trotzreaktionen, weil meine Eltern das vielleicht nicht unbedingt gern gesehen haben oder vielleicht hat es mir auch mehr Spaß gemacht, als Hausaufgaben zu machen, und die Freizeit, die musste ja irgendwie gestaltet werden und; das könnte ein Grund sein, ein Grund könnte aber auch sein, dass ich von meinem $0 \mathrm{pa}$, der so religiös war und auch praktiziert hat, sehr viel mitbekommen hatte, schon vom Kleinkindalter an und da ist wahrscheinlich auch was hängen geblieben, und dann hat mich das natürlich auch interessiert und so ist das jetzt eigentlich (unv.), wollte wahrscheinlich ein bisschen besser kennenlernen, das Ganze. Und ja, das könnte es sein." (Birol, Z.: 36ff.)

In der Koranschule lernte Birol das Koranlesen, Beten sowie Werte und hatte zudem dort viel Spaß (vgl. Birol, Z.: 188-192). Besonders die Atmosphäre in der Gemeinschaft und der hoca (türk. für Lehrer, auch: Imam), der einen lockeren Umgang zu seinen Schülern pflegte (vgl. ebd., Z.: 198), motivierten Birol, regelmäßig hinzugehen. Die Inhalte, die sie dort vermittelt bekamen und die Freizeitmöglichkeiten, die im Anschluss an die religiöse Unterweisung gegeben waren, machten die Koranschule für ihn attraktiv:

"... beten natürlich, ja, dass man dort auch das Beten gelernt hat. Ja, also man bekommt dann natürlich auch immer wieder der hoca, der erzählt einem irgendetwas, das sind Anekdoten, das sind aus der Geschichte oder ganz aktuelle Sachen. Man lernt da natürlich sehr viel! Also man lernt da vor allem auch die, ja so die universellen Werte halt auch, ne? Ich sage Dir, also ich war eigentlich noch relativ jung, als ich da war, da ist man noch nicht so weit, dass man dann in die Tiefe wahrscheinlich geht. Ja, das war an sich so [...]. Ja, wir haben da zum Beispiel Sport gemacht und also wir hatten da eine Halle und da konnten wir turnen, ringen, miteinander spielen, solche Sachen auch [...]. Ne, also er hat uns gezeigt, wie wir ... also wenn wir Hausaufgaben bekommen haben, wir sollten halt Elifbe [türk. für das arabische Alphabet, Anm. d. Verf.] lernen und ich war ein guter Schüler damals, habe das gerne gelesen, habe das gerne gemacht, ja, und wenn wir die Hausaufgaben quasi gemacht haben, dann haben wir Lob bekommen und dann durften 
wir uns eben austoben [...]. Also ich habe es, ich habe es positiv in Erinnerung! Also ich habe, also ich erinnere mich gerne an die Zeit zurück!“ (Birol, Z.: 194-206)

Heute nimmt die religiöse Erziehung für Birol einen »wichtigen« Stellenwert ein. Es ist für ihn von Bedeutung, dass er Grundprinzipien und Grundwerte der Religion »mitnimmt«, aber es muss nicht alles »akribisch « genau religiös begründet werden. Für Birol stellt die Religion, wie schon anfangs aufgezeigt, somit nicht den Hauptbezugspunkt in seinem Leben dar. Es hängt für ihn zudem von der Situation ab, ob er eine religiöse Begründung für sein Verhalten heranzieht oder ob er sich verschiedenen Werthaltungen aus »humanitären« Gründen heraus verpflichtet:

"[...] Also es ist schon wichtig. Also ich achte schon darauf, dass man Grundprinzipien, Grundwerte der Religion mitnimmt, dass man auf gewisse Sachen achtet. Ich bin aber nicht jemand, der jetzt akribisch darauf achtet, dass man wirklich, ja, dass das, alles religiös zu begründen. Ja, also in jedem Handeln oder in jedem Tun oder jedem Unterlassen, dass das dann unbedingt religiös begründet wird. Ich leite sehr viel daraus ab ..." (Birol, Z.: 46)

Als Beispiel für dieses »Handeln, Tun oder jedem Unterlassen« führt er die Pflicht eines Muslims auf, seinen Besitz mit anderen Menschen zu teilen. Dabei sind für ihn sowohl religiöse Deutungsmuster als auch universal-ethische Begründungen, die aus humanitären Gründen auf das vorbildhafte soziale Verhalten abzielen, von gleichrangiger Bedeutung:

"[...] Also, wenn man das Teilen zum Beispiel betrachtet: Ja? Wenn mein Kind vor der Entscheidung steht: Soll ich jetzt etwas teilen oder nicht? Ja, dann sollen wir das natürlich auch aus religiöser Sicht, aus religiösen Aspekten tun, man kann das aber natürlich auch anders begründen und es ist bei mir nicht so: Ich mach das auch nicht bewusst, aber es ist dann nicht, dass ich das erkläre, wenn man teilen sollte, dass das gut ist, dann berufe ich mich da nicht unbedingt immer auf religiöse Werte, sondern versuche das auch mal anders zu erklären. Anders im Sinne von, ja, dass es eben Menschen gibt, die vielleicht einfach nicht so viel haben. [...] Also aus einem humanitären Gedanken heraus, vielleicht. Auch da fließt natürlich bei mir das Religiöse auch immer mit ein, nur, das Erklären, bzw. das Vermitteln dieser Werte das geschieht nicht nur mit religiösen Gründen also ..." (Birol, Z.: 48-52)

Die Erklärung und Vermittlung von Werthaltungen, hier das »Teilen« mit anderen bedürftigen Menschen, geschieht demnach auf mehreren Bedeutungsebenen. Dabei sollten dem Kind die nötigen Kenntnisse bzw. Grundprinzipien vermittelt werden, damit es sich selbstständig weiterentwickeln könne. Birol betont die Freiwilligkeit, die er selbst in seiner Jugendzeit erlebt habe. Des Wei- 
teren ist er sich auch der Tatsache bewusst, dass er im Grunde nur ein Mindestmaß an religiöser Erziehung an seine Kinder tradieren möchte:

"Also ich, was ich erwarte, ich erwarte zumindest so viel, dass man dem Kind so viel mitgeben sollte, dass es sich selbst, darauf aufbauend, weiterentwickeln kann. Also das heißt: Interesse wecken, ja! Die Grundprinzipien zumindest so vermitteln, dass das Kind dann eben sich selbst fortentwickeln kann, ja! Wenn es dann eben Interesse zeigt, wenn es wünscht, das ist so das, was ich denke, das man vermitteln sollte. Das ist so der Anspruch, das ist meines Erachtens aber auch, da bin ich mir auch drüber im Klaren, nicht unbedingt sehr viel, weil das, was ich jetzt sage, ist das Minimum, ja? Aber ich würde also? Also mit meinem Sohn zum Beispiel kann ich mir schon vorstellen, dass wenn er mal älter ist, dass ich ihm dann auch mal die Moschee von innen zeige, dass man zusammen mal beten geht, dass er das einfach mal miterlebt, mitbekommt, ja? Und dass er dann hoffentlich irgendwann von sich aus eben eine Moschee aufsucht." (Birol, Z.: 54)

An dieser Stelle zielt Birol ferner auf eine Religionsmündigkeit ab, die dem Kind ein hohes Maß an Entscheidungsfreiheit einräumt. Dabei solle im Kind auch das Interesse bei der Vermittlung von Grundprinzipien geweckt werden, indem religiöse Orte aufgesucht und die religiöse Praxis, wie bspw. das Beten, verrichtet würden.

Gerade die ethisch-sozialen Aspekte der Religion spielen bei der Vermittlung als »Grundprinzipien« für Birol eine wichtige Rolle:

"[...] also besonders wichtig sind mir diese eher so grundsätzlichen Sachen, also es geht mir bei der Religion; also wie gesagt, ich bin jetzt nicht der, der nach außen religiös auftritt, weder in meinem Erscheinen noch in meinen Handlungen. Aber ich achte zum Beispiel sehr darauf, dass ich niemandem Unrecht tue, dass ich niemanden kränke, dass ich, ja, man sagt ja einfach, ein guter Mensch zu sein. Und das versuche ich dann schon zu machen, das ist ja, das ist meine Religion, jetzt so [...]. Genau! Dass ich helfe, wo ich kann, dass ich etwas Gutes tue." (Birol, Z.: 83ff.)

Hier sind Werthaltungen, wie Gerechtigkeit, sozial verantwortliches Verhalten, das Kränkungen des anderen ausschließt, Hilfsbereitschaft und der Vollzug guter Taten (»Gutes« tun), benannt. Kurzum, Birol versucht selbst ein »guter Mensch«zu sein, was er auch seinen Kindern nahelegt. Das Ziel einer religiösen Erziehung liegt für ihn somit darin, dass seine Kinder zu »guten/ gesegneten« Menschen heranwachsen: 
"[...] ich würde sehr viel Wert darauf legen, dass meine Kinder zu, man sagt ja zu guten/ gesegneten Menschen ${ }^{18}$ [türk. hayırlı bir insan = dt. auch gutgeraten/karitativ, Anm. d. Verf.] [...]. Ein guter Mensch, ein Mensch, der auch seiner Umgebung, seinen Nächsten, seinen Mitmenschen, seinen [...] ja, einfach dienlich ist, natürlich auch, das steckt da mit drin. Aber ein Mensch, dass dieser einfach, von dem etwas Gutes ausgegangen ist, also, dass er eine positive Ausstrahlung hat, dass er auch Positives tut, auch Gutes tut, und das auch gerne tut und nicht als etwas tut, was man irgendwann in der Hoffnung macht, dass man es vielleicht, in welcher Form auch, wieder zurückbekommt, also einfach selbstlos auch mal was zu tun." (Birol, Z.: 119-125)

Mit einem »guten« Menschen verbindet Birol auch einen »karitativ« veranlagten Menschen, der seinen Mitmenschen dient, ohne eine Gegenleistung zu erwarten. Hier werden altruistische humanitäre Grundprinzipien bzw. Werthaltungen aufgegriffen, worin besonders der soziale Charakter dieser Eigenschaften hervortritt. Seine Umgebung, seine Nächsten und seine Mitmenschen erfahren von einem guten Menschen ausschließlich Positives (vgl. oben), weil er dies um der Sache Willen tut und sich dabei keinen Vorteil erhofft. Der Ursprung dieser Werthaltungen, ist wie bereits ausgeführt, sowohl religiöser Natur als auch auf universal-ethische Grundeinstellungen zurückzuführen.

Der letzte Elternteil dieses Typs ist Adem, ein Vater, der, ähnlich wie Melek und Belk1s, sowohl ethischen Grundsätzen in der religiösen Erziehung als auch dem Glauben eine gleichwertige Bedeutung schenkt. Bei Adem liegt in allen in dieser Untersuchung genannten Bereichen eine starke Betonung auf Dialog, Vielfalt, Respekt und Toleranz. Die sozial-ethische Verantwortung, die man seinen Mitmenschen entgegenbringt, gleich welcher Religion sie angehören oder welche Ideologie sie vertreten, hat für ihn eine zentrale Bedeutung. Hier spiegelt sich der universaleethische Aspekt einer Erziehung bzw. einer religiösen Erziehung wider, genauso wie bei allen Eltern dieses Typs auch. Nur drückt sie sich bei Adem mehr in seinem Handeln als in einer von ihm beschriebenen »Konzeption« aus.

Adem entstammt einem Elternhaus, in dem er mit Religion nur wenig zu tun hatte. Trotz der Tatsache, dass er mit seiner Mutter sehr viele Gespräche über die Religion geführt hat, beschreibt er seine Familie als »säkular«, in der auch die religiöse Erziehung keinen Platz hatte:

"Sehr wenig, sehr wenig, [...] von meiner Mutter aus, waren sehr viele Gespräche zu führen, aber väterlicherseits hat er sich immer ferngehalten von dieser, von diesen Sachen,

18 | Diese Redewendung wird im türkischen Sprachgebrauch besonders häufig im erzieherischen Bereich verwendet. 
von der Religion. [...] unsere Familie war sehr modern, sehr laïque, säkular, ja." (Adem, Z.: 12-16)

Die Religion stellt heute für Adem den Lebensmittelpunkt dar, wonach er sein Leben gestalten möchte. Die religiöse Erziehung nimmt inzwischen demzufolge einen sehr wichtigen Stellenwert ein:

"Die religiöse Erziehung heute, in meiner Familie, ist mir sehr wichtig, weil das Leben, der Mittelpunkt in unserem Leben, die Gestaltung des Lebens ist die Religion." (Adem, Z.: 18)

Durch die religiöse Erziehung solle insbesondere der Respekt gegenüber den anderen gestärkt werden. Dazu sei es erforderlich, von klein auf zu verstehen, was »überhaupt Religion ist«. Für Adem drückt sich darin nicht ausschließlich die rituelle Befolgung des Gebets aus, wie dies in den Medien dargestellt wird. Religion bedeutet für ihn vielmehr zweierlei, d.h., zum einen werde durch die Religion der Glaube an den Einen Gott angestrebt (arab. tauhid), zum anderen müsse ein Mensch darüber Rechenschaft ablegen, welche Umgangsform er zu seinem Nachbarn oder Nächsten pflege. Er zielt hier zunächst auf die wesentlichste Glaubensgrundlage im Islam ab, die einen absoluten Monotheismus anstrebt. Dann verweist er auf die Rechenschaftspflicht eines Muslims bzgl. seiner Verhaltensweisen gegenüber anderen Menschen, jedweder Religion oder Weltanschauung. Das Miteinanderauskommen mit muslimischen und nichtmuslimischen Nachbarn steht für ihn neben dem Glauben zu dem Einen Gott an oberster Stelle (»sehr sehr wichtig, sehr sehr groß geschrieben«). Ebendies will er auch seiner Familie nahelegen:

"Zuerst Respekt gegenüber anderen, das muss man so verstehen, man muss erst mal dazu beitragen, dass die Kinder im kleinen Alter es verstehen, was überhaupt Religion ist. Religion ist nicht nur das Beten, wie wir das von den Medien kennen, sondern Religion ist natürlich als erstens das Anbeten von dem einzigen Gott für uns Moslems und als zweites, wo wir auch als zweiten Punkt zur Rechenschaft gezogen werden: Das gute Miteinanderauskommen mit dem Nachbarn und bei dem Nachbarn ist es so, dass es nicht der muslimische Nachbar ist, sondern der Nachbar kann sein Christ, Jude, Atheist, das spielt überhaupt keine Rolle, eben diese Nachbarschaft ist sehr sehr wichtig, sehr sehr großgeschrieben und das muss man denen, der Familie, den Kindern beibringen." (Adem, Z.: 20)

$\mathrm{Zu}$ erwähnen ist hier noch der Aspekt des Dialogs oder der Vielfalt, wenn er Bezug zu Menschen anderer Religionen nimmt: »Christ, Jude, Atheist, das spielt überhaupt keine Rolle« (vgl. oben). 
An einer anderen Stelle nimmt er nochmals auf den sozialen Aspekt seiner ethischen Grundhaltung Bezug, wobei er dies selbstverständlich wieder im Zusammenhang mit dem Glauben und der daraus resultierenden Gottesfurcht sieht:

"Der gefährlichste Mensch für mich, ist derjenige, der nicht gottesfürchtig ist. Wenn ein Mensch gottesfürchtig ist, mit einem gesunden Menschenverstand, dann würde er auch sofort reagieren, wenn er merkt, dass er für andere Menschen oder auch für Tiere auch etwas nicht Korrektes macht. Und das hält inn eben davon ab, sich immer positiv zu verhalten oder Acht zu geben, was er macht, was er tut, ob er andere Menschen verletzt." (Adem, Z.: 24)

Gottesfurcht bedeutet für Adem, seinen gesunden Menschenverstand darauf zu konzentrieren, kein Unrecht gegenüber Menschen und Tieren zu begehen. Es ist auch die Gottesfurcht, die gemäß seiner Vorstellung, den Menschen dazu bringt, seine Verhaltensweisen zu kontrollieren und darauf »Acht zu geben« sich »positiv zu verhalten«, indem er beispielsweise keine anderen Menschen verletzt. Demnach ist für Adem auch die Gottesfurcht ein wesentliches Ziel in der religiösen Erziehung. Zusammenfassend bringt er seine Vorstellung, was religiöse Erziehung bewirken soll, folgendermaßen zum Ausdruck:

"Wie ich schon gesagt habe, ich sehe meine Religion, also ich sehe meine Religion so, wenn wir, wenn die Moslems sterben, werden die Moslems als Erstes über ihre Pflichtgebete zur Rechenschaft gezogen von Allahu teala [arab. für Allah der Erhabene, Anm. d. Verf.], [...], der alles erschaffen hat, als Zweites ist es so, dass die Gläubigen zur Rechenschaft gezogen werden über das Miteinanderleben vom Nachbarn, so: Und das das soll die religiöse Erziehung bewirken, dass die Kinder gottesfürchtig sind und somit nicht nur ihre Nachbarn, auch wenn diese andersgläubig sind, die Betonung liegt auf Nachbarn und nicht auf muslimischen Nachbarn, also das kann ein Sozialist sein, es kann ein Atheist sein, Jude sein, Buddhist sein; also immer korrekt sehr gut mit denen umgehen, mit der Natur sehr bewusst umgehen, auch mit der Tierwelt sehr bewusst umgehen; das soll die religiöse Erziehung als Ziel bewirken."(Adem, Z.: 254)

\section{Die Religiöse Erziehung in den Familien}

In diesem Kapitel werden zu den oben aufgeführten Erziehungsvorstellungen bzw. zu den jeweiligen religiösen Erziehungstypen einige weitere Aspekte der religiösen Erziehung in den Familien vorgestellt. Mit den Erziehungsvorstellungen stehen auch die Erziehungsmethoden und Erziehungsstile, die die Intensität der elterlichen Einflussnahme verdeutlichen, in einem engen Zusammenhang. 
Die Religiosität als Erziehungsziel ist auch ein zentraler Kernaspekt dieser Untersuchung, sodass die erfahrenen (»affektiv«), gelebten (»handlungsorientiert«) bzw. auf die kognitive Ebene bezogenen (»kognitiv«) Dimensionen dieser Religiosität innerhalb der Familie hier veranschaulicht werden sollen. Ausgehend von den Glock'schen Dimensionen (vgl. Kap. II. 3.1.4.) der Religiosität, wird hier beschrieben, welche Schwerpunkte die jeweiligen religiösen Erziehungstypen in ihre Religiosität legen bzw. welche Ausprägungen hierbei festzustellen sind. Wichtig ist es, vorab zu klären, ob die Dimension des Glaubens sozusagen als die theoretische Grundlage bzw. das normative Bezugssystem für elterlich religiöse Grundeinstellungen gesehen werden kann. Wie dies schon bei der Typenbildung auch an vielen Stellen ansatzweise verdeutlicht wurde, spiegeln sich in den Vorstellungen über den Glauben die Ideen und die Gedanken zur religiösen Erziehung wider und finden darin ihre Entsprechungen. Die Konsequenzen, die daraus abgeleitet werden, beinhalten sowohl erzieherische Prinzipien, die sich auf die emotionale Ebene, d.h. auf die Dimension der Erfahrungen als auch auf handlungsleitende Prinzipien (hier auch auf die rituelle Dimension) beziehen. Um Wiederholungen zu vermeiden, sollen diese synoptisch dargestellt werden, sodass diese nicht in aller Ausführlichkeit hier beschrieben wurden, sondern lediglich die wesentlichen Merkmale aufgeführt sind.

Hinsichtlich des religiösen Wissens ging es darum, zum einen zu beantworten, welches a) religiöse Wissen sich die Kinder aneignen sollen, und zum anderen, welche b) religiösen Fragen die Kinder haben. Der letztere Aspekt sollte Aufschluss darüber geben, »was« die Kinder wissen wollen und welchem Aspekt der Religion sie aus ihrer kindlichen Perspektive besonders viel Bedeutung beimessen. Auch hier finden sich Äquivalenzen zu den von den Eltern dargelegten Erziehungsvorstellungen.

Die Erläuterungen zu den Aussagen über das Eltern-Kind-Verhältnis (»Erziehungsstile«) und die von den Eltern angewandten Erziehungsmethoden sind aus dem analytischen Bezugsrahmen (vgl. Kap. II. 3.1.3b) zu entnehmen. Verzichtet wurde hier auf eine eindeutige Bezugnahme auf theoretische Konzeptionen, die in der Erziehungsstilforschung vordergründig sind. Die Art und Weise, wie die Eltern mit ihren Kindern umgehen bzw. wie diese charakterisiert sind, wurde in der vorliegenden Untersuchung induktiv, d.h. auf den Aussagen der Eltern basierend, ermittelt (vgl. für die Vorgehensweise Kap. III. 2.2). Lediglich die Erläuterungen im analytischen Bezugsrahmen dienten als erste Orientierung für die induktive Kategorienbildung. Um die Erziehungsstile näher bestimmen zu können, wurde neben der Regelbefolgung zudem die Konfliktlösungsstrategie der Eltern berücksichtigt. Gerade darin unterscheiden die Eltern vornehmlich zwischen allgemeiner und religiöser Erziehung. In dieser Untersuchung werden nur die religiös konnotierten Aspekte vorgestellt, anhand derer die Erziehungsstile der Eltern dargelegt werden können. 
Hierzu konnten die »Förderung der Selbstständigkeit«, die »Übernahme von Verantwortung« durch das Kind, »Disziplin«, »Liebe/Geduld«, der Ausschluss von Zwang, d.h. »kein Zwang« und schließlich noch »Respekt vor Älteren« herausgearbeitet werden.

In den folgenden Ausführungen werden zunächst die Religiosität und im Anschluss die Erziehungsmethoden und die Erziehungsstile aufgegriffen.

\subsection{Religiöse Erziehung in den Familien der "Idealisten "}

\subsubsection{Die Religiosität in den Familien der "Idealisten “}

Die Vorstellungen über den Glauben und was diese für die Eltern bedeuten, beinhalten auf mehrere Dimensionen der Religiosität bezogene Aspekte. Die Konsequenzen aus ihren Glaubensvorstellungen, die die Eltern dieser Gruppe für ihre Kinder ziehen, geben zugleich ihre erzieherischen Prinzipien wieder. Der Glaube, als die zentralste Grundlage der religiösen Erziehung überhaupt, verweist für die Eltern nicht nur auf die Existenz Gottes als ein Wissensmoment, d.h. auf einen Gott, den Schöpfer, dessen Existenz kognitive Zustimmung erfährt, sondern besonders stark auf die emotionale Ebene, d.h. auf die Erfahrung bezogene Grundfähigkeit, die den Kindern vorgelebt bzw. weitergegeben werden soll. Das Vertrauen, das zu Gott aufgebaut wird, ist dabei wesentlich, um eine sichere emotionale Bindung zu Gott herzustellen. Das rechtleitende Prinzip, das Sinn und Orientierung im Leben bietet, ist für Eltern dieses Typs, wie bereits ausgeführt, zentral:

"[...], ich denke, wichtig ist auch, dass es auch einen emotionalen Moment gibt, also ein Vertrauen darauf, dass dieses Buch letztendlich auch von Gott kommt, dass die Aussagen darin richtig sind und dass sie eine Rechtleitung, eine Wegweisung für uns für das eigene Leben darstellen können. Also eine Kombination von beidem, sowohl Wissen als auch ein Vertrauen darauf. Eine emotionale Bindung dahingehend, sind für mich die zwei zentralen Momente des Glaubens." (Ethem, Z.: 42)

Die Bindung, die zu Gott hergestellt wird, und das daraus resultierende Gottvertrauen sollen dabei helfen, das Leben mit der von Gott gegebenen »Wegweisung« (vgl. Ethem oben) in einem ausgewogenen Verhältnis zwischen »Hoffen und Bangen« gut »zu meistern« (vgl. Nermin, Z.: 87). Es soll die Fähigkeit bei den Kindern aufgebaut werden, Orientierung und Sinn im Leben zu finden, was sich durchaus nicht nur auf das Leben selbst bezieht. Der Glaube an den Schöpfer bedingt und bedeutet für die Eltern auch, den Weg zur Selbsterkenntnis zu gehen. Des Weiteren soll die »Suche« nach Allah/Gott, die bei den Kindern angeregt werde, neben der angestrebten Selbsterkenntnis dazu führen (auf der spirituellen Ebene), Zufriedenheit, Glück und Vollkommenheit zu erlangen (vgl. Lale, Z.: 81-85, Dilek, Z.: 45f. und Nermin Z.: 72-83). Dabei wird 
hier auch auf die Entwicklung einer Persönlichkeit angespielt, die gezielt suche, um Antworten auf ihre Fragen im Leben zu finden (vgl. Lale, Z.: 85 und Dilek, Z.: 43-46, Nermin, Z.: 83). Das Wissen um den Schöpfer sei hierfür ein wesentliches Fundament, was letzten Endes durch die Auseinandersetzung mit dem Wort und der Botschaft Gottes/Allahs, d.h. mit dem Koran als einem »Wegweiser« angestrebt werde. Der Sinn des Lebens könne sich nur dahingehend erschöpfen. Eine deutlich erfahrungsbezogene Sicht vom Glauben zeigt schließlich noch Nisa auf. Hier wird aber auch auf die praktische Konsequenz hingewiesen:

"Iman [arab. für Glauben, Anm. d. Verf.] bedeutet Hingabe. So mit seinem ganzen Sein wahrnehmend/fühlend zu glauben und danach zu leben, bedeutet iman." (Nisa, Z.: 17)

Die Konsequenzen, die sich aus diesem Glauben ergeben, deuten auf mehrere Aspekte der Religiosität hin. Zum einen wird auf handlungsleitende Prinzipien, wie bspw. die rituelle Befolgung von Geboten Gottes Bezug genommen, und zum anderen auf ethisch-moralische Grundhaltungen, die darauf abzielen, ein Mensch zu werden, der ein Pflichtbewusstsein vor Gott entwickelt. Sowie Dilek nehmen sich die anderen Eltern auch in ihrer Vorbildfunktion wahr, wenn es um ihr Glaubensverständnis geht:

"An Allah zu glauben. Alle Botschaften, die verkündet wurden, ins Leben zu rufen, ein guter Diener zu werden, gütig zu sein, ja, wie sagt man ein gutes Vorbild sein; ich kann da vieles hineintun. Zuallererst an Gott glauben und ein guter, aufrichtiger Mensch werden, das kann ich dazu sagen [...]." (Dilek, Z.: 42)

Die religiöse Praxis als Folge des von ihnen intendierten Glaubens nimmt bei allen Eltern dieses Typs einen hohen Stellenwert ein. Hierbei geht es darum, seiner Verantwortung so gerecht zu werden, um Rechenschaft über das eigene Tun und Handeln vor Gott/Allah abzulegen:

"Der Einfluss ist natürlich, dass ich dann auch möglichst versuche, die Kinder im dementsprechenden Glauben dann auch aufzuziehen. Also ich gehe davon aus, dass die Aussagen dieses Glaubens richtig sind, dass die Aussagen auch dahingehend, dass es einen Schöpfer gibt, dass es auch eine Sicht zur Rechenschaft gibt über das eigene Tun über das eigene Handeln richtig sind, zentral sind und bei meiner Erziehung lege ich dann natürlich auch Wert darauf, dass meine Kinder in diesen Glauben auch eingeführt werden und dann auch die Möglichkeit bekommen, ihr Leben entsprechend auszurichten." (Ethem, Z.: 44)

Die Vorstellung vom Glauben beinhaltet für Nermin eine lebenspraktische Komponente, wonach das Bestmögliche getan wird, um letztendlich den Rest 
Gott/Allah zu überlassen. Dies heißt, man solle ein Gottvertrauen dahingehend entwickeln, um im Leben, so gut es geht, mit Gottvertrauen zurechtzukommen:

"Ja! Ja, so eine praktische Vorstellung, es heißt ja in der Religion: Man muss das tun, was man in der Hand hat. Alles, was menschenmöglich ist sozusagen, und den Rest dann Allah überlassen, ne? Und wenn man das schafft, wenn man das wirklich schafft, nicht nur machen und sagen: ,So, jetzt habe ich gemacht, sondern auch sagen: So, ich habe es gemacht, jetzt vertraue ich auf dich. Das wäre so dieses tevekkül [türk. für Gottvertrauen, Anm. d. Verf.], so ist so dieses I-Tüpfelchen, denke ich. Wenn man das schafft, den Kindern mitzugeben, dann hat man schon viel gewonnen." (Nermin, Z.: 89)

Als »lebenspraktisches « Beispiel nennt sie den Tod des Großvaters, der in ihrer jüngeren Tochter Zweifel aufkommen ließ, mit der sie deshalb noch an ihrem »Glauben« $z u$ arbeiten habe, um das von ihr verinnerlichte Prinzip der Hoffnung (vgl. oben) zu vermitteln. Hier soll der Glaube den Sinn des Unverständlichen erklären und deuten helfen, um über eine erlebte Krise hinwegzukommen:

"Ja. Ja, bei der Jüngsten ist das ja noch ein bisschen schwierig. Da ist grad mein Schwiegervater gestorben und da sagt meine Tochter: Ja, ich liebe meinen Opa, am meisten liebe ich Allah.، Aber eines, wenn ich sage: ,Allah erfüllt uns die Wünsche natürlich, wir beten dann dafür dann sagt sie: Ja, aber ein, eins hat er mir nicht gut gemacht, ne, nichts Gutes für mich. ' Was ist denn passiert? 'Ja, mein Opa ist ja gestorben.` Nicht, dass er gestorben ist, sondern, dass er im Krankenhaus gestorben ist, das hat ihr so sehr leid getan, sodass sie dann sagt, das war für sie nicht so [...]. Es hat ihr weh getan, dass er nicht zu Hause, sondern im Krankenhaus gestorben ist, wir werden noch öfter darüber sprechen, aber da sagt sie: Ja, das fand ich jetzt nicht so gut.ı (Nermin, Z.: 95ff.)

Nisa sieht als Folge ihres Glaubens die besondere Erziehungsverantwortung, die Gott/Allah ihr auferlegt habe. Dabei nimmt sie ihre Kinder als ihr von Gott/ Allah anvertraute Wesen wahr, für die sie vor Gott/Allah eine Verantwortung trage und über die sie Rechenschaft ablegen müsse. Dies veranlasst sie dazu, umso genauer und bewusster mit ihrer Erziehungsverantwortung umzugehen:

"Natürlich will der Mensch auf diese Weise damit umgehen, also wie man sein Kind erzieht. Man will es im Namen Allahs tun. Wenn der Mensch liebt, sagt er, es ist mir von Allah anvertraut [türk. emanet, Anm. d. Verf.]. Man sieht das Anvertraute. Das, was einem anvertraut wurde, behandelt der Mensch viel genauer. Man sagt sich; ich habe ja gar kein Anrecht darauf. Weil es einem ja anvertraut wurde, muss ich aufpassen oder 
man muss sich zurücknehmen. Auch wenn du vergisst, musst du dich zugleich zurücknehmen, ich muss da aufpassen und ich muss es [die Erziehung des Kindes, Anm. d. Verf.] im Namen Allahs tun. [Der Glaube, Anm. d. Verf.] gibt einem das, ja." (Nisa, Z.: 19)

Bezogen auf konkrete religiöse Erfahrungen, wurde vonseiten aller Eltern vornehmlich die rituelle Dimension angesprochen. Dieser Bereich weist eine hohe Kohärenz hinsichtlich der Bedeutung auf, die die Eltern bestimmten Ritualen, wie z.B. den täglichen Gebeten, beimessen.

Für alle Eltern sind die täglich verrichteten Gebete von höchster Priorität. Die Gebete stellen auch den wichtigsten gemeinsamen religiösen Erfahrungsbereich dar, den die Eltern zuallererst benennen. Nicht zuletzt ist es, nach dem Glaubensbekenntnis, die zweite wichtigste Säule des Islams. In den Familien wird je nach Alter und Situation darauf geachtet, dieses religiöse Gebot in den Alltag zu integrieren. Für Ethem fing es schon im Babystadium an, die Kinder durch ein aktives Vorlebenan den gemeinsamen Gebeten teilhaben zu lassen:

"Also das fing eigentlich schon im Babystadium an, also, dass wir (überlegt), dass ich oder auch meine Ehefrau mit den Kindern zusammen gebetet haben, innen vorgebetet haben, auch zu einer Zeit, wo sie gar nicht gesprochen haben, also Koranrezitationen und so weiter; und dann fing auch, je älter sie wurden, dann natürlich auch die Phase der Nachahmung an, dass die Kinder, während wir gebetet haben, sich dann dazugesetzt haben, die Bewegungen nachgemacht haben auch komplett entgegengesetzt (lachen) alles gemacht haben; also sie waren letztendlich bei der religiösen Praxis, die wir an den Tag gelegt haben, immer präsent, haben diese mitgemacht [...]." (Vgl. Ethem, Z.: 48)

Wichtig erscheint hier allen Eltern, dass die Kinder die Befolgung dieses Rituals selbstständig (vgl. Ethem, Z.: 54 und Z.: 62; Nermin, Z.: 120ff.), freiwillig (Lale, Dilek, Nisa) und mit Liebe verrichten. Das gemeinschaftliche Gebet wird in der Familie von Nermin und Ethem eigenverantwortlich durch die Kinder selbst verrichtet, was eine sinnlose Nachahmung der Eltern ausschließt und die Kinder anregt, Verantwortung zu übernehmen:

"[...] wir haben auch sehr früh, ich habe. Wir haben auch sehr früh zum Beispiel dann auch die Kinder vorbeten lassen, also, sodass sie halt der Imam [arab. für Vorbeter, Anm. d. Verf.], sein durften und auch bei meiner Tochter [...] Letztendlich auch, um den Kindern das Gefühl zu geben, dass sie halt nicht nur konsumieren, sondern auch mitgestalten [...]." (Ethem, Z.: 56)

Die gegenseitige Motivation der Kinder für das Gebet, findet sich auch in Nermins Familie. Es erfüllt sie mit Stolz, zu sehen, wie sich die Kinder dahingehend entwickelt haben: 
"Also wie ich zum Beispiel meinen Kindern das Beten beigebracht habe, die beten ja erst mit, aber bis die mal selber überhaupt das gelernt haben, vollkommen, habe ich immer neben denen gesessen und habe immer ..., die konnten ja die duas [arab. für Bittgebete, Anm. d. Verf.] und dann habe ich immer gesagt: 'So, jetzt musst du das lesen! ‘ Und dann habe ich zehn Minuten, eine Viertelstunde bei denen gewartet und das immer vorgesagt; und dann waren die immer sehr stolz und für mich war das auch sehr, sehr positiv, zu sehen, wie die Kinder da reifen, ne, so zum einen [...]. Die Entwicklung, genau! [...]. Ja, dass die lernen erst mal, wie das Gebet ist, und dieses Gemeinsame und mittlerweile meine drei Jungs, die beten dann zusammen, einer ist hoca, Vorbeter, der andere ist dann muezzin [türk. für jn. der den Gebetsruf verrichtet], und dann beten die halt zu dritt und so; und die wissen dann halt so, wie das geht und [...]. Ja, das finde ich sehr schön. Das finde ich sehr positiv! (Nermin, Z.: 114-122)

Zudem bereite das Gebet mit dem Vater den Kindern viel Freude. Das gemeinsame Gebet in der Familie sei somit für die Kinder ein schönes Erlebnis:

"[...] Wenn es klappt, betet dann mein Mann und dann beten die unheimlich gern mit dem Papa. Das ist schon etwas Besonderes. Das ist schön [...]." (Nermin, Z.: 127)

Berücksichtigt wird von allen Elternteilen zudem das Alter ihrer Kinder, um sie nicht zu überfordern (Ethem, Z.: 62; Nermin, Z.: 129; Lale, Z.: 145; Dilek, Z.: 122), sodass die älteren Kinder ein wenig mehr in die Verantwortung genommen werden als die jüngeren. Hier wird gerade auch auf die Schulsituation Rücksicht genommen (vgl. Nermin, Lale, Dilek, Nisa). Die freiwillige Verantwortungsübernahme für die täglichen Gebete ist für alle Eltern besonders wichtig, sodass z.B. Lale den folgenden Umkehrschluss zieht und »Zwang« und »Druck« bei der Einhaltung des Gebets ausschließt:

"Nein, keine Strenge, bestimmt, bis das Kind, wie soll ich das sagen, in sein Herz [...], ich brauche das Gebet, nicht das Gebet braucht mich. [...]. Kein Zwang. [...] Kein Druck." (Lale, Z.: 149-154)

Hier soll das Kind somit aus innerer Überzeugung (»mit Herz«) ein Subjekt werden, um innere Befriedigung zu erfahren, und sich als kein Objekt einer sinnlosen Nachahmung verstehen, die durch Druck und Zwang erzeugt wurde.

Für Dilek ist das gemeinschaftliche Gebet innerhalb der Familie, das sie zum Teil auch aufgrund der Schulsituation (Nachmittagsunterricht) und dem Arbeitsverhältnis des Mannes (Schichtarbeit) nicht einhalten können, so wichtig, dass sie sich diesbezüglich selbstkritisch äußert. Für sie sei dies ein Defizit, für das sie die Verantwortung trage und woran sie auch arbeiten möchte, »Allah möge mir Kraft geben« (vgl. Dilek, Z.: 122 und Z.: 174). Auch wenn die 
Töchter beten würden, fehle ihr hier jedoch die Regelmäßigkeit. Gerade weil sie der Erfüllung dieser rituellen Praxis eine orientierungsstiftende Funktion zuschreibt, möchte sie erreichen, dass die Töchter (zuerst die ältere) regelmäßig fünfmal am Tag beten. Schließlich wird in der Verrichtung des Gebets auch eine wesentliche Grundlage gesehen, die zur Rechtleitung führe und das Wohlgefallen Allahs zur Folge habe. Diese Sichtweise ist zugleich typisch für die Gruppe der Idealisten:

"I...] ich sage zu meinem Kind: 'Du weißt, dass du beten sollst, oder? ' Ja Mutter, ich weiß.' Sie steht dann auf und betet. Sie betet das Mittagsgebet, das Nachmittagsgebet nicht. Sie betet das Abendgebet, das Nachtgebet nicht. Eine Phase lang habe ich es mir sogar zur Aufgabe gemacht. Ich sage immer wieder, ,Stell den Wecker!, ja, wir stellen die Weckerfunktion der Handys. [...]. Ja, da habe ich gesagt: ,Du musst es [das Gebet, Anm. d. Verf.] zuerst verinnerlichen. Je mehr du betest, wirst du dadurch Rechtleitung erfahren. Dir wird möglicherweise eine Tür geöffnet. Ja, du machst es [das Gebet, Anm. d. Verf.] zwar sinngemäß, aber du musst es mehr dazu machen, um das Wohlgefallen Allahs zu erreichen.' So bin ich vorgegangen. Der Vater ärgert sich manchmal und sagt dann etwas dazu, aber wir machen zu keiner Zeit Druck." (Dilek, Z.: 28)

Schließlich geht Nisa noch von einem strukturierenden Effekt des Alltags aus, wenn über das Gebet gesprochen werde (vgl. Nisa, Z.: 24).

Neben den gemeinsamen Gebeten stellen die Bittgebete (arab. dua) einen wichtigen Erfahrungswert für die Eltern dar. Hierzu äußern sich die Eltern zwar etwas weniger, doch sind Bittgebete regelmäßige Bestandteile des Familienalltags, die diese als Rituale in die täglich durchgeführten Gebete aufnehmen oder in verschiedenen Alltagssituationen anwenden. Insbesondere Lale führt dazu Folgendes aus:

"Bittgebete haben wir auch, z.B. Rituale wie vor dem Schlafengehen werden bestimmte Gebete vorgesprochen, nur also, ich spreche vor und sie sprechen immer nach, oder Schlussgebete, das ist sehr wichtig, diese Muavvizeteyn [arab. al Muawwizat für Schutzsuren, Anm. d. Verf.] lesen wir immer wieder. Und dass es bestimmte [...] oder das Aufstehen, das Schlafen, Bittgebete, das ist [...]. Natürlich, am Anfang, natürlich manchmal war es auch, Faulheit gibt es auch da manchmal: 'Mama, heute möchte ich nicht. Dann akzeptierten wir das auch, aber mit der Zeit, wenn die älter werden, merken die dann: 'Mama kannst du mir das Gebet noch mal sagen? Mach mir das Bittgebet bitte nochmal.' Das kommt. Aber natürlich, da muss man immer wieder [...], das sage ich allen Eltern so, schau dein Kind mal an, wie ist die Lage jetzt, hat es Lust dazu." (Lale, Z.: 131-135; vgl. auch: Z.: 101ff.)

Wie in der zweiten Interviewpassage deutlich wird und auch schon oben beschrieben wurde, wird vonseiten aller Elternteile viel Wert auf die freiwillig 
und selbstständig durchgeführte religiöse Praxis gelegt. Hier machen die Kinder von Lale und Nermin (vgl. oben) auf dem Weg zu mehr Selbstständigkeit eine ähnliche Entwicklung durch. Auch Nisa konnte die Erfahrung machen, dass die Kinder für das in sehr jungem Alter Gelernte (hier dua für Bittgebete) auch später Interesse zeigten und dieses aufgriffen (vgl. Nisa, Z.: 21).

Der Umgang mit Literatur und Büchern ${ }^{19}$ ist einigen Eltern als religiöser Erfahrungshintergrund besonders wichtig. Zudem ist das gemeinsame Koranlesen auf Arabisch, je nach Situation, manchmal auch unregelmäßig, ein fester ritueller Bestandteil in den Familien, vorausgesetzt natürlich, dass die Eltern und Kinder sich die Zeit dazu nehmen können und das Koranlesen durch die Familienmitglieder beherrscht wird (vgl. Ethem, Z.: 48 und 128; Nermin, Z.: 127 und 184; Lale Z.: 137; Nisa, Z.: 26 und 30). Gerade das gemeinsame Lesen von religiös geprägten Büchern bereitete den Kindern von Ethem viel Freude. Hier wird insbesondere der gemeinschaftliche Aspekt betont:

"[...] bei der Literatur, die wir innen zum Beispiel vorlesen, ausgewählt haben, war das auch weitgehend religiöse Literatur, also Geschichten über den Propheten, moralisch geprägte Geschichten; es waren natürlich auch Märchen usw. dabei, aber eine sehr große Rolle spielten eigentlich religiös motivierte Erzählungen, die wir ihnen dann vorgetragen haben. [...]. Also die haben sich jedes Mal gefreut, wenn wir vorgelesen haben, [...]! Für die Kinder war natürlich der besondere Aspekt, dass wir es gemeinsam gemacht haben." (Ethem, Z.: 48ff.)

Sitzungen, in denen religiöse Inhalte oftmals weniger strukturiert ausgetauscht werden und zumeist auch mehr die religiösen Gefühle ansprechenden Charakter haben, nennt man im gängigen türkischsprachigen Gebrauch sohbet. ${ }^{20}$ Sohbets, in denen hadithe (Überlieferungen des Propheten (s) in Worten und Taten) vorgelesen und besprochen wurden, sind für Nisa, vor allem als die Kinder klein waren, wichtig gewesen (vgl. Nisa, Z.: 21). Ansonsten überließ sie diese Aufgabe, als sie größer wurden, der Gemeinschaft, wo sie auch vieles erlernt hätten.

Der typische Charakter der Eltern, die nach Sinn und Orientierung streben, wird besonders prägnant durch Lale verdeutlicht. Demnach wird das einfache »Herunterrezitieren« des Korans abgelehnt und es wird ein Sinnbezug hergestellt. Das gemeinsame Koranlesen bedeutet für Lale eine aktive kindgerechte Auseinandersetzung mit den Inhalten des Korans, sodass sich auch dessen Sinn erschließen könne. Zudem wird am Ende noch auf Geschichten (hier sind religiöse Erzählungen gemeint) verwiesen:

19 | Darauf wird noch später zum Thema "Medien " gesondert eingegangen.

20 | (=dt. auch Gespräch, Unterhaltung). Diese spielen insbesondere im Zusammenhang mit außerschulischen religiösen Bildungseinrichtungen eine wichtige Rolle. 
"Wir lesen mit Yuşa, ja. Ist ja sieben Jahre alt, seit einem Jahr ist er im Korankurs. Wir lesen mit ihm den Koran, so, auch wenn es nur ein Vers ist, nicht sehr viel, und ich versuche immer wieder die Bedeutung zu sagen, denn in meiner Kindheit hat das gefehlt, wir haben sehr vieles auswendig gelernt, meine Mama hat uns in die Moschee geschickt, aber ohne Wissen, was da ...; ich habe das immer gesagt, warum lerne ich das, wieso lerne ich das, ich musste das lernen, ja? Aber ich versuche immer [zu erklären, Anm. d. Verf.], [...], was er lernt; und elhamdulillah [arab. für "Gott sei Dank", Anm. d. Verf.] es hat sich sehr viel geändert in den Moscheen, was diese Kinder auswendig lernen auch die Bedeutung, wir haben auch die Geschichten, und das ist sehr wichtig." (Lale, Z.: 182)

Als ein weiteres wichtiges Ritual ist das Fasten im Ramadan als eine der fünf Säulen des Islams für alle Familien von essenzieller Bedeutung. Der Monat Ramadan wird von allen Elternteilen mit unterschiedlichen religiösen Erfahrungen in Verbindung gebracht. Bei den Kindern lässt sich eine durchgehend hohe Motivation feststellen, was die Einhaltung des Fastengebots angeht, trotz einer langen Fastenzeit im Sommer (vgl. Ethem, Nermin, Lale, Dilek, Nisa), wobei hier erwähnt werden muss, dass die Eltern auch bei diesem Ritus darauf achten, die Kinder nicht zu überfordern, und daher eine altersgemäße Vorgehensweise präferieren. So wird in den Familien oftmals zum Beispiel das Çocuk orucu (türk. für Kinderfasten) ${ }^{21}$ eingeführt, um die Kinder an das Fasten langsam heranzuführen (vgl. Ethem Z.: 105-117; Nermin s. unten; Lale Z.: 159). Nermin gibt mehr oder weniger stellvertretend für alle Eltern zusammenfassend wieder, wie z.B. der letzte Ramadan erlebt wurde:

"Letztes Jahr waren wir in der Türkei. Das war sehr sehr schön. Ne, auch sehr besonders! Auch mit meinen Eltern zusammen. Ja, wir versuchen schon, den Koran zu lesen, besonderes Essen zu machen, zumal einige Kinder dann auch fasten und mein Jüngster hat auch mal ein/zwei Tage gefastet, wo ich gesagt habe: 'Nee, das brauchst du nicht. ‘ Aber das fand der schon wichtig und hat das dann auch durchgehalten." (Nermin, Z.: 133)

Das tarawih-Gebet, das im Anschluss an das Fasten in den Moscheen verrichtet wird, ist ein wichtiges Erlebnis, das ausnahmslos alle Eltern dazu veranlasst, die Kinder in die Moschee mitzunehmen, um sie an der spirituellen Atmosphäre in der Gemeinschaft Anteil nehmen zu lassen. Diese Atmosphäre sei es letztendlich, die die Kinder von Ethem dazu motiviere, trotz später Stunde, noch »durchzuhalten«:

21 | Dieses beinhaltet nicht, bis zum Sonnenuntergang zu fasten, sondern lediglich bis zur Mittags- oder Nachmittagszeit. 
"Und natürlich die tarawih-Gebete [arab. für Gebete im Anschluss des Nachtgebets im Monat Ramadan, Anm. d. Verf.], also dazu kommen die Kinder mit, wollen sie auch mit; also zum Ende hin wird ja die Motivation, weiter hinzugehen, etwas schwächer, und da muss ich sagen, waren es insbesondere die Kinder, die dafür gesorgt haben, dass wir weiter zum tarawih gehen, weil sie einfach diese Atmosphäre sicherlich auch gemocht haben. Sie haben aber auch mitgebetet, durchgehend." (Ethem, Z.: 120)

Lale setzt zudem auf Belohnungen und bereitet, ähnlich einem Adventskalender einen Ramadankalender vor. Im Vergleich zur Elterngeneration betrachtet sie dies als einen innovativen Schritt, den sogar der 21-jährige Sohn befürworte. Sie schildert ihre Erlebnisse mit ihren Kindern in einer ähnlichen Weise wie Nermin:

"Ramadan ist bei uns so, dass wir einen Kalender haben. Ramadankalender ist [...] immer wichtig bei uns, denn die Älteren vergessen das auch nicht, wenn die manchmal aus der Türkei kommen, 'Mama, bitte mach uns das auch،, obwohl er 21 Jahre alt ist, 'Bitte mach uns bei diesem Kalender auch ein Geschenk', immer wieder; und das ist sehr wichtig. Jeden Tag was Kleines und obwohl unser Jüngster, der Kleine. Auch als die anderen klein waren, immer wieder haben wir sie morgens zu sahur [arab. für das Essen am Morgen als Vorbereitung für die Fastenzeit, Anm. d. Verf.] aufgeweckt, auch wenn das Kind nicht gefastet hat. Dieses Kind soll sehen, wir stehen auf für das Fasten, okay? Und da haben wir immer sehr geachtet darauf. Bei allen Kindern und elhamdulillah [arab. für "Gott sei Dank", Anm. d. Verf.] bei den beiden haben wir auch gar keine Probleme damit [...] und am Abend, dass wir dieses dua [s.oben, Anm. d. Verf.] machen, dieses Fasten-dua. Und sie dann auch zu tarawih [s. oben, Anm. d. Verf.] mitnehmen." (Lale, Z.: 157-165)

Das Fasten im Ramadan hat einen wichtigen sozialen Charakter, der den Gemeinschaftsbezug unter verschiedenen Gesichtspunkten in den Fokus stellt. Neben den gemeinsamen tarawih-Gebeten wird z.B. in der religiösen Gemeinschaft von Dilek darauf geachtet, dass die Kinder, die fasten, belohnt werden: Sie bekommen besondere Sitzplätze und mehr Wertschätzung durch die Gemeinde. Es wird versucht, das zu kochen, worauf die Kinder Lust haben. Gerade dann, wenn sie in der Gemeinschaft seien, möchten die Kinder in jedem Fall fasten (vgl. Dilek, Z.: 126f.).

Bei Nisa ist es die spirituelle Atmosphäre und die Ruhe, die in ihrem Heim einkehre, was die Kinder zur Fastenzeit mit Freude erfülle (vgl. Nisa, Z.: 22 und 26).

Das Feiern von religiösen Festen nimmt in jeder Religion, gleich in welcher Intensität die Religion ausgelebt wird, einen wichtigen Stellenwert ein. So ist nicht verwunderlich, dass religiöse Feste in den befragten Familien vornehmlich mit den Familien und den näheren Verwandten gefeiert werden. Es werden 
Vorbereitungen getroffen, die Wohnungen hergerichtet; Verwandte, Freunde und Bekannte besucht. Es wird vor allem darauf geachtet, dass den Älteren Respekt erwiesen wird (Nermin, Nisa, Dilek, Lale) und insbesondere diese besucht werden. Den Kindern wird mit verschiedenen Geschenken eine Freude gemacht. Dies scheint, wie einige Eltern ausführen, ein neuer Brauch zu sein, der in Anlehnung an Weihnachten zunehmend an Bedeutung gewonnen hat (vgl. Nermin, Z.: 146-154). Nicht zuletzt sind Geldgeschenke ein wesentlich verbreiteter Brauch in muslimisch-türkischen Familien (vgl. Dilek, Nermin). Das Festtagsgebet in den religiösen Gemeinden oder Moscheen ist ein wesentlicher Bestandteil, ohne den ein religiöser Festtag nicht denkbar sei (Ethem, Z.: 124; Nermin, Z.: 156).

Das Feiern in der religiösen Gemeinde und das Erzählen von Geschichten sollten den Kindern dabei helfen, einen Sinnbezug herzustellen. Lale betont zudem, dass »nicht nur in der Familie« gefeiert werden solle, sondern auch in der Gemeinschaft:

"Ja, ja. Zusammenkommen auch mit der Moschee feiern wir das auch. Das ist wichtig, dass wir z.B. dieses letzte Opferfest [...], da haben wir dann gesagt, alle Frauen, macht was Leckeres, und für die Kinder haben wir dann extra so Geschenke, Spiele und so, sodass sie unter sich gespielt haben, Geschenke bekommen haben, sich über den Ramadan und auch über das Opferfest auch so ein bisschen Geschichte eingeprägt haben; gesellschaftlich [hier ist Gemeinschaft gemeint, Anm. d. Verf.], auch unter den Frauen, soll gefeiert werden; und unter den Kindern [...]. Muss nicht nur in der Familie bleiben." (Lale, Z.: 169-173)

Für die Kinder werden im Vergleich zu früher dahingehend auch mehr Angebote gemacht:

"Ja, ja. Spiele gemacht, Fragen gemacht, über dieses Fest und gegessen und beschenkt. [...]. Ja, Wettbewerbe ..., das macht es ja interessanter. [...] Ja, ist aber sehr schön." (Lale, Z.: 175-179)

Als eine Tradition, die sie einführen will, möchte Nermin an religiösen Festtagen muslimische Gräber besuchen. Sie sieht darin religiöse Motive, die auf das Leben nach dem Tod hindeuten und durch ihre Kinder als ein Teil des Glaubens wahrgenommen werden sollen:

"Auch, auch! Weil ich denke, der Tod gehört zum Leben dazu, der Tod ist jetzt, auch wenn er noch so traurig ist, der Tod ist ja eigentlich, aus meiner Sicht, nie etwas Schlimmes gewesen, sondern der Tod ist ja eigentlich wie eine Befreiung. Es ist ja die Prüfung, die abgelegt worden ist. Und dann kann man sagen: 'Hurra, er hat seine Prüfung geschafft! Ist ja eigentlich positiv, sodass die Kinder schon so ein bisschen auch das mitbekom- 
men und nicht immer ... In Deutschland ist der Tod ja Trauer und ne und es ist alles dunkel und schwarz und Depression und so ... und ..." (Nermin, Z.: 158)

Hinsichtlich des religiösen Wissens geben die Eltern unterschiedliche Antworten. Im Vergleich zur rituellen Dimension der Religiosität, bei der die Antworten eine große Ähnlichkeit zueinander aufwiesen, fällt das, was den Eltern auf der intellektuellen Ebene wichtig erscheint, etwas unterschiedlich aus. Vor diesem Hintergrund ist es den idealistischen Eltern als gemeinsames Merkmal dennoch wichtig, auch auf der Ebene des Wissens den Sinn hinter dem, was die Kinder sich aneignen sollen, zu sehen. Es lassen sich hier grob zwei Richtungslinien feststellen: Es werden Bezüge sowohl zum Wissen über die Rituale und deren Befolgung als auch zum Wissen um die Grundlagen des Islams hergestellt. In diesem Zusammenhang wird auch gerne darauf abgestellt, dass weltliches Wissen mindestens ebenso wichtig sei wie religiöse Bildung.

Die Kinder sollten neben den Grundlagen des Islams, d.h. dem Wissen um den Koran und dessen Inhalte, auch die Sunna des Propheten (s) erlernen. Hier spricht Lale bzgl. religiöser Bildung am deutlichsten die klassisch-islamischen Vorstellungen an. Demnach ist ihr neben weltlichem Wissen (vgl. auch Nisa und Nermin) auch das Wissen über die eigene Religion, d.h. über die Grundlagen des Islams, wichtig. Beide sollten in einem ausgewogenen Verhältnis zueinander stehen. Um dieses Verhältnis darzustellen, bedient sie sich eines Verses aus dem Koran; darin wird durch Gott gebeten, sowohl im Weltlichen als auch im Jenseits Gutes zu empfangen:

"Allgemeinwissen soll das Kind mitbekommen; das Kind lebt ja in dieser Welt, soll ja nicht immer so weltlich und wie nennt man ahiret [türk. für das Jenseits, Anm. d. Verf.]? Wir wollen ja auch nicht, dass Jenseits nur da ist, auch unsere dua: ,Rabbena atina fiddünya haseneten ve fil ahireti haseneten ... [arab. für "Gib mir, Allah, Gutes im Diesseits und im Jenseits«; vgl. Koran 2: 201; Anm. d. Verf.], alle beide sollen in einer Waage [ausgewogen sein, Anm. d. Verf.] [...]" (Lale, Z.: 205ff.)

Bezogen auf religiöses Wissen solle der Koran als Grundlage bzw. als »Handbuch « nicht nur dazu dienen, Verse daraus auswendig zu lernen, sondern auf ethisch-moralische Grundhaltungen (ahlak) zu achten, den Propheten und seine Gefährten als »Vorbild « anzusehenund ihn (den Koran) in seiner sinngemäßen Bedeutung zu verstehen. Gerade die »Ausübung« bzw. Befolgung der religiösen Praxis, könne nur über diese Quellen (Koran und Sunna) erlernt werden (vgl. Lale Z.: 215-223).

In diesem Zusammenhang können auch die Aussagen von Dilek gesehen werden. Sie wünscht sich für ihre Töchter, dass sie sich zum einen, um die täglichen Gebete zu verinnerlichen bzw. zu verrichten, das Wissen über diese religiöse Praxis aneignen. Daneben sollen sie über alles Bescheid wissen, 
was zu einer vorbildhaften Persönlichkeit führt, und sich mit dem Leben des Propheten Muhammad (s) und der anderen Propheten aus dem Koran auseinandersetzen. Zum anderen ist ihr die Fähigkeit zur reflektierenden Auseinandersetzung mit dem Koran von besonderer Bedeutung, sodass sie das Hinterfragen und das Reflektieren (von Koranversen) ihrer jüngeren Tochter begrüßt. Letztendlich seien darin alle »Vitamine« für ein gottgefälliges Leben enthalten (vgl. Dilek, Z.: 133-139). Hier scheint der typische Charakter der idealistischen Eltern durch, bei denen die Beschäftigung mit dem Koran eine orientierungsstiftende Funktion haben soll. Gerade Nermin befürwortet auch die Auseinandersetzung mit dem Koran, die der Tochter helfen solle, »ihren Weg« zu finden:

"[...] und meine Große, die ist da maşAllah [arab. maschAllah für "Gott beschütze sie", Anm. d. Verf.], schon meine Älteste, ich glaube, die findet da schon ihren Weg, sie liest und überlegt; sie liest jetzt auch den Koran auf Deutsch und erforscht und so [...]." (Nermin, Z.: 103)

Daneben sind Nermin zudem das Auswendiglernen von Koransuren, wenn möglich der längeren Suren (»Yasin, Tebareke, Amme«) und die Grundlagen der Religion wichtig (vgl. Nermin, Z.: 192 und 210ff.). Als ein typisches Merkmal der idealistischen Eltern, ist ihr auch das Wissen um die »Bedeutungen« der religiösen Grundlagen bedeutsam. All die »religiösen Hintergrundinformationen: warum, wieso, weshalb « betrachtet sie demgemäß als eine wichtige Voraussetzung, um die Bedeutung hinter dem Erlernten, wie z.B. das Leben des Propheten (s), zu erkennen (vgl. Nermin, Z.: 210).

Etwas anders argumentiert Ethem, wenn auch hinsichtlich der Wissensaneignung seiner Kinder einige Überschneidungen zu den anderen Eltern festzustellen sind. Er sieht sich als Vorbild seiner Kinder in der Pflicht, ihnen den Islam als Bestandteil ihres Lebens zu vermitteln. Dabei geht es ihm bei der Wissensaneignung auch um die konkrete Umsetzbarkeit im tatsächlichen Leben. Folglich sei dazu erforderlich, eine moralische Grundhaltung, gleich einer Weltanschauung, an den Tag zu legen. Diese solle es ermöglichen, als ein »religiös muslimischer Mensch« in die Welt hinauszublicken, um eine religiös motivierte Perspektive (»eine islamische Perspektive«) einzunehmen. Dies ist für ihn zentral, wie auch die Ausführung des Gebets, wozu es aber »nicht unbedingt« des Elternhauses bedürfe. Vielmehr sei die Familie in der Pflicht, eben die beschriebene moralische Grundhaltung weiterzugeben:

"Also, wo ich die Familie schon in der Pflicht sehe, oder wo ich als Grundsatz Vater oder Mutter in der Pflicht sehe, ist, den Kindern Wissen, das über dieses Rezitieren und Auswendiglernen hinausgeht, mit auf den Weg zu geben. Das heißt, ihnen die Möglichkeit zu geben, sich anzueignen oder zumindest auch an unserem Beispiel dann auch zu sehen, 
dass der Islam auch im Leben eine Rolle spielt und dort auch umsetzbar ist und dann auch für ihr Leben dann halt auch eingesetzt werden kann. Also mir geht es insbesondere um die moralische Komponente des Islams, um die Frage, welche Weltanschauung sich damit verbindet, also die Frage, wie blicke ich als religiöser muslimischer Mensch in die Welt hinaus? Wie schätze ich Situationen und Entwicklungen ein, wie bewerte ich das um mich herum, was geschehen wird, dass meine Kinder die Möglichkeit bekommen, auch dort eine religiöse Perspektive, also eine islamische Perspektive einzunehmen [...], spielt für mich eine zentrale Rolle [...]." (Ethem, Z.: 134).

Eine ganz andere Ansicht vertritt Nisa bezüglich der Wissensaneignung. Im Vergleich zu allen anderen Eltern stehen für Nisa das Wissen um Gott/Allah und das Erlernen der Glaubensgrundlagen im Vordergrund. Dies solle die Kinder dazu bringen, sich Gott/Allah zu nähern (Nisa, Z.: 32).

$\mathrm{Zu}$ den religiösen Fragen der Kinder innerhalb der Familie stellen die Fragen nach der Existenz Gottes und den Glaubensgrundlagen die meist benannte Kategorie dar. Alle Eltern können dahingehend auf Erfahrungen zurückgreifen. Die Fragen, warum überhaupt an Gott geglaubt wird, wer er ist, was er macht oder welche Eigenschaften er besitzt und wo man ihn sich räumlich vorzustellen hat (vgl. Ethem, Z.: 144; Lale, Z.: 243 und 249; Dilek, Z.: 141 und 150; Nisa, Z.: 50), stellen Eltern hinsichtlich ihrer Beantwortung vor große Herausforderungen. Bei Fragen zur Schöpfung, wer der erste Mensch war, warum es schwarze und weiße Menschen gibt, wird zur Beantwortung zumeist ein hoca (türk. für Lehrer, auch Imam) zurate gezogen (vgl. Nermin Z.: 220-224). Die Frage, wie das Leben nach dem Tod im Jenseits sei, wo auch die Gerechtigkeit Gottes erfahren werde, bezieht sich auf einen Glaubenspfeiler des Islams (vgl. Nermin Z.: 224). Aber auch die Frage bzgl. der eigenen Schöpfung und der Existenz der Seelen noch vor Beginn der Schöpfung beschäftige einige Kinder (vgl. Lale, Z.: 258-274).

Der Umgang mit diesen Fragen veranlasst wiederum einige Eltern dazu, sich ein Repertoire an Büchern und Informationen zu beschaffen, um eine altersgerechte Herangehensweise bei der Beantwortung von Fragen (zur Existenz Gottes) sicherzustellen (vgl. Lale, Z.: 251ff. und 272ff.; Dilek, Z.: 141 und 146; Nisa, Z.: 172). Vor allem für Lale stellt es im Vergleich zu früher eine Bereicherung dar, dass inzwischen solche Bücher auf dem Markt zur Verfügung gestellt werden.

Auch wahrgenommene Widersprüche, sei es in Bezug auf das Alltagsleben oder in Bezug auf die Religion des anderen, bringen die Kinder dazu, Fragen zu stellen:

"[...], gut zum Beispiel bezüglich Weihnachten, kam dann halt auch die Frage: Warum feiern wir kein Weihnachten? Warum feiern die anderen? Warum feiern wir das nicht mit? Die Fragen kamen zum Beispiel auch gerade letzte Woche, auch im Zusammen- 
hang mit den ganzen Weihnachtsaktivitäten in der Schule; die wollen natürlich auch dann eine Antwort haben. Auch die Frage: Warum sind die Christen, warum sind wir Muslime?، [...] auch jene, die einen direkten Bezug zu seinem Alltagsleben haben. [...]. Auch dann zum Beispiel so Fragen wie, 'Wer ist [...]; es gibt aber auch Deutsche bei uns in der Klasse, die feiern kein Weihnachten. Was ist dann mit denen?; also beobachten tut er schon ganz gut." (Ethem, Z.: 146-150)

Gerade die erlebten Widersprüche, die aus Einflüssen aus dem Umfeld, dem Handeln und den Einstellungen der Eltern herrühren, werfen bei den Kindern Fragen auf:

"[...], ralso warum macht ihr das jetzt so? Andere machen das nicht!، Bei religiösen Fragen ist dann natürlich auch das nichtmuslimische Umfeld da. Auch es ist halt in Anführungsstrichen ein Maßstab oder ein Kriterium, an dem man das messen kann. Also da scheinen die Kinder auch sehr viel Beobachtungsgabe an den Tag zu legen, also die Fragen kommen dann auch sehr oft." (Ethem, Z.: 169)

So sind auch die Fragen der Kinder von Nisa zu sehen, die, beeinflusst durch die unterschiedliche Regelbefolgung innerhalb der eigenen religiösen $\mathrm{Ge}$ meinschaft (Essen, Alkoholverbot) und der Verwandtschaft, sensibel auf erlebte Widersprüche reagieren. In einer ähnlichen Weise hinterfragen diese auch, warum Gott/Allah z.B. die Produktion von Alkohol oder überhaupt Leid und Naturkatastrophen zulasse, wenn diese doch schlecht seien und den Menschen schaden würden (vgl. Nisa, Z.: 34-38).

Ferner taucht die Frage über die Gerechtigkeit Gottes/Allahs bei einigen Kindern auf. Hier wird sie im Zusammenhang mit Andersgläubigen gestellt; aber auch bezogen auf das Verhältnis zu den Geschwistern scheint die Gerechtigkeit sehr wichtig zu sein:

"[...] Dann, was hatten die noch gefragt? Ja, natürlich Fragen, die dann über Gerechtigkeit [...], wie wird das halt nach dem Tod sein? Und wenn jemand dann kein Muslim ist und trotzdem sehr viel Gutes tut und so ...? Und ... oder die Fragen, was ich ganz komisch fand: Ja, zum Beispiel, wenn die kleine Schwester die Großen ärgert und Ausdrücke sagt, wird sie auch dafür bestraft, oder ...? Inwiefern werden dann Bestrafungen? [...]. Ja, Gerechtigkeit ist sehr wichtig! (Nermin Z.: 224-228)

Schließlich sind es die Sinnfragen, die die Tochter von Ethem, wohl auch angeregt durch die »spezifische« Erziehung (vgl. oben Ethem, Z.: 134), besonders interessieren: 
"Bei meiner Tochter waren es auch sehr frühzeitig halt diese (überlegt) kindlichen Grundsatzfragen. [...] Sinnfragen, die kommen [...] überhaupt: Wieso sind wir Muslime? Warum glauben wir an Gott? Wer ist Gott? Und was macht er? (Ethem, Z.: 140-144)

\subsubsection{Die Erziehungsmethoden und Erziehungsstile in den Familien der "Idealisten "}

Was die Erziehungsmethoden in der Familie angeht, klangen schon bei der Beschreibung von Religiosität einige Aspekte an. Hier soll nun konkreter beschrieben werden, welche Erziehungsmethoden Eltern hinsichtlich ihrer religiösen Erziehung befürworten bzw. anwenden.

Hier wird in erster Linie das Vorleben bzw. die Vorbildfunktion der Eltern unterstrichen. Alle Eltern versuchen, ihren Kindern beim Ausleben der Religion ein möglichst gutes Vorbild zu sein. Dies soll sie sowohl bei der Übernahme von Grundeinstellungen als auch bei der Befolgung von religiösen Regeln unterstützen (vgl. oben Ethem, Z.: 48 und 134; Nermin, Z.: 236; Lale, Z.: $96 \mathrm{ff}$. und 276; Nisa, Z.: 40). Nisa betont zudem, dass auch andere ältere Personen im Umfeld diesen Anforderungen gerecht werden sollten (vgl. Nisa, Z.: 42).

Lale beschreibt die Art und Weise, wie sie sich selbst in ihrer Vorbildfunktion wahrnimmt, folgendermaßen:

"[...] indem ich das ausübe, das ist mir sehr wichtig [...] Ausüben bedeutet, indem ich ganz normale tägliche rituelle Sachen mache, das, was mein Glaube mir sagt, zu sagen, und ich versuche, es weiterzugeben, weiterzuleiten, weiterzuleben. Ich versuche es, indem ich selber als Vorbild da bin und auch meine Zufriedenheit, immer wieder persönlich, [...] also so immer wieder zu sagen." (Lale, Z.: 96ff.)

Der kommunikative Aspekt, d.h. »immer wieder«, wie Lale anführt, »zu sagen« bzw. über die Religion zu sprechen, ist neben der Regelbefolgung der zumeist benannte methodische Aspekt. Es wird in der Kommunikation zum einen die gewählte Form (Überzeugen, Sprechen, Erklären an Beispielen usw.) dargestellt und zum anderen Aussagen über die Art und Weise (alltagsnah, altersgemäß, empathisch usw.), wie diese Kommunikation im Eltern-Kind-Verhältnis stattfindet, aufgezeigt. Letzterer Aspekt wird nochmals im Zusammenhang mit den Erziehungsstilen aufgegriffen. Wichtig ist, dass Überschneidungen bei der Darstellung der Ergebnisse unumgänglich sind. Dennoch soll darauf geachtet werden, Wiederholungen zu vermeiden.

Allgemein wird das Sprechen oder werden Unterhaltungen über die Religion durch verschiedene Kommunikationsformen unterstützt. Das Begründen und die Kinder zu überzeugen, ist für die Eltern eine selbstverständlich angewandte Form, um auch die Bedeutung des Besprochenen nachvollziehbar zu machen. Dabei werde versucht, »um die Welt auch mit der Religion zu begründen und zu durchleuchten«, die kindliche Perspektive oder die Lebens- 
welt, in der sie sich befänden, zu berücksichtigen (vgl. Nermin, Z.: 63). Auch die Bedeutung des Korans wird unter Berücksichtigung des Alters des Kindes erklärt. Wichtig erscheint hier zudem, möglichst wiederkehrend zu erläutern, »warum « und »wieso « das Erlernen erfolge, um einen Sinnbezug herzustellen (vgl. Lale, Z.: 182 und 98; Dilek, Z.: 28; Nisa, Z.: 49). Vor allem sollten die Eltern ihre Überzeugungsfähigkeit einsetzen, um möglichst viel mit ihren Kindern über ihren Glauben zu sprechen. Letztendlich würden sich gerade Jugendliche logische Erklärungen und Argumente wünschen, die sich auf ihren Glauben (wie z.B. auf das Jenseits) bezögen (vgl. Nisa, Z.: 42, 49 und 176).

Das Erklären an Beispielen aus der Lebenswelt der Kinder ist eine weitere Form des Eltern-Kind-Austausches. Wenn sich Situationen ergaben, die für die Kinder verständlich gemacht werden sollten, wurden/werden Erklärungen für das Verhalten der Eltern dargelegt:

"[...] dass sich aus der Lebenssituation heraus Möglichkeiten ergeben, Themen anzusprechen. Es hat sich eigentlich schon eingespielt, dass wir dann halt auch bei unserem eigenen Tun dann auch immer wieder erklären, warum wir das getan haben, also insbesondere, wenn es ein bisschen auffallend ist, dann auch sagen, warum wir das jetzt getan haben, was der Hintergrund ist; oder wenn wir es halt nicht machen, kriegen wir dann auch direkt die Frage von den Kindern: ,Warum habt ihr das jetzt so gemacht? Warum habt ihr so gehandelt?» (Ethem, Z.: 167)

Gerade auch bei der Regelbefolgung wird als Erklärungsmuster auf die eigene religiöse Zugehörigkeit hingewiesen..$^{22}$ Im Gegensatz zu den »anderen«, kennen die Kinder ihre Speisevorschriften und setzen diese entsprechend um:

"[...] Also nicht folgen wollen, wenn das Thema Essen [...], da nicht folgen wollen, war eigentlich gar nicht der Fall. Ich habe immer gesagt: ,Das ist nichts für uns (=) Bize göre değil zum Beispiel.` Ne, das war nie ein Problem, dass die gesagt haben (...), wir haben ja immer Ausweichmöglichkeiten. Wenn da im Kindergarten was mit Gelatine angeboten wurde, dann wussten die, aha, darf ich nicht essen, wir haben anderes. Ne, das war nie ein Problem." (Nermin, Z.: 251)

Das Hinterfragen und Reflektieren des Korans ist insbesondere für Dilek wichtig, um die Kinder anzuregen, weiter zu forschen und ihre eigene Wahrheit zu finden. Dabei gehe sie als Vorbild vor und möchte keine endgültigen Antworten geben, die die Kinder verstummen lassen würden. Die Kinder sollten demnach die Fragezeichen in ihr Gedächtnis aufnehmen, um sich viel mit ihrer Religion auseinanderzusetzen. Ihre umfassende Bibliothek sorge dafür, dass

22 | Hier könnte man auch von einer identitätsstiftenden Funktion des religiösen Gebots sprechen. 
sie sich mit ihren Kindern Zeit für geistige Auseinandersetzungen nähmen. Dabei werde sie auch von ihrem Ehepartner unterstützt (vgl. Dilek, Z.: 93-97 und 142-146).

Aktives Zuhören gepaart mit einer entsprechenden Empathiefähigkeit lässt Nisa indirekte Fragen stellen, die die Kinder wiederum dazu motivieren, selbst eine Position einzunehmen. Dabei geht es ihr darum, die Kinder auf indirektem Wege auf ihre Fehler hinzuweisen. Sie schätzt dabei eine geduldige Vorgehensweise, die sie vor übereilten Rückschlüssen bewahrt. Gerade dies schaffe Vertrauen zwischen ihr und ihren Kindern (vgl. Nisa, Z.: 46f.). Um die Fragen der Kinder zu beantworten, wählt Dilek eine interaktive Vorgehensweise. So rede sie mit einer Freundin über das Thema, das die Kinder interessiere und sie gerne besprechen möchte. Als Respektsperson helfe die Freundin sozusagen bei der Eröffnung eines Dialogs. Dadurch seien die Kinder schon zu verschiedenen Ergebnissen und Erkenntnissen gelangt (vgl. Dilek, Z.: 156).

Ein bedeutungsvolles Charakteristikum der angewandten Erziehungsmethoden bzw. der diversen Sprechformen ist die Lebensweltorientierung. Das Sprechen über die Religion wird möglichst lebens- und alltagsnah eingesetzt. Religion soll aber auch im Alltag gespürt werden:

"[...] Und, wo es dann auch darum geht, dass die Kinder auch in inrem Alttag Religion spüren, also nicht nur, wenn sie zu Hause sind, diese fünf oder zehn Minuten im Gebet als einzig religiöses Moment fühlen sollen, sondern auch wissen, dass man diese Haltung auch als Muslim letztendlich an den Tag legen muss [...]." (Ethem, Z.: 64)

Wichtig ist demnach für Ethem, eine Art und Weise auszuwählen, die diese Vorstellung stützt. So wird weniger ein Thema ausgewählt, über das gesprochen wird, sondern vielmehr aus der Lebenssituation heraus zu religiösen Themen Bezug genommen:

"Also möglichst im Leben, also wir haben zwar auch Situationen, wo wir uns dann auch gesondert hinsetzen, einfach nur, um uns zu unterhalten, und wo das Thema dann auch auf religiöse Fragen kommt, aber ... (überlegt). Das habe ich dann eher weniger gern, weil es dann ein bisschen, na ja schon gekünstelt rüberkommt, habe ich den Eindruck. [...]. Ja, was ich dann nicht mache, ist, dass ich mich mit den Kindern hinsetze und sage, 'So Kinder, heute behandeln wir mit euch das Thema so und so', und dann Vorträge darüber zu halten. Viel lieber habe ich es dann, dass wir, dass sich aus der Lebenssituation heraus Möglichkeiten ergeben, Themen anzusprechen [...]." (Ethem, Z.: 165ff.)

Neben ihrer Vorbildfunktion nehmen die Eltern die Religion zudem als einen selbstverständlichen Bestandteil in ihren verschiedenen Lebenswelten (u.a. zu Hause, in der Freizeit) wahr (vgl. auch Dilek, Z.: 155). So werden anstehende Themen bewusst im Alltag besprochen und auch praktiziert: 
"[...] man versucht ja schon im Alltag, bewusst zu leben, und auch wenn Themen halt angesprochen werden, dass man diese anspricht, diese bespricht, und ja [...]. Ja, das Besprechen, Vorleben [...] und wir versuchen auch, wenn wir mit Freunden zusammen sind, wenn wir dann gemeinsam weggefahren sind oder so, für einige Tage, das machen wir [...], dass wir dann nicht sagen 'So, Religion war zu Hause, hier haben wir Urlaub, hier gehört das nicht hin`, oder so, sondern dass wir das dort auch [...] praktizieren, dort auch weiterhin praktizieren." (Nermin, Z.: 236-242)

Auch eine altersgemäße Förderung der Kinder ist ein weiteres Merkmal der religiösen Kommunikation zwischen Eltern und Kindern (vgl. oben »Religiosiät«, vgl. auch Lale, Z.: 145, 253 und 270). Gerade um Überforderungen zu vermeiden, sollten, angefangen vom Kleinkindalter, die verschiedenen Entwicklungsphasen der Kinder berücksichtigt werden (vgl. Nisa, Z.: 4off.).

Neben den verschiedenen Kommunikationsformen nimmt die Regelbefolgung, die nächst wichtige Stellung innerhalb der angewandten Methoden ein. Wie oben schon zum Teil darauf hingewiesen wurde, nehmen alle Eltern die Befolgung von religiösen Geboten im Alltag sehr ernst. Hierzu zählt beispielsweise die Einhaltung des muslimischen Speisegebots (vgl. Nermin Z.: 246 und oben), die rituelle Waschung vor dem Gebet (türk. abdest; vgl. Lale Z.: 139), das Verrichten des Gebets selbst (vgl. alle Eltern, insbesondere Lale und Dilek; vgl. auch oben »Religiosität«) oder aber auch das Unterlassen von religiös Verworfenem. Hier wird darauf geachtet, »was das Kind sich anschaut, was das Kind sich anguckt, liest ...«, oder ob es an Veranstaltungen wie Karneval teilnehmen kann (vgl. Lale, Z.: 139; vgl. Nisa, Z.: 40). Eine wichtige Regel ist beispielsweise für Lale auch der wöchentliche Besuch einer religiösen Bildungseinrichtung (vgl. Lale, Z.: 318f.). Doch auch diverse andere Rituale (vgl. oben Religiosität) werden im Laufe der Woche umgesetzt. Für Eltern, deren Kinder schon über 16 Jahre alt sind, stellt die Regelbefolgung vonseiten der Jugendlichen (z.B. die täglichen Gebete zu verrichten, das Ausgehverbot ernst zu nehmen oder bspw. das Tragen des Kopftuches) eine große Herausforderung dar (vgl. Lale, Z.: 361f.; Dilek, Z.: 28; Nisa, Z.: 48; vgl. auch unten »Erziehungsstile«).

Insbesondere Lale und Nisa, die sich persönlich auch viel mit religionspädagogischen Themen auseinandergesetzt und pädagogische Seminare besucht haben, legen viel Wert auf kreativ-spielerische Aspekte der religiösen Erziehung. Neben dem Basteln, Spielen u.ä. Aktivitäten wird auch gerne die Freizeit mit den Kindern verbracht (vgl. Lale Z.: 139ff. und 157; Nisa, Z.: 41). Gerade die kreativen Aspekte stellen im Vergleich zu früher eine Innovation dar, die zunehmend an Bedeutung gewinnt.

Hingegen sind Belohnungen schon immer eine häufig angewandte Methode in der religiösen Erziehung. Sie dienen dazu, die Kinder vor Regelverstößen zu bewahren, oder bei Positivem, wie z.B. der Einhaltung von Ritualen oder dem Besuch der Moschee, sollen sie einen verstärkenden Charakter haben. Dabei 
werden sowohl emotionale Zuwendung und persönliche Anerkennung (vgl. Ethem, Z.: 56-60 und 179-187; Dilek, Z.: 161) als auch Aktivitäten (Nermin, Z.: 257; Lale, Z.: 311) und Geschenke (Nermin, Z.: 662ff.; Nisa, Z.: 54f.) eingesetzt.

Neben der Belohnung stellt sich die Frage, ob auch Strafen als Sanktionsmittel angewandt werden. $\mathrm{Zu}$ dieser Frage haben alle Eltern zwischen allgemeiner Erziehung und religiöser Erziehung unterschieden. Bei Regelverletzungen, die keinen religiösen Charakter haben, kommt es vor, dass Eltern Strafen vergeben: Hausarrest, Verbote, Ausgleiche (vgl. Ethem, Nisa, Lale, Dilek) unter Geschwistern, indem man dem anderen etwas Gutes tut (vgl. Nermin). Jedoch wird bei Regelverstößen, die die Religion betreffen, wie z.B. der Nichteinhaltung des Gebets, vielmehr auf die Kommunikation mit den Kindern Wert gelegt, um die Kinder dahingehend zu motivieren. Dabei kommen auch Belohnungen zum Einsatz (vgl. oben und »Erziehungsstile«).

\section{Erziehungsstile}

Es können im Zusammenhang mit Regelbefolgung (z.B. bei den Ritualen) und auch Regelverstößen Aussagen über das Eltern-Kind-Verhältnis und demzufolge über die Erziehungsstile gemacht werden. Die Reaktion der Eltern bei Nichteinhaltung von religiösen Geboten gibt Aufschluss über ihren bevorzugten Erziehungsstil.

Zur Lösung von Konflikten wird vonseiten der Eltern stets die Kommunikation mit dem Kind als primäre Strategie benannt. Hierbei kommen verschiedene Kommunikationsformen zum Einsatz (vgl. oben). Hinsichtlich der religiösen Erziehung werden kaum Konflikte benannt, als dass hier darauf Bezug genommen werden könnte.

Bezogen auf die Regelbefolgung oder den Regelverstoß wird insbesondere auf das Verrichten der täglichen Gebete verwiesen (vgl. oben »Religiosität«). Aber auch der Moscheebesuch bzw. der Besuch einer religiösen Bildungseinrichtung gibt den Eltern Anlass, darauf zu achten, dass die Kinder diese besuchen. Schwierigkeiten existieren in den Familien bezüglich des Ausgehverbotes (Disco, Party) ${ }^{23}$ oder im Hinblick auf das Tragen des Kopftuches. Auch spielt das Alter des Kindes bei der Regelbefolgung eine große Rolle. Demnach werden jüngere Kinder, die nicht das religiös mündige Alter erreicht haben, weniger zur Verantwortung gezogen als ältere Kinder.

Zunächst soll im Folgenden anhand der täglichen Gebete verdeutlicht werden, welches Erziehungsverhalten (»idealistische«) Eltern besonders auszeichnet. Es konnte schon in der Typologie und der »Religiosität« aufgezeigt werden, dass ausnahmslos alle Eltern viel Wert auf die Förderung der Selbstständigkeit

23 | Hier könnte der Jugendliche sich im Bereich des Sündhaften (z.B. Interesse gegenüber dem anderen Geschlecht, Alkoholkonsum, vorehelicher Geschlechtsverkehr) bewegen, sodass sich die Eltern diesbezüglich Sorgen machen. 
und die freiwillige bzw. selbstständige Verantwortungsübernahme im Zusammenhang mit der Befolgung von religiösen Geboten und erzieherischen Prinzipien legen.

Auch wenn Ethems Kinder nicht in dem Alter sind, wo sie beten »müssen«, verrichten sie das Gebet auch selbstständig:

"[...] Also das Alter ist zwar jetzt noch nicht in dem Stadium, wo sie es machen müssen, aber, wenn wir zum Gebet gehen, rufen wir die Kinder auch zum Gebet und sie stellen sich auch meist dazu oder beten es auch selbstständig, motivieren sich auch gegenseitig, das zu machen. Das ist sehr wichtig [...].» (Ethem, Z.: 62)

Sie sollen auch zwischen Gutem und Bösen »selbstständig « unterscheiden lernen und dahingehend Verantwortung übernehmen:

"[...] Das ist zum Beispiel für mich auch ein sehr wichtiger Aspekt in der Erziehung, dass die Kinder auch selbstständig in die Lage versetzt werden, zu unterscheiden, was gut und was schlecht ist, und dass man innen nicht jedes Mal einzeln aufzählen muss, das ist jetzt gut und das ist schlecht [...]." (Ethem, Z.: 38)

Bei Ethem steht die »Förderung der Selbständigkeit« dermaßen im Vordergrund, sodass bei ihm ein gleichberechtigtes Mitgestalten, z.B. bei den Gebeten (vgl. Ethem Z.: 54ff.), sehr wichtig ist. Im Vergleich zu den anderen Eltern dieses Typs, sieht er auch nicht die Notwendigkeit, sich von »Zwang « oder Restriktionen abzugrenzen. Zudem lässt sich bei ihm kein Hinweis auf »Disziplin« finden. Dies könnte aber auch mit dem Alter (elf und neun Jahre) der Kinder zusammenhängen. Schließlich wünscht sich Ethem eine Selbstständigkeit und Autonomie, die die Kinder dazu in die Lage versetze, eigene Entscheidungen zu treffen und ein selbstbestimmtes Leben zu führen:

"Ach, dass sie ein gesundes, erfolgreiches, selbstbestimmtes Leben führen, letztendlich dann auch ihre Entscheidung für ihr Leben, auch in der Lage sind, selbst zu treffen." (Ethem, Z.: 362)

Die selbstständige Verantwortungsübernahme für die eigenen Gebete ist auch für Nermin bedeutsam. Dabei bevorzugt sie eine altersgemäße Vorgehensweise, mit der sie die Jüngeren belohnt und die Älteren durch Erinnerungen auf ihre eigene Verantwortung hinweist:

"Ja. Also wenn ich dann zum Beispiel sage, 'Das Gebet ist jetzt soweit, und die Kinder haben keine Lust oder so, dann sage ich der Großen: 'Es ist meine Pflicht, es dir zu sagen, und mehrmals zu sagen und wenn du es nicht machst, ist das nicht, ist das deine Verantwortung. $\mathrm{Ne}$, da sag ich jetzt bewusst, dass sie weiß, aha, okay, es liegt in meiner 
Verantwortung. Und wenn du es vergisst oder nicht machst, ist das deine Sache. Ich muss es dir sagen, es ist meine Verantwortung, dich daran zu erinnern. Bei den Jüngeren bin ich natürlich eigentlich dafür verantwortlich, sodass ich sage: 'Hast du nicht gemacht, machst du nicht.، Da versuche ich solche Regelverstöße nicht als Regelverstoß zu sehen, sondern eher andersherum, dass ich dann sage: 'Komm, danach können wir das und das machen, mach das schnell !« (Nermin, Z.: 257)

In einer anderen Situation wollte die Tochter aus persönlich motiviertem Trotz nicht beten. Nermin zeigt hier durch Erklärungen klare Grenzen, die es der Tochter nicht erlauben, das Gebet zu verweigern. Hier wird insbesondere ihre Disziplin deutlich, die für sie bei fünf Kindern unerlässlich ist (vgl. Nermin, Z.: 267 und 287ff.). Dennoch könne sie in anderen Fällen, z.B. beim Vergessen durch »schusseliges« Verhalten, das Nichtbeten auch mal durchgehen lassen:

"Einmal war das. Einmal hat es das gegeben, wo meine Tochter zu mir gesagt hat, die war sauer auf mich, und gesagt hat, dann bete ich auch nicht. Und da habe ich gesagt, 'Also, wenn du jetzt nicht betest, werde ich echt sauer, weil das hat nichts mit mir zu tun, dein Gebet, ne das ist, das ist was ganz ganz, du machst da einen Riesenfehler, ne, wenn du jetzt durch die Wut auf mich mit deiner ..., jetzt einen auf Gebetsverweigerung machst. Das war halt so eine bewusste Verweigerung; und weil die mir damit zeigen wollte, , Guck mal!‘, habe ich gesagt: , Nee, so nicht, ne du kannst wütend auf mich sein, aber du musst beten, sonst kann ich echt sauer werden. [...]. Und dann hat sie es getan, weil ich ihr klargemacht habe, dass ich das überhaupt nicht akzeptiere. Es passiert schon, dass die mal schusselig ist und nicht betet. Dann sage ich: 'Ne, das war jetzt nicht gut. A Aber wenn sie dann so bewusst aus einer ganz falschen Intention heraus nicht betet, da zeige ich ihr schon die Grenzen." (Nermin, Z.: 261ff.)

Nermin bezeichnet sich selbst, gerade dann, wenn die Kinder Regeln nicht einhalten, als »mal ein bisschen strenger« und »mal ein bisschen lockerer«. Eine Rigorosität schließt sie für sich aus (»[...] rigoros kann man nicht sein«). Zudem versucht sie, eine gemäßigte Form von Strenge zu praktizieren, indem sie auch vieles übersehe: »[...] mal alles sehen und dann mal nicht so viel sehen« (vgl. Nermin, Z.: 271). Folglich kann hier nicht von einem rigoros-autoritären Erziehungsstil gesprochen werden, wohl aber von einem Erziehungsstil, der sich durch Disziplin auszeichnet.

Eltern wie bspw. Dilek, Nisa und Lale, mit Kindern über 16 Jahren, die das religiös mündige Alter erreicht haben, sehen sich eher vor Herausforderungen gestellt als Eltern mit jüngeren Kindern. In diesen Familien steht neben der Förderung der Selbstständigkeit und der Verantwortungsübernahme die Disziplin stärker im Vordergrund. Bei Regelverstößen verhalten sich die Eltern unterschiedlich streng und disziplingeleitet. Sie distanzieren sich auch sehr viel stärker vom Zwang als Erziehungsmittel, weil sie sich dessen bewusst 
sind, dass damit nur sehr wenig zu erreichen ist. Interessanterweise berichten Eltern, die sich vorzugsweise vom Zwang distanzieren, auch gleichzeitig von einem liebevoll-fürsorglichen (»Liebe/Geduld«) Verhalten gegenüber ihren Kindern. Dementsprechend wird die geforderte Disziplin, die in manchen Fällen auch nicht einhaltbar ist, immer auch durch eine liebevoll-fürsorgliche und geduldige Verhaltensweise begleitet. Die Einhaltung der Gebetsvorschriften ist, wie schon ausgeführt, ein wichtiges Kriterium, um elterliche Erziehungsstile zu charakterisieren. Aber auch andere Regeln werden angesprochen. Hier hat insbesondere Lale über ihre Erfahrungen mit ihren Kindern berichtet. Sie beschreibt ihren Ehemann, den Vater ihrer Kinder, als jemanden, der die »Zügel « in der Familie nicht loslasse und sich damit beim ältesten Kind durchsetzen könne:

"Alle Kinder sind anders, der ältere, der ist noch, der ist ja Teenager, ist ganz anders. Zum Glück, da spielt der Papa eine Rolle. Und der Papa lässt die Zügel nie los, elhamdulillah. Ich habe einen starken Mann, das ist sehr wichtig, dass er immer ..., da bin ich barmherzig. Manchmal sagt [der Sohn, Anm. d. Verf.] einen Grund, dass er nicht gegangen ist heute zu sohbet ${ }^{24}$. Papa sagt: ,Warum gehst du nicht? Ich will, dass ... du lebst unter meinem Dach, deshalb wirst du mir auch folgen،, [...]. Elhamdulillah, er befolgt es, auch wenn er manchmal keine Lust hat, macht er es, weil elhamdulillah dieses familiäre ist ja da." (Lale, Z.: 308)

In diesem Interviewabschnitt werden gleich mehrere Aspekte verdeutlicht. Zum einen lässt der Vater die »Zügel« nicht los und fordert die Teilnahme am sohbet-Besuch durch den älteren Sohn. Deutlich wird auch, dass er sich mit der Begründung, unter demselben »Dach« zu leben, durchsetzen kann, und der Sohn dem Willen des Vaters gehorcht, auch wenn er »manchmal keine Lust« dazu habe. Die Eltern betrachten dies als eine Regel, die eingehalten werden muss. Hier kommt ein Erziehungsstil zum Ausdruck, der besonders durch Disziplin gekennzeichnet ist. Zum anderen beteuert Lale, im Vergleich zum Vater, »barmherzig « zu sein, was auf einen liebevollen Umgang hindeutet. Schließlich verweist sie noch auf das »familiäre«, womit der Zusammenhalt nochmals vor Augen geführt wird. Dem mittleren Sohn (17 Jahre) und dem jüngsten Sohn (sieben Jahre) fällt die Regelbefolgung hingegen weniger schwer. Der jüngste Sohn wird durch Belohnungen (Spielplatz, Besuch der Freunde, Freizeitpark) angeregt, die Moschee zu besuchen. Auch wenn ihm dies manchmal schwerfalle, müsse er wöchentlich hingehen. Die Mutter argumentiert damit, dass er manchmal auf die Schule auch »keine Lust« habe und er trotzdem hingehen müsse (vgl. Lale, Z.: 311-317). Hinsichtlich der Gebets-

24 | Das sind Sitzungen, in denen religiöse Inhalte besprochen werden. Diese Treffen können in Moscheen oder religiösen Bildungseinrichtungen stattfinden. 
vorschrift sind auch ähnliche Verhaltensweisen der Eltern zu beobachten. Lale zeigt auf, dass die Kinder ab einem bestimmten Alter selbst die Verantwortung für ihre Handlungen übernehmen müstsen, so auch für die Gebetsverrichtung. Sie sieht ihre »Aufgabe« darin, ihren Sohn durch Begründungen an die eigene Verantwortung zu erinnern:

"[...] das ist so eine Sache, bis zu einem bestimmten Jahr, bis also bis 14/15 hat der Papa, haben die Eltern so eine Macht. Ab einem bestimmten Alter hat man diese nicht mehr, dann musst du das auch akzeptieren, ja? Z. B. mit Ruhullah ${ }^{25}$ ist es so 'ne Sache. Wenn der Papa sagt: Jetzt ist Betenszeit, dann steht er auf und macht es, elhamdulillah. Aber wenn wir nicht da sind, ich weiß ganz genau, dass er da Probleme hat, und manchmal betet er, manchmal nicht; und er sagt es mir ja auch offen ins Gesicht: Mama, ich habe da Probleme, ich möchte es sehr gerne machen, aber irgendwie schaffe ich nicht fünfmal am Tag zu beten, okay? I Ich sage es inm, aber ab einem bestimmten Alter ist er jetzt selber verantwortlich. Ich muss es, er ist jetzt eine Persönlichkeit, die [selbst entscheidet, Anm. d. Verf.]. Aber ich als Mama, muss es immer wieder sagen, ja? [...]. Das mache ich auch, z.B. gestern, [...], 'Achte auf deine Gebete, ja? Das schützt dich Ruhullah, du weißt es, ja?، Er weiß es, er weiß auch seine negativen Seiten, aber ich sage auch, wir haben, ja, bis wir [...] [an diesen Punkt, Anm. d. Verf.] gekommen sind, hatten wir auch manchmal Tage, wo wir nicht gebetet [haben, Anm. d. Verf.]. Allah soll vergeben, ja, nicht gebetet haben, auch kaza [türk. für Pflichtgebete, die nachgeholt werden, Anm. d. Verf.] gemacht haben, ja? Aber das Kind muss damit auch lernen, ich kann doch keinen Zwang [...] Allah. Es soll ja von Herzen für Allah sein, nicht für mich. Und ab einem bestimmten Alter, ich habe meine görev [türk. für Aufgabe, Anm. d. Verf.], [...].« (Lale, Z.: 325-331).

Auch hier legen die Eltern unterschiedliche Verhaltensweisen an den Tag. In Gegenwart des Vaters werden die Gebete befolgt, aber in Gegenwart der Mutter wird von diesbezüglichen Schwierigkeiten gesprochen. Das Vertrauensverhältnis zwischen Mutter und Sohn erlaubt es dem Sohn, sich mitzuteilen. Lale erinnert ihn an seine eigene Verantwortung und versucht ihn zu verstehen, indem sie ihm Empathie und Verständnis entgegenbringt, denn sie hätten ja auch nicht gebetet, und zugleich um Vergebung für ihren Sohn bittet. Ihr Erziehungsstil ist durch Liebe/Geduld gekennzeichnet. Zu unterstreichen ist auch, dass das Gebet ja »von Herzen für Allah« kommen solle, d.h. freiwillig und ohne »Zwang«. Wie auch bereits an einer anderen Stelle verdeutlicht, so werde zudem durch den Vater kein Zwang ausgeübt, auch wenn sein »Ton« manchmal »hoch« (laut, Anm. d. Verf.) sei und er eine »gewisse Härte« besitze (vgl. Lale, Z.: 333-337).

25 | Ruhullah ist zum Interviewzeitpunkt bereits über 18 Jahre alt. 
Dilek hat ähnliche Erfahrungen wie Lale gemacht. Ihre Tochter hat Schwierigkeiten, das Gebet regelmäßig zu verrichten (vgl. »Religiosität«). Hier setzt sie insbesondere auf die selbstständige Verantwortungsübernahme durch das Kind. An dieser Stelle übt Dilek Selbstkritik, indem sie sich selbst vorwirft, womöglich nicht »streng « genug zu sein (vgl. Dilek, Z.: 165 und 174). Dennoch übe sie in religiösen Fragen keinen Zwang aus, weil sie dadurch negative Konsequenzen, wie die totale Abkehr von der Religion, befürchte. Jedoch fordert sie in Fragen der allgemeinen Erziehung Disziplin und die Befolgung von Regeln, gerade wenn sie liebevoll erklärt und die Kinder auffordert, diese einzuhalten. Da sie sehr viel Wert auf Ordnung legt, kann sich Dilek letztendlich in den meisten Fällen durchsetzen. Die Verantwortung muss dann von den Kindern übernommen werden. Schließlich reagiere sie bei ernsthaften Problemen und Konflikten dennoch »positiv« und »fürsorglich«, d.h. mit Liebe/ Geduld (vgl. Dilek, Z.: 158-174). Wie bereits bei Lale gesehen, finden wir auch hier einen Erziehungsstil vor, der sowohl durch Disziplin als auch durch Liebe/ Geduld gekennzeichnet ist.

Ein wichtiges Thema scheint für Dilek das Tragen des Kopftuches, anhand dessen nochmals die Haltung beider Elternteile verdeutlicht werden kann, zu sein. Gerade als die Tochter anfing, das Gymnasium zu besuchen, wünschte sich Dilek für sie das Tragen des Kopftuches:

"Als sie anfing, dahinzugehen, sagte ich ihr: ,Schau Beyza, du musst deinen Schulkameradinnen zeigen, dass du anders bist. Du bist ein muslimisches Kind, das heißt für dich, dass du dich nicht wie Deutsche, wie deine deutschen Schulkameradinnen locker [türk. rahat, Anm. d. Verf.] verhalten kannst. Ja, sie können vielleicht flirten. Ja, sie sind ja auch hier aufgewachsen, wahrscheinlich kennen sie das ja auch. Wenn sie dich anschauen [...]. Beyza trägt kein Kopftuch. In der fünften Klasse haben wir nicht darauf bestanden. Ich hatte so gedacht: Ich weiß nicht, ob ich richtig oder falsch lag. Bis sie sich behauptet und beweist, sollte sie sich ...; ja, sie war auch noch nicht im religiös mündigen Alter [türk. akıl-baliğ, Anm. d, Verf.], so sollte sie normal in die Schule gehen, nachdem sie sich beweist, wie sagt man das?, mit ihrer Intelligenz, mit ihrer Vernunft. Ich wollte nicht, dass die Lehrer sie benachteiligen. Sie wissen ja, die Kinder haben Freunde, die wegen des Kopftuches in den Grundschulen oder weiterführenden Schulen Schwierigkeiten erleben, so dachte ich. Sie sollte erst so die Schule besuchen, dann könnte sie, wenn sie das religiös mündige Alter erreicht hätte, das Kopftuch tragen, aber sie legte es nicht an (lacht). [Ist es für Sie ein Problem?, Anm. d. Verf.] Nein. Für mich überhaupt nicht. Dem Vater fällt es von Zeit zu Zeit schwer [...]. Ich sehe das so, dass meine Kinder zunächst die täglichen Gebete verrichten sollen. [...]. Ja, erst wenn ein Kind es verinnerlicht, die täglichen Gebete zu verrichten, sollte es das andere machen. Aber ich hätte meinem Kind sagen können, 'Trag das Kopftuch!ı, es hätte es getragen. Aber ich sage meinem Kind: ,Du weißt, dass du beten sollst, nicht? [...]." (Dilek, Z.: 26ff.) 
Hier wird deutlich, dass die Eltern sich zwar wünschen, die Tochter möge das Kopftuch tragen und sich wie ein »muslimisches Kind« verhalten. Dies beinhaltet zugleich, auch die Sexualmoral zu beherzigen, was Flirts mit dem Gegengeschlecht ausschließt. Jedoch scheinen sie zumindest mit dem Tragen des Kopftuches keinen Erfolg gehabt zu haben. Dies könnte mit mehreren Faktoren zusammenhängen: zum einen damit, dass die Befürchtung der Eltern eintritt, die Tochter könne durch die Lehrer benachteiligt werden, und zum anderen damit, dass die Tochter sieht, wie es um ihre Freundinnen mit Kopftuch steht. Auch wenn es dem Vater schwerfalle, dies zu akzeptieren, hätten sie der Tochter letztlich die Freiheit gelassen, selbst zu entscheiden, ob sie es trage oder nicht. Dennoch werde von ihr erwartet, die täglichen Gebete zu verrichten, um Rechtleitung zu erlangen, d.h. dem »rechten Weg« zu folgen (vgl. ebd.). Der Vater »ärgert sich von Zeit zu Zeit«, aber es wird kein »Druck« ausgeübt:

"Wir üben keinen Druck aus. Ich sage nur so: Ich bin, was dies [die Einhaltung der Bekleidungsvorschriften, Anmerkung d. Verf.] angeht, etwas sensibel. Sei es die Kleidung, sei es die Brust, das Dekolleté, wenn die zu offen sind [...] 'Gut, du bist zwar nicht bedeckt, aber ich sage dann Folgendes zu ihr: Zieh dich lang an. Ja, dein Arm [...]. Ich weiß nicht, kann ich mich richtig ausdrücken? Was das angeht, musst du sensibel damit umgehen. Wenn du dich bückst, aufstehst, musst du darauf achten, dass alles bedeckt bleibt. Ja, darin bin ich sensibel. Wenn sie in die Schule geht, kann es vorkommen, dass ich unter die Jacke schaue, was sie angezogen hat. Ja (lacht), manchmal mache ich auch Stress." (Dilek, Z.: 30)

Diese Interviewpassage macht deutlich, dass zwar kein Zwang ausgeübt wird, aber dennoch von der Tochter erwartet wird, sich zumindest an bestimmte Regeln der Bekleidungsvorschriften zu halten. Dass die Mutter »stresst« und der Vater »sich ärgert«, deutet wiederum auf das Missfallen und die von den Eltern geforderte Disziplin hinsichtlich des Kopftuchtragens und der Gebetsvorschriften hin. Dennoch wird kein Druck und Zwang ausgeübt. Die Verantwortung soll die Tochter demnach selbst in die Hand nehmen, um letztendlich vor Allah/Gott zu bestehen und seinem Willen zu gehorchen, nicht dem der Eltern (vgl. Dilek, Z.: 28).

Der Erziehungsstil von Nisa ist sowohl durch Liebe/Geduld (»keine Eile«) als auch durch eine Erwartungshaltung, die von Respekt vor den Älteren zeugt, geprägt. Dabei wünscht sie sich, im Vergleich zur deutschen Gesellschaft, einen größeren Respekt vor Älteren und auch Lehrern in der Schule. Schließlich möchte sie, wie dies auch für alle anderen Eltern gilt, keinen Zwang ausüben (vgl. Nisa, Z.: 46 ff.). 


\subsection{Religiöse Erziehung in den Familien der "Ritualisten “}

\subsubsection{Die Religiosität in den Familien der "Ritualisten“}

Wie schon erwähnt wurde, beinhalten die Vorstellungen über den Glauben und was diese für die Eltern bedeuten auf mehrere Dimensionen der Religiosität bezogene Aspekte. Die Konsequenzen aus ihren Glaubensvorstellungen, die die Eltern dieser Gruppe für ihre Kinder ziehen, spiegeln sich zugleich in ihren erzieherischen Prinzipien wider.

Wichtig ist hier, hervorzuheben, dass die Aussagen, die »ritualistische« Eltern treffen, im Vergleich zu anderen Typen weniger differenziert ausfallen und sich dies folglich in der Beschreibung ausdrückt. Die Länge der Beschreibung orientiert sich im Folgenden demnach an den Aussagen der Eltern. ${ }^{26}$ Diese sind zumeist kurz und im Wesentlichen auf die Praxis bezogen, sodass weniger auf Grundeinstellungen und die Auseinandersetzung damit, sondern eher auf die praktische Umsetzung einfacher, klarer in der Religion vorzufindender Regeln Wert gelegt und auch entsprechend argumentiert wird.

Der Glaube beinhaltet für ritualistische Eltern sowohl Aspekte, die sich um das Wissen über die Existenz Gottes drehen, als auch um den religiösen Erfahrungsbereich. Hier werden spirituelle Perspektiven des Glaubens benannt, welche die Kinder durch die Eltern erfahren und erlernen sollen. Die Konsequenzen, die aus der Glaubensvorstellung gezogen werden, beziehen sich zum einen in charakteristischer Weise auf das Befolgen religiöser Regeln und Vorschriften, z.T. auf die Beantwortung von Sinnfragen im Zusammenhang mit dem Glauben, und zum anderen gerade auf die Spiritualität, die sich in Form von Schutz, Sicherheit und Geborgenheit und letztendlich auch im Gottvertrauen äußern soll. Im Vergleich zur Spiritualität der Eltern, die nach Sinn und Orientierung streben, sollen die religiösen Erfahrungsmomente für Eltern dieses Typs viel stärker einen schützenden Effekt hervorrufen und einen Halt bieten. Das heißt, der ordnungsstiftende Moment, der nicht nur aus der Regelbefolgung hervorgehen soll, äußert sich hier eindrücklich auch im religiösen Erfahrungsbereich. Waren idealistische Eltern aktive Gestalter ihrer Bedingungen, treten ritualistische Eltern hier sozusagen als »Ordnungshüter« auf. Dies zeigt sich nicht nur im äußerlichen Bereich der Religiosität, sondern auch im Innenleben (im religiösen Erfahrungsbereich) der befragten Eltern, die daraus auch Konsequenzen für ihre Erziehungsvorstellungen ziehen.

Der »Glaube« als Begriff wird durch Mecelle zunächst unter Abgrenzung zum christlichen Glaubensverständnis umgedeutet. Es scheint so, als ob schon mit der Verwendung des Begriffs ein anderes religiöses Paradigma angestoßen worden ist (vgl. hierzu Kap. III. 1.5 »Zur Bedeutung der Sprache«). An dieser

26 | Auch die Interviewlänge war den ritualistischen Eltern gemeinsam, sodass diese alle um die 60-70 Minuten betrugen. 
Stelle zeigt sich auch der Wunsch nach einer klaren Beschreibung dessen, was der Islam vorschreibt:

"Erst mal muss ich den Begriff umdeuten. Es heißt der iman. Und was im christlichen Verständnis ist, ist nicht gleich, was der iman bei den Muslimen ist. Aber wenn ich einem Kind das erkläre, ist es ja der Glaube. Wenn wir den Glauben übersetzen, ist es, kommt etwas anderes raus, als wenn bei uns mit iman der Glaube beschrieben wird. Deswegen versuche ich, den Glauben von uns [...] zu vermitteln. Ja." (Mecelle, Z.: 60ff.)

Mit dem »Glauben von uns « verknüpft Mecelle in einer klassisch-islamischen Weise die Glaubensgrundlagen des Islams, über die Konsens unter den Muslimen herrscht. Der von ihm kognitiv gewählte Zugang äußert sich auch darin, dass der Glaube oder vielmehr der (arabische Begriff) iman dazu dienen soll, den Sinn hinter den Glaubensaussagen bzw. -grundlagen zu verstehen. Um dies zu erreichen, ist ihm die Aneignung von religiöser Bildung von Bedeutung (vgl. auch Kap. II. 3.1.3c) und d). Nicht zuletzt sei das Erlernen der Glaubensgrundlagen ein wesentlicher Bestandteil einer klassisch-islamischen religiösen Bildung überhaupt:

"Ja, das sind die Glaubensinhalte: dass man Gott, also Allah erkennt (überlegt), seine Eigenschaften und was der Islam bedeutet. Warum sind Propheten da; und warum sind Bücher da und was das überhaupt sein soll." (Mecelle, Z.: 64)

Religiöse Begründungen sind für Mecelle besonders wichtig, um den Sinn des Daseins mit dem Glauben/iman zu durchleuchten. Die Konsequenzen, die sich durch diesen Glauben für die erzieherische Praxis ergeben, sieht Mecelle zum einen in der Beantwortung von Sinnfragen und zum anderen darin, sich ethischen Grundsätzen zu verpflichten:

"Der Glaube, denke ich, manchmal fragt man sich, ja Kinder fragen ja nach dem Warum: 'Papa, warum sind wir auf der Welt?` Irgendwann kommen ja Fragen und durch diese Glaubensgeschichte, (überlegt) Glauben, haben wir schon Antworten parat. [...] Den Sinn, genau den Sinn, für die Kinder und das erzieht die Kinder ja auch. Ich mein, wenn ich anderen Menschen nicht wehtue und was Gutes machen will, das erzieht die ja und diszipliniert sie auch, auf eine besondere Art, denke ich." (Mecelle, Z.: 68-71)

In diesem Interviewabschnitt wird auch deutlich, dass der Glaube aus Mecelles Perspektive die Kinder auf eine besondere »Art« erzieht und diszipliniert und zudem handlungsleitende Prinzipien zur Folge hat. Der Glaube soll bewirken, anderen Menschen nicht weh zu tun und Gutes zu verrichten.

War für Mecelle der kognitive Zugang (durch einen Sinnbezug) zum Glauben primär, ist für die anderen Eltern (Rabia, Selma, Ali) die emotionale Kom- 
ponente des Glaubens vordergründig. So wird im Glauben eine "große Macht«, »ein Vertrauen « und das Gefühl, »sich anlehnen « zu können, sowie »eine große Liebe und Ehrfurcht« vor dem Schöpfer gesehen. Gerade die »Liebe und Ehrfurcht« seien nicht voneinander trennbar (vgl. Ali, Z.: 30).

In ähnlicher Weise verbinden Rabia und Selma mit dem Glauben spirituelle Aspekte, die bei den Kindern für innere Ordnung sorgen würden und zudem Schutz und Sicherheit bieten sollten. Den »Glauben an den Schöpfer«, »den Allmächtigen«, zu beschreiben, fällt Rabia sichtlich schwer, weil sie damit einerseits einen emotionalen Bereich berührt und andererseits die von ihr angedeuteten Inhalte womöglich auf Türkisch erlernt hat. So wechselt sie zunächst ins Türkische über, um ihren Glauben zu beschreiben (vgl. Kap. III. 1.5 »Zur Bedeutung der Sprache«). Allah/Gott ist für sie derjenige, der

"I...] uns erschaffen hat. Der uns Leben gegeben hat, der uns all die Schönheiten gegeben hat, ja, der uns mit diesen Eigenschaften erschaffen, vollkommen erschaffen hat." (Rabia, Z.: 107)

Erst mithilfe unterstützender Übersetzungen seitens der Interviewerin und Verfasserin der vorliegenden Untersuchung (vgl. ebd., Z.: 108-120), kann Rabia das zum Ausdruck bringen, was der Glaube für sie letztlich alles bedeutet:

"[...], dass man dann, ja. Ich glaube, das ist umso mehr man sich damit [...] beschäftigt, desto mehr merkt man, wie schön das ist. Und was einem auch an Wissen fehlt, also man kann das nicht beschreiben, aber man weiß, dass es einem Frieden gibt, dass es einem eine Erleichterung gibt im Leben, zu wissen, dass man einen hat, der einen beschützt für immer und ewig, so, das ist wichtig zu wissen. Also ich wollte nicht ohne einen Glauben leben, also, ... [also ohne dieses Gefühl von Ruhe, innerer Ruhe, das Gott einem gibt, Anm. d. Verf.], und einen Halt. Das ist ein Halt für mich, zu wissen, dass ich den Glauben habe und dass ich nach dem Tod [die Auferstehung erleben werde, Anm. d. Verf.]. [...]." (Rabia, Z: 121-125)

Auch wenn der Glaube für Rabia letztendlich nicht zu beschreiben ist, weiß sie, dass er einen »Frieden«, »eine Erleichterung im Leben« gibt. Mit Gott/Allah habe sie eine Instanz, die einen »immer und ewig«»beschütz ««. Ohne den Glauben würde zudem auch ein wichtiger »Halt« im Leben fehlen. Kurzum: Der Glaube biete Schutz und Sicherheit sowohl im diesseitigen Leben als auch im Jenseits am Tag der Auferstehung bzw. des jüngsten Gerichtes. Der Glaube beinhaltet für Rabia ordnungsstiftende und sicherheitsbringende Elemente, die kennzeichnend für ritualistische Eltern sind.

Auch Selma fällt es zunächst nicht leicht, über ihren Glauben zu sprechen. Erst durch den Begriff iman, der ihr durch die Interviewerin genannt wird, kann sie entsprechende Assoziationen herstellen: 
"Iman bedeutet für mich, huzur [türk. für innere Ruhe, Anm. d. Verf.] Reinheit [...] bedeutet es für mich und einfach Sicherheit! Überall! Ist das für mich ...; auch also in ... [in Ihnen selbst?, Anm. d. Verf.]. Genau! Also in mir selber auch! Vor mir selber auch [...], vor meinen eigenen Bedürfnissen. [Also auch das, was eigentlich so negativ an einem selbst ist?, Anm. d. Verf.]. Genau! [...] [Dass das eigentlich Sicherheit bietet?, Anm. d. Verf.]. Ja. [...]. Das ist auch einfach so Schutz, glaube ich, für mich. Also, so wie eine Mauer, ist dieser iman das, was mich vor schlechten Sachen einfach oder vor Sachen, die mich einfach schützen tut." (Selma, Z.: 69-97)

Der Glaube bedeutet für Selma somit konkret »innere Ruhe«, »Reinheit« und »Sicherheit«. Diese Sicherheit soll für sie überall präsent sein, sie auch vor sich selbst und ihren »eigenen Bedürfnisse « schützen. Hier spricht Selma von einem Glauben, der sie vor ihren eigenen egoistisch motivierten Bedürfnissen oder einfach »vor schlechten Sachen«, wie bspw. einer Schutzmauer, schützen, gar »Reinheit« bieten sollte. Der Wunsch nach Sicherheit birgt auch hier einen Ordnungssinn und damit die Befolgung von Regeln, die diese Ordnung sichern und schützen. Auf bezeichnende Art und Weise soll sich dies auch im Innenleben der Eltern (vgl. auch Rabia und Ali) ausdrücken.

Die Konsequenzen, die aus diesen Glaubensvorstellungen für die religiöse Erziehung gezogen werden, äußern sich für ritualistische Eltern stärker in den Handlungen und regelgeleiteten Prinzipien (»Einhaltung von religiösen Vorschriften«). Es überwiegen gerade die praktischen Aspekte einer religiösen Erziehung. Insbesondere die Mütter dieses Typs wünschen sich, die eigenen religiösen Erfahrungen an ihre Kinder weitergeben zu können.

Waren (für Mecelle) neben der Beantwortung von Sinnfragen nach dem eigenen Dasein, das Verrichten von guten Taten und das Befolgen von ethischen Grundsätzen von Bedeutung, so betrachtet Ali die Befolgung religiöser Regeln als Zeichen von Ehrfurcht und der Liebe zu Gott/Allah; wer sich an die Regeln halte, werde somit dafür belohnt, und wer es versäume, erhalte eine Strafe. Dieser Ansatz solle den Kindern »in einer ausgewogenen Weise « vermittelt werden (vgl. Ali, Z.: 32). Die Einhaltung von Ritualen, wie bspw. dem Beten, dem Koranlesen, dem Aussprechen der besmele (arab. basmala), d.h. das Ansinnen, dass alles im Namen Gottes/Allahs begonnen wird, ist auch für Rabia neben dem kontinuierlichen Gedenken bzw. Erinnern an Gott/Allah eine wesentliche Konsequenz, die sie aus ihrem Glauben zieht. Ihre Kinder könnten wahrnehmen (»spüren«), wie wichtig ihr der Glaube sei, sodass sie sich wünsche, dass diese »auf diesem Wege gehen« möchten:

"Die spüren das, dass mir das wichtig ist, dass ich möchte, dass die auf diesem Wege gehen, dass die halt beten, dass die den Koran können und lesen, das Wissen, dass man an Gott denken muss, jede Stunde, jeden Schritt, den man macht, dass man halt besmele [ausspricht, Anm. d. Verf.]. Im Namen Gottes, alle Wege mit seinem Namen. 
[...] Hoffe ich! Möchte ich! Also das ist mein Wunsch. Also ich möchte, dass das so wird, dass die auch das innere Kribbeln, was ich habe, auch [...] also diese Gott ..., Liebe, die ich in mir spüre." (Rabia, Z.: 128-136)

Gerade das religiöse Erleben, das Rabia in Form eines »inneren Kribbelns« in Anbetracht der Liebe zu Gott wahrnimmt, möchte sie auch in ihren Kindern erwecken. Der Glaube solle in ihnen genauso »erlebt« werden, denn es sei die Nähe Gottes, bei der Rabia »Frieden« und »Glück empfinde. Dabei spielt es für sie keine Rolle, ob die Kinder dies jetzt oder erst ab einem bestimmten Alter erfahren und diesen »Weg« kontinuierlich, »jede ... jede Stunde, jeden Schritt, den man macht« gehen. Schließlich seien Rituale wichtige Begleiter auf diesem Weg.

Nicht zuletzt möchte Selma die »Schutzmauer«, die sie in ihrem Glauben für sich sieht, auch ihren Kindern weitergeben. Sie sollten Geborgenheit in ihrem Glauben finden:

"[...] Also, dass dieser iman einfach auch einen Menschen schützen tut ... dass das einem Geborgenheit gibt [...]." (Selma, Z.: 101)

Die Suche nach einer (inneren) Ordnung im Glauben drückt sich bei Selma auch darin aus, dass sie sich neben der schützenden Funktion des Glaubens auch die Entwicklung von mehr Selbstsicherheit und »Selbstbewusstsein« für ihre Kinder erhofft (vgl. Selma, Z.: 113-119).

Konkrete religiöse Erfahrungen, die die Eltern gemeinsam mit ihren Kindern gemacht haben, treten zumeist in Verbindung mit der rituellen Dimension der Religiosität auf. Hierbei werden das Fasten oder, wenn auch weniger, die gemeinsam verrichteten Gebete und Bittgebete benannt. Vor allem soziale Aspekte, wie der Moscheebesuch und das Verrichten der umra (arab. kleine Pilgerfahrt nach Mekka) oder die Spendenabgabe, die der Gemeinschaftsförderung dienen, werden vonseiten ritualistischer Eltern besonders betont. Eine Mutter spricht gar die gegenseitige Ermahnung der Kinder zum Guten, bei der sie als Mutter präsent sei, als eine besonders positive Erfahrung an.

Überraschenderweise werden vonseiten ritualistischer Eltern die täglichen Gebete nicht bevorzugt als gemeinsamer Erfahrungshintergrund benannt. Im Vergleich zu idealistischen Eltern liegt bei ihnen die Betonung besonders in den sozialen, gemeinschaftsfördernden Aspekten der Religiosität. Die Auswertung der Antworten ergab, dass hier im Gegensatz zu den idealistischen Eltern ein weniger homogenes Bild nachgezeichnet werden kann. Dennoch gibt es Gemeinsamkeiten, die ritualistische Eltern besonders charakterisieren.

Für Eltern dieses Typs sind, wie oben bereits erwähnt, diverse Rituale, die den Gemeinschaftsaspekt hervorheben, von Bedeutung. Darunter stellt der Moscheebesuch die am häufigsten benannte gemeinsame religiöse Erfahrung 
dar. Gerade die Atmosphäre in der Gemeinschaft ist für Mecelle wichtig, sodass er viel mit den Kindern in die Moschee gegangen ist:

"[...] Ich bin früher, wo die Kinder noch kleiner waren, bin ich viel in die Moschee gegangen, so damit sie diese Atmosphäre dort erleben. Und das war für die schon schön immer. Ja, jetzt sind sie bisschen größer geworden (zögert), die haben dann andere Schwerpunkte." (Mecelle, Z.: 92)

Um das Freitagsgebet oder das Festtagsgebet zu verrichten, besuchte Ali in Istanbul die großen Moscheen, deren Pracht den Sohn beeindruckte und ihn dazu verleitete, diese besondere Erfahrung mit seinen deutschen Freunden zu teilen. Schön war insbesondere, dass Alis Vater, sein Sohn und er selbst diese Erfahrung in einem Dreigenerationenverhältnis machen konnten (vgl. Ali, Z.: 35).

Auch für Rabia und ihre Kinder ist die Atmosphäre in der Gemeinschaft und das gemeinsame Gebet mit dem ganzen cemaat (türk. für religiöse Gemeinschaft) eine »besondere Erfahrung, wo die das mitkriegen«: »Gemeinschaft, ja, so (lächelt), das ist ja, das ist schön für die.« (vgl. Rabia, Z.: 204-208).

Dann ist interessanterweise die Spendengabe als die vierte große Säule des Islams ein von allen Eltern besonders wichtig eingestuftes Ritual, das sie mit ihren Kindern gemeinsam erfahren konnten. Neben der karitativ-sozialen Funktion der Spendenabgabe wird dadurch zudem der gemeinschaftsfördernde Aspekt der Religion untermauert. Mecelle beschreibt das gemeinsame Spenden mit den Kindern, das zur Solidarität mit anderen, vom Krieg betroffenen muslimischen Gruppen beigetragen habe, folgendermaßen:

"Ja, wir haben mal eine Spende gemacht, jetzt wo Krieg in Palästina war und da sehr viele Kinder auch umgekommen sind. Hat uns schon sehr berührt und (überlegt) dann haben wir den Kindern das auch vermittelt und die waren auch recht traurig und da haben wir eine Spende gemacht [...]. Ja, das war schon schön für uns [...]. Ja, Solidarität.» (Mecelle, Z.: 86-92)

Almosen (arab. sadaqa) an arme und bedürftige Menschen zu verteilen, ist auch Ali ein besonderes Anliegen. Gerade am Opferfest sollte der Sohn dies sinnhaft als einen wichtigen Charakterzug verinnerlichen. Ali ist es wichtig, in jedem Fall anonym zu spenden, da der Stolz des anderen/des Bedürftigen nicht verletzt werden dürfe. Beispielhaft sind für ihn die sozialen Einrichtungen der osmanischen Kultur, in denen dies so praktiziert wurde (vgl. Ali, Z.: 39). Rabia und Selma verweisen auf ähnliche Erfahrungen bei der Hilfe für notleidende Menschen. Dabei werde »allen« Menschen, gleich wer in Not ist, Unterstützung angeboten. Dies geschehe sowohl finanziell als auch »vom Wesen her«, d.h. als eine verinnerlichte Charaktereigenschaft. Menschen zu hel- 
fen, beeindruckt die Kinder von Rabia so sehr, dass sie schließlich versuchen, die Mutter darin nachzuahmen:

"Ja, genau. Ich habe halt Beispiele, wie wir als Spender auf jeden Fall helfen, wenn ich merke, dass einer in Armut ist und dass einer Hilfe braucht, wenn einer krank ist und, wie es zum Beispiel in der Türkei ist; das ist so, dann haben die keine Versicherung oder so und dann bekommen wir das mit und dann denken die, oh, da hat jemand so eine große Spende gemacht, wie auch, wenn man anderen auf der Straße hilft, wenn Ältere stürzen oder jetzt am Stolpern sind, dass man dann läuft oder so. Das hat die schon beeindruckt. Also dass ich und meine Kinder gucken und sehen, wie schön das ist, dass man einem hilft [...]. Das gefällt denen und die versuchen, das nachzumachen. Also genau. Also das ist auf jeden Fall, das fängt so schon an, finde ich, dass man weiß, dass man anderen hilft in der Not, sei es finanziell oder auch halt vom Wesen her." (Rabia, Z.: $161 \mathrm{ff}$.

Selma lädt arme und bedürftige Menschen zum Essen ein, um den Kindern die gemeinschaftliche Atmosphäre nahezubringen und spüren zu lassen. Sie motiviert ihre Kinder des Weiteren dazu, angespartes Geld an arme und bedürftige Menschen zu spenden:

"[...] Und dass man dann vielleicht auch, zum Beispiel vielleicht arme Leute dann auch einladen tut, ne? Also zum Essen einladen tut, dass sie das dann einfach auch mitbekommen sollen; [also, dass Arme unterstützt werden und so, Anm. d. Verf.]. Genau! Genau. Das wird einem ja eigentlich immer erzählt, also, dass man spontan mehr die Armen unterstützen soll und dass man dann auch viel Geld spenden soll, also das Geld, das wir angespart haben [...]." (Selma, Z.: 172ff.).

Soweit es den gemeinschaftlichen Aspekt betrifft, sind auch die Erlebnisse bei der umra-Reise ${ }^{27}$ (kleiner Hadsch, Pilgerfahrt nach Mekka) einzubeziehen. Ali und Mecelle konnten diese Erfahrung mit ihren Kindern teilen:

"Also ich war mal auf umra, die kleine Pilgerfahrt, das war für mich ein schönes Erlebnis; und als ich zurückgekommen bin, war das für die Kinder auch schön, also das war auch schon für die positiv und für mich positiv; die haben mich vermisst, ich habe sie auch vermisst, auf der anderen Seite habe ich vieles erzählt, was ich gesehen habe und den Glauben, den iman, habe ich den Kindern noch besser vermitteln können [...]. Ja, man sieht jetzt zum Beispiel die Kaabe [arab. Kaaba, bildet das Haus Gottes im Innenhof

27 | Die kleine Pilgerfahrt nach Mekka gilt als Vorbereitung auf die große Reise (Hadsch). Sie kann im Ggs. zur Pilgerfahrt Hadsch zu jeder Jahreszeit durchgeführt werden. Auch wenn die Umra gleiche Rituale wie Hadsch beinhaltet, kann diese die Pilgerfahrt Hadsch nicht ersetzen. 
der Heiligen Moschee in Mekka; Anm. d.Verf.] man sieht die anderen Menschen, sind ja viele Muslime anderer Herkunft, kommen ja aus der ganzen Welt dorthin, nur um eines zu erleben: Gott, Allah näherzukommen [...] ja, das kann man dann den Kindern geben und sich selbst [...]." (Mecelle, Z.: 78-82)

Muslime aus allen Ländern kommen zusammen, um an den heiligen Pilgerstätten »Gott, Allah näherzukommen« und ihrer zu gedenken. Die Stärkung des Gemeinschaftsgefühls ist eines der wesentlichsten Ziele des Hadsch (hac) oder der Umra (umra). Gerade dies konnte Ali mit seinem Sohn gemeinsam vor Ort erleben. Beeindruckend war für den Sohn vor allem, dass Menschen aus allen möglichen Ländern in ähnlicher Kleidung zusammengekommen waren. Da der Sohn viele Fragen stellte, musste darüber hinaus ein Sinnbezug hergestellt werden. Dabei fiel es Ali nicht leicht, über die auftretenden neuen Gefühle zu sprechen. Jetzt, nachdem der Sohn drei Jahre lang eine religiöse Erziehung erhalten habe, könne er vieles besser verstehen und nachvollziehen, z.B. warum Menschen die Pilgerreise unternehmen und warum Menschen vor emotionaler Berührung weinen usw. (vgl. Ali, Z.: 34).

Das Ermahnen zum Guten ist auch eine wichtige religiöse Erfahrung, die Selma mit ihren Kindern erlebt hat. Bezeichnenderweise spiegeln die Kinder von Selma das von ihr intendierte Erziehungsziel, nämlich die Einhaltung religiöser Vorschriften, untereinander wider. Sie ermahnen sich somit gegenseitig, um das Sündhafte zu unterlassen bzw. sich ein Verhalten anzueignen, das zu einem Muslim »passt«. Selma freut diese vernünftige Haltung ihrer Kinder. Nicht zuletzt gibt es ihr das Gefühl, das zu ernten, was sie ihnen zu Hause weitergegeben hat. Das, was sie ihnen zu vermitteln versucht hat, wurde somit durch die Kinder aufgenommen und untereinander weitergegeben:

"[...] Ja, zum Beispiel letztes Mal, da war (leise) was ganz Schlimmes eigentlich vorgefallen, also die Kinder, wie soll ich das sagen? Çocuklar birbirlerini uyarıyorlar ... [türk. für "Die Kinder ermahnen sich gegenseitig", Anm. d. Verf.] Zum Beispiel also, ne? Wenn die zum Beispiel jetzt sagen, jetzt vom Essen her: ,Warum hast Du das gegessen, also was soll ich essen, was darfst du denn nicht essen? Das ist ja in unserem Glauben günah [türk. für Sünde, Anm. d. Verf.], das darfst du ja nicht machen.r Oder, vom Verhalten her, 'Das gehört sich nicht für einen Moslem, das passt nicht zu einem Moslem!‘ [Also, dass sie sich gegenseitig ermahnen im Guten?, Anm. d. Verf.]. Genau! [...]. Das ist für mich eine positive Erfahrung, also, wenn wir dann sagen, das dürfen wir nicht machen. Das freut mich dann und dann sehe ich auch, dass das, was ich zu Hause dann erzähle oder wiedergebe, dass das bei den Kindern einfach ankommt. Ich erzähle das ja nur den Kindern, dass sie das aufnehmen sollen, und ich weiß nicht, inwiefern sie es ja aufnehmen. Und wenn sie es nachher wiedergeben, dann freue ich mich darüber einfach. Weil ich ja, okay, es kommt da an, wo es auch ankommen soll, eigentlich [...]. Das ist dann schön. Also dann freut man sich darüber." (Selma, Z.: 126-134) 
Schließlich werden durch die Eltern diverse andere Rituale genannt, die (ebenfalls) zum religiösen Erfahrungsbereich gehören. Es ist zum einen das Vorlesen von Prophetengeschichten, was den Kindern Freude mache und von den Kindern als besonderes Erlebnis wahrgenommen werde (vgl. Mecelle, Z.: 151), zum anderen sind es gemeinsam verrichtete Gebete, bei denen die Kinder anwesend seien (vgl. Selma, Z.: 124; vgl. oben Ali), und Bittgebete, die die Kinder anregen und motivieren sollten (vgl. Rabia, Z.: 165-175). Gerade im Alltag ist es für Selma wichtig, vor dem Schlafengehen ein Bittgebet auszusprechen, vor dem Essen mit der besmele/basmala (d.h. im Namen Gottes/Allahs) zu beginnen, mit Dankbarkeit (elhamdullillah) aufzuhören »und einfach für den Tag zu danken, also Gott, das ist sehr wichtig für mich, dass sie dann sagen >Allaha şükür, bugün çok güzel günümüz geçti< [türk. für »Gott sei Dank, der heutige Tag verlief gut«, Anm. d. Verf.], also, dass sie das einfach wiederholen, das ist sehr wichtig [...].«(vgl. Selma, Z.: 142)

Was das gemeinsame Verrichten der täglichen Gebete anbelangt, antworten die Eltern etwas zögerlicher. Hierzu sind sie vom Alltag (Zeitdruck, Arbeitsverhältnisse) viel zu sehr gefordert, sodass die täglichen Gebete nicht gemeinsam ausgeführt werden könnten (vgl. Mecelle, Z.: 102; Ali, Z.: 37). Selbst wenn die Familie zeitweilig die Gebete gemeinsam mit dem Ehemann verrichtet, wünscht sich Rabia, dieses Ritual bzw. religiöse Gebot noch stärker in den Alltag zu integrieren und irgendwann regelmäßig befolgen zu können:

"Also ich hoffe, dass meine Kinder das aus, bin dabei und möchte natürlich sehr gern, dass meine Kinder das auch machen, vor allem mein Sohn. Der ist zwölf. Der ist Hauptschüler; dass der das auch macht." (Rabia, Z.: 180)

Rabia und Selma möchten darin als Beispiele (Vorbildfunktion) vorangehen. Es ist ihnen wichtig, dass die Kinder die Gebete »mit Freude« verrichten und »kein Zwang« ausgeübt wird. Dabei solle den Kindern die freie Wahl gelassen werden, daran teilzunehmen (vgl. Rabia, Z.: 182-196; Selma, Z.: 148-152; vgl. auch »Erziehungsstile«).

Der Ramadan wird als Fastenmonat von allen Eltern als bereichernd empfunden. Hier tritt nochmals das charakteristische Merkmal ritualistischer Eltern hervor. Auch das Fasten zielt neben der persönlichen inneren Läuterung auf die sozialen, gemeinschaftsfördernden Aspekte der Religion ab. Für Ritualisten tritt diese Eigenschaft im Ramadan besonders hervor, denn gerade die »Gemeinschaft mit den anderen « und die »schöne Atmosphäre« während des iftar (arab. für das Fastenbrechen) seien es, die die Kinder dazu animieren würden, trotz langer Fastenzeiten im Sommer auch zu fasten:

"[...] und für die Kinder ist es momentan wegen der Sommerzeit sehr schwer, zu fasten. Die müssen ja noch nicht fasten. Im Moment. Erst mit der Geschlechtsreife ist es für die 
Pflicht. Und aber die möchten auch manchmal am Wochenende mal fasten, wenn sie keine Schule haben. Ja, das ist schön die Atmosphäre natürlich, wenn man diese iftarEssen, also abends, wenn die Sonne untergeht, zum ersten Mal isst und eine Gemeinschaft hat mit den anderen, das ist schon was Schönes für die Kinder auch." (Mecelle, Z.: 105)

Auch die gemeinsamen Gebete im Anschluss an das Fasten (tarawih-Gebet) werden, neben dem Fasten selbst von den Kindern als besonders und »schön« erlebt (vgl. Rabia, Z.: 204-208). Im Großen und Ganzen wird der Ramadan auch durch Selma mit Familie, Verwandten, Freunden und Nachbarn verbracht, damit die Kinder »mitbekommen«, was der Ramadan bedeutet:

"[...] im Allgemeinen sind wir immer mit der Familie eigentlich immer zusammen gewesen oder mit Nachbarn, die eng, also befreundeten, dass wir uns immer abends getroffen haben und dass sie dann auch die Kinder mitbekommen haben jetzt iftar gegessen und [...]. Ja. Also wir haben das eigentlich immer so gemacht. Wir waren immer so eine Gruppe gewesen mit Frauen, dass wir [...]; weil unsere Männer ja immer gearbeitet haben, dass wir uns dann zusammengetan haben und dass wir dann alle vier oder fünf Frauen zusammen also das Abendbrot gegessen haben. Ne, also als Gruppe. Wir haben uns immer gegenseitig eingeladen, ne, dass das auch die Kinder mitbekommen, also wie das auch so im Ramadan eigentlich auch ist. Ne?"(Selma, Z.: 166ff.)

Das gemeinsame Koranlesen, als ein weiteres wesentliches Ritual des Islams, wird von ritualistischen Eltern weniger wahrgenommen. Lediglich eine Mutter (Rabia) versucht, gemeinsam mit ihren Kindern den Koran zu lesen (vgl. Rabia, Z.: 188). Die Gründe, warum dieses Ritual nicht befolgt wird, sind verschiedener Art: Es wird das Nichtbeherrschen der arabischen Lesart (vgl. Mecelle, Z.: 115) oder die fehlende Zeit beklagt (vgl. Ali, Z.: 41). So gefällt es Selmas Kindern vielmehrals das Koranlesen selbst, Geschichten aus dem Koran zu lesen, da diese »kindgerechter geschrieben« seien (vgl. Selma, Z.: 178).

Religiöse Feste werden hauptsächlich mit den Familien gefeiert. Man besucht aber auch Freunde, Bekannte und Nachbarn. Um eine Festtagsstimmung zu erzeugen, »sollte man das schon groß « feiern, so Mecelle. Hier wird auch auf die fehlende Bereitschaft hingedeutet, zu wenige Feierlichkeiten für die Kinder stattfinden zu lassen (vgl. Mecelle, Z.: 107-113). Einen Sinnbezug herzustellen, um den Kindern die Bedeutung des Festtags näherzubringen, wird durch Ali hervorgehoben. Beklagt wird durch ihn auch die fehlende Festtagsstimmung, wie sie in der Türkei an Fest- und Feiertagen existiere (vgl. Ali, Z.: 37ff.). Der Festakt solle von seiten der Kinder wahrgenommen werden, um den Festtag als solchen anzuerkennen: 
"Ja, das ist für die Kinder dann sehr wichtig. Das ist dann, da sehen die halt: Upp, ja da sind wir alle zusammen und das ist halt unsere Feier jetzt und das muss einfach sein. Mit Kleinigkeiten und so mit Geschenken und noch dazu." (Rabia, Z.: 217)

Hier wird deutlich erkennbar, dass zudem ein Gemeinschaftssinn und ein Identitätsgefühl entwickelt werden soll. Dies betont auch Selma. Ihre Kinder sollen in jedem Fall auch ihre muslimischen Freunde besuchen, um den Festtag gebührend feiern zu können (vgl. Selma, Z.: 158-162).

Schließlich würden Geschenke, die »nicht nur Kleines« sind oder »Kleinigkeiten«, zu jedem Fest dazugehören (vgl. Mecelle, Z.: 113; Rabia, Z.: 217-223).

Was das religiöse Wissen angeht, wird größtenteils analog zu den Erziehungsvorstellungen geantwortet. Wie schon dargelegt wurde (vgl. Kap. III. 3.2), spielt die Aneignung religiöser Bildung für ritualistische Eltern eine große Rolle. Auch spicht deren Argumentation stark für eine Erziehungsvorstellung, die auf eine klassisch-islamische Bildung verweist, sodass im Zusammenhang mit dem religiösen Wissen dieses kennzeichnende Element vorzufinden ist. So wünschen sich die Eltern für ihre Kinder, den Koran und die Sunna des Propheten (s) als die wesentlichen Hauptbezugspunkte zu verinnerlichen. Dabei ist ihnen zuallererst wichtig, Allah und seine Eigenschaften zu erkennen:

"[...] und für die Kinder, die sollen ja Allah erkennen an seinen Eigenschaften, weil wir sehen ja inn nicht [...]. Und das ist ja was Schweres. Und Koran selbst ist ja auch ein schwieriges Buch, das können sie ja nicht direkt so übernehmen, wie es dort steht; also brauchen sie ein Vorbild und dieses Vorbild ist der Prophet und wenn sie das noch nicht verstanden haben, dann gibt's hier schon ein Problem (überlegt) durch; Prophet ist sehr wichtig dann kommt ja in den Vordergrund und eben, man muss dann schauen, was der Prophet will und sagt und was er uns als Vorbild gegeben hat. Der Koran ist die Quelle da und die Umsetzung macht ja der Prophet, weil ja vieles wir nicht aus dem Koran anscheinend nehmen können und nicht verstehen, deswegen ist der wichtig. Doch das ist unser Vorbild. Das vermitteln wir auch den Kindern. Die Propheten ..., [dass sie das Wissen, dass das so der Leitfaden für sie ist?, Anm. d. Verf.]. Der Leitfaden, diese Liebe, das ist wichtig." (Mecelle, Z.: 131-145)

In diesem Interviewabschnitt wird auch gezeigt, dass die Umsetzung des Korans als »Quelle« und »Leitfaden« eines Vorbildes bedarf, das durch den Propheten Muhammad (s) erfüllt werde. Eben dies und die »Liebe« dazu werden den Kindern vermittelt. Die Aneignung des tafsir (arab. für die Auslegung des Korans) und der hadithe (arab. für Überlieferungen des Propheten) sowie das Lernen und Lesen des Arabischen sind Bestandteile (vgl. Ali, Z.: 43), die den Fokus auf den Koran und die Sunna des Propheten richten. Die Eltern wünschen sich zudem, dass sich die Kinder mit den wesentlichen Grundlagen und den »[...] wichtigen Regeln des Islams« befassen sollten (vgl. Rabia, Z.: 237). 
Andererseits wird durch eine Mutter (Selma) noch eine intensivere und bewusstere Auseinandersetzung mit dem Koran, wie sie in der Argumentationsform für idealistische Eltern typisch ist ${ }^{28}$, für die Kinder angestrebt. Der Koran solle wie ein »Handbuch « als ein orientierungs- und richtungsleitender Bezugspunkt gehandhabt werden, was auch heißt, sich mit der Bedeutung und dem Sinn dessen auseinanderzusetzen und sich von einem einfachen Nachahmen abzugrenzen:

"... das Wissen, dass sie einfach den Glauben bewusst leben also, dass sie den Koran, nicht so wie wir, nur das Arabische gelernt haben, sondern auch die Übersetzung auch das typische Lesen, was steht im Koran drin. Also was will eigentlich der Koran von uns? Dass sie einfach bewusst leben und dass sie den Koran einfach wie ein Handbuch benutzen sollten und nicht wie wir, einfach an die Wand aufhängen und dann einmal die Woche, zweimal in der Woche lesen, wie sie es gelernt haben, sondern wirklich wie ein Handbuch diesen Koran benutzen " (Selma, Z.: 182)

Die religiösen Fragen der Kinder lassen größtenteils darauf schließen, dass sie in ritualistischen Familien aufwachsen, denn vonseiten aller Eltern wird bestätigt, dass die Kinder Fragen zu gottesdienstlichen Handlungen bzw. Ritualen stellen. Diese betreffen Fragen zum Fasten, »warum und wieso « (vgl. Mecelle, Z.: 105), die umra (viele W-Fragen: "Warum sind wir hierhergekommen? Wo sind wir hier? «) oder die täglichen Gebete (vgl. Ali, Z.: 34 und 47; vgl. Selma, Z.: 192). Aber auch Fragen zu religiösen Geboten, wie dem Kopftuchtragen, dem halal-Essen, oder der Vorgabe, nicht zu lügen, die typisch für Ritualisten sind, werden durch die Kinder gestellt (vgl. Selma und ebd.).

Ohne von einer eindeutigen Tendenz zu sprechen, sind es ansonsten insbesondere die Fragen nach Gott/Allah, den Propheten und anderen Glaubensinhalten, die die kindliche Neugier wecken. Gerade die Unsichtbarkeit Gottes/ Allahs und anderer Wesenheiten beschäftigt die Kinder einiger Eltern:

"Zum Beispiel hat mich jetzt vorgestern mein Sohn gefragt: Ja, wir glauben ja an einen Gott, aber wir sehen inn nicht. Warum sehen wir inn nicht? Oder, wenn unsere Freunde fragen: ,Wo ist Gott?, was sollen wir dann sagen? [...] und dann sage ich zum Beispiel: ,Warum kann man Gott nicht sehen? Kannst du die Luft sehen, die wir einatmen? Dann

28 Hier grenzt sich Selma von einem einfachen Nachahmen ab und intendiert für ihre Kinder eine bewusste Beschäftigung im Hinblick auf den Koran. Sie unterscheidet sich lediglich in ihrer Ausdrucksweise (einfache Worte, brauchte die Unterstützung der Interviewerin für die Deutung, vgl. Z.: 183-188) von idealistischen Eltern.

Auf den Umstand, dass es Überschneidungen und Überlappungen gibt, was die wesentlichen Merkmale der Eltern angeht, wurde bereits im Methodenteil verwiesen (vgl. Kap. III. 2.3). 
kannst du so eine logische Antwort geben. Ja،, sagt er, 'das ist ja, das ist eine ganz tolle Antwort; dann sage ich darauf: 'Ne? Dass es den Gott ja gar nicht gibt, weil wir die Luft ja auch nicht sehen können. Ne?، Und ich war dabei nachher ganz stolz gewesen." (Selma, Z.: 192)

An dieser Interviewpassage wird deutlich, dass die Kinder sich auch untereinander mit der Existenz Gottes auseinandersetzen. Es kommen aber auch dahingehend Zweifel auf, was die Eltern vor Herausforderungen stellt, angemessene Antworten zu geben:

"Ja, da kommt manchmal schon so Zweifel bei den Kindern, was die mich dann fragen [...] Zum Beispiel fällt mir jetzt also (schweigt), ja, dass wir halt Gott nicht sehen. Es ist manchmal auch schwer zu beschreiben. Also für mich auch. [...]. Nicht sehen kann, wer das als Person ist und wie der aussieht, ob das ein; [also wie er aussieht, wie er beschaffen ist, wo er ist, Anm. d. Verf.]. Genau." (Rabia, Z.: 241-249)

Die Kinder machen sich auch Gedanken über die Beschaffenheit der Engel und »warum man sie nicht sieht« oder aber über das Aussehen des Propheten. Zudem ist die Frage nach der eigenen Existenz, d.h. warum Gott/Allah die Menschen erschaffen hat und welcher »Sinn« dahintersteckt, zentral. Es sind Fragen, die die Eltern anregen, sich mit ihrem Glauben intensiver auseinanderzusetzen, um Antworten parat zu haben (vgl. Mecelle, Z.: 69ff. und 157-161). Hierzu zählen auch Sinnfragen, die erklären sollen, warum es Gott gibt und warum er die Menschen prüft. Gerade wenn dies die Kinder an ihrem Glauben zweifeln lässt, fühlen sich Eltern aufgefordert, damit richtig umzugehen:

"Das ist bei den Kindern manchmal schwer, das so hinzubringen, weil, die sagen ... die haben Zweifel. Das muss man dann halt entweder mit der Zeit werden die diese Erfahrungen machen, diese, wenn ich jetzt bete [...], Ja, ich habe jetzt gebetet, Mama, ich habe aber trotzdem noch nicht meine gute Note bekommen. So. Aber das ist, das ist halt man sagt ja imtihan. Man sagt ja [das ist Prüfung, Anm. d. Verf.]. Das ist unsere Prüfung. Das ist, wir werden geprüft mit unseren guten Taten und schlechten Taten und der Glaube ist ja nicht für gute [Resultate, also nur Erfolg?, Anm. d. Verf.]. Genau. Also nicht nur für Erfolg und das ist halt. Man muss halt, halt mit auch mit den schlechten Dingen klarkommen im Leben." (Rabia, Z.: 165-175)

Viele Kinder werden durch Schul- oder Kindergartenfreunde und durch Freunde/Bekannte aus ihrer Umgebung beeinflusst und stellen Fragen, die sie versuchen, zu beantworten. Diese treten zumeist im Alltag auf (vgl. Fragen oben) und betreffen zum einen die eigene Religion, inwieweit alles richtig ist (vgl. Selma, Rabia und auch Ali, Z.: 47), oder die Religion des anderen. Gerade diese 
brächten die Eltern und auch die Kinder dazu, sich mit ihrer eigenen muslimischen Identität (vgl. auch Selma, Z.: 203-209) wahrzunehmen:

"[...] Oder, wenn unsere Freunde fragen: 'Wo ist Gott?, was sollen wir dann sagen? Ne, also das sind solche Fragen, oder: ,Warum gibt es das Christentum? Warum gibt es den Islam? Und seit wann gibt es das denn, [...]? Das sind also eigentlich immer diese Alltagsfragen, was die Kinder an mich haben, also was die im Alltag ja so erleben mit anderen ja, Schulfreunden, den Kindergartenfreunden; mehr diese Fragen kommen also auf. Es gibt bei uns immer so Fragen. [...] Alltagsfragen. [...] ist also zum Beispiel am meisten immer mit dem Essen: ,Warum dürfen wir das nicht essen? Oder: 'Warum dürfen wir zum Beispiel nicht lügen?، Ne, das ist dann so. Oder: Warum müssen wir uns dann einfach [...]?, das sind also mehr so Alltagsfragen oder Fragen bei den Kindern, also mehr ..." (Selma, Z.: 192-200)

Die wahrgenommenen Widersprüche unter Muslimen, bedingt durch das Leben inmitten von Nichtmuslimen, werden auch von Rabias Kindern zur Sprache gebracht:

"Von der Schule, von Freunden halt Freunden, Bekanntschaften sind viele Kinder, die sind von anderen Kulturen und der Glaube ist dann auch nicht der gleiche. Es gibt auch viele Moslems, die ihre Kinder halt, die sind zwar Moslem, aber die werden halt auch einfach nicht so erzogen. Und da sind die, dann sagen natürlich die Kinder: 'Mama, das, der ist auch ein Moslem. Warum macht der das nicht? « (vgl. Rabia, Z.: 276)

\subsubsection{Die Erziehungsmethoden und Erziehungsstile in den Familien der "Ritualisten "}

In ritualistischen Familien werden weniger differenziertere Angaben über ihr methodisches Vorgehen bzgl. der religiösen Erziehung gemacht. Dabei wird gerade die Regelbefolgung wider Erwarten auffällig wenig benannt. Die Kommunikation über die Religion ist jedoch wie für alle anderen Eltern jeden Typs ein wesentlicher Bestandteil des methodischen Repertoires. Auch hier zeichnet sich im Vergleich zu anderen Typen ein weniger differenziertes Bild ab.

In ritualistischen Familien wird, wie in allen anderen Familien auch, als wichtigstes methodisches Vorgehen die Vorbildfunktion der Eltern unterstrichen. Wenn der Islam durch beide Elternteile vorgelebt wird, »können die Kinder das auch lernen«, d.h., das »Umsetzen« der Religion könne hierbei durch vorgelebte »Handlungen « der Eltern unterstützt werden (vgl. Mecelle, Z.: 4off. und 165ff.; vgl. auch Rabia, Z.: 182-186). Gerade bei den Gebeten hält Selma das Vorleben für besonders wichtig, damit die Kinder die Eltern »freiwillig « nachahmen könnten (vgl. Selma, Z.: 124/148 und 215 vgl. dazu auch »Erziehungsstile«). 
Die Kommunikation über die Religion ist für alle Eltern von Bedeutung. Gerade das »Reden« über die Religion durch den Einsatz von Kommunikationsmitteln, wie z.B. von Büchern, dem Internet, Videos usw., wird in allen Familien eine große Bedeutung beigemessen (Rabia, Z.: 254ff.; Selma, Z.: 338; Ali, Z.: 49f.). Rabia betont indes zudem die ilahi (türk. für einen religiös geprägten Gesang) als ein wichtiges Medium, um den Kindern den »Glauben« in »Liedform« nahezubringen:

"[...] Und dann ilahi? Lieder, [...] bei denen über den Glauben als Liedform halt gesprochen wird oder gesungen wird. Ja. So was hören wir uns an und ich finde, dass beeindruckt die sehr, das ist, ich merk das, das beeindruckt meine Kinder sehr, wenn die diese Lieder hören, das wird dann klar, das sind Kinder, die müssen das einfach so als Form von Liedern auch hören, denke ich mal, die können sich das so auch besser einprägen. Wenn man redet geht vieles auch verloren." (Rabia, Z.: 258-266)

Daneben sind Begründungen und Überzeugungen, die den Kindern religiöse Gegebenheiten in einer angemessenen Weise darlegen, die am häufigsten angewandte Kommunikationsform. Mecelle betont insbesondere, dass das Vorleben, welches zu einem einfachen Nachahmen führe, nicht genüge, wenn nicht durch »Bildung« das »Warum« und »Wieso« einer Handlungsweise nachvollziehbar seien:

"Wenn sie jemandem etwas beibringen wollen, brauchen sie ihr Wissen; das ist durch Bildung zu erreichen. Das ist besser, als wenn jemand innen das vorgelebt hat oder der sagt einfach: 'So ist das richtig! ‘ Aber warum und wieso, das kann er nicht erzählen zum Beispiel. Das ist halt nicht gut. Derjenige soll wissen, warum wir beten und warum fünf Tage und nicht drei Tage. [...]. Erklärungen sind immer wichtig! Wenn jemand was fragt, dass die das begründen können. Das ist mir sehr wichtig. [...]. Warum tue ich das dann überhaupt? Das ist wichtig. Das setzt schon Bildung voraus." (Mecelle, Z.: 54-58, vgl. auch Z:: 64ff.)

Auch Selma setzt gerade im Zusammenhang mit der Regelbefolgung Begründungen ein, um die Kinder dahingehend zu überzeugen. Dabei solle dies den Kindern »Sicherheit« bieten und sie, ebenso wie bei Mecelles Kindern, vor einem einfachen sinnlosen Dahinleben schützen:

"Ich erkläre es erst mal den Kindern, warum das eigentlich so ist, warum wir uns an diese Regeln überhaupt halten müssen. Das ist, dass es auch eine Sicherheit für die Kinder ist, wenn man sich an bestimmte Regeln hält/halten muss, und dass das sehr gut ist und dass man nicht einfach nur vor sich hinleben soll und ... [das erklärt?, Anm. d. Verf.], ich erkläre ganz gut [...]." (Selma, Z.: 213ff.) 
Des Weiteren ist das Erklären an lebensnahen Beispielen eine weitere wichtige Kommunikationsform, die zum Einsatz kommt. Es sind, so Selma, »praktische « »logische Beispiele«, notwendig, warum die Kinder das »so « »ausleben« sollten und nicht ein einer anderen Art und Weise (vgl. Selma, Z.: 234; vgl. auch Rabia, Z.: 270).

Als beispielhaft können ebenfalls die Aussagen von Mecelle zur Weihnachtsfeier angesehen werden. Demnach dürften die Kinder aus einem religiösen Selbstverständnis heraus nicht daran teilnehmen. Mecelle erkläre seinen Kindern dies mit »Liebe«:

"[...]. Wir können das, nur das geben, was wir als richtig empfinden, was unser Glaube vermittelt. Und das leben wir denen vor und wenn mal; ne Schule geht ja auch mal in die Kirche, wenn die anderen Kinder gehen, und da haben wir ja kein Problem. Sie sollen auch in die Kirche gehen und sehen dort, wie die anderen Religion praktizieren und die sollen das unterscheiden. Aber, wenn die zum Beispiel Weihnachten feiern möchten, wir feiern kein Weihnachten und machen das auch nicht den anderen zuliebe. Wir feiern einfach nicht und das, das sagen wir den Kindern: 'Das ist nicht unser Feiertag.' Schön und nett, aber die verstehen das, wenn man das denen so mit Liebe das erklärt, gibt es auch kein Problem, meistens, und, wie gesagt, [...]. Viel erklären und beim Gebet haben wir gesagt, sie sollten schon demnächst mit dem Gebet anfangen, weil das wird im Glauben schon verlangt und ja, die müssen halt das lernen langsam noch ..." (Mecelle, Z.: 167171; vgl. auch "Erziehungsstile»).

Die Regelbefolgung beinhaltet (auch), mit dem Gebet anzufangen (vgl. oben Mecelle). Sie ist die nächste Methode, die ritualistische Eltern, bis auf Selma, überraschenderweise nicht stark hervorheben. Jedoch ist es den Eltern wichtig, dass die Kinder irgendwann die Gebete regelmäßig verrichten (vgl. Mecelle oben; vgl. Rabia Z.: 178ff.; Selma s. unten). Außerdem ist der Besuch einer religiösen Bildungseinrichtung für Ali der Grund für eine konsequente Regelbefolgung (vgl. Ali, Z.: 83).

Hingegen erklärte Selma die Regelbefolgung schon zu einem Erziehungsziel (vgl. Kap. III. 3.2), sodass diese, neben ihrer Vorbildfunktion im Alltag, die größte Rolle spielt. Es konnte im Zusammenhang mit Religiosität bereits aufgezeigt werden, dass die Kinder sich bei der Einhaltung von religiösen Vorschriften gegenseitig ermuntern und motivieren. Dies betraf insbesondere das Unterlassen von Sünden und die Erinnerung an das Gute (vgl. Selma, Z.: 126134). Auch die »freiwillige« Befolgung der Gebete solle regelmäßig geschehen: »Sie sollen schon frei entscheiden« (Selma, Z.: 150). Sie schildert dazu auch ihre Erfahrungen, die sie mit ihrem damals neunjährigen Sohn gemacht hat. Dabei weist ihr Ehemann sie auf den strengen Umgang mit dem Sohn hin: 
"[...] Ich habe zum Beispiel bei meinem großen Sohn, der ist ja jetzt elf, habe ich eben mit neun Jahren zu inm gesagt, komm, wir beten jetzt jeden Tag einmal zusammen und er hat sich daran gehalten, ja, ich sag, ich habe inn nicht dazu gezwungen. Ich habe gesagt: ,Wir können ja langsam anfangen und erst mal mit dem Mittagsgebet und wenn du möchtest. Und das hat eigentlich ganz gut geklappt und irgendwann hat er dann nachher keine Lust gehabt und dann habe ich inn, ich habe ihn mal daran erinnert und dann nacher, 'Ach, lass inn doch, du zwingst inn nur dazu', obwohl das gar nicht so war. Aber für ihn [für den Sohn, Anm. d. Verf.] war das schon ... [schon zu viel?, Anm. d. Verf.], also für sein Alter eigentlich gewesen [...] was ich im Grunde eigentlich ganz in Ordnung fand in dem Alter mit neun. Also [...]." (Selma, Z.: 271-277).

Wie oben herauszulesen ist, spielt folglich die altersgemäße Förderung für Selma und ebenso für Ali eine bedeutsame Rolle:

"Wenn das Kind noch in jungem Alter ist, können sie es nicht streng behandeln, ansonsten wird man sich beim Kind die Sympathien für die Religion verscherzen. Daher muss man bedachtsam an [das Kind, Anm. d. Verf.] herangehen, d.h. sich folglich langsam annähern. Manchmal muss man sich streng oder warmherzig geben und manchmal muss man sich auch kühl verhalten." (Ali, Z.: 55)

Ali bezieht sich mit »kühl verhalten« auf die Konsequenzen, mit welchen als Folgen von religiös begründeten Regelverstößen zu rechnen ist. Dies legt ausschließlich die Haltung nahe und weniger eine Konsequenz, die auf Strafen der allgemeinen der Erziehung (wie z.B. Internetverbot o.Ä.) verweist.

Auch Belohnungen erfolgen, gerade im Zusammenhang mit den Feiertagen der Muslime (vgl. Ali Z.: 175) oder bei erfolgreich durchgeführtem Koranlesen (vgl. Rabia, Z.: 281), in Form von Geschenken. Ansonsten ist beispielsweise für Selma die persönliche Anerkennung oder das Aussprechen von Lob von größerer Bedeutung, als z.B. Sachgeschenke zu überreichen (vgl. Selma, Z.: 242ff.).

Strafen werden als Sanktionsmittel nur in der allgemeinen Erziehung eingesetzt (u.a. Fernseh-, Internet-, Spieleverbot). Bei religiösen Themen, in denen Überschreitungen stattfinden, wird vielmehr Wert auf die Kommunikation mit dem Kind gelegt, um die Kinder von bestimmten Verhaltensweisen zu überzeugen. Ali setzt hier Grenzen, indem er sowohl eine »kühle Haltung « (vgl. auch oben) an den Tag legt, als auch dem Sohn klarmacht, dass er sich nicht von seinen Werten abbringen lassen wird:

"Er muss wissen. In manchen Themen muss er wirklich wissen, gleich in welchem Alter und in welcher Situation er sich befindet, dass weder wir noch unsere Community [von unseren Werten, Anm. d. Verf.] ablassen werden." (Ali, Z.: 57) 
Bei Regelverstößen bevorzugt es Rabia, mit den Kindern zu kommunizieren. Sie versucht, ihre Kinder mit Erklärungen von ihrem Standpunkt zu überzeugen. Dabei stellt sie auch fest, dass die Kinder, je älter sie werden, unterschiedlichen Fremdeinflüssen wie Schule, Freunden oder dem Umfeld ausgesetzt sind, was es den Eltern erschwere, die Kinder von ihrer Auffassung zu überzeugen bzw. sie zu beeinflussen:

"[...] Ja, ich versuche denen immer wieder zu erklären, zu erzählen, dass es halt Sünde ist, dass man hört, was Eltern sagen, weil die immer das Gute möchten für ihre Kinder [...]. Ja, wo die, wenn die klein sind, da hören die mehr, umso älter die werden, weil die ja auch viel von außen haben [...], viele Einflüsse von außen, [zum Beispiel?, Anm. d. Verf.] von der Schule, von Freunden, Bekanntschaften; sind viele Kinder, die sind aus anderen Kulturen und der Glaube ist dann auch nicht der gleiche. Es gibt auch viele Moslems, die ihre Kinder halt, die sind zwar Moslem, aber die werden halt auch einfach nicht so erzogen [...]." (Rabia Z.: 269-276)

\section{Erziehungsstile}

Die Erziehungsstile von ritualistischen Eltern sind insbesondere durch Liebe/ Geduld gekennzeichnet. Allen Eltern dieses Typs erscheint ein liebevoll-geduldiger Umgang mit ihren Kindern von herausragender Bedeutung. Zudem lassen sich Disziplin, kein Zwang, Respekt vor Älteren als charakteristische Merkmale des Eltern-Kind-Verhältnisses beschreiben. Die Verantwortungsübernahme durch das Kind als auch die Förderung der Selbstständigkeit werden lediglich am Rande erwähnt.

Wie auch schon oben bei der Beschreibung der Methoden anklang, wird insbesondere im Zusammenhang mit den täglichen Gebeten ${ }^{29}$ u.a. deutlich, wodurch das Eltern-Kind-Verhältnis charakterisiert ist und welchen Erziehungsstil Eltern bei ihren Kindern bevorzugen. Daher konnten hier Überschneidungen und Wiederholungen mit den methodischen Aspekten nicht ohne Weiteres vermieden werden.

Mecelle betont im Zusammenhang mit religiösen Begründungen und Erklärungen sowie der Wissensaneignung, wie wichtig »die Liebe« als Leitfaden für ihn sei (vgl. Mecelle, Z.: 145). Wenn man den Kindern alles mit »Liebe« erkläre, entstünden auch »keine Probleme« (vgl. ebd., Z.: 167). Des Weiteren sei es wichtig, gerade wenn es um die Gebete gehe, geduldig vorzugehen:

29 | Dies war auch schon bei idealistischen Eltern der Fall. 
"Viel erklären und beim Gebet haben wir gesagt, sie sollten schon demnächst mit dem Gebet anfangen, weil das wird im Glauben schon verlangt und ja, die müssen halt das lernen... langsam noch." (Mecelle, Z.: 171)

Die »Liebe« zu und die »Ehrfurcht« vor Gott/Allah ist wichtig, um Regeln einzuhalten, so Ali. In einer »ausgewogenen Weise« sei es daher notwendig, den Kindern diese beiden Tugenden weiterzuvermitteln. Dabei sei es ihm wichtig, geduldig und weichherzig vorzugehen, wenn die Kinder noch klein seien, damit diesen das Interesse an der Religion erhalten bleibe (vgl. Ali oben, Z.: 32 und 55). Auch Selma ist eine geduldige und ruhige Vorgehensweise bei Erklärungen wichtig, um die Kinder nicht abzuschrecken, sodass sie sich von der Religion abwenden könnten:

"Genau! Aber im Grunde: Ich tue nicht sehr viel, weil wenn ich also merke, die sind davon abgeneigt, dann lasse ich sie in Ruhe! Weil ich habe dann nacher Angst, dass sie dann sich ganz abwenden nachher von der Religion. Da lasse ich die ein bisschen in Ruhe und wenn so ein bisschen Zeit darüber vergangen ist, dann rede ich erst drüber. Aber [...]. [Ja? Also so eine gewisse Pause ...?, Anm. d. Verf.]. Genau! Die Pause braucht man, ich, am Anfang (stottert) bin ich immer drauf losgegangen, habe dann auf sie eingeredet: 'Musst das dann so und so und so machen und das gehört sich einfach nicht. Und das kam bei den Kindern nicht an. Die Kinder brauchen einfach so ein bisschen Abstand und man muss einfach so praktische logische Beispiele geben, warum die Kinder das einfach so ausleben [sollten, Anm. d. Verf.]." (Selma, Z.: 230-234)

Innerhalb dieser Interviewpassage veranschaulicht Selma zudem, dass durch einfache Befehle und Verurteilungen, »Musst das dann so und so und so machen und das gehört sich einfach nicht«, die Kinder nicht zu erreichen seien. Vielmehr solle man sich Zeit lassen und mit Abstand an die Sache herangehen, folglich auch keinen Zwang ausüben. Diese Haltung sei ihr auch bei den gemeinsamen Gebeten von zentraler Bedeutung:

"Ich zwinge sie nicht dazu! Ich bete immer vor den Kindern, sodass sie mich immer sehen können, also meine Tochter, die kommt dann immer ab und zu mal zu mir. Also ich leg ja einen Gebetsteppich daneben hin und sie machen dann mit, aber ich zwinge sie nicht dazu. [...] Sie soll schon frei entscheiden." (Selma, Z.: 148ff.)

Dass die Kinder »mit Freude« und ohne »Zwang« Rituale ausführen, ist auch für Rabia wichtig. Da sie dies genauso in ihrem Elternhaus erlebt hat, empfindet sie es entsprechend so, dass sie das weiter gebracht habe:

"Also gemeinsam lesen wir halt den Koran, das versuchen wir halt, durchzuführen, und ich hoffe auch, dass wir auch zusammen mal beten können, weil ich möchte den Kindern 
das auch nicht so aufdrängen, also die sollen Freude [...] Freude genau! Kein Zwang! Weil ich hatte selber keinen Zwang und muss sagen, bin jetzt viel, viel weiter, als ich es war." (Rabia, Z.: 188ff.)

Dennoch zeichnet sich das Eltern-Kind-Verhältnis auch durch Disziplin aus. Insbesondere Ali und Selma zeigen auf, dass eine konsequente Regelbefolgung Bestandteil ihres Erziehungsverständnisses ist (vgl. Ali oben »Methoden«). Als Erziehungsziel soll »Disziplin« Selmas Kindern dabei helfen, Regeln zu befolgen, um »Struktur« und »Sicherheit« im »Alltag « und im »Leben « zu haben (vgl. Selma, Z.: 43-48). Da sie sich manchmal bei der Regelbefolgung etwas zu strikt verhält, warnt ihr Mann sie, mit ihrer Intensität nicht zu weit zu gehen. Hier tritt der Ehemann, in seiner unterstützenden Funktion, als der gelassenere, geduldigere Elternteil hervor, wohingegen Selmas Erziehungsverhalten in einer gewissen Weise auch auf sehr viel Strenge hindeutet:

"[...] aber wenn der manchmal anmerkt [...], dass ich dann zu intensiv geworden bin mit meinen Regeln, dann sagt er ja, 'Stopp, du bist zu weit gegangen`. Dann warnt er mich. [Also er ist derjenige, der so ein bisschen mehr zulässt?, Anm. d. Verf.]. Genau." [Und Sie sind diejenige, die dann schon Grenzen setzt und klare Regeln einfordert?, Anm. d. Verf.]. Genau!» (Selma, Z.: 267-271)

Diese Strenge zeigt sie zunächst bei der Einhaltung der täglichen Gebete, was beim damals neunjährigen Sohn zur Unlust führte. Daraufhin habe sie ihr Ehemann aufgefordert, den Sohn in Ruhe zu lassen: »[...] >Ach, lass ihn doch, du zwingst ihn nur dazu<, obwohl das gar nicht so war [...].« (vgl. Selma oben »Methoden«, Z.: 271).

An diesem Beispiel zeigt sich auch, wie unterschiedlich die Eltern ihre eigene Erziehung bewerten. Selma fasst ihr Verhalten weniger als ein Mittel auf, das durch Zwang gekennzeichnet gewesen sei, sondern durch Disziplin: »Weiß ich, was ich im Grunde eigentlich ganz in Ordnung fand in dem Alter mit neun. Also ...« (Selma, Z.: 277). Der Vater sehe es da schon »lockerer« (vgl. ebd.: 278f.). Gleichwohl muss schließlich hier zum einen auch erwähnt werden, dass Selma in der Präsenz des Ehemannes den unterstützenden Ausgleich für ihre strenge, auf Disziplin angelegte Erziehung sieht (vgl. Selma, Z.: 266-279). Zum anderen ist es so, dass sie sich, wohl auch geläutert durch ihre Erfahrungen, die »freiwillige« Teilnahme der Kinder am Gebet durch einfaches Vorleben wünscht (vgl. oben und »Methode«).

Der Wunsch nach mehr »Respekt vor Älteren« ist in türkischen Familien ein geläufiger Wert (vgl. Hunner/Kreisel 2010 und Boos-Nünning 2011a). Der Respekt vor älteren Menschen soll primär dem Familienzusammenhalt und der Bindung innerhalb der eigenen Community dienen und erfüllt somit eine ordnungsstiftende Funktion. 
Gerade für Ali (und Rabia) ist der Respekt vor Älteren schon entsprechend als Erziehungsziel (vgl. Kap. III. 3.2) von Bedeutung. Als ein verinnerlichter Charakterzug, der aus der von ihm intendierten religiösen Erziehung hervorgeht (vgl. Ali, Z.: 16), ist Respekt für ihn ein Wert, von dem weder er noch die »Community« abweichen werde (vgl. Ali, Z.: 57). Hier ist sodann eine Disziplin herauszuhören, wodurch sein Erziehungsverhalten gekennzeichnet ist (vgl. Ali bei »Methoden«).

Als Schutz vor Fremdeinflüssen, wie z.B. den Medien und schlechten Freunden (vgl. auch Rabia bei »Methoden«), ist auch Rabia der Respekt vor Älteren zugleich als Erziehungsziel wichtig. Da der Einfluss der Eltern durch andere Wirkfaktoren minimiert werde (»Jetzt ist das, was die Eltern sagen, weniger wichtig.«), wünscht sie sich, dass mehr Achtung und Respekt vor den Eltern gezeigt werde und dass das, was sie sagen, mehr Bedeutung haben solle. Schließlich sei darin nicht zuletzt auch ein Gebot der Religion zu sehen (vgl. Rabia, Z.: 8off.).

Die selbstständige Verantwortungsübernahme der Kinder wird eher am Rande, d.h. ausschließlich durch einen Vater, erwähnt. So wünscht sich Mecelle, dass die Kinder, wenn sie älter sind, eigene Entscheidungen treffen können. Die Eltern könnten die Kinder z.B. bei der Befolgung von Regeln lediglich mit ihrer Vorbildfunktion und durch Erklärungen (vgl. Mecelle oben »Methode«) unterstützen:

"Ne, ich, genau das wollen wir vermitteln, sie haben [...], die werden ja demnächst groß, sie möchten ja selber Entscheidungen treffen. Wir können das, nur das geben, was wir als richtig empfinden, was unser Glaube vermittelt. Und das leben wir denen vor [...]." (Mecelle, Z.: 167)

Auch spielt für Mecelle, als einzigem Vater von allen, die Förderung der Selbstständigkeit, »[...], dass sie auf eigenen Füßen stehen« (vgl. Mecelle, Z.: 12off.), eine wichtige Rolle. Dies könnte damit zusammenhängen, dass er, im Vergleich zu den anderen Eltern dieses Typs, über einen akademischen Abschluss verfügt und damit stärker von eigenverantwortlichem Verhalten ausgeht.

\subsection{Religiöse Erziehung in den Familien der "Identitätssucher"}

\subsubsection{Die Religiosität in den Familien der "Identitätssucher"}

Die Religiosität der Eltern, die den Identitätsaspekt der religiösen Erziehung in den Vordergrund stellen, ist dadurch gekennzeichnet, dass die verschiedenen Facetten der Religiosität unter dem Blickwinkel der Identitätsentwicklung betrachtet werden. Gemeinsam ist beiden Elternteilen dieses Typs die Herstellung von erziehungswissenschaftlichen Bezügen. Zudem geht es diesen, wie 
bereits erwähnt wurde, um ein hohes Maß an Dialogbereitschaft im Zusammenhang mit der Suche nach der eigenen Identität.

Bei der Darstellung bzw. Betrachtung der Ergebnisse ist zu berücksichtigen, dass die Interviewpartnerinnen Mütter von Kleinkindern sind, sodass z.T. einige Aspekte unerwähnt bleiben bzw. Antizipationen aufgezeigt werden. Auch sind beide Mütter sowohl professionell (Hülya) als auch ehrenamtlich (Lema) in ihren religiösen Gemeinden tätig. Die Erfahrungen der Pädagoginnen als professionell Handelnde fließen mit in die Auswertung ein.

Den Glauben definiert Lema für sich in einer praktischen Art und Weise. Er habe in jedem Fall praktische Konsequenzen, indem er ausgelebt werden könne. Gerade die Freiheit zu haben, diesen in staatlichen Bildungseinrichtungen, wie z.B. Schulen und Kindergärten, auszuleben und die Anerkennung bzw. der Respekt vor der eigenen Religion, ist für Lema besonders wichtig:

"Ja, Glaube. Für mich ist Glaube, die Lebensart, die Lebensweise. Es darf jetzt nicht so theoriemäßig sein, sondern man muss inn ausleben können. Auch das Ausleben, die Freiheit dazu zu haben, das ist ja für mich und für meine Tochter in erster Linie wichtig. Dann käme der Punkt in den Schulen, in den Kindergärten, kann sich denn mein Kind im Kindergarten entfalten? Also, jetzt vielfältig, und dass man auch mit den eigenen Werten respektiert wird. In der Schule und so ..." (Lema, Z.: 34)

Als eine »Lebensweise, Lebensart, Lebensphilosophie« solle der Glaube dazu führen, dass der Mensch zur »Vollkommenheit« gelange. Der Mensch komme als »unbeschriebenes Blatt« auf die Welt, das erst durch die religiöse Erziehung zu einem »Menschen « gemacht werde, d.h. sich zu einer Persönlichkeit entwickele. In diesem Zusammenhang fließt auch für Lema die »Disziplin« mit in die aus dem Glauben resultierende religiöse Erziehung ein. Dieser sei somit wichtig, damit die Kinder und Jugendlichen zu Hause lernen würden, »Respekt gegenüber anderen Kindern, auch Disziplin« zu zeigen (vgl. Lema, Z.: 4off., vgl. auch Kap. III. 3.3).

Diese philosophische Grundstimmung scheint auch bei Hülya zum Ausdruck zu kommen. Der Glaube, der für sie im Vordergrund steht, ist zum einen von der Vorstellung bestimmt, im Diesseits, d.h. auf der »Welt« zu leben, und zum anderen dann irgendwann ins »Jenseits« überzugehen:

"[...] ja und für mich ist es natürlich, an die Schöpfung zu glauben, dass wir also von irgendetwas bestimmt sind, dass wir automatisch mit unserer Seele, mit unserem Körper, mit unserem Verstand hier auf dieser Welt leben und irgendwann dann auf jedem Fall gehen werden. Und ich glaube, das ist der Gedanke und ich glaube das kann man gar nicht leugnen, dass man irgendwann gehen wird, wie nennt man das, ... immigrieren (lacht) wird in die andere Welt, ins Jenseits, genau." (Hülya, Z.: 30) 
Das Leben mit den drei Grundkomponenten des Daseins (Seele, Körper, Verstand) ist Teil dieser Vorherbestimmung im Diesseits, aber auch die Jenseitsorientierung zeichnet den Glauben von Hülya aus. Die Konsequenzen, die sich daraus für ihre religiöse Erziehung ergeben, betreffen sowohl die Handlungsebene als auch den emotionalen Bereich. »Die Bindung zu Gott« ist für Hülya der Glaube, der durch Erfahrungen, gestützt durch das Umfeld, in dem man sich bewegt, und durch das Gesagte, erlernt und ausübt ${ }^{30}$ werde:

»Also Kinder erlernen den Glauben durch Erfahrungen, so habe ich das auch gemacht, also automatisch durch mein Umfeld, durch die Dinge, die mir gesagt wurden, dadurch habe ich erfahren, was Glaube ist; also automatisch habe ich dann an Dinge geglaubt und die dann auch so ausgeübt. Ich glaube, Glaube ist, dass man so eine Bindung hat zu Gott. Das ist Glaube für mich und deshalb versuche ich, das meinen Kindern so zu vermitteln, indem ich sage: $>$ Gott ist in jedem Menschen drin, im Herzen [...]<. (Hülya, Z.: 32)

Indem sie auf die Fragen ihrer Kinder bezüglich ihres Glaubens eingeht und sie für diese mithilfe von Erklärungen für die Geschehnisse auf der Welt eine Verbindung zu Gott herstellt, versucht sie, ihren Kindern den Glauben nahezulegen:

"Also, so versuche ich, das dann meinen Kindern zu erklären, wie diese Bindung ist, zu Gott, also was Gott überhaupt ist, weil es gibt keine Vorstellung, aber man versucht halt, die Dinge zu erklären, die auf dieser Welt passieren, und dann damit die Verbindung zu Gott herzustellen. Das ist dann sehr wichtig und mein Glaube an Gott sagt mir, also bewegt mich eben dahin, dass ich dann was tue mit meinen Kindern, dass ich denen das weiter erkläre [...]." (Ebd.)

Eine weitere Konsequenz, die sie aus ihrem Glauben ableitet, ist die Motivation, ihre Kinder zu »guten Menschen« bzw. zum »Positiven« zu erziehen. An dieser Stelle geht sie auch auf Mütter ein, die aus einer intrinsischen Motivation heraus ihre Kinder umsorgen. Ähnlich wie diese Mütter, die die Grundbedürfnisse ihrer Kinder ihrer Natur entsprechend befriedigen, sieht Hülya ihre »Pflicht« darin, die Kinder zum »Glauben« und »zum Positiven« zu erziehen:

"Ich glaube, das ist die Motivation, dessen, dass ich also meine Kinder erst mal als gute Menschen erziehe und denen das Ganze dann auch vermittele, das ist meine Motivation. Ich weiß, es gibt bestimmte Dinge ne, die eine Mutter ..., ich bin eine Mutter, ich habe die Pflicht, meine Kinder zu erziehen, und das ist auch meine Motivation sozusagen. Es gibt auch eine ja, natürlich, ja, die nicht gesteuerte Motivation von einer Mutter, die kümmert sich automatisch um alles. Das sieht man auch bei Tieren z.B., dass sie sich um die eigenen Kinder kümmern, sie füttern, also die Grundbedürfnisse beheben,

30 | Hier nimmt sie auch auf die Sozialisation des Menschen Bezug. 
und das ist halt meine Motivation. Durch meinen Glauben bin ich motiviert, meine Kinder zu erziehen, zum Positiven." (Ebd.)

Religiöse Erfahrungen der Eltern beziehen sich, ähnlich wie bei den anderen Eltern auch, auf Rituale, die Beschäftigung mit religiöser Literatur oder den Gemeinschaftsbezug. Der letztere Aspekt bildet den gemeinsamen Nenner der beiden Eltern dieses Typs. Beide verfügen über Erfahrungen in Gemeinden, die sie zudem als engagierte Pädagoginnen gemacht haben.

Konkrete religiöse Erfahrungen konnte Lema schon mit ihrem Baby machen. Es fällt ihr auf, dass die ausgeglichene, ruhige Grundstimmung, die sich aus der Beschäftigung mit religiösen Büchern oder durch die Gebete ergebe, sich auf ihr Baby übertrage. Gerade dies und die Erfahrungen im Zuge ihres eigenen Aufwachsens zeigen ihr, dass dies dem Menschen zum einen angeboren und zum anderen in ihm die wesentliche Anlage zur Vollkommenheit gelegt worden ist. Die religiöse Erziehung helfe nunmehr dabei, dem Ganzen eine »Form« zu geben:

"Ja also, ich merke z.B., wenn ich zu Hause bin, in Ruhe mal meine Gebete einrichten kann, auch mal mich so mit meinen Büchern, religiösen Büchern mich mal unterhalte, sehe ich automatisch an mir, dass ich ausgeglichener bin. Das ist für mich sehr wichtig, weil ich selber auch so aufgewachsen bin und ich dadurch auch gesehen habe, ich sehe [es bei den Leuten in meinem, Anm. d. Verf.] Freundeskreis, die nicht so aufgewachsen sind. Es muss ja nicht heißen, dass es 100-prozentig so ist, es ist ja meine Empfindung. Und da sehe ich auch, dass mein Kind auch ruhiger wird, diese Anschauung von der Mutter überträgt sich auf das Kind und ich denke auch, angeboren irgendwie. Also, ich finde meine Religion, in der Religion ist es so, dass der Mensch so geboren wird, vollkommen eigentlich. Und durch die Erziehung, durch die religiöse Erziehung, je nachdem, auch dann zu einer Form gestaltet wird. Das ist ja." (Lema, Z.: 45)

Auch die Erfahrungen, die sie in ihrer religiösen Gemeinde mit den Jugendlichen macht, die beispielsweise einen Monat lang den Gemeindebesuch versäumt haben, zeigen ihr, wie dadurch Probleme entstehen können; denn durch die geringere Beschäftigung mit dem Glauben entstünden Lücken, die die Besinnung auf sich selbst, als Menschen, verhindern würden. Hingegen gebe die Beschäftigung mit der Religion Sinn und Orientierung im Leben. In einer von der Technologie und den Medien bestimmten schnelllebigen Zeit sei es umso wichtiger, über sich selbst und seine Zukunft nachzudenken. Wichtig sind für Lema die typischen Fragen nach dem eigenen Dasein, die einer Beantwortung 
bedürfen. Damit könne auch die Perspektivlosigkeit unter Jugendlichen aufgehoben werden ${ }^{31}$ :

"[...]. Also es ist ja so, dass wir leben in einem Zeitalter, wo alles so schnell und so man kann gar nicht mehr nachdenken über sich selbst; die ganzen Technologien, diese Medien und so ... es ist ja, nimmt ja einen mit, da hat man wenig Zeit über sich und über seine Zukunft nachzudenken. Und ich denke, Religion ist ja dann so etwas, dann kommt man wieder zu sich. Also man denkt wieder über sich als Mensch nach, als Mensch, warum bin ich denn hier? Warum bin ich erschaffen worden? Was ist mein Ziel? Also diese Perspektivlosigkeit wird dann, dann aufgehoben, was heutzutage die meisten Jugendlichen haben, keine Perspektive. Also, ja." (Lema, Z.: 47)

Hinsichtlich religiöser Erfahrungen bezieht sich Hülya auf Rituale (vgl. unten) oder wie Lema auf den Gemeinschaftsbezug, indem sie mit ihren Kindern wöchentlich die Moschee besucht. Aber auch ilahis (türk. für religiös geprägter Gesang) mit Glaubensinhalten, bewirkten bei ihren Kindern einen positiven Effekt. Hülya unterstreicht insbesondere die Beziehung ihrer Kinder zur Moschee. Dort gründete sie mit einer Freundin eine Krabbelgruppe (vgl. Hülya, Z.: 24), die erst die Teilnahme in der Moscheegemeinde ermöglicht habe:

"[...] und dann war danach, dass wir z.B. die Moschee besucht haben, also das war okay. Am Anfang kann man mit den Kindern wenig die Moschee besuchen, es sei denn, die sitzt noch im Maxi-Cosi und bewegt sich nicht (lacht). Aber danach ist das wirklich unmöglich, ich hab echt, ... eine Zeit lang war ich gar nicht in der Moschee. Ja, es geht einfach nicht, weil die schreit dann rum und die anderen stört das. Ja, und in der Moschee fand sie das sehr schön, dass wir aufgrund der Krabbelgruppe, dann gab es dann z.B. fünf Minuten, wo die auf die Plätze fertig los und rennen durften, das fanden die sehr schön. Also, die Beziehung zu der Moschee war eben eine sehr gute Erfahrung [...]." (Hülya, Z.: 34)

Über die Befolgung von Ritualen können nur eingeschränkte Aussagen gemacht werden. ${ }^{32}$ Gemeinsam ist den beiden Eltern (»Identitätssuchern«), dass sie viel Wert auf den Moscheebezug (vgl. oben) und das Verrichten der Gebete (vgl. auch Lema, Z.: 49 unten) legen:

31 Diese Vorstellungen bzw. religiösen Erfahrungen können hier als Antizipationen betrachtet werden, wodurch auch ihre religiösen Erziehungsvorstellungen gekennzeichnet sind.

32 | Da die Kinder weder fasten noch den Koranlesen können, werden diese rituellen Aspekte nicht behandelt. Die Kinder von Hülya hören lediglich Koranrezitationen mit (vgl. Hülya, Z.: 44). Hinsichtlich des Gebetes und anderer Rituale teilt Lema ihre Ansichten bzw. Antizipationen mit. 
"[...] und dass man z.B. vor dem Beten mit den Kindern zusammen betet, dass man auch sogar schon daran denkt, dass die Kinder ihre eigene seccade [türk. für Gebetsteppich, Anm. d. Verf.] haben, so im Kleinformat eventuell mit der eigenen Namenssignatur usw. also, dass man automatisch die Kinder damit konfrontiert, bewusst konfrontiert, das war sehr wichtig für mich; und ich denke, das habe ich schon ein wenig [...] geschafft." (Hülya, Z.: 24, vgl. auch Z.: 40)

Als wichtigste gemeinsame religiöse Erfahrung schildert Hülya ihre Erlebnisse bei der Verrichtung der Gebete mit ihren Kindern folgendermaßen:

"Ja, ja, ja ... also auf jeden Fall, als meine Tochter z.B. gemerkt hat, dass ich bete (lacht), dann ist sie natürlich auf meinen Kopf gestiegen und hat sich dann irgendwie festgehalten und ist mit mir wieder runtergegangen auf jeden Fall. Beten ist [...] also automatisch war das die erste Erfahrung so, glaube ich, und dann war [...]." (Hülya, Z.: 34)

Ansonsten sind das Auswendiglernen von Suren (vgl. Hülya, Z.: 40) und die Beachtung der Tischregeln rituelle Bestandteile in ihrem Alltag:

"Esstischregeln, z.B. Bismillahirrahmanirrahim [arab. für "im Namen Allahs des Allerbarmers, des Barmherzigen“, Anm. d. Verf.], das sagt sie immer noch heute, ohne dass ich sie jetzt mittlerweile daran erinnern muss; Bismillahirrahmanirrahim, elhamdulillah sagt sie auch automatisch." (Hülya, Z.: 34)

Das Koranlesen beherrschen die Kinder von Hülya noch nicht. Sie hätten jedoch bereits im Bauch der Mutter die Koranrezitationen mitgehört. Dadurch habe die Tochter beispielsweise das arabische Alphabet schnell auswendig gelernt:

"[...]. Und aber allgemein von klein an habe ich damit angefangen, schon im Bauch, dass ich z.B. aus dem Koran vorgelesen habe oder auch gehört; und das dann auch meine Kinder habe hören lassen. Das hat schon bei mir da angefangen im Bauch (lacht). [...] $\mathrm{Ja}$, und ich glaube dadurch ist z.B. meine Tochter sehr musikalisch geworden, ja, ich habe es im Nachhinein auch so geerntet, die hört sehr gerne Musik, zum Beispiel Lieder; und die kann sehr schnell auswendig lernen beispielsweise; die ist jetzt fünf. Die kann auch schon das Elif Be auswendig [...] also so nachdem meine nicht einmal auf der Welt waren, sondern, sogar noch im Bauch waren, war das für mich schon ein Thema." (Hülya, Z.: 24)

Schließlich haben für Lema Rituale, wie die Gebetswaschung (arab. wudu), die täglichen Gebete und die sich ständig wiederholende Auseinandersetzung mit der Koraninterpretation, eine außerordentliche Bedeutung (vgl. auch oben, vgl. Lema, Z.: 49). 
Religiöse Feste nehmen für die Eltern dieses Typs (identitätssuchende Eltern) eine identitätsstiftende Funktion ein. Einerseits wird mit dem Feiern von Festen in staatlichen Bildungseinrichtungen das Bedürfnis nach Anerkennung bzgl. der eigenen religiösen Identität befriedigt (vgl. Lema Z.: 26 in Kap. III. 3.3). Andererseits solle durch die Integration religiöser Symbole, wie dem Weihnachtsmann oder dem Weihnachtsfest, in den Alltag erreicht werden, dass die Kinder nicht »zwischen zwei Stühlen« stünden. Dabei solle gleichzeitig auch das Bewusstsein für die eigene religiöse Identität unter Bezugnahme auf die eigenen Glaubensvorstellungen gewahrt werden:

"[...] Also, dass die dann sagen, ja irgendwann wird es auf jeden Fall kommen, dass sie dann sagen: Ja, das bin ich،. Zum Beispiel jetzt, wo wir den Weihnachtsmann haben z.B., den Nikolausso. Meine Tochter weiß dann genau, dass wir an den Weihnachtsmann nicht glauben, automatisch, also sie kann natürlich mitmachen, aber, ich sag dann: ,Wir glauben an Gott und wir glauben nicht an den Weihnachtsmann. Ich glaube, dass ich das Recht dazu habe, das zu sagen, wir glauben nun mal nicht an den Weihnachtsmann, aber ich möchte auch nicht, dass mein Kind irgendwie zwischen zwei Stühlen sitzt, also innerlich vielleicht. Und ich mache das dann auch geschickt, dass ich dann trotzdem ein Geschenk kaufe, ja, weil es ist nun einmal ein Kind, weil sie sieht das und sie findet das schön, aber ich kann das trotzdem mit einem Hintergrund erklären, dass es einfach bei den Freundinnen alles gemacht wird und dass es genauso 0stern; sie liebt, sie mag das, z.B. also Karneval, ne, also das darf sie alles und. Und aber ich möchte schon ihr auch unsere Seite dann beibringen, dass sie beide Seiten kennt und ja, aber glauben tut sie dann, was ich dann ..., wo ich dran glaube." (Hülya, Z.: 44)

In diesem Interviewabschnitt werden zwei verschiedene Ebenen angesprochen: Das Feiern der religiösen Feste (Weihnachten, Ostern) oder des Karnevals hat auf der Alltagsebene eine integrative Funktion. Das Kind darf die Annehmlichkeiten der Feste zwar wahrnehmen (»sie findet das schön«, »sie liebt ..., sie mag das«), mitmachen und bekommt auch »ein Geschenk« an diesen Feiertagen. Dennoch wird auf einer anderen Ebene (Glauben) erklärt, dass diese Feste nicht Bestandteile des eigenen Glaubens seien. Auch wenn die andere Seite erklärt und kennengelernt wird, liegt somit auch ein besonderes Augenmerk auf der Vermittlung der eigenen Glaubensvorstellung: »[...] aber glauben tut sie dann, was ich dann ..., wo ich dran glaube« (vgl. ebd.).

So ist damit das Feiern von »eigenen« religiösen Festen sehr wichtig für Hülya. Es fällt auf, dass an dieser Stelle der Bezug zu Weihnachten nicht fehlt. Ähnlich wie an Weihnachten, gibt es auch an den eigenen religiösen Feierta- 
gen Geschenke ${ }^{33}$. Die Feste werden mit Aktivitäten für die Kinder, organisiert durch die religiösen Gemeinden, ganz groß gefeiert:

"[...], wir schmücken unsere Wohnung, ja, und dann dürfen die auch mit schmücken, also Fenster und Ballons, also im Kinderzimmer allerdings. Dann decken wir den Tisch schön ja, dann [besuchen, Anm. d. Verf.] wir Oma und Opa (lacht), ja, und schöne Kleider kaufen ist sehr wichtig und Geschenke. Also, wir machen das auch ungefähr so ähnlich wie Weihnachten, dass wir dann Geschenke austauschen, finden die dann sehr schön. Die wissen, dass wir bayram [türk. für Fest, Anm. d. Verf.] haben; dann gibt es auch immer von den Moscheegemeinden große Organisationen, also bayram-Feste im Saal Hochzeitssaal, wo dann sehr viel für die Kinder gemacht wird; dann wissen die genau, 'Mama, jetzt ist bayram, jetzt gehen wir dahin.'“ (Hülya, Z.: 42)

Das Wissen, was sich die Kinder aneignen sollen, betrifft zum einen die Glaubensgrundlagen bzw. die fünf Säulen des Islams und zum anderen die Erfüllung der religiösen Pflichten (vgl. Hülya, Z.: 44 und 48-52, vgl. Lema unten). Hierbei geht Hülya im Wesentlichen stärker von einer traditionell-religiösen Bildung aus, als es bei Lema der Fall ist. Dennoch zeichnet sich ihre Herangehensweise bei der Weitergabe religiöser Bildung durch innovative Elemente aus, indem sie diese auf eine spielerisch-kreative Weise an ihre Kinder heranträgt (vgl. im nächsten Unterkapitel: »Methoden [...]«).

Die Vermittlung des Wissens um Gott/Allah mit seinen besonderen Eigenschaften, ist für Lema wesentlich. Daneben soll das Kind Wissen erwerben, um sich zu einem »guten Menschen« zu entwickeln, welcher seine »Pflichten« vor Gott/Allah erfüllt:

"Ja, dass es einen Gott gibt oder einen Allah, woran wir glauben, und dass er uns erschaffen hat, dass er uns sehr liebt und dass er auch nur Gutes für uns möchte, das Gute sowohl im Jenseits als auch im Diesseits. Dass man einfach ein guter Mensch sein soll. Mehr eigentlich auch nicht; die Pflichten zu erfüllen und einfach ein guter Mensch zu sein." (Lema, Z.: 59)

Dabei betont Lema insbesondere die Unkompliziert der religiösen Lebensweise. Es gehe letztlich um eine einfache Pflichterfüllung bzw. darum, das »Richtige $\ll \mathrm{zu}^{\mathrm{tun}}{ }^{34}$ :

33 | Auch Nermin (vgl. Kap. III 4.1) betrachtet die Geschenke als einen, in Anlehnung an Weihnachten eingeführten Brauch in muslimischen Familien.

34 | Hier findet sich auch ein Verweis auf einen Hadith Muhammads (s), der besagt, es sich nicht zu erschweren, sondern zu erleichtern: "Macht es leicht und erschwert nicht, bringt frohe Kunde und schreckt nicht ab." Überliefert von Buhari 3: 72. 
"[...] ja, es ist nicht schwierig. Unser Prophet Muhammed sagte ja auch, dass man es nicht einfach nur so [erschweren solle, Anm. d. Verf.], sondern wirklich, ja, nicht erschweren, sondern einfach die Pflichten erfüllen, [erleichtern, Anm. d. Verf.]. Ja, erleichtern. In dem Sinne auch dann, dass man einfach nur wirklich auch das Richtige tut." (Lema, Z.: 61-65)

Schon im rituellen Bereich hob Lema die Auseinandersetzung mit der Koraninterpretation hervor. Die Bedeutung und den Sinn des Korans zu verstehen, darüber nachzudenken und $\mathrm{zu} »$ philosophieren«, spielt für Lema schon seit ihrer Kindheit eine große Rolle. Dabei grenzt sie sich auch deutlich von einfachen, nachahmenden Verhaltensweisen ab. Es sei ihr z.B. beim Gebet und im Allgemeinen wichtig, immer den Sinnzusammenhang hinter den Gegebenheiten durch die Erforschung und die Beantwortung von Warum-Fragen zu erkennen:

"[...] das Lesen ist auch ganz, an sich ist es wichtig für mich, dass es gibt ja auch ganz viele Interpretationen vom Koran. Man sagt ja auch z.B., dass die meisten, also ich verstehe Arabisch nicht! An sich ist für mich insofern wichtig, dass ich auch mal ein Werk habe, wo ich dann die Interpretation nochmal nachlesen kann. Was sagt denn der Koran wirklich aus? Wie gesagt, leider kann ich kein Arabisch, aber ich bin halt bemüht; seit meiner Kindheit auch, weil ich auch in dieser Gemeinde bin, habe ich auch gelernt, die Interpretation halt mir anzueignen; und das ist dann halt für mich wichtig. Das ist so, dass man wieder darüber nachdenkt, wieder philosophiert, also das ist dann sehr wichtig für mich. Einfach nicht nur dieses Abgucken, genau!» (Lema, Z.: 49).

Die Fragen, die die Kinder stellen, beziehen sich zumeist auf die Existenz Gottes. Es sind die Sinnfragen, von denen Lema meint, dass ihre Tochter sie zu gegebener Zeit auch stellen werde (vgl. oben).

In Gesprächen mit ihren Kindern stellt Hülya fest, dass die Beantwortung all jener Fragen, die die Kinder beschäftigen, einen noch einmal überlegen lässt, ob man auch das »Richtige« gesagt hat (vgl. Hülya, Z.: 32). Hierzu zählen insbesondere die Fragen nach Gott: »also was Gott überhaupt ist«, »wo er ist«, »was er im Herzen macht«, »wieso sehe ich ihn nicht« (vgl. ebd. und Z:. 54/58). Gerade die Frage nach dem Geschlecht Gottes führt Hülya auf die momentane Entwicklungsphase ihrer Tochter zurück:

"[...] z.B. einmal hatte sie mich gefragt: ।st Gott ein Junge oder ein Mädchen? So und [...] weil sie sich in der Entwicklung befindet, wo sie halt entscheidet, also nachdem Geschlecht, ne, die Geschlechterunterschiede erkennt; und dann ist es automatisch. Ich finde das überhaupt wichtig, dass sie die Frage stellt, dass sie über Gott auch fragt, das ist sehr wichtig für mich, also das sind die Fragen." (Hülya, Z.: 58ff.) 
Fragen nach der eigenen Identität und der Zugehörigkeit würden des Weiteren auch gestellt: »Was heißt denn >wir überhaupt? Wer bin ich?« (vgl. Hülya, Z.: 24).

\subsubsection{Die Erziehungsmethoden und Erziehungsstile in den Familien der "Identitätssucher"}

Die Erziehungsmethoden und Herangehensweisen der beiden Elternteile dieses Typs unterscheiden sich voneinander. Dies hat zum einen damit zu tun, dass sich die Kinder in unterschiedlichen Entwicklungsstadien, wie dem Kleinkindalter (Hülya) und dem Säuglingsalter (Lema), befinden, zum anderen sind sie als Expertinnen in unterschiedlichen Bereichen tätig, sodass ihr pädagogischer Zugang zu religiösen Themen jeweils ein anderer ist.

Zudem wurden im Bereich der Religiosität zwar die Gemeinsamkeiten im perspektivischen Zugang zur religiösen Erziehung unterstrichen, jedoch die Merkmale, die sich voneinander unterscheiden, nicht genügend berücksichtigt. Diese haben jeweils wesensgemäße Auswirkungen auf den pädagogischen Umgang bzw. auf die angewandten Methoden hinsichtlich religiöser Themen.

Hierbei ist für Lema schon im Hinblick auf ihr Erziehungsziel wichtig, dass sie ihrem Kind neben der Entwicklung einer Persönlichkeit auch Sinn und Orientierung durch die intellektuelle Auseinandersetzung mit den Koraninterpretationen geben kann (vgl. oben »Religiosität [...]«). Ihre Erziehungsvorstellungen decken sich z.T. mit denen der idealistischen Eltern, die auch immer nach der Bedeutung und dem Sinn des Daseins fragen. Die Art und Weise ihres pädagogischen Zugangs teilt sie als Expertin sowohl theoretisierend als auch in der Rolle einer Jugendgruppenleiterin mit ihrer religiösen Gemeinde.

Dagegen ist Hülya eher in praktischer Hinsicht als versiert zu bezeichnen. Auch wenn dies zunächst nicht in ihrer Argumentation und dem perspektivischen Zugang zur religiösen Erziehung erkennbar ist, ähnelt ihre Religiosität stärker jener der ritualistischen Eltern, mit denen sie in jedem Fall das Erlernen der Glaubensgrundlagen und der fünf Säulen des Islams gemeinsam hat. Dennoch verfügt sie sowohl als Expertin, die Krabbelgruppen gründete und leitete, als auch als Mutter von Kleinkindern über ein durchaus differenziertes Repertoire an Methoden, die im Folgenden näher beschrieben werden sollen.

Schließlich erschien es aus den oben genannten Gründen als sinnvoll, die Erziehungsmethoden und -stile beider Elternteile und Expertinnen noch einmal jeweils gesondert darzustellen.

Lema unterstreicht insbesondere die Vorbildfunktion der Eltern. Die Kinder ahmen die Verhaltensweisen der Eltern nach, wobei hier insbesondere die Rolle der Mutter reflektierend wahrgenommen wird. An dieser Stelle nimmt Lema auch Bezug zu ihrer eigenen Kindheit, in der sie sich durch den religiösen 
Hintergrund der eigenen Eltern zum Positiven entwickelt habe, sodass sie z.B. in der Schule bis zum Abitur als »liebes Kind « bezeichnet worden sei:

"[...] das ist ja so, das ist ja so, wie Theoretiker behaupten, dass die Mutter in erster Linie auch das Hauptbeispiel ist für das Kind, dass das Kind quasi von der Mutter abschaut Also, was macht denn die Mutter? Wie ist die Mutter? Wie spricht die Mutter? Wie geht sie mit den Nachbarn um? Wie geht sie [...] Wie ist sie zu Hause? Wie kleidet sie sich? Wie verhält sie sich? Und (zögert) das war ja auch für uns so, da meine Eltern ja auch einen religiösen Hintergrund hatten. Dass sie das so natürlich auf uns übertragen, insofern, dass wir als liebes Kind immer so bezeichnet wurden ..., sogar bis zum Abitur. Und das fand ich dann gut. Es ist ja natürlich irgendwo auch positiv [...]." (Lema, Z.: 20)

An einer anderen Stelle weist sie darauf hin, dass die Väter eine ebenso wichtige Rolle bei der Erfüllung einer Vorbildfunktion einnähmen. In diesem Zusammenhang veranschaulicht sie auch das Beziehungsverhältnis der beiden Elternteile zueinander, das durch das Kind beobachtend »aufgenommen und gespeichert« werde:

"[...] Dass die Mutter, auch natürlich der Vater ist auch ganz wichtig, hat eine ganz wichtige Position, ne. Die Mutter ist ja so ..., das ist ja eine Vorbildfunktion, aber der Vater, ist ja auch mit eingebunden. Das ist ja nicht so, dass sie mich nur beobachtet, sondern der Vater wird ja auch beobachtet, wie wir z.B. miteinander kommunizieren, wie wir z.B. essen, wie wir einkaufen, das wird ja alles so; was wir einkaufen, das ist alles so ..., wird ja alles so aufgenommen und gespeichert [...]." (Lema, Z.: 80).

Des Weiteren zeigt Lema die Vorbildfunktion der Eltern metaphorisch unter Bezugnahme auf einen Gelehrten auf. Das Kind lerne dabei durch das Beobachten. Das Fundament für ein »Haus« werde durch die Mutter gelegt. Alles, was man sich selbst aneigne, werde darauf aufgebaut. So finde später bei Lemas Tochter, ähnlich wie bei ihr selbst, eine Vertiefung und Verfeinerung des Erlernten statt:

"Sie beobachtet mich halt. Man kann ja sagen, dass der Gelehrte [...], sagt ja auch, dass der erste Gelehrte des Kindes ist die Mutter an sich. Also er hat ja auch selber damals auch, was er von der Mutter gelernt hat, quasi waren so Grundbausteine. Was er sich dann selbst angeeignet hat, hat sich darauf aufgebaut, so wie ein Haus, so wie man ein Haus baut. Es ist ja so, dass ist ja ähnlich. Ich denke auch, ich habe ja z.B. von meiner Mutter so schöne Sachen gelernt. Und das, hat sich ja später bei mir verfeinert, noch vertieft. Und das wird ja ... bei meiner Tochter, denke ich, ähnlich, weil sie ja nur noch beobachtet. Was macht denn die Mutter? Wie ist sie? Wie redet Sie? Es ist ja nur Beobachtung pur." (Lema, Z.: 57) 
Auf die Frage, in welcher Art und Weise sie die religiösen Inhalte später an ihr Kind weiter vermitteln möchte, hebt sie deren lebens- und alltagsnahe Vermittlung hervor. Auch hier spielt das nachahmende und beobachtende Verhalten des Kindes eine zentrale Rolle. Das Ausleben der Religion ist nach ihrem Verständnis ein selbstverständlicher Bestandteil im Alltag, das »ja in einem verankert« sei. Man könne dies nicht von einem selbst »trennen«:

"Also, ich denke persönlich, ich brauche da glaube ich keine neuen Methoden anzuwenden, weil das macht sie ja automatisch. Also ich mach das ... z.B. stand ich letztens in der Küche, ich hatte sie im Wohnzimmer liegen lassen, und da hat sie anscheinend mit ihren Spielzeugen gespielt, aber da hatte ich, als ich mal zu ihr blickte, da habe ich gesehen, wie sie mich wirklich beobachtet, so richtig stark, da habe ich irgendwie Angst bekommen, was ist denn jetzt los? (lacht). Weil da habe ich man unterschätzt die Kleinen, aber die sind echt [So erlebt man den Alltag zusammen, Anm. d. Verf.]. Ja, das ist ja auch so. Man kann ja jetzt nicht sagen, okay, jetzt lebe ich meine Religion aus und lebe ich nicht, sondern das ist ja in einem verankert. Und das ist ja, man kann das irgendwie nicht von sich aus trennen. Und ja." (Lema, Z.: 71-75)

Auch die Regelbefolgung in Form einer »Pflichterfüllung « nimmt eine wichtige Stellung ein. Hierbei geht es darum, die Pflichten »einfach« zu erfüllen:

"Sondern wirklich, ja, nicht erschweren, sondern einfach die Pflichten machen. [...] Ja, erleichtern. In dem Sinne auch, dass man einfach nur wirklich das Richtige tut." (Lema, Z.: 63ff.)

Als letzten Aspekt betont Lema, viel Zeit mit dem Kind zu verbringen. Auf diesen Aspekt nimmt kaum ein anderer Elternteil ${ }^{35}$ Bezug. Es könnte damit zusammenhängen, dass dies durch die Eltern bereits als eine Voraussetzung betrachtet wird. Ein anderer Grund ist womöglich darin zu sehen, dass Kinder einfach an andere Bildungseinrichtungen »delegiert« werden, um von ihnen »erzogen« zu werden, so Lema (vgl. Lema, Z.: 8o).

Die Religion bietet für Hülya eine Orientierung im Leben, sodass sie die Religion in Form von Vorleben an ihre Kinder weitergibt (vgl. Hülya, Z.: 24). Vorbilder seien gerade für die Identitätsentwicklung der Kinder wichtig. Daher werde eine Verbindung zu religiösen Themen gesucht. Auch wenn die Kinder von Hülya das Koranlesen noch nicht beherrschen, so haben sie ihr eigenes Büchlein ${ }^{36}$, mittels dessen sie ihr Identifikationsbedürfnis mit Gleichgesinnten bzw. in diesem Fall mit muslimischen Kindern stillen könnten. Irgend-

35 | Eine Ausnahme bildet hier bei den idealistischen Eltern Lale (Z.: 139f.).

36 | Dieser Aspekt könnte auch dem Kapitel "Medien als didaktische Mittel« zugeordnet werden. 
wann, wenn die Zeit komme, werde daraus ein entsprechendes Bewusstsein für ihre Identität erwachen:

"Ja, die hören mit, noch nicht, die sind noch klein [den Koran, Anm. d. Verf.]. Die haben ihr eigenes Büchlein, also wo dann abgebildet ist, wie man betet usw. Dann gibt es einen Jungen und ein Mädchen mit einem pinken Kopftuch, da sagt meine Tochter, Ja, das bin ich, , und mein Sohn sagt, 'Das bin ichı, und so. Also, ich meine, ich versuche immer, so eine Bindung herzustellen zwischen dem Kind, dass sie das mit Liebe dann mit sich selbst verbinden. Also, dass die dann sagen, ja, irgendwann wird es auf jeden Fall kommen, dass sie dann sagen: Ja, das bin ich.‘ (Hülya, Z: 44).

Auch wiederkehrende Rituale seien von Bedeutung, damit die Kinder erkennen könnten, womit sie sich gerade beschäftigen würden (vgl. Hülya, Z.: 74). Damit hätten diese eine ordnungsstiftende Funktion.

Die Kommunikation über religiöse Inhalte, in Form von »kleineren Gesprächen« über Gott (vgl. Hülya, Z.: 24 und ${ }_{56} 6$ ) und andere Themen, nähme des Weiteren eine wichtige Stellung innerhalb des Familienalltags ein:

"[...] und ich rede sehr viel mit den Kindern [...] und zuhören, damit man den Kindern die Möglichkeit auch gibt. Die fühlen sich dann ernst genommen und über ein bestimmtes Thema zu reden, ist sehr wichtig, z.B. Respekt, was ist das? [...]." (Hülya, Z.: 74)

Das Erklären an Beispielen wendet Hülya als Kommunikationsform des Öfteren an. Da die Kinder noch sehr klein seien, würden sie noch nicht hinterfragen; sie nähmen die Erklärungen der Mutter und die Bedeutung des Erklärten somit als selbstverständlich an. Weil sie sich so ernst genommen fühlen würden, gefalle es den Kindern und es mache ihnen »Spaß«, der Mutter zuzuhören:

"Ja, die hinterfragt jetzt nicht, sie zweifelt an nichts, wenn ich ihr was sage, z.B. dass wir Bismillahirrahmanirrahim sagen oder 'warum sagen wir das? [...]. Ja, ist für sie eine Selbstverständlichkeit, weil ich immer eine Erklärung dafür habe, also die Wichtigkeit oder die Bedeutung, und dann gefällt den Kindern das, weil es macht Spaß (lacht), die werden ernst genommen." (Hülya, Z.: 62-66)

Überdies »philosophiert« sie mit ihren Kindern, indem sie zu den Gegebenheiten, »die auf der Welt passieren«, immer eine Verbindung zu Gott/Allah sucht. Durch Erklärungen möchte sie die Beziehung ihrer Kinder zu Gott/ Allah herstellen und stärken:

"[...] aber indem man mit den Kindern philosophiert sozusagen, kommt man dann zum Schluss, zum Endpunkt, und dann sieht man auch das Ergebnis, glaube ich. Also, so versuche ich das meinen Kindern zu erklären, wie diese Bindung ist, zu Gott, also was 
Gott überhaupt ist, weil es gibt keine Vorstellung, aber man versucht halt, die Dinge zu erklären, die auf dieser Welt passieren, und dann damit die Verbindung zu Gott herzustellen. Das ist dann sehr wichtig und mein Glaube an Gott sagt mir, also bewegt mich eben dahin, dass ich dann was tue mit meinen Kindern, dass ich denen das weiter erkläre [...]." (Hülya, Z.: 32)

Kaum ein anderer Elternteil schenkt Belohnungen und Geschenken eine solche Aufmerksamkeit wie Hülya. Interessant ist zudem, wie sie sie damit zum einen zu einem guten »Verhalten« motivieren möchte (vgl. auch Hülya, Z.: 87) und zum anderen auch immer eine Verbindung zu Gott bzw. zu anderen religiösen Themen wie Dankbarkeit herstellt:

"[...] Er weiß, dass wir über Gott reden und dann sagt er: Ja dann!` Manchmal überrasche ich die und sage dann, weil ihr dieses Verhalten gemacht habt, hat Gott halt ein Geschenk geschickt (lacht) [Freut er sich?, Anm. d. Verf.]. Ja, meine Tochter freut sich und mein Sohn hat sich jetzt vor ein paar Tagen über ..., was hatte ich denn gekauft? Also, ich erzähle denen, dass wir z.B. dafür beten sollten, dass es uns gut geht, dass wir Gott danken sollten, dass wir überhaupt z.B. die Möglichkeit haben, diese Geschenke zu kaufen." (Hülya, Z.: 56ff.)

Geschenke stehen in Hülyas Familie auch im Zusammenhang mit der Regelbefolgung im Vordergrund. Gerade nach dem Verrichten der Gebete oder wenn die Kinder Suren auswendig gelernt haben, kommen Belohnungen zum Einsatz:

"[...] Das gehört einfach dazu und, also die Suren z.B. ab und zu mal auswendig lernen; und dann versuche ich das mit Belohnungen zu machen. Also meine ganze Familie setzt sich da eigentlich ein (lacht), dann sagt der Opa mal, Ja, wenn du das jetzt gelernt hast, dann kriegst du das von mirı, (lacht). Ja, durch Belohnung [...]." (Hülya, Z.: 40)

Hülya erwartet von ihren Kindern aufgrund ihres Alters eine weniger strikte Befolgung der Regeln. Negatives wird gar übersehen (»Auf negative Sachen gehe ich jetzt nicht ein«) (vgl. Hülya, Z.: 76). Positivem, wie dem zeitweiligen Verrichten des Gebets, oder einem bestimmten Verhalten, bringt Hülya besonders viel Wertschätzung und Anerkennung entgegen. Die Tochter wird belohnt, indem die Mutter ihr beispielsweise verbal Zustimmung signalisiert, sie »fotografiert« bzw. mit der Kamera aufnimmt, ihr »Küsschen gibt« oder ihr einfach aufgrund ihres Verhaltens »Freude« zeigt:

"Also, die können mir noch nicht so viel befolgen, da kann ich jetzt nichts dazu sagen, ich meine ich erwarte nicht, dass die fünfmal am Tag beten (lacht). Das wäre jetzt unpädagogisch; aber ich belohne die schon, wenn die dann mitgebetet haben, z.B. also ... 
ich nehme das immer auf, fotografiere das und ..., also ich gebe ihr ganz viele Küsschen, wenn sie das gemacht hat. Sie macht das mittlerweile dann auch mit Kopftuch und mit pinken Kopftüchern (lacht). Und also da sage ich ihr schon, dass ich mich sehr gefreut habe, also verbale Belohnung ist auch sehr wichtig, so eine Zustimmung. Und genau, dass man auch selbst dadurch glücklich geworden ist und dass Gott auf jeden Fall sich sehr darüber gefreut hat, das sage ich ihr: 'Gott ist sehr glücklich im Moment, weil du das gemacht hastı, so sage ich ihr das dann." (Hülya, Z.: 85)

In diesem Interviewabschnitt wird deutlich, dass zudem das Geben eines Feedbacks eingesetzt wird: Auf der kommunikativen Ebene wird die Verbindung zu Gott gesucht, indem das Kind darauf hingewiesen wird, dass Gott über sein Verhalten »glücklich« ist und sich freut. Dieses Feedback, das auf verbal eingesetzte Belohnungen deutet, soll beziehungsfördernd bzgl. des Verhältnisses des Kindes zu Gott wirken und das positive Verhalten, hier das Tragen des Kopftuches, das Verrichten des Gebets usw., fördern.

Schließlich sind es auch kreativ-künstlerische Elemente, die in die religiöse Erziehung von Hülya einfließen. Hier schenkt sie insbesondere dem Hören von religiösem Gesang eine besondere Beachtung. Wie auch bereits oben erwähnt wurde, setzte sie Koranrezitationen ${ }^{37}$, schon als die Kinder in ihrem Bauch waren, ein (vgl. oben »Religiosität«). Neben der muttersprachlichen religiösen Unterweisung unterstreicht Hülya den Einsatz von (muttersprachlichen) religiösen Liedern, um beispielsweise die Glaubensgrundlagen näher zubringen:

"Aber ich finde es wichtig, dass sie in der Muttersprache die Religion auch lernen, das ist für mich sehr wichtig, z.B. die ganzen religiösen Lieder. Und ich kann mir das jetzt nicht vorstellen; vielleicht gibt es irgendwann deutsche religiöse islamische Lieder, aber im Moment lerne ich das mit den Kindern so automatisch. Aber grundsätzlich möchte ich, dass sie das Grundwissen haben, das ist immer, je nach Alter, also man [...] jetzt nicht mit 5-Jährigen über otuz iki Farz [türk. für Glaubenspflichten des Islams, Anm. d. Verf.] [...] reden; das Ganze kann ich mit dem nicht lernen. Ich mach das eben auf eine spielerische Art und Weise und das bleibt noch mehr hängen, also die Grundsachen wie: aschhadu an la-ilaha-ill-Allah [arab. für "Ich bezeuge, dass es Gott gibt", Anm. d. Verf.] [Also die Glaubensinhalte, die Säulen des Islam, Anm. d. Verf.] Ja, richtig. Die sind ja z.B. mittlerweile immer in ilahis enthalten wie imanın şartı altıdır altı [türk. für die Glaubensgrundlagen sind sechs, Anm. d. Verf.] (lacht). Das ist automatisch im Unterbewusstsein durch diese Lieder, und ich setze das sehr bewusst ein. Und aber die genauen Inhalte werde ich erst ab neun oder zehn machen können, [...]." (Hülya, Z.: 48-52)

37 | Natürlich unterscheiden sich die Koranrezitationen, die häufig im rhythmischen Wortlaut, dem Gesang ähnlich vorgetragen werden, vom religiös geprägten Gesang. Dieser beinhaltet vor allem religiöse Themen. 
Da die Kinder noch klein sind, zieht sie eine altersgemäße Förderung vor, die »auf eine spielerische Art und Weise« hindeutet. Durch den Einsatz von Liedern sollen religiöse Inhalte im Unterbewusstsein gespeichert werden, damit diese später im Alter von »neun oder zehn Jahren« aufgegriffen werden können.

Auch das Basteln (hier von Schäfchen) als einem weiteren kreativen Element betrachtet Hülya als ein Ritual, das immer wieder eingesetzt werde:

"Also, basteln mäßig ... Ja, doch, basteln machen wir sehr viel, also, z.B. kurban bayramında [türk. für beim Opferfest, Anm. d. Verf.] machen wir Schäfchenbasteln usw. Also, Kinder brauchen immer Rituale; ja, ist sehr wichtig, das etwas immer wiederkehrt [...]." (Hülya, Z.: 74)

Das Malen anhand von Moscheevorlagen ermögliche den Kindern beispielsweise die Deutung bzw. das Erkennen einer religiösen Symbolfigur, hier der Moschee:

"Also, mit Malen z.B. machen wir sehr viel, hab dann immer viele Vorlagen, z.B. Moscheevorlagen, und die wissen ganz genau, was eine Moschee ist usw." (Hülya, Z.: 82).

Bei Konflikten mit den Kindern löst Hülya einerseits die Probleme mit Kommunikation (vgl. Hülya, Z.: 82). Anderseits fördert sie »das Positive« und ignoriert »das Negative« (vgl. Hülya, Z.: 89). Auch wenn die Kinder noch zu klein sind, um von Konflikten zu sprechen, achtet Hülya darauf, die Entscheidungen ihrer Kinder mit »Respekt« zu behandeln:

"Ich habe einmal meiner Tochter z.B., als wir in die Moschee gegangen sind, angeboten, vielleicht Kopftuch zu tragen, da hat sie nein gesagt. Ich darf da jetzt nicht noch mehr drauf bestehen, wenn sie einmal nein gesagt hat, dann ist es nein, ich akzeptiere das; und wenn ich keinen Respekt zeigen würde, wie soll mein Kind dann Respekt lernen?» (Hülya, Z.: 103)

\section{Erziehungsstile}

Die Erziehungsstile der »Identitätssucher« sind primär durch Liebe/Geduld gekennzeichnet. Auch lassen sich ansatzweise Erziehungsstile vorfinden, die auf Disziplin und der Förderung der Selbstständigkeit beruhen.

Lema findet es sehr wichtig, viel Zeit mit dem Kind zu verbringen (vgl. oben, vgl. Lema, Z.: 80 und 86). Dies zeigt, dass ihr Erziehungsstil in erster Linie von Geduld geprägt wird.

Schon die Vermittlung von Werten, wie »Vertrauen« oder »Liebe«, die in der Religion vorzufinden seien, beschreibt den Kernaspekt der religiösen Er- 
ziehung von Hülya. Sie versucht, eine Bindung zwischen ihren Kindern und zu religiösen Inhalten herzustellen, die durch »Liebe« geprägt sei:

"Also, ich meine, ich versuche immer, so eine Bindung herzustellen zwischen dem Kind, dass sie das mit Liebe dann mit sich selbst verbinden." (Hülya, Z.: 44)

Auch im Umgang mit Erklärungen und dem Beantworten von Fragen verhält sich Hülya wertschätzend, denn dadurch würden sich die Kinder »ernst« genommen fühlen. Es mache ihnen somit Spaß, sich mit der Bedeutung des Erklärten auseinanderzusetzen (vgl. Hülya, Z.: 66 und 74). Gerade die verbalen motivierenden Zustimmungen, die sie als Belohnungen einsetzt, stellen einen Erziehungsstil dar, der sich durch Liebe und Geduld ausweist (vgl. ebd., Z.: 85).

Hülya legt zudem großen Wert auf ein gleichberechtigtes Mitgestalten. Dies zeigt sich durch die Akzeptanz und den Respekt, den sie vor den Entscheidungen der Tochter (im Kleinkindalter) zeigt (vgl. oben »Erziehungsmethoden $[. ..] \ll)$. Diese Herangehensweise zielt, wenn auch indirekt, auf die Förderung der Selbstständigkeit ab. Folglich würde Hülya auch keinen Zwang anwenden, wenn sich die Tochter später beispielsweise gegen das Kopftuchtragen entscheide:

"Ich habe meine Tochter gefragt: ,Würdest du ein Kopftuch tragen, wenn du groß bist? Sagt sie: ,Nee`, (lacht) 'warum auch?، Also das sind so Fragen, ich bin so ne überzeugte Kopftuchträgerin. Die Kinder sehen das anders, die Jugendlichen, da darf man auch niemanden zwingen, auf keinen Fall." (Hülya, Z.: 305)

Es ist die »Disziplin«, die Lema im Hinblick der Glaubenserziehung fordert. Die religiöse Erziehung solle helfen, Disziplin und Respekt, z.B. gegenüber Gleichaltrigen, aufzubringen. Diese sollte »zu Hause«, d.h. in der Familie erlernt werden, damit keine Probleme entstünden:

"[...] z.B. die Disziplin, dass das heutzutage immer mehr untergeht, das sieht man ja auch; das ist ja bei den Jugendlichen, das ist ja auch mal ein Problemfall, dass das Kind auch mal zu Hause lernt, mal Respekt gegenüber anderen Kindern, auch Disziplin ... Ja, das fließt ineinander, denke ich mal." (Lema, Z.: 42).

\subsection{Religiöse Erziehung in den Familien der "Ethiker"}

\subsubsection{Die Religiosität in den Familien der "Ethiker"}

Die Vorstellungen vom Glauben variieren etwas unter den Eltern, für die ethische Grundsätze im Vordergrund stehen (den »Ethikern«). Zur Erklärung ihrer Glaubensvorstellungen benennen sie eher Aspekte, die primär die »ideologische« Dimension der Religiosität berühren (vgl. Kap. II. 3.1.4b). Diese Vorstellungen vom Glauben heben zum einen die Existenz Gottes und die In- 
halte bzw. Ziele des göttlichen Willens hervor. Zum anderen werden Glaubensgrundlagen bzw. -aussagen angesprochen, die das korrekte Verhalten des Menschen gegenüber Gott und seinen Mitmenschen bzw. seinem Umfeld darlegen sollen. Aus diesen Grundüberzeugungen ergeben sich für die erzieherische Praxis neben handlungsleitenden Prinzipen auch Konsequenzen, wie die Aneignung von normativ-ethischen Grundhaltungen. Diese sind insbesondere für Eltern dieses Typs kennzeichnend, was sich auch, analog dazu, in ihren religiösen Erziehungsvorstellungen ausdrückt (vgl. Kap. III. 3.4). Im Vergleich zu den ritualistischen und idealistischen Eltern spielt die religiöse Praxis, die sich in der Befolgung von Ritualen äußert, als Konsequenz aus diesen Glaubensüberzeugungen hier kaum eine Rolle. ${ }^{38}$ Auf Fragen zur Befolgung von Ritualen wird gesondert eingegangen (vgl. in diesem Kapitel).

Selbst wenn auf der emotionalen Ebene, die dem religiösen Erfahrungsbereich zugeordnet wird, einige wenige spirituelle Aspekte (Melek) angesprochen werden und dem Glauben eine Orientierungs- und Schutzfunktion (Birol) zugewiesen wird, so sind emotional besetzte Deutungen des Glaubens bei den Eltern dieses Typs nicht besonders ausgeprägt.

Der Glaube an Gott bedeutet für Belkıs den »Sinn des Lebens«, den sie an ihre Kinder weitergeben möchte (vgl. Belkıs, Z.: $37 f f$.$) .$

Feride definiert, in Abgrenzung zum Begriff »Glauben« den iman (arab. für Glauben) eines Muslims als etwas, was »keine Bestätigung«, sondern einfach »Gottvertrauen « erfordere. Dieses Gottvertrauen werde als ein »gegebenes Phänomen«, woran »keinerlei Zweifel, keinerlei Bedenken« bestünden, vorausgesetzt. Überdies sei der iman etwas, was in einem selbst »verankert« bzw. »internalisiert« sei. Dieser Vorstellung zufolge ist der iman ein »selbstverständlicher« Bestandteil des Menschen. Er beschreibe etwas, das im Wesenskern des Menschen schon durch die Schöpfung Gottes vorhanden sei. Und er sei so existenziell, dass man ihn wie die »Luft zum Atmen« oder »zum Leben« brauche (vgl. Feride, Z.: 52-58).

Adem sieht im Glauben mehrere Aspekte. Zum einen beinhalte der Glaube den Glauben an den Schöpfer, der alles erschaffen und allem einen Sinn gegeben habe. Zum anderen folgert er aus diesem Glauben, dass Gott Regeln verkündet habe, die im Koran niedergeschrieben seien. Für ihn persönlich bedeutet daher der Glaube, die handlungsleitenden Prinzipien der verkündeten Botschaft Gottes/Allahs »am Leben« zu erhalten:

38 Melek bildet hier eine Ausnahme. Wichtig ist, zu erkennen, dass Rituale auf Nachfragen schon eine Rolle spielen. Die rituelle Praxis nimmt im Vergleich zu allen anderen Eltern (aller drei Typen) eine lediglich untergeordnete Position ein. Vielmehr stehen andere Aspekte, die als Konsequenzen aus den Glaubensvorstellungen gezogen werden, hier im Vordergrund. 
"Meiner Meinung nach, Glaube ist, dass man an etwas glaubt, an ein, wie soll ich das sagen, an eine Kraft, die alles hier, was wir uns vorstellen und was wir uns nicht vorstellen können, erschaffen hat, dass alles einen Sinn hat. Das ist Glaube! [...] Nur, wenn wir davon ausgehen, dass alles, was wir jetzt hier sehen und hier erleben dürfen, von einem Gott erschaffen worden ist, dann ist auch das richtig, dass dieser Gott auch diese Regeln, diese Naturgesetze und so weiter und so fort für uns gegeben hat und uns verkündet hat und dass es in einem Buch drin geschrieben [steht, Anm. d. Verf.], das sich der Koran nennt und seit 1.400 Jahren nicht verändert worden ist, in der ursprünglichen Form, ist für uns, für meinen Glauben sehr sehr wichtig, dass wir diesen Glauben eben durch diese Regeln am Leben erhalten."(Adem, Z.: 22)

Die Konsequenzen, die die drei Elternteile aus ihren Glaubensüberzeugungen ziehen, sind typisch für »Ethiker«. Insbesondere ist ihnen die Weitergabe von ethischen Grundhaltungen an ihre Kinder wichtig.

Für Belk1s bedeutet der Glaube die Grundlage der Entwicklung bestimmter charakterlicher Eigenschaften. Somit sind diese angeeigneten Werte, die »gut« für einen selbst, für die Umgebung und für ein Miteinander seien, nicht unabhängig von Gott zu verstehen:

"[...], zum Beispiel bestimmte charakterliche Eigenschaften, dem Kind nahezubringen. Wie eben gesagt, ne Ehrlichkeit und so weiter. Das ist das, das bildet so die Basis. [...] Also, dass wir bestimmte Werte nicht unabhängig von Gott machen. Dass ich meinem Kind nicht sage: 'So, wenn du ehrlich bist, ist das halt gut für dich und für deine Umgebung und für die Menschen, wenn du denen nicht schadest،, sondern dass ich sage: ,Das ist gut für deine Umgebung, für dein Miteinander, aber es ist gleichzeitig auch ein religiöses Gut.`“ (Belkıs, Z.: 45-49)

Feride folgert aus ihrem Glauben, dass sie gerade die »internalisierten Werte« des Islams an ihre Kinder übertragen möchte. Hierbei nimmt sie sich auch in ihrer Vorbildfunktion wahr: Die »Lebensart und -weise und -form und Denkweise und Einstellungen und Aussagen«, die bei ihr vorhanden sind, möchte sie »selbstverständlich« aus ihrem »Sein« (vgl. Feride, Z.: 62) heraus weitergeben:

"Ja, ich versuche das, soweit es bei mir ausgeprägt ist, zu leben, wobei es auch Glaubensinhalte gibt, die ich praktisch in meinem Leben noch nicht aufgenommen habe oder aufnehmen konnte oder was auch immer. Wo ich auch davon überzeugt bin, dass die richtig sind, und ... also das Vorleben einerseits ist natürlich eine Art der Erziehung meiner Kinder, andererseits ist es für mich natürlich umso bedeutender, dass ich deren Inhalte also [...] die Werte der religiösen Erziehung oder die Werte des Islam an meine Kinder weitertragen möchte." (Feride, Z.: 64) 
Auch Adem, der, wie oben bereits ausgeführt, nach den verkündeten »Regeln« des Islams leben möchte, betrachtet die Gottesfurcht als ein Resultat seines Glaubens. Diese Gottesfurcht, gepaart »mit einem gesunden Menschenverstand «, verleite den Menschen dazu, sich achtsam, positiv und korrekt gegenüber seiner Umwelt zu verhalten. Es sind hier insbesondere die sozialethischen Aspekte des zwischenmenschlichen Miteinanders angesprochen:

"Der gefährlichste Mensch für mich ist derjenige, der nicht gottesfürchtig ist, wenn ein Mensch gottesfürchtig ist, mit einem gesunden Menschenverstand, dann würde er auch sofort reagieren, wenn er merkt, dass er für andere Menschen oder auch für Tiere auch etwas nicht Korrektes macht. Und das hält inn eben davon ab, sich immer positiv zu verhalten oder Acht zu geben, was er macht, was er tut, ob er andere Menschen verletzt." (Adem, Z.: 24)

$\mathrm{Zu}$ Beginn wurde schon auf verschiedene Glaubensvorstellungen bei den »Ethikern« hingewiesen. Dies wird besonders durch die folgenden beiden Elternteile deutlich gemacht.

Ähnlich wie Adem verknüpft Melek zunächst mit ihrem Glauben eine »Lebensordnung (vgl. Melek, Z.: 73), aus der sich die Einhaltung von Regeln und Pflichten ergibt. Der Glaube beinhaltet für sie zudem, neben der Gotteserkenntnis, die Befolgung des »Weges« vom Propheten Muhammad (s). Hier wird der Vorbildcharakter des Propheten unterstrichen. Ferner verbindet sie als einzige der Eltern dieses Typs spirituelle Aspekte wie » nere Ruhe/Frieden« mit ihrem Glauben:

"Iman? Ich denke, dass der iman eine Lebensordnung ist. [...] Ohne ihn geht es nicht. Es ist die Glückseligkeit schlechthin. [...] Die Gewissheit bzw. die Überzeugung [türk. mutmain, Anm. d. Verf.] im Herzen kann nur mit dem Glauben entstehen. Das weiß ich. Indem ich Gott erkenne, dem Weg des Propheten folge, kann sie entstehen. Dessen bin ich mir bewusst. Wir versuchen, unser Heim auf diese Weise aufzubauen. Wie haben sie es gemacht und haben ihre Ruhe [türk. huzur, Anm. d. Verf.] gefunden? Wenn wir diese Gewissheit/Überzeugung im Herzen suchen, dann bin ich überzeugt davon, dass dies so sein muss [und wir ihnen folgen, Anm. d Verf.] [...]." (Melek, Z.: 77, vgl. auch Z.: 87)

Die Konsequenzen, die sich aus diesen Überzeugungen ergeben, betreffen zum einen die Einhaltung von religiösen Vorschriften (vgl. Melek, Z.: 83), die durch sie anhand des Kopftuchtragens konkretisiert werden (vgl. ebd., Z.: 85). Zum anderen betreffen sie spirituelle Aspekte ihres Glaubens, wie oben schon teilweise ausgeführt. Es sei die »Ruhe«, die durch die Befolgung der Regeln 
in ihrem Heim einkehre: »[...] die Atmosphäre zu Hause ist ganz anders« (vgl. ebd., Z.: 87). ${ }^{39}$

Ihr Glaube gebe ihr außerdem die Stärke und die Fähigkeit, Schwierigkeiten und Probleme im Lebensalltag gut zu meistern (vgl. ebd.).

So sieht auch Birol in seinem Glauben eine emotionale Ressource, einen »Anker«, der ihm helfe, »schwierige Situationen« durchzustehen:

"[...] Also Glaube ist, was einem selbst, ja, was in einem selbst ist und was einem Rückhalt gibt, was einen stärkt, was einem vor allem in schwierigen Situationen hilft; und deswegen auch etwas ganz Wertvolles ist, weil immer dann, wenn der Mensch in größter Verzweiflung ist, denkt man doch immer wieder an Gott und an die Religion und deswegen ist das für mich also etwas ganz Besonderes." (Birol, Z.: 68)

Gerade diesen »Anker« möchte er auch seinen Kindern zur Verfügung stellen:

"[...] diesen Anker, den ich habe, möchte ich auch meinen Kindern eben zur Verfügung stellen, dass die dann auch irgendwann sagen können: Ilch habe etwas. Selbst in meiner größten Verzweiflung oder was auch immer, weiß ich, dass der liebe Gott noch da ist. So, und das möchte ich dann schon vermittelt haben." (Birol, Z.: 70)

Als konkrete religiöse Erfahrungen mit den Kindern benennen alle »Ethiker« die Bittgebete bzw. duas (arab. für Bittgebete). Ausnahmslos alle Eltern beziehen sich auf gemeinsame Erlebnisse mit ihren Kindern beim Anrufen Gottes/ Allahs. Des Weiteren werden Rituale, wie bspw. die gemeinsamen Gebete, zu denen sich bereits die Kinder im Kleinkindalter hinzugesellen, angegeben. Schließlich spielt für einige Eltern das Hören von Koranrezitationen eine wichtige Rolle. Damit sprechen Eltern, die sich ethischen Grundsätzen verpflichten, im Vergleich zu den Eltern anderer Typen, eher den persönlich-privaten Raum für religiöse Erlebnisse an. Es wird eine intensive persönliche Beziehung zu Gott/Allah gepflegt, die anders als bei den vorher aufgeführten religiösen Erziehungstypen nicht in Orten, wie z.B. den Moscheen (vgl. »Idealisten«, »Ritualisten«, »Identitätssucher«) bzw. an den heiligen Stätten des Islams (»Ritualisten«), zum Ausdruck kommt.

Um ein »positives Gottesbild« zu vermitteln, nahm Belkıs nach Verrichtung der täglichen Gebete die Kinder auf den Schoß, um mit ihnen Allahs zu gedenken:

39 Im Vergleich zu den anderen Eltern dieses Typs argumentiert Melek typischerweise eher wie die ritualistischen Eltern. Es wurde schon mehrfach darauf hingewiesen, dass sich Überschneidungen nicht vermeiden lassen und eindeutige Abgrenzungen an dieser Stelle nicht möglich sind. 
"Also mir ist es sehr wichtig, dass ich meinen Kindern immer ein sehr positives Gottesbild vermitteln möchte, als Erstes. Und das habe ich versucht, zu vermitteln, indem ich beim Beten zum Beispiel, dass ich sie auf den Schoß genommen habe und dass wir zusammen dann zikir [das Gedenken an Gott, z.B. mit einem Gebetskranz; Anm. d. Verf.] gemacht haben oder das [...]. Ja, sie haben das gerne gemacht und sobald sie das nicht mehr wollten. Ich habe innen halt immer wieder vorgeschlagen IIch bete jetzt, möchtest du mitmachen? Und dann haben sie ihre kleinen Gebetsteppiche rausgeholt, war total aufregend. Und irgendwann hat es dann keinen Spaß mehr gemacht." (Belkıs, Z.: 63ff.)

Auch Feride nahm die Kinder im Anschluss an die täglichen Gebete, zu denen sie sich schon im Kleinkindalter krabbelnd dazugesellten auf den Schoß, um mit ihnen dua zu machen bzw. Bittgebete auszusprechen:

"Also zum Beispiel beide meiner Kinder. Wenn ich zum Beispiel täglich gebetet habe, als sie dann auch so krabbeln ... oder mit anderthalb Jahren, als sie dann schon gut gehen konnten, war das halt dann für die selbstverständlich, dass sie dann auch so neben mich auch irgendwie sich hingestellt haben und irgendwie meine Bewegungen nachgeahmt haben oder sich einfach auf meinen Schoß gesetzt haben und da versucht haben, meine dua zu machen und das, da habe ich die halt auch mit aufgenommen in die dua, habe gesagt, dass sie das machen sollen, ja, so." (Feride, Z.: 83)

In Birols Familie flüstert die Mutter, wenn die Schlafenszeit kommt, ihrem kleinen Sohn im Babyalter die Gebete ins Ohr, auf die er lauschend reagiere (Birol, Z.: 72-76). Dagegen hinterfragte die Tochter von Adem, die sich schon in der Adoleszenzphase befindet, die Bedeutung und den Sinn hinter den Bittgebeten, die nicht erhört würden. Durch Erklärungen und Begründungen erreichte der Vater, dass sie ihren Glauben an Gott/Allah und an die Erfüllungder Bittgebete vertiefen konnte. So stellte dies für die Tochter eine »sehr positive Erfahrung« dar:

"Mir fällt dabei ein, wo meine Tochter zu mir gekommen ist und gesagt hat, warum die Gebete nicht von Allahu teala [arab. für Allah der Erhabene, Anm. d. Verf.] erhört werden. Daraufhin hatten wir eine Unterredung von ca. 45 Minuten, wo sie dann verstanden hat, dass jedes Gebet auf seine eigene Art und Weise erhört wird, weil Allahu teala alles weiß. Manchmal sind unsere Gebete falsch oder schaden uns [...]; und deswegen tut Allahu teala manchmal zu dem Zeitpunkt etwas anderes, was wir erhofft haben, und nach fünf Jahren oder nach sechs Jahren oder nach zehn Jahren, wenn man ein anderes Erlebnis hat oder eine andere positive Türe öffnet, dann versteht man erst, warum diese Tür vor fünf, sechs Jahren geschlossen war. Und meine Tochter hat sehr positive Erfahrungen dadurch gemacht, hat es auch verstanden und deren Glaube an Gott und an die Gebete hat sich mit dieser Erklärung auch dann vertieft." (Adem, Z.: 26) 
Melek macht auf eine interessante Erfahrung mit ihrem Sohn aufmerksam. Der unerwartete Unfalltod des Großvaters habe beim Sohn eine tiefe Sehnsucht nach seinem Opa bewirkt, woraufhin ihm die Mutter Bittgebete beigebracht und den Glauben an ein Leben nach dem Tod, an die Engel und das Paradies (arab. djanna, türk. cennet) nahegelegt habe. So habe sie ihn zum einen beruhigen können, da der Verlust ihn häufig zum Weinen gebracht und ihn in eine traurige Stimmung versetzt hätte. Zum anderen sei eine Verbindung zu Gott/Allah und dem verstorbenem Opa gesucht und hergestellt worden:

"[...] Dann habe ich inm einmal gesagt: ,Abdul-Metin, bete mal zu Allah, bete mal zu Allah, dass es deinem 0pa gut geht, dass du inn irgendwann mal sehen wirst und so ...; wir haben so einiges besprochen, dann bin ich ins Wohnzimmer gegangen, bin ich noch mal hin, um zu kontrollieren, in sein Zimmer gegangen. Ich habe gesehen, dass er, er hat so gegrinst so laut, ich habe dann gesagt: ,Du hast gerade eben geweint, was hast du jetzt?، Mama, ich habe gebetetı, (lacht), 'Was hast du denn gemacht?، Meleklere söyledim ki anne، [türk. für »ich habe den Engeln gesagt"; Anm. d. Verf.] [...] Er hat gesagt: 'Mama, ich habe meinem Opa eine SMS geschickt. Ich habe gesagt: ,Wie hast du das denn gemacht? Du hast kein Handy hier, du hast keinen Computer hier. Wie hast du das denn gemacht? Obwohl, er kann das auch nicht. 'Mama, ich habe die Engel dafür gebraucht، (M und I lachen). ,Was hast du denen gesagt?، Ich habe denen gesagt: ,Engel, ich hoffe, dass es meinem Opa sehr sehr gut geht. Ich habe inn sehr sehr vermisst, aber ich weiß auch, irgendwann werde ich inn einmal wiedersehen. ' Mama, ich bin mir sicher, die haben das sofort Allah weiter übermittelt und Opa weiß auch jetzt Bescheid, Mama.` (I und M lachen). Dann hat der mich dann einmal gefragt, an einem anderen Tag: 'Mama, hast du nicht das Handynummer von meinem Opa. Sag ich: Ja, das habe ich Abdulmetin, aber wozu brauchst du denn die Handynummer von deinem Opa? Du weißt doch, Opa ist nicht mehr auf der Welt! , Mama, wenn du die Handynummer von meinem 0pa hast, dann kannst du inn ja immer noch anrufen im cennet. Ich sag: 'Nee, Abdulmetin, wenn man im cennet ist, wenn man nicht mehr auf der Welt lebt, dann hat man, darf man nichts von der Welt mitnehmen, auch nicht sein Handy. Das Handy ist bei uns Abdul-Metin. ' Mama, ruf inn doch einfach an, wenn du die Nummer hast!، (lacht). Also er, er kann diese Grenze noch nicht unterscheiden. Also cennet ist eine ganz andere Welt wie jetzt die Welt selber, aber ich fand das schön. [...]. Er weiß, wir werden irgendwann mal Opa wiedersehen, wenn wir gute Menschen sind. Wenn Opa ein guter Mensch war und wenn wir gute Menschen sind, dann sehen wir uns im cennet wieder. Das weiß er, das beruhigt inn sehr, sehr." (Melek, Z.: 95ff.)

Das Hören von Koranrezitation haben einige Mütter ${ }^{40}$ schon gepflegt, während die Kinder noch im Bauch heranwuchsen oder im Babyalter waren. Dies solle eine Auswirkung auf die Seele des Menschen haben, die charakterliche Ent-

40 | So z.B. auch Hülya bei den "Identitätssuchern «. 
wicklung beeinflussen und positive Eigenschaften beim Kind zur Folge haben (vgl. Feride, Z.: 71-79). Es bereitet Melek eine große Freude, dass der Sohn ihr gerne beim Koranlesen zuhört, da dies und einige weitere Rituale wichtige Bestandteile ihres Lebens darstellen. Hier wird auch der identitätsstiftende Charakter dieser Rituale angedeutet:

"Aber es hat mich sehr gefreut, dass ihm das gefallen hat, denn man hört, dass viele nicht das mögen, wenn Koran gelesen wird. Also es hat mich wirklich sehr sehr gefreut. Also ich brauche inm nicht zu sagen: ,Du bist Moslem. Du musst das machen. Wenn ich sehe, dass er das akzeptiert: Koran gehört zu unserem Leben. Ramadan gehört zu unserem Leben. Das Gebet gehört zu unserem Leben dazu. Allein, dass er das alles akzeptiert, das ist für mich eine Bestätigung." (Melek, Z.: 134)

Bei den Ritualen heben »Ethiker« im Vergleich zu anderen Typen, wenngleich nicht sehr ausgeprägt, die zwischenmenschlichen Beziehungen bzw. ethischen Aspekte hervor (bei den Gebeten, im Ramadan, im Zusammenhang mit der Wissensaneignung). Der Gemeinschaftsbezug (zu einer religiösen Gemeinde) spielt, wie oben schon angedeutet, für die Eltern dieses Typs kaum eine Rolle. Es werden diverse Rituale benannt, die im Alltagsleben der Eltern und ihrer Kinder einen bedeutenden Stellenwert besitzen. Die Mehrheit der Eltern betont die wiederkehrenden Gespräche über religiöse Themen, die eine intellektuelle Auseinandersetzung bzw. die Wissensaneignung über die Religion nahelegen.

Die Befolgung der täglichen Gebete nimmt für einige Eltern einen wichtigen Platz ein. Auch wenn diese, da die Kinder zu klein sind oder aus anderen Gründen, nicht regelmäßig eingehalten werden.

Insbesondere Belkıs Vorgehensweise zeichnet sich als pädagogisch aus. Gemäß dem Rat des Propheten (s), die Kinder ab sieben Jahren an das Gebet heranzuführen, führt sie ein Belohnungssystem ein, um die Kinder dahingehend fortschreitend zu motivieren. Zudem unterstreicht sie insbesondere die freiwillige Teilnahme an den Gebeten (vgl. in »Methoden [...]«, vgl. Belkıs; Z.: 78).

Mit Stolz verkündet Melek, dass die ältere Tochter das fünfmalige Gebet einhalte. Der Sohn bete, unterstützt durch den Vater, gelegentlich mit:

"[...]. Er betet. Er versucht zu beten, sag ich mal. So; natürlich verlangen wir nicht, dass er betet. Aber von unserer Tochter verlangen wir das. Aber es ist kein Problem jetzt für sie. Sie weiß: Das gehört zu meiner Religion. Das akzeptiert sie auch! Das verläuft auch eigentlich ohne Probleme." (Melek, Z.: 111) 
Adem unterstreicht die Folgen der täglichen Gebete, die sie auf die zwischenmenschlichen Beziehungen hätten. Demnach behandele man seine Mitmenschen mit mehr Respekt, wenn man die täglichen Gebete einhalte:

"Die rituellen Pflichten sind das fünfmal Beten am Tag [...]. Ich selber habe auch erlebt, wo ich vom Gebet abgekommen bin, dass man mehr auf die weltliche Seite rüberschwankt und weniger Respekt für den Mitmenschen hat, und deswegen ist es für mich das $A$ und 0 , dass man die fünf Gebete einhält [...]." (Adem, Z.: 32)

Was die gemeinsamen Gebete mit seinen Kindern angeht, so ist Adem, wie allen Eltern dieses Typs die freiwillige Teilnahme wichtig. Als sie klein gewesen seien, hätten sich die Kinder gewehrt und weniger Lust gehabt, mit dem Vater zu beten. Erst durch die überzeugenden Argumente des Vaters seien die Kinder mittlerweile so weit, dass sie manchmal den Vater an die Gebetszeiten erinnern müssten:

"Also zuerst war es so, dass sie sich da dagegen gewehrt haben, keine Lust gezeigt haben, wo sie noch Kinder waren, aber später habe ich innen erklärt, warum, wieso, weshalb, aber ich habe sie niemals gezwungen, dass sie das machen sollen. Ich habe sie jedes Mal höflich eingeladen, weil im Islam ist es so, dass man nichts zwingen darf, man muss überzeugen und mit der Zeit ist es dann so gekommen, dass wir jetzt zurzeit, manchmal ich selber aufgefordert werde von meinen Kindern: ,Papa, es ist Zeit zu beten, weil die Zeit geht weg oder Die Zeit geht vorüber!‘ [...], das freut mich natürlich." (Adem, Z.: 32)

Ansonsten sind es Bittgebete bzw. Dankgebete, das Aussprechen der basmala, »dass man immer Bismillah sagt, wenn man bestimmte Sachen anfängt«, oder die Gebetswaschung, die als Rituale zur Geltung kommen (vgl. Belkıs, Z.: 72). Feride betont insbesondere die Schutzsuren, die sie morgens und abends mit ihren Kindern aufsagt:

"[...] wir lesen morgens und abends Ayat al-Kursi [Thronvers, Sure 2: 284; Anm. d. Verf.], bevor wir in die Schule gehen, abends vor dem Schlafengehen beispielsweise, meine Tochter kann das zwar nicht, aber mein Sohn zum Beispiel vor dem Schlafengehen sagen wir: 'Okay. Lass uns ein dua machen`, dann fängt er an und dann murmelt [...] meine Tochter auch etwas dazwischen und ich und so weiter, wo dann noch mal aufgeführt wird, wofür habe ich heute zu danken, für das und für jenes und danke Gott für ... und das und das wünsche ich mir aber noch, bitte und dass [...]. Bittgebete, Dankgebete, Ayat al-Kursi auf jeden Fall. [...]. Als Schutzsure, abends und auch morgens, damit wir auch rechtgeleitet werden und auch vor dem Bösen geschützt werden." (Feride, Z.: 85-89) 
Wie schon bei den religiösen Erfahrungen erläutert wurde, wird das Koranlesen als Ritual in den meisten Familien gepflegt. Die kleineren Kinder üben hierbei zunächst das arabische Alphabet (vgl. Belk1s, Z.: 94; Feride, Z.: 79 und 89; Melek, Z.: 12off., Adem, Z.: 42).

Schließlich nehmen noch die abendlichen Gespräche, auch über religiöse Inhalte einen wichtigen Stellenwert in einigen Familien ein. Hier wird insbesondere auf das gemeinsame Lesen von Büchern viel Wert gelegt:

"[...] Und das man zusammen auch liest und auch religiöse Inhalte bespricht, also vor allem beim Schlafengehen haben wir halt uns auch ...; mittlerweile gibt es ja gute Literatur, Gott sei Dank! Was ja vor zehn, 15 Jahren noch nicht da war; dass wir vieles besprechen und so weiter." (Belkıs, Z.: 72).

Bücher, die ein bestimmtes Wertesystem vermitteln und die zumeist noch auf den Islam zurückgeführt werden, liest Feride ihren Kindern vor dem Schlafengehen vor. Manchmal stelle sie, wenn der Bezug zur Religion in den Büchern nicht gegeben sei, diesen auch selbst her (vgl. Feride, Z.: 89ff.). Auch in Adems Familie werden Bücher gelesen, dabei ist es gleich, »ob es religiöse Bücher sind oder ob es Sachbücher sind « (vgl. Adem, Z.: 28). Hier deutet Adem auf die Auseinandersetzung mit Wissen überhaupt hin. Doch darauf wird nochmals im Zusammenhang mit der Wissensaneignung ausführlicher Bezug genommen.

Der Ramadan wird in den Familien der »Ethiker « entweder eher zurückgezogen innerhalb der eigenen Familie (Belk1s, Melek) oder aber insbesondere im eigenen sozialen Umfeld verbracht (Feride, Adem, Birol). Bei den letzteren Elternteilen wird das zwischenmenschliche soziale Miteinander, das kennzeichnend für diesen Typ ist, ausdrücklich betont. Hier fällt auch auf, dass im Vergleich zu anderen Typen der Bezug zu religiösen Gemeinschaften nur in deutlich abgeschwächter Form vorhanden ist.

Melek versucht, den Ramadan mit ihrer Familie »sehr harmonisch « zu verbringen. Es werden Gebete gemacht und die Dankbarkeit für die Gaben Gottes/Allahs ausgesprochen. Da der ezan (türk./arab. adhan für Gebetsruf) nicht vorhanden ist, wird durch den Gebrauch einer Ezan-Uhr ${ }^{41}$ eine ähnliche Stimmung erzeugt (vgl. Melek, Z.: 113). Damit spielt für Melek die religiöse Symbolkraft des ezan eine zentrale Rolle. Der Ruf zum abendlichen Gebet markiert die Zeit, in der das Fastenbrechen stattfindet. Innerhalb der muslimischen Welt gilt der ezan als eine Selbstverständlichkeit.

Auch Belkıs setzt ein kreativ-gestalterisches Element ein, um die Kinder »einfach spüren« zu lassen, dass der Ramadan etwas »Besonderes« ist. Das

41 | Diese Uhren sind spezielle Wecker, mit denen die täglichen Gebetsrufzeiten eingestellt und der ezan zu den gegebenen Zeiten automatisch wiedergegeben wird. 
Basteln von Moscheen, »wo die Menschen zusammen beten«, solle den Kindern die Möglichkeit geben, einen Bezug zum Ramadan herzustellen (vgl. Belkıs, Z.: 80). Auch hier fungiert die Moscheevorlage zum Basteln als ein religiöses Symbol. Das gemeinsame Gebet, wenn auch auf Bildern, deute auf den gemeinschaftlichen Aspekt des Ramadans bzw. des Islams.

Für Feride und Adem stehen das Einladen von Gästen oder der Besuch von Freunden, Familien und Bekannten während des Ramadans besonders im Vordergrund. (vgl. Feride, Z.: 93-99; Adem, Z.: 35). Damit solle zum einen das Wohlwollen Allahs erlangt werden:

"[...] im Islam ist es halt so, dass der beste Gast der ist, für den man nicht zu großen Aufwand machen muss und insbesondere im Ramadan ist das halt so, finde ich, dass man ..., also ich berufe mich irgendwie immer, mein Mann genauso, auf den auf die Aussage, dass derjenige, der jemanden, der einem Fastenden ein Essen ausgibt oder etwas zu essen gibt, der bekommt genauso viel Wohlwollen Gottes wie derjenige, der gefastet hat. Und ich denke mir, wenn ich die Möglichkeit habe, dann lade ich Menschen ein, so viel ich kann und so gut es nur möglich ist und wenn ich die Möglichkeit dann nicht habe, dann sorge ich doch dafür, dass irgendein anderer Mensch vielleicht von dem Gleichen abbekommt, in gleicher Menge, als sevab [türk. für Wohlwollen Allahs gewinnen, Anm. d. Verf.] zum Beispiel, wie ich jetzt für das Fasten bekommen habe und da ist es mir halt wichtig, die Menschen, die ich am meisten mag, soweit wie möglich, dann zu beschenken [...] Das wäre dann nicht, nicht ich, der das Wohlwollen Gottes schenkt, aber zumindest dafür sorgen oder als Mitwirkung irgendwie da noch mit aufzutauchen, denke ich." (Feride, Z.: 99-101).

Zum anderen solle der »Kontakt« zu den Menschen z.B. durch »das Helfen« in der Gemeinde ${ }^{42}$ gepflegt werden. Hier kommt auch der soziale Charakter der verrichteten Rituale sehr deutlich zum Ausdruck:

"[...] Natürlich ist es so, dass man, dass ich in der Gemeinde dann auch für das Ramadanessen, Fastenbrechenessen auch helfe und somit dann auch mit Menschen in Kontakt komme ... und sehr viele Erfahrungen [im Umgang mit innen gemacht habe, Anm. d. Verf.] [...] Natürlich ist es so, dass wir in den Ramadanmonaten Freunde eingeladen werden, zum Fastenbrechen. Auch wir werden eingeladen. Es ist immer so ein Nehmen und Geben. Es ist sehr positiv." (Adem, Z.: 35)

Gerade für die Kinder bringt der Fastenmonat viel Freude. Zudem geht Adem »gelassen« mit ausgelassenen Fastenzeiten um:

42 | Adem ist hier der Einzige, der den Gemeindebezug erwähnt. 
"Na ja, mit meinen Kindern ist es so, dass sie die ganze Sache etwas leichter sehen, aber trotzdem ein Erlebnis für meine Kinder, deshalb kann ich sagen, dass sie sich auch auf den Ramadanmonat freuen und liebend gerne auch, sehr gerne fasten, wenn sie die Möglichkeit bekommen, und falls sie eine Arbeit schreiben oder so tun sie pausieren in der Zeit, was auch im Islam erlaubt ist, und deswegen sehen wir es gelassen." (Adem, Z.: 37 )

Aufgrund der langen Fastenzeiten in den Sommermonaten vermisst Birol das Zusammenkommen mit anderen Muslimen:

"... was jetzt natürlich, was ich dann so vermisse, ist vielleicht so ... das bisschen mehr Zusammenkommen, das Zusammensein ne beim Fastenbrechen zum Beispiel. Aber Sie kennen die Jahreszeit! [Ja. Sommer!, Anm. d. Vef.]. Es ist spät, wenn man essen kann, und am nächsten Tag hat man dann schon wieder was zu tun oder muss arbeiten gehen und das vermisse ich in diesem, also gerade wenn Ramadan also auf die Sommermonate fällt, aber ansonsten ändert sich mein Tagesablauf eigentlich nicht wesentlich." (Birol, Z.: 99ff.)

Ansonsten unterscheidet sich Birols Verhalten, im Vergleich zu den anderen Eltern dieses Typs, noch dadurch, dass er neben seiner sozialethischen Verantwortung gegenüber anderen Menschen auch dem Spenden einen besonderen Wert beimisst. Interessanterweise hebt er seine ethische Grundhaltung im Zusammenhang mit Ritualen hervor:

"[...] also es geht mir bei der Religion, also wie gesagt, ich bin jetzt nicht der, der nach außen religiös auftritt, weder in meinem Erscheinen noch in meinen Handlungen. Aber ich achte zum Beispiel sehr darauf, dass ich niemandem Unrecht tue, dass ich niemanden kränke, ja, man sagt ja: ein guter Mensch zu sein einfach. Und das versuche ich dann schon, zu machen, das, das ist für mich. Ja, das ist meine Religion, jetzt so ... [Wie Sie sie verstehen?, Anm. d. Verf.]. Genau! Dass ich helfe, wo ich kann, dass ich etwas Gutes tue." (Birol, Z.: 83ff.)

Birol nimmt seine Vorbildfunktion gegenüber seiner Tochter bspw. dann wahr, wenn er einem Bettler auf der Straße eine Spende zukommen lässt. Die gute Tat, die er darin sieht, erfordere eine Begründung, was ihn auf das Religiöse zurückkommen lässt:

"[...]. Ja, wenn man jetzt einfach mal; ja, zusammen spazierengeht ja und dann, sieht oder wird angesprochen. Ja, es gibt ja immer mehr Bettler auf der Straße z.B., denen man vielleicht einen Euro zusteckt. Und dann kommt die Frage: Wieso machst du das? $\mathrm{Ne}$, wieso hast du das jetzt gemacht, der kann doch arbeiten gehen. $\mathrm{Ne}$, halt wie Kinder eben manchmal so denken. Klar, können die, aber es ist halt nicht immer einfach, ich 
versuch das eben zu erklären, die Situation, wieso die betteln müssen, dass die vielleicht nicht arbeiten dürfen und weil das eben auch eine gute Tat ist! Und dann komme ich eben auf das Religiöse vielleicht zurück." (Birol, Z.: 66)

Religiöse Feste werden in allen Familien der »Ethiker« mit Verwandten, nahen Bekannten und Freunden gefeiert. Es werden zum Teil Vorbereitungen getroffen, durch die eine Festtagsstimmung aufkommen soll. Daneben seien das Verrichten des Festtagsgebets (vgl. Adem, Z.: 39) und Geschenke in verschiedenen Formen feste Bestandteile der Feiertage.

Gerade Melek legt sehr viel Wert auf Geschenke. Wie schon einige Mütter ${ }^{43}$ vor ihr, möchte sie ihren Kindern vor dem Hintergrund der weihnachtlichen Stimmung durch Geschenke eine Freude bereiten. Hierbei achte sie auch an einzelnen muslimischen Feiertagen (kandil) darauf, diese Tradition umzusetzen:

"Wir versuchen es, sehr schön zu feiern, also damit die Kinder - Weihnachten wird ja sehr groß gefeiert, Ostern, Ostergeschenke - auch an kandil [türk. für besondere religiöse Feiertage, Anm. d. Verf.] versuche ich meinen Kindern, Geschenke zu kaufen, sodass sie sich auch freuen. Unsere Tochter, weil die zwölf ist, so Geschenke sind weniger was für sie, sie bekommt mehr Geld (lacht), darüber freut sie sich mehr, aber unser Sohn der bekommt nicht genug von Geschenken, sodass sie, dass die auch wissen, der Tag ist was Besonderes, wir haben dafür was bekommen. Auch an kandil oder an den Festen. Und wenn die Zeit es erlaubt, treffen wir uns mit unseren Eltern, mit meinen Geschwistern und mit der Verwandtschaft und wenn es am Wochenende sein sollte, dann schmücken wir den Raum, sodass die Kinder wissen: Heute ist bayram. Geschenke werden eingepackt, jeder darf sich sein Geschenk aussuchen, sodass es auch etwas spannender wird. Das gefällt innen." (Melek, Z.: 115)

In dieser Interviewpassage wird deutlich, dass, zunächst in Anlehnung an Weihnachten und Ostern, die Geschenke in ihrer Familie an Bedeutung gewonnen haben. Dessen ungeachtet grenzt sich Melek auch eindeutig von der christlichen Tradition ab. So sollen die Kinder erfahren, dass das Schenken nicht ein ausschließlicher Bestandteil des Christentums ist, sondern vielmehr jeder Religion. Demnach sei es in jeder Religion wichtig, »Kinder glücklich zu machen«. Hier scheint die gegenseitige Beeinflussung der Religionen der Fall zu sein, womit die eigene Position gestärkt hervortritt:

"Also die sollen nicht denken, das Christentum ist so, die Kinder haben ständig Geschenke, aber das hat nichts mit dem Christentum mit der ... hıristiyanlıkla alakası olmayan bir durum olduğunu anlasınlar [türk. für "sie sollen verstehen, dass das nicht

43 | Nermin bei den "Idealisten" und Hülya bei den "Identitätssuchern". 
(ausschließlich) mit dem Christentum zu tun hat", Anm. d. Verf.] Das gleiche gilt auch für ... Also Kinder glücklich zu machen, ist glaube ich in jeder Religion wichtig." (Melek, Z.: 117)

Es fällt auf, dass unter »Ethikern« stärker Kritik geäußert wird. Demnach wird der fehlende Sinnbezug oder die fehlende Festtagsstimmung aufgrund des Lebens in Deutschland bemängelt.

Belk1s, die ihre Familie als »türkisch-traditionell« wahrnimmt, fehlt der »islamische Aspekt«, der hier verloren gehe:

"Leider ist es bei uns noch so, dass wir halt sehr türkisch traditionell sind, weil wir meinerseits und von der Seite meines Mannes auch eine sehr große Familie haben und dann sind wir, also was natürlich auch schön ist, aber der islamische Aspekt geht ja so ein bisschen verloren, finde ich persönlich." (Belkıs, Z.: 86)

Kritisiert wird des Weiteren der fehlende Sinnbezug der Festtage. Auch die Teilnahme an religiösen Festen bestimmter Organisationen habe kein Bewusstsein für die Bedeutung und den Sinn der Festtage erwecken können:

"Ja, das ist halt so ein geselliges Zusammensein. Man isst, trinkt zusammen und die ganzen rituellen Gebete werden schon gemacht, aber es geht schon ein bisschen unter, der Geist, also zum Beispiel beim Ramadanfest ist es ja oder beim Opferfest, warum man das Tier opfert und so weiter. Geht ja alles so ein bisschen verloren, was ich eigentlich sehr schade finde. Und wir haben ein Mal auch oder einige Male auch bei den Festen bis jetzt haben wir auch an religiösen Festen teilgenommen [...]. Die haben so Feste gehabt und so. Aber jetzt die letzten ein, zwei Feste leider nicht mehr, das heißt nicht sehr bewusst [...]." (Belkıs, Z.: 88)

Auch ihren Kindern hat sie die Bedeutung der Feiertage nahegelegt. Da die Kinder altersbedingt (sieben und zwei Jahre) den Sinn noch nicht verstehen könnten, habe Belkıs am Opferfest Schafe gebastelt, worauf sie auch Überlieferungen des Propheten (s) geschrieben habe. Diese habe sie in ihrer Umgebung verteilt. Als »innovatives« Zeichen sei diese Aktion mit Erstaunen und Glück entgegengenommen worden:

"[...] Also ich habe meinen Kindern natürlich schon erklärt, worum es geht und wir haben mit denen auch zum Beispiel: Zum Opferfest haben wir kleine Schafe gebastelt und dann haben wir auf alle Schafe so kleine hadithe drauf geschrieben und das dann so in der Umgebung verteilt und die Leute waren natürlich auch total erstaunt, weil sie das gar nicht kennen und natürlich auch glücklich und so weiter. Und für die Kinder war es auch was Schönes, aber ich glaube, das ist jetzt noch nicht so wirklich der Geist (lacht) 
des Opferfestes, was man den Kindern so nahebringt. Aber das ist auch eine Alterssache, natürlich auch." (Ebd.).

Schließlich werde der fehlende Sinnbezug, den die Mutter wahrnimmt, auch durch die Kinder gespürt. Es solle somit mehr Bedeutungszuwachs stattfinden. Wie das genau geschehen und umgesetzt werden soll, erläutert Belkıs jedoch nicht:

"Ja, genau, das könnte mehr. Also wenn es mir fehlt, fehlt es den Kindern natürlich auch. Die spüren das dann dementsprechend auch nicht!“ (Belkıs, Z.: 92)

Feride und Birol weisen auf die fehlende Festtagsstimmung hin, da in Deutschland im Vergleich zur Türkei, in der religiöse Festtage einen »Ausnahmezustand « wie »ungefähr in der vorweihnachtlichen Zeit« darstellen und diese mit »Vorfreude « erwartet werden, an muslimisch-religiösen Feiertagen gearbeitet werde. In Deutschland müsse man somit für den Sohn in der Schule einen Tag freinehmen:

"Genau, hier ist es zum Beispiel so, wir wissen, dass wir kurban [türk. für Opferfest, Anm.d.Verf.] und Ramadan gefeiert haben, nachdem wir halt in Deutschland waren, für kurban musste ich extra für meinen Sohn freinehmen, weil er in der Schule war, natürlich im Kindergarten haben wir gesagt, dass er nicht kommen würde, das war auch soweit okay. Und einige seiner Freunde sind dennoch zur Schule gegangen, die auch muslimisch waren oder nicht, das ist okay. Jedermanns Sache, ne, aber hier war das unter anderem auch so, dass auch diese Atmosphäre nicht soo hergestellt werden konnte, weil die Übrigen, mit denen man ja zusammen feiern würde, entweder arbeiten sind oder halt anderweitig beschäftigt sind, also der Alltag überholt einen hier doch, das Festgefühl ist hier nicht so prägnant ausgeprägt wie in der Türkei. In der Türkei ist es ein Fest und man feiert es wirklich und hier ist es auch ein Fest; man [begeht, Anm. d. Verf.] [...] gewisse Rituale und vielleicht auch religiöse Forderungen, die einem für den Festtag vielleicht angebracht sind, aber dieses Feiergefühl ist nicht so ausgeprägt, würde ich sagen." (Feride, Z.: 121)

Etwas ratlos, wie man das in Deutschland letztlich anders gestalten könnte, »weil das Ambiente einfach nicht da ist«, blickt Birol auf die Situation:

"[...] man sieht sich, aber weiß ich nicht, sonst hat das eigentlich nicht so großen; ich wüsste eigentlich auch nicht, wie man das hier in Deutschland viel anders gestalten könnte, weil, das Ambiente ist einfach nicht da; weil in der Türkei ist das zum Beispiel, da ist schon alles darauf eingestellt, die gesamte Umgebung, wie jetzt in Deutschland Weihnachtszeit, ja also da ist, da ist das Ambiente da und das ist hier nicht gegeben und deswegen kommt man da wahrscheinlich auch nicht so emotional rein und deswegen 
vergehen diese Tage eigentlich auch wie, wenn es jetzt nicht in die Woche fällt, wo man dann sowieso arbeitet eigentlich wie ganz andere, ganz normale Tage auch." (Birol, Z.: 113)

Wie schon in Kap. III. 3.4 bei der Beschreibung dieses Typs die Differenzierung zwischen »allgemeiner« und »religiöser« Erziehung auffiel, drückt sich diese Differenzierung selbstverständlich auch hinsichtlich der Wissensaneignung aus. Neben der Aneignung von religiöser Bildung wird die Aneignung allgemeiner Bildung als ebenso wichtig eingestuft. Jedoch unterscheiden sich hier die Eltern, in dem von ihnen gewählten perspektivischen Zugang zur Bildung. Da es ein kennzeichnendes Merkmal der »Ethiker« ist, wird der Zusammenhang zwischen allgemeinem und religiösem Wissen hier näher ausgeführt.

Birol formuliert in abstrakter Art und Weise, in welcher Form seine Kinder mit Wissen umgehen sollen. Dabei ist es ihm wichtig, dass seine Kinder in die Lage versetzt werden, »kritisch « zu hinterfragen und sich die Fähigkeit aneignen, eine Synthese zwischen allgemeiner und religiöser Bildung herzustellen:

"Also meine, was ich mir so daraus heraus ableite, ist Folgendes: Dass ich [...] meinen Kindern definitiv nicht sagen werde, 'So jetzt ist Ramadan, wir fasten`, sondern, dass ich denen vor allem erkläre, wieso wir fasten, ne, was dieser Monat an sich hat, die Hintergründe einfach erklären. Was ich mir daraus ableite, welche Folgen das Fasten hat für mich, was ich davon habe, was ich davon nicht habe. So, dass ich mein Kind auf jeden Fall in eine Lage versetze, wo es selbst später kritisch reflektieren kann. Ja? Also dass er hinterfragen kann, dass er sein Wissen, was er erlangt hat, [...], ja? Dass er das religiöse, aber auch das das weltliche Wissen, ja, kombinieren kann, miteinander verknüpfen kann, ja, auch das, das ... [Eine Synthese?, Anm. d. Verf.] Ja. Genau. [...] Das." (Birol, Z.: 518-522)

Die Erklärungen für die Erfüllung einer religiösen Pflicht sollen das Kind vor einer einfachen Nachahmung bewahren. Die Kombination von religiösem, aber auch weltlichem Wissen, d.h., das Herstellen einer Verbindung bzw. einer Synthese der beiden, solle dazu führen, dass sein Kind sein »Wissen« aktiv anwende. Hier wird auch die individuelle Wahrheitsfindung unterstrichen, was bedeutet, dass jeder für sich »wissen«, »lernen«, »forschen« soll. Letztendlich gebe es auch keine »Instanz«, die vorgebe, was »erlaubt« oder »verboten« sei:

"... dass er sein Wissen auch aktiv anwendet und nicht einfach nur ja, nachäfft, ja? Also dass man, dass man aktiv ist und ich denke, dass unsere Religion das eigentlich auch so vorschreibt, ja? Wissen. Lernen. Wissenschaft, dass man forscht. Auch das ist ein Forschungsprozess, finde ich. Jeder für sich selbst vielleicht, ja, aber das ist auch das Schöne. Dadurch, dass es eben keine oberste Instanz gibt, die sagt, das ist jetzt verbo- 
ten, das ist erlaubt. Und dann Religion gibt jedem Einzelnen selbst diese Möglichkeit, zu fragen, dass man ja ..." (Birol, Z.: 524)

Als Resultat des oben beschriebenen Forschungsprozesses soll das Kind dazu imstande sein, seine eigenen Gedanken zu bilden, um den Sinn und die Bedeutung seiner Verhaltensweisen nachzuvollziehen bzw. nachzuempfinden. Wichtig sei es demnach, auch eine Einheit zwischen Verstand und Gefühl herzustellen, um »mit sich selbst« eins zu sein und »so seine innere Ruhe« zu haben:

"[...] Und dass er auf jeden Fall immer, ja ich sage mal, sich seine Gedanken machen kann. Ja. Also man tut nichts umsonst. Ja. Also es hat alles schon so seinen Sinn, es hat alles seine Gründe und wenn man etwas tut oder unterlässt, dann hat auch das irgendeinen Grund; und dass man dann einfach mal irgendwann mal sich dessen bewusst wird, klar wird, wieso mache ich das ein oder andere oder andere nicht, ne, und welche Konsequenzen hat das und wie fühle ich mich eigentlich auch dabei? Ich denke [...]. Ja. Natürlich! Ne, dass man sich, dass man sich mit sich selbst und auch, ich sage mal, eins ist, dass man sich, dass man so eine innere Ruhe hat, gegen einen, mit sich selbst." (Birol, Z.: 546-550)

Auch für Melek ist die Allgemeinbildung neben der religiösen Bildung von Bedeutung. Ähnlich wie Birol erläutert sie ihren Kindern, warum ein religiöses Gebot eingehalten werden sollte, und bedient sich dazu Kenntnissen aus anderen (Fach-)Bereichen, wie z.B. der Medizin und der Geschichte (vgl. Melek, Z.: 149-153 und 163). Das Herstellen einer Verbindung zwischen weltlichem und religiösem Wissen soll allerdings im Vergleich zu Birol dazu dienen, »den Islam zu verteidigen« (vgl. ebd., Z.: 159). Hier nimmt Melek eine defensive Haltung ein und stellt nicht, wie Birol, die Rolle des aktiven Gestalters der eigenen subjektiven Wahrheit in den Vordergrund.

Auch Adem legt viel Wert auf die selbstständige Wahrheitsfindung, zu der er seine Kinder anregt. Indem er ihnen den »Weg« zeige und sie über die Konsequenzen des eingeschlagenen Weges unterrichte, wären und seien diese imstande, »ihren eigenen Weg« zu gehen (vgl. Adem, Z.: 82-86). Dies habe sich darin geäußert, dass sie aus religiöser Sicht »für ihr Alter gebildet« seien und sich ständig weiterbilden würden. Gerade die Fragen, die sie über ihre Religion stellten, würden bekräftigen, dass sie nicht nur gleichgültig gegenüber ihrer Religion, sondern auch dazu bereit seien, Mühen auf sich zu nehmen und sich »einen Platz auf dieser Welt« zu suchen. Auch hier wird die Kombination zwischen religiöser und allgemeiner Bildung (»modern denken«) gesucht und hergestellt: 
"Die Kinder? Also religiös hat sich das geäußert, dass, ich denke mal, sie immer noch für ihr Alter sehr gebildet sind. Sie bilden sich immer noch weiter. In den Medien irgendwie schon. Sie fragen sehr viel und das macht mich natürlich glücklich; das ist für mich ein Beweis, dass innen die Religion nicht gleichgültig ist. Andererseits ist es auch so, dass sie sich wirklich sehr große Mühe geben, sich auch einen ganz bestimmten Platz auf dieser Welt zu [erarbeiten, Anm. d. Verf.] [...] indem der Sohn vorhatte, Maschinenbau zu studieren, und meine Tochter gerne Biologin werden möchte. Und das gibt mir natürlich auch die Zuversicht, dass sie nicht nur streng religiös, sondern auch sehr modern denken können." (Adem, Z.: 88)

Das religiöse Wissen, das sich die Kinder von den »Ethikern« aneignen sollen, lässt sich verschiedenen Bereichen zuordnen. Das Erlernen von Grundlagen der Religion wird durch die Mehrheit der Eltern befürwortet. Hierbei geht es um das »Basiswissen des Islams«, was das »Leben der Propheten und der anderen Propheten« (vgl. Belk1s, Z.: 99); die Vermittlung eines positiven Gottesbildes (vgl. ebd., Z.: 63), die fünf Säulen des Islams (vgl. Melek, Z.: 141), die rituellen Pflichten, d.h. die ibadah (arab. Gottesdienst/Rituale) (vgl. Melek, Z.: 137f.; Feride, Z.: 138) und die Koranrezitation/das Auswendiglernen von Suren (vgl. Feride, Z: 138) einschließt.

Die Auseinandersetzung mit dem Koran pflegt Adem mit seinen Kindern, wohl auch deshalb, weil die Kinder altersmäßig dazu in der Lage seien. Dabei gehe es um die aktive Beschäftigung mit den Übersetzungen des Korans auf Türkisch und Deutsch, was auch die Beantwortung verschiedener Fragen beinhalte (vgl. Adem, Z.: 42).

Das Erlernen von Gottesfurcht ist für ihn notwendig, um eine ethisch-moralische Grundhaltung, wie Respekt gegenüber Gott, sich selbst, seinen Mitmenschen und seiner Umgebung, zum Ausdruck zu bringen. Hierzu zählt auch der positive Umgang mit Herausforderungen und Zielen im Leben:

"[...] Es ist wichtig, dass man als Erstes ein gottesfürchtiger Mensch ist, somit [...] Respekt für Gott [sondern auch der Umgebung gegenüber, Anm. d. Verf.], sei es die Pflanzenwelt, Tierwelt oder seien es Menschen, Nachbarn hat, [gläubig ist, Anm. d. Verf.] und [...] dass man, auch wenn man ein Ziel im Berufsfeld oder so nicht schafft, immer das Positive daran sieht. Also, dass man das ganze Leben mit einem positiven Blick betrachtet und nicht nur die eine Seite der Medaille ansieht." (Adem, Z.: 44)

Das Internalisieren von Werthaltungen bzw. die Wertebildung nimmt für Feride einen zentralen Stellenwert ein. Um ihre Kinder »zu guten Menschen zu erziehen«, ist es für sie zwar entscheidend, dass sie die »notwendigen Grundlagen des Islams« (vgl. oben) kennenlernen. Darüber hinaus möchte sie aber, insbesondere mit »abendlichen Vorlesungen« unter Zuhilfenahme moralischer Geschichten, erreichen, dass die Kinder »die Werte, das Wertsystem, das 
Wertsystem, das ahlak-System« verinnerlichen und »überhaupt so ein positives Gefühl« entwickeln (vgl. Feride, Z.: 128-140).

Schließlich spielt für Belkıs, neben den Grundlagen der Religion (vgl. oben), die Erkenntnis über die Bedeutung bzw. den Sinn des eigentlichen Daseins, Gottes, der Schöpfung usw., eine wichtige Rolle. Belk1s umschreibt dies mit der »Seele der Religion«:

"[...] Der andere wichtige Punkt ist für mich so die Seele der Religion an sich. [...]. Ich glaube, das ist etwas, was man Kleinkindern in den Anfängen vermitteln kann, aber später wird sich das dann eher manifestieren, der Sinn, warum es, warum wir da sind, warum es Gott gibt. Was ist überhaupt Gott, wer ist Gott und was bezweckt er damit, dass Menschen hier sind und wie müssen Menschen handeln usw. All diese Fragen, also all diese Antworten auf all diese Fragen, quasi auf all diese Fragen. Also ich möchte nicht, dass meine Kinder so eine hohle Religion für sich in Anspruch nehmen und [...]." (Belkıs, Z.: 103)

Die persönliche Wahrheitsfindung, die schon bei Birol und Adem anklang (vgl. oben), und die bei Belk1s durch die Beantwortung von Sinnfragen hinsichtlich des eigenen Daseins angeregt werden soll, betrachtet sie als etwas, was sie auch für ihre Kinder anstrebt. So sollten diese in der Religion Antworten auf ihre »individuellen Fragen« in Bezug auf den Grund ihres Daseins (»Wie müssen Menschen handeln?«) finden:

"[...] Sie sollen Antworten auf ihre persönlichen Fragen finden, ich glaube, dass gerade in der Religion, also Religion hat etwas sehr Verbindendes, aber auch sehr Individuelles, dass sie auf ihre individuellen Fragen wirklich gute Antworten finden können." (Belkıs, Z.: 106)

Zusammenfassend können im Zusammenhang mit der Wissensaneignung mehrere Aspekte festgestellt werden. Wir haben es bei »Ethikern« mit Eltern zu tun, die für ihre Kinder nach individueller, persönlicher oder subjektiver Wahrheitsfindung im Verhältnis zu ihrer Religion streben (vgl. Birol, Adem, Belk1s). Der zudem weniger ausgeprägte Gemeinschaftssinn erweckt hier den Anschein, dass »Ethiker« stärker individualistisch orientiert sind als alle anderen Eltern. Doch der soziale Charakter, den sie in den zwischenmenschlichen Beziehungen betonen, schwächt wiederum diese Behauptung ab, sodass hier vielmehr lediglich von einer Vermutung ausgegangen werden kann.

Ferner scheint auch unter dem Aspekt des religiösen Wissens die Aneignung von ethisch-moralischen Grundhaltungen, wie auch bei den anderen Aspekten der Religiosität (vgl. oben) gesehen, ihre Bedeutung nicht zu verlieren (vgl. insbesondere Feride, Adem). 
Es fiel schließlich noch auf, dass ein Teil der Eltern »Positives « für die Kinder erhofft: »ein positives Gottesbild« (vgl. Belk1s, Z.: 63); das »ganze Leben mit einem positiven Blick betrachten« (vgl. Adem, Z.: 44); »überhaupt so ein positives Gefühl« gegenüber der eigenen Religion entwickeln (vgl. Feride, Z.: 138). Anhand dieser Beispiele kann verdeutlicht werden, dass hier auf eine Lebenseinstellung abgezielt wird, die von einem großen Optimismus geprägt ist.

Die religiösen Fragen der Kinder betreffen die vier am häufigsten benannten Bereiche: die Fragen nach Gott, der Bezug zum Alltagsleben/zur Gesellschaft und wahrgenommene Widersprüche seitens der Kinder.

Die Fragen nach Gott drehen sich bei den Kindern überwiegend um die Eigenschaften Gottes. Die Beantwortung dieser und ähnlicher Fragen, führt bei den Eltern nicht selten zu Überforderungen. Die Kinder von Belkıs hinterfragen zum Beispiel die Macht und die Stärke Gottes. Die kindliche Vorstellung von Gott lässt sie auf menschliche Eigenschaften, wie das Fahrradfahren zurückschließen. Diese und ähnliche Fragen treten insbesondere im Kleinkind- und Vorschulalter auf:

"Also meine Tochter, als die noch kleiner war, sagte sie: 'Kann Allah mit dem Fahrrad auf diese Wolken fliegen?، Für sie war das so schwierig wahrzunehmen, wie mächtig und wie stark Gott sein kann zum Beispiel. Also da fängt es an und da wird es schon komplizierter, wenn es heißt, ja, 'Warum gibt es so viele arme Menschen auf der Welt, wenn Allah doch alles machen kann?, Und so weiter. Und die kann man eben nicht alle gut beantworten, weil es fehlt einfach so viel Wissen, das man dem Kind nicht vermitteln kann bzw. das das Kind in so einem Alter noch nicht versteht, dann kann ich einfach nur sagen, dass man halt manche Sachen nur mit der Zeit verstehen kann." (Belkıs, Z.: 110)

Bei der Beantwortung der Fragen achtet Belkıs auch darauf, ihre Kinder nicht zu überfordern, und lenkt sie auf ein späteres Verstehen:

"Ja, ich also das, was sie wirklich verstehen können, vermittle ich ihnen, versuche ich ihnen, soweit wie möglich, in einer einfachen Sprache zu erklären, aber es gibt dann auch Sachen, wo ich sage: 'Liebes, das wirst du später besser verstehen können. Also momentan sind die auch ganz zufrieden, aber dann sagen die: 'Okay [...].‘ (Belkıs, Z.: 112)

Die Glaubensinhalte, wie der Glaube an das Paradies: »wie ist cennet, wer kommt alles in den cennet rein?« (vgl. Melek, Z.: 175); oder die Eigenschaften bzw. Beschaffenheit Gottes/Allah, beschäftigen Meleks Sohn:

"[...] 'Mama ich kann es einfach nicht verstehen, wie kann uns Allah überall sehen? Wie geht das nur? [...]. Das geht doch gar nicht, Mama! Wie groß ist der, wie ist der, wie sieht der aus?" (Melek, Z.: 179ff.) 
Die Frage nach dem Bösen bzw. Geschöpfen im Islam, wie den dschinn (arab. für Geistwesen), interessieren Ferides Sohn und Meleks Tochter. Hierbei geht es Ferides Sohn u.a. darum, ob diese Wesen wirklich existieren oder ob die Botschaft des Korans auch für sie gilt:

"[...] Ja, wie das mit die dschinn ist; ob sie wirklich existent sind und ob der Kuran-ı Kerim jetzt auch gültig für die dschinn ist und nicht nur für die muslimischen Menschen, weil Allahu Teala ist ja so groß und so mächtig, dass er eigentlich auch für die dschinns und nicht nur für die muslimischen Menschen, weil Allahu teala ist ja so groß und so mächtig, dass er eigentlich auch für die dschinn einen extra [...] also Propheten schicken könnte und Hz. Muhammed bräuchte nicht irgendwie." (Feride, Z.: 153)

Hingegen sind die Fragen von Meleks Tochter von Angst vor dem Bösen, wie den dschinn (arab. für Geistwesen, Dämonen) und dem schaitan (arab. für Teufel, Satan), bestimmt. Hier sei die Beruhigung der Tochter auch nicht einfach gewesen:

"Unsere Tochter hat im Moment sehr große Angst vor dschinn, schaitan, das ist ein großes Problem. Ich weiß es ja nicht, vielleicht hat es wirklich etwas mit dem Alter zu tun. Aber ich habe das letztens mit dem hoca besprochen, weil sie sehr große Angst hat und wenn sie betet zum Beispiel fühlt sie sich nicht alleine, als ob ihr jemand oder etwas Angst machen würde oder so. Ich habe das mit dem hoca besprochen. Also die hat auch gesagt: Also wir merken an den Kindern in dem Alter, sie möchten das unbedingt wissen, gibt es dschinn, gibt es schaitan und so, aber wir haben ihr das so erklärt: , Halte die einfach aus deinem Leben raus. Mit denen hast du nichts zu tun. Du bist auf der Welt. Du hast dein eig ..., also Menschen haben [...] eine andere Lebensweise, halte die aus deinem Leben raus! Lass die einfach in Ruhe ihr Leben leben und du leb dein Leben. A Also wir müssen das wirklich radikal machen [...], weil wir sie sonst nicht beruhigen konnten. Das hat auch geklappt, ehrlich gesagt." (Melek, Z.: 169ff.)

Wiederum andere Fragen beziehen sich auf den Alltag bzw. auf gesellschaftliche Aspekte (vgl. Feride, Z.: 147 und 157). Adems Kinder setzten sich bspw. mit ihren Fragen über den »Islam und Terrorismus« (vgl. Adem, Z.: 48) oder mit Gruppierungen im Islam (Wahhabiten, Salafisten) auseinander. Hierbei unterstreicht Adem auch den Einfluss der Medien, wie dem Internet. Die Widerlegung der dort aufgestellten Äußerungen sei für Adem selbstverständlich:

"Also der Sohn, dessen Frage bezieht sich so auf die Gruppierungen des Islams, Wahhabiten, Salafisten, wie man sie überzeugen kann. Im Internet sind sehr viele Beiträge, leider sehr viele Beiträge über Salafismus und Wahhabismus. [...] Also im Internet, bei YouTube zum Beispiel. In den Medien. Genauso. Und leider sind auch sehr viele Anhängervon dort, also Jugendliche, die das dann gut finden, wie zum Beispiel ein Pastor oder 
ein Pfarrer schachmatt gesetzt wird, durch die Äußerungen und so weiter und so fort. Und das ist leider falsch, wie sie da vorgehen und darüber reden wir sehr viel, wie wir diese Thesen vor denen darlegen können und zeigen können, dass es eben falsch ist." (Adem, Z.: 50-54)

Schließlich sind es wahrgenommene Widersprüche, die die Kinder kritisch nachfragen lassen. So falle den Kindern z.B. auf, dass manche Frauen kein Kopftuch tragen (vgl. Belk1s, Z.: 119ff.), oder sie würden sich fragen, warum sich manche Verhaltensweisen mit den Aussagen der Eltern nicht decken (vgl. Melek, Z.: 191).

\subsubsection{Die Erziehungsmethoden und Erziehungsstile in den Familien der "Ethiker"}

Die Erziehungsmethoden, die in den Familien der »Ethiker« angewandt werden, unterscheiden sich im Vergleich zu den anderen Typen dahingehend, dass sie das Hinterfragen/Reflektieren von religiösen Themen in den Vordergrund stellen. Damit wird auch auf die intellektuelle Auseinandersetzung mit der Religion abgezielt (vgl. oben »Religiosität«). Sehr häufig wird hier vonseiten der Eltern auch die Lebensweltorientierung unterstrichen. Demnach solle die Religion besonders im Alltag erlebt und lebensnah an die Kinder übermittelt werden.

Ansonsten fiel auf, dass Eltern jeweils individuelle unterschiedliche Schwerpunkte in Bezug auf die von ihnen gewählte Methode setzten. Diese werden im Folgenden ausgeführt.

Die Vorbildfunktion nimmt, wie auch schon bei den Methoden in anderen Familien deutlich wurde, eine außergewöhnlich wichtige Stellung ein. So werden die Kinder z.B. »eingeladen«, an einer rituellen Praxis teilzunehmen (vgl. Belk1s, Z.: 65 und Z.: 78; Birol, Z.: 54; vgl. auch Feride, Z.: 83 und 2ooff.) oder sie sollen durch das Vorleben z.B. eine ethische Grundhaltung einnehmen (vgl. Feride, Z.: 62ff.). Indem sie selbst den Propheten (s) als Vorbild betrachtet, möchte Melek ihre Religion ausleben und dabei ihren Kindern ein Vorbild sein (vgl. Melek, Z.: 81f.). Die Tochter nehme die Mutter beim Kopftuchtragen (vgl. ebd., Z.: 85) und der Sohn hingegen den Vater beim Verrichten der täglichen Gebete als Vorbild (vgl. ebd., Z.: 111ff.). Das Vorleben durch die Mutter habe auch den Sohn motiviert, Gefallen z.B. am Koranlesen oder am Ramadan zu finden. Es erfreut Melek, ihn nicht zusätzlich an die zu verrichtende religiöse Praxis erinnern zu müssen, womit sie symbolisch zugleich auch eine muslimische Lebensweise bzw. die religiöse Zugehörigkeit zum Islam verbindet:

"Aber es hat mich sehr gefreut, dass inm das gefallen hat, denn man hört, dass viele das nicht mögen, wenn Koran gelesen wird. Also es hat mich wirklich sehr sehr gefreut. Also ich brauche inm nicht zu sagen: 'Du bist Moslem. Du musst das machen.' Wenn 
ich sehe, dass er das akzeptiert: Der Koran gehört zu unserem Leben. Ramadan gehört zu unserem Leben. Das Gebet gehört zu unserem Leben dazu. Allein, dass er das alles akzeptiert, das ist für mich eine Bestätigung." (Melek, Z.: 134)

Es wird deutlich, dass Melek in diesem Zusammenhang auch Selbstkritik übt und an sich arbeitet, um auftretende Widersprüche, die die Kinder aufmerksam wahrnähmen, gar nicht erst entstehen zu lassen:

"Um, also ich versuche, auf meine eigene Lebensweise sehr zu achten [...], Vorbild zu sein, ein richtiges Vorbild zu sein. Ich weiß nicht, ob ich das immer schaffe; und wenn ich sehe, dass mein Mann irgendetwas falsch macht, dann gucke ich so mit den Augen: Nein, das passt jetzt nicht! Also das passt, das ist jetzt kein gutes Vorbild! Da müssen wir was ändern! [...] die Kinder, üben dann direkt Kritik! Wieso machst Du das so? Die achten wirklich auf jede Kleinigkeit! Mama, das hast du aber so gemacht! Und die grinsen mich auch dabei an! Also war das falsch. Daran merke ich ja auch: Oh, da muss ich besser aufpassen!“ (Melek, Z.: 189ff.)

Gespräche über die eigene Religion (die Kommunikation), die die Auseinandersetzung mit der Religion anregen soll, sind rituelle Bestandteile im Familienalltag der »Ethiker« (vgl. oben). Daher überrascht es nicht, dass sie in Bezug auf die von ihnen gewählte Kommunikationsform insbesondere das kritische Reflektieren bzw. Hinterfragen bei ihren Kindern anregen. Daneben sind Begründungen/Überzeugungstechniken und das Erklären durch Beispiele die am häufigsten benannten Kommunikationsformen.

Das Hinterfragen und Reflektieren ist ein entscheidendes Merkmal der »Ethiker«. Für Feride ist das Reflektieren, das in regelmäßige Gespräche innerhalb der Familie integriert ist, ein wichtiger Aspekt ihrer Erziehung überhaupt ${ }^{44}$. Sie verdeutlicht dies anhand der Dankbarkeit, die die Menschen in sich tragen bzw. ihr Sohn den Gaben Gottes/Allahs erweist. Auch ist darin der Gedanke, sadaqua (arab. für Spenden) an Bedürftige und arme Menschen abzugeben, enthalten:

"Was ich ganz wichtig finde: Das ist jetzt nicht nur im Hinblick auf die religiöse Erziehung, sondern überhaupt, was meine Erziehung, finde ich, mehr oder weniger ausmacht ist, finde ich, dass eine Sache, dann wenn es angebracht ist, auch thematisiert wird, auch ausgesprochen wird; und wenn dann zum Beispiel die Zeit dafür knapp sein sollte, dann zu einem späteren Zeitpunkt noch mal aufgegriffen wird. Beispielsweise, wenn eine Verschwendung, zum Beispiel im Sinne von, was weiß ich, Brot anbeißen, aber nicht aufessen, dass man da zum Beispiel sagen kann: Ja, guck mal, Allahu teala hat uns

44 | Hier zeigt sie nochmals auf, dass für sie die religiöse und allgemeine Erziehung getrennte Bereiche darstellen. 
so viele schöne Sachen gegeben und unter anderem auch dieses Essen und es gibt so viele Menschen, die überhaupt nicht einmal die Hälfte von dem haben, was wir jetzt zurückgelassen haben; und wie dankbar wir eigentlich dafür sein müssten, für diese eine Sache, die wir halt jetzt hier verschwenden, dann lieber demnächst entweder weniger auf den Teller nehmen oder halt anders damit umgehen. Und da auch nebenbei zum Beispiel noch mal unsere Pflicht zu benennen, dass wir als diejenigen, die reicher beschenkt wurden, abzugeben haben von dem, was wir haben, nicht nur im Sinne von zakat ${ }^{45}$, sondern auch im Sinne von sadaqa; und dass der Arme ein Recht auf den Besitz des Reichen hat und so weiter; diese Themen zum Beispiel, kurz, dass die angeschnitten werden, thematisiert werden, dass noch mal Fragen zugelassen werden oder auch Äußerungen von dem Kind noch mal zugelassen werden [...]." (Feride, Z.: 165)

In diesem Interviewabschnitt zeigt Feride auf, dass sie zu den angesprochenen Themen Fragen und Äußerungen ihres Kindes zulässt und dieses damit anregt, selbstständig zu denken. Dies drücke sich im Verhalten ihres Sohnes aus, der z.B. die Idee gehabt habe, für arme Menschen Essen und Geld zu sammeln und dieses nach Afrika zu schicken (vgl. ebd., Z.: 165 ff.).

Auch Adem regt seine Kinder zum Nachdenken und Weiterforschen an, indem er die Sunna (=Überlieferungen des Propheten (s) in Worten und Taten) und die Verse aus dem Koran, als Hauptquellen (des Islams), heranzieht. Dabei reiche es nicht aus, nur bestimmte Bücher zu lesen, sondern es müssten mehrere Meinungen zugelassen werden, um Lösungen bzw. Antworten auf Fragen zu finden. Wichtig ist Adem daher, seinen Kindern keine vorgefertigten Lösungen zu präsentieren, damit die Kinder auch weiterhin motiviert seien, ihre eigenen Antworten zu finden:

"Die Methode ist erst mal der Koran, also mit Versen und mit den Sagen von unseren Propheten, die Bücher spielen eine sehr sehr große Rolle. Es reicht nur uns eben nicht aus, ein Buch zu lesen und von diesem Buch diese Antwort zu bekommen, sondern wir vergleichen sehr viel aus verschiedenen Büchern, von verschiedenen Autoren. Wie sie die Sache sehen, angehen und dafür suchen wir dann immer die Lösung zu finden. Und meine Technik bei den Kindern ist, dass ich die Antwort nicht direkt sage, so, das ist so und so und so und so, sondern in ein Frage-Antwort-Spiel übergehe, damit sie selber auf die Antwort kommen. Wenn sie selber, ich habe das Gefühl, wenn sie selber auf die Antwort kommen, dass es dann viel mehr wert ist, als wenn [...] innen [das auf dem, Anm. d. Verf.] Präsentierteller angeboten wird." (Adem, Z.: 56, vgl. auch Z.: 42)

Gerade wenn die Kinder nicht folgen oder bestimmte Grenzen nicht einhalten möchten, spornt Adem seine Kinder an, selbst »zu lesen und zu erforschen«,

45 | Almosengabe. Jeder Muslim ist verpflichtet, einen bestimmten Teil seines Besitzes an Arme abzugeben. Dies stellt die vierte Säule des Islams dar. 
damit sie ihre eigenen Erfahrungen machen und Erkenntnisse darüber gewinnen könnten:

"[...] Man versucht, zu erklären; mit Geduld, mit Beweisen, schwarz auf weiß am besten! Manchmal ist es so, dass man, dass es auch bei den Erwachsenen so ist, dass sie irgendetwas nicht glauben wollen; und daher ist es angebracht, dass sie selber an den Punkt kommen, zu lesen und zu erforschen. Erst nachdem sie gelesen haben und das selber in Erfahrung gebracht haben, ist es so, dass sie sich meistens auch dagegen immer noch sträuben werden, aber spätestens dann, wenn sie alleine zu Hause sind oder im Bett liegen und wirklich abschalten, sich diese Sachen noch mal durch den Kopf gehen [lassen, Anm. d. Verf.]; und früher oder später ist es dann so, dass sie die Erkenntnis bekommen, dass es doch richtig war." (Adem, Z.: 60)

Sowohl für Adem als auch für Birol ist bei Grenzverletzungen das »Hinterfragen« der gegebenen Situation eine wichtige anzuwendende Kommunikationstechnik (vgl. Adem, Z.: 70). Birol findet hierbei auch Erklärungen, die mit dem erhobenen Zeigefinger durchgeführt würden, oder gar Strafen nicht angebracht:

"Also zu erklären in der Weise, dass die das beim nächsten Mal zumindest hinterfragen. Ja, also ich mache das nicht mit dem [erhobenen, Anm. d. Verf.] Zeigefinger - das Erklären - sondern nach dem Motto: Das macht man nicht, sonst wird man bestraft! Jetzt nicht im Diesseits oder Jenseits, sondern das macht man nicht, weil das einfach nicht gut ist! Ne, die sollen das, ich lege viel Wert darauf, dass die etwas tun, weil es gut ist, und nicht, weil sie Angst haben [...] ja vor einer Bestrafung oder so." (Birol, Z.: 143ff.)

Das Kritische Reflektieren ist, ähnlich wie bei Feride auch bei der Befolgung der rituellen Praxis von Bedeutung. Hier möchte Birol seinen Kindern den Weg aufzeigen, folgen sollen sie ihm selbst. Das Wissen, was sie erlangen, sollen sie reflektierend in ihre Handlungen übersetzen. Dabei sollen sie weniger nachahmen, sondern aktiv forschen, lernen, fragen und schließlich das Erlernte umsetzen:

"[...] Dass ich [...] meinen Kindern definitiv nicht sagen werde, , So jetzt ist Ramadan, wir fasten`, sondern dass ich denen vor allem erkläre, wieso wir fasten, [...] die Hintergründe einfach erklären. Was ich mir daraus ableite, welche Folgen das Fasten hat für mich, was ich davon habe, was ich davon nicht habe; sodass ich mein Kind auf jeden Fall in eine Lage versetze, wo es selbst später kritisch reflektieren kann. Ja? Also, dass es hinterfragen kann, [...] dass es sein Wissen auch aktiv anwendet und nicht einfach nur ja, nachäfft, ja? Also dass man, dass man aktiv ist; und ich denke, dass unsere Religion das eigentlich auch so vorschreibt. Ja? Wissen. Lernen. Wissenschaft, dass 
man forscht. Auch das ist ein Forschungsprozess, finde ich [...]." (Birol, Z.: 518-524, vgl. auch 525-540 für Beispiele).

Religiöse Begründungen werden vielfach eingesetzt, um die Kinder von bestimmten Verhaltensweisen (Feride, Z.: 165-169; Melek, Z.: 95; Adem, Z.: 60 und Z.: 150) bzw. Grundhaltungen (vgl. Feride, Z.: 26; vgl. Melek Z.: 169ff.; Adem, Z.: 74) zu überzeugen. Adem erwartet, ähnlich wie Birol, weniger, welche Gebote eingehalten oder unterlassen werden sollen. Er versuche vielmehr, die »Kindergedanken« verstehend, die »Herzen zu erobern«. Dabei setze er neben dem aktiven Zuhören auch Erklärungen und religiöse Begründungen ein, die den »Sinn« (»warum, wieso, weshalb«) ihres Glaubens an Gott, ihrer Handlungsweisen bzw. der religiösen Gebote darlegen sollen:

"Für mich ist es jedes Mal wichtig gewesen, nicht nur bei meinen Kindern, auch da, wo ich tätig war, in der [...] Moschee, dass wir den Kindern nicht einfach auftragen dürfen, was sie zu glauben haben und was nicht; und was richtig und was falsch ist. Wichtig ist es, die Herzen zu erobern! Das ist das Wichtigste! Und bei meinen Kindern, bei meinen eigenen Kindern habe ich das Gleiche gemacht. Das bedeutet, wenn irgendeine Frage kam, habe ich das dann so versucht, dass sie das dann, das auch mit ihren Kindergedanken auch verstehen können. Also das musst du machen! Das ist verboten und das ist erlaubt! Hab ich, so bin ich niemals vorgegangen. Ich habe innen erklärt, warum, wieso, weshalb das so ist. Also wenn ein Verbot da ist oder ein Gebot da ist, was für einen Sinn es hat, damit man diese Sache auch besser verstehen kann. [...]. Und meine Tochter hat sehr positive Erfahrungen dadurch gemacht, hat es auch verstanden und deren Glaube an Gott und an die Gebete haben sich mit dieser Erklärung auch dann vertieft." (vgl. Adem, Z.: 26, vgl. auch Z.: 32)

Über die Gründe für ein Tun oder eben Unterlassen sollen sich auch Birols Kinder bewusst werden. Neben einer selbstständigen und subjektiven Wahrheitsfindung (vgl. oben »Religiosität«) soll die innere Motivation für ein religiöses Verhalten nicht aus Angst vor »jenseitlicher Bestrafung« erfolgen. Diese solle vielmehr darin bestehen, den Sinn für die eigenen Handlungsweisen zu erfassen, um das Gute und Richtige zu tun:

"[...] ja, ich hatte ja gesagt, nicht etwas tun, weil es Angst hat. Vor der [...] $\mathrm{Ne}$ ? Ob das jetzt eine weltliche oder eine, eine jenseitliche Bestrafung, was auch immer, dass es etwas tut, weil es, weil es meint, dass es richtig ist, weil es gut ist. Ne? Das gehört dazu. Und dass es auf jeden Fall immer, ja ich sage mal, sich seine Gedanken machen kann. Ja. Also man tut nichts umsonst. Ja. Also es hat alles schon so seinen Sinn, es hat alles seine Gründe; und wenn man etwas tut oder unterlässt, dann hat auch das irgendeinen Grund; und dass man dann einfach mal irgendwann mal sich bewusst wird, klar wird, 
wieso mache ich das ein oder andere oder andere nicht, ne, und welche Konsequenzen hat das und wie fühle ich mich eigentlich auch dabei? Ich denke." (Birol, Z.: 544ff.)

Das Erklären an lebensnahen Beispielen hat für alle Eltern dieses Typs eine Bedeutung. Hierzu zählen religiöse Feste (Belk1s, Z.: 88), der Besuch einer nichtmuslimischen Freundin (vgl. ebd. und Z.: 137ff.), religiöse Grundlagen (Feride, Z.: 26; Melek, Z.: 169ff.), die religiöse Praxis (vgl. Melek, Z.: 163 und Birol, Z.: 518), Spenden und die Bereitschaft dazu (vgl. Feride Z.: 165ff. und Birol, Z.: 66) sowie ethische Grundhaltungen (Feride, Z.: 167; Adem Z.: 74; Birol Z.: 48 und Z.: 52 ).

Ein charakteristisches Merkmal der religiösen Vermittlungsform stellt die Lebensweltorientierung dar. Auch hierzu haben fast alle Eltern dieses Typs Stellung genommen. Demnach solle die Religion selbstverständlich, lebensnah im Alltag ausgelebt werden und durch die Kinder auch so wahrgenommen werden. Belkıs versucht einen Mittelweg zu finden, indem sie weder eine Sache zu sehr betont noch etwas vernachlässigt. Stattdessen sei der »beste Weg«, religiöse Aspekte selbstverständlich in den Alltag einfließen zu lassen bzw. diese entsprechend auszuleben:

"[...] dass ich denke, dass man bestimmte Sachen weder zu sehr betonen soll, zu sehr darauf pochen soll, noch zu sehr vernachlässigen soll. Ich glaube, der beste Weg, bestimmte Dinge Kindern nahezubringen, dass es so selbstverständlich in den Alltag [einfließt, Anm. d. Verf.] [...]. Für meine Kinder soll es selbstverständlich sein, ohne das fünfmalige Gebet gibt es einfach kein ..., entweder bist du Muslim und machst das oder bist es nicht und machst es nicht. Das versuche ich zu vermitteln, weil, wenn man zu sehr darauf pocht, dann denken sich Kinder irgendwann: 'Aha, also irgendwie ist da irgendwas ... ja, weil irgendwas ist da Besonderes dran.' Das es halt nichts Außergewöhnliches ist, dass das normal ist, dass wenn man Muslim ist, dass man da fünfmal am Tag betet oder wenn man eine muslimische Frau ist, dass man sich bedeckt [...]." (Belkıs, Z: 117-119)

In diesem Interviewabschnitt zielt Belk1s auf Selbstverständlichkeiten ab, die das Muslimsein kennzeichnen. Das tägliche Gebet oder beispielsweise das Kopftuch treten hierbei als identitätsstiftende Merkmale auf. In einer ähnlichen Weise erfreut sich Melek über die Akzeptanz religiöser Elemente, die im Alltag ausgelebt (vgl. Melek, Z.: 189 und 210) werden:

"[...] Also ich brauche inm nicht zu sagen: 'Du bist Moslem. Du musst das machen.' Wenn ich sehe, dass er das akzeptiert: Koran gehört zu unserem Leben. Ramadan gehört zu unserem Leben. Das Gebet gehört zu unserem Leben dazu. Allein, dass er das alles akzeptiert, das ist für mich eine Bestätigung." (Melek, Z.: 134) 
Gerade Feride betont besonders stark eine lebens- bzw. alltagsnahe Vermittlung von religiösen Inhalten. Religion werde von ihr demzufolge nicht primär vorgelebt, sondern gehöre in den Alltag (vgl. Feride, Z.: 159ff.). Gerade dann, wenn religiöse Themen angesprochen würden, oder auch im Zusammenhang von religiösen Geboten, wie der Einhaltung des muslimischen Speisegebots, sei es wichtig, diese selbstverständlich in den »Alltag« zu integrieren:

"Dass er dann, so einfach sagt: ১a, stimmt. Allahu teala verzeint zwar alles, aber kul hakkı [türk. für das Recht eines Muslims/Dieners Allahs, Anm. d. Verf.] nicht, weil, da müssen wir uns ja noch bei demjenigen entschuldigen und so weiter; dass solche Sachen irgendwie in den Alltag und auch überhaupt dann, wenn es angebracht ist, auch aufgeführt und auch aufgenommen werden. Das würde ich sagen [...]. Ich meinte jetzt generell, dass im Alltag, wenn eine Sache anfällt, dass man das einfach noch zum Beispiel einkaufen gehen muss [...]. Also das ist dann selbstverständlich für meine Kinder, dass sie halt nichts Gelatinehaltiges essen, dann ist es zum Beispiel so, dass wenn die irgendwie im Regal mal ein Bonbon oder so sehen, dass er [Feride spricht ab hier von inrem Sohn, Anm. d. Verf.], das in die Hand nimmt und versucht zu lesen, ist da jetzt Gelatine drin oder nicht oder fragt er: 'Mama, ist da jetzt wirklich Gelatine drin oder nicht? Oder wenn wir, was weiß ich, Blut spenden sind, wenn den, was weiß ich was angeboten wird, irgendwelche Bonbons: $\mathrm{Ha}$, nee, das dürfen wir nicht nehmen, weil wir essen kein, wir essen keine Schweinegelatine. Das ist einfach so, ne, im Alltag, ..." (Feride, Z.: 169-175)

Auch Adem wendet Beispiele aus dem Alltag an, um seinen Kindern die Zeitlosigkeit einer islamischen Lebensweise aufzuzeigen:

"Also mit dem Alltag ist es so, dass wir diese, egal was für eine Form von religiösen Fragen so gestalten, dass wir immer ein Beispiel aus dem Alltag nehmen, sodass wir das Kind oder dass der Jugendliche vergleichen kann, erfahren kann, dass der Islam nicht 1.400 Jahre vorher gelebt worden ist, sondern immer noch beständig ist." (Adem, Z.: 58)

Die altersgemäße Förderung der Kinder stellt ein weiteres wichtiges methodisches Kriterium einer religiösen Erziehung dar. Hierzu äußerte sich Belk1s gleich an mehreren Stellen. So bestimme das Alter ihrer Kinder, welche Themen sie ihnen ausführlich erkläre (vgl. Belkıs, Z.: 11off. bzgl. der Wissensaneignung) oder welche rituelle Praxis sie im Alltag befolgen sollten (vgl. ebd., Z.: 65-69 hinsichtlich der Gebete; Z.: 80 zum Fasten; Z.: 88 zum Sinn des Opferfestes). Um bei ihren Kindern keine Abneigung gegenüber der Religion zu erzeugen, möchte Feride ihren Kindern keine altersgerechten Verpflichtungen aufbürden: 
"Ja, also ich gehe auch ... ich möchte nicht, dass meine Kinder, jetzt in dem Alter, wo sie das noch nicht müssen, also gewisse Sachen als aufgebürdet ansehen, [...] dann haben sie auch eine gewisse Abneigung dagegen immer [...]." (Feride, Z.: 207)

Eine weniger wichtige Stellung, im Vergleich zu diversen Kommunikationsformen, nimmt bei den »Ethikern« die Regelbefolgung, als eine methodisch angewandte Technik, ein. Dies verdeutlicht gerade Feride, für die im Vergleich zum Internalisieren von Werthaltungen die Regelbefolgung eine weniger gewichtige Rolle im Erziehungsalltag spielt. So weist sie ihren Sohn zwar einerseits darauf hin, z.B. am Donnerstagabend auf das Koranlesen zu achten oder die Bittgebete vor dem Schlafengehen aufzusagen. Bei Nichteinhaltung pflegt sie jedoch einen toleranten Umgang und versucht, den Sohn durch Erklärungen zu überzeugen, bzw. regt sie den Sohn dazu an, Verantwortung für sein Verhalten zu übernehmen (vgl. Feride, Z.: 182-209; vgl. auch »Erziehungsstile«).

Eltern wie Melek und Belkıs achten gezielter auf die Befolgung von Regeln. Dabei richtet Belk1s ihre Aufmerksamkeit auf eine altersgemäße Vorgehensweise (vgl. oben) und setzt zudem ein Belohnungssystem ein, um den Kindern z.B. die täglichen Gebete gemäß dem Rat des Propheten (s) langsam anzugewöhnen:

"Also bis jetzt war es so, dass ich sie immer eingeladen habe; und wenn sie wollen, haben sie mitgemacht. Und bei meiner Siebenjährigen haben wir jetzt angefangen, dass sie jeden Tag sich aussucht und dass sie dann ein Mal mit mir betet und ...; also ich habe bis jetzt, habe ich auch das mal durchgehen lassen, weil sie auch dann Hausaufgaben hat und wir haben Winter und es ist so schnell schon dunkel und so weiter. Das es ab und zu mal ausgelassen wurde. Jetzt habe ich mir aber überlegt, dass ich so einen Plan mache, das ist jetzt ganz aktuell, und sich dann jedes Mal ein Herzchen machen kann, zu welchem Gebetszeiten sie halt beten möchte; und dann wird sie dafür irgendwann belohnt; dass man das so peu à peu macht und nicht mit der Tür ins Haus fällt. Der Prophet sagt ja auch, mit sieben Jahren sollen sie langsam anfangen zu beten die Kinder und später wird das dann zur Regelmäßigkeit, das hoffe ich." (Belkıs, Z.: 78)

Auch Melek versucht, alles aus ihrem Leben »rauszuhalten«, was nicht den religiösen Vorschriften entspricht:

"[...] Also ich habe was anderes im Kopf, aber ich weiß, meine Religion verbietet es mir. Das gehört nicht zu der Familie. Dann versuchen wir, es rauszuhalten, auch wenn es uns schwerfällt. Zum Beispiel, wie soll ich sagen jetzt? Was ist jetzt das Populärste? (überlegt) Kleidung vielleicht. Kleidung könnte man sagen. Meine Tochter zieht sich mittlerweile, versucht sich, so wie ich anzuziehen, aber ich weiß, die hat mich als, also ich merke, dass; sie hat mich als Vorbild genommen. Ich sage: 'Büşra du bist jetzt in dem Alter. Du kannst ruhig das noch anziehen!‘ 'Nein, Mama, möchte ich aber nicht!، Also sie 
hat mich da als Vorbild genommen. Sie weiß: Das passt nicht zu meiner Religion, diese Kleidung. Sie hat es selber aus ihrem Leben rausgehalten [...]." (Melek, Z.: 83ff., vgl. Z.: 111 für die Gebetsvorschrift).

Es wurde schon verdeutlicht, dass Rhythmik/Gesang eingesetzt wird, um die Kinder zu religiösem Verhalten zu motivieren. Zudem soll damit eine emotionale Bindung erzeugt werden, welche die Kinder bei ihrer religiösen Entwicklung unterstützen soll (vgl. Feride »Religiosität«). Insbesondere Belk1s ist eine kindgerechte spielerische Herangehensweise wichtig. Dabei solle weniger das Auswendiglernen zum Einsatz kommen, sondern vielmehr rhythmisch-kreativen Elementen ein Platz eingeräumt werden:

"Ich glaube (hustet), wie wir eben schon gesagt haben, also der spielerische Weg ist ganz wichtig! Dinge, die den Kindern wirklich Spaß machen, sollen sie auch mit religiösen Inhalten assoziieren, also wenn sie später zurück[schauen, sollen sie, Anm. d. Verf.] nicht sagen, so ich habe da drei Stunden gesessen und versucht, das auswendig zu lernen, sondern, sagen wir mal, wenn man zum Beispiel ein bestimmtes dua den Kindern mit einem rhythmischen Singsang beibringt oder mit bestimmten Bewegungen, ja, dass man dann im Kreis läuft oder, was weiß ich, in die Hände klatscht, so was bleibt dann eher hängen und das machen sie auch gerne [...], wenn die Motivation da ist, bestimmte Dinge zu lernen, macht man das auch besser und schneller, anstatt, wie gesagt, da wirklich stundenlang zu sitzen und sich das in den Kopf einzuhämmern." (Belkıs, Z.: 115)

Hier wird stärker die Motivation angesprochen, die es den Kindern ermögliche, »Spaß « beim Erlernen von religiösen Inhalten zu empfinden. Deutlich Abstand wird auch vom traditionellen Auswendiglernen genommen. Um diese Motivation aufrechtzuerhalten, findet Belk1s zudem weitere kreative Möglichkeiten, wie das »Basteln von Schafen« zum Opferfest (vgl. Belkıs, Z.: 88) oder das Basteln einer Moschee »mit so einer schönen Vorlage« (vgl. ebd., Z.: 80).

Motivieren sollen des Weiteren auch Belohnungen, die durch alle Eltern in verschiedener Weise zur Anwendung kommen. Um ihre Kinder für die Gebete zu motivieren (vgl. oben, Belk1s, Z.: 78), entwickelt Belkıs ein eigenes Belohnungssystem:

"[...] wir haben einen Plan und so einen Punkteplan, wir erstellen halt Punkte für jedes Lobenswürdige oder für jede Regel, die eingehalten wird, und für jede, die nicht eingehalten wird, gibt es halt einen negativen Punkt und dann rechnen sie sich das am Ende der Woche oder am Ende des Monats aus, kommt halt auf die jeweilige Tätigkeit an, es wird zusammengerechnet und dann sehen sie dann auch selbst, was sie wie oft wann gemacht haben und dementsprechend gibt es eine Belohnung oder nicht. Und das läuft eigentlich supergut." (vgl. ebd., Z.: 129) 
Zudem werden auch materielle Belohnungen eingesetzt (vgl. Melek, Z: 206 und 212), wobei Adem daran auch Kritik übt. Es sei heutzutage schwer geworden, den steigenden Ansprüchen der Kinder gerecht zu werden bzw. diesen Grenzen zu setzen, sodass er ihnen nur »ab und $\mathrm{zu}$ « Belohnungen gebe:

"Bei den Belohnungen muss man immer sehr sehr aufpassen, natürlich belohnt man seine Kinder auf die eine Art und Weise, aber wenn man nicht aufpasst heutzutage, dann kommt das oft vor, dass die Belohnungen dann immer größer werden, die Ansprüche dann immer höher werden und man keine Grenzen, dass man keine Grenzen mehr setzen kann. Und deswegen ist es so, dass man den Kindern natürlich ab und zu mal eine Belohnung gibt, in was für einer Art und Weise Form? Als sie noch Kinder waren, war es so, dass man entweder eine Süßigkeit gegeben hat oder ein Spielzeug besorgt hat." (Adem, Z.: 64)

Heute, nachdem die Kinder inzwischen älter geworden seien, schenke er ihnen bei besonderen Leistungen eher persönliche Anerkennung. Dabei betrachtet er die Förderung zur Selbstständigkeit als die größte Belohnung (vgl. auch »Erziehungsstile«):

"Jetzt im Erwachsenenalter habe ich das so gemacht, dass diese Erfahrungen und (überlegt) diese Einhaltung von Geboten für sie schon eine Belohnung ist, wenn sie das ausführen. Da es eine Investition in die Zukunft ist und dass sie [...]. Gott sei Dank haben meine Kinder das verstanden. Also Belohnung, denke ich mal, aus dem Alter sind sie raus; und diese Belohnung ist, denke ich mal, in der Erziehung ein Mittel zum Zweck. Ich denke, dass die Belohnung heutzutage das ist, wenn man den Kindern die Möglichkeit gibt, der Antwort selbst auf die Sprünge zu kommen und diese nicht einfach vorlegt. Das ist die größte Belohnung, denke ich mir mal." (Adem, Z.: 66)

Auch Birol zeigt bei verrichteten guten Taten seine persönliche Wertschätzung und Anerkennung, um seine Kinder zu belohnen:

"Natürlich! Also das halte ich für sehr wichtig! Also das Loben beispielsweise, wenn etwas gut gemacht wird, das steht ..., wird auch ausgiebig gelebt! (I und B lachen); [...] darauf achte ich sehr. Dass das die Kinder auch mitbekommen, wenn sie etwas Gutes tun, dass das gewürdigt wird, dass das mitbekommen wird, dass ich das wahrgenommen habe; und das denen auch zeige." (Birol, Z.: 153)

Hingegen werden Strafen als Sanktionsmittel bei der religiösen Erziehung nicht verhängt. Die Strafen in der allgemeinen Erziehung beträfen in erster Linie ein Fernseh-, Internet- oder iPod-Verbot (vgl. Feride, Z.: 188-198; Melek, Z.: 214). 
Bei Konflikten oder vielmehr Regelverletzungen, die an religiöse Themen angrenzen, werden vornehmlich die oben vorgestellten kommunikativen Strategien angewendet. Um Wiederholungen zu vermeiden, erschien es sinnvoll, diese ausführlicher unter dem Aspekt des Eltern-Kind-Verhältnisses, d.h. der Erziehungsstile zu behandeln.

\section{Erziehungsstile}

Aus den Aussagen der »Ethiker« konnten sehr ausführliche Beschreibungen ihrer Erziehungsstile gewonnen werden. Deutlich wird hier, wie schon im Zusammenhang ihrer Religiosität, spezifischer jedoch in der Wissensaneignung und den von ihnen bevorzugten Erziehungsmethoden (vgl. oben »Hinterfragen/Reflektieren « in »Methoden [...]«) dargelegt werden konnte, ihre intellektuell-reflektierende Auseinandersetzung mit religiösen Themen, die sich auch entsprechend im Verhältnis zu ihren Kindern widerspiegelt. Demnach fällt bei diesem Typ insbesondere die Förderung der Selbstständigkeit auf, die bei den Kindern dazu führen solle, Verantwortung zu übernehmen, bzw. ihnen ein gleichberechtigtes Mitgestalten zu ermöglichen.

Auffällig stark distanzieren sich »Ethiker« auch von der Anwendung restriktiver Methoden, woraus resultiert, »keinen Zwang « in ihrer Erziehung zuzulassen. Folglich ist das Eltern-Kind-Verhältnis vielmehr durch Liebe/Geduld gekennzeichnet. Schließlich ist die Disziplin hier lediglich zwei Elternteilen wichtig, jedoch grenzen sich gerade diese Eltern (Mütter) auch stark vom Zwang ab.

Die Förderung der Selbstständigkeit ist vor allem den Vätern dieses Typs wichtig (Birol, Adem). Beiden Vätern ist es ein sehr starkes Anliegen, die Individualität ihrer Kinder zu fördern, die sie dazu führe, ihre eigene Wahrheit zu finden oder ihren eigenen zu Weg gehen.

Nach der Vermittlung wesentlicher »Grundprinzipen « oder dem Erwecken »von Interesse« an religiösen Themen bzw. Ritualen (Gebete, Fasten) solle sich das Kind von Birol, auf diesen Werten aufbauend, selbst weiterentwickeln können. Demnach möchte Birol Vorschläge machen, für die die Kinder selbst die Verantwortung übernehmen sollen (vgl. Birol, Z.: 54). Sie sollten somit »in die Lage« versetzt werden, das erlernte Wissen in einem Forschungsprozess »kritisch zu reflektieren« und »aktiv anzuwenden«. Hier spielte schon im Zusammenhang mit der Wissensaneignung die subjektive Wahrheitsfindung eine wichtige Rolle (vgl. »Religiosität [...]«; vgl. Birol, Z.: 518-526 und Z.: 546). Auch in Situationen, in denen unterschiedliche Meinungen aufeinandertreffen, »soll das Kind selbstbewusst seine Position seinen Standpunkt, sein Handeln [...] auch erklären [...] begründen « können (vgl. Birol, Z.: 554-558). Hier solle das Kind auch lernen, Verantwortung zu übernehmen. Insofern sind Birol Autonomie und Selbstständigkeit wichtige Werte (vgl. ebd., Z.: 563 ff.), die sich 
(hier) das Kind auf der Grundlage der von ihm vermittelten »Basics« durch Selbstreflexion aneignen solle:

"Und wenn er, also wer gute Argumente hat, der kann sich auch, denke ich, gut behaupten in so einer Situation; und diese Argumente kann man zum Teil vermitteln, aber man kann natürlich nicht alles vermitteln. Wichtig ist, das ist dieses ...; gibt man dem Armen einen Fisch oder gibt man inm eine Angel? [...], dass man dem Kind eben eine Angel zur Verfügung stellt, dass er sich quasi selbst versorgen kann, also die Basics einfach vermittelt; und der Rest muss dann eben durch Selbstreflexion erarbeitet werden." (Birol, Z.: $560 f f$.

Adem legt ebenfalls viel Wert auf die Förderung der Selbstständigkeit, sodass er darin sogar die »größte Belohnung« sieht, die man dem Kind machen könne (vgl. oben »Methoden [...]«; Adem, Z.: 66). Es konnte bereits aufgezeigt werden, dass er es bevorzugt, seinen Kindern keine fertigen Lösungen zu präsentieren, sondern sie vielmehr dazu anregen möchte, ihre eigenen Antworten zu finden (vgl. Adem, Z.: 42/56/6o; vgl. oben). Bei Grenzüberschreitungen würden die Kinder mittels Begründungen und Überzeugungstechniken dazu gebracht, eine Stellungnahme abzugeben bzw. Verantwortung für ihr Verhalten zu übernehmen:

"[...] Zum Beispiel haben sie irgendeine Grenze überschritten, dann habe ich meine Kinder immer gefragt, warum er das getan hat oder sie das getan hat. Es muss einen Grund geben für diese Handlung und ich habe immer [...] so versucht, diese Sache zu regeln, dass ich innen bewusst gemacht habe, dass sie falsch gehandelt haben." (Adem, Z.: 70)

Auch bei erlittenen Fehlschlägen und Misserfolgen wünscht sich Adem für seine Kinder, dass sie lernen, »wieder aufzustehen und auf den beiden, auf den eigenen (betont) Beinen auch zu stehen« (vgl. Adem, Z.: 196).

In ähnlicher Weise wie Adem versucht Feride in Situationen, in denen die Kinder z.B. die Gebete nicht machen oder nicht den Koranlesen wollen, »Kompromisse zu finden und ihnen nichts aufzubürden (»kein Zwang«), was sie ohnehin nicht einhalten müssen. Hier solle die Selbstständigkeit des Kindes gefördert und dem Kind das Gefühl gegeben werden, dass es gleichberechtigt mit entscheiden könne (vgl. Feride, Z.: 209ff.). Zudem werden religiöse Themen durch sie »angeschnitten« bzw. »thematisiert«. Dabei achtet sie darauf, nochmals »Fragen« und »Äußerungen« des Kindes zuzulassen, um es zur aktiven Verantwortungsübernahme zu motivieren (vgl. Feride, Z.: 165ff.).

Im Gegensatz zu den drei weiteren Elternteilen (Birol, Adem, Feride) ist das Eltern-Kind-Verhältnis von Belk1s und Melek durch »Disziplin« geprägt. Sie distanzieren sich zudem auffällig häufig vom »Zwang«als Erziehungsmit- 
tel. Wie noch ausgeführt wird, ist dies ein Merkmal, worauf sich neben »Liebe und Geduld « alle »Ethiker« berufen.

Sowohl Belk1s als auch Melek erwarten z.B. bei der Verrichtung der täglichen Gebete einen disziplinierten Umgang mit dieser Praxis. Durch den Einsatz eines Belohnungssystems versucht Belk1s, regelgeleitet, die Kinder $\mathrm{ab}$ dem Alter von sieben Jahren an die täglichen Gebete heranzuführen (vgl. Belkıs, Z.: 78 und Z.: 129; vgl. oben). Meleks Tochter hält sich an die Regeln, da die Eltern dies von der Tochter einfordern würden, wohingegen vom Sohn (fünf Jahre) diese Pflicht noch nicht verlangt werde:

"[...] Er betet. Er versucht, zu beten, sag ich mal. So ... Natürlich verlangen wir nicht, dass er betet. Aber von unserer Tochter verlangen wir das. Aber es ist kein Problem jetzt für sie. Sie weiß: Das gehört zu meiner Religion. Das akzeptiert sie auch! Das verläuft auch eigentlich ohne Probleme." (Melek, Z.: 111)

Melek führt zudem hierzu weiter aus, dass die Tochter immer wieder durch die Eltern an die Gebetszeiten erinnert worden sei. Die selbstständige Entscheidung der Tochter z.B. das Kopftuch anzulegen, wurde in Meleks Familie unter der Bedingung einer konsequenten Befolgung des Gebots erlaubt. Dabei sei jedoch kein »Zwang« ausgeübt worden; es wäre die eigene Entscheidung der Tochter, das Kopftuch zu tragen, jedoch wurden von ihr die Übernahme von Verantwortung und eine Kontinuität bei der Einhaltung des Gebots erwartet, was hier auf Disziplin hindeutet:

"Zwingen kann man nicht, das wissen wir, das haben wir auch schon längst eingesehen, aber ehrlich gesagt, gab es noch nie diese Situation. Also wir haben, wir mussten zum Beispiel unserer Tochter nicht sagen: ,Du musst jetzt ein Kopftuch tragen!، Das hat sie von sich aus gemacht. Wir mussten sie immer wieder daran erinnern: 'Büşra, Gebetszeit ist jetzt, du musst jetzt beten!،, aber ehrlich gesagt, haben alle beide uns noch keine so großen Probleme gemacht. Wir haben zum Beispiel bei unserer Tochter gesagt: ,Vielleicht ist es noch zu früh, ein Kopftuch zu tragen, Büşra. Fühlst du dich wirklich dazu bereit? Denn ich bin nicht damit einverstanden, wenn du sagst: 'Nein, ich trage jetzt mein Kopftuch', aber nach einer Zeit lang dann sagst du: ,Nee, das war doch nicht die richtige Entscheidung. Damit kann ich mich nicht abfinden, Büşraı. , Nein, Mama, ich bin mir sicher! Ich möchte es so machen! « (Melek, Z.: 200)

Da sie noch zu klein sind (vier und sieben Jahre.), haben die Kinder von Belk1s bei Nichteinhaltung von religiösen Geboten noch keine Konsequenzen zu befürchten:

"Religiöse Aspekte, da, die haben noch keine Konsequenzen für meine Kinder. Im Moment [...]. Es gibt nichts, wozu ich meine Kinder im Moment, die Kleine ist ja noch vier, 
die Ältere ist sieben, also es gibt kein Muss, was das Religiöse im Moment angeht. Für später überlege ich mir noch etwas (lacht)." (Belkıs, Z.: 133ff.)

»Für später« möchte Belk1s Konsequenzen einführen, was darauf hinweist, dass sie in Zukunft ein regelgeleitetes Vorgehen bevorzugen wird. Das Untersagen vom Besuch nichtmuslimischer Freunde deutet auf einen äußerst disziplinierten Erziehungsstil hin. Belkıs setzt sich mit Erklärungen durch, wobei ihr auch bewusst ist, dass die Tochter »trotzdem hingegangen« wäre:

"Konflikte gibt es dahingehend, dass zum Beispiel ich nicht möchte, dass meine ältere Tochter ein nichtmuslimisches Kind zu Hause bei sich besucht, dessen Familie ich nicht wirklich sehr gut kenne; und da gab es zum Beispiel ein/zwei Konflikte, dass meine Tochter das unbedingt machen wollte, aber ich ihr das unterbunden habe, ihr das erklärt habe. [...]. Also hätte ich ihr das trotzdem erlaubt, wäre sie trotzdem hingegangen, weil es ist halt ein Kind und macht gerne das, was es möchte, auch wenn es das logischerweise das nachvollziehen kann." (Belkıs, Z.: 137-141)

Ferner ist der Erziehungsstil aller Eltern dieses Typs durch Liebe/Geduld gekennzeichnet. Sie versuchen, religiöse Inhalte besonders durch eine geduldige Grundhaltung zu vermitteln bzw. vorzuleben. Das Wort »Liebe« wird im Vergleich zu anderen Eltern hier weniger verwendet, was möglicherweise darauf hindeutet, dass sie weniger emotional mit verschiedenen Situationen umgehen.

Gerade wenn Belk1s< Kinder Erklärungen oder Antworten auf bestimmte Fragen nicht als befriedigend erleben oder diese nicht altersgerecht sind, erinnert sie sie daran, geduldig zu sein. Geduld sei dabei auch etwas Kostbares, was sich die Kinder auch als eine Charaktereigenschaft aneignen sollten:

"[...] Also momentan sind die auch ganz zufrieden, aber dann sagen die: , Okay. Weil ich habe innen beigebracht, dass es auch wichtig ist, Geduld zu haben, dass Geduld so ein wirklich sehr kostbares, wie nennt man das, dann Charaktereigenschaft ist, die man sich wirklich auch aneignen muss." (Belkıs, Z.: 112)

Auch Feride pflegt einen geduldigen Umgang, wenn die Kinder z.B. aus Müdigkeit ihre Gebete nicht verrichten können. Die Kinder könnten dann »spüren«, dass die Mutter dies für sie stellvertretend übernehme:

"Dann sage ich: ,Wollt ihr noch beten? Oder sollen wir das Ayat-al Kursi [arab. Thronvers, auch Schutzsure; Anm. d. Verf.] zum Beispiel aufsagen?`, ah ja, stimmt, dann setzen sie sich hin und machen das. Aber manchmal sagt mein Sohn dann auch: 'Ha, Mama, ich bin so müde! ، Dann lass ich inn halt dabei, dann beuge ich mich zu inm oder lege mich zu inm und sag, so dann, so lese ich das leise, sodass er das dann aber auch noch halblaut 
mitbekommt oder auch nicht, aber so, dass er dann auch spürt: Okay, das ist wichtig, denn wenn ich das nicht mache, dann macht das halt meine Mutter." (Feride, Z.: 182)

Der Glaube ermöglicht in Meleks Familie neben einer spirituellen Atmosphäre die Aneignung einer geduldigen Umgangsweise. Schwierigkeiten und Probleme, die im Alltag entstehen, werden demnach mit Geduld, d.h., indem man nicht sofort »ausflippt«, behandelt:

"[...] die Atmosphäre zu Hause ist ganz anders. Also wenn man weiß: Das gehört nicht dazu. Man reagiert auch ganz anders. Man flippt nicht sofort aus. Man weiß, man muss die Sache ganz anders angehen." (Melek, Z.: 87)

Bei entstehenden Konflikten wird viel Wert auf die Kommunikation gelegt. Melek achtet überdies darauf, Empathie zu üben, um die Reaktionen der Kinder einzuschätzen. Auch empfindet sie »Druck« als Erziehungsmittel bei der Lösungssuche als kontraproduktiv:

"Konflikte weniger. Wenn auch dann [...]. Das wird direkt besprochen! [...]. Vielleicht reagiert sie in dem Moment sehr aufgewühlt, sie geht auch nicht darauf ein. [...]. Ja. Dann geht sie erst mal ins Zimmer. Wir müssen sie erst mal lassen, sie muss sich erst mal wieder beruhigen. Vielleicht nach einer halben Stunde oder zehn Minuten oder einer Stunde, je nachdem, wie groß für sie die Kritik war, kommt sie wieder raus, mit einem ganz anderen Gesicht. Sie hat sich wieder beruhigt. Aber wenn wir direkt jetzt in sie, sie unter Druck setzen würden, dann würde die Sache eskalieren. Ich glaube, man muss in der Hinsicht die Kinder selber sehr gut kennen. Wie würden die jetzt reagieren?" (Melek, Z.: 216-222)

Adem und Birol versuchen bei Regelverletzungen, geduldig mit ihren Kindern umzugehen und ihnen Erklärungen für bestimmte Verhaltensweisen darzulegen (vgl. Adem, Z.: 6o; Birol, Z.: 141). Dabei solle nicht der erhobene »Zeigefinger « auf sie gerichtet, sondern vielmehr demonstriert werden, dass eine Verhaltensweise nur »weil es gut ist« nicht »aus Angst« befolgt werden soll (vgl. Birol, Z.: 143, vgl. auch Z.: 542ff.). Schließlich sei es im Umgang mit den Kindern wichtig, wie oben schon erwähnt (vgl. »Methoden [...]«), »die Herzen $z u$ erobern«, die »Kindergedanken« zu verstehen und auf sie einzugehen (vgl. Adem, Z.: 26)

Fast alle Eltern beziehen sich interessanterweise im Zusammenhang mit den täglichen Gebeten ${ }^{46}$ bzw. Bittgebeten auf »Zwang« als ein Erziehungsmittel, von dem unbedingt abgesehen werden sollte. Wenn die Kinder auf die Vor-

46 | Gerade in der Beziehung der Eltern (aller Typen) konnten, gerade bei der Verrichtung der täglichen Gebete, ihre Erziehungsstile nachgezeichnet werden. 
schläge, beispielsweise am Gebet teilzunehmen, nicht mehr eingehen wollten (vgl.Belkıs, Z.: 65 und Z.: 78), ließ Belkıs sie in Ruhe, da sie ihren Kindern das »positive Grundgefühl« hinsichtlich ihrer Religion nicht nehmen wollte:

"Ich möchte innen halt dieses positive Grundgefühl, [...] was meiner Meinung nach sehr wichtig ist, was die Religion angeht, möchte ich denen nicht nehmen, indem ich sie irgendwelchen Zwängen aussetze oder indem ich innen etwas vorschreibe, dass sie es machen müssen, zumindest in dem Alter noch nicht." (Belkıs, Z.: 69)

So ist sie davon überzeugt, dass man ein ausgewogenes Verhältnis zwischen dem Fordern und dem Fördern finden müsse, d.h., »dass man bestimmte Sachen weder zu sehr betonen soll, zu sehr darauf pochen soll, noch zu sehr vernachlässigen soll.« (vgl. Belk1s, Z.: 117)

Im Zusammenhang mit der Einhaltung von religiösen Vorschriften (Kopftuch, tägliche Gebete) äußert Melek gleich an mehreren Stellen, wie wichtig es ihr neben der Erfüllung einer Vorbildfunktion sei, sich von restriktivem Vorgehen abzugrenzen: »Zwingen kann man nicht, das wissen wir ...« (vgl. oben; vgl. Melek, Z.: 113 und Z.: 200). Da die religiöse Lebensweise selbstverständlich in ihr Leben gehöre, akzeptiere dies die Tochter auch ohne »Druck« (vgl. auch Melek, Z.: 222). So hofft Melek, sich »keine Sorgen« machend, dass der Sohn dies auch verinnerlichen werde:

"Genau! Also bei unserer Tochter haben wir es so gelassen, es ist wirklich super gelaufen; und wir denken auch, weil wir ..., die Religion kommt ja bei uns an erster Stelle und er lebt es ja so. Er weiß auch, bei uns gibt es keinen Druck, das gehört zu unserer Lebensweise. Wir vermuten auch mal, wir hoffen es, dass er so darin gestärkt wird, also wir denken schon, dass er wie unsere Tochter das auch so akzeptiert [...].« (Melek, Z.: 210)

Um keine »Abneigung « gegen die Religion hervorzurufen, möchte Feride ihren Kindern nichts »aufbürden«, was sie altersgemäß auch nicht einhalten müssen. Vielmehr stehen für Feride ein gleichberechtigtes Mitgestalten und die Übernahme von Verantwortung im Vordergrund (vgl. oben; vgl. Feride, Z.: 182 ff. und Z.: 207-211).

Für Adem und Birol gilt das Prinzip, den Kindern nichts aufzutragen und ihnen vorzuschreiben, was zu tun ist oder wie sie vorgehen sollten. Stattdessen sei es wichtig, sie zu gewinnen und zu überzeugen, indem man ihre »Herzen« erobere (vgl. oben »Methoden [...]«). Gerade hinsichtlich der Befolgung der Gebete drückt sich diese Grundeinstellung (von Adem) aus. Dabei zwinge er seine Kinder »niemals«, sondern lade sie durch Erklärungen »höflich « ein (vgl. oben Adem, Z.: 32). Auch in Situationen, in denen die Kinder nicht folgen wollen, erklärt Adem, dass in der Religion kein Zwang herrschen dürfe. Statt- 
dessen solle mit Geduld und »Beweisen« versucht werden, zu überzeugen (vgl. oben (vgl. oben Adem, Z.: 6o).

Als Beispiel nennt Adem den Moscheebesuch des Sohnes, den dieser anfangs verweigerte. Adem zeigte in dieser Situation Empathie, indem er dem hoca seine eigenen Erfahrungen und Schwierigkeiten mit der Moschee in der Kindheit schilderte. Ausgehend von der Situation, wählte der hoca einen »pädagogischen« Umgang, um den Sohn zur freiwilligen Teilnahme zu motivieren. Dabei sei keinerlei »Zwang« zum Einsatz gekommen, sondern es wurde versucht, sich auf die Ebene des Kindes zu begeben (»hat sich heruntergestuft«) und zu überzeugen:

"Natürlich, am Anfang hat mein Sohn sich gesträubt, in die Moschee zu kommen und so weiter und so fort. Ich habe nachher mit dem damaligen hoca, Ausbildungsleiter da gesprochen, die Problematik erklärt, auch meine Problematik erklärt, was für Probleme ich damals mit zwölf Jahren hatte, wo ich zum ersten Mal in die Moschee kam. Und er ist sehr pädagogisch vorgegangen und hat sich heruntergestuft und hat gesagt: 'Muhammed،, so heißt mein Sohn, 'Gib mir bitte drei Wochen Zeit und wenn du es dir in diesen drei Wochen anders überlegen solltest, nicht zu kommen, werde ich dich nicht zwingen und dein Vater wird dich auch nicht zwingen. . Und er hat das dann geschafft, dass dieser Junge freiwillig sonntags aufgestanden ist und in die Moschee gegangen ist. $\mathrm{Ne}$, also zwingen nicht, überzeugen mehr!» (Adem, Z.: 62)

\section{Religiöse Sozialisation in anderen Kontexten}

\subsection{Bedeutung und Stellenwert der Sozialisationsinstanzen}

In diesem Kapitel werden die Bedeutung und der Stellenwert diverser Sozialisationsinstanzen bzw. Einrichtungen, die zur Unterstützung der religiösen Erziehung dienen, dargestellt. Eltern messen verschiedenen Einrichtungen einen unterschiedlichen Stellenwert bei.

Dabei werden folgende Sozialisationsinstanzen mit unterschiedlicher Gewichtung benannt:

- Die Moscheen (folglich gilt hier auch das religiöse Gemeindeleben als Einflussfaktor)

- Religiöse Bildungseinrichtungen, die in die Moscheen integriert sind oder als unabhängige Vereine religiöse Bildungsangebote machen (vgl. auch Kap. II. 1.3). Diese sind auf verschiedene Altersgruppen ausgerichtet und nehmen unterschiedliche Formen an, wie z.B.:

- Korankurse bzw. Koranschulen

○ Frühfördergruppen 
- Sohbet ${ }^{47}$-Gruppen, die in der Regel einen informellen Austausch über die Religion ermöglichen. Sie sind sowohl an religiöse Gemeinden als auch, unabhängig davon, an religiöse Bildungseinrichtungen gebunden.

○ Erwachsenenbildung

- Die Familie

- Freunde/Bekannte

- Staatliche Bildungseinrichtungen, wie die Schule, in der auch der IRU ermöglicht wird.

Alle Religiösen Erziehungstypen verhalten sich unterschiedlich zu den oben genannten Sozialisationsinstanzen und setzen dabei individuelle Schwerpunkte. Es soll hier auch ihr Beitrag im Hinblick auf die religiöse Sozialisation aufgezeigt werden.

Zweifellos wird allen Typen, den Moscheen und religiösen Bildungseinrichtungen, eine außergewöhnliche Bedeutung für die religiöse Sozialisation zuerkannt. Sie können als eine wichtige Säule einer islamisch begründeten religiösen Erziehung überhaupt gesehen werden. Dabei kann eindeutig, wie schon die Untersuchungen und Expertisen belegen (vgl. Kap. II. 2.2), von einem unterstützenden und fördernden Effekt für die religiöse Sozialisation bzw. von einer wichtigen Sozialisationsleistung gesprochen werden.

\subsubsection{Das Verhältnis der "Idealisten " zu den Sozialisationsinstanzen}

Alle Eltern dieses Typs heben, im Vergleich zu den anderen Typen, das religiöse Gemeindeleben, in der die Religiosität der Muslime in differenten Formen zum Ausdruck kommt, auffällig stark hervor. ${ }^{48}$ Moscheen bzw. religiöse Gemeinden nehmen als Orte des muslimischen Lebens eine tiefgreifende Stellung in den »idealistischen « (die vornehmlich nach Sinn und Orientierung streben) Familien ein. So gelten Moscheen und religiöse Gemeinden als Orte ${ }^{49}$, an denen soziale Kontakte zu Bekannten/Freunden und Gleichaltrigen (Peers) gepflegt werden, die Verrichtung der Rituale zum Ausdruck kommt, religiöse Bildungsangebote wahrgenommen werden (vgl. Ethem Z.: 220 und Z.: 246; vgl. Lale, Z.: 302; Nermin, Z.: 349), bei denen eine tiefe Spiritualität erlebt wird (vgl. Lale, Z.: 432), die ein Zugehörigkeitsgefühl vermitteln (vgl. Dilek, Z.:

47 | Wörtlich bedeutet sohbet auf Deutsch so viel wie Unterhaltung, Gespräch.

48 | Den Gemeinschaftsaspekt heben auch Ritualisten hervor. Bei ihnen dient die Gemeinschaft dazu, ihre Rituale zu verrichten und ihre Kinder religiös zu erziehen. Hingegen nehmen sie für idealistische Eltern eine tiefergehende Stellung ein.

49 | Vgl. Schiffauer (2010: 36-54) für eine tiefgehende ethno-methodologische Analyse zur Bedeutung der Moscheen seit Beginn der Migration. 
59f. und 113), die das Identifikationsbedürfnis stillen (vgl. Nisa, Z.: 68f.) und die Heimatgefühle, Sicherheit und Geborgenheit bieten (sollen) (vgl. Lale, Z.: 432/441/485-489/503-505; Nermin, Z.: 445ff.; Dilek, Z.: 60).

Besonders prägnant bringt Ethem sein Verständnis über die Bedeutung der Moscheen für die religiöse Erziehung folgendermaßen zum Ausdruck:

"Also die religiöse Erziehung ... also der Religionsunterricht in der Moschee ist mir sehr wichtig. Also ich ..., auf den Unterricht würde ich auch nicht verzichten. Auch wenn es zum Beispiel Religionsunterricht an der Schule gibt. Weil einfach für mich auch die Moschee der Ort ist, wo das soziale Leben stattfindet, wo die Kinder nicht nur hingehen, damit sie bestimmte Gebete auswendig lernen, sondern auch, wo sie auch soziale Kontakte haben, also ... auf einer anderen Ebene lernen, wie man als Muslim zusammenkommt, auch das gemeinsame Gebet dort, dass sie halt mit den anderen Kindern dann auch ein gemeinsames Gebet verrichten. Auch sich bewusst werden, es gibt auch andere Kinder, die halt eine religiöse Erziehung erfahren, deren Eltern beten und so weiter; dafür ist mir dieses soziale Umfeld und auch diese sozial religiöse Prägung viel zu wichtig, als dass ich sagen könnte, darauf könnte ich verzichten [...]. (Ethem, Z.: 220)

Lale betrachtet die religiösen Gemeinschaften bzw. Moscheen als »Haus des Allahs« (türk. Allah'in evi), in dem allein schon die dort erlebte Atmosphäre z.B. bei der Verrichtung der Freitagsgebete ihr für die Darstellung ihres Stellenwertes genüge, auch wenn keine religiöse Bildung stattfinde:

"[...] also das ist sehr wichtig in der Moschee. Aber für mich ist auch diese Moschee nicht nur das Lernen, für mich ist dieses das ... wo, das ist ..., eine Moschee hat was anderes, auch in der Religion, im Islam hat das auch eine große Bedeutung, Haus des Allahs, Allah'in evi. Auch nur dieses Atmosphäre, auch wenn mein Kind nichts lernen würde, ja, nur der Moscheebesuch ist schon was für mich, auch manchmal mit Papa diese Freitagsgebete, nur Gebet gehen und kommen, auch dieses mit denen zusammen zu sein genügt mir." (Lale, Z.: 432)

Darüber hinaus sind religiöse Bildungseinrichtungen in Form von Frühfördergruppen (Ethem, Lale), nach Klassenstufen eingeteilte Kurse (Dilek, Nermin) oder als religiöse Bildungsanstalt bezeichnete medrese (Nisa), worin in früheren Zeiten der türkisch-osmanischen Kultur neben religiösen Wissenschaften auch Naturwissenschaften unterrichtet wurden, als von den Eltern wichtig erachtete Einrichtungen, die zum Teil sowohl ergänzend zur religiösen Erziehung in der Familie als auch fördernd wahrgenommen werden.

Dabei betonen einige Eltern auch ergänzende Angebote, die den Gemeinschaftsbezug hervorheben. Das Kind (oder vielmehr die Kinder) lerne vielfältige Aspekte des muslimischen Lebens, wie die Verrichtung der Rituale, das Zusammenkommen von Muslimen mit unterschiedlicher ethnischer Herkunft, 
was Kindern unterschiedliche Perspektiven und Betrachtungsweisen eröffne, die über eine religiöse Bildung in türkischen Moscheen hinausgehen würden. Dabei bieten gerade solche Möglichkeiten, so Nermin, den Kindern das Erlernen von Toleranz und Respekt gegenüber anders praktizierenden Muslimen:

"Zum Beispiel waren die mal beim [...], wo dann wirklich ganz viele, ja, viele Kinder, viele Jungs aus vielen verschiedenen Kulturkreisen auch dort waren, fand ich sehr interessant, wo die dann von allem so ein bisschen was mitbekommen haben und wo sie gelernt haben, es gibt nicht nur unsere, unser Wissen, das was wir halt wissen, sondern es gibt halt: das wichtige im Islam ist halt das Gebet, das Fasten u.s.w. Und die Grundsäulen stimmen, aber die praktizieren das ein bisschen anders, das fand ich sehr interessant [...]. Und das die dann lernen, auch das zu tolerieren und zu akzeptieren, dass sie dann nicht sagen: 'Nein, das was ich weiß ist so richtig; denn wenn sie nur in der türkischen, in türkische Moscheen gehen, dann lernen sie ja schon so ein bisschen das Gleiche ... [...]. Also diese unterschiedlichen Einrichtungen geben auch immer unterschiedliche Betrachtungsweisen und das finde ich schon wichtig." (Nermin, Z.: 395-413)

Viele idealistische Eltern verweisen neben der hohen Bedeutung des muslimischen Gemeindelebens, in das die religiösen Bildungseinrichtungen in den meisten Fällen integriert sind, auch auf die (Institution) Familie. Diese solle eine größere Rolle bei der Vermittlung von religiösen Einstellungen und Grundorientierungen einnehmen:

"[...]. Und natürlich die eigene Familie; also sich nur auf Institutionen zu verlassen bei der religiösen Kindererziehung, erscheint mir dann doch zu gewagt, weil auch gerade diese über die Wissensvermittlung hinausgehenden Elemente, wie eine grundsätzliche moralische Einstellung, wie überhaupt die grundsätzliche Einstellung, die überhaupt auch meiner Meinung nach nur in der Familie vermittelbar sind." (Ethem, Z.: 220)

Ähnlich wie Ethem, sind auch laut Dilek moralische Einstellungen vielmehr in der Familie vermittelbar, sodass sie ihre Erwartungen an die zuständigen Institutionen minimiert:

"[...]. Ich erwarte nicht sehr viel von Schulen, Vereinen, Moscheen, von hier und dort. Ich verfolge die folgende Logik: wenn der Einzelne seinem Kind und sich selbst zu Hause oder den anderen [untereinander, Anm. d. Verf.] etwas weitergeben konnte, d.h., wenn ⿺emand selbst dafür zuständig ist ..., folglich wenn ich selbst feststelle, dass mein Kind eine schlechte Eigenschaft hat, einen schlechten Charakterzug oder irgendetwas anderes hat, ist das nicht das Problem der Gesellschaft, ist das nicht das Problem der religiösen Gemeinschaft. Es ist mein Problem, was ich nicht lösen konnte." (Dilek, Z.: 222) 
Die Moscheen bilden im Vergleich zur Familie nochmals »außerhalb der Familie« einen Ort bzw. »eine unabhängige« Stelle, innerhalb derer Aspekte erlernt werden, die ein Muslim sich aneignen solle (vgl. Ethem, Z.: 232). Die Familie »als Einrichtung in dem Sinne«, d.h. als religiöse Bildungseinrichtung, ist auch bei Nermin von Bedeutung. So übernahm sie zunächst die Aufgabe, ihren Kindern »erst mal zu Hause « religiöse Inhalte zu vermitteln, bis sie sich $\mathrm{ab}$ ihrem dritten Kind überfordert fühlte und die Unterstützung einer außerfamilialen Einrichtung benötigte. Dennoch ist sie davon überzeugt, dass die Moschee allein nicht genügt. So sind für sie Ferienangebote eine wichtige Ergänzung zum Moscheeunterricht (vgl. Nermin, Z.: 357 und 389; vgl. auch Kap. II. 2.2.1).

Schließlich deuten die Eltern noch auf die Bedeutung von Freundschaften hin, die sowohl innerhalb der Moscheegemeinden als auch außerhalb von ihnen durch die Kinder gepflegt würden. Hier wollen die Eltern ihren Kindern die soziale Seite der Religion erlebbar machen bzw. die Allgegenwärtigkeit der Religion näherbringen (vgl. dazu Kap. III. 5.4 Peers [...]).

Auffällig häufig werden gerade vonseiten idealistischer Eltern (insbesondere Lale und Dilek, auch Nisa) Fortbildungsangebote, die der persönlichen Weiterbildung dienen, genutzt. Diese Weiterbildungen beinhalten die Auseinandersetzung mit religiösen und auch (religions-)pädagogischen Themen.

\subsubsection{Das Verhältnis der "Ritualisten" zu den Sozialisationsinstanzen}

Ein hoher Gemeinschaftsbezug kennzeichnet die Religiosität der Ritualisten. Dieser bezieht sich primär auf die Verrichtung diverser Rituale, die einen gemeinschaftsfördernden Effekt nach sich ziehen (vgl. Kap. III. 4.2). Zumindest dem Anschein nach, werden die Bedeutung und der Stellenwert von religiösen außerschulischen Bildungseinrichtungen bzw. Moscheen derart hervorgehoben, wo sie Ritualen bzw. der Einhaltung von religiösen Geboten nachgehen könnten. Dabei wird besonders auf die religiöse Bildung abgezielt, die im Rahmen dieser Einrichtungen vermittelt werde (vgl. ebd.).

Die Moschee und die dort angebotenen Kurse (Rabia, Selma) nehmen einen sehr wichtigen Stellenwert in der religiösen Erziehung ein (vgl. auch Kap. III. 5.2). Dabei wird auch von religiösen Bildungseinrichtungen gesprochen, die unabhängig von Moscheen ${ }^{50}$ existieren (Mecelle), oder von Frühfördergruppen bzw. in Altersstufen eingeteilte Kurse (Ali) oder von sohbet-Gruppen, in denen sich gleichaltrige Kinder oder Jungendliche zusammenfinden, um sich über ihre Religion auszutauschen (Selma, Rabia).

50 | Im Fall von Mecelle wurde die Unabhängigkeit der religiösen Bildungseinrichtung (angebunden an einen Verein) von Moscheen bzw. Moscheegemeinden besonders betont (vgl. ebd., Z.: 230-241). Die Gründe hierfür wurden jedoch nicht benannt. 
Die Einrichtung, die die Kinder von Mecelle besuchen, ermögliche ihnen eine Vermittlung des Islams oder sie sei vielmehr »eine Quelle«, in der sie Inhalte über ihre Religion erlernen könnten (vgl. Mecelle, Z.: 165). So wird ein unterstützender Effekt (vgl. Mecelle, Z.: 303f.) durch die religiösen Einrichtungen erhofft, da den Eltern die Zeit hierzu fehle (vgl. die Väter Mecelle, Z.: 296/565 und Ali, Z.: 76). Die Familie sei der Ort, an dem die Kinder durch das Vorbild der Eltern ihre Religion erlernen würden. Die religiösen Bildungseinrichtungen hingegen würden den Kindern einen anderen, möglicherweise disziplinierteren Zugang (»ich bin ja freundlich, ich kann ja denen nicht alles beibringen«) ermöglichen, in denen sie ihre Religion »vollziehen, erleben, lernen« könnten (vgl. Mecelle, Z.: 29off.).

Außerdem wird, neben dem Besuch einer religiösen Bildungseinrichtung, durch die Einführung des IRU (islamischer Religionsunterricht) an deutschen Schulen eine unterstützende Wirkung für ihre religiöse Erziehung erhofft (vgl. Mecelle, Z.: 296-306; vgl. auch Kap. III. 5-3).

\subsubsection{Das Verhältnis der "Identitätssucher" zu den Sozialisationsinstanzen}

Die »Identitätsucher« betonen, im Vergleich zu allen anderen Typen und Eltern, insbesondere die Familie als den wichtigsten religiösen Sozialisationsort. Religiöse Erziehung dürfe demnach nicht einfach an religiöse Gemeinden und Moscheen delegiert werden. Dennoch heben beide Elternteile dieses religiösen Erziehungstyps die Moscheen und religiösen Gemeinden als Orte, an denen eine religiöse Erziehung vermittelt werde, nicht weniger hervor als ritualistische oder idealistische Eltern. Auffällig ist bei diesen Eltern zudem, dass sie der Schule oder den Kitas einen wichtigen Stellenwert bei der Vermittlung ihrer religiösen Werthaltungen beimessen. Demnach streben sie zum einen danach, dass der IRU im schulischen Rahmen (Hülya, Lema) eingeführt werden soll, zum anderen wird durch ihr Dialogverständnis auf ein Zusammenleben zwischen Muslimen und Nichtmuslimen abgezielt. Die Schule solle als Ort des Lernens hierfür Möglichkeiten eröffnen. Insofern wird durch diesen $\mathrm{Typ}^{51}$ ein komplementäres und ausgewogenes Dreiecksverhältnis zwischen Familie/Moschee/religiöser Gemeinde und Schule anvisiert.

Die Familie sei der Ort, an dem primär religiöse Werthaltungen vermittelt und erlernt würden. Alles andere stellt für Lema lediglich einen »Aufbau« dar:

"Ja, also das ist für mich so ... wie wir es am Anfang gesagt haben, für mich ist es ja auch; die erste religiöse Erziehung fängt zu Hause an, mit der Geburt, also ich als Mutter, der Vater, wie sind wir so drauf? Wie behandeln wir das Kind? Wie behandeln wir uns untereinander? Und das ist, ich kann das Kind ja jetzt schlecht in eine Einrichtung, in

51 | Bei den Ritualisten war es lediglich ein Elternteil, der sich dafür aussprach. 
eine religiöse Einrichtung schicken, insofern wird sie ja uns sehen, die ganze Verwandtschaft, uns beobachten und das ist ja schon mal sehr viel Input, was sie ja in einer sehr kurzen Zeit bekommt. Das, was später stattfindet, ist dann eher, glaube ich, eine Art Aufbau."(Lema., Z.: 118)

Auch wenn die religiösen Gemeinden einen wichtigen Beitrag bei der Vermittlung von religiösen Inhalten und sozialen Aspekten, wie z.B. der Pflege von Freundschaftsbeziehungen, leisten würden (vgl. Kap. III. 3.3 und III. 4.3; vgl. Lema, Z.: 110), könne die Aufgabe der religiösen Erziehung nicht an die Moscheegemeinden delegiert werden (vgl. auch Lema, Z.: 80). Die Überforderungen oder die Vernachlässigungen der Eltern in der Erziehung könne eine Einrichtung schlecht ausgleichen. Bei der Beschreibung fließen im Folgenden auch die Erfahrungen Lemas als Pädagogin in der Gemeinde ein:

"Nur Aufbau und Unterstützung, weil das Problem war ja, ich habe ja auch gesagt, das ist ja auch meine Überlegung auch ...; die Mädchen, die ich ja betreute damals, deren Eltern waren ja auch schwerst, also die hatten ja selber auch Probleme gehabt oder waren auch beschäftigt, die Kinder waren wirklich, irgendwo auch vernachlässigt worden, und dann kann man schlecht sagen, okay das Kind wird ..., schicke ich jetzt in eine Einrichtung, da wird es erzogen, nein, das kann ich, glaube ich, jetzt so nicht sagen. Das ist [...]. Dieses Delegieren, diese Arbeit einfach abgeben an andere. Das ist eher glaube ich, [...] nicht Sinn und Zweck der Sache. Auf jeden Fall!" (Lema, Z.: 122-126)

Ähnlich wie Lema und einige idealistische Eltern es betrachten, können laut Hülya Charaktereigenschaften und Werthaltungen nur innerhalb der Familie vermittelt werden. Demzufolge könnten Eltern diese Aufgabe nicht einfach der Moschee überlassen. So strebt sie als Pädagogin, die schon Angebote im Rahmen der Moschee im Bereich der Frühförderung an Eltern gerichtet hat (vgl. Kap. III. 4.3; vgl. Hülya Z.: 24), zukünftig nach einer Ausarbeitung von Eltern-Kind-Konzepten (vgl. Kap. III. 5.2 unter Verbesserungsvorschläge). Diese Konzepte sollen ein einfaches Delegieren verhindern und die Eltern stärker an ihre Erziehungsverantwortung erinnern. So möchte sie ein komplementäres Modell, innerhalb dessen die Moschee unterstützend wirke, aber die Hauptaufgabe den Eltern überlassen bleibe:

"[...] Charaktereigenschaften sollte man nicht der Moschee vielleicht überlassen, das verwechseln viele Eltern. Also, viele Eltern denken ja, jetzt schicke ich mein Kind in die Moschee und dann wird es gut. Ne, das geht aber nicht, ich habe als Erziehungsberechtigte die Aufgabe, mein Kind zu erziehen; und das, was da gemacht wird, sind wirklich nur Kleinigkeiten, die einfach für das soziale Leben eines Kindes in Bezug auf die Religion, einfach mit, mit auf den Weg gegeben werden und ist trotzdem immer noch die Frage, wie das Kind das Ganze aufnimmt, ja? Ob es wirklich zugehört hat in dem Moment, 
ob es ..., ich sehe dann auch andere Kinder, die sprechen mit den anderen, die werden ständig ermahnt, also wie in einer Schule eigentlich; aber, wenn ich persönlich bei meinen Kindern bin, noch in dem Alter, hören sie gut zu, weil die sind unter meiner Kontrolle noch. Und ich finde das vielleicht für die Zukunft so ein Konzept, also eher Eltern-KindKonzepte für mich, auch in Bezug auf die religiöse Erziehung im Kleinkindalter [...]. Ja, sehr, sehr effektiv, weil das fehlt uns noch." (Hülya, Z.: 138ff.; vgl. auch Z.: 150ff.)

Neben den religiösen sind staatliche Bildungseinrichtungen, wie die Kita oder die Schule, wichtige Sozialisationsinstanzen, denen die Eltern dieses Typs Bedeutung beimessen (vgl. Hülya, Z.: 109). Für Lema spielen diese Einrichtungen gerade für den Identitätsbildungsprozess und den Aufbau des Selbstbewusstseins eine wichtige Rolle. Eine zu einseitige Festlegung, z.B. auf die Gemeinde, ist für sie demnach nicht erstrebenswert. Es sei wichtig, in den staatlichen Bildungseinrichtungen $\mathrm{zu}$ lernen, sich $\mathrm{zu}$ »äußern«, »ohne sich zu verstellen, ohne sich dafür zu schämen« (vgl. Lema, Z.: 116). Durch die Schule konnte sie in ihrem eigenen Sozialisationsverlauf Stellung (Position) zu ihrem Muslimsein beziehen (vgl. auch Klinkhammer 2000; Wensierski/Lübcke 2012) und z.B. auch ein erfolgreiches Studium ablegen:

"Wichtig, ja, das war ja bei uns auch so. Ich selber persönlich hatte damals kein Problem, mit Kopftuch an der Uni zu studieren, mein Abitur mit Kopftuch zu machen. Das war also für mich kein Problem, auch, dass man da mal Stellung nimmt, wenn man gefragt wird: 'Warum trägst du Kopftuch? Warum betest du fünfmal am Tag? Dass man da auch selbstbewusst [...], das ist ja sehr wichtig, weil, das Kind darf die religiöse Erziehung [...] nicht einseitig bekommen und weil, genau deswegen darf es nicht nur [einen Bezug zur, Anm. d. Verf.] Gemeinde [haben, Anm. d. Verf.] [...], dass es so erzogen wird, dass es auch woanders sich äußern kann, wie gesagt, ohne sich dafür zu schämen, dass sie ein Kopftuch trägt oder dass sie z.B. am Schwimmunterricht nicht teilnehmen kann; das ist ja ..." (Lema, Z.: 112-116)

Folglich sei die Schule sehr wichtig, um Identitäts- und Selbstvergewisserungsprozesse anzuregen (vgl. Wensierski/Lübcke 2012).

Lemas Vorstellung bzw. das von ihr bevorzugte Modell legt ein ideales und ausgewogenes Dreiecksverhältnis zwischen Familie/Gemeindeleben/Moschee und Schule nahe. Darin äußert sich auch ihre Vorstellung von einem »Miteinander«, das auch interreligiöse Begegnungen und einen interreligiösen Dialog einschließe:

"Ja also, ich finde, wie gesagt, religiöse Erziehung, Sozialisation findet in erster Linie für mich in der Familie statt. Also in den vier Wänden, was da so abläuft. Das ist jetzt nicht so, dass es [ausschließlich, Anm. d. Verf.] zu Hause [abläuft, Anm. d. Verf.] sondern auch, wenn ich rausgehe, irgendwo mich aufhalte, das Kind guckt ja mit. Aber auch, 
dass das Kind in der Gemeinde ist, aber dass das Kind auch in der Schule ist. Das wäre natürlich die beste Vorstellung, Lösung. Vielleicht auch, dass andere religiöse, Religionen mit eingebunden werden, dass z.B. auch in den Schulen wie Weihnachten gefeiert wird auch mal Opferfest gemeinsam gefeiert wird. Also Ramadanfest. Das ist dann halt wieder dieses Miteinander." (Lema, Z.: 160)

Nicht zuletzt verweisen beide Elternteile neben den anderen Einrichtungen der religiösen Sozialisation auf die Peers und die Freundschaften als weitere wichtige Sozialisationsinstanzen (vgl. Lema, Z.: 110). Hierbei »achtet« Hülya auf die Freunde der Kinder und deren Familien, zu denen die Kinder Kontakt haben (vgl. Hülya, Z.: 109) (vgl. dazu Kap. III. 5.4 Peers [...]).

\subsubsection{Das Verhältnis der "Ethiker" zu den Sozialisationsinstanzen}

Unter den Ethikern ist ein differenziertes Bild, was die Wahrnehmung unterschiedlicher Bildungsangebote in den außerschulischen Bildungseinrichtungen angeht, festzustellen. Da es sich bei »Ethikern« um reflektierte und eine tendenziell intellektuell ausgerichtete Gruppe handelt, verwundert dieses Ergebnis nicht. Es konnte in ihrem Religiositätsprofil festgestellt werden, dass sie einen niedrigen Gemeinschaftsbezug aufweisen, was für einen individualisierten Zugang zur Religion sprach (vgl. Kap. III. 4.4). Dennoch scheint unter den »Ethikern« für alle Eltern gerade die Moschee ihren besonderen Stellenwert bei der religiösen Erziehung nicht einzubüßen. Dabei nehmen sie, wie im weiteren Verlauf gezeigt wird, Angebote der Moscheen wahr, aber auch andere außerschulische religiöse Bildungsangebote. Die Familie als Sozialisationsort findet kaum oder nur nebenbei Erwähnung. Die Schule spielt lediglich für eine Mutter (Feride) eine wichtige Rolle. Die Freundschaften, die im Rahmen der Moschee geknüpft werden, sind auch für einen Großteil der Eltern von Bedeutung (Belkıs, Melek, Birol) (vgl. auch Kap. III. 5.4).

Ansonsten zeichnet sich ein buntes Bild ab. Demnach erachten einige Eltern das Gemeindeleben in der Moschee (Belkıs, Adem) als einen Ort, an dem schon atmosphärisch und räumlich »außerhalb des Familienkreises« soziale Kontakte zu Gleichaltrigen aufgebaut und gepflegt würden und an dem auch gebetet $^{52}$ werde. Belk1s erhofft sich durch den Moscheekontakt zudem, ihren Kindern ein Umfeld zu bieten, das islamisch geprägt ist. So sollen die Kinder erfahren, dass jenseits einer nichtmuslimischen Umwelt auch eine muslimische Lebenswelt (im Kontext der Moschee) existiert, vor der sie »Respekt« haben. Hier wird auch auf den äußerlich symbolischen Wert (»das Gebäude allein«) einer Moschee hingewiesen:

52 | Dieser Aspekt wurde auch schon vonseiten idealistischer Eltern benannt. 
"Ja, weil ich denke, das ist so eine, zumindest ist das ein islamisches Umfeld, auch schon das Gebäude allein, dass sie zumindest weiß, wie es aussieht innerlich, dass sie da hingeht, dass sie weiß, dass man da betet [...] dass sie vielleicht auch mal aus dieser häuslichen Umgebung rauskommt; und das ist so die einzige muslimische Institution hier, außerhalb des eigenen Familienkreises. [...]. Also dass sie merkt, dass sobald ich meinen Fuß vor die Tür setze, ist nicht ALLES (betont) nichtmuslimisch, da gibt es noch etwas. Also das ist vielleicht eine emotionale Sache meinerseits. Vielleicht macht es nicht so viel Sinn, [...], aber ich hoffe zumindest, dass sie so dieses Grundgefühl hat, ja, wenn ich in die Moschee gehe, das ist eine Moschee, sie weiß wie es ist, dass sie einen gewissen Respekt davor hat." (Belkıs, Z. : 207-213)

Adem wünscht sich für seine Kinder, bezogen auf religiöse Gemeinden, einen pluralistischen Blickwinkel ${ }^{53}$, aus dem hervorgeht, »keine Unterschiede « zwischen den »verschiedenen Gemeinschaften« zu machen und die jeweiligen Stärken dieser anzuerkennen (vgl. Adem, Z.: 93).

Feride, die zeitweilig in der Türkei lebte, konnte dort besonders positive Erfahrungen mit einem muslimischen Kindergarten machen, in dem auch eine religiöse Erziehung angeboten wurde (vgl. Feride, Z.: 79/151/225-233). In Deutschland besucht der Sohn nun als Schulkind eine sohbet-Gruppe bzw. mit Ferides Worten ausgedrückt »ein[en] Freundeskreis«, der einen informellen Austausch über die Religion anregt. Auch Meleks Sohn nimmt an einer Frühfördergruppeteil, die an eine außerschulische religiöse Bildungseinrichtung angebunden ist (vgl. Melek, Z.: 248ff.).

Da alternative Angebote (wie die sohbet-Gruppe, außerhalb der Moschee) nicht genügen, erwartet Feride von der Schule die Anerkennung der islamischen Religion im Schulalltag durch die Lehrer/-innen. Dabei sei es wichtig, eine Sensibilität gegenüber muslimischen Kindern zu entwickeln, um sie in ihrem Selbstvertrauen zu stärken, »den muslimischen Kindern das Gefühl zu geben, ja, meine Religion ist auch wichtig, ist nichts, wofür ich mich zu schämen habe« (vgl. Feride, Z.: 253; vgl. auch Kap. III. 5.3). Ähnlich wie oben (unter den »Identitätssuchern«) sollen hierbei Selbstvergewisserungsprozesse angeregt werden, die muslimischen Kindern das Gefühl des Angenommenseins und der Gleichwertigkeit ihrer Religion vermittelt.

Schließlich nehmen für Birol, der insbesondere die ethisch-soziale Verpflichtung eines Muslims betonte (vgl. Kap. III. 4.3), neben der Moschee zudem humanitäre Hilfsorganisationen einen wichtigen Stellenwert ein. Hierbei sei es nicht wichtig, dass das Religiöse im Vordergrund stehe, sondern die »Aktion Mensch« zähle, wie es typischerweise von Ethikern hervorgehoben wird (Birol, Z.: 184ff.).

53 | Das ist hier ähnlich zu bewerten wie bei Nermin aufseiten der idealistischen Eltern. 


\subsection{Religiöse Erziehung in außerschulischen Bildungseinrichtungen}

Außerschulische Bildungseinrichtungen werden, wie bereits erläutert wurde, durch alle Eltern als Unterstützung der eigenen religiösen Erziehung außerhalb des eigenen familialen Rahmens wahrgenommen. Moscheen und ähnliche Bildungseinrichtungen, in denen religiöse Erziehung vermittelt wird, haben für alle religiösen Erziehungstypen einen Stellenwert, dem, wie es im ersten Moment scheint, beinahe die Hauptrolle im religiösen Sozialisationsprozess zugewiesen wird. Die Gründe hierfür sind, nicht wie frühere Untersuchungen belegen, in der Uninformiertheit über die eigene Religion (vgl. vgl. Kap. II. 2.1 und Kap. II. 2.2.1) zu sehen, die Eltern dazu veranlassen würden, ihre Kinder an die Koranschulen usw. zu übergeben.Vielmehr liegt es am Interesse und den gestiegenen Erwartungen bezüglich einer möglichst professionell und religionspädagogisch vermittelten religiösen Erziehung. Dabei wurde außerdem deutlich, dass das religiöse Gemeindeleben für fast die Hälfte aller befragten Eltern eine vielschichtige und tiefergehende Bedeutung aufweist. So sollen Moscheen und religiöse Gemeinden sogar »Heimatgefühle« vermitteln, die in der Fremde, obwohl man bereits in der dritten Generation in Deutschland lebt, zum Teil schmerzlich vermisst werden (vgl. oben). Hinzu kommen noch weitere Funktionen, die schon anhand früherer Untersuchungen beschrieben (vgl. Kap. II. 2.2.1) und gleichermaßen vonseiten der Eltern erwähnt wurden (vgl. oben und Kap. III. 4).

Doch bei genauerem Hinschauen wird auch Kritik an religiösen Bildungseinrichtungen und Moscheen geäußert, was dazu führen soll, dass diese vielmehr komplementär zur religiösen Erziehung innerhalb der Familie, und obgleich dies weniger häufig erwähnt wird, zur Schule wahrgenommen werden. Dementsprechend wird ihr Stellenwert von einer großen Zahl an Eltern verringert und sie sollten gleichrangig neben den Sozialisationsinstanzen, wie z.B. der Familie und Schule, stehen.

So erscheint es interessant, welche religiösen Inhalte und Angebote in den jeweiligen außerschulischen Einrichtungen gemacht werden. Hierbei ist $\mathrm{zu}$ berücksichtigen, dass aus der Perspektive der Eltern geantwortet wird, sodass möglicherweise in der Interviewsituation nicht alle Inhalte angegeben wurden, die in den jeweiligen Einrichtungen auch tatsächlich angeboten werden. Die Angaben decken sich weitgehend mit den Ergebnissen aus den Untersuchungen (vgl. Kap. II. 2.2.1) und darüber hinaus zeigt sich ein verstärkt differenziertes Bildungsangebot (vgl. auch Kap. II. 1.3), das im Folgenden aufgrund der Übersichtlichkeit tabellarisch aufgeführt wird. Dabei wurde dies wieder jeweils typspezifisch zusammenfassend wiedergegeben. Da schon im vorangegangenen Kapitel angegeben wurde, welche Einrichtungen bzw. Gruppen 
u.ä. besucht werden, wurde hier auf eine nochmalige Erwähnung derselben verzichtet.

Die angegebenen Inhalte sind in drei Bereiche gegliedert: a) Die Wissensvermittlung ${ }^{54}$, worunter auch das Lernen des Koranlesens fällt; b) das Erlernen von Ritualen und c) die Wertevermittlung. Die Methoden, die bei der Vermittlung zum Einsatz kommen, werden in der äußeren rechten Spalte aufgeführt. Freizeitangebote, die in diesem Rahmen wahrgenommen werden, sind am Ende gesondert angeführt.

Im Anschluss an diese tabellarische Illustration werden die Bewertungen, Erwartungen und Verbesserungsvorschläge der Eltern erläutert. Dabei beziehen sich die Eltern zum einen auf das, was sie sich für ihre Kinder im Rahmen der religiösen Bildungseinrichtungen wünschen, und zum anderen auf die Einrichtungen selbst. Die Wünsche und Erwartungen, die sie im Hinblick auf Inhalte und Wissensvermittlung, Qualifikation des Lehrpersonals und Räumlichkeiten zum Ausdruck bringen, beinhalten Verbesserungsvorschläge, die in Zukunft eintreten sollen. Hierbei kann, im Vergleich zur Elterngeneration, wie auch schon frühere Ergebnisse (vgl. Kap. II. 2.1 und Kap. II. 2.2.1) deutlich machen, von gestiegenen Erwartungen und Anforderungen an eine religiöse Erziehung und den damit zusammenhängenden Einstellungen gesprochen werden.

54 | Die in Klammern angegebenen Zahlen beziehen sich auf die Anzahl der Eltern, die darüber Auskunft gaben, d.h., wenn eine (3) hinter einem Aspekt steht, haben drei von fünf Eltern diesen Aspekt benannt usw. Hieraus lässt sich womöglich auch die Bedeutung ablesen, die die Eltern den jeweiligen Inhalten beimessen. 


\subsubsection{Religiöse Bildungsangebote und -inhalte, die die Kinder der "Idealisten " wahrnehmen}

\begin{tabular}{|c|c|c|c|}
\hline Wissensvermittlung & $\begin{array}{l}\text { Das Erlernen } \\
\text { von Ritualen }\end{array}$ & Wertevermittlung & Methoden \\
\hline $\begin{array}{l}\text { - Glaubensinhalte (5) } \\
\text { - Propheten- } \\
\text { geschichten (3) } \\
\text { - Auseinandersetzung } \\
\text { mit dem Koran und } \\
\text { Hadithen (3) } \\
\text { - Auswendiglernen } \\
\text { von Suren (2) } \\
\text { - Lernen } \\
\text { des Koranlesens } \\
\text { - Rezitieren } \\
\text { des Korans (3) }\end{array}$ & $\begin{array}{l}\text { - gemeinsame Gebete } \\
(4) \\
\text { - Rezitation, duas (4) } \\
\text { - Waschungen vor } \\
\text { dem Gebet (1) } \\
\text { - Religiöse Feste (2) } \\
\text { - Spenden } \\
\text { für Bedürftige(1) } \\
\text { - Einübung } \\
\text { des Hadsch (2) }\end{array}$ & $\begin{array}{l}\text { - Verhaltensregeln } \\
\text { (nicht Lügen, } \\
\text { Loyalität usw.) } \\
\text { - moralische Aspekte } \\
\text { (5) } \\
\text { - soziale Fertigkeiten, } \\
\text { - religiöses Gemeinde- } \\
\text { leben } \\
\text { - soziales Umfeld (5) } \\
\text { - Vorbilder (2) }\end{array}$ & $\begin{array}{l}\text { - pädagogische } \\
\text { Qualifikation } \\
\text { der Lehrenden (2) } \\
\text { o altersgemäße (4) } \\
\text { o spielerische Ver- } \\
\text { mittlung (3) } \\
\text { o Liebe/ } \\
\text { Wertschätzung } \\
\quad \text { Geduld (2) } \\
\text { - Vorbildfunktion (2) } \\
\text { - Curriculum (3) } \\
\text { - Hausaufgaben (3) } \\
\text { - Medieneinsatz (2) } \\
\text { - Tests/Noten (2) } \\
\text { - Sohbet-Sitzungen (2) } \\
\text { - Gruppenarbeit (1) } \\
\text { - moralische Aspekte } \\
\text { - (Geschichten, } \\
\text { Erzählungen, } \\
\text { Rollenspiele) (2) } \\
\text { - Nachdenken } \\
\text { (tefekkür) (1) } \\
\text { - kritische Reflexion/ } \\
\text { - Forschen (1) } \\
\text { - Auswendiglernen (2) } \\
\text { - kreative Elemente (2) } \\
\text { - Spiele/ } \\
\text { Wettbewerbe (2) } \\
\text { - religiöse Lieder (1) }\end{array}$ \\
\hline
\end{tabular}

Tab. 1: Beschreibung (Quelle: eigene Darstellung)

Die Ergebnisse, die aus dieser Tabelle abzulesen sind, deuten darauf hin, dass »idealistische« Eltern insbesondere die Glaubensinhalte, die gemeinsam verrichteten Gebete, die Wertevermittlung sowie das muslimische Gemeindeleben (vgl. Kap. III. 5.1.1) in den Vordergrund stellen.

Die in den Bildungseinrichtungen angewandten Methoden zeugen, im Vergleich zu früher, von einer höheren Professionalisierung und Differenzierung der religiösen Bildungsarbeit. Dabei haben manche Einrichtungen auch einen schulischen Charakter. Es bestehen Curricula und altersgemäß aufgeteilte Unterrichtsklassen, die einen planmäßigen Ablauf der Unterrichtseinheiten gewährleisten sollen, es werden Hausaufgaben aufgegeben, Tests 
durchgeführt etc. Auch die Einführung von Frühfördergruppen, die einen qualifizierten kindgerechten Umgang erfordern, zeigt die gestiegene Vielfalt an Bildungsangeboten.

Schließlich werden folgende Freizeitangebote gemacht:

- Sommer- und Wintercamps ${ }^{55}$ bzw. Übernachtungsangebote in Jugendherbergen in den Schulferien

- Besuch von Freizeitparks, Zoos, Picknicks usw.

- Spiele

- gemeinsam durchgeführte Reisen, auch Umra-Reisen

\section{Erwartungen/Bewertungen/Verbesserungsvorschläge}

Was die Bewertung der Bildungseinrichtungen bzw. Moscheen angeht, bringen fast alle Eltern zunächst ihre diesbezügliche Zufriedenheit zum Ausdruck.

Die fortschreitende Professionalisierung des Lehrpersonals (auch der hocas) in den Einrichtungen, die eine bessere pädagogische Qualifikation mitbringen (»spielerisch«, »pädagogisch«, »geht auf das Kind ein«) und die Weiterentwicklung des pädagogischen Lehrmaterials werden positiv aufgenommen. Die frühere Monotonie und Einseitigkeit sei heute einer kindgemäßen Herangehensweise gewichen (vgl. Lale, Z.: 459-483). Auch Ethem empfindet diese Entwicklung als positiv. Allerdings sei sie im Vergleich zu früher auch gewöhnungsbedürftig:

"Also ich bin zufrieden damit, sowohl die Art und Weise als auch das Ergebnis, das ich dann bei meinen Kindern sehe. Es ist natürlich gewöhnungsbedürftig dahingehend, dass es nicht mehr genau das Gleiche ist, wie ich es zu meiner Zeit erfahren habe. Ist befremdend, aber man muss sich aber auch als Eltern, die das vorher anders erfahren haben, dann auch erst mal daran gewöhnen. [...]. Und man merkt dann, also anfangs war es dann immer so, dass wir uns die Frage gestellt haben: 'Wohin sollte das jetzt führen?; und dann erst nach dem dritten oder vierten Wochenende plötzlich dann da bei den Kindern sich etwas einstellte, wo man dachte, schon versteht: 'Aha, da hat sich halt etwas gesetzt über Wochen, was halt wahrscheinlich beim ersten Mal nicht möglich gewesen wäre.`" (Ethem, Z.: 260)

Dilek und Nisa, die jeweils (von den muslimischen Dachverbänden her) unabhängigen religiösen Vereinen angehören, unterstreichen die Bedeutung der in diesen Gemeinden angebotenen Inhalte und bringen somit ihre Zufriedenheit zum Ausdruck. Dabei zeigen sich bei einem Vergleich der beiden Pro-

55 | In einem geregelten Ablauf kommen Kinder und Jugendliche bestimmter Altersgruppen zusammen, um religiöse Inhalte im Alltag gemeinsam unter der Aufsicht von Betreuern und Lehrpersonen zu erleben und zu praktizieren bzw. das Erlernte zu vertiefen. 
bandinnen auch die unterschiedlichen Schwerpunkte, die das Angebot ihrer Gemeinden kennzeichnet. Es ist gerade die Vermittlung von Glaubensinhalten, die Nisa als besonders positiv erachtet (vgl. Nisa, Z.: 91). Für Dilek ist es hingegen die Ausgerichtetheit auf das Koranverstehen, die vergleichsweise in anderen Moscheen nicht in dieser Form angeboten werde, ein wesentliches Kriterium für die Entscheidung, ihre Kinder an diesem Unterricht teilnehmen zu lassen. Methodisch stehe die intellektuelle Auseinandersetzung mit dem Koran, die durch das Forschen und die (kritische) Reflexion angeregt werde, im Vordergrund. Die Gemeinde unterstütze mit dieser Vorgehensweise, die sie ihren Kindern in jedem Fall vermitteln möchte, die eigene Wahrheitsfindung. Sie ist mit dem Lehrpersonal und dem methodischen Ablauf entsprechend den gegebenen Umständen zufrieden. Das Engagement der Lehrerin erachtet sie zudem als vorbildhaft (vgl. Dilek, Z.: 73-113).

Neben der hervorgebrachten Zufriedenheit werden jedoch auch Verbesserungsvorschläge gemacht und weitere Wünsche formuliert, die in der Zukunft eintreten sollen.

Eltern wünschen sich von ihren Gemeinden, dass das Erlernen des Koranlesens, d.h. das Erlernen der arabischen Schriftsprache, stärker in den Fokus treten soll (vgl. Dilek, Z.: 73 und 118; Nisa, Z.: 91; vgl. Nermin oben). Ethem, dem die »neuen« Methoden zwar prinzipiell zusagen, erwähnt in diesem Zusammenhang jedoch auch, dass traditionelle Unterrichtsformen, wie das Auswendiglernen, gerade für die Ausübung der rituellen Praxis nicht aus dem Blick geraten dürften:

"Manchmal wünscht man sich, dass die, gerade Aspekte, wie Auswendiglernen und so weiter, nicht völlig aus dem Fokus verloren geraten, also dass die auch weiterhin eine zentrale [Rolle, Anm. d. Verf.] spielen, weil es ist einfach auch eine Notwendigkeit, um halt auch eine gewisse religiöse Praxis auch am Leben zu erhalten, also wenn man nicht ein Mindestmaß an Versen auch auswendig gelernt hat, kann man einfach das Gebet nicht verrichten. Also das ist dann auch eine praktische Notwendigkeit, das ist zum Beispiel etwas, wo man nicht darauf verzichten darf, nur, weil man sagt, ich gehe, ich mache eine moralische Erziehung. Das reicht den Kindern ..., das reicht meiner Meinung nach nicht. Also da darf meiner Ansicht nach der Fokus einfach auch nicht zu weit [verschoben werden, Anm. d. Verf.], sondern das muss ein zentrales Standbein dieser Erziehung sein, aber sonst hätte ich da jetzt grundsätzlich keine weitergehenden Wünsche." (Ethem, Z.: 283)

Auch könne sich die Auswahl an Freizeitangeboten verbessern. Hierbei geht es den Eltern vor allem darum, dass sich die Kinder in den Einrichtungen bzw. Gemeinden »heimisch« und »aufgehoben« fühlen: 
"Ja, vielleicht können die da wirklich Freizeitaktivitäten usw. anbieten, sodass die Kinder sich da heimischer fühlen, sich da, ja, vielmehr aufgehoben, besser aufgehoben fühlen. Das ist nur der Unterricht und dann kommen sie ... ja, wäre schöner, wenn die da mit eingebunden wären, das fände ich schon ganz gut. Ne, dass sie ..." (Nermin, Z.: 445)

Die Moschee solle als »Heimat«, als ein »zweites Zuhause« »aufgemacht« werden, um den Jugendlichen z.B. mehr Sportangebote, wie Turnen, Karate, Fußball usw., zu ermöglichen (vgl. Lale, Z.: 497-506). Mit mehr Spiel- und Bewegungsmöglichkeiten könnten sich die Jugendlichen viel mehr in ihren Gemeinden aufhalten. Daher wäre es schön, so Nisa, wenn mehr attraktivere Freizeitangebote gemacht würden, damit die Jugendlichen auch andere Freunde einladen und begeistern könnten (vgl. Nisa, Z.: 91ff.). Doch dazu würden den Gemeinden oft angemessene Räumlichkeiten fehlen. Beanstandet werden demnach auch die fehlenden Räumlichkeiten, wie Turnhallen, Cafés, Spielplätze, oder die zu engen und zu kleinen Klassenzimmer, die nicht zum Wohlfühlen der Kinder und Jugendlichen beitrügen (vgl. Lale, Z.: 451-457 und Nisa, Z.: 93).

Schließlich wünschen sich die Eltern trotz einer zunehmenden Professionalisierung eine bessere Qualifikation des Lehrpersonals. Dabei sei nicht nur die Informationsvermittlung wichtig, sondern auch die Fähigkeit, zu lehren, indem die Lehrperson emotional auf die Kinder eingehe und eine altersgemäße Vorgehensweise wähle (vgl. Dilek, Z.: 117). Auch die Anzahl an qualifiziertem Personal solle zunehmen, damit viel mehr pädagogische Arbeit in den Moscheen geleistet werden könne (vgl. Lale, Z.: $497 \mathrm{ff}$.).

So solle zudem die Kommunikation der erwachsenen Gemeindemitglieder, die durch eine wertschätzende Haltung bestimmt sei, dazu beitragen, dass sich Kinder in den Gemeinden aufgehoben fühlen würden (vgl. Dilek, Z.: 6467).

Eltern dieses Typs wünschen sich für ihre Kinder, dass diese sich mehr für den Unterricht (Nermin) oder den Verein engagieren (Dilek). Dabei wird nochmals auf das Zugehörigkeitsgefühl hingewiesen, das im Rahmen des Gemeindelebens entstehen solle (Lale, Dilek, Nermin, Nisa). Es genüge auch ohne Unterricht, allein aufgrund der religiösen Atmosphäre am Gemeindeleben teilzunehmen (vgl. oben; vgl. Dilek, Z.: 113). So wünscht sich Dilek von ihrer Tochter (17 Jahre), die in ihrer Gemeinde eine Menge gelernt habe, dass sie sich für die religiöse Bildung und Erziehung der nächsten Generation einsetzt (vgl. Dilek, Z.: 115).

Nermin wünscht sich, dass die Kinder dem Moscheeunterricht eine höhere Priorität einräumen, indem sie z.B. regelmäßig lernen und ihre täglichen Aufgaben und Rituale (z.B. das Koranlesen, »als Vorbereitung für die Moschee«) erfüllen (vgl. Nermin, Z.: 439ff.). 


\subsubsection{Religiöse Bildungsangebote und -inhalte, die die Kinder von "Ritualisten ${ }^{56}$ wahrnehmen}

\begin{tabular}{|c|c|c|c|}
\hline Wissensvermittlung & $\begin{array}{l}\text { Das Erlernen } \\
\text { von Ritualen }\end{array}$ & Wertevermittlung & Methoden \\
\hline \begin{tabular}{|l} 
- Glaubensinhalte \\
(=Aqida) (2) \\
- Das Leben \\
des Propheten (s) \\
(=Sira) (2) \\
- Hadithe \\
(=Überlieferungen \\
des Propheten[s]) (2) \\
- Auseinandersetzung \\
mit dem Koran \\
$(=$ Tafsir) (2) \\
- Auswendiglernen \\
von Suren (1) \\
- Erlernen \\
des Koranlesens \\
- Rezitieren \\
des Korans (4)
\end{tabular} & $\begin{array}{l}\text { - gemeinsame Gebete } \\
\text { (4) }\end{array}$ & $\begin{array}{l}\text { - Werte (2) } \\
\text { Ahlak (=Charakter- } \\
\text { bildung) (1) }\end{array}$ & $\begin{array}{l}\text { - pädagogische } \\
\text { Qualifikation } \\
\text { der Lehrenden (1) } \\
\text { - altersgemäße (1) } \\
\text { - spielerische } \\
\text { Vermittlung (2) } \\
\text { - Vorbildfunktion (1) } \\
\text { - Curriculum (2) } \\
\text { - Hausaufgaben (1) } \\
\text { - Sohbet-Sitzungen (2) } \\
\text { - Auswendiglernen (2) }\end{array}$ \\
\hline
\end{tabular}

Tab. 2: Beschreibung (Quelle: eigene Darstellung)

Was hier als Erstes auffällt, ist, dass im Vergleich zu »idealistischen« Eltern weniger differenzierte Angaben über die wahrgenommenen Bildungsangebote gemacht werden. $\mathrm{Zu}$ vermuten ist, dass primär diejenigen Inhalte erwähnt werden, worauf die Eltern besonders viel Wert legen. Die Wortwahl ist gerade im Hinblick auf die Wissensvermittlung eine wichtige Gemeinsamkeit, die die Eltern dieses Typs kennzeichnet. So werden arabische Fachbegriffe für die verschiedenen Unterrichtseinheiten verwendet, um die Bildungsinhalte in den Einrichtungen zu beschreiben. Daraus lässt sich ableiten, dass auf eine

56 | Bei den Ritualisten fällt wieder insbesondere die einfache knappe und verallgemeinernde Wortwahl auf. Da die Verfasserin dieser Arbeit über Hintergrundinformationen der religiösen Bildungseinrichtungen, welche die Kinder dieser Eltern besuchen, verfügt, fiel auf, dass weniger religiöse Inhalte vermerkt wurden, als in den Einrichtungen tatsächlich angeboten werden. Eltern waren sich dieser Tatsache während der Interviewsituation nicht unbedingt bewusst. Es ist jedoch wichtig, zwischen der elterlichen Wahrnehmung der Angebote und den tatsächlichen Bildungsangeboten zu unterscheiden. 
klassisch-islamische Bildung ${ }^{57}$ viel Wert gelegt wird und die Wissensaneignung bzw. die religiöse Bildung eine herausragende Stellung bei den »ritualistischen« Eltern einnimmt (vgl. Kap. III. 3.2). Im vorausgegangenen Kapitel konnte außerdem festgestellt werden, dass Rituale, insbesondere die fünf Säulen des Islams, wichtige Bestandteile ihrer Religiosität darstellen. Überraschenderweise wurden die Gebete innerhalb des familiären Rahmens weniger eingehalten, selbst wenn der Wunsch dazu vorlag. Dass die Gebetverrichtung für alle ritualistischen Eltern (vier von vier) dennoch von Bedeutung ist, kann aus der obigen Tabelle abgelesen werden. Es scheint so, als ob die Aufgabe, die Gebete zu verrichten, an die Moscheen delegiert wird und sie als »Rituale« eben doch ihren Stellenwert bei der religiösen Erziehung beibehalten. Hier schließt sich bezeichnenderweise ein Kreis, der zunächst (bei der Verfasserin) Fragen aufwarf ${ }^{58}$. Diese Folgerung kann auch für das Koranlesen bzw. -lernen gezogen werden. Das Erlernen der arabischen Schriftsprache stellt wohl eine der wesentlichsten Motivationen dar, die »ritualistische« Eltern dazu bewegt, ihre Kinder in religiöse Bildungseinrichtungen zu schicken. Zudem deckt sich die Intensität, die der Wertevermittlung zuerkannt wird, mit den Angaben, die sie bei ihren religiösen Erziehungsvorstellungen machen. Die weniger differenzierte Beschreibung der angewandten Methoden stimmt mit dem Wunsch nach einer Verbesserung des pädagogischen Umgangs in den Bildungseinrichtungen überein (vgl. unten).

\section{Freizeitangebote}

Die Teilnahme an sohbet-Gruppen wird durch »ritualistische« Eltern als Freizeitangebot wahrgenommen. Darin werden religiöse Inhalte besprochen, »Geschichten gelesen « (vgl. Rabia, Z.: 298), es wird »zusammen gebetet«, »also die unterhalten sich dann über Antworten auf Fragen von den Kindern« und die Kinder werden seitens älterer Jugendlicher betreut (vgl. Selma, Z.: 325-330; vgl. auch Rabia, Z.: 423ff.).

Darüber hinaus werden Sportangebote gemacht (Rabia), die in der Regel eher größere Gemeinden anbieten können, oder Parks usw. besucht (Ali).

57 | Worin insbesondere das katechetische Wissen, wie die Glaubensgrundlagen und die fünf Säulen des Islams, enthalten ist.

58 | Es war überraschend, dass die Gebetsverrichtung bzw. das Koranlesen in den Familien der "Ritualisten " nicht mit einer hohen Priorität umgesetzt wurde. Es könnte doch eigentlich von Ritualisten erwartet werden, dass gerade die Gebetsverrichtung bei diesen einen wichtigen Stellenwert einnimmt. 


\section{Erwartungen/Bewertungen/Verbesserungsvorschläge}

Insgesamt zeigen sich Eltern dieser Kategorie engagiert, was sich z.B. auch darin äußert, sich im Anschluss an den wahrgenommenen Unterricht darüber auszutauschen. Es werden Hausaufgaben gemacht, das Nichtverstandene geklärt, Informationen über die Befindlichkeiten eingeholt oder über Freunde geredet (vgl. alle Eltern).

Doch kritisieren sie insbesondere die Erziehungsmethoden, die in außerschulischen Bildungseinrichtungen ausgeübt werden. Dennoch zeigen die Erwartungen, die sie an diese Einrichtungen formulieren, nochmals ihren hohen Stellenwert, den diese für die Eltern haben.

Selbst wenn sich einige Erwartungen erfüllt haben, wie z.B. das Erlernen von religiösen Grundlagen, machten drei von vier Elternteilen einen sehr unzufriedenen Eindruck. Lediglich ein Vater drückt seine Zufriedenheit aus, indem er, entsprechend den gegebenen Umständen und Möglichkeiten, keine besseren Alternativen zu der vom Sohn besuchten Einrichtung sieht. Sein guter Eindruck wird auch nicht durch Defizite getrübt, die übersehen werden, da entsprechend der Kapazitäten schon das Bestmögliche angeboten werde (vgl. Ali, Z.: 92-99).

Durch eine gesteigerte Professionalisierung des Lehrpersonals und die Erweiterung bzw. Verbesserung der Lehrmethoden erhoffen sich die Familien, dass die Kinder motiviert sind, in den Bildungseinrichtungen zu lernen.

Kritisiert wird insbesondere die wenig altersgemäße Vermittlung von Lehrinhalten, die dazu führe, dass Kinder sich langweilen oder unterfordert fühlen würden (vgl. Rabia, Selma). Wichtig sei hier, dass Kinder Erfolgserlebnisse hätten, indem ihnen altersgerechte und interessante Themen vermittelt würden (vgl. Rabia, Z.: 350-360; vgl. Selma, Z.: 394) und dass sie auf ihre Nachfragen Antworten bekämen, die sie nachvollziehen könnten (vgl. Rabia, Z.: 427). Gerade die Durchmischung verschiedener Altersgruppen mit unterschiedlichen religiösen Vorkenntnissen sorge für Unruhe und Disharmonie innerhalb einer Klasse, was behoben werden solle, damit das »Interesse« der Kinder und der »Spaß«am Unterricht aufrechterhalten würden (vgl. Rabia, Z.: 344-350). Diese Unterteilung sei auch für Kinder notwendig, die die türkische Sprache nicht beherrschen würden. Es sei in der Zukunft somit erforderlich, deutschsprachigen Unterricht in den religiösen Bildungseinrichtungen anzubieten, damit die Kinder sich über ihre Religion in der deutschen Sprache ausdrücken könnten

"Weil ich finde auch, dass man den Islam auf Deutsch den Kindern vermitteln sollte, weil wir leben hier in Deutschland und wenn ein deutsches Kind eine Frage stellt, sollte es auf Deutsch den Islam erklären können und nicht auf Türkisch, weil es gibt auch Termini-Begriffe, die das nicht [erläutern, Anm. d. Verf.], [die Kinder, Anm. d. Verf.] können das nicht erklären den anderen gegenüber ... deswegen sollten der Islamunterricht auf Deutsch sein." (Mecelle, Z.: 343, vgl. auch Z.: 588) 
Auch Stör- und Unruhefaktoren, die durch »unerzogene« (vgl. Mecelle, Z.: 322-330) oder »verhaltensauffällige« Kinder (vgl. Selma, Z.: 396) hervorgerufen werden, würden einen geregelten Unterrichtsablauf verhindern. Um die Motivation bei den Kindern aufrechtzuerhalten, solle daher durch die Lehrpersonen eine angenehme Unterrichtsatmosphäre erzeugt werden. Wenig produktiv seien auch zu große Klassen, in denen der Lehrer den Kindern nicht genügend Aufmerksamkeit schenken könne, was die Kinder wiederum belaste und demotiviere (vgl. Selma, Z.: 364).

Es verwundert nicht, dass infolgedessen vielseitige Anforderungen an die Qualifikationen der Lehrpersonen gestellt werden. So wird von einer Lehrperson erwartet, dass sie sich in ihrer Vorbildfunktion wahrnimmt und mit viel »Liebe und Geduld« Konflikte austragen und den Kindern zuhören könne (vgl. auch Selma, Z.: 364 und Z.: 394; vgl. Rabia, Z.: 362). Zudem solle der Unterricht durch sie auf Deutsch vorgetragen werden (vgl. Mecelle, Z.: 588 ; vgl. oben). Die Lehrpersonen sollten die Kinder beeindrucken können und durch ihre vorbildhafte Haltung und »Charakter« einen positiven Einfluss auf diese ausüben:

"Also die sollen meine Kinder beeindrucken können. Die sollen mit ihrem Wissen das so schön rüberbringen können, dass meine Kinder auch da gerne hingehen, dass die auch mit Inhalten vom Islam, von dem was so schön ist, was so beeindruckend ist, nach Hause kommen und sagen, ,Das war so toll, das war ...', dass ich auch an meinen Kindern durch deren Charakter auch sehen kann, dass die davon was gelernt haben." (Rabia, Z.: 465).

Eine Haltung des hocas, die durch Ungeduld und Missstimmung (»irgendwie ist der hoca da unglücklich «) gekennzeichnet sei, präge die Kinder eher negativ (vgl. Selma, Z.: 366). Auch wird eine zu »strenge« und »kritische« Art, welche die Kinder »erschreckt«, abgelehnt. Ein Lehrer solle vielmehr die »positiven Seiten« hervorheben anstatt die »negativen Seiten« (vgl. Selma, Z.: 372-384). Daher sei es von Bedeutung, dass die kommunikativen Fähigkeiten der Lehrer verbessert würden, damit die Kinder mit viel Liebe und Wertschätzung und nicht kühl oder nur auf das Auswendiglernen beschränkt, behandelt werden könnten. Ferner wird nochmals auf die Vorbildfunktion der Lehrer hingewiesen, die gerade im Zusammenhang mit der Regelbefolgung hervortreten müsse. Lehrer sollten sich selbst an Regeln halten. Die von Kindern erlebten Widersprüche zwischen den zu Hause und in der Moschee gültigen Regeln, erschwere zudem die familiäre Erziehung (vgl. Selma, Z.: 394ff.).

Schließlich werden durch Eltern noch weitere Vorschläge gemacht, die im Rahmen der religiösen Gemeinden und Bildungseinrichtungen eintreten sollen. Neben der Einführung von Elterngesprächen (vgl. Mecelle, Z.: 341) sollen in den Moscheen alternative Angebote, wie Frühfördergruppen entstehen, die 
der Vermittlung der eigenen religiösen moralischen Werthaltungen dienen. Die Kinder sollten in jedem Fall mehr Religiosität erfahren (vgl. Selma, Z.: 397).

Für ihre Kinder wünschen sich »ritualistische« Eltern, dass sie etwas über ihre Religion erlernen, wie z.B. über den Propheten, über den Koran, über ihren Glauben usw., und dass sie verstehen, warum sie etwas tun. Dabei sollten sie auch dazu befähigt werden, Antworten auf die gestellten Fragen zu geben (vgl. Mecelle, Z.: 336; vgl. Ali, Z.: 90).

Die Mütter dieses Typs wünschen sich, dass die Moschee ein Ort wird, den sie als »Gebetshaus « wahrnehmen, wo sie »ständig hingehen« und wo ihre Erwartungen sich erfüllen:

"Insgesamt wünsche ich mir eigentlich ein Gebetshaus, wo meine Kinder ständig hingehen ... [...]. Ja. Genau! Einen Ort, wo meine, wo ich meine Erwartungen da auch finden kann, also dass die auch meine Erwartungen erfüllen [...].» (Rabia, Z.: 461f.)

Dabei solle bei den Kindern »das Interesse« (vgl. Rabia oben) und »die Lust« geweckt werden, am Moscheeunterricht teilzunehmen:

"Also für mich ist momentan hauptsächlich wichtig, dass die Kinder einfach mit Lust dahingehen, ne? Dass die da nicht sagen: , Och können wir heute nicht mal zu Hause bleiben? Das finde ich immer so traurig für die Kinder. Die gehen ja hauptsächlich da nur hin, um sich mit den Freunden zu treffen. $\mathrm{Ne}$ ? Und ich finde es eigentlich schön, wenn die da hingehen: , Ne, jetzt lernen wir was, wieder für unsere Religion،; ich möchte einfach, dass sie an diesen Punkt einfach kommen, dass es denen Spaß macht, was über Gott zu lernen, was über unsere Religion zu lernen, und ja, dass die einfach unsere Religion auch lieben einfach [...]. Ja. Dass sie einfach sehen, darin aufblühen, irgendwie [sich wohlfühlen?, Anm. d. Verf.]. Genau. Das ist sehr wichtig für mich!، (Selma, Z.: 400-406) 


\subsubsection{Religiöse Bildungsangebote und -inhalte,} die die Kinder der "Identitätssucher ${ }^{59}$ wahrnehmen

\begin{tabular}{|c|c|c|c|}
\hline Wissensvermittlung & $\begin{array}{l}\text { Das Erlernen } \\
\text { von Ritualen }\end{array}$ & Wertevermittlung & Methoden \\
\hline $\begin{array}{l}\text { - } \text { Glaubensinhalte (2) } \\
\text { - Auseinandersetzung } \\
\text { mit dem Koran (1) }\end{array}$ & $\begin{array}{l}\text { - gemeinsame } \\
\text { Gebete (1) } \\
\text { - Rezitation, } \\
\text { duas (1) } \\
\text { - religiöse Feste (1) }\end{array}$ & $\begin{array}{l}\text { - religiöses } \\
\text { Gemeinde- } \\
\text { leben, } \\
\text { soziales } \\
\text { Umfeld (1) }\end{array}$ & $\begin{array}{l}\text { - pädagogische Qualifikation } \\
\text { der Lehrenden (2) } \\
\text { o altersgemäße (1) } \\
\text { o spielerische Vermittlung } \\
\quad(1) \\
\text { - Medieneinsatz (1) } \\
\text { - Sohbet-Sitzungen (1) } \\
\text { - Nachdenken (tefekkür) (1) } \\
\text { - Auswendiglernen (1) } \\
\text { - kreative Elemente (1) } \\
\text { - religiöse Lieder (1) }\end{array}$ \\
\hline
\end{tabular}

Tab. 3: Beschreibung (Quelle: eigene Darstellung)

Die Vermittlung von Glaubensgrundlagen steht für beide Elternteile dieses Typs im Vordergrund. Dabei kommen diverse Methoden (religiöse Lieder, kreative Elemente bei Kleinkindern) zum Einsatz, die zum Teil besonders oft erwähnt werden (vgl. Hülya). Bei älteren Jugendendlichen wird auf den Einsatz von Medien und auf das Nachdenken über religiöse Inhalten in sohbet-Sitzungen geachtet (vgl. Lema). Die Identitätssucher beschreiben die Familie als den wichtigsten Ort der Wertevermittlung, die nicht der Moschee überlassen werden dürfe (vgl. Kap. III. 5.1). Insofern werden durch sie weniger Bildungsangebote erwähnt, die dem Aufbau von Werthaltungen dienen:

"[...] Wenn ich irgendetwas zu Hause mache, wenn ich auf die Sauberkeit Wert lege, legen auch meine Kinder automatisch auf die Sauberkeit Wert. Wenn ich auf Ordnung Wert lege, legen meine Kinder Wert auf Ordnung und wenn ich dann in einer Moschee z.B. Ordnung nicht vorfinde, ja, Disziplin und Ordnung nicht vorfinde, dann werden's meine Kinder nicht vor Ort lernen, sondern zu Hause lernen müssen, deshalb kann jetzt, ich kann's erwarten, aber ich muss das nicht vorfinden." (Hülya, Z.: 150)

Dennoch sei die Moschee als »soziales Umfeld « wichtig, da die dortige »Atmosphäre« und die Gruppe die Kinder präge und beeinflusse (vgl. Hülya, Z.: 122).

59 | Hier wird auch auf diejenigen Inhalte Bezug genommen, die die beiden Elternteile als Professionelle in ihren Gemeinden vermitteln. 
In der Gemeinde von Lema werden den Jugendlichen Betreuungsangebote gemacht, die den Mädchen eine Anlaufstelle für verschiedene Fragen bietet. So steht ihnen bspw. eine Vertrauensperson zur Verfügung, die sie bei persönlichen, sozialen und schulischen Themen unterstützt (vgl. Lema, Z.: 78 und Z.: 136-140). Zusätzlich werden Sommer- und Wintercamps organisiert, die der Intensivierung des bereits Erlernten dienen und eine bildungsunterstützende Funktion, gerade im Hinblick auf schulische Themen, erfüllen sollen (vgl. ebd.).

\section{Erwartungen/Bewertungen/Verbesserungsvorschläge}

Hier äußert sich ausschließlich Hülya, die auch als engagierte Pädagogin Erfahrungen im Frühförderbereich (Krabbelgruppe) gemacht hat (vgl. Kap. III. 4.3). Als Mutter und Pädagogin erwartet Hülya, dass ihre Kinder möglichst »professionell« betreut werden. Da sie diesbezüglich Zweifel hat, begleitet sie ihre Kinder in den Unterricht, um zu »beobachten« und »mitzuhören«, ob die Kinder »auch richtig verstanden haben« (vgl. Hülya, Z.: 128ff.). Aus diesen Erfahrungen resultierend, wie eben das »Kind das Ganze aufnimmt«, wünscht sich Hülya für die Zukunft die Entwicklung von Eltern-Kind-Konzepten, was die Beteiligung der Eltern vorsieht:

"[...] und ist trotzdem immer noch die Frage, wie das Kind das Ganze aufnimmt, ja? Ob es wirklich zugehört hat in dem Moment, ob es ..., ich sehe dann auch andere Kinder, die sprechen mit den anderen, die werden ständig ermahnt, also wie in einer Schule eigentlich; aber, wenn ich persönlich bei meinen Kindern bin, noch in dem Alter, hören sie gut zu, weil die sind unter meiner Kontrolle noch. Und ich finde das vielleicht für die Zukunft so ein Konzept, also eher Eltern-Kind-Konzepte für mich, auch in Bezug auf die religiöse Erziehung im Kleinkindalter [...] sehr effektiv, weil das fehlt uns noch. [...]. Manche Eltern, nicht alle Eltern, um Gotteswillen, ich kann nicht alle in einen Topf schmeißen, aber ich habe es sehr oft gehört: Ja jetzt sind die mal drei Stunden nicht zu Hause, da kann ich aufräumen.، usw. Ich persönlich mach das überhaupt nicht so, ich bin dann dabei und verfolge das, und wenn es nötig ist, ergänze ich manches, wie das gemeint ist [...], damit die nichts Falsches lernen, was nicht in meinem Sinne ist, ja. Es kann ja ab und zu mal vorkommen, dass dann plötzlich irgendjemand irgendetwas sagt oder so. Meine Kinder erschrecken sich z.B., wenn jemand zu laut schreit und wenn da jemand lauter wird, dass ich meinen Kindern, ja, den Rücken stärke und sage: Ja, ihr braucht jetzt keine Angst zu haben.ı (Hülya, Z.: 138ff.)

Gerade aufgrund der verhaltensauffälligen Kinder müsse in der Konzeptentwicklung auch auf einen geeigneten Umgang mit diesen Rücksicht genommen werden. Die Konzepte sollten »insbesondere für Kinder unter sechs neu im islamischen Sinne erarbeitet werden, weil die Kinder können manchmal nicht ruhig sitzen, die sind ständig in Bewegung« (vgl. ebd. Z.: 141-144). Es sollten 
diverse religionspädagogische Methoden in einer effektiven Weise zum Einsatz kommen. Eltern sollten sich viel mehr engagieren (vgl. ebd. Z.: 146-150).

Schließlich kritisiert sie die Lehrperson, deren Qualifikation nicht ausreiche, um angemessene Lehrmethoden anzuwenden (vgl. Hülya, Z.: 130-136). So sei in Zukunft auch darauf verstärkt zu achten.

\subsubsection{Religiöse Bildungsangebote und -inhalte, die die Kinder der "Ethiker" wahrnehmen}

\begin{tabular}{|c|c|c|c|}
\hline Wissensvermittlung & $\begin{array}{c}\text { Das Erlernen von } \\
\text { Ritualen }\end{array}$ & Wertevermittlung & Methoden \\
\hline $\begin{array}{l}\text { - Glaubensinhalte (2) } \\
\text { - Propheten- } \\
\text { geschichten (3) } \\
\text { - Auseinandersetzung } \\
\text { mit dem Koran } \\
\text { und Hadithen (3) } \\
\text { - Auswendiglernen } \\
\text { von Suren (1) } \\
\text { - Lernen } \\
\text { des Koranlesens } \\
\text { - Rezitieren } \\
\text { des Korans (4) }\end{array}$ & $\begin{array}{l}\text { - gemeinsame } \\
\text { Gebete (4) }\end{array}$ & $\begin{array}{l}\text { - Verhaltensregeln } \\
\text { (nicht lügen, } \\
\text { Loyalität usw.) } \\
\text { • moralische Aspekte } \\
\text { (3) } \\
\text { - Vorbilder (1) }\end{array}$ & $\begin{array}{l}\text { - pädagogische } \\
\text { Qualifikation } \\
\text { der Lehrenden (2) } \\
\text { o altersgemäße (2) } \\
\text { o spielerische } \\
\text { Vermittlung (3) } \\
\text { o Liebe/ } \\
\text { Wertschätzung/ } \\
\text { Geduld (2) } \\
\text { - Vorbildfunktion (2) } \\
\text { - Curriculum (1) } \\
\text { - Hausaufgaben (1) } \\
\text { - Sohbet-Sitzungen (2) } \\
\text { - moralische Aspekte } \\
\text { - (Geschichten, } \\
\text { Erzählungen/ } \\
\text { Rollenspiele) (1) } \\
\text { - Auswendiglernen } \\
\text { (3) } \\
\text { - Frontalunterricht (2) } \\
\text { - kreative Elemente (1) } \\
\text { - religiöse Lieder (1) }\end{array}$ \\
\hline
\end{tabular}

Tab. 4: Beschreibung (Quelle: eigene Darstellung)

Es wird deutlich, dass für »Ethiker« insbesondere das Erlernen des Koranlesens und die Gemeinschaftsgebete im Vordergrund stehen. An dieser Stelle ähneln sie insbesondere »ritualistischen« Eltern, bei denen ein ähnliches Ergebnis zu verzeichnen war. Jedoch fällt hier die unterschiedliche Begriffsverwendung auf, die wiederum weniger auf eine klassisch-religiöse Bildung hindeutet. Dass die Wertevermittlung hier zwar wichtig erscheint, aber nicht differenziert wiedergegeben wird, verwundert zunächst etwas, da es sich bei dieser Gruppe doch um Eltern handelt, denen die Befolgung von ethischen Grundsätzen besonders am Herzen liegt. Erst als sie ihre Erwartungen und Verbesserungsvorschläge 
hinsichtlich des religiösen Bildungsangebots darlegen, nehmen sie schließlich darauf Bezug. Betont wird das Beziehungsverhältnis des Lehrpersonals zu den Kindern, die in diesen das »Individuum « bzw. den »Menschen « wahrnehmen und ihnen zudem als »Vorbilder« dienen sollen.

Im Vergleich zu »ritualistischen« Eltern können sich »Ethiker« auf eine differenziertere methodische Umsetzung des religiösen Bildungsangebots berufen. Es fällt auf, dass das Auswendiglernen und der Frontalunterricht hier Erwähnung finden, auch wenn diese mit einem kritischen Unterton aufgezählt werden. Im Großen und Ganzen zeigt sich ein zunehmend professionalisiert vermitteltes Bildungsangebot, das in Zukunft wohl noch eine stärkere Erweiterung erfahren wird.

Als Freizeitangebote würden Ausflüge gemacht (vgl. Adem, Z.: 107), Freizeitparks besucht (vgl. ebd. und Melek, Z.: 310) oder sportliche Betätigungen, wie Fußballspielen oder Schlittschuhlaufen, durchgeführt (vgl. ebd.).

\section{Erwartungen/Bewertungen/Verbesserungsvorschläge}

Die Eltern zeigen sich engagiert, was sich darin äußert, dass sie im Anschluss an den Unterricht großes Interesse daran zeigen, mit den Kindern über den Moscheeunterricht zu reden, sie zu motivieren, zum Lehrer in der Moschee Kontakt zu halten oder über das Gelernte hinaus religiöse Themen zu besprechen.

Ebenso drücken fast alle Eltern ihre Zufriedenheit mit den von ihnen wahrgenommenen Unterrichtsangeboten aus. Gerade die Teilnahme der Kinder an Frühfördergruppen wurde positiv bewertet (vgl. Feride, Z.: 230-233 und Melek, Z.: 323-328). Melek, für die weniger das Erlernen von Wissen, sondern dessen Umsetzung eine zentrale bedeutende Rolle spielt, zeigt sich von der religiösen Unterweisung beeindruckt:

"Ich finde das sehr gut! Vor allem dieses Jahr, wenn ich sehe, was die alles in hadithen gemacht haben. Also ich habe das letztens auch der hoca selber gesagt. Ich fand es wirklich sehr sehr schön. Den Inhalt überhaupt, dass die Kinder so viel über sahaba [arab. für die Gefährten des Propheten, Anm. d. Verf.] und Hadithewissen, was für eine Bedeutung der hadith für unser Leben, also was für einen Einfluss auf unser Leben hat; das den Kindern so zu vermitteln, das war sehr sehr schön! Das wissen die Kinder auch! Also für die hoca war es nicht so wichtig, dass die Kinder mehrere hadithe auswendig lernen, sondern einen hadith auswendig lernen, aber das auch praktizieren können." (Melek, Z.: 334)

Zudem erfüllte sich ihre Erwartung, dass die Lehrer und hocas Vorbilder für ihre Kinder darstellen sollen: 
"Dass sie so, die richtige Lebensweise den Kindern vermitteln können. Dass wir selber als Eltern dazu beitragen als Vorbilder; und das sind natürlich auch Vorbilder für unsere Kinder, die hocas. Nicht nur wir! Wir sind die Vorbilder innerhalb der Familie, aber das sind natürlich Vorbilder außerhalb der Familie. Und unsere Kinder nehmen die als Vorbilder!“ (Melek, Z.: 338)

Es ist gerade die pädagogische Qualifikation des Lehrers, die für Adem ausschlaggebend war, seine Kinder dem Lehrer in der Moschee anzuvertrauen. Dabei habe der Lehrer schon Erfahrungen mit dem Religionsunterricht in der Türkei gehabt, sodass er zum einen ein System eingeführt habe, das zur Zufriedenheit der Eltern beitrug; zum anderen habe er es verstanden, jedes Kind als Individuum zu betrachten, dem eine besondere Aufmerksamkeit geschenkt werden müsse. Die Sensibilität, die er in der Kommunikation erkennen ließ, sei weit von einem autoritären Stil entfernt, sodass im Vergleich zu früher eine Entwicklung stattgefunden habe (»in der Hinsicht hat sich da wirklich sehr viel getan«) (vgl. Adem, Z.: 103ff.). In ähnlicher Weise kann Birol, trotz einiger Defizite, auf positive Erfahrungen mit dem hoca bzw. Lehrer der Moscheegemeinde zurückgreifen (vgl. Birol, Z.: 206ff.).

Trotz der angedeuteten Zufriedenheit werden auch Kritik und Verbesserungsvorschläge geäußert, die zum Teil auf sehr hohe Anforderungen an einen professionell vermittelten Unterricht in den Moscheegemeinden hindeuten. Dabei soll gerade die pädagogische Qualifikation der Lehrenden sehr stark verbessert werden.

Dem Wunsch nach »einer stärker pädagogisch geprägten Erziehung«, bei der nicht der Frontalunterricht und das Auswendiglernen im Vordergrund stehen, soll in Zukunft entsprochen werden, damit die Kinder gerne am Unterricht teilnehmen (Belkıs). Die Eltern wünschen sich insbesondere, dass eine altersgerechte bzw. kindgemäße Vermittlung der Bildungsinhalte stattfindet (vgl. Belk1s, Z.: 203/215; Feride, Z.: 251). Die Methoden sollen so gewählt werden, dass das Interesse beim Kind geweckt wird. Es müsse darauf geachtet werden, dass kreative Elemente eingeführt würden und die Bedeutung hinter den vermittelten Inhalten nahegelegt werde (vgl. Belk1s, Z.: 217-225). Die Beantwortung von Fragen oder das Nachlesen und Erlernen von Inhalten erscheint auch bedeutsam (vgl. Feride, Z.: 251).

Vom Lehrpersonal werden insbesondere Fähigkeiten im Umgang mit den Kindern erwartet (»die Art und Weise, mit den Kindern überhaupt zu reden«) (vgl. Belk1s, Z.: 221). Aber auch eine Kompetenz hinsichtlich religiöser Inhalte sei wünschenswert: 
"... und toll fände ich es auch, wenn ich eine Moscheegruppe hätte, die für meinen Sohn angebracht wäre, [...] damit mein Sohn halt da, dahingehen kann, wo ich aber auch weiß, dass der Mensch, der inn da unterrichtet, nicht nur kompetent ist im Hinblick auf religiöse Inhalte, sondern auch kompetent ist im Hinblick auf pädagogische Eingehensweise." (Feride, Z.: 271)

Zusätzlich solle neben einer altersgerechten Vermittlung die pädagogische Qualifikation dazu ausreichen, »eine gewisse Beziehung zu dem Kind herzustellen«, damit die Kinder »gute Menschen werden« (Feride, Z.: 275). Ähnlich wie Melek (vgl. oben) betont sie zudem die Vorbildfunktion des Lehrenden: Die Kinder sollten die Möglichkeit bekommen, auf einen »Menschen« zuzugehen, »der auch vorbildhaft vorlebt« (vgl. Feride, Z.: 288).

Adem erwartet von Lehrpersonen, dass sie über psychologische Grundkenntnisse verfügen, damit sie imstande sind, beispielsweise mit pubertierenden Jugendlichen umzugehen, und damit sie auch »regelmäßige Dialoge« mit den Familien führen können (vgl. Adem, Z.: 128).

Es sollen auch organisatorische Aspekte verbessert werden, indem durch Jahrespläne eine bessere Koordination gewährleistet wird. Dies solle nicht zuletzt dazu beitragen, dass weniger Klassen mit unterschiedlichem Lernniveaus gebildet würden. Außerdem sei es wichtig, »kindgerechte Lernmaterialien« zu entwickeln und verstärkt auf Freizeitangebote zu achten (vgl. ebd., Z.: 132). Im Vergleich zu früher, wo der Unterricht zum Teil auch in Fabrikhallen stattgefunden habe, sollten Moscheen »bunte« und »kindgerechte« Räumlichkeiten für Kinder zur Verfügung stellen, damit sich die Kinder in ihrer Umgebung wohlfühlen würden (vgl. Birol, Z.: 212).

Schließlich wünscht sich Adem insgesamt für seine eigenen Kinder und die Kinder, die er ausbildete, Folgendes:

„Im Hinblick auf die Moschee? Also ich würde mir wünschen, für meine Kinder und für die Kinder, bei denen ich die Möglichkeit hatte, diese dort auszubilden, [...], auch nachdem sie den Besuch, die Bildung in der Moschee aufgehört haben, nicht nur einfach aufgeben und 'Das war's' sagen, dass sie das, was wir innen beibringen wollten, auch in die Tat umsetzen, indem sie das auch leben. Den Moscheen würde ich mehr wünschen, dass sie mehr an die Kinder, jedes Kind als ein Individuum ansehen und sich wirklich für die Kinder auch viel mehr Zeit nehmen."(Adem, Z.: 135) 


\subsection{Muslimische Kinder und Jugendliche im Kontext von institutionellen Bildungseinrichtungen}

Ausgehend von der Fragestellung, ob institutionelle Bildungseinrichtungen einen fördernden oder hemmenden Einfluss auf die religiöse Sozialisation ausüben, wird in diesem Kapitel der Umgang mit dem Islam in öffentlichen Bildungseinrichtungen thematisiert. Dabei lassen sich mehrere Themenfelder bestimmen, die hier aufeinanderfolgend entsprechend den Vorstellungen der jeweiligen Typen dargestellt werden:

- Der Umgang mit dem Islam in Schulen und Kindertagesstätten

- Religiöse und kulturelle Elemente im Schul- bzw. Kindertagesstättenalltag

- Die Einführung des islamischen Religionsunterrichts (IRU)

- Interreligiöse Begegnungen

Die Haltung der Lehrer/-innen und Erzieher/-innen gegenüber Muslimen und dem Islam, wie die Eltern sie wahrnehmen, zeigt, wie viel Verständnis und Toleranz im Umgang mit der Religion aufgebracht wird. Dabei ist insgesamt festzustellen, dass ein Teil der Pädagog(inn)en sich positiv und verständnisvoll verhält, wohingegen ein relativ hoher Anteil Vorurteile gegenüber den Muslimen und dem Islam zeigt. Fast jeder Elternteil, gleich welchen Typs, berichtet von negativen Erfahrungen, die auf ihre religiöse Zugehörigkeit zurückzuführen sind. Alarmierend sind insbesondere Diskriminierungserfahrungen und Benachteiligungen, die einen toleranten Umgang mit ihrer Religion erstrebenswert machen. Jedoch zeugen die berichteten positiven Erfahrungen von einem Vertrauensverhältnis, das sich die Eltern auch mit den staatlichen Bildungseinrichtungen wünschten. Es werden zudem Perspektiven aufgezeigt und Lösungsvorschläge gemacht, die auf ein konstruktives Miteinander abzielen.

Religiöse Elemente, die im Schul- bzw. Kindergartenalltag vereinzelt eingesetzt bzw. zugelassen werden, haben größtenteils positive Auswirkungen auf die Kinder und Schüler. In Fällen, wo dies nicht geschieht, wünschen sich die Eltern eine adäquate Berücksichtigung bzw. zumindest Respekt ihren religiösen Überzeugungen und Handlungen gegenüber (z.B. das Tragen des Kopftuches).

Mit der Einführung des islamischen Religionsunterrichts werden vordergründig integrationsfördernde und identitätsbestimmende Erwartungen verbunden (vgl. Kap. II. 2.2.2b). Des Weiteren soll dadurch die Fähigkeit der Kinder, über ihre eigene Religion sprechen zu können, gefördert werden. Hier sind fast alle Eltern davon überzeugt, dass der IRU flächendeckend in allen Schulen eingeführt werden sollte. Im Folgenden werden die Erfahrungen der Eltern mit dem bereits in manchen Schulen eingeführten islamischen Religionsunterricht erläutert. 
Interreligiöse Begegnungen und ein interreligiöser Dialog sollen gemäß vieler Eltern für ein friedliches Zusammenleben sorgen. Sie erhoffen sich dadurch für ihre Kinder Vorteile, wie die erfolgreiche Integration in den Schulalltag u.a. ihre Einstellungen und Meinungen dazu geben ein differenziertes Bild wieder.

Es sollen im Folgenden zu den oben vorgestellten Themenfeldern die jeweiligen Einstellungen, Wahrnehmungen und Bewertungen der Eltern erläutert werden. Dabei werden unterschiedliche Perspektiven und Blickwinkel deutlich. Die Verbesserungsvorschläge werden am Schluss wiedergegeben bzw. fließen diese auch in die Bewertungen mit ein.

\subsubsection{Wahrnehmungen und Erwartungen der "idealistischen" Eltern}

\section{Der Umgang mit dem Islam in Schulen und Kindertagesstätten}

Eltern berichten, was die Haltung der Lehrpersonen in öffentlichen Bildungseinrichtungen angeht, sowohl von positiven als auch negativen Erfahrungen. Es fällt auf, dass in Kindertagesstätten und Grundschulen ein toleranterer Umgang mit Muslimen und ihrer Lebensweise gepflegt wird als in weiterführenden Schulen. Auch betonen einige Eltern die Bedeutung ihrer eigenen Haltung in der Beziehung zum pädagogischen Fachpersonal.

Es werden zunächst positive Aspekte im Umgang mit dem Islam in Schulen und Kindertagesstätten beschrieben. Dabei wird auch die zentrale Rolle der eigenen Perspektive, die zu einem positiven und konstruktiven Umgang beitragen kann, dargelegt. Im Anschluss werden dann negative Aspekte des Umgangs, wie bspw. Diskriminierungserfahrungen und Vorurteile, näher ausgeführt.

Als positiv und verständnisvoll wurden Erzieherinnen erlebt, die auf das muslimische Speisegebot geachtet und z.B. keine gelatinehaltige Nahrung an die Kinder weitergegeben hätten (vgl. Nermin, Z.: 525; Lale, Z.: 566). Auch der Wunsch, die muslimische Bekleidungsvorschrift einzuhalten, die das nackte Spielen von Kleinkindern in Planschbecken ausschließt, sei in einer Kita respektiert worden (vgl. Lale, Z.: 566) (vgl. auch Kap. II 2.2.2c) »Muslimische Kinder in Kindertagesstätten «).

Positiv wurde auch ein Lehrer wahrgenommen, der in der Grundschule eine große Offenheit gegenüber der Religion dargelegt habe, sodass ein ständiger Austausch stattgefunden habe:

"[...] ich, wir hatten das Glück auf der Grundschule meines mittleren Sohnes, dass der Lehrer sehr offen war und sehr viel auch über Religion gesprochen hat und auch sehr viel nachgefragt hat und sodass [...], dass wir im ständigen Austausch standen." (Nermin, Z.: $477 f f$. 
Die Tatsache, dass es zu keinen Komplikationen im Zusammenhang mit dem Schwimm- und Sportunterricht oder den Klassenfahrten ${ }^{60}$ (vgl. Kap. II. 2.2.2) kam, wird durch Nermin als ein Entgegenkommen seitens der Lehrer bewertet. Dabei sei dem Kind und seiner Familie die freie Entscheidung hinsichtlich der Teilnahme überlassen worden (vgl. Nermin, Z.: 584). Hier sei insbesondere die Haltung der Lehrer oder des Direktors dafür bestimmend, ob die Kinder vom Schwimmunterricht befreit werden dürften:

"[... z.B. Mamas, [die Kinder haben, Anm. d. Verf.], die sich bedecken und eine Kopftuch tragen, haben viel mehr Probleme oder das Schwimmen ist auch so eine Sache. Aber Schwimmen war, weil die noch klein waren, habe ich die geschickt, da war es kein Problem, in der Pubertät hatten die kein Schwimmen mehr, auch gar keine Konflikte mehr. Aber jetzt zurzeit gibt es, höre ich Mamas, die damit Probleme haben, die sind ja, z.B. 13-/12-jährige Mädchen wollen nicht mehr schwimmen gehen, die haben es natürlich schwieriger; und da gibt es schon manche Lehrerinnen sind super, da sagen sie, sie soll kommen, soll sich dahin setzen oder an anderem Unterricht teilnehmen, aber das hängt schon vom Direktor oder von der Lehrerin ab." (Lale, Z.: 619)

Die Toleranz gegenüber dem Kopftuch vonseiten der Lehrer/-innen bestärkte Ethem darin, sich (richtig) für ein katholisches Gymnasium entschieden zu haben:

"Jetzt auf der Schule, wo meine Tochter also, wie gesagt, das ist wiederum ein katholisches Gymnasium, war nicht das einzige Kriterium dafür, aber es war auch mit eines der Kriterien, warum für uns die Schule dann auch gut gewesen ist. Bisher, also meine Tochter hat jetzt die fünfte Klasse auch mit Kopftuch angefangen und bisher hat sie eigentlich keine negativen Erlebnisse zu erzählen gehabt, im Gegenteil: Sie ist im Klassenverband gut angekommen, sie ist sehr beliebt bei ihren Lehrern und bei ihren Lehrerinnen. Bisher haben wir nichts zu beklagen." (Ethem, Z.: 292)

Die meisten Eltern (drei von fünf 5) betonen auch ihre eigene Haltung in der Beziehung zu den Lehrpersonen. Dabei sind sie engagiert und in der Elternpflegschaft vertreten (vgl. Nermin, Z.: 461ff.) oder sind immer präsent und stehen in Kontakt zu den Lehrern (vgl. ebd., Z.: 475). Den Respekt, den sie vor den Lehrpersonen ihrer Kinder hatte, führt Lale letztlich auf ihre eigene Offenheit und Authentizität zurück: »Das Zeigen ist auch sehr wichtig, wie man ist.« Auch wenn es möglicherweise Vorurteile gegeben habe, sei sie aufgrund ihrer eigenen Haltung trotzdem mit Respekt behandelt worden (vgl. Lale, Z.: 572ff.).

60 | Die Teilnahme stellt für einen weiteren Elternteil (Ethem) kein Problem dar, da er Klassenfahrten als selbstverständliche Bestandteile des Schulalltags betrachtet (vgl. Ethem, Z.: 313ff.). 
Auch Dilek empfindet die eigene wohlwollende Grundhaltung als unabdingbar. Gerade in Elterngesprächen sei es wichtig, einen konstruktiven Umgang zu pflegen: Freundlichkeit und gute Absichten brächten in den meisten Fällen Positives hervor. Auch die Teilnahme an allen möglichen schulischen Aktivitäten sei für sie sehr wichtig (vgl. Dilek, Z.: 181-185).

Negative Erfahrungen beziehen sich größtenteils auf Vorurteile, die seitens der Lehrpersonen an die Eltern und Kinder herangetragen würden. Beklagt werden zudem diskriminierende Verhaltensweisen, die zu Auseinandersetzungen mit den Lehrern geführt hätten. Hierbei spiele neben den Themen rund um das Kopftuch die »Zuschreibung als Muslim« (vgl. Bukow 2007) eine wichtige Rolle. Es träten hier häufig Mechanismen hervor, die zu Etikettierungen und damit möglicherweise sogar zu Stigmatisierungen von muslimischen Kindern und Jugendlichen führen würden.

Als die Tochter anfing, das Kopftuch zu tragen, berichtet Nermin, der die einmalige schlechte Note auf das Kopftuchtragen zurückführen konnte, von dem entsprechenden Vorfall mit einem der Lehrer:

"[...] wo meine Tochter halt inr Kopftuch angefangen hat zu tragen und ihr Mathelehrer war halt seit dem Sommer, seit August, September da und sie hat dann halt in den Herbstferien das Kopftuch getragen. Dann hat sie eine Mathearbeit nach ein paar Wochen geschrieben und die Mathearbeit war eine fünf. $\mathrm{Ne}$, und dann war ich auf dem Elternsprechtag, sollte auch hin, bin ich sonst auch hingegangen. Sagt der Lehrer: Ich glaube, das lag am Kopftuch.“" (Nermin, Z.: 461)

Dem Lehrer wird entgegengesetzt, dass das »Muslimsein « nicht mit einem Dummsein in Verbindung gebracht werden dürfe, zumal beide Eltern Akademiker sind (Informatiker und Mathestudium der Mutter). Zudem wurde die Freiwilligkeit des Kopftuchtragens betont. Im Anschluss an diese Arbeit schrieb die Tochter dann auch eine gute Note, was das Vorurteil des Lehrers widerlegte (vgl. ebd., Z.: 462-476).

In ähnlicher Weise wurde die zurückhaltende Art einer Schülerin bei verschiedenen Aktivitäten (Eislaufen, Teilnahme am Weihnachtsmarkt) vonseiten der Lehrer auf ihr Muslim sein zurückgeführt. Dabei wurde in einem Elterngespräch durch die Lehrerin nach der vermeintlichen Ursache gesucht und sie seien dann im Gespräch auf die Kopftuchfrage gekommen. Die Eltern wurden gefragt (ebd.), ob sie die Tochter dahingehend beeinflusst hätten. Wohingegen sie klarstellten, dass die Entscheidung der Tochter für oder gegen das Kopftuch vonseiten der Eltern respektiert werde (vgl. Dilek, Z.: 180-183). Hier kommt ebenso der Mechanismus einer Zuschreibung und Etikettierung als Muslim zum Tragen, was die Eltern gezwungenermaßen dazu veranlasste, Stellung zum Thema zu beziehen. Des Weiteren weist Dilek an einer anderen Stelle darauf hin, dass die Tochter sich, aus Angst vor Benachteiligungen, gegen das 
Kopftuch entschieden habe. Nicht zuletzt habe die Erfahrung ihrer kopftuchtragenden Freundinnen sie negativ geprägt, woraufhin sie dann das Kopftuch nicht anlegt habe (vgl. Dilek, Z.: 26).

Das Tragen des Kopftuches veranlasste auch einige Schulen dazu, von vornherein Unterschriften von muslimischen Eltern zu sammeln, weil die Kinder am Schwimmunterricht oder an den Klassenfahrten teilnehmen sollten. Dabei fällt den Eltern die ungleiche Behandlung auf, da diese Unterschriften von deutschen Eltern nicht eingeholt worden wären (vgl. Lale, Z.: 64-652; vgl. auch Boos-Nünning 2007).

Auch das Kopftuch der Mütter sei in einigen Fällen ausschlaggebend für diskriminierende Verhaltensweisen gewesen. So wurde z.B. eine Mutter von der Gesamtschule direkt an die Hauptschule verwiesen:

"Auch, wenn es z.B. manche Mamas [...], wie z.B. [mit der] Hauptschule und [sie] gehen dann zur Gesamtschule und die haben auch keine Plätze für Kopftuchmamas, immer ... leider haben sie da auch Vorteile, die sagen: ,Es gibt ja die Hauptschule ... dar; aber die Mamas möchten die Gesamtschule [für ihre Kinder, Anm. d. Verf.], aber da kriegen die auch keinen Platz; gibt es leider." (Lale, Z.: 643)

Beklagt werden auch Benachteiligungen bei der Notengebung, die kopftuchtragende Mädchen erführen. Diese Mädchen seien dennoch bereit, »härter« zu arbeiten, um diese Benachteiligungen zu kompensieren:

"Es ist oft, das ..., die sagen das immer wieder und ich das nur so sagen, aber zum Glück sind diese Mädchen auch bereit, wenn es nur eine Note ist, wir schreiben das Gleiche, aber leider kriege ich immer wieder eine Note schlechter. Aber sie wissen es. Aber dafür arbeiten sie auch härter." (Lale, Z.: 641)

Im Vergleich zur Grundschule, wo sie mehr Toleranz gegenüber ihrer Religion erfahren habe, sei das Gymnasium, das die Söhne besuchen, weniger von Offenheit und Toleranz geprägt. Die generelle Sichtweise ihrer Religion, beeinflusst durch die Medien, sei insbesondere von Vorurteilen und Terrorismusverdacht geprägt. Sein »Anderssein« bzw. Muslimsein habe der ältere Sohn immer durch die Lehrer zu spüren bekommen (vgl. Nisa, Z.: 98-102). Dies bringt sie folgendermaßen zum Ausdruck:

"Also sie haben meiner Meinung nach folgende Sicht auf unsere Religion, sie suggerieren das, sie suggerieren das den Kindern in ihrem Unterricht, meiner Meinung nach sind sie der islamischen Religion gegenüber nicht positiv gestimmt, es gibt ein/zwei Lehrer, die positiv sind, der Deutschlehrer und so weiter, aber generell wird die islamische Religion, beeinflusst durch die Medien und die Zeitungen, als terroristisch betrachtet. Und deine muslimische Identität, wird dir ständig vor die Nase gehalten, sodass der ältere 
Sohn dies immer spürt, immer zu spüren bekommen hat. [Also, du bist ein Muslim, und deswegen bist du anders, Anm. d. Verf.]. Ja genau, das haben sie inn immer spüren lassen [Gibt es Diskriminierungen?, Anm. d. Verf.]. Ja, die gibt es, gab es schon immer. [...] Es ist sein letztes Jahr, er ist seit sieben Jahren auf derselben Schule, er konnte sich immer noch nicht an die Schule gewöhnen, dies hat inn also in jedem Fall sehr stark geprägt." (Nisa, Z.: 103-110)

Obwohl Nisa die Kinder in ihren Aussagen nicht unterstützen möchte, damit sie nicht noch ein schlechteres Bild von der Schule haben und sich innerlich völlig von der Schule distanzieren, fühlen sich die Kinder dennoch ausgegrenzt (vgl. ebd., Z.: 115).

Ansonsten sind Konflikte und Diskriminierungserfahrungen zu verzeichnen, die sich auf weitere Aspekte, wie die Notengebung, Vorurteile und Benachteiligungen aufgrund des Muslimseins und auf die Befolgung des muslimischen Speisegebots, beziehen.

Der Umgang bei der Befolgung des muslimischen Speisegebots brachte auch Konflikte hervor, die Lale dadurch löste, indem sie selbst zu Hause Essen kochte und ihrem Kind dieses mitgab. Dazu sprach sie mit der Leitung, um sie von ihrer Absicht zu überzeugen, da die Erzieherinnen dies zunächst nicht akzeptieren wollten (vgl. Lale, Z.: 601-619). Nermin schildert die ungleiche Behandlung im Vergleich zu einer deutschen Mutter folgendermaßen:

"Nee, meine Jüngste war, ist mit eineinhalb in den Kindergarten gekommen und ich habe gesagt, 'vegetarisch bitte،. Die sollte vegetarisch essen, dann haben die ..., aber wenn es Fleisch gibt? Dann hatten die halt kein extra vegetarisches Essen angeboten. Wenn die dann halt so Fleischragout oder so etwas haben, dann hätte ja meine Tochter nichts gehabt. Dann wollten die ihr ein Brot geben. Dann habe ich gesagt, , Dann bringe ich ihr Würstchen mit. War okay. Und dann erfahre ich plötzlich, dass eine Deutsche gesagt hat, 'Mein Sohn soll vegetarisch essen`, und für diesen Jungen wurden Nudeln gekocht, da bin ich aus allen Wolken gefallen. Das war eine Mutter, ne das war mein fünftes Kind in jedem Kindergarten und dann hieß es ..., wurde mir so etwas gar nicht angeboten, warum auch immer, aber, ne bei einem deutschen Kind hieß es immer: Ja, dann machen wir ihm Nudeln،. Ne, ich muss immer dafür sorgen, dass mein Kind etwas zu essen hat, obwohl ich das gleiche Geld bezahle, so, also [...] das hat mich wütend gemacht, ich war sauer, das habe ich auch gesagt, natürlich! Die Erzieherin hat geweint und gesagt: , Das habe ich so nicht gemeint. Ich habe gesagt: 'So ist das aber rübergekommen und ich fühle mich hier diskriminiert und ich finde es eine Unverschämtheit, dass Sie sagen [...], warum haben Sie mir das nicht angeboten? 'Bin ich nicht auf die Idee gekommen. 'Was soll das denn? « (Nermin, Z.: 520-523)

Die Lehrer und auch deutsche Eltern verhalten sich zum Teil, gerade auf weiterführenden Schulen, somit offenkundig nicht neutral gegenüber muslimi- 
schen Eltern. Befürchtet wird aufgrund der Präsenz eines »ausländischen« Kindes ein Leistungsabfall der anderen (deutschen) Kinder. Nermin spürt diese Vorurteile, obwohl der Sohn zu den Besten in seiner Klasse gehört (vgl. Nermin, Z.: 6o6-614).

Eltern fühlen sich diskriminiert, da ihnen z.B. die Zugangsmöglichkeiten, beispielsweise dem Elternbeirat beizutreten, von vornherein nicht gegeben werden. Ähnlich wie ihre Kinder (vgl. oben) konnte die Familie auch keine Akzeptanz vonseiten der Klassenpflegschaft erfahren (vgl. Nisa, Z.: 123-127).

Zusammengefasst kann gesagt werden, dass Vorurteile und Diskriminierungserfahrungen von muslimischen Eltern als sehr unangenehm wahrgenommen werden. Hingegen sind auch positive Erfahrungen vorhanden, die die negativen Erfahrungen zwar nicht minimieren, aber dennoch Hoffnung darauf machen, dass ein toleranter Umgang mit Muslimen und ihren Kindern grundsätzlich möglich ist. Da die meisten Aussagen um das »Kopftuch « und die »religiöse Identität« kreisen, scheinen für »idealistische« Eltern gerade diese Themen Konfliktpotenzial zu enthalten. Es kann nicht eindeutig gesagt werden, ob diese negativen Erfahrungen auch hemmende Wirkungen auf die religiöse Sozialisation ihrer Kinder haben. Im Falle eines Mädchens, welches das Kopftuchtragen aufgrund befürchteter Benachteiligungen seitens der Lehrer ablehnt, kann von einem negativen Effekt gesprochen werden, was sich jedoch nicht unbedingt auf die gesamte religiöse Sozialisation niederschlagen muss. ${ }^{61}$ Eltern erleben Verunsicherungen, die durch verschiedene Diskriminierungen im Schulalltag herbeigeführt werden. Ob diese sie in ihrer religiösen Lebensweise einschränken und inwieweit diese Einschränkungen Einfluss auf die religiöse Sozialisation haben, bleibt hier offen und bedarf der weiteren Erforschung.

\section{Religiöse und kulturelle Elemente im Schul- bzw. Kindertagesstättenalltag} In diesem Abschnitt gibt es einige Überschneidungen zu den oben genannten Aspekten, wie z.B. zum Tragen des Kopftuches. Der entscheidende Unterschied ist die Frage, inwiefern sich Schüler und Eltern mit religiösen Themen und Elementen einbringen und welche positive Rückmeldung sie bekommen.

61 Das Kopftuchtragen ist nur ein, wenn auch sichtbares Kriterium muslimischer Religiosität. Dennoch dürfe die Bedeutung des Kopftuches nicht unterschätzt werden, markiere es doch den Beginn einer religiösen Lebensweise (vgl. in Kap. III. 3 Sozialisationsverläufe, z.B. von Selma, Melek, Rabia, für die Bedeutung des Kopftuches u.a.). Oftmals berichten Frauen, die das Kopftuch ablegten, dass die Hemmschwelle für die Nichteinhaltung von religiösen Geboten dadurch gesunken sei. Daher könnte eher dazu tendiert werden, dass die Schule hier einen hemmenden Einfluss auf die religiöse Sozialisation ausübt. Erst eine Untersuchung der Jugendlichen selbst könnte hier jedoch eindeutige Ergebnisse liefern. 
Hier soll auch darauf geschaut werden, ob dabei ein fördernder Effekt für die religiöse Sozialisation festzustellen ist.

An religiösen Feiertagen der Muslime sei es erlaubt, sich an diesen Tagen freizunehmen (vgl. Nermin; Nisa, Z.: 113) jedoch werde nicht genügend Rücksicht darauf genommen:

"Ja, wäre schon schön, die bekommen zwar frei an den muslimischen Feiertagen [...]. Es wird nicht thematisiert. Also was so Thema wird, ist manchmal in den Unterrichtsfächern, ne, PP, Ethik, praktische Philosophie, da wird das schon thematisiert, sodass die Kinder sich einbringen können, soweit sie möchten. Dann fragen sie auch manchmal oder suchen, wenn sie möchten, wenn sie nicht möchten, dann lassen sie das und schweigen und hören oder die Kinder haben auch untereinander, ne das, was halt normal. Aber die Schule als Institution an sich vernachlässigt das." (Nermin, Z.: 493-49ff.)

An ihren religiösen Festtagen bringen sich muslimische Kinder mit dem Verteilen von Süßigkeiten ein:

"Unser Fest und deshalb ... Oder auch nicht nur an den großen Festen, sondern auch an den kleinen Festen, sodass die dann halt mitnehmen und sagen. Zum Beispiel hat mein Sohn heute auch Süßigkeiten mitgenommen, hätte gestern ..., aber wir haben es vergessen, weil der Geburtstag des Propheten war oder so, ne, dass die schon so ein bisschen das mit reinbringen und sagen und so ein bisschen auch in die Kommunikation, in Kontakt zu kommen und erzählen, ne; ,Wir hatten das und das und deshalb verteile ich das.'" (Nermin, Z.: 504)

Außerdem werde der Islam in den verschiedenen Unterrichtsfächern hin und wieder aufgegriffen, was dazu führe, dass sich muslimische Schüler engagiert zeigen würden. Es würden Referate über den Islam im (Ethik-)Unterricht gehalten. Die Schüler gäben sich hierbei sehr viel Mühe und würden sich gründlich vorbereiten (vgl. Dilek, Z.: 208). Auch religiöse Diskurse um die Existenz Gottes im Deutschunterricht hätten schon einmal das Lob der Lehrerin hervorgerufen (vgl. Nisa, Z.: 77). Im Politikunterricht sollte über das Kopftuch debattiert werden, sodass im Vorfeld Vorbereitungen dafür getroffen wurde:

"Also letztens hatten die im Politikunterricht über die Kopftuchfrage debattiert. Fünfte Klasse war jetzt ehrlich gesagt für mich ein bisschen zu früh, aber das Thema kam dran und meine Tochter wusste auch, dass es drankommt. Wir haben dann im Vorfeld uns darüber unterhalten, auch über Ansichten, die gegen das Kopftuch sind, wo die herrühren, was man dagegen auch sagen kann; also spielt schon eine Rolle." (Ethem, Z.: 294)

Darüber hinaus werde, wenn auch nur eine Stunde die Woche, der Türkischunterricht angeboten (vgl. Nermin, Z.: 489; Lale, Z.: 738ff.; Nisa, Z.: 115). Ge- 
rade die Existenz von türkischstämmigen Lehrerinnen und Lehrern rufe bei den Kindern mehr Selbstvertrauen und Identifikationsmöglichkeiten hervor (vgl. Nisa, Z.: 115).

Die Auseinandersetzung mit dem Islam im Unterricht führe bei den Kindern und Jugendlichen zu mehr Selbstvertrauen und Stärke. Es würden Selbstvergewisserungsprozesse angeregt (vgl. Klinkhammer 2000; Wensierski/Lübcke 2012), die den Kindern und Jugendlichen ein Selbstbewusstsein hinsichtlich ihrer eigenen religiösen Identität und eine tiefergehende Beschäftigung mit ihrer eigenen Religion ermöglichen würden. Dies bringt Ethem folgendermaßen zum Ausdruck:

"Also die Notwendigkeit, sich damit auseinanderzusetzen. Auch Fragen beantworten zu müssen. Also ich habe mindestens ab der achten Klasse irgendwie grundsätzlich jedes Referat, dass irgendwie mit Islam, Türkei und so weiter [...] zu tun gehabt hat [übernommen, Anm. d. Verf.] [...]. Irgendwo nervt es zwar, dass man immer die gleichen Themen bekommt. Auf der anderen Seite hat das dann aber dazu geführt, dass ich mich mit meiner eigenen Religion auf einer ganz anderen Ebene beschäftigen musste. Also auch was den Konsum von Literatur und auch Literaturrecherche und so weiter angeht, habe ich damit natürlich auch die Möglichkeit bekommen, mich mit meinem eigenen Glauben sehr tief, viel tiefergehender auseinanderzusetzen, als es jetzt bei anderen der Fall gewesen ist, die halt nie mit solchen Fragen konfrontiert worden sind [Also es stärkt, Anm. d. Verf.]. Man wird auch selbstbewusster, selbstsicherer auch im Auftreten und, also insbesondere selbstbewusster im Auftreten." (Ethem, Z.: 301)

Schließlich bringen sich Eltern an Elternsprechtagen ein, um für gegenseitiges Verständnis und Aufklärung zu sorgen. Sich gerade z.B. von Themen wie Ehrenmorden und Terrorismus abzugrenzen, sei bedeutsam, damit Vorurteile abgebaut würden:

"[...] weil sie über den Islam so denken und sagen, sie geben gleich ein Beispiel, es gibt zum Beispiel einen Film, in dem ein Mädchen einen deutschen Jungen heiratet, der Vater oder der ältere Bruder haben sich auf den Islam berufen und sie ermordet. Mein Mann klärt auf, indem er zeigt, dass es so etwas im Islam nicht gibt und dass diese kulturellen Dinge mit der Religion durcheinandergebracht werden, dass sie [die Lehrer, Anm. d. Verf.] die Religion nur aus den Medien kennen. Erversucht, so lange er Zeit dazu hat, aus der Sicht des Islams zu erklären; und sie sehen dann auch diese Dinge anders; sie mögen meinen Mann, wenn er so erklärt.. (Nisa, Z.: 121)

\section{Die Einführung des islamischen Religionsunterrichts (IRU)}

Der IRU wurde in manchen Schulen, wie bereits mehrfach erörtert wurde, zum Teil schon eingeführt. Dabei wird auch vom religionskundlichen Unterricht gesprochen, der dem Türkischunterricht angebunden ist. Es werden zu- 
nächst die Erfahrungen der Eltern mit den schon bestehenden Unterrichtsangeboten aufgeführt, sodass im Anschluss die Erwartungen und Ziele, die sie mit dessen Einführung verknüpfen, aufgezeigt werden.

Die Erfahrungen der idealistischen Eltern mit dem IRU an Schulen geben ein durchwachsenes (Meinungs-)Bild ab. Obgleich einige Aspekte des Unterrichts bei ihnen Gefallen finden, wird auch Unzufriedenheit deutlich gemacht, die bei einem Elternteil sogar dazu führte, die Kinder aus dem Unterricht zu nehmen.

Einige Eltern empfinden den Unterricht nicht gerade als »supergut«, weil sich das Ganze noch im Anfangsstadium befinde und dieser nur eine Stunde die Woche angeboten werde (vgl. Nermin, Z.: 576). Auch werden sowohl die unzureichenden Kenntnisse der Religionslehrer über den Islam kritisiert (vgl. Nisa, Z.: 141) als auch die ideologische Ausgerichtetheit der Religionslehrer, die sich in einem Fall auf die alevitische Zugehörigkeit (vgl. ebd.) und in einem anderen Fall auf die laizistische Orientierung des Lehrers (»Atatürk« sei wichtig im Unterricht gewesen) ${ }^{62}$ bezogen habe (vgl. Dilek, Z.: 210-213). Diese Eltern wünschen sich, dass keine Inhalte vermittelt werden, die der Weltsicht der Lehrer entspringen, sodass in einem Fall die Kinder letztendlich aus dem Unterricht genommen wurden (vgl. Nisa, Z.: 141).

Es werden jedoch auch die positiven Aspekte des Unterrichts betont. Anders als in der Moschee würden religiöse Grundkenntnisse in »strukturierter Unterrichtsform« vermittelt, was Lale als »sehr schön« empfindet und was zu ihrer Zufriedenheit beitrug (vgl. Lale, Z.: 728). Auch wurden und werden durch die Einführung des Religionsunterrichts identitätsbestimmende »Zeichen« gesetzt, was zur »Bestätigung« bei den Kindern geführt habe:

"[...] aber es war schon, es war für inn eine Bestätigung, dass es okay ist, halt Muslim zu sein; und, ne, dass der dann auch in der Schule dann seinen religiösen Unterricht hatte, [...]. Genau, der war auch in der Schule angekommen, das war so halt nur das Zeichen. [...] Das war gut. Ja." (Nermin, Z.: 576-580).

Lale beschreibt den Unterricht, den die älteren Söhne besuchen konnten, als etwas »Schönes«, der leider in der Grundschule des jüngsten Sohnes nicht angeboten werde:

"[...] Und das war so super, die haben ja immer wieder islamische Dinge geredet, auch wenn es nur oberflächlich war, aber das war schon schön. Aber leider hat dieses Kind nicht, diese Schule macht das nicht." (Lale, Z.: 712).

62 | Der religionskundliche Unterricht wurde im Rahmen des Türkischunterrichts angeboten. 
Die Erwartungen die Eltern in einen flächendeckend eingeführten IRU setzen und die Ziele, die damit erreicht werden sollen, resultieren zum Teil aus ihren Vorerfahrungen. Im Vordergrund steht der integrationsfördernde Effekt, der sich durch einen IRU an Schulen ergeben soll. Außerdem werden noch andere Aspekte, wie die Sprachfähigkeit oder die Entwicklung eines Identitätsbewusstseins benannt, die für einen IRU sprechen.

Der IRU solle dazu führen, dass die Religion eine »Normalität« darstelle und auch »Raum in der Schule« bekomme:

"In der Schule!? Also DER (betont) Unterricht in der Schule; da erhoffe ich mir eigentlich zum einen integrationspolitischen Aspekt, nämlich den, dass die Kinder auch spüren und auch sehen, dass auch ihre Religion einen Raum in der Schule bekommt, dass ihre Religion auch zur Normalität gehört, also, dass dieser Unterricht auch Normalität vermittelt [...]." (Ethem, Z.: 354)

Dieses »Ankommen«, die Akzeptanz bzw. die Integration der islamischen Religion als eine der Weltreligionen ist das »Wichtigste«, so Nermin:

"Zum einen einfach dieses Ankommen. Ja, der Islam, ne, wie Herr Wulff es gesagt hat: 'Der Islam ist hier angekommen. $\mathrm{Ne}$, dass man nicht sagt: , Nee, du darfst nicht und so'; dass man uns nicht immer ausschließt, immer und überall, sondern dass man sagt: Ja, es gibt so viele Muslime, ihr dürft auchı-; ne, der Islam ist eine der Weltreligionen. Und das ist für mich so das Wichtigste [...]." (Nermin, Z.: 582)

Neben der integrationsfördernden Leistung des IRU (»Der Islam ist auch wichtig. Ist auch ein Unterricht«) solle der Unterricht zu mehr Selbstbewusstsein und zur Wahrnehmung der eigenen muslimischen Identität beitragen (vgl. Lale, Z.: 732-747). Dabei könne der IRU nicht den Unterricht in der Moschee ersetzen, sondern sei eine andere Form des Lernens, die zur Unterstützung eingesetzt werde:

"Was soll man [...] dort lernen? Also das Wichtigste, sagen wir. Das ist ja ein Unterricht, ja? Ja, ich glaube nicht, dass es nicht wie in der Moschee sein wird. Ja? [...] nur das Wichtigste, auch diese Form zu lernen; und es ist schön, auch einen Unterricht über den Islam zu haben." (Lale, Z.: 728ff.)

Des Weiteren wird der IRU als eine Unterstützung der eigenen religiösen Erziehung gesehen, sofern die Inhalte nicht den eigenen Vorstellungen widersprächen und »gut« seien (vgl. Nisa, Z.: 144). Vom »Nutzen und Gewinn« des IRU spricht auch Dilek, unter der Bedingung, dass die Inhalte, die dort vermittelt werden, mit ihren Vorstellungen übereinstimmen. Auch ist sie sich dessen 
bewusst, dass sie die Entwicklung beobachten und gegebenenfalls ihre Kinder aus dem Unterricht nehmen darf (vgl. Dilek, Z.: 216-219).

Ferner solle durch den Islamunterricht »die Sprachfähigkeit, im Sinne von die eigene Religion auch im Deutschen erklären zu können sich damit auseinandersetzen zu können ... auch gesteigert [...] werden (vgl. Ethem, Z.: 354). Da die Kinder schon ihre Religion in der Moschee erlernen würden, könne der Verdienst eines IRU darin liegen, Begriffe, die sie im Türkischen erlernen, auch in der deutschen Sprache zu lernen:

"[...] Was so der Inhalt [...] sollte dann schon so sein, dass man auch die Begriffe ... ne, wir haben die Begriffe im Türkischen gelernt und wenn die Kinder dann die Begriffe auf Deutsch lernen, das tun sie sowieso mittlerweile schon in der Moschee, aber das ist schon etwas anderes, wenn die das noch in der Schule machen." (Nermin, Z.: 582)

Was die religiöse Sozialisation seiner Kinder durch den IRU angeht, werden die Vorstellungen durch Ethem folgendermaßen zum Ausdruck gebracht:

"[...] Also ich erhoffe mir ganz ehrlich gesagt für meine Kinder jetzt persönlich nicht, dass sie dadurch noch mal religiöser werden. Also die Hoffnung habe ich nicht! Ich kann mir aber gut vorstellen, dass es für viele muslimische Kinder auch die einzige Möglichkeit sein wird, irgendetwas über ihre Religion überhaupt zu erfahren. Vielleicht wird dann auch der Fokus auch vielmehr auf diesen Kindern liegen als auf Kindern, wie jetzt meine eigenen, die sowieso schon eine gewisse religiöse Erziehung bekommen. Also von, aus der Perspektive will, dürfte es sicherlich positiv sein und auch positive Auswirkungen haben und auch notwendig sein." (Ethem, Z.: 354)

Demnach werde der IRU inhaltlich nur den Kindern etwas bringen, die über den Islam erst in der Schule erführen. Diejenigen Kinder, die von zu Hause aus eine religiöse Erziehung bekämen und den Moscheeunterricht besuchen würden, könnten von seinen übergeordneten Zielen (Integration in den Schulalltag, vgl. oben) einen Nutzen ziehen (vgl. auch Lale und Nermin). Letztendlich sei die Einführung des IRU nur unter der »Voraussetzung« der Mitwirkung der religiösen Dachverbände vertrauenseinflößend, sodass die Kinder nur unter dieser Bedingung an einem IRU teilnehmen dürften (vgl. Ethem, Z.: 352).

\section{Interreligiöse Begegnungen}

Auch zu diesem Themenfeld nehmen die Eltern unterschiedliche Positionen ein. Dabei zeigen sie sich interessiert, jedoch haben sie, wie es scheint, zum Teil keine angemessene Basis für einen Austausch gefunden. Einig sind sich alle Eltern darin, dass die Religion des anderen in irgendeiner Weise Teil des gemeinsamen Zusammenlebens in dieser Gesellschaft darstellt. Die im Fol- 
genden aufgeführten Beispiele zeigen das Interesse und das mit unterschiedlicher Intensität verfolgte Engagement der Eltern.

Interreligiöse Begegnungen seien wichtig, um »mit Menschen anderer Religionen « zusammenzukommen, und sie würden eine »Selbstverständlichkeit« darstellen (vgl. Ethem, Z.: 321). Um ein friedliches Zusammenleben zu gewährleisten, sei es wichtig, die Präsenz anderer Religionen nicht aus den Augen zu lassen:

"Natürlich. Wir leben ja in dieser Gesellschaft. Und diese Kinder sollen auch zusammenleben. Muss ..., müssen auch damit zusammenleben. Wie wir auch leben, man kann es ja nicht, abkapseln. Ja? Sollten sehen, sollten sehen, es gibt auch diese Religionen, ja? Und sehen, das ist schon ne, da bin ich frei. Also ..." (Lale, Z.: 658).

Gerade der interreligiöse Dialog ermögliche es, sich auf gemeinsame ethische Grundwerte zu beziehen. Es sei im Gegensatz zur Religionslosigkeit erstrebenswert, Gemeinsamkeiten zwischen den Religionen zu betonen: Man glaube an einen Gott, an die Propheten, Engel usw. Daher müsse man einen aktiven Dialog betreiben, der insbesondere in der Schule vorangetrieben werden müsse (vgl. Nisa, Z.: 132-137).

Es werden insbesondere religiöse Feste als Gelegenheiten wahrgenommen, um Begegnungen mit der Religion des anderen einzurichten bzw. interreligiösen Dialog zu führen. Eltern motivieren ihre Kinder auf unterschiedliche Art und Weise, damit sie sich im Kindergarten- bzw. Schulalltag einbringen:

"a, also ich versuche schon, auch unsere Sichtweise einzubringen, bzw. einmal hat meine Tochter, also Weihnachten zum Beispiel ist ja so eine Sache ...; da sollten die Kinder sich einbringen. Und da hat der Lehrer gesagt, ,Überlegt euch, was ihr macht. Macht ein Rahmenprogramm`, und die Kinder wollten dann natürlich eine Weihnachtsfeier ... weiß ich nicht, vielleicht auch so ein Christkind oder so; sie hat gesagt: 'Mama, eigentlich will ich da gar nicht mitmachen, ne, weil Weihnachten ist ja nicht unser Fest. Und dann habe ich gesagt: Ja, dann schreib doch mal vielleicht, was du über Weihnachten denkst, ne? Und dann hat sie da so ein Gedicht geschrieben, was Weihnachten für sie ist, ne, und das hat sie dann dort zitiert, rezitiert und also das ist; was ganz Tolles ist da entstanden ne, fand ich auch [...]. Ja. Da ist etwas sehr Positives entstanden, zum Teil hat, ne zum einen hat sie sich halt eingebracht in diese Weihnachtsfeier, zum anderen hat sie ihre Gefühle ausgedrückt, ne, es ist kein Ablehnen von Weihnachten [...] sondern, dass Jesus halt auch mit, zu uns ein Prophet ist und dass sie das schon mag, ne, diesen Duft von ... oder diese Geschenke oder es glitzert überall und so ne, dass das schon schön ist und dass wir ein bisschen einen Anteil haben, aber dass das nicht unser Fest ist und so." (Nermin, Z.: 535-539) 
Es sind die Feste, die die Kinder beeindrucken, da es »glänzt und glitzert« (vgl. Nermin, Z.: 549). Außerdem erscheint es ihnen interessant und schön, eine Laterne zu basteln und am Martinszug teilzunehmen (vgl. Dilek, Z.: 203). Dennoch legen Eltern darauf Wert, dass ihre Kinder zwar wissen, um welche christlichen Fest- oder Feiertage es sich handelt (vgl. ebd., Z.: 545), aber dass diese nicht die eigenen Festtage darstellen (vgl. ebd.; Lale, Z.: 592; Dilek, Z.: 202). Sie wünschen sich Respekt durch die Schule, wenn die Kinder an manchen Feierlichkeiten, wie z.B. Karneval, nicht teilnehmen (vgl. Lale, Z.: 586; Dilek, Z.: 202).

Schließlich wird zu Hause auch über die christliche Religion gesprochen. Es werden Informationen darüber und die eigene Position dazu bzw. Perspektiven an die Kinder weitergegeben (»Wie sehen wir das als Muslime?«) (vgl. Nermin, Z.: 545ff.; vgl. Lale, Z.: 684ff.). Hierbei werden auch Gemeinsamkeiten bzw. gemeinsame Werte von Muslimen, Christen und Juden betont (vgl. Lale, Z.: 688-700).

\section{Verbesserungsvorschläge/Erwartungen}

Die Eltern tragen sehr unterschiedliche Verbesserungsvorschläge und Erwartungen vor. Diese beziehen sich auf ihre eigenen Kinder bis hin zur Gesellschaft. Der letztgenannte Aspekt, d.h. diejenigen Erwartungen, die die gesellschaftliche Dimension berühren, werden im betreffenden Kapitel aufgeführt. Hier sollen die Wünsche für die eigenen Kinder, Erwartungen und Verbesserungsvorschläge, die sie für die Schule haben, dargestellt werden.

Der Wunsch, dass die Lebenswirklichkeit der Muslime durch die Institution Schule stärker berücksichtigt wird, soll sich nicht nur auf das »vegetarische Essen« beziehen, sondern vielmehr auf Normen und Werte der Muslime. Auch wenn einige Lehrer/-innen entgegenkommend handeln würden und Toleranz gegenüber der muslimischen Lebensweise aufbrächten (vgl. oben), finde die Präsenz von muslimischen Schüler/-innen durch die Schule nicht genügend Berücksichtigung, sodass es zu Diskriminierungen komme. Dabei soll sie eine Selbstverständlichkeit darstellen und muslimische Kinder sollen sich als »Teil« dieser Gesellschaft sehen. Letztendlich sollten Diskriminierungen und Vorurteile in Schule und Gesellschaft abgebaut werden, sodass die Kinder »ankommen« könnten und sich integriert fühlen würden (vgl. Nermin, Z.: 584-623).

Hiermit soll eine grundsätzlich andere Sicht auf Religion und Religiosität entwickelt werden, die auf der gesamtgesellschaftlichen Ebene angeregt werden muss. Dem »religiösen Analphabetismus«, der auch schon Bestandteil in der Schule geworden sei, solle das »Religiöse « als ein »möglicher Lebensweg« entgegengesetzt werden dürfen, ohne dass es »abartig « wirke oder als ein »Problem behandelt wird« (vgl. Ethem, Z.: 356ff.). Nicht zuletzt solle dieser Weg eingeschlagen werden, damit das Zusammenleben von Menschen mit unter- 
schiedlichen Vorstellungen und Religionen gelinge (vgl. Lale, Nisa, Ethem; vgl. auch Kap. III. 5.6).

Neben der Einführung des IRU sollen Lehrpersonen mit Migrationshintergrund eingesetzt werden, damit die Kinder mehr Identifikationsmöglichkeiten haben und dadurch Selbstvertrauen gewinnen können. Ein Ort zum »Beten« wäre ebenfalls wünschenswert (vgl. Nisa, Z.: 115; vgl. Nermin, Z.: 730).

Auf der zwischenmenschlichen Ebene ist die Aufhebung von Respektlosigkeit gegenüber Lehrer/-innen und Erwachsenen ein wünschenswertes Ziel (vgl. Lale, Z.: 551; vgl. Nisa, Z.: 146). Nicht zuletzt solle die Aggressivität der Jugendlichen abgebaut werden. Folglich sei eine tiefe »Spiritualität« (türk. maneviyat) erforderlich, die zukünftig einen Schwerpunkt darstellen soll (vgl. ebd.). Dies bedeute, dass sich gegenseitige Hilfsbereitschaft, Fürsorge und Toleranz in den Schulen entwickeln müsse. Da die Kinder von einer zunehmenden Individualisierung beeinflusst werden (»Ich kann das « » $\underline{\text { Ich bin stark } «, ~ » ~} \underline{\mathrm{Um}}$ gut zu sein, muss ich den anderen übertrumpfen«, »Warum soll ich dir ohne Gegenleistung helfen?«), die sie $\mathrm{zu}$ egoistischen Verhaltensweisen verleite, sollten insbesondere diese Werthaltungen gefördert werden. Der Islam gebiete bei auftretenden Schwierigkeiten Mitmenschlichkeit durch Hilfsbereitschaft, Lächeln und Toleranz (vgl. Nisa, Z.: 148ff.).

Für ihre Kinder wünschen sich die Eltern, wie schon in ihren »Erziehungsstilen« (vgl. Kap. III. 4.1) deutlich wurde, dass sie ein »gesundes, selbstbestimmtes und erfolgreiches Leben « führen, das sie in die Lage versetzt, selbstständige Entscheidungen zu treffen (vgl. Ethem, Z.: 362). Die Kinder sollen eine Selbstständigkeit und ein Selbstbewusstsein entwickeln, die sie dazu befähigt, als »starke« Persönlichkeiten aufzutreten und sich in der Gemeinschaft oder Gesellschaft ohne Schamgefühle zu äußern. Die Schule solle hierbei behilflich sein:

"Ja. Insgesamt sollten sie für ihre Zukunft, ja? Ein selbstbewusster, bewusster Mensch. Wenn sie eine Gemeinschaft, in eine Gesellschaft reinkommt, sich zu äußern, seine Meinung sagen zu können, dieses Wissen zu haben, diese Sprache zu haben, zu verständigen, zu erklären, das sollten sie haben. Wir hatten es nicht, ja? Manchmal sind wir immer noch da, soll ich reden, soll ich nicht reden, soll ich was sagen? Sie sollen selbstständiger sein, selbstbewusster sein, die Schule soll also, dass sie sich ohne Scham ohne nicht alles erzählen, erklären können. Wie sie es [...] ein persönliches, ein bewusstes [...], das würde ich sehr gerne haben, die Schule soll helfen, dass Religion; am meisten soll Religion dabei helfen, dass es eine starke Person ist." (Lale, Z.: 755) 


\subsubsection{Wahrnehmungen und Erwartungen der "ritualistischen " Eltern}

\section{Der Umgang mit dem Islam in Schulen und Kindertagesstätten}

Im Vergleich zu idealistischen Eltern, bei denen sowohl positive als auch negative Erfahrungen im Umgang mit dem Islam zu verzeichnen waren, sprechen ritualisitsche Eltern überwiegend von negativen Erfahrungen, die sie im Umgang mit ihrer Religion gemacht hätten. Dabei verweisen sie insbesondere auf Diskriminierungserfahrungen und Vorurteile, die ihnen seitens der Lehrer/innen und anderer nichtmuslimischer Eltern widerfahren seien. Das Kopftuch nimmt eine wichtige Stellung innerhalb dieser Erfahrungen ein. Gleichermaßen nehmen sie eine zurückhaltende bis defensive Haltung ein, wenn es darum geht, sich mit auftretenden Problemen und Konflikten auseinanderzusetzen. Sie zeigen sich, bis auf einige Ausnahmesituationen, weniger engagiert, da sie entweder davon ausgehen oder ihnen nahegelegt wird, dass kein Interesse an ihrer Religion besteht, oder sie nicht noch mehr Probleme verursachen möchten.

Auffällig stark fühlen sich ritualistische Eltern Vorurteilen ausgesetzt, die ihnen durch Lehrpersonen vermittelt werden. Diese Vorurteile beziehen sich zum einen auf ihr Muslimsein oder auf den Islam und zum anderen besonders stark auf das Kopftuch als sichtbares Merkmal des Muslimseins.

Klischees (»Von der türkischen Mutti, die nur zu Hause kocht«) und Vorurteile werden als unangenehm empfunden, da sie das Gefühl vermitteln würden, einer Andersbehandlung ausgesetzt zu sein (vgl. Mecelle, Z.: 355). Diese Andersbehandlung bzw. Diskriminierung bekommen, so Mecelle, insbesondere kopftuchtragende Frauen und Mädchen in Schulen zu spüren:

"[...] Und wenn man Kopftuch hat oder so, da wird man ganz anders behandelt. [...] Ja, da sind halt viele der Geschwister als Putzfrau tätig, leider, weil der Staat das ja so haben möchte, weil diese, weil die Muslime werden schon diskriminiert in dieser Richtung; das spürt man auch in den Schulen." (Mecelle, Z.: 359)

Mit dem Tragen des Kopftuches fühlen sich entweder Mütter Vorurteilen ausgesetzt (vgl. Mecelle, oben; vgl. Ali, Z.: 104-132) oder kopftuchtragende Schülerinnen werden in verschiedener Form unter Druck gesetzt. Dabei verweisen die befragten Eltern ebenso auf Erfahrungen, die sie in ihrem Verwandtenkreis gemacht hätten. Es wird in Schulen, so Ali, »Überzeugungsarbeit« geleistet, ob muslimische Mädchen das Kopftuch freiwillig tragen oder dies nur unter vermeintlichem Druck und Zwang ihrer Eltern anlegen (vgl. Rabia, Ali). Seiner Nichte sei als 14-Jähriger unterstellt worden, das Kopftuch unter dem Druck der Eltern zu tragen, was sie als traumatisch erlebt habe. Insgesamt sei ein hoher Druck zu beobachten, der auf den Schultern der muslimischen 
Schülerinnen laste (vgl. Ali, Z.: 146-149). Nicht kopftuchtragende muslimische Schülerinnen müssen zudem an weiterführenden Schulen ihre Meinung über das Kopftuch äußern, was nach Ali einer Ungleichbehandlung nahekommt, da dieselbe Erwartung nicht an nichtmuslimische Schülerinnen herangetragen werde (vgl. Ali, Z.: 144).

Gerade als eine Mutter, die kein Kopftuch trägt, erlebte Rabia, wie ihre Tochter mit ihrer Entscheidung, das Kopftuch anzulegen, den »blöden« Sprüchen (»[...] lass das zu Hause«) einer Lehrerin ausgesetzt gewesen sei und dadurch sehr »traurig gemacht« wurde:

"Ja, also ich weiß auf jeden Fall, dass die mal ..., das ist ja nicht von mir gekommen, sie wollte mal, glaube ich, mit dem Kopftuch in die Schule gehen; da hat die Lehrerin da einen total blöden Spruch gelassen. [Zum Beispiel? Was hat sie gesagt?, Anm. d. Verf.]. [...] dass die das zu Hause [lassen soll, Anm. d. Verf.] [...]. Auf jeden Fall, auch so was, was mein Kind eigentlich traurig gemacht hat. [...] Negativ! Auf jeden Fall, also ich kann das jetzt wirklich nicht so einzeln sagen, aber es war auf jeden Fall negativ, weil es sie da traurig gemacht hat." (Rabia, Z.: 502-506)

Rabia findet das Verhalten der Lehrerin vor allem deshalb »ungerecht«, weil sie die Tochter weder zum Kopftuchtragen »gezwungen« hat noch selbst ein Kopftuch trägt. Es fällt der Mutter sichtlich schwer, diese Erfahrung bzw. die Beschuldigung in Worte zu fassen. Sie wünscht sich, dass es den Kindern überlassen wird, ob sie glauben, wie sie glauben und ob sie das Kopftuch tragen oder nicht:

"Nee. Ich kann ..., ich das jetzt so nicht, ich kann das jetzt nicht wörtlich beschreiben, vor allem weil das ja nicht von mir kommt. Ich bin ja selber nicht bedeckt. Von daher das kam einfach so, als ob das von mir kam oder ... [Also man hat Sie beschuldigt?, Anm. d. Verf.]. Ja. Man hat mich beschuldigt und ich finde das ist ungerecht! Also man muss den Kindern das überlassen, ob die glauben, wie die glauben oder nicht, ob die jetzt zu ist oder nicht zu [...] bedeckt ist oder nicht." (Rabia, Z.: 508-512)

Verletzend werden auch Sprüche erlebt, die einen geringen Respekt gegenüber der muslimischen Lebensweise deutlich werden lassen:

"Manchmal kommen schon blöde Bemerkungen Ist kein Schwein drin oder dies und das, das sind überflüssige Sachen und dann, dann verletzt das schon, solche Sprüche." (Mecelle, Z.: 410)

Außerdem sei das »Bild« über den Islam sehr schlecht (»Der Islam wird einfach nicht gut angesehen«), was dazu führe, dass die Religion weder »wahrgenommen« noch »anerkannt« werde: 
"... nicht wahrgenommen, nicht anerkannt. Und ich finde, das ist ein ... (zögert). Wie soll ich das beschreiben? Also auf jeden Fall bei meinem Sohn ist das so, der Lehrer hat sehr oft über den Glauben geredet, also der hat dann immer so zwischendurch so viele Meinungen von sich gegeben. Da wird es in den Schulen natürlich nicht anerkannt. Also die Lehrer kommen dann mit so Sprüchen dann. [...]. Ich finde das schon öfters erniedrigend dann so also [...] abwertende Sprüche." (Rabia, Z.: 482-486)

Die Ignoranz und abweisende Haltung der Direktorin (»Die, sie ist immer so; sie ist immer abweisend irgendwie, also sie versucht auch keinen Kontakt mit uns aufzunehmen«) einer evangelischen Grundschule, die keinen Kontakt zu den muslimischen Eltern suchte, führt Selma auf Konflikte zurück, die im Zusammenhang mit der Einführung des Türkischunterrichts entstanden seien. Dabei seien neben der Direktorin auch die Lehrer nicht positiv gestimmt gewesen (vgl. Selma, Z.: 414-448). Außerdem wird die schlechtere Bewertung (bei der Notenvergabe und dem Übergang in weiterführende Schulen) von Kindern mit Migrationshintergrund beobachtet (vgl. ebd., Z.: 450-456). Die Benachteiligung erstrecke sich auch auf das Verhalten von Lehrpersonen, wenn es darum gehe, Eltern das Fehlverhalten ihrer Kinder zu melden:

"Ja. Oder die türkischen Kinder, die muslimischen Kinder die fallen immer mehr auf, also, wenn sie zum Beispiel Unsinn machen, Unfug machen, ne? [Und woran merkt man, woran merken Sie das?, Anm. d.Verf.]. Woran ich es merke? Wenn mein, wenn meiner was anstellt, gehe ich immer dahin, aber, aber bei den deutschen Kindern, die werden gar nicht [...]. Oder wenn ein deutsches Kind was angestellt hat, wird es gar nicht dafür bestraft immer." (Selma, Z.: 458-462)

Benachteiligungen würden insbesondere gerade diejenigen Jugendlichen erleben, die den »Glauben richtig streng « leben wollten, was z.B. heiße, fünfmal am Tag zu beten, ein Kopftuch zu tragen oder die islamische Sexualmoral zu beachten, welche Regeln im Verhalten gegenüber dem Gegengeschlecht auferlegt würden (vgl. Rabia, Z.: 572-580).

Einzig das Verhalten der Erzieherin in einer Kindertagesstätte wurde als positiv bewertet. Sie sei unterstützend, tolerant und offen mit muslimischen Eltern umgegangen, sodass sich die muslimischen Eltern dort auch einbringen konnten (vgl. ebd., Z.: 472-476).

Vorurteile und Diskriminierungen, die sich auf die muslimische Lebensweise, vordergründig das Kopftuchtragen und andere Aspekte beziehen, wie die Einhaltung von muslimischen Geboten oder die Einführung des Türkischunterrichts, worin der islamische-religionskundliche Unterricht integriert ist, 
werden benannt, aber nicht als Probleme und Konflikte verstanden, die es zu lösen gilt. ${ }^{63}$

Zur Konfliktbewältigung im Umgang mit den genannten Vorurteilen und Stereotypen werden lediglich durch (zwei) Eltern unterschiedliche Strategien erwähnt, wobei ein Elternteil (Rabia) eine defensive Grundhaltung einnimmt. Hier spiele auch die Geduld, die der Glauben vorschreibe, eine wichtige Rolle:

"Also wir dramatisieren das einfach nicht, wir gehen das locker an und hoffen, dass das anders wird. [...]. Hoffnung ist da. Ja! [...] Ja. Ich hoffe, dass die Meinungen besser werden. [...] Ja. Ich tu ja aktiv nichts, ich rede nicht [...] solange es noch erträglich ist, rede ich natürlich nicht. Ich will das nicht dramatisieren. Ich [warte, Anm. d. Verf.] die Zeit [ab]. Also ich versuche es einfach, ich warte es einfach ab, sage ich mal [...] Ich will, ich bin kein Typ, der das alles so dramatisiert und gerne so streitet, also schlechte ja also, ... [Also Sie sind da geduldig, sagen wir mal?, Anm. d. Verf.]. Geduldig. Ja. Was der Glaube uns gegeben hat." (Rabia, Z.: 552-564)

Auch den Kindern möchte sie diese Geduld vorleben, da im Leben nicht alles so laufen könne, »wie man das möchte« (vgl. ebd., Z.: 570).

Ali, der sein Kind auf eine katholische Grundschule schickt, beschreibt seine Erfahrungen im Umgang mit Vorurteilen, die sich auf die Angst vor Muslimen oder das »Bild« von Muslimen beziehen, als eine prozesshafte Entwicklung. Die aktive Auseinandersetzung mit den Ängsten nichtmuslimischer Eltern (im Rahmen eines Elternstammtisches) sei ein Erfolg gewesen, der auf dem Engagement von ihm und seiner Frau beruhe. Dieses Engagement habe viel Akzeptanz und Anerkennung zur Folge gehabt. Verwunderlich erscheint ihm rückblickend dennoch, dass sich nichtmuslimische Eltern trotz dreijähriger Bemühungen seinerseits, eine Begegnung zu schaffen, zu Beginn sehr zurückhaltend und distanziert gezeigt hätten (vgl. Ali, Z.: 103-132). Hier wurden durch einen aktiven Dialog und die Absicht muslimischer Eltern schließlich »Brücken geschlagen« (vgl. ebd., Z.: 105).

Zusammengefasst kann gesagt werden, dass Diskriminierungserfahrungen durch Eltern dieser Gruppe besonders schmerzhaft erlebt und zum Teil erduldet werden. Inwiefern diese Benachteiligungen einen Einfluss auf die

63 Hier habe ich mich als Autorin gefragt, ob nicht noch größere Nachteile befürchtet werden und die Eltern daher ihre Schwierigkeiten bagatellisieren und somit vieles verschweigen. Oftmals werden auch negative Konsequenzen befürchtet, die später auf den Rücken der Kinder ausgetragen werden, so dass Eltern vielerorts in die Defensive gedrängt werden oder sich freiwillig dazu entscheiden, sich nicht zu äußern. Ebenso könnte die fehlende Sprachfähigkeit im Umgang mit Lehrern und Lehrerinnen ein Grund für die zurückhaltende Haltung sein. 
religiöse Sozialisation haben und dadurch eine hemmende Wirkung ausüben, konnte vorerst nicht eindeutig belegt werden.

Jedoch wird im Kapitel über die Gesellschaft nochmals durch die Eltern verdeutlicht, dass ein hemmender religiöser Sozialisationseffekt nicht auszuschließen bzw. vorhanden sei ${ }^{64}$ (vgl. Kap. III. 5.6).

\section{Religiöse und kulturelle Elemente im Schul- bzw. Kindertagesstätten-Alltag} Religiöse und kulturelle Elemente, die im Schul- bzw. Kindertagesstätten-Alltag zur Geltung kommen, werden durch die Eltern eher zurückhaltend wahrgenommen. Auch hier unterstützen sie ihre Kinder weniger und bringen sich selbst kaum ein, da sie davon ausgehen, dass kein Interesse dafür vorhanden ist (»Ja, wo soll ich mich denn einbringen? Will doch keiner wissen!«) (vgl. Mecelle, Z.: 385; Rabia, Z.: 544). Jedoch wünschen sich die meisten Eltern, dass eine Aufklärungsarbeit über den Islam stattfindet.

Wiederum andere Eltern motivieren ihre Kinder, sich bei religiösen Festen der Muslime einzubringen, und geben z.B. ihren Kindern etwas (z.B. Süßigkeiten) mit, damit sie das an andere Kindern verteilen (vgl. Ali, Z.: 134). Oder aber sie bemühen sich aktiv darum, religiöse Feste in der Kindertagesstätte zu feiern (vgl. Selma, Z.: 472). Hier muss angemerkt werden, dass diese Idee sehr gut durch die jeweilige Erzieherin aufgenommen wurde (vgl. ebd.), sodass auch internationale Festtage stattfanden, an denen die Frauen gemeinsam kochten. Die Schule hingegen verhalte sich dahingehend sehr reserviert (vgl. ebd.; Z.: 483ff.).

Außerdem werde in einer weiteren Grundschule bei religiösen Festen der Muslime den Schülern und Schülerinnen freigestellt, was als etwas »Schönes« wahrgenommen werde (vgl. Mecelle, Z.: 377) und was von Interesse gegenüber muslimischen Kindern zeuge:

"Ein ..., also wäre sehr schön eigentlich. Ich habe jetzt von einer Bekannten gehört: In der Realschule war das so, dass sie dann durchgesagt haben, dass die Kinder am nächsten Tag frei haben, weil die Ramadanfest hatten, ne? Und das fand ich toll! Sollen andere, alle Schulen so machen, ne? Dass sie, einfach den Kindern auch freigeben an unseren (stottert) Feiertagen ne und so eine Durchsage fand ich ganz schön eigentlich. Das zeigt auch, dass sie Interesse auch an den muslimischen Kindern haben." (Selma, Z.: 485)

64 | Es sind die Benachteiligungen und die Diskriminierungserfahrungen, die als Hemmfaktoren verstanden werden. Zu beantworten, inwiefern sich dies auf die Religiosität auswirkt, erfordert eine tiefergehendere Analyse, die die betreffenden Kinder und Jugendlichen in die Untersuchung einschließt. 
Ansonsten sei der Türkischunterricht auf Wunsch der Eltern eingeführt worden (vgl. Mecelle, Z.: 377), wobei dies in einem anderen Fall zu Konflikten mit Lehrern und Eltern geführt habe (vgl. Selma, oben).

Zeigt sich lediglich ein Vater engagiert, Aufklärungsarbeit zu leisten und grundlegende Kenntnisse über den Islam zu vermitteln (vgl. Ali, oben), so wünschen sich die anderen Eltern, dass verstärkt eine Aufklärungsarbeit in Bezug auf den Islam stattfindet (vgl. Mecelle, Z.: 388). Dabei sollen auch die Schüler/-innen über die Religionen aufgeklärt werden (vgl. Rabia, Z.: 546ff.; vgl. Ali, Z.: 139).

Insgesamt verhalten sich die Eltern, trotz ihres Wunsches nach mehr Aufklärung in institutionellen Einrichtungen eher zurückhaltend. Ob in diesem Zusammenhang ein hemmender oder fördernder religiöser Sozialisationseffekt vorhanden ist, lässt sich kaum belegen, daes hier, im Vergleich zu anderen Eltern, weniger diesbezügliche Aussagen über die Wahrnehmung vonseiten der eigenen Kinder gibt.

\section{Die Einführung des islamischen Religionsunterrichts (IRU)}

Mit der Einführung des IRU erhoffen sich Eltern dieses Typs insbesondere eine religiöse Bildung, die den Kindern Grundinformationen über ihre Religion vermittelt. Dieser Wunsch korrespondiert mit ihren eigentlichen Erziehungszielen (vgl. Kap. III. 3.2 »typologie [...]). Sie sollten sich Wissen aneignen, sodass sie »mehr Ahnung« von ihrer Religion hätten (vgl. Mecelle, Z: 450; Rabia, Z: 641). Der IRU solle ergänzend wirken, indem von »studierten« Fachkräften religiöses Wissen an die Kinder weitergegeben werde:

"Mehr Wissen auf jeden Fall, das, was mir halt fehlt! [...] Also die, ich denke mal, da sind dann halt Lehrer, die dann halt mehr wissen und die dann ergänzend zu meinem Wissen halt da viel mehr bieten können, als das, was ich meinen Kindern biete. Ich bin da ja nicht eine studierte Kraft oder habe das ja nicht, habe das halt von meinen Eltern gelernt und habe ein bisschen gelesen, aber viel mehr reicht mein Wissen da nicht so aus, was eigentlich traurig ist." (Rabia, Z.: 639ff.)

Rabia delegiert die Aufgabe der religiösen Bildung zum Teil an die Schule, jedoch erkennt sie auch an, dass diese Bildung ergänzend zu ihrem eigenen Wissen stattfinden sollte.

Mit der Einführung des IRU verbindet Mecelle den Wunsch der Gleichbehandlung. Die Tatsache, dass christliche Kinder Religionsunterricht erhalten, wirft bei ihm die Frage auf, warum muslimische Kinder keinen Religionsunterricht erhalten sollen:

"Ja, die haben doch auch von ihrer Religion, wird denen vermittelt; warum nicht unsere Kinder nicht; warum müssen wir die denn in unabhängige Einrichtungen bringen und 
noch Geld drauf zahlen? [Wo sie's doch in der Schule lernen können?, Anm. d. Verf.]. Ja, genau." (Mecelle, Z.: 453ff.)

Ansonsten soll der IRU dazu führen, dass die Kinder ihre Religion in deutscher Sprache erlernen, da sprachliche Defizite sie daran hindern würden, in türkischsprachigen außerschulischen religiösen Bildungseinrichtungen zurechtzukommen (vgl. Kap. III. 5.2, vgl. Mecelle, Z.: 457). Zudem ist die Auseinandersetzung mit dem Glauben in deutscher Sprache besonders wichtig, so Selma, damit die Kinder sich mit ihren nichtmuslimischen Freunden über ihre eigene Religion unterhalten und austauschen können und somit eine Diskursfähigkeit entwickeln:

"Weil es haben auch sehr viele andere deutsche Kinder auch gefragt gehabt: 'Gibt es überhaupt den islamischen Unterricht auf Deutsch?^ $\mathrm{Ne}$, und das fand ich eigentlich ganz toll, aber es ist schade, das gibt es nicht. [...] Genau! Genau die Freunde von meinem Sohn haben dann gefragt, ob das auch auf Deutsch unterrichtet wird." (Selma, Z.: 536-546, vgl. auch Z.: 561-566).

Mit der Einführung des IRU wird schließlich noch auf den integrationsfördernden Aspekt Bezug genommen. Es solle dadurch erfahrbar werden, dass der Islam »selbstverständlich« zu Deutschland gehöre (vgl. Mecelle, Z.: 459462).

Mit der Einführung des IRU wird durch die Ritualisten zwar stärker auf die religiöse Bildung abgezielt, die auch dazu beitragen soll, eine Sprachfähigkeit über die eigene Religion hinaus zu entwickeln, doch welche Auswirkungen der IRU auf die religiöse Sozialisation ihrer Kinder haben sollen, bleibt hier offen.

\section{Interreligiöse Begegnungen}

Das Interesse an interreligiösen Begegnungen wird durch manche Eltern bekundet (Ali, Selma) und durch andere eher weniger geäußert (Rabia, Mecelle).

Die Kinder und Jugendlichen sollen sich allen Religionen gleichmäßig annähern können und in der Schule grundlegende Kenntnisse über die Religionen vermittelt bekommen:

"I...]. Wenn den Kindern tatsächlich über alle Religionen Wissen vermittelt würde, wäre es von größerem Nutzen zum Beispiel die Feste von innen, worin der Sinn und die Bedeutung der Feste besteht und sie gefeiert werden, die Feinheiten, die religiösen Feinheiten und dass alle Jugendlichen mehr darauf achten, ich glaube das muss ihnen vermittelt werden; aber allen Jugendlichen [...]. Über alle Religionen." (Ali, Z.: 139ff.) 
Ebenso sollen die Kinder etwas über andere Religion lernen, indem sie Gotteshäuser (Kirchen, Moscheen und Synagogen) besuchen (vgl. Ali, Z.: 139; vgl. Selma, Z.: 507). Zudem wird die Teilnahme an interreligiösen Veranstaltungen gepflegt (vgl. Selma, Z.: 511-515).

Eine zurückhaltende und sich gegenüber anderen Religionen abgrenzende Position nimmt Mecelle ein. Die Kinder sollten zwar die Kirche besuchen und sehen, wie die »anderen « ihre Religion praktizieren, aber sie sollten auch das Eigene vom anderen unterscheiden lernen:

"[...] ne Schule geht ja auch mal in die Kirche, wenn die anderen Kinder gehen und da haben wir ja kein Problem. Sie sollen auch in die Kirche gehen und sehen dort, wie die anderen Religionen praktizieren und die sollen das unterscheiden. Aber, wenn die zum Beispiel Weihnachten feiern möchten, wir feiern kein Weihnachten und [machen das auch, Anm. d. Verf.] nicht anderen zuliebe oder so. Wir feiern einfach nicht und das sagen wir den Kindern: ,Das ist nicht unser Feiertag; ; schön und nett, aber die verstehen das, wenn man das denen so mit Liebe erklärt, gibt es auch kein Problem, meistens und, wie gesagt, ..." (Mecelle, Z.: 167)

\section{Verbesserungsvorschläge/Erwartungen}

Wie schon oben angedeutet wurde, wünschen sich ausnahmslos alle Eltern, dass mehr Aufklärung über den Islam stattfindet. Dabei solle gegenüber ihrer Religion mehr Offenheit, Toleranz und Respekt gezeigt werden.

Das Bild, das durch negative Berichterstattungen in den Medien erzeugt werde, solle einem »lockeren« Umgang weichen, da der Islam sehr viele positive Seiten aufweise (vgl. Rabia, Z.: 645-66o).

Der gegenseitige Austausch solle auch verstärkter zwischen muslimischen und nichtmuslimischen deutschen Eltern stattfinden (vgl. Ali, oben; Selma). Dabei sollten Brücken gebaut werden, die Begegnungen ermöglichen:

"Genau. Also das ist auch immer so in den Schulen, da ist einmal diese muslimische Gruppe und da ist einmal die deutsche Gruppe. Ne? Also, die kommen irgendwie nicht zusammen. Und das ist traurig. Also man möchte schon als Moslem, muslimische Eltern auch mit christlichen Eltern auch Kontakte haben, aber es kommt nicht immer zustande. Das finde ich traurig eigentlich." (Selma, Z.: 695)

Der Wunsch, dass ihre Kinder einen Gebetsraum zu Verfügung gestellt bekommen, damit sie ihre täglichen Gebete verrichten können, entspringt der Vorstellung eines ritualistischen Elternteils:

"Aber was ich noch ganz gut, schön finden würde; zum Beispiel in der Schule, das war damals zu meiner Zeit so: Wir konnten auch in der Schule beten. Das fand ich ganz 
schön, wir hatten extra so einen Raum bekommen gehabt. Das haben aber die Kinder hier nicht mehr." (Selma, Z.: 493)

Für ihre Kinder wünscht sich Selma, dass sie sich, neben ihrem Schulerfolg, wie »ein muslimisches Kind« verhalten, was Folgendes bedeute, nämlich sensibel, hilfsbereit und mitfühlend mit anderen Kindern umzugehen:

"Schule; mir ist es also sehr wichtig, dass die erfolgreich in der Schule sind, aber hauptsächlich, dass sie sich wie ein muslimisches Kind behandeln, verhalten. $\mathrm{Ne}$, also, dass sie zeigen, wie ein muslimisches Kind ist [...] vom Verhalten her; also es ist hilfsbereit, es ist sensibel, es ist aufmerksam, es hat Mitgefühl mit anderen Kindern." (Selma, Z.: 549-553)

\subsubsection{Wahrnehmungen und Erwartungen der "Identitätssucher"}

Kaum ein Typ misst den staatlichen Bildungseinrichtungen so viel Bedeutung bei, wie es die »Identitätssucher« tun. Auffällig stark führt ihr Dialogverständnis dazu, ein friedliches Zusammenleben zwischen Muslimen und Nichtmuslimen anzustreben. Die Schulen und Kindertagesstätten sollen als Orte des Lernens Möglichkeiten hierfür eröffnen. Gerade im Zusammenhang mit Identitätsbildungsprozessen und dem Aufbau eines Selbstbewusstseins sollen die institutionellen Bildungseinrichtungen zum einen dazu dienen, Stellung bzw. Position zum eigenen Muslimsein zu beziehen. Zum anderen sollen durch Kooperationen und eine Zusammenarbeit gegenseitiger Respekt, Wertschätzung und Toleranz erlernt und dadurch auch Vielfalt gefördert werden (vgl. Kap. III. 5.1, vgl. auch Kap. III. 3.3).

Nachfolgend werden sowohl die Wahrnehmung und Erwartungen von Hülya als auch die Antizipationen und die eigenen Erfahrungen aus der Schulzeit von Lema aufgeführt.

\section{Der Umgang mit dem Islam in Schulen und Kindertagesstätten}

Der Umgang mit ihrer Religion in der Kindertagesstätte, die die Kinder besuchen, ist durch Respekt vor der eigenen religiösen Lebensweise gekennzeichnet. Die Erzieherin pflegt einen »sensiblen« Umgang mit der Religion, was zu einer hohen Zufriedenheit Hülyas beiträgt (vgl. Hülya, Z.: 182). Gleich zu Beginn wurde auch durch die Kita-Leitung auf die muslimische Speisevorschrift Wert gelegt:

"Ja habe ich, das habe ich direkt am Anfang auf jeden Fall gesehen, von der Kita-Leitung her, weil die mich gefragt haben, ob meine Kinder, also wie die zu Bonbons stehen, also so gelatinemäßig. Und ich habe dann gesagt, genauso wie alle muslimischen Kinder natürlich; und sie selbst legt sehr viel Wert darauf, wenn z.B. Kinder Geburtstage haben und Gummibärchen verteilen, dass meine Kinder das nicht in die Hand nehmen oder 
dass die z.B. keine Würstchen essen von der Kita, oder also, wenn wir dann Veranstaltungen haben, beauftragt sie mich, auf jeden Fall direkt, dass ich türkische, also helalWürstchen, mitbringe, also sie legt viel Wert drauf." (Hülya, Z.: 156)

Auch die Gratulation für die eigenen Feste nimmt Hülya positiv auf (vgl. ebd., Z.: 160).

Die Tatsache, dass sie keine Konflikte oder Benachteiligungen erlebte, führt sie auf die bewusste Wahl der Kindertagesstätte zurück. Diese sei zwar mit dem Auto zwanzig Minuten von ihrem Wohnort entfernt, doch die Mühe bei der Auswahl habe sich gelohnt (vgl. ebd., Z.: 176 und Z.: 184).

Im Vergleich dazu erlebe sie, wie zum Teil andere Kinder aufgrund ihrer Religion »niedergemacht« würden. Gerade ihr Bekanntheitsgrad und ihr aktives politisches Engagement hätten dazu geführt, dass sie eine »offene Kommunikation« mit der Kindertagesstätte pflegt(e). Inwieweit die offene Kommunikation gelinge, hänge dabei von einem selbst ab:

"Ich habe von vielen Eltern gehört, also mittlerweile habe ich auch wirklich von weinenden Eltern gehört, dass muslimische Kinder auch in den Kitas zum Teil niedergemacht werden. [Weil?, Anm. d. Verf.]. Ja, weil sie z.B., wenn die nicht in der Kita das essen, was vor innen liegt, weil die nun mal zu Hause eine andere Essgewohnheit haben, dass durch die Kita-Lehrerin ein Kind angeschrien wird oder andere Dinge, also, weil die Mutter ein Kopftuch trägt, dass die da halt nicht ernst genommen wird und solche Dinge. Und ich glaube, das hängt wirklich von einem selbst ab, dadurch, dass ich auch viele politische Kontakte hatte und bekannt war in, hatten die mit mir eine offene Kommunikation. Ich glaube auch, das liegt auch daran." (Hülya, Z.: 178ff.)

Hülya geht davon aus, dass Benachteiligungen auch vom Belastungsgrad der Kindertagesstätten abhängen, sodass dies in der Auswahl der Kitas ein Kriterium für muslimische Eltern darstellen sollte (vgl. ebd., Z.: 184).

In Konfliktsituationen bzw. damit Konflikte erst gar nicht entstehen, wird (vgl. Hülya, Z.: 241) und soll Aufklärungsarbeit betrieben und nach Lösungen gesucht werden (Lema), die von gegenseitigem Respekt und Wertschätzung (vgl. unten) geprägt sein sollten:

"Ja, dazu natürlich Lösungen finden ne. Sich darüber einen Kopf machen und dann versuchen, was kann man da machen? Also, wie gesagt, ich, sie ist ja jetzt noch viel zu klein [...]." (Lema, Z.: 170)

Bei Benachteiligungen solle in jedem Fall mit dem Direktor oder dem jeweiligen Lehrer der Schule zusammengearbeitet bzw. kooperiert werden, um gemeinsame Lösungen zu suchen: 
"Ja, dass man da vielleicht viel mehr mit der Schule also spricht, mit dem Direktor oder auch mit dem Lehrer, dass man, ja fragt, warum das so ist und was man da machen könnte? Man muss das wirklich gemeinsam koordinieren. Koordinieren auch zusammenarbeiten. Kooperieren, weil man das einfach nicht mehr so trennen kann, okay ja, das Kind in den Schulen, das ist dann so." (Lema, Z.: 178)

\section{Religiöse und kulturelle Elemente im Schul-bzw. Kindertagesstätten-Alltag}

Die Beachtung der muslimischen Speisevorschrift ist ein religiöses Element, das mit viel Respekt behandelt wurde (vgl. oben).

Auch wenn in der Kita religiöse Feste nicht gefeiert würden, da diese säkular ausgerichtet sei (vgl. Hülya, Z.: 165f.), wird die Gratulation für das Fest positiv wahrgenommen (vgl. oben). Gerade die Beachtung der eigenen religiösen Feste $^{65}$ sind es, die sich Lema von staatlichen Bildungseinrichtungen erhofft. An dieser Stelle werden auch Erfahrungen aus der eigenen Schulzeit und Erfahrungen der Verwandten, die weniger Respekt vor ihrer Religion erlebten, aufgezeigt:

"[...] aber, es ist jetzt so, dass unsere Verwandte, die schon in den Kindergarten geht. Sieht man ja auch, die feiert Weihnachten mit, Ostern usw. und sofort oder Halloween. Da sieht man ja auch, das ist ja auch schön und gut. Ich habe ja auch Weihnachten gefeiert. Wo wir Kinder waren, haben wir auch so Nikoläuse bekommen usw. Aber wie gesagt jetzt, man vermisst schon das andere auch, dass das Kind dann auch sieht, dann wächst das Kind ja so auch auf. Okay, in den Schulen wird nur Weihnachten gefeiert, aber kein Ramadanfest. Ja, warum ist das so? Das ist ja auch irgendwo paradox, irgendwo auch, dass man ..." (Lema, Z.: 170)

Ein Aufwachsen mit den entsprechenden eigenen Werten bzw. religiösen Elementen erscheint als eine wichtige Lösung. Gerade für die Entwicklung der eigenen Identität, ohne ein Sich-verstellen-Müssen, sei diese Wertschätzung und der Respekt vor der eigenen Religion wichtig. Hier sollen Selbstbewusstseins- und Selbtvergewisserungsprozesse(vgl. Wensierski/Lübcke 2012) durch die gleichwertige Anerkennung beider Religionen angeregt und unterstützt werden. »Die beste Lösung« sei schließlich, dass die Religionen nicht »getrennt« wahrgenommen werden dürften. Hier wird auch der Ansatz eines interreligiösen Dialogs deutlich:

"[...] irgendwie dieses Verstellen fängt dann ja auch an. Das Kind, die Identität, die Identität ist ja auch, gehört ja auch mit dazu. Das ist ja auch wiederum Respekt, dass das Kind auch so respektiert wird, und dann wird es ja mich fragen: Ja Mutter, warum ist das denn so? Warum wird denn Weihnachten gefeiert und kein Ramadanfest? Das ist

65 | Das religiöse Fest wird hier als ein identitätsbestimmendes Merkmal aufgefasst. 
ja irgendwo auch traurig, finde ich. [Das ist dann so getrennt?, Anm. d. Verf.]. Getrennt. Genau. Dass es dann wiederum ja [eigentlich zusammengehört?, Anm. d. Verf.]. Das wäre die beste Lösung gewesen. Ja." (Lema, Z.: 172-176)

Des Weiteren ist Lema bereit, sich aktiv für ihr Anliegen einzusetzen und durch die Zusammenarbeit mit anderen muslimischen Eltern, »nicht nur türkischen«, sondern auch mit Muslimen, die »anderen Nationalitäten « angehören, Positives zu bewirken (vgl. Lema, Z.: 166). Das Kind könne dann über die Religionen lernen, es lerne die Vielfalt kennen und schätzen (»dass man dann das zusammen [feiert]«) und habe zugleich Partizipationsmöglichkeiten erlangt:

"Genau, das Kind lernt dann halt, okay Christen feiern Weihnachten, aber Muslime feiern dann Opferfest, dass man dann das Zusammen, dieses ...? Dann hat jeder vom Kuchen etwas, kann man so sagen." (Lema, Z.: 168)

Die Kinder sollen schließlich dazu imstande sein, dass sie sich mit »ihrer eigenen Identität« »selbstbewusst« äußern können, »ohne sich zu verstellen, ohne sich dafür zu schämen« (vgl. Lema, Z.: 110). Die eigene Auseinandersetzung mit religiösen Themen, wie z.B. dem Kopftuch, den Gebeten (»Warum betest du?«), warum sie z.B. in der Schulzeit nicht am Schwimmunterricht teilnahm, regten sie dazu an, Stellung zu ihrem Muslimsein zu beziehen und daraus gestärkt und erfolgreich hervorzugehen (vgl. Lema, Z.: 110-116).

Es besteht die Hoffnung auf eine sozialisationsrelevante Entwicklung, die in Zukunft eintreten soll. Gerade die eigenen Erfahrungen, die eine Auseinandersetzung mit religiösen Themen im Rahmen der Schule zufolge hatten, führten bei beiden Elternteilen dazu, sich der eigenen »muslimischen Identität« zu vergewissern (vgl. auch Kap. III. 3.3). Insofern wird hier ein fördernder religiöser Sozialisationseffekt gewünscht, der sich mit den eigenen positiven Erfahrungen deckt. Hemmende Wirkfaktoren sollen durch Dialog, Toleranz, gegenseitigen Austausch und durch konstruktive Konfliktbewältigung aufgelöst werden.

\section{Die Einführung des islamischen Religionsunterrichts (IRU)}

Mit der Einführung eines IRU verknüpfen die beiden Elternteile verschiedene Ziele und Erwartungen. Dabei spielen der Dialog zwischen Muslimen und Andersgläubigen, die Anerkennung von Vielfalt, die Aufklärung über den Islam, der Wunsch des Respekts und der Wertschätzung gegenüber der eigenen Religion sowie die Integration von muslimischen Kindern in den Schulalltag eine besondere Rolle. Es werden hier weniger sozialisationsrelevante Erwartungen vorgetragen, sondern vielmehr dialogische sowie integrative Aspekte betont. 
Mit der Einführung des IRU werde nicht nur, neben dem christlichen Religionsunterricht, ein Zeichen für Vielfalt und Toleranz gesetzt, sondern der Glaube eines Menschen könne jenseits aller nationalen Zugehörigkeiten im Vordergrund stehen. Gerade die Auswahlmöglichkeit aus den Angeboten gebe dem Schüler oder der Schülerin die Freiheit, selbst zu entscheiden:

"Das wäre natürlich das Beste, also, dass man auch neben dem christlichen Unterricht auch mal Islamunterricht auch, es ist jetzt auch keine Sache ne, die Religion, man kann ja heutzutage jetzt nicht mehr sagen, dass die Religionen eine Sache der Nationalität sind ... man kann auch hier [nicht sagen, Anm. d. Verf.], die ganzen Türken sind Muslime und die ganzen Deutschen sind jetzt Christen. Nein! Das ist jetzt so, das ist einfach eine Glaubensfrage und je nachdem, wie der Mensch ist, wählt er halt die entsprechende Religion. Dann wäre es ja auch sinnvoller ne, dass in den Unterricht auch solche Angebote einfließen. Ja, es ist dann halt auch freier und man hat auch die Option und ja ..." (Lema, Z.: 193)

Ein IRU könne auch dazu beitragen, dass muslimische und nichtmuslimische Kinder lernen würden, miteinander umzugehen, was somit der Aufklärung diene:

"Islamischer Unterricht ist ja dann so, dass dann die anderen, die anderen Schüler dann auch mitbekommen, auch lernen: Okay, ein muslimisches Mädchen muss ein Kopftuch tragen, ja warum? Das und das z.B. das ist da genau Aufklärung, hatten wir ja auch gesagt, das ist ja, das wird dann dazu führen, dass mehr Aufklärung stattfindet über den Islam und über auch; dann wird's ja allen besser gehen, glaube ich, dann wird diese Gruppierung irgendwie nicht mehr stattfinden, das finde ich immer so schade? Dass man mehr aufeinander zugeht. Aber durch diese Aufklärung wird das vielleicht auch beseitigt, sodass die Kinder aufeinander zugehen, miteinander ruhig sprechen können, auch über Religion." (Lema, Z.: 197ff.)

Schranken könnten aufgehoben und Brücken gebaut werden, indem viel mehr Wert auf Vielfalt gelegt wird und damit in Zukunft »noch mehr Miteinander« möglich wird. Möglicherweise könne dadurch zudem »eine Art Integration« stattfinden (vgl. ebd., Z.: 199-205).

Auch Hülya betrachtet den IRU als eine wichtige Ergänzung zu den außerschulischen religiösen Bildungseinrichtungen (vgl. Kap. III. 5.1 und Hülya, Z.: 48), damit die Kinder Kenntnisse über die eigene Religion erlangen. Dabei zielt sie insbesondere darauf ab, dass Religion nicht »abgesondert« in der Moschee erlernt wird, sondern auch in der Schule, wodurch muslimische Kinder eine Wertschätzung sowie die Integration in den Schulalltag erfahren könnten: 
"Also, ich glaube, die Kinder sehen das nicht als etwas Separates an, sondern als einen Teil in der Schule. Da fühlen die sich viel wichtiger dadurch, also ich habe es immer so gehabt bei mir, ja, Religion lernt man in der Moschee, das ist abgesondert in der Moschee, da hat Schule nichts mit zu tun und weiß auch nichts darüber. Aber jetzt ist das mit der Schule zusammen, deshalb ist das für mich Wertschätzung, wenn ich weiß, dass ich wertgeschätzt werde; dann fühle ich mich automatisch, oder auch meine Kinder werden sich automatisch wohler fühlen [...]." (Hülya, Z.: 196)

Nicht zuletzt könne der IRU die Konflikte der Jugendlichen minimieren helfen, sodass der IRU auch präventiv gegen die Jugendkriminalität wirken könne (vgl. ebd.)

\section{Interreligiöse Begegnungen}

Wie oben schon mehrfach angedeutet wurde, sind Eltern dieses Typs besonders am interreligiösen Dialog und Begegnungen interessiert und bereit, sich dafür zu engagieren (vgl. oben). Die Kinder sollen lernen, mit den Religionen umzugehen, daher sei auch eine Kooperation zwischen Angehörigen verschiedener Religionen notwendig. Die verschiedenen »Glaubensgemeinschaften« könnten so eine Art »Gemeinschaft bilden«, was einer möglichen Lösung nahekomme. Dabei sei dies gerade für die Integration, worüber »ständig« gesprochen werde, von zentraler Bedeutung:

"Ja das ist als, ja also wie gesagt, ich sag jetzt nicht z.B., dass das Kind nur ..., dass in der Schule nur Opferfest gefeiert werden soll. Das kann auch Weihnachten, aber auch Ramadanfest sein. Das ist ja so, es lernt dann halt, man lernt mit anderen Religionen umzugehen, zusammen zu kooperieren, das ist ja auch dann diese Gemeinschaft, das ist ja auch eine Gemeinschaft innerhalb einer Gemeinschaft. Das ist ja so, dass sich mehrere Gemeinschaften zu einer Gemeinschaft bilden und das wäre ja auch eine Lösung, finde ich, weil es wird ja ständig über Integration gesprochen, aber irgendwo tut sich da wirklich noch nichts so ja, aber es ist ja halt noch bemüht, man kann ja auch sagen, aber ..." (Lema, Z.: 186)

Für ein friedliches Zusammenleben und gegenseitigen Respekt sei ein Kennenlernen des anderen unabdingbar. Wie schon des Öfteren darauf verwiesen wurde (vgl. Lema oben; und alle anderen Eltern zum Thema »Kopftuch«) zeigt die Erfahrung, die Hülya in ihrer Schulzeit mit dem Kopftuch machte, wie wichtig es ist, die Religionen zu kennen und zu respektieren:

"Sehr, auf jeden Fall; ich denke, auch meine Kinder sollten über andere wissen und auch andere Kinder sollten über uns wissen. Das ist einfach die Bedingung des Zusammenlebens auch in Zukunft, darauf lege ich sehr viel Wert, weil, wenn wir uns gegenseitig nicht kennenlernen, können wir nicht gemeinsam leben oder friedlich leben. Und wer 
weiß, also ich kann mich noch zu meiner Zeit noch daran erinnern, ich bin aus der Türkei gekommen ohne Sprachkenntnisse und als ich dann in der sechsten Klasse angefangen habe, ein Kopftuch zu tragen, kamen wirklich Jungs und haben mir mein Kopftuch runtergezogen. Das war das Zeichen davon, dass die andere Seite diese Religion nicht kannte und auch nicht respektieren konnte und deshalb finde ich, dass man die Kinder von klein auf damit konfrontiert und klarmacht, dass es wichtig ist, dass es auch andere gibt, die anders denken, die anders aussehen, die sich anders kleiden." (Hülya, Z.: 186).

Auch die konkreten Vorschläge für Formen von interreligiösen Begegnungen zeigen ihre Erfahrungen und ihr Engagement in diesem Bereich. Dass sich Familien und Kinder untereinander träfen, baue Vorurteile ab. Auch könne im Rahmen organisierter Veranstaltungen ein Austausch zu verschiedenen Themen stattfinden:

"Dass man z.B. auch die Kinder spielen lässt gemeinsam, auch Familientreffen macht, dass man sich mit Eltern auch trifft, mache ich auch auf jeden Fall. Also, meine Tochter darf dann auch die Freundinnen besuchen zu Hause, ich hole sie nach zwei Stunden wieder ab, die Eltern wissen ganz genau, sie weiß selbst, dass sie kein Schwein essen wird oder keine Gummibärchen, aber ich sage das noch mal, trotzdem. Sie fragen mich auch, was darf sie essen, was nicht. Also, ich glaube da schafft man sehr viel oder man baut Vorurteile ab, indem man wirklich persönlich die Menschen kennenlernt und auch die Familien einander kennenlernen lässt, dass man die auch einlädt, ob das jetzt Kindergeburtstage sind oder Sonstiges. Ansonsten kann man sich in Veranstaltungen, man kann auch Veranstaltungen machen über bestimmte Themen und sich dann auch so austauschen." (Hülya, Z.: 188)

\section{Verbesserungsvorschläge und Erwartungen}

Da schon oben sehr viele Aspekte und Verbesserungsvorschläge gemacht wurden, soll im weiteren Verlauf dieser Arbeit auf Wiederholungen verzichtet werden.

Für ihre Kinder wünschen sich die Eltern, dass sie respektiert und mit ihrer »Identität« aufgenommen werden, ohne sich »verstellen« zu müssen (vgl. Lema, Z.: 207). Sie sollen primär als »Menschen« wahrgenommen werden und sich zu »guten Menschen« entwickeln, die »respektvoll und ausgeglichen« leben können (vgl. Hülya, Z.: 204).

Von der Schule bzw. den Lehrpersonen wird erwartet, dass zum einen der IRU eingeführt wird, und zum anderen über die Religionen und Kulturen gesprochen wird, damit beispielsweise eine Unterscheidung zu Themen wie »Zwangsheirat« usw., die »nichts mit der Religion zu tun haben«, stattfindet (vgl. Lema, Z.: 209). Das Miteinander reden, gepaart mit Empathie soll mehr »Mitmenschlichkeit« zum Vorschein bringen. Durch aktive »Kooperation« 
und Zusammenarbeit soll zudem die Gewaltbereitschaft unter Jugendlichen minimiert werden:

"[...] eben dieses Miteinanderreden und dass man auch, wenn das andere Kind irgendwie weint, dass man es auch mal tröstet; so diese Menschlichkeit, irgendwo ist es ja auch so, dass diese Menschlichkeit irgendwo abhanden kommt, weil immer mehr Jugendliche, vielleicht ja, dass diese Religion vielleicht zu kurz kommt, dass man auch irgendwie keine Angst mehr hat, zur Rechenschaft gezogen zu werden ${ }^{66}$, ne deswegen, immer diese, dass auch diese Gewalt dann auch irgendwo verschwindet. [Weniger Gewalt dadurch auch stattfindet, Anm. d. Verf.]. Ja, stattfindet durch diese Zusammenarbeit, auch [...] Kooperation." (Lema, Z.: 211ff.)

An dieser Stelle wird auch deutlich, dass die Religion und der IRU möglicherweise helfen können, präventiv gegen die Jugendkriminalität vorzugehen (vgl. Lema, ebd.; vgl. Hülya oben bei IRU).

Überdies sollten in Schulen offene Angebote bzw. Nachmittagsangebote, in Kooperation mit der muslimischen Community, gemacht werden:

"Es sollte in den Schulen im Nachmittagsbereich viel, z.B. was die muslimische Community anbelangt auch offene Angebote geben, wo die die Möglichkeit haben, daran teilzunehmen. Zum Beispiel: Ich musste auf eine Gesamtschule und wir hatten immer AGs am Nachmittag und wir hatten die Möglichkeit, z.B. türkisch zu kochen, das war für mich, ich bin Türkin (lacht). Oder in der Mittagspause hatten wir eine Teeecke, wo wir mit dem Semaver [türk. für große Teekanne, Anm. d. Verf.] Tee gekocht haben und da kamen noch deutsche Kinder und ich finde solche Angebote sollten vielmehr in den Schulen [...]. Ob das jetzt das Malen ist oder Basteln oder Häkeln oder Sonstiges, so. Und ich wünsche mir einfach, dass z.B. in den Nachmittagsstunden, also, weil wir ja Ganztagsbetreuung haben, dass z.B. auch von muslimischen Trägern irgendetwas angeboten wird. Ich denke z.B., hatte ich ja schon gesagt, an Ebru-Kunst, das ist was Schönes, was Therapierendes, auch für Kinder. Ich habe das mit meinen Kindern auf einem Geburtstag gemacht mit deutschen Kindern, die fanden das alle so faszinierend, wie einfach das geht, wie das funktioniert [...]." (Hülya, Z.: 209-213)

66 | Diese Angst bzw. die Furcht, Rechenschaft abzulegen, bezieht sich auf Gott/Allah, insofern ist hier auch die Gewissensbildung gemeint, die durch religiöse Erziehung bzw. den IRU erreicht werden könnte. 


\subsubsection{Wahrnehmungen und Erwartungen der "Ethiker"}

\section{Der Umgang mit dem Islam in Schulen und Kindertagesstätten}

Der Umgang mit dem Islam durch Lehrpersonen bzw. Erzieherinnen wird durch die Eltern dieser Gruppe vorwiegend positiv dargestellt und bewertet. Dieses Bild wird auch nicht durch die wenigen negativen Erfahrungen getrübt. Möglicherweise kann dies damit zusammenhängen, dass zudem weniger (religiöse sozialisationsrelevante) Erwartungen an institutionelle Bildungseinrichtungen gestellt werden. Ebenso werden kaum Konflikte benannt und Benachteiligungen weniger beklagt, da sie zum einen eine ausgeprägte Dialogbereitschaft besitzen und daher für einen offenen Austausch bereit sind, und zum anderen größtenteils »lockere« Umgangsformen bei der Umsetzung religiöser Vorschriften pflegen.

Als verständnisvoll werden Erzieherinnen bzw. die Lehrerinnen der Kinder erlebt, zu denen die Mütter einen »guten Kontakt« haben (vgl. Belk1s, Z.: 233), die eine Offenheit gegenüber den religiösen Festen zeigen und die die muslimische Speisevorschrift (vgl. ebd.; vgl. Feride und Melek) beachten:

"Sie ist eine junge Lehrerin, sehr offene Lehrerin. Sie geht auch sehr viel auf uns ein. Sie versucht, uns zu verstehen. Auch wenn da Süßigkeiten ausgeteilt werden, versucht sie das im Kreis zu erwähnen. Es gibt ja muslimische Kinder und muslimische Kinder essen keine Gelatine. Das versucht sie allen Kindern so beizubringen, dass die Kinder das auch so akzeptieren können. Das finde ich sehr gut! [...] Sehr sehr offen!“ (Melek, Z.: 384)

Auch das »Bild« über die Muslime habe sich durch die Präsenz gebildeter muslimischer Eltern, die viel Wert auf die Bildung der Kinder legen, geändert:

"Das hat die Freundin unserer, das hat die Mutter unserer Freunde mir selber auch gesagt. Sie hat sich so geäußert: 'Seitdem ich euch kenne, habe ich ein ganz anderes Bild über Muslime. Ihr legt sehr viel Wert auf Bildung und das ganze Drumherum. Ich sage: 'Das gehört alles zu unserer Religion, diese Bildung, das Ganze, aber das Kopftuch selbst gehört auch zu unserer Religion. ‘ (Melek, Z.: 450)

Aufgrund seiner Dialogbereitschaft haben Adem und seine Kinder, trotz anderweitiger Schwierigkeiten (»im Hinblick auf die Bildung«) des Sohnes, keine Benachteiligungen und Konflikte erlebt, die auf die Religion zurückzuführen sind (vgl. Adem, Z.: 165-169). Gerade Vorurteile, so Adem, entstünden durch einen fehlenden »Dialog zwischen Eltern und Lehrern«, was durch eine vorbildhafte religiöse Lebensweise und entsprechende Handlungen eines Muslims gelöst werden könne (vgl. auch unten Interreligiöse Begegnungen). 
Konflikte, die auf die Religion oder die religiöse Lebensweise zurückzuführen sind, werden von keinem Elternteil benannt. Jedoch werden vereinzelt Benachteiligungen wahrgenommen, die sich auf verschiedene Themen beziehen. Gerade der noch nicht flächendeckend eingeführte islamische Religionsunterricht, der als ein ordentliches Unterrichtsfach angesehen, eine Selbstverständlichkeit für muslimische Kinder darstellen sollte, sorgt für ein Gefühl der Benachteiligung:

"Ja, finde ich schon! Weil ich würde mir wünschen, dass mein Kind auch religiöse Unterweisung an der Schule bekommt und zwar von kompetenten pädagogisch Ausgebildeten; wo unter anderem das auch nicht so als Kurs oder als Klub durch meinen Sohn jetzt gesehen wird oder durch meine Kinder gesehen wird, sondern wo das auch als genauso wichtig beachtet wird, wie ein Fach Erdkunde oder wie ein Fach, was weiß ich, Englisch, das gehört mit zu meinem Alltag, das gehört mit zu meinem Leben und das ist bedeutend für mich! Dass er das in der Form noch einmal." (Feride, Z.: 325)

Ähnlich steht es mit der Einführung des Türkischunterrichts, indem auch religiöses Wissen vermittelt werden soll. Da der Islamunterricht schon in manchen Schulen unterrichtet werde, möchten sie die geringe Akzeptanz für den Türkischunterricht nicht hinnehmen. So sei ihr Plan, sich an das zuständige Schulamt bzw. Bezirksamt zu wenden und dafür zu sorgen, dass Türkisch unterrichtet werde (vgl. Belk1s, Z.: 248).

Bezogen auf den Umgang mit dem Islam in öffentlichen Bildungseinrichtungen, scheint trotz einiger Schwierigkeiten und Benachteiligungen eine positive Grundstimmung der Eltern durch, die bei den anderen Typen entweder teilweise (Idealisten; Identitätssucher) oder gar nicht (Ritualisten) vorhanden ist.

Was die religiöse Sozialisation anbelangt, kann noch weniger als bei den anderen Eltern von hemmenden Wirkfaktoren auf die religiöse Sozialisation gesprochen werden. Jedoch zeigt sich im Falle der letzten beiden Eltern, die sich einen Islam- bzw. Türkischunterricht (in dem auch »religiöses Wissen« vermittelt wird) wünschen, und im Falle des Vaters und seiner Kinder, der seine religiöse Lebensweise durch eine ethisch-moralische Grundhaltung in Handlungen gegenüber Nichtmuslimen ausdrückt, dass Religion auch im schulischen Kontext von Bedeutung ist. Allerdings gibt es keine Angaben, die belegen, dass damit auch ein fördernder Effekt im Hinblick auf die religiöse Sozialisation erreicht werden soll.

\section{Religiöse und kulturelle Elemente im Schul- bzw. Kindertagesstättenalltag}

Der Respekt vor der muslimischen Speisevorschrift, wird durch diese Gruppe von Eltern besonders unterstrichen (vgl. oben: Feride, Belk1s, Melek; vgl. Birol unter Verbesserungsvorschläge). 
Auch das Feiern von religiösen Festen wird durch sie als ein Mittel zur Verständigung und hinsichtlich eines friedlichen Zusammenlebens besonders unterstrichen bzw. hervorgehoben. Darin äußert sich für sie auch die Akzeptanz der muslimischen Schülerschaft.

Für das gemeinsame Feiern von religiösen Festen würden die Kindertagesstätten eine größere Offenheit zeigen:

"Also bei der Erzieherin weiß ich, mit denen habe ich recht guten Kontakt, da weiß ich, dass sie sehr offen sind der islamischen Religion gegenüber; und zwar war es auch so, dass wir bei den islamischen Festen, dass wir da auch, den Kindern Süßigkeiten gebracht haben, das wurde gut angenommen, das war sogar wünschenswert [...]. Die sind eigentlich recht offen dort, was das angeht." (Belkıs, Z.: 233)

Anders hingegen gehen Schulen mit religiösen Festen der Muslime um: Die Kinder bekommen zwar an religiösen Festen frei, was »geduldet« wird. Ansonsten gebe es in der Schule jedoch kaum Möglichkeiten, sich einzubringen, nicht zuletzt deshalb, weil der Anteil der muslimischen Kinder in den Grundschulen gering sei (vgl. Belk1s, Z.: 236f., vgl. Melek, Z.: 392 und 398). Dennoch könnten sich Mütter vorstellen, sich noch mehr zu engagieren: »Wenn die Lehrerin mich auf, noch auf irgendetwas ansprechen sollte, dann würde ich natürlich gerne was machen.« (Melek, Z.: 414; vgl. auch Feride, Z.: 307).

Gleichwohl werden durch einige Eltern an religiösen Feiertagen Süßigkeiten, Bonbons bzw. Muffins mitgegeben, damit die anderen, nichtmuslimischen Kinder diese Festtage auch mitbekommen (vgl. Melek, Z.: 400; Feride, Z.: 307).

Damit die nichtmuslimischen Kinder keine Überraschungen erleben, wenn die Kinder an muslimischen Festtagen nicht in der Schule erscheinen und wenn sie Süßigkeiten u.ä. verteilen, wünscht sich Feride eine diesbezügliche Aufklärung durch die Lehrer. Auf diese Weise könne das »Befremdende« bzw. die Angst, vor dem was fremd sei, aufgehoben werden:

"Ich würde mir wünschen, dass der Klassenkamerad von B ... weiß, okay, der B ... ist heute nicht da, weil heute ist sein Opferfest und der ist jetzt irgendwie deswegen für zwei Tage nicht da. [...]. Das ist einfach nur [...]. Bewusst wird! Genau! Und erlebt wird. [...]. Nichts Befremdendes, weil ich denke nach Adorno die Xenophobie, also die Angst vor dem, was fremd ist, ist immer da und deswegen sollte es einem nicht fremd sein, nicht fremd bleiben, aber wie gesagt, dafür muss es erst mal in den Köpfen der Lehrerschaft etwas anders laufen." (Feride, Z.: 313-319)

Adem betont im Kontext der öffentlichen Bildungseinrichtungen die zwischenmenschlichen Aspekte des friedlichen Zusammenlebens, wie sie typisch für die Ethiker ist. Seine Kinder sollen Lehrern und Schülern den Islam praktisch 
vorleben. Dabei sei z.B. im Umgang mit Lehrern oder Schülern auf Verhaltensweisen zu achten, die der Islam vorschreibe:

"Also die Religion hat auf jeden Fall Platz in der Schule, solange man [...] nach dem Islam leben kann. Zum Beispiel, wie ich schon eben gesagt habe, mit Freunden, mit Lehrern zum Beispiel, mit Lehrern respektvoll umgehen, auch wenn es nicht passt. Das ist der Islam, das gibt der Islam vor! So! Und solange sie das tut und das praktiziert, lebt sie nach dem Islam. Wenn sie, wenn zum Beispiel mein Sohn eine Handlung im Schulhof sieht, was, wo ein Stärkerer einen Schwächeren misshandelt, verprügelt, dass er da einschreitet, um Frieden zu stiften zwischen den beiden, das ist der Islam! [...] Man verübt nicht den Islam, indem man fünfmal am Tag betet, auf der Arbeitsstelle oder in der Schule, ob man ein Kopftuch trägt oder ob man diese Gebetshaube trägt, das ist nicht nur der Islam! Den Islam sollte man nicht [...] [nicht so eng fassen, Anm. d. Verf] Man muss rausgehen, die Welt beobachten, das ist der Islam, der Umgang mit den Menschen, die Gedanken, die Gedanken müssen rein sein. Der Umgang mit den Lehrern, die Sprache mit den Lehrern, der Dialog mit den Lehrern. Das ist der Islam! Und ich denke immer, dass meine Kinder den Islam sehr gut auch draußen vertreten." (Adem, Z.: 153)

Wie oben deutlich wird, spielt hier nicht nur die Einhaltung religiöser Vorschriften eine wesentliche Rolle (»[...] das ist nicht nur der Islam«), sondern auch »[...] der Umgang mit den Menschen«, womit auf eine ethische-soziale Haltung und einen »Dialog mit den Lehrern« abgezielt wird. Der Islam solle vorbildhaft im Rahmen der Schule vor- und ausgelebt werden, um letztlich Frieden zu stiften (vgl. ebd. und Z.: 161).

Alles in allem wird in diesem Kapitel deutlich, worauf die Eltern besonders viel Wert legen bzw. das, was von ihrer Wahrnehmung und Erfahrung ausgehend im schulischen Rahmen wichtig ist: die muslimische Speisevorschrift, religiöse Festtage, eine ethisch-soziale Grundhaltung und die Aufklärung über den Islam. Dabei wird auch deutlich, dass ein guter »interkultureller « ${ }^{67}$ und »interreligiöser Dialog erwünscht wird, der einen Austausch zwischen Lehrerschaft, Schülern und Eltern ermögliche. Im Vergleich zu den »Identitätssuchern« (vgl. oben), deren Wünsche auf die Persönlichkeitsentwicklung und damit auf die Sozialisation hindeuten, wollen »Ethiker« lediglich, dass ein »respektvolles « und »gutes « Zusammenleben möglich wird, d.h. auch, dass die Erwartungen hier niedriger angesiedelt sind und von keinem fördernden Effekt auf die religiöse Sozialisation ausgegangen wird.

Inwiefern Benachteiligungen einen hemmenden Effekt auf die religiöse Sozialisation haben, kann auch hier nicht eindeutig nachgewiesen werden.

67 | Man hat den Eindruck, dass hier zwar religiös konnotierte Aspekte bzw. Elemente angesprochen werden, diese aber ebenso einen kulturellen Hintergrund (Speisevorschrift, Feste, soziales Miteinander) haben könnten. 


\section{Die Einführung des islamischen Religionsunterrichts (IRU)}

Die Eltern dieses Typs verbinden mit der Einführung des IRU relativ unterschiedliche Vorstellungen, Erwartungen und Ziele. Dabei zeigen sich einige Eltern im Vergleich zu den anderen Eltern dieses Typs weniger interessiert (Melek und Birol). An die zukünftigen Religionslehrer/-innen werden zudem Erwartungen gestellt, die sich auf ihre Kompetenzen und Kenntnisse beziehen. ${ }^{68}$

Der IRU soll, gemäß aller Eltern, dazu dienen, Informationen und Grundlagen des Islams an die muslimischen Kinder zu vermitteln. Damit beziehen sich die Eltern jeweils auf unterschiedliche Aspekte des Islams und der Wissensvermittlung.

Es steht für sie nicht die ausschließliche Wissensvermittlung im Vordergrund, wie es sich Ritualisten (vgl. oben IRU) für ihre Kinder wünschen, sondern vielmehr die intellektuelle Auseinandersetzung, die die Kinder z.B. in die Lage versetze, $\mathrm{zu}$ verstehen, warum »man fastet oder warum man beten muss « (vgl. Belkıs, Z: 283), und sie dazu befähige, »die Auseinandersetzung mit der Religion, nicht nur aus dem Alltag betrachtet, sondern auch als Wissenschaft ...« zu ermöglichen. Es sei gerade die im Vergleich zum Alltagsverständnis, andere (intellektuelle) »Zugangsweise« zur Religion, welche die religiöse Unterweisung kennzeichnen solle (vgl. Feride, Z.: 328ff.). Inhaltlich sei nicht nur die Vermittlung eines »positiven Gottesbildes « wünschenswert, sondern das Erlernen von religiösen Begrifflichkeiten, wie z.B. des fünfmaligen Gebets usw. (vgl. Belkıs, Z.: 291ff.). Im Vergleich dazu sollen die Kinder die Befolgung der Rituale in der Moschee erlernen (»[...] dass man fünfmal beten muss, das finde ich sehr wichtig!«) (vgl.ebd., Z.: 283-289).

Neben der Informationsvermittlung, die in der Schule zu kurz komme, könne der IRU auch helfen, Vorurteile abzubauen bzw. ihnen entgegenzuwirken (vgl. Adem, Z.: 184). Im Zusammenhang mit (den Erwartungen an den IRU und) der Wissensvermittlung wird auch auf eine zeitgemäße Interpretation des Korans verwiesen, die den Kindern das »Zeitlose« an ihrer »Bedienungsanleitung« für das Leben vermittele:

"Der islamische Religionsunterricht sollte für die Kinder auf jeden Fall das bringen, erst mal, wie der Islam aufgebaut ist und dass der Islam nicht vor 1.400 Jahren gelebt worden ist, [...] der Islam eine Religion ist, die mit der Zeit geht. Sie müssen sich das so vorstellen, [...] die Interpretation von diesem Kuran-al Karim [Koran, Anm. d. Verf.] ist

68 | Dazu äußerten sich die Eltern anderer Typen kaum. Die "Ethiker" haben bereits, gerade im Zusammenhang mit der Qualifikation des pädagogischen Personals in Moscheen, ihre hohen Erwartungen vorgetragen (vgl. Kap. III. 5.2). Zudem wird deutlich, wie im Folgenden noch festzustellen, dass sie sich mit dieser Thematik intellektuell auseinandergesetzt haben. 
eben und sozusagen eine Bedienungsanleitung für unser Leben, wie wir unser Leben am besten gestalten. Und deswegen sollte dieser Islamunterricht auch so aufgebaut werden, dass man den Islam nicht in der Vergangenheitsform, nicht nur in der Vergangenheitsform erzählt, sondern in der Gegenwartsform, wie wir zum Beispiel verschiedene Gebote und Gesetze für heute interpretieren können und leben können. Das wünsche ich mir von dem." (Adem, Z.: 194)

Wiederum andere Eltern (Melek und Birol) sehen mit der Einführung des IRU »eine Chance « für diejenigen Kinder, die in ihren Familien oder in den Moscheen keine religiöse Erziehung bekämen, die »Grundsätze des Islams« kennenzulernen (vgl. Melek, Z.: 540) bzw. etwas über ihre »Religion zu erfahren« (vgl. Birol, Z.: 194):

"Also ich denke, dass also ich wünsche mir diesen Unterricht ... vor allem deswegen, weil ich denke, jedes Kind sollte einfach mal die Chancen bekommen, Religion zu erfahren, weil ich selbst jetzt nicht unbedingt aus einer Familie komme, bei der jetzt Religion so stark im Vordergrund stand und hätte ich andere Freunde, wäre ich wahrscheinlich gar nicht in die Moschee gekommen damals und dann denke ich mir, würde mir heute was fehlen; so und Kinder wie ich, gibt es ganz viele. Also nicht alle türkischen oder alle Familien sind irgendwie religiös. Ne? Es gibt ganz viele Jugendliche, die wachsen auf, ohne damit je in Berührung zu kommen, und würde das in der Schule vermittelt werden, dann hätten diese Kinder zumindest auch zumindest so ein Stück weit die Chance, das zumindest mal zu erfahren, ja, darüber einfach mal was gehört zu haben; und aus dem Grund fände ich das ganz gut [...]." (Birol, Z.: 260)

An dieser Stelle wird durch beide Eltern der Stellenwert des IRU minimiert, da dieser für Kinder, die entweder in ihren Familien oder in der Moschee eine religiöse Erziehung erhalten würden, weniger Relevanz besitze:

"[...] aber für Familien, in denen Religiosität sowieso, ich sage mal, wo das sowieso präsent ist, da glaube ich nicht, dass die Kinder jetzt unbedingt sehr viel aus diesem Religionsunterricht mitnehmen können oder werden. Also jetzt zurzeit zumindest noch nicht, irgendwann in der Zukunft, wenn die Lehrer entsprechend gut ausgebildet sind, vielleicht, möglicherweise." (vgl. ebd.)

Dennoch wird mit der Einführung des IRU auch eine identitätsstiftende Wirkung erhofft. Der Islam und das Muslimsein sollen durch die muslimischen Kinder als eine »Selbstverständlichkeit« bzw. als ein selbstverständlicher Teil ihrer eigenen muslimischen Identität wahrgenommen werden, nicht jedoch als etwas, was im schulischen Rahmen kein Platz hat: 
"... damit die vielleicht auch wissen: Müslümanız! [türk. für "Wir sind Muslime!«, Anm. d. Verf.]. Das gehört zu unserem Leben. Wir sind Moslems. [...] Ja. Schulische [...] auch, aber der Islam gehört auch zu unserem Leben! Auch in der Schule. [...] Das ganze Leben! [...] also ich bin nicht nur, zum Beispiel ich bin nicht nur fünf Stunden in der Schule ein normaler Schüler und außerhalb bin ich ein Moslem. [...] Genau! Überall Muslim." (Melek, Z.: 550-560)

Lediglich Feride verweist auf die Wertevermittlung, die typisch für diese Gruppe von Eltern ist (»Aber ganz wichtig sind, wie gesagt, die islamischen Werte«) (vgl. Feride, Z.: 330 ${ }^{69}$.

Im Gegensatz zu den anderen Typen stellen Eltern dieses Typs höhere Erwartungen an die Qualifikation der zukünftigen Religionslehrer/-innen (vgl. oben Birol, Z.: 260). Es wird von ihnen die Fähigkeit erwartet, mit verschiedenen didaktischen Mitteln und Sympathie zu unterrichten:

"[...] dass es mit verschiedensten didaktischen Mitteln an das Kind herangetragen wird und am besten auch von einem (lacht) sympathischen Lehrer. Oder Lehrerin. [...]. Sympathisch heißt, wo sich das Kind auch ohne Bedenken vorbehaltlos diesem gegenüber öffnet." (Feride, Z.: 332-336)

Des Weiteren solle ihre Religionslehrerausbildung ihnen, neben pädagogischen Kompetenzen, die notwendigen Kenntnisse über die islamischen Wissenschaften vermitteln, damit sie den Kindern einen angemessenen Unterricht anbieten könnten:

Ich wünsche mir auf jeden Fall einen solchen Unterricht! Aber dieser Unterricht sollte von denjenigen gemacht werden, die auch dieses Wissen über den Islam haben und nicht nur kurz mal einen Kurs besucht haben und dann den Kindern irgendetwas sagen. Es ist auch sehr sehr wichtig, wie dieser Islamunterricht ... erzählt wird [...]." (Adem, Z.: 192)

\section{Interreligiöse Begegnungen}

Interessant ist, welche Perspektiven und Blickwinkel die Eltern gegenüber dem interreligiösen Dialog bzw. interreligiösen Begegnungen einnehmen. Ähnlich wie oben zur Einführung des IRU wird durch jedes Elternteil ein unterschiedlicher Aspekt betont, der einen respektvollen Umgang mit den Religionen ermöglichen soll. Auch hier werden jeweils individuelle Vorstellungen deutlich

69 | Feride ist eine Mutter, die innerhalb der "Ethiker" ein Typus besonderer Ausprägung ist (vgl. Kap. III. 2.2). 
bzw. wird ein individueller Zugang gewählt, wie nach diesen Vorstellungen ein Miteinander der Religionen bzw. ein Zusammenleben funktionieren könnte ${ }^{70}$. In einigen Fällen wird zudem eine Unterscheidung zwischen Religion und Kultur deutlich, sodass in diesen Fällen vielmehr von einem interkulturellen Austausch gesprochen werden kann als von einem interreligiösen Dialog. Hier verschwimmen zum Teil die Grenzen. ${ }^{71}$ In jedem Fall lassen sich, bis auf eine Ausnahme (Melek), eine Offenheit und ein Interesse für einen Austausch (ob interkulturell oder interreligiös) aufzeigen.

Wie oben schon erläutert wurde, sorgt der Besuch des christlichen Religionsunterrichts für einen Austausch über die Religionen zwischen Eltern und Kindern innerhalb des familiären Rahmens, obgleich hier die eigene religiöse bzw. muslimische »Perspektive« über die besprochenen Inhalte für die Eltern besonders wichtig erscheint (vgl. Melek und Belkis):

"[...] Dann erzählt mir mein Kind das zu Hause und dann sage ich: 'Da und da sind Unterschiede. So glauben wir und so glauben Christen I Ich versuche natürlich, meinem Kind auch einen respektvollen Zugang, auch zur christlichen Religion zu ermöglichen, also ich möchte natürlich auch, dass mein Kind Respekt hat vor anderen Religionen. Ich sage dann nicht, liih, das ist nicht unseres und das ist so schlimm und das ist so،, so etwas erzähle ich meinem Kind nicht [...]." (Belkıs, Z.: 273)

Unabhängig vom christlichen Religionsunterricht werden hier interreligiöse Gespräche, ausgehend von konkreten Situationen, aus dem »Alltag« »aufgegriffen«:

"Natürlich auch, je nach Situation, genauso wie bei anderen Themen, wenn der gegebene Anlass da ist, darauf eingehen! Zum Beispiel, an Weihnachten; im Grunde wird ja vor Weihnachten das Ganze noch mal angefangen von Bethlehem über, ne, das noch mal aufgegriffen, das in der Schule sehr detailliert wiedergegeben, aber dass ich dann zum Beispiel auch zu gegebenem Anlass meine Kinder noch mal unterrichte und erkläre, wie das von dem Islam her gesehen wird und dass Weihnachten halt die religiöse Feier der Christen ist und so weiter [...].« (Feride, Z.: 352ff.)

70 | Interessant wäre dies für eine Typenbildung im Rahmen einer intensiveren Forschung zu dieser Thematik.

71 | Die Unterscheidung von religiösen bzw. kulturellen Elementen erfordert eine klare Definition dessen, was unter Religion und was unter Kultur grundsätzlich verstanden wird. Ein religiöses Element kann zugleich als kulturelles Element gelten, wenn kein deutlicher Sinn- und Transzendenzbezug vorgenommen wird und wenn dieses sich "nur" auf zwischenmenschliche Interaktionen, d.h. auf das Zusammenleben in Form des Auslebens der eigenen Tradition usw., bezieht. 
Es sind gerade die religiösen Feste bzw. Feierlichkeiten, die als Anlass für interreligiöse Begegnungen gesehen werden (vgl. oben »Religiöse und kulturelle Elemente [...]«; vgl. Birol, Z.: 246; vgl. Adem, Z.: 182). Dass religiöse Feste auch als ein kultureller Austausch verstanden werden können, veranschaulicht Belk1s folgendermaßen:

"[...] Also das Weihnachtsfest heißt mittlerweile Lichterfest, weil ja Weihnachtsfest dann so christlich geprägt ist (lacht); und dass wir auch bei unseren Festen, dass die Kinder so spüren, 'Aha،, weil es auch einen großen Anteil an Migrantenkindern, muslimischen Kindern gibt, 'da ist etwas anders und da wird auch sehr viel gemacht, jetzt nicht religionsspezifisch, sondern auch, dass man halt auch die verschiedenen Nationen auch vorstellt usw. [...]." (Belkıs, Z.: 233)

In einer ähnlichen Weise stellt sie fest, dass nicht »mit religiösen Motiven gearbeitet wird «, sondern man in der Kita vielmehr traditionellerweise »vielleicht mal backt« oder »bastelt« (Weihnachtsbacken, Weihnachtsbasteln) (vgl. ebd., Z.: 261-267).

Der Kontakt zu anderen »Kulturen« und »Religionen ${ }^{72}$ sei wichtig, um »Berührungsängste« und Vorurteile abzubauen; so schildert Birol seine Erfahrungen mit dem Kirchenbesuch in seiner Grundschulzeit wie folgt:

"Ja, also ich kann mich gut daran erinnern, wie ich selbst in der Schule, damals in der Grundschule mal in der Kirche war. Ich weiß nicht, woher das damals kam, aber als ich mitbekommen habe, dass wir jetzt in die Kirche mal gehen, habe ich erst mal Angst gehabt. [...] Angst. Ich wusste nicht, was, was jetzt passiert. Werde ich jetzt ..., bin ich dann kein Moslem mehr? [...]. Werde ich jetzt ..., ja was passiert dort? Ne, was machen die mit mir? Oder was machen die mit uns? [...] aber es war ne gute Erfahrung, dass ich da war, dass ich mal die Kirche von innen gesehen habe und dass ich dann rausgekommen bin aus der Kirche, ohne dass irgendetwas passiert ist. Ja, also das hat mir viel genommen, also viel Last oder viele dumme Gedanken, ja, bin ich sie einfach mal losgeworden. Von daher finde ich das schon wichtig, dass man auf jeden Fall mal die Erfahrung macht, die verschiedenen Religionen und Kulturen auch in Berührung, damit in Kontakt zu kommen, dass man einfach mal sieht, dass es eigentlich ganz harmlos ist." (Birol, Z.: 232-238)

Um den Abbau von Vorurteilen und die Aufklärung über die Religion geht es auch Adem. Dabei sei eine hohe Dialogbereitschaft besonders wichtig, damit Missverständnisse und Vorurteile gegenüber Religionen aufgehoben würden und ein friedliches Miteinander möglich werde:

72 | Auch hier verschwimmen die Grenzen zwischen Kultur und Religion. 
"Das ist für mich sehr wichtig! Wir leben hier in einem Deutschland, in einem christlichen Staat und die ganzen Vorurteile kommen nur deswegen, weil wir uns gegenseitig nicht kennen. Und durch diese Dialoge und durch diese Bekanntschaften werden eben diese Missverständnisse und diese Vorurteile aus der Welt geschafft; und das, deswegen ist es sehr sehr wichtig, dass man miteinander ohne irgendeine Grenze zu setzen, miteinander gut auskommt." (Adem, Z.: 176)

Sein besonderes Interesse für Religionen und den interreligiösen Dialog legt er auch seinen Kindern nahe, sodass er auch schon die »Bibel zu Hause durchgelesen « hat und regen Kontakt zu seinen nichtmuslimischen Nachbarn pflegt, indem er diese an Weihnachten besucht und sie im Ramadan zum Fastenbrechen einlädt (vgl. Adem, Z.: 178-182).

Die hohe Dialogbereitschaft Adems habe seinen Kindern und ihm eine positive Kommunikation zu den Lehrern ermöglicht. Die Lehrer, insbesondere die christlichen Religionslehrer des Sohnes, der am evangelischen und katholischen Religionsunterricht teilgenommen habe, seien »sehr sehr, stolz« auf ihn gewesen, was sich in den Noten niedergeschlagen habe. Dabei sei es ihm wichtig, dass die Kinder selbst eine Offenheit wahren würden und »keinen sturen Blick« gegenüber anderen Religionen hätten. Dies habe auch dazu geführt, dass die Tochter viele Freunde habe, die verschiedenen Religionen angehören würden (Buddhisten, Juden, Christen) (vgl. Adem, Z.: 144-148).

Feride zeigte sich schon in ihren Schuljahren engagiert und führte »interreligiöse Tagungen « zwischen der örtlichen Moscheegemeinde und Kirchengemeinden durch (vgl. Feride, Z.: 348). Dabei seien zwischen den Religionen so viele Gemeinsamkeiten vorhanden, dass man von »getrennten « Sachen gar nicht zu sprechen brauche (vgl. ebd.). Ein gemeinsamer Gottesdienst ${ }^{73}$, der unter Einbezug der Geistlichen aller Religionen, auch eines Imams, an der Grundschule des Sohnes abgehalten wurde, könne z.B. dazu dienen, dass die Präsenz der Religionen im Schulalltag an »Normalität« gewinne und als eine »Selbstverständlichkeit« wahrgenommen werde (vgl. Feride zu IRU und Kap. III. 5.1). Ferner sollen in Zukunft insbesondere nichtmuslimische Familien einbezogen werden, sodass der Islam auch in den »Köpfen der Eltern« an »Normalität« gewinne (Feride, Z.: 344).

73 | Der Besuch der Gottesdienste ist ja ein Aspekt, der durch Eltern wie Melek und Belkıs negativ wahrgenommen wurde. Hier wird sozusagen eine andere Perspektive eröffnet. Indem ein gemeinsamer Gottesdienst stattfinde, könnten die muslimischen Kinder Anerkennung erfahren. 


\section{Verbesserungsvorschläge und Erwartungen}

Auch hier zeigen sich Eltern vielseitig. So haben sie unterschiedliche Verbesserungsvorschläge, die sich zum Teil mit dem oben zu den verschiedenen Aspekten bereits Erwähnten decken.

So wünscht sich Belkıs ein größeres Engagement der muslimischen Eltern selbst. Dass sich Eltern aktiv bemühen, um eine Verbesserung der Situation von muslimischen Kindern hervorzurufen, betrachtet sie zudem als ein Aspekt des Muslimseins:

"Ich würde sagen, dass einfach auch noch sehr stark das Engagement der Eltern da wichtig ist, das ist halt auch eine Sache, die auch Zeit in Anspruch nimmt [...]. Aber das viele muslimische Eltern auch sich engagieren und sagen dann auch und fordern auch und sagen meine Kinder, was weiß ich, hier sind $20 \%$ oder $10 \%$ muslimische Kinder an der Schule, dass man halt sagt, das und das; wir möchten das, wir haben das Recht darauf, oder sich dafür einsetzt und kämpft; und das ist sehr wenig vorhanden, weil sehr wenige muslimische Familien auch wirklich sehr bewusst islamisch leben. [...]. Das ist für mich ein ganz wichtiger Aspekt des Muslimseins, aktiv zu sein." (Belkıs, Z.: 304ff.)

Auch die Kooperation zwischen den verschiedenen Einrichtungen, wie der »Bildungsabteilung der Moscheen«, den Schulen, »mit dem Jugendamt, mit den Lehrern oder mit den Kindergärten, mit den Leiterinnen und so weiter«, sei erstrebenswert (vgl. Adem, Z.: 125f.). Gerade der Dialog zwischen Lehrpersonen und Eltern sei sehr wichtig, damit keine Missverständnisse oder Vorurteile entstünden. Hierbei seien ein respektvoller Umgang und eine vorbildhafte muslimische Lebensweise, die sich in Handlungen gegenüber den Mitmenschen äußern, eine Bedingung, um Vorurteile (»was gegen den Islam ist«) aus der Welt zu schaffen (vgl. oben, ebd. Z.: 161ff.).

Für ihre Kinder wünschen sich die Eltern höhere Bildungsmöglichkeiten (»gute Bildung«), indem die Lehrer dazu beitragen, dass sie motiviert am Unterricht teilnehmen und ihnen "gute Vorbilder« sind (vgl. Melek, Z.: $\left.{ }_{567}^{6}\right)^{74}$. Und nicht zuletzt, wünschen sie sich, dass genügend und »gute « und »qualitative« Lehrer an Schulen eingestellt werden, damit die Unterrichtsqualität nicht darunter leide (vgl. Adem, Z.: 198 und 260).

Zudem solle in Schulen und Kindertagesstätten mehr Rücksicht auf die Besonderheiten von Andersgläubigen genommen werden, damit »[...] die Kinder nicht in Konflikt kommen, ja, mit ihrem Glauben« (vgl. Birol, Z.: 276). Ausgehend von Studien, die belegen, dass die »interkulturelle« bzw. die »inter-

74 | An dieser Stelle wird auch auf den Alkoholkonsum ("... das größte Problem war für mich der Alkohol «) von nichtmuslimischen Lehrern verwiesen, was nicht ihren Vorstellungen eines Vorbildes entspreche (vgl. ebd., Z.: 514-520). 
religiöse« Kompetenz bei Lehrpersonen stärker sein könnte, wünscht sich der Vater, dass Vorurteile und Klischees abgebaut werden:

"Also, dass die einfach mal wissen, wie man damit umgeht, dass Lehrer von ... ich sage mal jetzt ganz banal vom Kopftuch nicht unbedingt darauf schließen, dass das Kind jetzt aus einer bildungsfernen Familie kommen muss oder so etwas ... Ne? [...]. Also diese Vorurteile, diese Klischees, die man über die Medien ja auch vermittelt bekommt etc., dass man dann da nicht direkt Rückschlüsse zieht auf das Kind bzw. auf die Familie des Kindes." (Birol, Z.: 280ff.)

Schließlich wünscht sich Feride, dass in den Schulklassen stärker Aufklärung betrieben werden müsse (vgl. oben Feride), um eine »Sensibilisierung « für die Präsenz muslimischer Kinder zu schaffen (vgl. Feride, Z.: 253; vgl. oben im Zusammenhang mit IRU und Kap. III. 5.1). Letztendlich wünscht sich die Mutter, wie es insbesondere typisch für »Ethiker« ist, dass die Kinder »als Menschen, ganze Menschen«, zu denen auch der Glaube dazugehört, »angenommen« und »akzeptiert« werden. Dabei sei es insbesondere wichtig, dass die »Angst vor dem Fremden« durch Aufklärung abnehmen müsse (vgl. oben und vgl. Feride, Z.: 364).

Insgesamt spiegeln sich in den Verbesserungsvorschlägen die Grundgedanken wider, die Eltern schon im Zusammenhang mit ihren religiösen Erziehungsvorstellungen darlegten (»das Menschsein«, eine »ethische Grundhaltung « usw.) Auch bei diesem Typ fällt, trotz der in Bezug auf ihre Religion geringer wahrgenommenen Benachteiligung auf, dass sie Vorurteile und Klischees über Muslime und muslimische Familien als unangenehm registrieren. Wie oben aufgezeigt wurde, machen sie konkrete Lösungsvorschläge, die jeweils eine individuelle Herangehensweise bzw. einen entsprechenden Zugang zur Thematik deutlich werden lassen. Dies weist auf ihre Individualität hin, die auch schon in ihrer Religiosität erkennbar war (vgl. Kap. III. 3.4). Als gemeinsames Merkmal fällt bei ihnen zudem der Wunsch auf, dass die Religion, die religiöse Lebensweise und die Präsenz muslimischer Kinder im Schulalltag als »Selbstverständlichkeit« entweder vorgelebt oder schlichtweg wahrgenommen werden sollten (z.B. durch die Einführung des IRU, durch interreligiöse Begegnungen, Dialoge usw.).

\subsection{Peers, Freundschaften und deren Einfluss auf die religiöse Sozialisation}

Der Stellenwert der Peers und Freundschaften, die im Rahmen der religiösen Bildungseinrichtungen gefunden und gepflegt werden, wurde durch einige Eltern schon aufgezeigt (vgl. Kap. III. 5.1 »Idealisten« und »Identitätssucher«). Die Freundschaften, die dort geknüpft werden, haben demnach auch einen 
Einfluss auf die religiöse Sozialisation bzw. auf die Entwicklung der Religiosität ihrer Kinder.

Es spielen aber auch Freundschaften, die sich im Rahmen der Schule und Kindertagesstätte ergeben, eine wichtige Rolle. Dabei haben die Kinder sowohl muslimische als auch nichtmuslimische Freunde, zu denen sie unterschiedlich intensive Beziehungen und Kontakte pflegen. Daneben werden religiöse Themen von einigen Kindern aufgegriffen und thematisiert und wiederum für andere spielen sie in ihren Freundschaftsbeziehungen keine Rolle.

Welchen Einfluss die Freundschaften und die Peers auf die religiöse Sozialisation haben, hängt insbesondere von den Eltern ab, da sie ihre Kinder bei der Wahl ihrer Freundschaften in unterschiedlichem Maße beeinflussen. Auch spielt in vielen Fällen die Anlage der Kinder eine Rolle, was sich im verschiedenen Umgang der Kinder mit Freundschaftsbeziehungen zeigt, die innerhalb einer Familie aufgewachsen sind bzw. einer Familie angehören.

In diesem Zusammenhang ist natürlich des Weiteren zu berücksichtigen, dass hier die Sicht bzw. die Vorstellungen der Eltern hinsichtlich der Freundschaften ihrer Kinder wiedergegeben werden. Dessen ungeachtet zeigen die Ergebnisse, welchen Einfluss sie ausüben und welcher Sozialisationseffekt erhofft bzw. erkennbar wird.

\subsubsection{Peers und Freundschaften - die "Idealisten"}

Die Kinder der Idealisten pflegen Beziehungen $\mathrm{zu}$ muslimischen und nichtmuslimischen Kindern, wobei die Intensität der Freundschaftsbeziehungen variiert. Dies hängt sowohl vom Kind selbst als auch vom Einfluss der Eltern ab. Einige Eltern tragen hierzu ihre grundlegenden Vorstellungen vor.

Die Freundschaften sind gemäß den Eltern »bunt gemischt« (vgl. Nermin, Z.: 626) und »multinational« (Ethem):

"Von der Herkunft her, ist eigentlich sehr vieles vertreten, auch von der Religion her, sind Muslime dabei, Nichtmuslime dabei, auch bei meiner Tochter jetzt [...] eine Hindu; also da besteht der Freundeskreis auch, ist sehr vielfältig." (Ethem, Z.: 365)

Die Beziehungen zu deutschen Freunden der Kinder werden durch einige Eltern stärker ins Visier genommen, da die Werthaltungen der Familien hier sehr unterschiedlich seien (vgl. Lale). Hierbei sei es auch wichtig, dass die Kinder ihre eigenen Erfahrungen machen würden, damit sie feststellen könnten, dass manche Kinder »nichts« für sie seien:

"Ich versuche es; z.B. es gab einen Fall, Ruhullah wollte unbedingt mit einem deutschen [Freund, Anm. d. Ver.f.]; ich habe gesagt: , Natürlich kann er kommen, kein Problem`, das Kind ist aber direkt nach der Schule gekommen, da war schon für mich was ..., warum ist er nicht nach Hause gegangen? Er hat etwas gegessen: Ja meine Mama arbeitet immer 
und ich habe immer, ich habe Schlüssel. [...] und dann ist er gekommen ...; egal, dann haben wir natürlich [gefragt, Anm. d. Verf.]: ,Was machst du wie geht's dir und so? ' Ja, meine Mama arbeitet in einer Barr; und so und ich wollte, dass das Kind das alles mithört. Erst mal sieht, mit wem es da spielt, was es macht; und das Kind kam das zweite Mal, das dritte Mal und dann hat Ruhullah gesagt: 'Mama, das Kind ist doch nichts für mich und dann hat es ...' (Lale, Z.: 787)

Die unterschiedliche Lebensweise der Eltern (»[...] arbeitet in einer Bar $)^{75}$ veranlasste die muslimische Mutter, das eigene Kind zum Nachdenken anzuregen und es bei der Wahl der Freundschaften zu beeinflussen. Dabei wird oftmals vorgezogen, dass deutsche Kinder die muslimischen Familien besuchen, was umgekehrt weniger geduldet wird. Dies macht Dilek deutlich, deren Tochter vorwiegend deutsche Freundinnen hat. Schließlich seien diese Freundinnen »ordentliche« (türk. düzgün) Mädchen, deren Eltern sie auch kenne und die sich respektvoll verhalten würden. ${ }^{76}$ Dabei pflege die Tochter auch einen intensiven Kontakt zu ihren Freundinnen, da fast jeden zweiten Tag jemand bei ihnen übernachte (vgl. Dilek, Z.: 229-232). Hingegen habe die jüngere Tochter ausschließlich »türkische« Freundinnen, zu deren Müttern Dilek einen intensiveren Kontakt (gemeinsame Frühstücke, Hausbesuche) pflege als zu deutschen Familien bzw. Müttern (vgl. ebd., Z.: 233). Zudem würden auch andere muslimische Familien besucht (»unsere Freundeskreise«), um die Religion erlebbar zu machen (vgl. Lale, Z.: 876).

Auf der anderen Seite beobachtet Nisa, dass türkische und muslimische Kinder und Jugendliche stärkere Freundschaften mit ihresgleichen oder mit jenen mit interethnischem Migrationshintergrund (hier: italienische und persisch-deutsche) schließen ${ }^{77}$. Wünschenswert wäre dennoch ein gemischter Freundeskreis (vgl. Nisa, Z.: 153f.).

Auch Entwicklungen werden aufgezeigt, sodass Kinder, die zunächst »bewusst« ausschließlich nichtmuslimische Freunde hatten, sich mittlerweile darauf »besinnen«, bewusst muslimische Freunde auszuwählen ${ }^{78}$. So sei es möglich, dass muslimische Kinder sich an muslimischen Feiertagen gegensei-

75 | Hier wird auf das Alkoholverbot Bezug genommen.

76 | Da die Mutter sehr viel Wert auf die muslimische Sexualmoral legt, kann mit "ordentlich“ (türk. düzgün) die Befolgung dieser Moral verstanden werden, d.h., es ist davon auszugehen, dass diese (deutschen) Mädchen keine gegengeschlechtlichen Freundschaften eingehen.

77 | Nisa beklagte auch die Ausschlusserfahrungen ihrer Kinder im schulischen Kontext. So ist möglicherweise auch ein Zusammenhang zwischen den Erfahrungen und der Wahl der Freundschaften vorhanden.

78 | Dies kann damit zusammenhängen, dass die Tochter ab einem bestimmten Zeitpunkt anfing, das Kopftuch zu tragen. 
tig beschenken, damit sie feststellen: »[...] so das gehört zu uns« (vgl. Nermin, Z.: 626). Hier wirkt das Beschenken an religiösen Festtagen identitätsweisend und trägt zu einem Wirgefühl bei. Unter Umständen ermöglicht es auch eine Abgrenzung gegenüber den »anderen«, den Nichtmuslimen, wobei die Mutter an einer anderen Stelle auch eine Diskurskultur mit Nichtmuslimen befürwortet (vgl. Nermin, unten).

Für einige Eltern (Ethem, Nermin, Lale) spielt die bewusste Wahl von muslimischen Freunden und deren Familie eine wichtige Rolle, um einen positiven Einfluss auf die religiöse Sozialisation auszuüben (vgl. auch Kap. III. 5.1). Hierbei geht es darum, dass das soziale Umfeld und die »religiöse Prägung « stimmen müssen und dass die Kinder erleben, wie andere Kinder auch eine religiöse Erziehung erfahren und deren Eltern auch beten (vgl. Ethem, Z.: 220, vgl. Nermin, Lale) bzw. die religiöse Praxis ernst nehmen (vgl. Nermin, Z.: 240-244). Für einige Kinder sei es z.B. nicht leicht, im schulischen Kontext muslimische Freunde $\mathrm{zu}$ finden, sodass deren Freundschaften bei anderen muslimischen Familien gepflegt werden müssen (vgl. ebd., Z.: 626). Auch in Bezug auf muslimische Familien, mit denen die eigenen »Werte« übereinstimmen, zeigt sich Lale wählerisch. So ist auch nicht jedes muslimische Kind »das Richtige« für das eigene Kind, da schon der Prophet (s) auf den Einfluss der Freundschaften hinsichtlich der religiösen Entwicklung gedeutet habe:

"Ich picke mir da auch [...] bewusst [über diese Religion Bescheid, Anm. d. Verf.] wissende, diese Religion lebende, Personen [...] aus, ja? Nicht jede muslimische [Familie, Anm. d. Verf.] ist das Richtige ja, also, dass ich jetzt nicht nur deutsche, auch muslimische [Familien bewusst auswähle, Anm. d. Verf.] [...] ich leg sehr viel Wert darauf, denn, mit welchen Kindern mein Kind in Kontakt kommt ... das ist so, auch Prophet Muhammed sagt, dass es etkilediĝini [...]. [Also, dass Freunde, die Kinder beeinflussen, Anm. d. Verf.]. Beeinflussen können." (Lale, Z.: 773-779)

Demnach beeinflussen die Freunde die Religiosität des Kindes. Der Einfluss des muslimischen Freundes zeige sich z.B. darin, dass die Kinder mit dem Freund aus der Schule oder dem Freund aus dem Bekanntenkreis der Familie nach Schulschluss zum Freitagsgebet gehen würden (vgl. Nermin, Z.: 634ff.).

Es wird zudem deutlich, dass gerade die Kinder dieser Familien (Ethem, Nermin, Lale) sich mit nichtmuslimischen Freunden über ihre Religion austauschen, wobei auch der Charakter der Kinder dafür bestimmend sei.

In den Köpfen der Kinder kommen aufgrund der unterschiedlichen religiösen Praxis anderer muslimischer Kinder, Fragen auf, die dazu führen, sich mit der eigenen muslimischen Identität auseinanderzusetzen. Diese Unterschiede betreffen z.B. den Fleischverzehr im Kindergarten oder die Frage, warum manche muslimische Familien Weihnachten feiern (»Warum feiern die Weihnachten? Sind das jetzt keine Muslime? Sind das Muslime?«). Auch 
werde z.B. der Nikolaus aus muslimischer Perspektive besprochen (vgl. Ethem, Z.: 369-376, vgl. Lale, Z.: 682). Es bieten verschiedene weitere Themen bzw. religiöse Gebote Diskussionsstoff unter den Jugendlichen (»[...] warum rauchst du, warum hast du eine Freundin, darfst du nicht [...]«). Dabei werden auch unterschiedliche Umgangsformen der Söhne in der Familie von Lale deutlich. Während ein Sohn gerne diskutiert und sich mit seinen Freunden über religiöse Themen auseinandersetzt, bricht der andere Sohn den Kontakt ab (vgl. Lale, Z.: 810ff.).

Des Weiteren diskutieren die Kinder auch untereinander religiöse Fragen oder Sinnfragen, was mit dem Alter der Kinder zusammenhänge (vgl. Nermin, Z.: 640). Die Mutter regt den Austausch über die Religionen bzw. religiöse Themen besonders an, sodass die Tochter einen kleinen »Koran auf Deutsch« in der Tasche mitführe, damit sie gegebenenfalls darin nachschlagen könne, um religiöse Themen zu besprechen (vgl. Nermin, Z.: 644-649). Dadurch solle die Fähigkeit gestärkt werden, sich repräsentieren zu lernen und eine Diskurskultur zu entwickeln, die den Umgang und die Akzeptanz von anderen Meinungen ermögliche:

"Weil, genau! Also für mich ist das schon wichtig, dass die sich gegenseitig, dass die gucken so in dieser Gesellschaft, die Gesellschaft ist ja pluralistisch, es gibt viele verschiedene Meinungen; und sie müssen lernen, ihre Meinungen nach außen hin zu präsentieren und auch andere Meinungen zu akzeptieren und auch zu diskutieren. Ne ...?" (Nermin, Z.: 650).

Alles in allem zeigt sich eine unterschiedliche Intensität an Freundschaftsbeziehungen, die sowohl zu muslimischen als auch $\mathrm{zu}$ nichtmuslimischen Kindern und Jugendlichen gepflegt werden. Der Einfluss der Peers auf die religiöse Sozialisation wird dabei ebenso deutlich gemacht wie der Austausch über die Religionen bzw. religiöse Themen mit nichtmuslimischen Kindern und Jugendlichen, der in manchen Fällen dazu führt, sich auf die eigene muslimische Identität zu besinnen und sich dieser noch einmal zu vergewissern.

\subsubsection{Peers und Freundschaften - die "Ritualisten"}

Die Einhaltung religiöser Vorschriften ist ein Aspekt, den ein Teil der ritualistischen Eltern auch in den Freundschaften ihrer Kinder betonen. Zudem äußert sich der Gemeinschaftsbezug, der ihre Religiosität kennzeichnet (vgl. Kap. III. 3.2) auch in den Beziehungen der Kinder, die sich in Freundesgruppen (sohbet-Gruppen) ${ }^{79}$ oder in der Moschee mit anderen Kindern treffen, um sich über ihre Religion auszutauschen.

79 | Religion und religiöse Themen werden insbesondere in diesen Gruppen oder in der Moschee aufgegriffen, was z.B. für die Kinder anderer Typen eher variiert und daher 
Die Kinder ritualistischer Familien haben zumeist einen gemischten Freundeskreis mit unterschiedlichen Glaubensrichtungen (vgl. Mecelle, Z.: 480-483; Rabia, Z.: 663; Selma, Z.: 569-581), wobei auch hier unterschiedliche Abstufungen bzgl. der Intensität der Freundschaftsbeziehungen festzustellen sind. So ist es Selma besonders wichtig, obwohl ihre Kinder auch deutsche Schulfreunde haben, dass die Kinder vorwiegend türkische, muslimische Freundschaften schließen, mit denen sie die religiöse Praxis befolgen können:

"... also hauptsächlich türkische Freunde, muslimische Freunde. Also darauf lege ich auch sehr großen Wert, dass sie sich auch nur mit muslimischen Freunden also auch treffen, auch hauptsächlich mit Freunden, die auch dann auch beten, ne, weil die ..." (Selma, Z.: 569)

Wichtig ist der Mutter, dass sie sich mit muslimischen Kindern treffen, da die Freunde Einfluss auf die religiöse Entwicklung der Kinder hätten. Hierbei weist sie auch auf Schwierigkeiten hin, die sich beim Treffen mit deutschen Freunden ergäben. Dies betreffe insbesondere die Einhaltung der muslimischen Speisevorschriften, wodurch sich auch schon zwischen den Kindern Konflikte zugetragen hätten und die Kinder dadurch in die Außenseiterrolle (im schulischen Kontext) gedrängt worden seien. Diese Schwierigkeiten lösen in der Mutter und bei ihren Kindern nicht selten Identitätskonflikte aus: »Ja. Manchmal frage ich auch, warum sind wir dann Moslem eigentlich? Ne?« (Selma, Z.: 200-204).

Die Kinder unterhalten sich auch mit ihren nichtmuslimischen Schulfreunden, die sich bei ihnen zu Hause zum Hausaufgaben machen treffen ${ }^{80}$, über ihre Religion. Besprochen wurden Themen wie das Verhältnis zum Gegengeschlecht (»)a, ihr seid ja Moslems, also der Freund ..., ihr dürft ja keine Freundin haben. Ihr dürft ja erst dann Freunde haben, wenn ihr verheiratet seid.«) oder der Moscheebesuch (vgl. Selma, Z.: 583-587). Hierbei wird auch angemerkt, dass die Kinder sich untereinander beeinflussen würden: »[...] die erziehen sich aber auch sehr viel untereinander die Kinder; auch also, sind auch sehr neugierig.« (vgl. ebd.).

Hingegen unterstreichen andere Eltern, dass die Religion bzw. religiöse Themen in den Freundschaften, die gerade im schulischen Kontext geschlossen worden seien, keine Rolle spielen würden (Mecelle, Z.: 487ff.; Rabia, Z.: 677ff.):

auch außerhalb geschieht. Gerade daraus lässt sich auch der Gemeinschaftsbezug der Ritualisten ableiten.

80 Die Mutter betonte an einer anderen Stelle, dass die Kinder sich nachmittags nicht mit nichtmuslimischen Freunden treffen dürften (vgl. Selma, Z.: 579). Hier scheint es so, dass die Hausaufgaben Anlass für ein Treffen boten. 
"Ja, nur auf weltlicher Ebene ... genau! Die reden gar nicht über den Glauben, weil das ist; [es gibt ja auch, Anm. d. Verf.] viele Kinder, die an nichts glauben, in den Schulen so, ich denke mal die meisten Kinder, die an nichts glauben, die leben nicht ihren Glauben! Und von daher haben die ja wenig zu reden." (Rabia, Z.: 679)

Die muslimischen »Freundesgruppen« (vgl. Selma, Z.: 350) in der Moschee und die »Mädchenclique, wo die halt über den Glauben reden« (vgl. Rabia, Z.: 667) (sohbet-Gruppen, vgl. Kap. III. 5.1), prägen die Kinder, sodass z.B. die Tochter, davon beeinflusst, das Kopftuch anlegen möchte, obgleich die Mutter kein Vorbild für ihre Tochter darstellt:

"Ja. Die ist, also sie ist, sie, die geht halt, also das ist so eine Clique, wo ihre, wo die Freunde sich treffen, die reden über den Glauben. Ich würde sagen, die ist interessiert, die wollte auch schon so oft, dass ich ..., und da hat sie dann auch öfters gesagt: , Mama ich mach das vor dir. Du wirst dann، [Also sie wollte ein Kopftuch tragen, obwohl die Mama auch kein Kopftuch trägt, Anm. d. Verf.). Ja. Ja. Ja, die wollte das, sie war so interessiert und so beeindruckt und fand das so schön und hat, sagt auch immer: 'Mama, du siehst dann wie ein Engel aus, wenn du dann so bedeckt (lacht) bist. “" (Rabia, Z.: 372ff.)

Es seien insbesondere die Freunde in der Moschee (»Das prägt die mehr«), die die Kinder dazu motivieren würden, am Moscheeunterricht teilzunehmen (vgl. Selma, Z.: 348-356).

Schließlich wird die Rolle der Freundschaften für die religiöse Entwicklung, wie es typisch für ritualistisch geprägte Eltern ist, unter dem Aspekt der Einhaltung von religiösen Vorschriften betrachtet:

"[...] Ich finde es dann aber auch wichtig, dass die Kinder auch dann wissen, was ein Muslim machen darf und was er nicht machen darf, ne? Und dass sie dann auch Respekt haben und dann das Kind nicht dazu überreden, das zu tun, was sie eigentlich nicht tun sollten." (Selma, Z.: 591)

\subsubsection{Peers und Freundschaften - die "Identitätssucher"}

Eine Offenheit kennzeichnet die Mütter dieses Typs im Umgang mit den verschiedenen Freundschaften der Kinder, die im familiären Rahmen und im Rahmen der religiösen Gemeinden und der öffentlichen Bildungseinrichtungen geknüpft werden. Der Kontakt zu Nichtmuslimen gehört für diese Eltern schon aufgrund ihrer hohen Dialogbereitschaft (vgl. Kap. III. 3.3 und III. 4.3) selbstverständlich zu ihrer Lebensweise, weshalb Religion nicht explizit thematisiert werden muss, sondern vielmehr ausgelebt wird, indem nach Kooperation und Dialog gestrebt wird.

Selbst wenn darauf geachtet werden soll, welche Freunde die Kinder haben und entsprechend mit welchen Familien die Beziehungen gepflegt werden (vgl. 
Hülya, Z.: 109; Lema, Z.: 220), ist in erster Linie eine betont offene Haltung der Eltern gegenüber nichtmuslimischen Freunden festzustellen. Hierbei wird auf das Vorbild des Propheten (s) verwiesen, der mit »jedem« kommuniziere:

"Ja, es ist so, dass man in erster Linie das Kind natürlich erziehen möchte, aber es ist jetzt so, dass man jetzt nicht so willkürlich, einfach so Freunde, sondern man möchte natürlich darauf achten, aber jetzt nicht sagen: Okay, das ist jetzt z.B. [...], hat eine andere Religion, damit darfst du nichts zu tun haben. So nicht ne, das ist ja irgendwo auch paradox. Unsere Religion sagt ja jetzt, unser Prophet hat ja mit jedem kommuniziert, kooperiert, es ist jetzt nicht so, okay, ich rede jetzt nur mit dem Muslim [...]." (Lema, Z.: 220)

Weniger die Religion, sondern die zwischenmenschlichen sozialen Aspekte sind demnach die entscheidenden Kriterien für die Wahl der Freundschaften $^{81}$ : »Ja, also Freunde heißt ja auch in dem Sinne ... auch dem helfen, vielleicht auch, dass [das Kind, Anm. d. Verf.] auch lernt, Menschen zu helfen.« (Lema, Z.: 221-224)

Diese Grundhaltung wird auch im Fall von Hülya deutlich. Der Freundeskreis der Kinder ist »gemischt«, sodass sich die Kinder mit Nachbarskindern, mit den Kindergartenfreunden und Kindern aus deutschen Familien treffen und gemeinsam spielen. Dabei spiele Religion keine Rolle, da es vielmehr um »Kommunikation, Dialog und Gemeinsamkeit« gehe (vgl. Hülya, Z.: 216-219, vgl. hierzu auch Kap. III. 5.3 »Interreligiöse Begegnungen«).

\subsubsection{Peers und Freundschaften - die "Ethiker"}

Wie schon im Verhältnis zu allen anderen Sozialisationskontexten deutlich wurde, haben Eltern dieses Typs (Ethiker) jeweils individuelle Vorstellungen, was die Freundschaften ihrer Kinder angeht. Demnach geben sie auch im Zusammenhang mit den Peers insgesamt ein vielseitiges und »buntes« Bild ab (vgl. Kap. III. 5.1). Das Niveau der Beeinflussung fällt im Vergleich zu anderen Eltern bzw. Typen geringer aus. Hierbei stellen Eltern wie Belkıs und Melek eine Ausnahme dar. Bei ihnen wurde auch schon an ihren »Erziehungsstilen« (vgl. Kap. III. 4.4) deutlich, dass sie eine diszipliniertere Haltung unter den Eltern, die ethische Grundsätze in den Vordergrund stellen, einnehmen. Die Religion bzw. religiöse Themen spielen insbesondere für deren Kinder eine zentrale Rolle in ihren Freundschaften.

Es fällt schon in den unterschiedlichen Bezeichnungen auf, welche Werthaltungen (ethische Grundhaltung) die Eltern in Bezug auf die Freundschaften ihrer Kinder einnehmen. Demzufolge haben die Kinder »alle möglichen

81 Hierbei unterstreicht Lema auch die Freundschaften zu ihren ehemaligen, nichtmuslimischen Kommilitonen, mit denen der Kontakt andauere (vgl. Lema, Z.: 237). 
Freunde im Umfeld «, angefangen von Klassenkameraden, über Freunde im Fußballverein und auch nichtmuslimische Freunde, die keinen Einfluss auf die Religiosität der Kinder ausüben (vgl. Feride, Z.: 372-381). Oder sie haben unterschiedliche Freunde, worunter christliche und muslimische Kinder sind, und der Vater nichts über deren Einfluss aussagen kann ${ }^{82}$ (vgl. Birol, Z.: 296).

Die Offenheit und das hohe Interesse im Hinblick auf einen interreligiösen Dialog trugen dazu bei, dass die Kinder von Adem »sehr verschiedene Freunde mit verschiedenem Glaubenscharakter, wie zum Beispiel einen Buddhisten, einen Juden, einen Evangelisten, einen Katholiken«, haben. Der »sehr gute Kontakt« (vgl. Adem, Z.: 144) übe keinen negativen Einfluss auf die Religiosität bzw. religiöse Entwicklung der Kinder aus, was sich schließlich darin äußere, dass die Kinder sich nicht nur über den Islam, sondern auch über das Christentum unterhalten würden (vgl. ebd., Z.: 202-205). Der Einfluss von Freundschaften im Allgemeinen wird auch unterstrichen: So übe der Freundeskreis einen großen Einfluss auf die Religiosität aus, zumal wenn die Kinder die Pubertät überschreiten würden. In dieser Phase trete, im Vergleich zu den Familien bzw. Eltern selbst, der größere Einfluss der Peers hervor. Überdies würden die Kinder ohnehin »ihre eigenen Wege« (vgl. ebd., Z.: 201) gehen. Hier wird nochmals deutlich, dass Adem sehr viel Wert auf die »Selbstständigkeit« seiner Kinder legt (vgl. auch Kap. III. 4.4. »Erziehungsstile [...]«).

Die Freunde von Meleks Sohn, der die Grundschule besucht, sind »gemischt $\ll(»[. .$.$] da ist ein Mischmasch in der Schule, international«), d.h., sie$ gehören unterschiedlichen Ethnien an. Die Tochter habe hingegen vorwiegend muslimische Freunde, da sie zum einen ein Gymnasium besuche, das einen muslimischen Träger habe, und sich ihre Freundschaften zum anderen durch den Moscheebesuch ergeben hätten. Beide Kinder hätten somit auch nichtmuslimische Freunde, womit die Mutter »gar keine Probleme« hat (vgl. Melek, Z.: 579-594).

Die unterschiedliche Religionszugehörigkeit und das entsprechende divergierende Erscheinungsbild, bedingt u.a. durch das Kopftuchtragen, tragen zu Vorurteilen bei, die auch bei den Kindern zu Konflikten und Spannungen führen. Melek weist auf eine Erfahrung der Tochter hin, die sich auf Vorurteile gegenüber muslimischen Frauen beziehe und die zum Freundschaftsabbruch bei ihrer Tochter geführt habe. Stereotypisierend griff die nichtmuslimische

82 | An einer anderen Stelle verweist Birol auf die Bedeutung der eigenen muslimischen Freunde in seiner Schul- und Jugendzeit. Demnach beeinflusste inn weniger seine Familie, als inn seine muslimischen Freunde dahingehend prägten, die nahegelegene Moschee zu besuchen: "[...] hätte ich andere Freunde, wäre ich wahrscheinlich gar nicht in die Moschee gekommen damals und dann denke ich mir, würde mir heute was fehlen so und [...]." (Birol, Z.: 260) 
Freundin das Bild der muslimischen Frau auf und bezeichnete die Mutter als »dumm«, worauf sich die Kinder voneinander distanzierten:

"Hat sich sehr distanziert und sie hat sich auch sehr ... wie soll ich sagen? Nicht so nett ausgedrückt. Sie hat mich als Muslim zum Beispiel als dumm angesehen. Ja (lacht). Und das hat ihr sehr wehgetan. 'Mama, wieso sieht sie, sieht sie dich so? Ich sage: 'Büsra, ich bin vielleicht nicht die Klügste, aber ich bin auch nicht dumm! (lacht)." (Melek, Z.: 599)

Hier greift ein Mechanismus der Etikettierung bzw. einer Zuschreibung, was sehr verletzend auf die Tochter wirkt. Dennoch spielt für die Tochter die Religion bei der Wahl ihrer Freundschaften eine wichtige Rolle und büßt ihre Stellung auch nicht durch diese negative Erfahrung ein:

"Ich glaube, dass die religiöse [...] Sicht [den Ausschlag, dafür gegeben hat, Anm. d. Verf.] [...], dass sie sich auseinandergelebt haben. Aber bei unserer Tochter hat es jetzt nicht den Anschein gemacht: Meine Religion ist nicht schön. Die Leute distanzieren sich von mir. Sie hat später eingesehen, es tat ihr sehr leid, dass sie sich von mir distanziert hat, aber sie wusste: Religion kommt bei uns an erster Stelle. Freunde kann ich immer noch finden. Es hat ihr aber wirklich sehr sehr wehgetan. Sie, sie war eine Zeitlang wirklich sehr sehr unglücklich, dass die Freundschaft so einfach zerbrochen war." (Melek, Z.: 611)

Die Kinder unterhalten sich auch mit ihren nichtmuslimischen Freunden über ihre Religion. Die Mutter zeigt Respekt bzw. Akzeptanz gegenüber Andersgläubigen und ihrer Lebensweise (»Büsra, das hat was mit ihrer Religion zu tun. Das musst du auch so akzeptieren«), womit die Tochter keinerlei Probleme habe, der Sohn jedoch hartnäckig auf seine eigene Meinung poche (vgl. Melek, Z.: G13ff.).

Die muslimische Lebensweise ist für Belk1s ein wichtiges Kriterium bei der Auswahl der Freunde ihrer Kinder. Folglich haben die Kinder, beeinflusst durch die Haltung der Mutter, mehr muslimische Freunde und weniger deutsche, d.h. nichtmuslimische Freunde (vgl. Belk1s, Z.: 328-334). Außerdem werden die Kontakte zu Gleichaltrigen in der Moschee gesucht und gepflegt, was ja nicht zuletzt einen der wichtigsten Gründe für den Moscheebesuch darstellt (vgl. ebd., Z.: 173).

Da sie nicht möchte, dass Widersprüche zwischen den Freunden ihrer Kinder und den religiösen Einstellungen ihrer Familie entstehen, achtet sie zum »Schutz« ihrer Kinder darauf, dass Familien, mit denen sie sich regelmäßig trifft, für dieselbe Lebensweise wie sie eintreten. So wird sogar ein allzu intensiver Kontakt mit Kindern türkischer Nachbarn vermieden, da diese ihren Werthaltungen widersprechen (vgl. Belkıs, Z.: 312-321). Des Weiteren dürfen 
die Kinder deutsche Freunde, deren Familien die Mutter nicht kennt, nicht besuchen. Belk1s selbst sieht sich selbst vor der Herausforderung bzw. betrachtet es sogar als ein »Problem«, die Tochter durch Erklärungen dahingehend zu überzeugen und zu beeinflussen (vgl. ebd., Z.: 310; vgl. auch Kap. III. 4.4 »Erziehungsstile«). Begründet wird ihre Vorgehensweise mit der Schwierigkeit, in dieser Gesellschaft »islamische Werte« zu vermitteln:

"Genau! Das ist auch für mich schwer, für meine Kinder [ist es, Anm. d. Verf.] auch schwer. Ich denke in der jetzigen Gesellschaft, in der wir leben, ist es sowieso schwierig, wirklich islamische Werte zu vermitteln, und wenn man dann auch noch Menschen hat, die quasi vielleicht nicht bewusst, aber gegen dich als Eltern, als Mutter oder als Vater agieren, ist es noch schwieriger." (Belkıs, Z.: 322).

Schließlich möchte sie ihren Kindern dieses »Hin und Her« und die »innere Zerrissenheit«, die durch unterschiedliche »Lebensstile« und »Fremdeinflüsse« hervorgerufen werden könnten, ersparen. So seien die Religion und eine religiöse Lebensweise (islamische Verhaltensregeln, die islamische Sexualmoral, die muslimische Bekleidungsvorschrift) die wesentlichsten Faktoren für die Freundschaftswahl ihrer Kinder (vgl. Belk1s, Z.: 145ff. und Z.: 324ff.). Im Vergleich zu allen anderen Eltern dieser Gruppe beeinflusst Belkıs ihre Kinder somit diesbezüglich am meisten.

\subsection{Der Einfluss der Medien auf die religiöse Sozialisation}

In diesem Kapitel wird der Einfluss der Medien auf die religiöse Sozialisation dargestellt, zudem Eltern einen unterschiedlichen Umgang pflegen. Hierbei wurden zu zwei unterschiedlichen Kernkategorien Aussagen getroffen. Die Eltern wurden zum einen befragt, welche a) Haltung sie zur Nutzung von Medien als didaktische Mittel einnehmen, und zum anderen welche b) Ansichten sie zum »Islambild « in den Medien vertreten.

Nachfolgend wird, wieder jeweils typspezifisch, zunächst der fördernde Effekt der didaktisch eingesetzten Medien auf die religiöse Sozialisation aufgezeigt. Dabei spielt auch die Form des Einsatzes, die im familiären Rahmen zur Geltung kommt, eine wichtige Rolle. Insgesamt stehen, im Vergleich zu allen anderen Medien, Bücher mit religiösen Inhalten im Vordergrund, deren Einsatz für verschiedene Interaktionsformen und Kommunikation innerhalb der Familie sorgen. Den Büchern folgt der Einsatz anderer Medien, wie z.B. u.a. Fernsehen, Internet, Zeitschriften, PCs, CDs, DVDs, iPod, MP3-Spieler.

Alles in allem ist wohl in unterschiedlichem Maße, je nach Nutzung, ein fördernder Effekt auf die religiöse Sozialisation festzustellen. Dabei kristallisieren sich, auch wie in anderen Sozialisationskontexten, typspezifische Eigenheiten der Mediennutzung von Eltern und ihren Kindern heraus. 
Bezogen auf das von den Medien transportierte »Islambild «, das durch alle Typen besonders stark negativ wahrgenommen wird, kann kein negativer Effekt auf die religiöse Sozialisation festgemacht werden. Allerdings wird durch manche Eltern ein hemmender Effekt auf die religiöse Sozialisation befürchtet. Die produzierten Feindbilder, die Muslime unter General- bzw. Terrorismusverdacht usw. (vgl. Kap. II. 2.2.4) stellen, führen zu Ausgrenzungs- und Diskriminierungserfahrungen bei Kindern und Jugendlichen. Vorurteile und die erlebte Ablehnung, die an die Kinder herangetragen werden, versuchen Eltern durch verschiedene Strategien und Lösungswege auszugleichen, indem sie sich auf religiöse Quellen bzw. auf religiöse Deutungsmuster berufen, die sie ihren Kindern nahelegen oder sie zur aktiven Auseinandersetzung mit dem Thema anregen. Nicht zuletzt soll Aufklärungsarbeit über den Islam und Muslime helfen, um Ängste und »Feindbilder« abzubauen, damit ein friedliches Zusammenleben in dieser Gesellschaft ermöglicht wird.

An dieser Stelle ist es wichtig, zu unterstreichen, dass die Folgen des »Islambildes « in den Medien vor allem durch Kinder und Jugendliche, die über zehn Jahre alt sind, deutlich werden. Die jüngeren Kinder/Jugendliche bleiben von den Diskussionen und Berichterstattungen eher unberührt bzw. bekommen diese gar nicht mit.

\subsubsection{Der Umgang mit den Medien - die "Idealisten“}

\section{Medien als didaktische Mittel}

Für die Idealisten stehen Bücher mit religiösen Inhalten im Vordergrund. Dabei werden in den Familien insbesondere den jüngeren Kindern Bücher vorgelesen, es finden gemeinsame Lesungen statt oder die Kinder lesen selbst aus ihren Büchern. Hier ist eine unterschiedliche Intensität im Umgang mit religiöser Literatur zu vermerken, die sowohl von der Umgangsform mit Literatur innerhalb einer Familie abhängt als auch vom Interesse der Kinder. Auch führen sprachliche Defizite dazu, dass religiös geprägte, türkischsprachige Bücher seltener gelesen werden.

Sehr intensiv werden Bücher von Ethems Kindern gelesen. In ihrer Bibliothek befinden sich sowohl »altersgerechte« religiöse Literatur (u.a. Prophetenbiografien, die Gefährten des Propheten (s), moralische und religiös motivierte Erzählungen) als auch türkischsprachige Bücher (Prosa, Romane, Märchen usw.):

"[...] aber wie gesagt, Bücher stellen für uns da auch ein zentrales Moment dar, um auch den Kindern noch mal einen eigenen Zugang zu geben, den sie entwickeln können. Da haben sie es immer noch sehr gern, wenn wir ihnen etwas vorlesen." (Ethem, Z.: 414) 
Neben dem eigenen Zugang, den die Kinder entwickeln können ${ }^{83}$, wird ihnen auch vorgelesen. Es wird eine interaktive Vorgehensweise gewählt, die es den Kindern ermöglicht, Zwischenfragen zu stellen, um auch ihre eigenen Erfahrungen und Gedanken einzubringen (vgl. ebd., Z.: 414-420).

Da gerade Bücher besonders prägen, motiviert auch Nermin ihre Kinder dazu, Bücher zu lesen. Die Beschäftigung mit Literatur (»Bücher natürlich ohne Ende«) ist zudem eine von ihr gewählte Methode, um ihren Kindern die Religion nahezulegen (vgl. Nermin, Z.: 240) ${ }^{84}$. Nicht zuletzt sind es Bücher, die sie in ihrer Jugendzeit besonders geprägt haben und sie heute veranlassen, diese »bewusst« einzusetzen (vgl. Nermin, Z.: 708).

Darüber hinaus gibt es bestimmte rituell befolgte Lesezeiten (vgl. Lale, Z.: 874), die genutzt werden, um gemeinsam religiöse Bücher zu lesen. Auch werden in den Familien regelmäßige Lesungen durchgeführt, um sich intensiv mit dem Koran und seiner Interpretation zu befassen. Diese Zeit werde genutzt (vgl. Ethem oben), um die Kommunikation mit den Kindern aufrechtzuerhalten (vgl. Nisa, Z.: 166-170). Mit einem bestimmten Alter (ab der Pubertät) gewinnen andere Medien an Bedeutung (vgl. ebd.).

In Dileks Familie werden Bücher, trotz der vorhandenen riesigen Bibliothek, weniger genutzt, da die Kinder Schwierigkeiten mit türkischsprachiger religiöser Literatur hätten (vgl. Dilek, Z.: 249ff.; vgl. auch Nermin bzgl. dieser Schwierigkeit Z.: 698). Daher versucht die Mutter gezielt, situationsbezogen auf Fragen einzugehen. Falls die Kinder neugieriger sind, empfiehlt sie ihnen Bücher (vgl. Dilek, Z.: 155).

Daneben würden religiöse Kinder- und Jugendzeitschriften der jeweiligen religiösen Verbände ${ }^{85}$ abonniert (vgl. Nisa, Z.: 164), um Kinder aufgrund der zusätzlich angebotenen Geschenke zu erfreuen (vgl. Ethem, Z.: 423-426) oder um ihnen ein Zugehörigkeitsgefühl ${ }^{86} \mathrm{zu}$ vermitteln (vgl. Nermin, Z.: 698).

Auch würden Medien wie Filme und TV-Serien mit religiösen Inhalten (vgl. Nermin, Z.: 240; vgl. Lale, Z.: 855ff.), Hörspiele (vgl. Ethem, Z.: 408), altersgerechte CDs, DVDs, um verschiedene Spiele ${ }^{87}$ auf dem PC zu spielen, um religiöse Lieder zu hören (türk. ilahi) oder Suren spielerisch zu erlernen

83 | Ethems Erziehungsstil ist besonders durch die "Förderung der Selbstständigkeit“ geprägt (vgl. Kap. III. 4.1 "Erziehungsstile").

84 | Sie motivierte die Tochter dazu, stets einen Koran mitzuführen, damit sie ggf. nachschlagen könne, wenn religiöse Fragen aufkämen (vgl. Kap. III. 5.4 "Peers [...] «).

85 | Gemeint sind die religiösen Dachorganisationen, denen sie sich nahe fühlen.

86 | Hier fällt die türkische Sprache schwer, dennoch möchte die Mutter einen Bezug herstellen, sodass sie mit ihren Kindern darin blättert und innen etwas daraus vorliest.

87 | Auch hier hat sich in den letzten Jahren einiges entwickelt, so gibt es religiöse Frage-Antwort-Spiele auf dem PC, aber auch Gesellschaftsspiele usw. mit religiösen Themen wurden entwickelt. 
(vgl. Lale, Z.: 855), eine wichtige Rolle spielen. Das Internet werde genutzt, um über den Koran zu recherchieren bzw. um Frage-Antwort-Spiele zu spielen (vgl. Nisa, Z.: 166).

Zum Lernen von Bittgebeten (arab. dua) oder Koransuren kämen des Weiteren MP-3-Player (vgl. Nermin, Z.: 240), zum Herunterladen von Apps, verschiedenen religiösen Liedern (türk. ilahi) sowie Koranrezitationen, sowie iPods zum Einsatz (vgl. ebd., Z.: 688-696).

Manche Familien hätten keinen Fernseher (vgl. Ethem, Z.: 406), wieder andere würden versuchen, den Fernsehkonsum stark einzuschränken: Nermin möchte nicht, dass ihren Kindern durch das Fernsehen »Lebenszeit, Lebensqualität« und »Energien« verloren gehen. Dennoch sieht sie ein, dass es ein Teil der Lebenswirklichkeit geworden ist und versucht deshalb, den Fernsehkonsum zu minimieren bzw. mit ihren Kindern bewusst religiös motivierte Filme anzuschauen (vgl. oben und Nermin, Z.: 684). Da sie davon ausgeht, dass das Fernsehen »erzieht« und »lenkt« und »beeinflusst«, achtet Lale darauf, was ihr Kind sich anschaut. Dabei sei es ihr wichtig, »Alternativen« zu den bekannten Sendern zu finden (Lale, Z.: 868ff. und Z.: 139) und mit ihren Kindern Programme und Sendungen von religiösen Anbietern bzw. von Kanälen, die von Muslimen initiiert worden sind, anzuschauen (vgl. ebd. Z.: 857).

\section{Die Folgen des von den Medien vermittelten »Islambilds«}

Das Islambild in den geläufigen Medien (hier: Fernsehen, Zeitungen, Wahlplakate) ist gemäß den Eltern von Vorurteilen gegenüber dem Islam geprägt (vgl. Lale, Z.: 884-888; vgl. Ethem, Z.: 444). Dabei werde der Islam mit Konflikten, Terrorismus und Fanatismus in Verbindung gebracht, obwohl die hier lebenden Muslime »überhaupt nichts damit zu tun haben« (vgl. ebd.; vgl. Nisa, Z.: 103). So komme es zu Missverständnissen und Muslime stünden unter Generalverdacht, potenzielle Terroristen zu sein, was z.B. Nisas Söhne durch ihre Lehrer zu spüren bekommen hätten (vgl. Nisa, Z.: 179). Gerade Anfeindungen, »dass der Islam in den Medien nicht immer positiv dasteht«, werden auch von Nermins älterer Tochter ${ }^{88}$ wahrgenommen (vgl. Nermin, Z.: 712). Die Kinder bekämen jedoch wesentlich mehr mit, als man annehmen möchte, so Ethem. Die islamkritischen Beiträge in der Zeitung und die Wahlkampagne der Bürgerbewegung ProKöln in NRW ${ }^{89}$ führen schließlich zu regen Diskussionen und Fragen in der Familie (»Ja, was meinen die jetzt damit? Warum schreiben die das jetzt so?«) (vgl. Ethem, Z.: 440). Die Kinder würden irritiert reagieren:

"[...] teilweise auch irritiert, also irritiert in dem Sinne, warum Menschen jetzt plötzlich so gegen etwas sind, was sie jetzt als grundsätzlich positiv aufgreifen. Und sie haben

88 | Die jüngeren Kinder würden davon unberührt bleiben und «noch nichts" merken.

89 | Vgl. nächstes Kapitel III. 5.6. 
schon Probleme, den Hassmechanismus, der dahintersteht, auch zu begreifen, weil das, ehrlich gesagt, auch ein Mechanismus ist, wo wir darauf geachtet haben, dass die Kinder nicht damit aufwachsen und." (Ethem, Z.: 442)

Es widerspreche im Grunde Ethems Grundhaltung, die von Toleranz und Respekt gegenüber Andersgläubigen und anderen »Ansichten« geprägt sei und die er ebenfalls seinen Kindern nahegelegt habe. So falle es den Kindern schwer, die Vorurteile und den »Hassmechanismus« nachzuvollziehen:

"Also, es widerspricht eigentlich allem, was man bisher beigebracht hat, wie man mit anderen Menschen mit anderen Glauben und wie man mit anderen Ansichten umgeht. Also innen wurde bisher beigebracht, mindestens tolerant zu sein, wenn nicht eher Respekt dafür zu haben, andere wegen ihres Glauben, wegen ihrer Ansichten nicht als schlecht darzustellen [...]. Und dann begegnen sie zwangsläufig auch in der realen Welt Menschen, die mit dieser Ansicht überhaupt nichts anfangen können und hetzen, Vorurteile pflegen und so weiter. Das fällt innen, ehrlich gesagt, noch etwas schwer. Also das zu verstehen, warum Menschen so sein müssen." (Ethem, Z.: 444)

Zudem beeinflussen die Medien die Menschen (die Nachbarn usw.) negativ, so Lale, und beeinträchtigen das friedliche Zusammenleben von Muslimen und Nichtmuslimen in dieser Gesellschaft:

"Über die Religion Islam und leider, aber dass das nicht so ist, aber leider beeinflussen die Medien viele Menschen, auch unsere Nachbarn, das glaube ich schon. Das ist schon also, leider, [...] wir leben ja in einer Zeit, in der man noch toleranter sein sollte, in der sich das Bild ändern sollte, aber leider sind die Medien in bestimmten Händen, glaube ich, die den [Islam, Anm. d. Verf.] [...] bewusst schlecht machen, auch wenn viele Menschen sehen, dass das [in der Realität, Anm. d. Verf.] so nicht ist, [...]." (Lale, Z.: 890ff.)

Trotz des stark negativ wahrgenommenen Bildes in den Medien beeinflusst das nicht die religiöse Sozialisation von muslimischen Kindern und Jugendlichen:

"Auswirkungen auf die religiöse Erziehung, nein. Ich glaube nicht, nein. Nein, für meine Erziehung, also nein. Nein, nur es ist schade, man ist traurig." (Lale, Z.: 902)

Auch aus den Aussagen der anderen Eltern lässt sich kein negativer Einfluss auf die religiöse Sozialisation ableiten (vgl. Dilek, Z.: 254; Nisa, Z.: 174), zumindest nicht in konkretisierter Form. Demnach hat, gemäß den Eltern, das negative Islambild keine Folgen auf die religiöse Sozialisation. Jedoch entwickeln Eltern mit ihren Kindern unterschiedliche Strategien, wie sie mit dem transportierten Bild vonseiten der Medien umgehen möchten. Dies deutet 
dennoch auf einen Sozialisationseffekt hin, der entweder positiv oder negativ verstanden werden kann.

Die Strategien, die Eltern entwickeln, sind verschieden: Es findet zum einen eine Auseinandersetzung mit dem Thema statt, sodass zumindest eine Selbstverortung stattfinden kann und die Gefühle der Ablehnung und des Nicht-verstanden-worden-Seins minimiert werden:

"[...] meine Kinder hatten zumindest die Möglichkeit, die Fragen zu stellen und sich damit auseinanderzusetzen; auch in einen, quasi in einen Diskurs einzutreten mit ihrem Papa [...]« (Ethem, Z.: 446)

Auch die persönliche Weiterbildung, das Einnehmen einer positiven Grundhaltung und »es« anders vorzuleben, ist eine weitere gewählte Strategie, um mit den negativen Folgen umzugehen:

"[...]. Ich sage immer, lebe es anders vor, mehr kannst du auch nicht machen. Lebe es immer positiv vor und ja [...]. Es heißt ja bei uns in der Religion: Derjenige, der dir einen Stein wirft, dem sollst du eine Rose zuwerfen. Ne, nicht Auge um Auge, Stein um Stein, äh, Zahn um Zahn, sondern, wenn man dir einen Stein zuwirft, dann wirf eine Rose rüber. Und das versuche ich zu vermitteln, natürlich ist das in dieser Gesellschaft, wo es immer, ne Ellbogengesellschaft, sehr schwierig. Ne dann sagen die: ,Nee, wieso? Wenn der das mit mir macht, warum soll ich das nicht mit inm machen? Ne, das ist schon schwierig, aber ich." (Nermin, Z.: 712-716)

Es solle zudem mehr Aufklärung über den Islam stattfinden, z.B. Tag der offenen Moschee, Vorträge (vgl. Lale, Z.: 904; vgl. Nisa Kap. III. 5.2). Damit Kinder und Jugendliche mehr zum Nachdenken angeregt würden, solle eine gemäßigte Form gewählt werden, logische Argumente aus dem Koran und dessen Interpretation vorgetragen und Antworten für einen sinnvollen Umgang abgelesen werden. Dabei sei es wichtig, die Kinder selbst zum Nachdenken anzuregen und sie mit logischen Erklärungen, die sich auf ihren Glauben beziehen, zu überzeugen (vgl. Nisa, Z.: 174ff.).

\subsubsection{Der Umgang mit den Medien - die "Ritualisten"}

\section{Medien als didaktische Mittel}

Für alle ritualistischen Eltern spielen Bücher eine wichtige Rolle. Jedoch üben sie, nach Ansicht einiger Eltern (Rabia, Mecelle), keinen religiösen Sozialisationseffekt aus.

Bücher kommen als Medien (z.B. ein kindgerechter Koran) zum Einsatz, indem den jüngeren Kindern vorgelesen wird (vgl. Mecelle, Z.: 165; vgl. Selma, Z.: 656) oder indem mit älteren Menschen gemeinsam gelesen und im An- 
schluss über die Inhalte gesprochen und diskutiert wird (vgl. Ali, Z.: 50; Rabia, Z.: 268; Selma, Z.: 624 und 638-658). Allerdings erschweren sprachliche Defizite, religiös fundierte türkischsprachige Literatur zu lesen (vgl. Rabia, Mecelle). So werden deutschsprachige Bücher mit religiösen Inhalten vorgezogen, die die Kinder »verstehen« könnten (vgl. Mecelle, Z.: 521). Aber sie müssten noch interessanter gestaltet werden, damit die Kinder »interessiert« an den Büchern seien:

"Bücher haben wir auch, aber ich merke, das ist halt durch die ..., meine Kinder können halt noch die türkische Sprache nicht so gut beherrschen, deswegen fällt es denen schwer und die lesen zu wenig. Und das ist auch noch so ein Problem. Ich habe zwar jetzt auch, so jetzt auch in der deutschen Sprache auch ein paar Bücher, man muss es aber noch interessanter rüberbringen. Die sind noch nicht so interessiert an den Geschichten und an dem, was ..." (Rabia, Z.: 723)

Außerdem werden in der Familie von Selma ${ }^{90}$ regelmäßige Lesezeiten am Abend eingehalten, sodass, wenn sie ihnen nicht vorliest, die Kinder selbstständig lesen (vgl. Selma, Z.: 648-656). Da die Kinder vorwiegend religiös geprägte türkische Bücher läsen, habe sie die Kinderzeitschrift eines religiösen Verbandes abonniert (vgl. ebd., Z.: 638).

Interessanterweise spielen auch der PC und das Internet für die Kinder der Ritualisten eine wichtige Rolle. So werde auf einer Website der »Glaube spielerisch nahegebracht«, was als "gut« befunden wird, da wenige deutschsprachige religiöse Literatur zu finden sei (vgl. Mecelle, Z.: 521f.). Zudem werde hier für die Hausaufgaben des Moscheeunterrichts recherchiert (vgl. Ali, Z.: 86). Gerade an den Wochenenden würden am PC über das Internet religiöse Lieder (türk. ilahi) gehört (vgl. Rabia, Z.: 256-264) oder religiöse Filme (auch DVDs) gesehen (vgl. Selma, Z.: 630-636; Ali, Z.: 50).

Trotzdem kritisieren manche Eltern auch den negativen Einfluss des Internets (Ali, Rabia). Die Kinder und Jugendlichen entzögen sich dem Einfluss der Eltern, sodass ab einem gewissen Alter keine Kontrolle mehr darüber existiere, was sie konsumieren würden (vgl. Ali, Z.: 73). Die Zeit im Internet betrachtet Rabia gar als verlorene Zeit, die besser eingesetzt werden könne, um Bücher zu lesen. Auch werde viel »unnötiges Wissen« vermittelt (vgl. Rabia, Z.: 715). Um diesem negativen Einfluss vorzubeugen, sei es notwendig, den Kindern von klein auf Verhaltensregeln beizubringen. So sollen sie von klein auf lernen, »was zu tun ist « und »was sie zu unterlassen« haben (vgl. Ali, Z.: 73). Hier wird typischerweise auch die Haltung eines ritualistischen Elternteils deutlich.

Die Bedeutung der didaktisch eingesetzten Medien (hier vorzugsweise Bücher) für die religiöse Sozialisation ist gemäß den Aussagen zweier Eltern (vgl.

90 | Selma fiel durch inren besonders ausgeprägten Ritualismus auf. 
Rabia, Z.: 719-730; Mecelle, Z.: 526) nicht gegeben. Auch wenn hin und wieder gemeinsam gelesen wird, scheint es keine Bedeutung für die Entwicklung ihrer Religiosität zu haben. Hingegen spielen die Medien für Eltern wie Ali und Selma eine wichtige Rolle und es werden durch ihren Einsatz gemeinsame Rituale im familiären Rahmen (vgl. Selma, oben) gepflegt. Da dies ihre religiöse Erziehung unterstütze, sei hier von einem religiösen Sozialisationseffekt auszugehen (vgl. ebd., Z.: 644). Des Weiteren werden den Kindern für den Umgang mit den Medien Verhaltensregeln bzw. »Gebotenes und Verbotenes« (religiöse Vorschriften) nahegelegt. Schließlich deuten beide Aspekte auf einen Ritualismus hin, der hier nochmals zum Vorschein kommt (vgl. Ali, oben).

\section{Die Folgen des von den Medien vermittelten »Islambilds«}

Alle Eltern stellen einen negativen Einfluss fest, der vom Islambild in den Medien ausgehe. Jedoch bekämen jüngere Kinder dies weniger mit ${ }^{91}$. Einzig die Kinder von Rabia, die schon über zwölf Jahre alt sind, konnten (mussten) sich damit auseinandersetzen. Im Umgang mit dem von den Medien vermittelten Islambild werden daher nur ihrerseits Lösungsvorschläge benannt.

Vorurteile, die beeinflusst durch die Medien in die Öffentlichkeit gelangen und an die Lehrer in der Schule herantreten, werden als besonders unangenehm empfunden. Die Kinder würden dadurch negativ beeinflusst:

"... also einen Menschen, der Moslem ist, da verurteilt oder ..., da wird ja auch öfters viel schlecht geredet und ich finde das ist einfach nicht so [...] oft sind die Medien auch schuld daran, die reden so schlecht darüber und das wird, das kommt ja bei unseren Kindern dann schlecht an." (Rabia, Z.: 530)

Die negative Berichterstattung (»unwahr«, »nicht positiv«, »es ist traurig«, »störend«) in den Medien setze sich »in den Köpfen« der Kinder fest (vgl. Rabia, Z.: 646ff.und Z.: 747-751). Rabia befürchtet einen negativen Einfluss, der durch die Medien und zudem durch das Umfeld herbeigeführt werden könne, sodass die Kinder nicht mehr an ihrer Religion interessiert seien (vgl. ebd., Z.: 735):

"Man muss einfach als Eltern, als gläubige Eltern dranbleiben, dass das nicht so weit kommt. Vor allem als Eltern ist man dann ..., das reicht nicht aus. [...]. Man ist in Sorge, dass man als Eltern da nicht ausreichend an Wissen geben kann, dass das Umfeld die Kinder da mitziehen kann." (Rabia, Z.: 741ff.)

91 | Das geringe Interesse der Kinder von Selma, gleich, ob positiv oder negativ über den Islam berichtet wird ("[...] das interessiert die dann nicht, darauf reagieren die gar nicht"), wird vonseiten des Vaters kritisiert (vgl. Selma, Z.: 666-688). 
So sieht sie als Elternteil die Lösung darin, ihnen genügend Wissen zu vermitteln, um diesen negativen Einfluss zu minimieren. Es solle noch vielmehr Aufklärung in den Schulen (vgl. Kap. III. 5.2) stattfinden. So solle im Umgang mit Muslimen viel stärker differenziert werden, damit erkennbar werde, dass nicht alle Muslime dem medial vermittelten Bild entsprächen (vgl. Mecelle, Z.: 529).

Was den Einfluss auf die religiöse Sozialisation anbelangt, wird ein hemmender Sozialisationseffekt befürchtet, dem religiöses Wissen entgegengesetzt werden solle (vgl. Rabia, oben). Aufgrund des jungen Alters der Kinder in den anderen Familien und zum Teil geringen Interesses kann von keinem weiteren Sozialisationseffekt gesprochen werden.

\subsubsection{Der Umgang mit den Medien - die "Identitätssucher"}

\section{Medien als didaktische Mittel}

Beide Elternteile nehmen im Umgang mit den Medien eine unterschiedliche Position ein. Vertritt Lema eher eine kritische Haltung, so betont Hülya an mehreren Stellen die Bedeutung der Medien für ihre religiöse Erziehung (vgl. auch Kap. III. 4.3). Dabei setzt sie auch betont moderne mediale Interaktionsformen ein, um ihren Kindern die Religion nahezulegen. Alles in allem zeichnet sich ihr Umgang durch einen sehr bewussten Einsatz aus.

Hülya betonte insbesondere das Hören von religiösen Liedern z.B. mit islamischen Glaubensinhalten, die prägend auf ihre Kinder einwirken könnten (vgl. Hülya, Z.: 34/150/254).

Aber auch »Büchlein« mit vielen Bildern (z.B. eines betenden kopftuchtragenden Mädchens) böten ihren Kindern Identifikationsmöglichkeiten ${ }^{92}$ (vgl. ebd., Z.: 44). Auch legt sie Wert auf gut »pädagogisch ausgearbeitete« Lernbücher, mit denen z.B. die arabischen Buchstaben spielerisch erlernt werden könnten (vgl. ebd., Z.: 254). Wenn sie ihren Kindern Geschichten erzählt, werden diese durch Hülya mit ihrem Smartphone aufgenommen, damit die Kinder dadurch eine besondere Wertschätzung für das Nacherzählen der ausgedachten Geschichte erfahren. Die Aufnahmen wurden von ihr auf eine CD gebrannt, sodass sie als Dokument zu einem späteren Zeitpunkt erneut zur Verfügung stünden. Hülya betrachtet diese mediale Form des Geschichtenerzählens als eine Methode, den Kindern Selbstbewusstsein zu vermitteln, da sie auf diese Weise angeregt würden, ihre eigene Geschichte zu erzählen (vgl. Hülya Z.: 274-286).

92 | Es handelt sich ja um Eltern, die nach "Identität" streben und die Entwicklung der Persönlichkeit in den Vordergrund stellen. 
Des Weiteren würden Apps (als Spiele) auf dem Smartphone heruntergeladen, damit die Kinder z.B. arabische Buchstaben als Memory-Spiel auswendig lernen oder arabische Suren hören könnten (vgl. oben, Z.: 70 und Z.: 249-254).

Da der Vater viel Wert auf religiöse Bildung legt, wurden in Hülyas Familie, schon als sie Kinder waren, Filme (Videos) mit religiösem Inhalt (z.B. Prophetenbiografien) angesehen. Auch heute schaue sie mit ihren Kindern religiös motivierte Sendungen des türkischen Senders TRT-Çocuk an und setze ebenfalls entsprechende DVDs ein (vgl. Hülya, Z.: 266).

Die Bedeutung, die die Medien für ihre religiöse Erziehung haben, bringt Hülya folgendermaßen zum Ausdruck:

"Es prägt. Es prägt auf jeden Fall. Es geht bis in das Unterbewusstsein, meine Kinder haben dadurch sehr viel gelernt. So Begriffe wie cami [türk. für Moschee, Anm. d.Verf.] und hoca und kuran; und diese Begriffe alleine lernen Kinder, wenn man sie das wiederholt das Ganze gucken lässt. Kinder mögen Wiederholungen sehr und das habe ich auch gemacht [...]. Das ist çok şükür [türk. Ausdruck für Dankbarkeit, Anm. d. Verf.] und wichtig, ja, ja sehr wichtig, oder das ist schon prägend, deshalb setze ich das bewusst ein [...]." (Hülya, Z.: 272)

Lema ${ }^{93}$ nimmt, im Gegensatz zu Hülya, eine kritischere Haltung gegenüber dem Umgang mit den Medien ein. So müsse an Kinderbücher und das Internet »kritisch « herangetreten werden und eine bewusste Auswahl der zu rezipierenden Literatur und Websites getroffen werden (vgl. Lema, Z.: 253-262). Sie hat in ihrer Wohnung keinen Fernseher. Ihre Ablehnung für das Fernsehen geht sogar so weit, dass sie »allergisch « reagiere, wenn sie irgendwo zu Besuch seien und der Fernseher eingeschaltet werde. Aufgrund der Tatsache, dass sie ohne das Fernsehen mehr Zeit zum Bücherlesen findet und möchte, dass ihr Kind sie darin als Vorbild nimmt, möchte sie auch in Zukunft darauf verzichten:

"[...] aber seitdem wir keinen Fernseher haben, muss ich ehrlich gesagt gestehen, dass wir mehr lesen, ne das ist ja so, dass, dann hat man viel mehr Zeit, dann beschäftigt man sich anders. Ich bin ein Mensch, ich lese auch sehr gerne und ja, das Kind soll es ja auch mitnehmen, finde ich mal." (Lema, Z.: 266)

93 | Bei Lema handelt es sich lediglich um Antizipationen bzw. Prognosen, da sie diesbezüglich noch nicht über Erfahrungen verfügt. 


\section{Die Folgen des von den Medien vermittelten »Islambilds«}

Da die Kinder von Lema und Hülya ${ }^{94}$ noch zu klein sind, kann hier nicht von einem Einfluss des »Islambildes« auf ihre religiöse Sozialisation gesprochen werden. Allerdings tragen beide Elternteile ihre Meinungen und Ansichten zu dieser Thematik vor. Auch werden im Folgenden ihre Erfahrungen als engagierte Pädagoginnen im Umgang mit den Folgen des Islambildes aufgezeigt. Nicht zuletzt sind darin auch Strategien benannt, die in Zukunft angewandt werden sollen.

Das »falsche« Bild über den Islam werde vermittelt, indem die Religion mit der Kultur vermischt werde (vgl. Lema, Z.: 274ff.). Es würden »negative Sachen « über den Islam berichtet, sodass das Fernsehen »mit Vorsicht zu genießen« sei und ein »kritischer Blick« gewahrt werden müsse:

"Diese [...] [Medien, Anm. d. Verf.] haben ja auch ihre ganz eigene Meinung, die möchten das ja dann, dementsprechend dann irgendwie auch so vermitteln, z.B. die Bild-Zeitung; das ist ja so, das ist ja nicht alles da korrekt; die schreiben dann, was wir machen [...], also immer mit Kritik, immer mit kritischem Blick das betrachten, ja." (Lema, Z.: 282)

Auch solle das Kind von klein an »bewusst « erzogen werden, damit es das »wahre Bild« kennenlerne und durch die eigene religiöse Lebensweise und indem es »ein guter Mensch« werde, eine Antwort auf das falsche Bild geben könne: >Mama, wieso sieht sie, sieht sie dich so? <

"[...] wenn das Kind, also ich bin ja der Meinung, dass das Kind inschaAllah [arab. für "So Allah will") also von klein an auf bewusst vielleicht erzieht, erzogen wird, denke ich mal, dann wird es schon auch irgendwo gesehen, dass es auch nicht das wahre Bild ist, wie gesagt, z.B. diese zehn Gebote, was auch im Christentum auch ist, stehle nicht, lüge nicht, töte nicht ${ }^{95}$ etc. Das ist also, dass man einfach versucht, ein guter Mensch zu sein; und das wir ja sehen, also dann wird es sagen: 'Ah Mutter, das stimmt ja irgendwo nicht überein;; aber ich denke, das ist eine Frage der Zeit, das wird hoffentlich mit der Zeit auch beantworten, dass die Menschen es auch sehen werden." (Lema, Z.: 276)

Dem »verzerrten« Bild des Islams werden durch Hülya, ähnlich Lemas Ansatz, durch Aufklärungsarbeit Informationen entgegengesetzt, die es ermöglichen, die »wahre« Seite des Islams zu erleben (vgl. Hülya, Z.: 241 und 288).

94 | Hülya möchte ihre Kinder schützen und "würde es nicht zulassen ", dass ihre Kinder damit konfrontiert werden. Dies sei mehr eine "Erwachsenensache" (vgl. Hülya, Z.: 288).

95 | Hier wird nochmals ein Bezug zum Christentum hergestellt, wase typisch für diese Gruppe ist. 
So sieht sie, sich dabei auf ihre Erfahrungen berufend, gerade in alltäglichen Begegnungen eine Chance, der »negativen Darstellung des Islams und der Muslime« ein »anderes Bild« entgegenzusetzen:

"[...] und ich glaube, [...], dann könnte man viel schaffen, wenn man auch nicht nur durch die Medien den Islam so negativ kennt, sondern auch direkt vom Menschen Positives weiß, kennenlernt.." (Hülya, Z.: 288)

\subsubsection{Der Umgang mit den Medien - die "Ethiker"}

\section{Medien als didaktische Mittel}

Es sind Bücher, die Ethiker (Adem, Feride, Belkıs) vorzugsweise in ihrer religiösen Erziehung einsetzen. Medien spielen, gemäß ihren Aussagen, für die religiöse Entwicklung ihrer Kinder eher eine untergeordnete Rolle. Es kommen zwar neben Büchern auch andere Medienformen zum Einsatz, doch spielen sie entweder eine sehr geringe Rolle oder sie müssten stärker kindgemäß aufbereitet werden, damit die Wirkung nicht verfehlt werde. Mit einer Ähnlichkeit, wie sie ihre Erwartungen bzgl. einer höheren Professionalisierung der religiösen Erziehung in Moscheegemeinden usw. (vgl. Kap. III. 5.2) aussprechen, erwarten sie daher eine Verbesserung der Medien als didaktische Mittel (CDs, Bücher, Spiele-DVDs).

Wie schon erörtert wurde (vgl. Kap. III. 4.4 »Methoden [...]«), sorgen Bücher bzw. auch Zeitschriften in den Familien für Gespräche und eine Kommunikation über religiöse Themen. Dabei werden den jüngeren Kindern abends Geschichten bzw. Korangeschichten (vgl. Belk1s, Z.: 72 und 359ff.) oder »Geschichten, die ein bestimmtes Wertesystem « vermitteln (vgl. Feride, Z.: 8 gff. und Z.: 420), vorgelesen. Zudem verweist Birol auf den Bedarf an Büchern für Kleinkinder. Demnach hätte er sich für seinen zweijährigen Sohn Bücher, die eben religiöse Motive aufzeigen, mit Abbildungen, wie bspw. einer Moschee, gewünscht:

"Denke mal, das sind so die ersten Sachen, [wären zumindest, Anm. d. Verf.] die ersten zaghaften Motive, sodass sie mit religiösen Symbolen oder Motiven eben auch in Berührung gekommen wären; gab es halt nicht." (Birol, Z.: 343)

Mit den bereits älteren Kindern wird in Adems Familie die gemeinsame Zeit genutzt, um sich über religiöse Bücher auszutauschen. Methodisch bezieht er sich insbesondere gerne auf die Quellen des Islams, d.h. Koranverse und die Überlieferungen des Propheten (s). Auch werden verschiedene Bücher miteinander verglichen (vgl. Adem, Z.: 28/56/221). Das Internet diene seinen Kindern dazu, verschiedene Aspekte des Islams zu erforschen (vgl. Adem, Z.: 50-54 und Z.: 221). 
Überdies würden CDs mit religiösen Liedern gehört (vgl. Feride, Z.: 424432; Melek, Z.: 676ff.). Es kämen (Zeichentrick-)Filme (DVDs) mit religiösen Motiven (Korangeschichten) zum Einsatz, die zum Teil für ein »Nachbesprechen« sorgen würden (vgl. Feride, Z.: 420ff.); oder sie sind so schlecht gemacht und ziehen daher eine Kritik der Eltern und ihrer Kinder nach sich, »[...] da ist sehr viel Aufholbedarf in dem Bereich« (vgl. Belk1s, Z.: 373 und Melek, Z.: 683-686).

Kritik wird auch an Lern-CDs, die auf dem PC abgespielt werden, geübt. Diese bezog sich zum einen auf die arabischen Buchstaben, »[...] das hat nicht viel gebracht, das war gar nichts für meine Tochter«) (vgl. Belk1s, Z.: 363). Lernspiele mit religiösen Motiven seien zudem z.B. bei Ferides Sohn nicht gut angekommen (vgl. Feride, Z.: 434).

Für einen Teil der Eltern spielen Medien, ausgenommen Bücher (Belkıs), in der religiösen Erziehung keine Rolle (vgl. Belk1s; Birol, oben; Melek, Z.: 683$\left.{ }_{6} 96\right)$ und üben folglich auch keinen Einfluss auf die religiöse Sozialisation aus: »Also ich glaube, wenn da ein besseres Angebot wäre, hätte ich das wohl eher genutzt [...]«(Belk1s, Z.: 373).

Auf einen anderen (Eltern-)Teil üben sie, wenn auch im Vergleich zu anderen Eltern bzw. Typen, einen lediglich geringeren Einfluss aus. Dabei dienen für Feride z.B. eine »religiöse $C D$ « oder Bücher mit religiösen Motiven dazu, dass sie eine »Normalität« bzw. »Selbstverständlichkeit« im Alltag, neben anderen nichtreligiösen Angeboten darstellen (vgl. Feride, Z.: 446).

Für Adem wiederum ist der Umgang mit den Medien wichtig, damit die Kinder »selbstständig« auf »Informationen zurückgreifen« könnten (vgl. Adem, Z.: 227; vgl. auch Kap. III. 4.4 »Erziehungsstile [...]«).

\section{Die Folgen des von den Medien vermittelten »Islambilds«}

Was den Umgang mit dem Islambild in den Medien angeht, handelt es sich bei den Ethikern um eine sehr reflektierte Gruppe, die sich bewusst Gedanken über die Folgen der vonseiten der Medien übertragenen Bilder macht. Jedoch zeigen sie, auch wenn einige Wünsche deutlich gemacht werden, weniger Strategien auf, wie sie heute oder in Zukunft mit der negativen Darstellung des Islams umgehen möchten. Dies könnte auch damit zu tun haben, dass die meisten Kinder jünger als zehn Jahre sind und davon »noch« unbeeinflusst bleiben. Bei den älteren Kindern (von Adem und Melek) findet eine Reflexion statt, die es ihnen erlaubt, zu unterscheiden, dass diese transportierten Bilder nichts mit dem von ihnen gelebten Islam zu tun hat.

Sehr negativ fallen den Eltern die Vorurteile und Klischees (z.B. Ehrenmorde oder unterdrückte Frauen, Zwangsverheiratung) über Muslime und den Islam auf. Dabei zeigen die Ethiker, wie es jeweils typisch für ihre Gruppe ist, unterschiedliche und individuelle Wahrnehmungsmuster auf. 
Die Vorurteile, Klischees bzw. das »Hetzerische«, das von den Medien übertragen wird, bewirke, dass »der größte Teil« der nichtmuslimischen Bevölkerung »eher negativ zu dem Islam steht« (vgl. Belkıs, Z.: 385) oder nicht gut über den Islam denke. Auch werde der Islam in den Medien zumeist mit Gewalt und Terror in Verbindung gebracht:

"[...] mit Gewalt und negativ behafteten Themen in Zusammenhang gebracht und selbst wenn man in einem Beitrag mal liest, dass der Islam mit Gewalt und Terror nichts zu tun hat, steht Islam und Terror eben in ein und demselben Artikel. Ja? Und das führt eben dazu, dass das Bild eben nicht unbedingt positiv ausfällt über den Islam." (Birol, Z.: 370)

So haben diese Medienbilder auch diverse Auswirkungen auf die muslimische Bevölkerung selbst. Neben dem Gefühl, hier nicht heimisch zu werden, (»[...] ich habe so das Gefühl, dass es immer mehr Leute gibt, die eben nicht wollen, dass ich hier lebe, als das es solche gibt, die das möchten«) (vgl. Belkıs, Z.: 380), wird ein zunehmender Rechtfertigungsdruck, denen die Kinder ausgesetzt werden könnten, befürchtet. Dabei könne die negative Darstellung des Islams womöglich dazu führen, dass sich das Kind von der Religion abwende und das Bedürfnis entwickele, »seinen muslimischen Glauben irgendwie verheimlichen zu müssen«:

"Zum einen beeinflussen die Medienbilder mein Kind direkt erst mal, die beeinflussen aber auch seine Umgebung, also die Menschen um es herum, so in der Schule und später auf der Arbeit und für es selbst hoffe ich, dass es sich niemals (zögerlich) so fühlt, dass es sich irgendwie rechtfertigen muss. Weil eben schlechte Bilder vermittelt werden, dass es damit deswegen vielleicht sogar eine Abneigung entwickelt oder dass er sich schämt oder meint, seine Religiosität oder seinen muslimischen Glauben irgendwie verheimlichen zu müssen oder irgendwie so etwas. Ich hoffe, dass das nicht passiert, weil eben immer sehr negativ dargestellt wird ... die Religion, also der Islam vor allem." (Birol, Z.: 353)

Diese negativen Bilder würden bis ins Unterbewusstsein der Kinder befördert, sodass das »Antiislamische« in einer erschreckenden Weise zur »Normalität« werde. Dabei sollten z.B. wie in der Weihnachtszeit, in der religiös motivierte Sendungen üblich seien, auch muslimische religiöse Symbole bzw. die »Aufklärung « über die islamische Religion, angesichts der Anzahl der hier lebenden Muslime, eine »Selbstverständlichkeit« darstellen (vgl. Feride, Z.: 461-473).

Durch die negativen Berichterstattungen würden zudem alle Muslime in »einen Topf « geschmissen, sodass z.B. kulturell motivierte Handlungen allgemein auf den Islam und die Muslime zurückgeführt würden. Diese undifferenzierte Berichterstattung mache die Kinder von Adem »sehr traurig«: 
"Die Kinder sind natürlich über diese Situation auch sehr traurig und sie verstehen nicht, warum es so negativ wieder dargestellt, nicht so originalgetreu dargestellt wird [...]." (Adem, Z.: 232)

Auch die Tochter von Melek kann unterscheiden, dass die Berichte nichts mit dem von ihr gelebten Islam zu tun haben (»Sie weiß der Islam, den ich kennengelernt habe, das stimmt nicht mit dem überein. Das ist was anderes. Dann sagt sie, das, was ich erlebe, ist richtig«) (vgl. Melek, Z.: 728) und es macht sie ebenso »traurig« wie Adems Kinder. Melek versucht die Tochter zur »richtigen« Lebensweise zu motivieren, damit ein anderes Islambild entsteht:

"[...] sie weiß: 'Mama, der Islam ist aber nicht so،. Und ich sage: ,Das wissen wir ja, aber es gibt auch sehr viele Menschen, die den Islam nicht möchten, Büsra. Das war immer so! Das musst du auch so akzeptieren! Du musst versuchen, den Islam so gut wie möglich zu leben und du musst versuchen, den Islam auch so den anderen, deinen Mitmenschen weiterzugeben. Aber das ist immer, weil, solche Sachen erleben wir, damit musst du dich abfinden. Das ist, das gehört zum Leben leider dazu Ich glaube, das hat sie auch, mittlerweile akzeptiert. [...] Es macht sie sehr traurig! (Melek, Z.: 704ff.)

Schließlich wünscht sich Birol für seinen Sohn, dass er »selbstbewusst und offen « mit der Situation umgeht und sich so viel Wissen aneignet, um zu erkennen, dass diese »Bilder« nicht der Wahrheit entsprechen. Außerdem soll er in keine unangenehme Situation ${ }^{96}$ gebracht werden (vgl. Birol, Z.: 353 ).

Wie deutlich wird, werden vereinzelt Bewältigungsstrategien bzw. Umgangsformen aufgezeigt und es findet eine Reflexion statt, die den Kindern bezogen auf ihre eigene »Wahrheit« eine Selbstverortung ermöglicht. Dennoch verhalten sich Ethiker im Vergleich $\mathrm{zu}$ anderen Eltern (»Idealisten«, »Identitätssucher«), (»[...] musst du dich abfinden«, vgl. Melek oben) eher zurückhaltend und streben keine aktive Auseinandersetzung mit den Medien an.

Die Jugendlichen (Kinder von Adem, Melek) nehmen die negativen Islambilder mit Bedauern und Trauer auf, jedoch hat dies keinen Einfluss auf die religiöse Sozialisation, da sie dazu angeregt wurden, zwischen den vermittelten Bildern und der eigenen Wahrnehmung zu unterscheiden bzw. diese Thematik entsprechend zu reflektieren.

Die Sorge von Birol, dass der Sohn sich aufgrund negativer Islambilder von der Religion abwenden bzw. sich schämen oder seine Religion verheimlichen könnte, deutet jedoch auf einen potenziell befürchteten (hemmenden) Sozialisationseffekt hin.

96 | An dieser Stelle schildert Birol seine unangenehmen Erfahrungen mit Vorurteilen. 


\subsection{Die religiöse Sozialisation in einer pluralistischen Gesellschaft}

In diesem Kapitel werden Aspekte des Zusammenlebens von Muslimen und Nichtmuslimen in dieser Gesellschaft ausführlicher verhandelt. Dass dabei aufgrund des Umfangs und der Vielschichtigkeit der Themen keine tiefergehende Analyse erfolgen kann, sondern eher zusammenfassend (deskriptiv) Einstellungs- und Wahrnehmungsmuster wiedergegeben werden, hängt mit dem Thema »Sozialisation « zusammen. Ohne zu erwähnen, in welchem »Rahmen« die religiöse Sozialisation von muslimischen Kindern stattfindet, d.h., welche Themen im gesellschaftlichen Kontext für muslimische Eltern vordergründig sind, hätte ein grundlegender Pfeiler der Sozialisation gefehlt. Allerdings wurde aufgrund der Vielzahl der angesprochenen Themen deutlich, dass hier weiterführende Analysen erforderlich sind, um eindeutige Wechselwirkungsmechanismen aufzeigen zu können. Themen, wie bspw. Diskriminierung, Islamfeindlichkeit, Rassismus usw., die auf komplexe Zusammenhänge verweisen und die an sich schon eigenständige Untersuchungsgegenstände darstellen, können demgemäß im Rahmen der vorliegenden Dissertation nicht angemessen beschrieben werden.

Folglich wird ohne jegliche Ausführung wieder typspezifisch beschrieben, welche Themen und Aspekte auf der gesellschaftlichen Ebene für muslimische Eltern von Bedeutung sind und welche Konsequenzen diese für ihre Kinder oder für die religiöse Sozialisation haben.

Im Bereich des Zusammenlebens werden die Nachbarschaftsbeziehungen und der Kontakt zu Andersgläubigen thematisiert. Diese deuten auf den Umgang mit der nichtmuslimischen Umwelt hin. Auch hier sind unterschiedliche Verhaltensmuster und Umgangsformen, wie sie bezogen auf die anderen Sozialisationsinstanzen deutlich wurden, feststellbar und decken sich zumeist mit ihren Vorstellungen in anderen Sozialisationskontexten (z.B. Thema Schule, Interreligiöse Begegnungen, Peers, Medien).

Auch die Wahrnehmung, wie (einheimisch) Deutsche zum Islam stehen, betrifft das Zusammenleben (oder gar die Integration) der Muslime in dieser Gesellschaft. Die zumeist negative Wahrnehmung der Eltern korrespondiert mit dem negativen Islambild, welches über die Medien in die Gesellschaft transportiert wird (vgl. Kap. III. 5.5). Hier scheinen Mechanismen aufeinander zu wirken, die eine tiefergehende Untersuchung erforderlich machen.

Inwiefern die Familien und ihre Kinder ihre Religion in dieser Gesellschaft ausleben können, welchen Herausforderungen sie sich stellen müssen bzw. welche Chancen sich auftun, deuten auf Vor- und Nachteile der religiösen Sozialisation in dieser Gesellschaft hin.

Schließlich verweist der allerletzte Aspekt, welche Leistung die religiöse Erziehung für die Gesellschaft erbringen kann, primär auf den Wunsch, ein 
möglichst reibungsloses konstruktives Zusammenleben in dieser Gesellschaft zu erreichen. Hier wird auch die grundlegende Position der Eltern zur deutschen Gesellschaft deutlich.

Zusammengefasst handelt es sich um folgende Aspekte:

- Nachbarschaftbeziehungen und der Kontakt zu Andersgläubigen

- Die Wahrnehmung der Eltern, wie Deutsche zum Islam stehen

- Vor- und Nachteile der religiösen Sozialisation in dieser Gesellschaft

- Religiöse Erziehung in der Gesellschaft

- Der zweite Punkt wird tabellarisch wiedergegeben und kommentiert.

\subsubsection{Die religiöse Sozialisation in der Gesellschaft - die "Idealisten"}

\section{Nachbarschaftbeziehungen und der Kontakt zu Andersgläubigen}

Die Idealisten folgen unterschiedlichen Mustern der Nachbarschaftspflege. Dabei variieren unter den befragten Eltern die Form und die Intensität des Kontaktes. Es fällt bei einem Teil der Eltern ihr aktives Engagement für einen Austausch mit ihren nichtmuslimischen Nachbarn auf.

Ethem hat beispielsweise mehr Kontakt zu den muslimischen als zu nichtmuslimischen Nachbarn, mit denen, je nach Vertrauensverhältnis, ein Austausch stattfindet. Auch übernachten die Kinder jeweils gegenseitig beim anderen zu Hause (vgl. Ethem, Z.: 393-402).

Die nichtmuslimischen Nachbarn werden gegrüßt und die Beziehung findet eher auf »Bekanntschaftsebene« statt (vgl. ebd., Z.: 402; vgl. Dilek, Z.: 242).

Nermin und Nisa pflegen einen "guten« und »netten« Kontakt zu ihren nichtmuslimischen Nachbarn. Die Kinder besuchen sich auch gegenseitig, sodass Nermin nicht nur Nachbarn besucht, sondern vielmehr die »Eltern« (»[...] aber durch die Kinder besuche ich halt nicht nur Nachbarn, sondern auch die Eltern der Kinder oder so «) (vgl. Nermin, Z.: 672). Zudem findet ein Austausch über die Religionen statt. Es wurde z.B. über das »Kopftuch« der Tochter gesprochen oder über den Nikolaus:

"[...] Also ist dann schon sehr neugierig und fragt bewusst nach und zum Beispiel, wie ich dann dazu stehe: Nikolaus oder so. Es gibt ja auch Familien, wo die nicht möchten, dass das Kind dann beim Nikolaus da ist. Die fragt dann nach meiner Meinung und wir tauschen uns aus." (Nermin, Z.: 678)

Die Tatsache, dass Nermin ein Kopftuch trägt, führt zur Vorurteilsbildung bei einem weiteren nichtmuslimischen Nachbarn $(»[. .$.$] wir haben oben eine, die$ schimpfen und schimpfen über uns, ich bin die Einzige mit Kopftuch mit den anderen Türkinnen und so verstehen die sich, aber mit mir ...«), zu dem kein Kontakt besteht (vgl. ebd., Z.: 720). 
Ähnlich wie bei Nermin, waren aufgrund ihres äußeren Erscheinungsbildes (Kopftuch) Ängste bei den Nachbarn von Nisa vorhanden, die sie durch aktive Kontaktaufnahme abbaute. Sie tauscht sich trotz sprachlicher Schwierigkeiten mit ihren Nachbarn über ihre Religion aus. Auch motiviert sie ihre Kinder zum aktiven Austausch (vgl. Nisa, Z.: 134).

Für Lale findet der Austausch über ihre Religion durch Handlungen und durch das Vorleben der Religion statt (»Hoffentlich [...], die werden uns noch kennenlernen, wenn wir unsere Religion richtig so ausüben. Unsere Menschlichkeit sehen [...]«) (vgl. Lale, Z.: 971). Lale setzt daher besonders stark auf die zwischenmenschlichen Aspekte der Nachbarschaftspflege, sodass sie ihre Beziehung zu ihnen durch Hilfsbereitschaft, gegenseitiges Beschenken, Teilen an muslimischen Festtagen oder Grillveranstaltungen und sogar durch die Teilnahme am Begräbnis des nichtmuslimischen Nachbars pflegen möchte (vgl. Lale, Z.: 828ff.).

Dadurch trug sie dazu bei, auch wenn sie den ersten Schritt machen musste, dass Vorurteile abgebaut und das Vertrauen der Nachbarn gewonnen werden konnte:

"[...] Das glauben wir, als wir da eingezogen sind, hatten sie viele Vorurteile gegen uns, manche haben sogar nicht gegrüßt, aber mit der Zeit haben die gelernt, wir sind doch anders. [...] Also die haben nie gedacht, dass wir so sein könnten. Wenn wir den nicht kennengelernt hätten, hätten wir andere Vorstellungen, ja zum Glück haben wir das geschafft. Dass wir z.B, wenn wir z.B. was gegrillt haben, haben wir immer was abgegeben. Oder wir hatten z.B. sehr viele Obstbäume, ne, immer wieder wollt ihr sowas [...].» (Lale, Z.: 824)

Trotz ihres großen Engagements gibt es auch Nachbarn, zu denen sie ein schlechtes Verhältnis hat. Lale führt dies auf den negativen Einfluss der Medien zurück (vgl. ebd., Z.: 89o). 


\begin{tabular}{|c|c|}
\hline Themen & $\begin{array}{l}\text { Wie äußern sich Themen? } \\
\text { Für Eltern }\end{array}$ \\
\hline Ablehnung/Hass & $\begin{array}{l}\text { - Wahlplakat von Pro Köln NRW: für Eltern »dramatisch«, da Kinder } \\
\text { mit Entsetzen auf Ablehnung reagieren; Tochter fragt nach; Sohn: } \\
\text { »Wollen die jetzt unsere Moschee kaputt machen?« Signale und Symbole } \\
\text { wirken auf Kinder sehr negativ (Ethem, Z.: } 74 \text { und Z.: 446) } \\
\text { - Institutionelle Gruppenrechte nicht gewährt (z.B. Konflikte } \\
\text { im Moscheebau: Sichtbarkeit von religiösen Symbolen nicht erwünscht), } \\
\text { religiöser Pluralismus nicht vorhanden (Ethem, Z.: 46off.) } \\
\text { - Gesellschaft akzeptiert Muslime nicht } \\
\text { (Nermin, Z.: 6oo und 720; Dilek, Z.: 258) } \\
\text { - Ablehnung aufgrund des Kopftuches } \\
\text { (Nermin, Z.: 598; Lale, Z.: 9o8-922; Dilek, Z.: 268) } \\
\text { - Vorurteile aufgrund ethnischer oder religiöser Zugehörigkeit } \\
\text { (Nermin, Lale) } \\
\text { - Medien unterstützen Vorurteilsbildung } \\
\text { (Lale; Nisa, Z.: 179) } \\
\text { - Potenzieller Rassismus der Deutschen } \\
\text { (Dilek, Z.: 260-266) }\end{array}$ \\
\hline Gleichgültigkeit & $\begin{array}{l}\text { - Nährboden für Krisensituationen und Vorurteile } \\
\text { (Ethem, Z.: 450) }\end{array}$ \\
\hline $\begin{array}{l}\text { Fremdheitsgefühle/ } \\
\text { Diskriminierung }\end{array}$ & $\begin{array}{l}\text { - Islam wird als Fremdkörper wahrgenommen: Der Islam gehört nicht dazu } \\
\text { (Ethem, Z.: 452). Es erfolgt keine Integration des Islams in die Gesell- } \\
\text { schaft; Folgen: Ausgrenzung der Muslime } \\
\text { - Diskriminierung bei der Wohnungssuche: eine muslimische Familie mit } \\
\text { fünf Kindern, die Frau trägt Kopftuch } \\
\text { (Nermin, Z.: } 318-340 \text { ) }\end{array}$ \\
\hline $\begin{array}{l}\text { Angst vor } \\
\text { dem Fremden }\end{array}$ & $\begin{array}{l}\text { - Angst vor dem Islam bzw. »Fremden« (Nermin, Z.: 724; Lale, Z.: 967-971) } \\
\text { - Angst führt zur Diskriminierung der Muslime (Ethem, Z.: 454-456) } \\
\text { - Angst führt zu Vorurteilen (Lale) }\end{array}$ \\
\hline $\begin{array}{l}\text { Respekt vor } \\
\text { der Religion (Islam) }\end{array}$ & - Respekt vor der Religion (Lale, Dilek) \\
\hline
\end{tabular}

Tab. 5: Die Wahrnehmung der Eltern, wie Deutsche zum Islam stehen (Quelle: eigene Darstellung)

Auch wenn hier mehrere Aspekte aufgrund der Übersichtlichkeit tabellarisch wiedergegeben wurden, sind Wechselwirkungen zwischen diesen Aspekten bzw. wahrgenommenen Themen vorhanden, sodass hier verschiedene Mechanismen aufeinander wirken, die wiederum eigenständige Untersuchungsbereiche darstellen.

Wie der Tabelle zu entnehmen ist, haben einige Eltern das Gefühl, dass ihre Religion respektiert wird, aber es überwiegt das Gefühl der Ablehnung von Muslimen, deren Ursachen und Hintergründe vielfältig sind. 
Trotz vieler Einschränkungen (vgl. oben) und Nachteile, die sich aus dem Zusammenleben in dieser Gesellschaft ergeben, können die Eltern ihre Religion gut ausleben (alle Eltern). Positiv wird insbesondere die individuelle Religionsfreiheit erlebt (vgl. Ethem, Z.: 460; Lale, Z.: 913-916; Nisa, Z.: 181-184). Dabei könnten die Kinder aufgrund dieser Freiheit z.B. mit dem Kopftuch die Schulen besuchen (vgl. Dilek, Z.: 272; Nisa, Z.: 183; Nermin, Z.: 744).

Gerade das Gemeindeleben, das in Deutschland im Vergleich zum Heimatland eine höhere Bedeutung hat und daher eine engere Bindung unter den Muslimen ermöglicht, ergebe sich als ein positiver Effekt der Minderheitensituation von Muslimen (vgl. Dilek, Z.: 272; Nisa, Z.: 184 und Z.: 191).

Eltern wie Lale, Nisa und Dilek betonen den Gemeinschaftsbezug (vgl. oben, vgl. auch Kap. III. 5.1). Die Kinder könnten sich frei für das Gemeindeleben entscheiden, könnten beten usw. (vgl. Lale, Z.: 928; vgl. auch Kap. III. 5.1). Dass ihre Kinder »selbst entscheiden« könnten, d.h., dass sie die individuelle Religionsfreiheit genössen, sei ein Vorteil, den die Eltern und ihre Kinder insbesondere in Deutschland hätten: »Ich kann entscheiden, wo ich das Kind hinbringe, wie ich es mache; es ist schon ein großer Vorteil« (vgl. Lale, Z.: 930ff.).

Für die Kinder von Ethem ist Deutschland das Land, wo sie aufgewachsen sind: »[...] also die haben nichts anderes gekannt, auch ich habe nichts anderes kennengelernt [...]. Also für die ist das das Umfeld, in dem sie aufgewachsen sind « (vgl. Ethem, Z.: 465).

Nermin vermittelt ihren Kindern ein Gefühl, angenommen und akzeptiert zu sein, trotz der von ihr sehr stark wahrgenommenen Diskriminierungen von Muslimen (vgl. Nermin, oben). Hier wird die Mutter aufgrund ihres Schutzbedürfnisses (die Kinder sollen sich wohlfühlen) in eine ambivalente Situation gedrängt:

"Die Kinder? Ja, ich glaube, die sehen das so, wie ich als Kind das gesehen habe. Ne, die sind ein Teil der Gesellschaft und ich versuche denen nie Zweifel zu lassen was ich fühle, ich sage z.B. nicht [bewusst, Anm. d. Verf.], , Nee, hört mal, es gibt eine Islamfeindlichkeit oder so, da versuche ich schon, mich zurückzunehmen und zu sagen: 'Nein! Wir leben hier in dieser Gesellschaft. Wir sind ein Teil der Gesellschaft und wir sind hier angenommen und akzeptiert, obwohl ich das nicht so empfinde (leise). (Nermin, Z.: 732ff.)

\section{Vor- und Nachteile der religiösen Sozialisation in dieser Gesellschaft}

Die Vorteile, die Eltern für die religiöse Erziehung ihrer Kinder sehen, überschneiden sich mit den eben beschriebenen Aspekten, die das Ausleben ihrer Religion bzw. ihre muslimische Lebensweise betreffen. Wiederholungen konnten daher nicht vermieden werden.

So stellt Deutschland für Nermin, trotz gefühlter Diskriminierung (vgl. oben), »die Heimat irgendwo« dar. Sehr gut gefallen Nermin die positiven As- 
pekte der deutschen Kultur, wie die Ordnung oder das »Belesene«, das sie auch an ihre Kinder weitergeben möchte (vgl. Nermin, Z.: 744-748).

Neben dem aktiven Gemeindeleben, an dem sie im Vergleich zur Türkei in Deutschland besser teilnehmen könnten (vgl. Nisa und Dilek oben), sei die Wissensaneignung als Resultat der aktiven Teilnahme an der Gemeinschaft ein Vorteil (vgl. Dilek, Z.: 276). Da man in einer nichtmuslimischen Umwelt lebe, müsse man »präventiv« vorgehen und handeln und erziele dadurch eine engere Bindung zur Religion (vgl. Nisa, Z.: 184-188).

Es gibt jedoch auch Einschränkungen und Nachteile, die Erschwernisse oder hemmende Faktoren für die religiöse Erziehung bzw. Sozialisation darstellen können.

Auch wenn Nermin Deutschland als die »Heimat« bezeichnet (vgl. Nermin, oben), könne gerade durch die Entwicklungen der letzten Jahre, in denen die Islamfeindlichkeit und die Diskriminierung zugenommen hätten, kein eindeutiges Zugehörigkeitsgefühl empfunden werden. Für Nermin bedeutet dies zugleich Heimatlosigkeit bzw. gespaltene Gefühle:

"[...] und ein Nachteil ist auch, dass man halt weder Deutsch noch Türkisch ist, weder zum einen noch zum anderen gehört. Das sind so die Nachteile, wo ich, ja, yersiz yurtsuz [türk. für heimatlos, Anm. d. Verf.] so sage ich immer. [...] auch gespalten. Ja. So fühle ich mich, als Kind habe ich mich nicht so gefühlt, aber ich fühle mich schon heimatlos ein bisschen und kann sein, dass das die Kinder auch so ein bisschen spüren. Die fragen mich zwischendurch: 'Sind wir Türken oder sind wir Deutsche? Ist vielleicht nicht so von Bedeutung, was man da jetzt antwortet, aber es ist schwierig, überhaupt darauf etwas zu antworten." (Nermin, Z.: 752-756)

Es sind die (potenziellen) Ausgrenzungs- und Diskriminierungserlebnisse und die geringe Akzeptanz von »Religiosität«, denen die Kinder ausgesetzt seien und die sich demnach nachteilig auf die religiöse Erziehung auswirken könnten (vgl. Ethem, Z.: 471ff.; vgl. Nermin, Z.: 598-602).

Ferner werden Einschränkungen, die die Einhaltung von religiösen Vorschriften erschweren, als Hemmfaktoren betrachtet. Diese betreffen zum einen die unterschiedliche Sexualmoral (vgl. Dilek, Z.: 287; Nisa, Z.: 188) und zum anderen die Ausübung der Gebetspraxis bzw. der muslimischen Speisevorschrift (vgl. Nermin, Z.: 730).

Auch »Verlustängste« werden gespürt, sodass sich Nisa schon Sorgen machte, ob ihre Kinder »verloren« gehen könnten, d.h., dass sie sich z.B. unter dem Einfluss der Schule von der Religion abwenden könnten. Durch die negativen Einflüsse werde viel »verändert« (türk. tahrif olmak). Die zunehmende Individualisierung und der Egoismus seien z.B. das Ergebnis dieser Veränderung (vgl. nächstes Teilkapitel, vgl. Nisa, Z.: 150). Allerdings sind es gerade diese Verlustängste, die bei Nisa u.a. zu einem höheren Gemeinschaftsbezug 
führten und die so ins Positive umgewandelt wurden (vgl. oben). Daher könnte darin auch ein fördernder Effekt im Hinblick auf die religiöse Sozialisation gesehen werden.

\section{Religiöse Erziehung in der Gesellschaft}

Die religiöse Erziehung kann gemäß den Eltern für das Zusammenleben in der Gesellschaft viele Vorteile bringen. Demnach ist ein Großteil der idealistischen Eltern davon überzeugt, dass die religiöse Erziehung ihrer Kinder für ein friedliches Zusammenleben in dieser Gesellschaft sorgen und zu einem »positiven Miteinander« beitragen kann:

"Ja, ein positives Miteinander auf jeden Fall, ne, dass man ..., also unsere Religion ist ja eigentlich so, dass man positiv auf die anderen Religionen auch eingeht und diese auch akzeptiert und ne, wie ich gesagt habe, hatte ich ja schon im Vorfeld meine Wünsche zu der religiösen Erziehung meiner Kinder geäußert. Dass da wirklich eine positive Gesellschaft daraus entsteht." (Nermin, Z.: 760)

Werthaltungen, die dem Islam zugrunde liegen, wie Toleranz, Respekt, Solidarität, Ehrlichkeit, Offenheit, Hilfsbereitschaft und das Teilen mit anderen Menschen, könnten durch das Engagement von religiösen Menschen aufleben (vgl. Nermin, Z.: 766; Lale, Z.: 942; Nisa, Z.: 148; Dilek, Z.: 287-297). Gerade gegenseitiger Respekt der Religionen und der Menschen und die zwischenmenschlichen Aspekte des Islams würden für ein »friedliches Zusammenleben« sorgen:

"Es ist meine Religion und eure Religion ist auch ..., davor haben wir auch Respekt, alle sollten uns so akzeptieren, wie wir sind, wie die auch sind, müssen wir auch akzeptieren, miteinander leben, menschlich miteinander leben, sich respektieren, menschlich miteinander umgehen, behilflich sein, das sollte so sein. [...] denn Religion ist ja das [...]. Achte darauf! Achte darauf, dass du so Nachbarn [...] gut behandelst, niemandem schadest, niemanden angreifst. Religion ist normalerweise da [...] Ja, ein Modell [...] für uns alle." (Lale, Z.: 944-956)

An diesem Interviewabschnitt wird nochmals verdeutlicht, dass die Religion bzw. die Einhaltung von religiösen Geboten, die sich auf sozialethische Aspekte beziehen, einen Menschen vor Grenzverletzungen schützen. Menschenrechtsverletzungen könnten durch ein modellhaftes Vorleben der Muslime erst gar nicht entstehen (vgl. ebd.). Durch eine religiöse Erziehung wisse der Einzelne, dass Gott und seine Engel ihn beobachten würden, so könne er allein aufgrund dieser Tatsache keine Regelverletzungen oder Gesetzesübertretungen begehen. Eine solche Grundhaltung führe schließlich dazu, dass eine 
»Gesellschaft sich verbessert« (türk. toplum düzelir) und ein friedliches Miteinander möglich werde (vgl. Nisa, Z.: 193).

So bringe religiöse Erziehung, auf der Grundlage des »Verstandes« und des »Intellekts«, »verantwortungsvolle Menschen« hervor, die eine »Wohltat« für das Umfeld und insgesamt die Gesellschaft darstellen und wovon diese schließlich nur profitieren könne (vgl. Ethem, Z.: 475).

Auch Werthaltungen, wie z.B. der Familialismus und die muslimische Sexualmoral, können, so Dilek, eine Bereicherung für die Gesellschaft darstellen. Mit dem Familialismus der Muslime könne den Individualisierungstendenzen in der deutschen Gesellschaft entgegengewirkt werden (vgl. Dilek, Z.: 287-297). Besorgniserregend findet auch Nisa die zunehmende Individualisierung und den Egoismus in dieser Gesellschaft, von denen ihre Kinder nicht unberührt bleiben. So wünscht sie sich, dass durch die religiöse Erziehung das Schlechte mit dem Guten verwehrt bzw. überwunden wird und eine stärkere Mitmenschlichkeit und gegenseitige Fürsorge entstehen (vgl. Nisa, Z.: 148ff.).

\subsubsection{Die religiöse Sozialisation in der Gesellschaft - die "Ritualisten"}

\section{Nachbarschaftbeziehungen und der Kontakt zu Andersgläubigen}

Auch bei den Ritualisten sind unterschiedliche Muster der Nachbarschaftspflege vorhanden. Allen ist gemeinsam, dass kein Austausch über ihre Religion mit ihren nichtmuslimischen Nachbarn stattfindet.

Sie pflegen entweder gar keinen Kontakt zu den Nachbarn (vgl. Rabia, Z.: 706-709) oder die Beziehungen sind von einer unterschiedlichen Intensität, die jeweils von den Personen bzw. vom Alter abhängt:

"[...] Na ja, es gibt einige Nachbarn, die sind okay. Dann pflegt man schon. Da ist eine ältere Dame, da hat meine Frau mehr Kontakt; geht auch hin, hilft ihr auch, die hat auch vieles für sie getan, also, ne. Da ist schon der Kontakt, da ist schon; und ein Ehepaar, deutsches Ehepaar ist auch sehr nett, höflich; sind also mehr ältere Leute und mit jüngeren Leuten hat man eher weniger Kontakt." (Mecelle, Z.: 502f.)

$\mathrm{Zu}$ ihren muslimischen Nachbarn hat Selma einen intensiven Kontakt, wobei für sie die strenge Einhaltung der religiösen Gebote ein wichtiges Kriterium ist. $\mathrm{Zu}$ den eher »lockeren« muslimischen Familien hält sie Abstand, weil sie nicht möchte, dass ihre Kinder in einen »Zwiespalt« geraten könnten:

"Eigentlich sehr gut, sehr eng, also, wenn ich merke das sind sehr so strenge muslimische Nachbarn wie ich, treffen wir uns sehr oft, aber wenn es so eine lockere Familie ist, dann halte ich schon ein bisschen Abstand, weil ich möchte da nicht einfach, dass meine Kinder irgendwie in Zwiespalt kommen, weil das ist, ist schon in der Schule so 
ein Problem und dann mit den Nachbarn, da musst du, ne, immer wieder erklären und das ist dann schwer. Weil [diese Problematik, Anm. d. Verf.] gibt auch in meiner Familie: Meine Schwester trägt zum Beispiel auch kein Kopftuch und dann fragt man so: Und warum machst du das? Und warum macht das meine Tante nicht? Und das ist dann." (Selma, Z.: 602)

Zudem treffe sie sich mit ihren nichtmuslimischen Nachbarn zum »Kaffeetrinken«, wobei mit ihnen kein Austausch über die Religion stattfinde, sondern vielmehr über allgemeine Themen, wie über die Erziehung, gesprochen werde (vgl. Selma, Z.: 604-614). Auch für Mecelle sind die »Interessen« eher »informell, genau, eher weniger über Religion« (vgl. Mecelle, Z.: 510f.)

\begin{tabular}{|c|c|}
\hline Themen & $\begin{array}{c}\text { Wie äußern sich Themen? } \\
\text { Für Eltern }\end{array}$ \\
\hline $\begin{array}{l}\text { Ablehnung/ } \\
\text { Hass }\end{array}$ & $\begin{array}{l}\text { - Vorurteile geg. Muslime: Terrorismusverdacht, was »Angst« schürt } \\
\text { (vgl. Mecelle, Z.: 534; Selma, Z.: 691) } \\
\text { - Vorurteile geg. muslimischen Familien, dass sie ihre Kinder zu »streng« } \\
\text { erziehen und »zwingen« würden (Selma, Z.: 718) } \\
\text { - Medien beeinflussen negativ (vgl. Mecelle, Z: 534-539; Rabia, Z.: 774-784; } \\
\text { Ali, Z.: 112-115) } \\
\text { - Der Islam wird negativ dargestellt (Selma, Z.: 691) } \\
\text { - Der Islam ist in Deutschland nicht erwünscht (Mecelle; Ali, Z.: 24-27) } \\
\text { - Potenzieller Rassismus der Deutschen (Ali; Selma, Z.: 698) }\end{array}$ \\
\hline $\begin{array}{l}\text { Gleichgültig- } \\
\text { keit }\end{array}$ & - Kein Interesse an der eigenen Religion (Selma, Z.: 695) \\
\hline $\begin{array}{l}\text { Fremdheits- } \\
\text { gefühle/ } \\
\text { Diskriminie- } \\
\text { rung }\end{array}$ & $\begin{array}{l}\text { - Diskriminierung aufgrund religiöser Zugehörigkeit (Mecelle), } \\
\text { z.B. die Ermordung einer Muslimin im Gerichtssaal im Jahr } 2012 \text { und Attentate } \\
\text { durch die NSU (Mecelle, Z.: 543-547) oder Moscheebaukonflikte } \\
\text { (vgl. ebd., Z.: 557): Islam und Muslime sind nicht erwünscht! } \\
\text { - Diskriminierung aufgrund des Kopftuches (vgl. Ali, Z.: 144ff., Selma, Z.: 769; } \\
\text { Mecelle) }\end{array}$ \\
\hline $\begin{array}{l}\text { Angs } \\
\text { vor dem } \\
\text { Fremden }\end{array}$ & $\begin{array}{l}\text { - Angst, weil Vorurteile existieren (Mecelle; Ali, Z.: 106) } \\
\text { • Islamophobie (vgl. Ali, Z.: 25) }\end{array}$ \\
\hline $\begin{array}{l}\text { Respekt vor } \\
\text { der Religion } \\
\text { (Islam) }\end{array}$ & $\begin{array}{l}\text { - Es gibt »gute« Deutsche, aber die Allgemeinheit ist negativ gestimmt } \\
\text { (Mecelle, Z.: 539) }\end{array}$ \\
\hline
\end{tabular}

Tab. 6: Die Wahrnehmung der Eltern, wie Deutsche zum Islam stehen (Quelle: eigene Darstellung)

Die Ritualisten nehmen hauptsächlich Ablehnung und Vorurteile gegenüber dem Islam wahr. Diese seien insbesondere auf den Einfluss der Medien zurückzuführen. Auch Diskriminierungserlebnisse wurden aufgrund von Ras- 
sismus und Islamophobie erfahren oder werden befürchtet. Insgesamt drücken ritualistische Eltern eine stärkere Unzufriedenheit in Bezug auf ihre Eindrücke aus als alle anderen Eltern bzw. Typen.

Die negative Wahrnehmung des Islams trägt dazu bei, dass für die Eltern dieser Gruppe ein mehr oder weniger gutes Ausleben ihrer Religion möglich ist. Hier unterscheiden sie auch, inwieweit ihre Kinder dahingehend beeinflusst werden.

Auch wenn man »beten « und in die Moschee gehen könne, würden die Gefühle des Unerwünschtseins die individuell freie Religionsausübung überschatten: »Ja man ist hier nicht erwünscht. Man fühlt sich hier nicht mehr wohl, aber man hat keine andere Möglichkeit« (vgl. Mecelle, Z.: 549ff.). So bemerkt Mecelle ironisch:

"[...] aber die, die Freiheit ist schon da. Das find ich gut, dass man die Muslime in den Hinterhofmoscheen beten lässt ne [...] man [Muslime, Anm. d. Verf.] hinten, nicht sehen will, das ist gut, aber wenn in Köln eine große Moschee gebaut wird, dass eine Baugenehmigung, dass man die erst nach fünf sechs Jahren erst mal überhaupt bauen darf, das ist eine Zeit, da sieht man ja, die Muslime sind da leider nicht erwünscht." (Mecelle, Z.: $555 f f$.

Dies wirke sich aber noch nicht nachteilig auf die Kinder aus, da sie »noch nicht in dem Alter« seien: »Die Kinder die sind, die diskriminieren sich nicht, das sind halt Kinder, ne, die spielen auch mit einem Schwarzen, egal was der für eine Religion hat.« (vgl. ebd., Z.: 575).

Rabia stellt fest, dass man die eigene Religion zwar »ausreichend leben« könne, »wenn man das möchte«, jedoch gebe es Hindernisse, die von der Institution Schule ausgehen würden (vgl. Rabia, Z.: 786ff.; vgl. auch Kap. III. 5.3; vgl. Selma unten).

Selma findet, dass sie ihre Religion mit ihren Kindern zu Hause »eigentlich ganz gut« ausleben könne (vgl. Selma, Z.: 698-712). Jedoch sei es für sie »draußen« schwieriger:

"[...] draußen ist es, ist es teils, teils, also man wird da manchmal schon so ein bisschen schief angeguckt, ne? Wenn man draußen dann spazieren geht mit den Kindern, weil man einfach Kopftuch trägt oder also bekleidet ist. Oder zum Beispiel, wenn man draußen vielleicht betet oder so, dann ist es auch sehr komisch für die Leute." (Selma, Z.: 698)

\section{Vor- und Nachteile der religiösen Sozialisation in dieser Gesellschaft}

Die Ritualisten sehen keine Vorteile für die religiöse Erziehung ihrer Kinder in Deutschland. Hingegen sehen sie viele Nachteile, die insbesondere der rituellen Pflichterfüllung oder der Befolgung von religiösen Geboten (hier: Kopf- 
tuch) entgegenstünden. So sei es in einem Land, in dem überwiegend Muslime leben, einfacher, die Riten zu befolgen, da man z.B. »überall beten« könne. Dies stellen, ähnlich wie Mecelle (vgl. oben), auch Selmas Kinder fest:

"[...] Oder zum Beispiel in der Türkei kann man überall beten gehen und hier kann man das nicht, nein. Und dann sagen die [Kinder, Anm. d. Verf.] auch ... [Warum geht das hier nicht?, Anm. d. Verf.]. Ja. Ich habe hier, wenn man kein abdest [türk. für Gebetswaschung, Anm. d. Verf.] hat, ne? Wo sollst du abdest nehmen oder wo sollst du gehen und beten? Man betet im Freien und dann, aber in der Türkei ist es ja nicht so, da gibt es in jeder Ecke eine Moschee, wo du hingehen kannst; hier ist es einfach nicht so, also da ist man schon so, so ein bisschen eingeschränkt." (Selma, Z.: 732ff.)

In einem muslimischen Land gebe es zudem den Gebetsruf durch den muezzin, was in einem nichtmuslimischen Land nicht möglich sei (vgl. Mecelle oben und Z.: 553). Gebote, die ähnlich wie der Gebetsruf eine religiöse Symbolik beinhalten, würden durch die nichtmuslimische Umwelt zum Teil negativ beäugt. So fühlten sich die Kinder unwohl, wenn sie draußen seien und aufgrund des Kopftuches der Mutter angeschaut bzw. beobachtet würden: »Die Kinder bemerken das ja auch, wenn sich einer herumdreht und dich anguckt und sagen auch: >Warum guckt der so?« (vgl. Selma, Z.: 732).

Des Weiteren sind Rassismus und die Diskriminierungserfahrungen, die sich insbesondere im Rahmen der Schulen ausdrücken, für die Eltern besorgniserregend (vgl. oben und vgl. auch Kap. III. 5.3) und werden als Nachteile für die religiöse Sozialisation angesehen. Dementsprechend wird der hemmende religiöse Sozialisationseffekt ${ }^{97}$, der von der Schule ausgehe, hier (nochmals) bekräftigt bzw. untermauert. Alle Eltern, bis auf Mecelle, dessen Kinder noch $\mathrm{zu}$ jung sind, um Diskriminierungen als solche wahrzunehmen (vgl. oben), beschreiben verschiedene Aspekte von Diskriminierungen, die sie als Zurücksetzungen bzw. Nachteile für ihre religiöse Erziehung empfinden.

Hierzu gehöre neben der fehlenden Anerkennung des Islams in Deutschland (vgl. Ali, Z.: 24f. und vgl. oben) auch der Rassismus an Schulen, der in den Köpfen zu einem veränderten Gesellschaftsbild beigetragen und z.B. dazu geführt habe, dass die Nichte in die Türkei ausgewandert sei. Es laste zudem ein enormer Druck auf den Muslimen, der auch im Arbeitsleben zu spüren sei (vgl. Ali, Z.: 146-149).

Auch Rabia stellt fest, dass die Schule als Einflussfaktor insgesamt »eine große Rolle« spielt. Da es vielen muslimischen Eltern an genügend Bildung und Wissen fehle, um sich mit dem negativen Bild über den Islam bzw. den

97 | In Kap. III. 5.3 konnte dies noch nicht eindeutig belegt werden. Die Wiederaufnahme der Thematik als "Nachteil« für die religiöse Erziehung bekräftigt jedoch den hemmenden religiösen Sozialisationseffekt. 
Lehrern usw. auseinanderzusetzen, werden muslimische Schüler/-innen benachteiligt. Sie bringt ihre eigene Überforderung folgendermaßen zum Ausdruck:

"Genau! Weil es gibt ja so viele Kinder, wo die Eltern wenig an Wissen haben, wie ich auch, ich habe ja auch nicht viel Wissen! Und da fehlt es uns an wissenden Lehrern, Personen, da sind sogar die muslimischen Kinder ja benachteiligt, weil das ja fehlt! [...]. Ja. Also wenn man als Eltern nicht mithält also nicht da dranbleibt, dann ist man, also dann geht das unter." (Rabia, Z.: 798-804)

\section{Religiöse Erziehung in der Gesellschaft}

Die religiöse Erziehung soll bewirken, darin sind sich alle ritualistischen Eltern einig, dass eine stärkere Aufklärung über den Islam stattfindet, damit Vorurteile und negative Vorstellungen über den Islam abgebaut werden. Dies trugen sie insbesondere im Zusammenhang mit der Schule vor (vgl. Kap. III. $5.3 »$ Verbesserungsvorschläge«). Auch im gesellschaftlichen Rahmen erwarten sie, dass die Kinder durch die religiöse Erziehung hierzu einen entscheidenden Beitrag leisten.

»Zufriedenheit, Geborgenheit und Glück« und den »Halt«, den der Glaube bietet, soll nach außen gelebt und ausgestrahlt werden (vgl. Rabia, Z.: 825-836). Durch das Vorleben der Religion hätten Gesellschaftsmitglieder die Möglichkeit, den Glauben aus »erster Hand« zu erfahren, sodass Vorurteile und Klischees abgebaut (vgl. auch Rabia, ebd.) und ein tolerantes Miteinander (vgl. Selma, Z.: 738-748) möglich würden:

"Ja. Also, dass, dass sie das nicht einfach nur vom Fernsehen oder von den Nachrichten, die sie sich da angucken oder ansehen, [kennen], sondern direkt vor Ort einfach." (Selma, Z.: 754)

Auch Mecelle ist der Überzeugung, dass der verinnerlichte Glauben und die Aneignung von religiöser Bildung zum Dialog und Verständnis beitragen werden. Die Aufklärung der Gesellschaft, damit der Islam »richtig« verstanden werde, sei ein Ertrag, der aus der religiösen Erziehung hervorgehe:

"[...] Wenn sie mehr über den Glauben wissen, können sie auch der Gesellschaft, denke ich, was vermitteln, und so auch die Gesellschaft aufklären, dass der Islam nicht schlecht ist oder so. Wenn sie ihren Glauben richtig kennen, so denke ich." (Mecelle, Z.: 584)

Ferner könne die Gesellschaft von der religiösen Erziehung der Kinder profitieren, da sie zur Charakterbildung der Kinder beitrage. Dazu gehöre, dem »anderen Gutes zu tun«, indem man auf dessen Rechte achte, Gerechtigkeit übe und allgemein ein gesetzestreues Leben führe: 
"Ja, dass ich denke, dass es viel bringt, durch den Charakter [...] dass man für den anderen gut, dass man das Gute für (stottert) für die anderen auch möchte, dass man den anderen nicht [runtermachen], nicht mobben soll [...], gerecht sein soll, dass man gutmütig sein soll, dass man nicht stiehlt, dass man nicht, halt diese allgemeinen Regeln, die man beherrschen soll." (Rabia, Z.: 809-813)

Der Glaube bringe schließlich auch »Ordnung « ins Leben ${ }^{98}$, sodass er auch vor »schlechten Wegen«, wie Drogenmissbrauch, Gewaltbereitschaft und vor »schlechten Freunden«, schütze (vgl. ebd., Z.: 813-819).

\subsubsection{Die religiöse Sozialisation in der Gesellschaft - die "Identitätssucher"}

\section{Nachbarschaftbeziehungen und der Kontakt zu Andersgläubigen}

Typischerweise zeichnen sich die Identitätssucher durch ein hohes Maß an Dialog- und Austauschbereitschaft aus, welche sich auch in ihren Kontakten und Beziehungen zu Nichtmuslimen zeigt.

Selbst wenn die Anonymität des Großstadtlebens und die Arbeitsbedingungen dazu führen, dass weniger Nachbarschaftsbeziehungen gepflegt werden, begrüßen und beschenken sich die Nachbarn gegenseitig (vgl. Lema, Z.: 233ff.).

Aufgrund ihres Umzugs konnte Hülya noch keine intensive Beziehung zu ihren Nachbarn aufbauen. Trotzdem nahm sie eine neue Nachbarin mit der Absicht, »bewusst« Vorurteilen entgegenzuwirken, zu einem »Tag der offenen Moschee«-Veranstaltung mit. Durch die Kontaktaufnahme sollten Berührungsängste abgebaut und das falsche und verzerrte »Bild « über den Islam durch ein aktives Vorleben und Erleben der Muslime korrigiert werden:

"Ja, doch, da hat sie mir erklärt, dass ihre Tochter irgendwie Muslime als, also negativ kennt, dass sie wirklich denkt, dass Muslime halt nur Terroristen sind und dass man denen nicht vertrauen sollte, dass sie bloß nicht in eine Moschee gehen sollte. So hat sie die Mutter aufgeklärt und dann habe ich das Gegenteil natürlich dargestellt und hab dann mit der Tochter auch versucht, diese zu kontaktieren, und so bauen sich wirklich Kontakte auf, also die Berührungsängste gehen verloren und das versuche ich sehr bewusst zu machen. Weil wenn ich das jetzt nicht tue, das ist immer wieder der Gedanke, meine Kinder werden dann später wirklich Schwierigkeiten haben [...]." (Hülya, Z.: 241)

Auch Lema tauscht sich mit nichtmuslimischen Freunden, Bekannten, Menschen aus dem Alltagsleben über ihre Religion aus. Aufgrund ihres offenen Wesens, »Ich persönlich bin schon eine offene Person, finde ich also« (vgl.

98 | Vgl. dazu Kap. III.3.2 "Typologie [...] die Erziehungsziele bzw. das Religiositätsprofil«. 
Lema, Z.: 241), werden auch vertiefend religiöse Themen, wie z.B. das Kopftuch oder der Sinn des Daseins, besprochen:

"Was ist denn eigentlich, warum trage ich überhaupt Kopftuch? Oder warum bete ich? Und was ist der Sinn des Lebens? Warum leben wir eigentlich? Warum gibt es uns eigentlich? Was ist denn unsere Aufgabe? Und wie wird denn der Mensch glücklich? Solche Fragen." (Lema, Z.: 239)

Ferner werde an religiösen Feiertagen, wie z.B. an Weihnachten, Interesse an nichtmuslimischen Nachbarn, Bekannten und Freunden gezeigt (vgl. Lema, Z.: 237, vgl. Hülya), damit gegenseitiger Respekt entstehe:

"[...] Man wünscht den deutschen Nachbarn auch ein frohes Weihnachtsfest und die [respektiert, Anm. d.Verf.] anderen Fest, also das kann man ja alles machen. Man sagt, wenn du erwartest, dass man dich respektiert, dann solltest du auch andere respektieren. Vielleicht müssen wir immer den ersten Schritt machen, aber trotzdem, da kommt immer was Positives zurück." (Hülya, Z.: 243)

\begin{tabular}{|c|c|}
\hline Themen & $\begin{array}{l}\text { Wie äußern sich Themen? } \\
\text { Für Eltern }\end{array}$ \\
\hline Ablehnung/Hass & $\begin{array}{l}\text { - Vorurteile geg. Muslime (vgl. Lema, Z.: 272-281 und Z.: 285; } \\
\text { Hülya, Z.: 241). } \\
\text { - Medien beeinflussen negativ (vgl. Hülya, Z.: } 241 \text { und Z.: 295; } \\
\text { vgl. Lema, Z.: 282) } \\
\text { • Die Muslime sind »Sündenböcke« für gesellschaftliche } \\
\text { Schieflagen (vgl. Hülya, Z.: 295) }\end{array}$ \\
\hline Angst vor dem Fremden & • Islamophobie (vgl. Hülya, Z.: 291) \\
\hline $\begin{array}{l}\text { Respekt vor der Religion } \\
\text { (Islam) }\end{array}$ & $\begin{array}{l}\text { - »Netter«, »normaler« Umgang mit Nachbarn; die nächste } \\
\text { Generation wird anders, mit »mehr Verstand« mit dem Islam } \\
\text { umgehen (vgl. Lema, Z.: 285) } \\
\text { - Positiver, respektvoller Umgang mit der Religion (vgl. Hülya, } \\
\text { Z.: 291) }\end{array}$ \\
\hline
\end{tabular}

Tab. 7: Die Wahrnehmung der Eltern, wie Deutsche zum Islam stehen (Quelle: eigene Darstellung)

Die Wahrnehmung der »Identitätssucher« hinsichtlich der Frage, wie Deutsche zum Islam stehen, ist sowohl durch Vorurteile, die mitunter durch den Einfluss der Medien entstehen, als auch durch den Respekt vor der eigenen Religion bestimmt. Ihr Optimismus und Engagement für einen aktiven Austausch und Dialog kamen auch schon in allen anderen Kontexten zum Ausdruck. So liegt die Vermutung nahe, dass ihre offene und positive Grund- 
haltung gegenüber Andersgläubigen ihnen $\mathrm{zu}$ »positiven « und respektvollen Erfahrungen verholfen hat.

Gerade, was das Ausleben der Religion betrifft, betonen »Identitätssucher « die individuelle Religionsfreiheit, die es ihnen erlaube, z.B. mit dem Kopftuch an der Universität zu studieren oder über einen Gebetsraum zu verfügen und sich frei über die eigene Religion zu äußern (vgl. Lema, Z.: 291). So kann auch Hülya ihre Religion letztendlich ohne »Einschränkungen« ausleben (vgl. Hülya, Z.: 299).

\section{Vor- und Nachteile der religiösen Sozialisation in der Gesellschaft}

Die Identitätssucher betrachten die Vielfalt und das pluralistische Zusammenleben der Menschen, die verschiedenen Religionen angehören, als Vorteil für die religiöse Sozialisation ihrer Kinder (vgl. Lema, Z.: 294 und Z.: 310) bzw. für die Gesellschaft (vgl. Hülya, Z.: 307).

Die Nachteile ergeben sich aus der Minderheitensituation in einer nichtmuslimischen Umwelt, wo der Islam keine »Selbstverständlichkeit« darstelle. Im Gegensatz zur Türkei, wo mehr Muslime leben, müsse man sich in Deutschland »mehr Mühe« geben und trage eine größere »Verantwortung«, um seine Religion ausleben zu können:

"[...] hier muss man sich mehr Mühe geben, weil wir nicht in einem muslimischen Land leben; als Eltern hat man eine große Verantwortung, wirklich die Religion selbst auszuleben, erst mal ... Also, wenn ich jetzt mir vorstelle, wie wenn man die Religion in der Türkei bespricht mit den Kindern, da lebt man ja, mein Mann kommt aus der Türkei, für den waren viele Dinge selbstverständlich, was es für uns hier gar nicht ist, also, dass er z.B. den muezzin hört oder dass er halt automatisch um sich Muslime hat, also es ist etwas anderes, weil man in einer anderen Gesellschaft lebt." (Hülya, Z.: 303)

Als Beispiel für die Schwierigkeiten, sich dem Einfluss der Umwelt zu entziehen, erläutert sie, wie ihre Tochter (im Kleinkindalter) mit dem Thema Kopftuch umgeht. Hierbei sieht sie sich in der »Pflicht«, ihrer Tochter die »richtige Antwort zu geben, zu erklären«:

"Ja, genau, ich meine meine Tochter hat mich auch schon gefragt: 'Warum trägst du Kopftuch? Und hat mir auch schon gesagt, ja, 'wieso hast du keine blonden Haare?, Ja, ist so, diese Fragen würden ja in der Türkei nie kommen, weil die Leute ja fast alle, in den Großstädten nicht so, aber in kleineren Städten ist es ja selbstverständlich, dass die Frauen Kopftücher tragen. Da kommt diese Frage nicht, dann bin ich als Mutter, also in der Pflicht, diesem Kind die Antwort, die richtige Antwort zu geben, zu erklären. Ich habe meine Tochter gefragt: ,Würdest du Kopftuch tragen, wenn du groß bist? ' Sagt sie: 'Nee, (lacht), 'warum auch?^ Also das sind so Fragen, ich bin so ne überzeugte Kopftuchträge- 
rin. Die Kinder sehen das anders, die Jugendlichen, darf man auch niemanden zwingen, auf keinen Fall." (Hülya, Z.: 305)

»Konflikte«, die durch das Tragen des Kopftuches und den Schwimmunterricht entstehen, sind auch für Lema Nachteile, die sich aus dem Zusammenleben in dieser Gesellschaft ergeben. Sie ist jedoch davon überzeugt, dass diese Konflikte zu einem besseren »konstruktiven« Miteinander und Zusammenleben von Muslimen und Nichtmuslimen in dieser Gesellschaft führen werden (vgl. Lema, Z.: 298-302). Ihren Optimismus bringt sie folgendermaßen zum Ausdruck:

"Ja, eher optimistisch. Ja, Optimismus muss sein (lacht). Das braucht der Mensch. Ja, Lebensfreude und Optimismus und kreativ, das ist eigentlich unsere Hauptaufgabe, nicht weglaufen, sondern auch versuchen, welche Wege können wir eingehen? Was brauchen wir dazu? Um mehr mit den Menschen da zu kommunizieren, ne? Auch da, wie gesagt, da kann man einseitig da nichts machen. Man muss schon, denke ich, gemeinsam da vorangehen, es auch gemeinsam meistern vielleicht, ja." (Lema, Z.: 304)

\section{Religiöse Erziehung in der Gesellschaft}

Für die Gesellschaft kann eine religiöse Erziehung Lema zufolge dazu beitragen, dass Werthaltungen, wie bspw. Solidarität, Mitmenschlichkeit und Empathie, die sich vor allem auf die zwischenmenschlichen Aspekte des gesellschaftlichen Miteinanders beziehen, mehr an Bedeutung gewinnen (vgl. Lema, Z.: 308ff.).

Neben dem Ziel, dass Kinder durch die Religion zu »guten« Menschen erzogen werden, stellen alle monotheistischen Religionen, so Hülya, Ressourcen zur Verfügung, um mit persönlichen Krisen und Schwierigkeiten umzugehen: »Religion kommt ja oft in schwierigen Tagen in den Vordergrund. Wenn jemand stirbt oder wenn ein Unfall passiert, dann denken viele Menschen an Religion« (vgl. Hülya, Z.: 307).

Demgemäß bieten Religionen die nötige Kraft, dass ein »stärkeres Selbstbewusstsein oder eine starke Persönlichkeit« entstehen, eine gefestigte Person eben, die sich auch verantwortungsvoll gegenüber ihren Mitmenschen verhält. Gerade Einsamkeit und Individualisierungstendenzen in der Gesellschaft könne dadurch etwas entgegengesetzt werden. Darüber hinaus könne die Religion entscheidend dazu beitragen, dass mit Tieren, Pflanzen, mit dem Essen, mit dem Körper sowie mit der Gesundheit sorgfältiger und verantwortungsvoller umgegangen werde (vgl. Hülya, Z.: $309 f f$.$) .$ 


\subsubsection{Die religiöse Sozialisation in der Gesellschaft - die "Ethiker"}

\section{Nachbarschaftbeziehungen und der Kontakt zu Andersgläubigen}

Die Ethiker zeichnen sich unter allen Typen beim Pflegen von Nachbarschaftsbeziehungen zu Nichtmuslimen als die »offenste« Gruppe aus. Unter ihnen sind einige (Feride, Adem), die in einem intensiven und vertrauensvollen Kontakt zu ihren Nachbarn stehen. Die anderen sind sehr bemüht, ein gutes Verhältnis zu ihren Nachbarn zu haben. Auf mehreren Ebenen findet zudem ein Austausch über die Religionen statt.

Das Verhältnis von Feride und Adem zu ihren deutschen Nachbarn ist durch ein ausgeprägtes gegenseitiges Interesse gekennzeichnet und von Fürsorge geprägt. Da auch schon Ferides Eltern sehr viel Wert auf die zwischenmenschlichen Beziehungen legten, konnte sie erfahren, wie man sich ohne Ängste und Vorurteile begegnen kann und sich füreinander öffnet: Es wurde gemeinsam gekocht und sich gegenseitige Hilfe angeboten (vgl. ebd. Z.: 489 ff.).

Auch Adem hat einen »sehr guten Kontakt« zu seinen Nachbarn, sodass er sich mit ihnen sowohl zwischenmenschlich als auch über die Religion austauscht (vgl. Adem, Z.: 212ff.). Zudem betrachtet er es als eine religiöse Pflicht, sich dem Nachbarn gegenüber angemessen zu verhalten:

"Die Muslime werden als Zweites zur Rechenschaft gezogen über das Miteinanderleben mit den Nachbarn und dieses Gebot ist für mich und für meine Familie sehr sehr wichtig." (Adem, Z.: 93)

Ähnlich wie Adem, jedoch ohne sich über die Religion auszutauschen oder »Hausbesuche« zu machen, ist Melek bemüht, einen »guten Kontakt« zu ihren Nachbarn »zu halten«, um ein »gutes Bild« vom Islam und den Muslimen zu vermitteln. Es wird einzig die »ältere« nichtmuslimische Nachbarin besucht, um sich nach ihr zu erkundigen: »Oder wir haben zum Beispiel eine alte Nachbarin, der geht es nicht so gut, sie ist krebskrank. Dass ich sie mal öfters sehe und frage, wie es ihr geht, ob sie was braucht und so.« (vgl. Melek, Z.: 655ff.).

Auch wenn Birol in einem »freundlichen Kontakt« zu seinen Nachbarn steht und sich mit ihnen gut versteht, würde er sich mehr das »typisch Südländische«, das über einen Gruß hinausgehe und z.B. einen Kaffeebesuch möglich mache, in den Beziehungen suchen und wünschen. So sollten vielmehr »Hemmschwellen« abgebaut werden, damit man mehr miteinander zu tun habe (vgl. Birol, Z.: 312ff.).

Belkıs wohnt in einer Gegend, in der sehr viele Muslime leben, sodass sie es vorzieht, sich mehr mit ihnen zu treffen (vgl. auch Kap. III. 5.4 »Peers«). Sie tauscht sich in erster Linie mit ihren muslimischen Nachbarn über ihre 
Religion aus (vgl. Belkıs, Z.: 349ff.). Jedoch besucht sie auch regelmäßig einen »christlichen Kreis«, wo sie den interreligiösen Dialog pflege:

"Also es gibt einen Kreis [...] von Christen, es sind aber auch sehr gläubige Christen, und so einmal im Monat haben wir uns bis jetzt mit denen ausgetauscht, kamen wir zusammen. Aber nicht mit Kindern!“ (Belkıs, Z.: 353)

Außerdem tauschen sich die Ethiker mit ihren nichtmuslimischen Nachbarn anlassbezogen z.B. über das Opferfest aus: »Also jetzt nichts Spezielles um uns gegen[seitig] aufzuklären, sondern, wenn der gegebene Anlass da ist, auch so, ja okay so zum Opferfest« (vgl. Feride, Z.: 406). Die Nachbarn werden zum Fastenbrechen eingeladen bzw. an Weihnachtsfesttagen besucht und es besteht ein reger Austausch über die Inhalte der Religion (vgl. Adem, Z.: 182 und Z.: 216).

\begin{tabular}{|c|c|}
\hline Themen & $\begin{array}{l}\text { Wie äußern sich Themen? } \\
\text { Für Eltern }\end{array}$ \\
\hline Ablehnung/Hass & $\begin{array}{l}\text { - Medien beeinflussen negativ (vgl. Belkıs, Z.: } 385 \text {; Feride, Z.: 479; } \\
\text { Melek, Z.: 751; Birol, Z.: } 370 f f .) \\
\text { - Der Islam werde im Zusammenhang mit Gewalt und Terrorismus } \\
\text { thematisiert, dadurch gebe es ein negatives Bild über den Islam, ein } \\
\text { schlechtes »Image« entstehe (vgl. Birol, Z.: 366-370) } \\
\text { - Es würden nach dem Kalten Krieg neue »Feindbilder« produziert, wie } \\
\text { z.B. Al-Qaida oder die Salafisten (vgl. Feride, Z.: 691) } \\
\text { - Vorurteile gegen Muslime: »unterdrückte Frauen« und »Ehrenmorde« } \\
\text { (vgl. Belkıs, Z.: 385) } \\
\text { - Vorurteile und Ablehnung von türkischen Kindern, weil sie »respekt- } \\
\text { los und laut« seien (vgl. Melek, Z.: 739) } \\
\text { - Rassismus vonseiten der Deutschen (vgl. Melek, Z.: 745) }\end{array}$ \\
\hline $\begin{array}{l}\text { Angst vor } \\
\text { dem Fremden }\end{array}$ & $\begin{array}{l}\text { - Angst, weil »Feindbilder« und boshafte »Islam-Bilder« produziert } \\
\text { würden (vgl. Feride oben und Z.: 479) }\end{array}$ \\
\hline $\begin{array}{l}\text { Respekt vor } \\
\text { der Religion (Islam) }\end{array}$ & $\begin{array}{l}\text { - Auch »normale Beziehungen« zu Nichtnuslimen (vgl. Feride, Z.: } 479 \text {, } \\
\text { vgl. Birol, Z.: 374ff.), wodurch das Fremde, das Beängstigende und Vor- } \\
\text { urteile aufgehoben würden (vgl. ebd., Z.: 483-490) } \\
\text { - Es gebe auch Deutsche (z.B. christlich orientierte), die Respekt und } \\
\text { Verständnis für die eigene Religion hätten (vgl. Melek, Z.: 751) } \\
\text { - Offenheit werde erlebt, z.B. beim »Tag der offenen Moschee«-Veran- } \\
\text { staltung, Vorurteile könnten abgebaut werden (vgl. Adem, Z.: 237). } \\
\text { - Niemand denke aufgrund persönlicher Erfahrungen mit Muslimen } \\
\text { schlecht über den Islam, sondern vielmehr aufgrund des negativen } \\
\text { Islambildes in den Medien. Es gebe auch positive Erfahrungen (vgl. } \\
\text { Birol, Z.: 372-376) }\end{array}$ \\
\hline
\end{tabular}

Tab. 8: Die Wahrnehmung der Eltern, wie Deutsche zum Islam stehen (Quelle: eigene Darstellung) 
Wie hier deutlich wird, haben Ethiker eine gemischte Wahrnehmung, wie die Deutschen letztlich zum Islam stehen. Zum einen empfinden sie es als besonders störend, dass aufgrund des in den Medien vermittelten Islambildes massive Vorurteile in der Bevölkerung vorherrschen. ${ }^{99}$ Zum anderen unterstreichen fast alle Eltern auch die positiven Aspekte, die sie bei der Begegnung mit Einheimischen auf unterschiedlichen Ebenen gemacht hätten. Ihre Offenheit und wohl auch weniger intensiv ausgelebte Religiosität ${ }^{100}$, die zu größeren Schwierigkeiten in einer nichtmuslimischen Umwelt führen könnte, könnte ein möglicher Grund für die positiven Erfahrungen mit Nichtmuslimen sein. So nehmen sie zwar einige Einschränkungen wahr, die das Ausleben der Religion in dieser Gesellschaft erschweren, betonen jedoch die individuelle Religionsfreiheit in Deutschland, die es allen Eltern dieser Gruppe ermöglicht, ihre Religion »gut« auszuleben:

"Gut. Ja, also man muss trotz aller Schwierigkeiten, trotz aller Defizite, klar feststellen: Also Deutschland ist schon ein Land, wo man [...] seine Religion ausleben kann oder möchte (leise)." (Birol, Z.: 380)

Die Einschränkungen beträfen zum Beispiel die geringen Schwimmmöglichkeiten für muslimische Frauen (vgl. Belk1s, Z.: 387), die potenzielle Gefahr von Diskriminierungen am Arbeitsplatz, z.B. durch das Tragen des Kopftuches oder durch einen muslimischen Namen (vgl. Feride, Z.: 501f. und Z.: 507; Birol, Z.: 390), oder die Tatsache, dass die Gebete nicht überall verrichtet werden könnten (vgl. Feride, Z.: 509).

\section{Vor- und Nachteile der religiösen Sozialisation in der Gesellschaft}

Die Vorteile, die Eltern für ihre religiöse Erziehung bzw. die religiöse Sozialisation sehen, beziehen sich sowohl auf das Gemeindeleben, das in Deutschland eine höhere Bedeutung hat als im Herkunftsland, als auch auf das Zusammenleben von Menschen mit unterschiedlichen Religionen.

Das Gemeindeleben ist ein Vorteil, der in der Diasporasituation besonders hervortritt (vgl. Kap. III. 5.1). Melek schätzt insbesondere das im Vergleich zur Türkei größere Engagement ${ }^{101}$ und die Religiosität der Muslime in Deutschland: »Aber hier, wenn ich das so sehe, und wenn ich dann im Urlaub sehe,

99 | In diesem Zusammenhang handelt es sich bei den Ethikern um eine besonders (argumentativ) reflektierte und informierte Gruppe (vgl. auch Kap. III. 5.5 "Die Medien $[\ldots]$ «).

100 | Im Vergleich zu den Idealisten und Ritualisten.

101 Freilich ist das die Wahrnehmung von Melek, die von dem Herkunftsort der Eltern in der Türkei abhängt. Es gibt durchaus Städte und Umgebungen, in denen das Gemeindeleben auch in der Türkei intensiv ausgelebt wird. 
bin, dann merke ich, in Deutschland da sind wir viel mehr aktiv für den Islam [...] (vgl. Melek, Z.: 760). Auch Belkıs unterstreicht die Bedeutung des Gemeindelebens, das aus der Situation der muslimischen Migranten in Deutschland resultiere und noch verbessert werden könne:

"Ja, ich würde mir wünschen, dass muslimische Eltern inre Kinder bewusster erziehen und dass wir auch aktiver sind [...] vor allem der muslimischen Gemeinde gegenüber auch verantwortungsvoller agieren, dass jeder seine Kräfte und Ressourcen und seine Talente in seinem Bereich einsetzt, dass wir hier einfach ein besseres Leben haben, weil die wenigsten können wirklich in inre Ursprungsländer zurückkehren und das als Heimat bezeichnen. Wir sind eben so zwischen den Stühlen, das ist so." (vgl. Belkıs, Z.: 428)

Als einen weiteren Vorteil betrachten Birol und Feride das Zusammenleben von Menschen mit verschiedenen Religionen, was es ihren Kindern ermögliche, »über den eigenen Tellerrand « hinauszublicken, um möglicherweise Verantwortung für sein Gegenüber zu übernehmen:

"Also Vorteil ist, also ich denke, in einem muslimischen Land, wenn wir in einem muslimischen Land wären, wo man eigentlich nur Islamisches um sich herum hätte, hätte man auch nicht die Möglichkeit, über den Tellerrand vielleicht mal hinauszuschauen. $\mathrm{Ne}$, man hat dann ein sehr eingeschränktes Bild, denke ich, über die Welt, über die Religion, über Menschen. In Deutschland sind wir in der glücklichen Situation, sage ich mal, wo man mehrere Religionen erfahren kann, mit mehreren oder mit Menschen zusammenkommen kann, Menschen kennenlernen kann, die eben unterschiedliche Glauben haben. Und das ist, denke ich, bereichernd einfach." (Birol, Z.: 388)

Feride glaubt zudem, dass durch das Zusammenleben verschiedener Religionen der Respekt für Andersgläubige erlernt und nochmals reflektierend auf das eigene »Bild« von der Religion geschaut werden könne:

"[...] Da noch mal so einen Spiegel vorgehalten, davor gehalten zu bekommen und zu sagen, Ja, das ist meine Religion, okay, so wird das von den anderen aufgenommen oder gesehen. (Das ist auch noch eine Bereicherung, finde ich. Aber dann noch irgendwie für sich selbst noch das Bild zu entdecken. Ha, es gibt ja noch ganz viele andere. Und das konnten die, finde ich, aus der Türkei heraus nicht so, nicht in der Intensität erfahren. Das finde ich halt gut [...]." (Feride, Z.: 520)

Neben den Vorteilen gibt es auch Nachteile, die als Hindernisse für die religiöse Sozialisation der Kinder in der Gesellschaft wahrgenommen werden.

Es ist die Minderheitensituation bzw. die unterschiedlichen Werte, die nachteilig auf die religiöse Sozialisation der Kinder wirken könnten. Dennoch sieht Belkıs in der Auseinandersetzung mit der Gesellschaft weniger ein Kon- 
fliktpotenzial als eine mögliche Wachstumschance, die durch ein Aufeinandertreffen von unterschiedlichen Werthaltungen zustande kommen könnte:

"Also sie werden natürlich immer in Konflikt kommen mit der Mehrheitsgesellschaft, weil sie natürlich immer in der Minderheit sein werden. [...]. Aber ich denke, als erwachsener Mensch wird man immer in Konfliktsituationen kommen. Weil Ziel der Erziehung ist ja auch, das Kind so zu erziehen, dass es damit fertig wird, es gibt keinen Menschen auf der Welt, der nie irgendwie irgendwelche Reibereien hat. Und wenn man halt eine Minderheit ist, das habe ich auch selber zu spüren bekommen, gerät man immer in Situationen, wo es halt Menschen gibt, die anders denken, sind und ich denke nicht, dass es meine Kinder unbedingt negativ; es wird vielleicht schmerzhaft, aber so ist das Leben halt, jeder Mensch macht schmerzhafte Sachen durch und reift halt dadurch. Also so, so Nachteile sind halt so, dass diese Konflikte entstehen können und die werden auch entstehen, aber es ist eigentlich kein eigentlicher Nachteil in meinem Denken." (Belkıs, Z.: 410)

Vorurteile gegenüber Muslimen und die Gefahr potenzieller Diskriminierungen ausgesetzt zu werden, wurde oben schon vielfach benannt und als Nachteil für das religiöse Aufwachsen in der Gesellschaft aufgeführt (vgl. Birol, Z.: 382 und Z.: 390). Hinzu kommen Gefühle der Fremdheit, obwohl die Eltern in Deutschland geboren worden:

"[...] Man ist hier, auch wenn man eingedeutscht ist, wie zum Beispiel ich, ich bin hier in Köln geboren, fühle mich als Kölscher Jung, trotzdem fühle mich trotzdem einigermaßen fremd. Also man ist irgendwie dazwischen [...]." (Adem, Z.: 249)

Als weiterer Nachteil werden die fehlenden »positiven « Vorbilder und der fehlende muslimische Freundeskreis gesehen. Die Jugendlichen könnten vor allem in den Großstädten dazu verleitet werden, in das »Nachtleben einzudringen«, das dem islamischen Wertmaßstab widerspreche (vgl. Adem, Z.: 249; Feride, Z.: 533).

Auch die im Vergleich zur Türkei fehlende Möglichkeit, die Kinder in eine muslimisch orientierte Kindertagesstätte zu schicken, in der auch eine altersgerechte »religiöse Unterweisung und religiöse Kenntnisse « spielend vermittelt werden, ist ein Nachteil für die religiöse Sozialisation der Kinder. So müssen die Eltern von Kindern im Kleinkindalter zu Hause mehr Verantwortung für die religiöse Erziehung ihrer Kinder übernehmen und es spielen sich viele Rituale nur im häuslichen Rahmen ab: »Dann heißt es halt: Okay das machen wir nur, wenn wir zu Hause sind. Wenn wir woanders sind nicht. Also das ist schon eine andere Auswirkung« (Feride, Z.: 533). 
Beklagt wird auch die fehlende Festtagsstimmung, die es Kindern nicht ermögliche, eine Atmosphäre des Feierns zu spüren (vgl. Feride, Z.: 533; vgl. auch Kap. III. 4.4).

\section{Religiöse Erziehung in der Gesellschaft}

Für die Gesellschaft, darin sind sich alle Ethiker einig, soll religiöse Erziehung primär ein friedliches Zusammenleben von Menschen mit verschiedenen Glaubensrichtungen bewirken. Typischerweise werden durch die Eltern insbesondere sozialethische Eigenschaften betont, die verschiedene Aspekte des Zusammenlebens in dieser Gesellschaft berühren.

Der Islam bedeute Frieden und nicht Krieg, so Melek. Demgemäß könne der Islam in »jeglicher Hinsicht« dafür sorgen, dass Frieden zwischen den Menschen herrsche (vgl. Melek, Z.: 773-781). Für das Zusammenleben könne durch die religiöse Erziehung bewirkt werden, dass ein »bewusster Umgang« mit Andersgläubigen und Andersdenkenden, ja mit der Umwelt, der Natur und der Tierwelt gepflegt werde (vgl. Adem, Z.: 254). So sei es schließlich möglich, dass Barrieren und Vorurteile aufgehoben würden und eine Dialogfähigkeit entstehe:

"Also man darf über die Menschen keine verschiedenen Vorurteile machen, also der ist so, der ist so, also alle Menschen sind in der Hinsicht gleich. Man darf, wenn man zwischen den Menschen, sag ich mal, Grenzen setzt, dann bauen sich automatisch Vorurteile auf. So, und jeder Mensch ist ein Individuum, man muss nur wissen, wie man mit den Menschen umgeht oder wie man mit den Menschen einen Dialog führt." (Adem, Z.: 256)

Durch eine religiöse Erziehung könne erreicht werden, dass gemäß dem Bedürfnis eines jeden Menschen nach Anerkennung und Liebe im Sinne von »Empfangen und Weitergeben« eine Nächstenliebe zu allen Geschöpfen Gottes/Allahs entstehe. Dies sei nicht nur im christlichen Sinne zu verstehen, sondern vielmehr als Nächstenliebe zu den Menschen um des Schöpfers Willen (türk. Yaratılanı sev, yaratan da ötürü) ${ }^{102}$. Doch müssen laut Feride zunächst Ängste und Vorurteile abgebaut werden, damit der »eingeschlagene Weg« zur Nächstenliebe bei den Menschen bzw. den Geschöpfen Gottes führe (vgl. Feride, Z.: 541-571).

Ein »religiöses Kind« bzw. später ein »religiös geprägter Mensch« könne positiv auf die Gesellschaft einwirken, indem dieser »seine Verantwortung gegenüber der Gesellschaft « wahrnehme und sich durch Hilfsbereitschaft und Solidarität für die Belange der Menschen in der Gesellschaft engagiere:

102 | Hier wird auf den großen türkischen Mystiker Yunus Emre Bezug genommen. 
"Ja, das ist mein, ich hoffe, dass wir, dass ein religiöses Kind, [...] wirklich positiv auf die Gesellschaft einwirkt, dass es sich seiner Verantwortung gegenüber der Gesellschaft nicht entzieht und denkt, Ich lebe in meinen vier Wänden und solange es mir gut geht, ist meine Welt gut, sondern auch mal den Blick über den eigenen Tellerrand wagt und guckt, was machen die Menschen? Was machen andere Menschen? Geht es denen gut? Und wenn es denen nicht gut geht, dann helfe ich denen in irgendeiner Art und Weise. [Also eine gewisse Solidarität?, Anm. d. Verf.]. Natürlich, dass ich mich auch politisch engagiere, dass ich zum Beispiel gucke, wo in einer Gesellschaft: Wo sind die Schwachpunkte? Und mich da wirklich dafür einsetze." (Belkıs, Z.: 419 ff)

Auch Birol hebt die sozialethische Komponente des zwischenmenschlichen Daseins hervor. Religiöse Erziehung vermittle Grundwerte, die im zwischenmenschlichen Bereich »das Gute« betonen würden. So könne der Blick der Leistungsgesellschaft, die das Materielle in den Vordergrund stelle (»[...] ja, sich nicht über das definiert, was man hat, also materiell hat, mein Haus, mein Auto, mein Boot...«), vielmehr auf das Immaterielle gelenkt werden. Der veränderte Blick könne dazu beitragen, dass Notleidenden und Menschen, die weniger hätten, auf der ganzen Welt geholfen werde, indem ein Teil des Besitzes bzw. des Geldes gespendet und dabei Freude empfunden werde:

"Dass man dann einfach einen Teil seines Geldes, ja auch mal spendet und damit auch Freude hat, ja, dass man was Gutes tut, anstatt sich die neueste, ich weiß nicht, Spielekonsole zu kaufen, oder so, dass man dabei auch Freude empfinden kann." (Birol, Z.: 401)

\section{Zusammenfassung deR Wichtigsten ERgEBNISSE AUS DER UNTERSUCHUNG}

Die Auswertung des empirisch gewonnenen Materials ergab eine Typologie von vier religiösen Erziehungstypen, die die Perspektive von muslimischen Eltern wiedergibt. Es konnten sowohl typspezifische Eigenschaften als auch eine Binnendifferenzierung zwischen den Proband(inn)en eines Typs vorgestellt werden. Bisher wurden diese Typen getrennt nach den jeweiligen Untersuchungskategorien herausgearbeitet und vorgestellt: die religiöse Erziehung innerhalb der Familie mit den jeweils dazugehörigen Aspekten, wie den Erziehungsstilen und den Erziehungsmethoden, die Religiosität als Folge der religiösen Sozialisation in den Familien sowie die (fördernden oder hemmenden) Einflüsse der Sozialisationsinstanzen, wie bspw. der außerschulischen Bildungseinrichtungen, der staatlichen Bildungseinrichtungen, der Peers, Medien und der Gesellschaft, auf die religiöse Sozialisation. Im Folgenden sollen nun die Ergebnisse der typologischen Analyse unter dem Blickwinkel der 
Gemeinsamkeiten und Unterschiede zwischen den Typen zusammenfassend aufgezeigt werden.

Wie bereits dargelegt wurde, konnten aus dem empirischen Material die religiösen Erziehungstypen anhand ähnlicher Deutungsmuster, die sich insbesondere auf die Ziele der religiösen Erziehung bezogen, gewonnen werden. Die Gemeinsamkeiten lassen sich mit unterschiedlichen Stellenwert- und Prioritätensetzungen, die die jeweiligen Untersuchungsgruppen bzw. Typen angaben, wiedergeben (vgl. zur Typenbildung auch III. 2.3 Methode).

\subsection{Die Typen religiöser Erziehung}

Mit der vorliegenden Untersuchung konnte aufgezeigt werden, dass den Familien neben den religiösen Bildungseinrichtungen im (religiösen) Sozialisationsprozess eine der wichtigsten Rollen zukommt. Die in den Familien tradierte religiöse Erziehung bzw. die dort gelebte und erlebte Religiosität kann als die wichtigste Bedingung für eine spätere Religiosität angesehen werden. Die Pluralität von religiösen Erziehungsvorstellungen der befragten Eltern verweist auf differente religiöse Erziehungsmuster, die bisher nicht erforscht wurden. Nicht zuletzt konnte dadurch auf keine Untersuchungen zurückgegriffen werden, die die Perspektive der Eltern zur religiösen Erziehung in den Familien berücksichtigte. Um dieses Defizit auszugleichen, wurde zunächst versucht, anhand der Literatur über Jugendliche, die primär auf ihre Religiosität abzielt, eine Erziehungswirklichkeit in den Familien zu rekonstruieren bzw. nachzuzeichnen. Es konnte bei einem Vergleich der Forschungsliteratur mit der vorliegenden Arbeit festgestellt werden, dass hier Ähnlichkeiten mit zwei Typen der Religiosität in einer vorgestellten Untersuchung existieren (vgl. Karakaşoğlu-Aydın 2000). So werden in der vorliegenden Untersuchung bei der Typenbildung Eltern, die in ihrer religiösen Erziehung nach Sinn und Orientierung streben, als Idealisten und Eltern, für die die Einhaltung von religiösen Vorschriften im Vordergrund stand, als Ritualisten bezeichnet. Diese Typen beziehen sich in der vorliegenden Untersuchung erstmalig primär auf religiöse Erziehungsvorstellungen und nicht auf die Religiosität. Da ja die Religiosität ein subjektiver Ausdruck der vermittelten religiösen Erziehung ist, ist nicht zuletzt darauf hinzuweisen, dass eine scharfe analytische Trennung der beiden Kategorien »religiöse Erziehung« und »Religiosität« nicht immer möglich ist. So stehen die religiösen Erziehungsvorstellungen und die in der Familie gelebte Religiosität in einem engen Zusammenhang.

Ferner konnte die Entstehung zweier weiterer neuer Typen festgestellt werden: die Identitätssucher, die die Entwicklung der Persönlichkeit des Kindes in den Vordergrund stellen, und die Ethiker, die sich primär ethischen Grundsätzen in der religiösen Erziehung verpflichten. 
Für die vorliegende Untersuchung wurden Proband(inn)en gewählt, die einen türkischen Migrationshintergrund haben und denen die religiöse Erziehung ausdrücklich von Bedeutung ist. Die meisten von ihnen standen in direkter Verbindung oder zumindest bei der Wahrnehmung von religiösen Bildungsangeboten in Verbindung zu den (türkischen) religiösen Dachverbänden, sodass ein breites Spektrum an Muslimen erfasst werden konnte. Jedoch konnte kein eindeutiger Zusammenhang mit den Typen religiöser Erziehung und einer bestimmten Verbandszugehörigkeit bzw. -nähe ausgemacht werden. Die Proband(inn)en, die verschiedenen Typen angehören, sind quer durch alle religiösen Gemeinschaften vertreten und vorzufinden oder haben aufgrund der Wahrnehmung von religiösen Bildungsangeboten einen mehr oder weniger starken Bezug zu diesen (Moscheebezug).

Durch eine höhere Anzahl an Proband(inn)en würden sich möglicherweise noch Zwischenformen von religiösen Erziehungstypen bilden lassen. Bei den befragten Eltern handelt es sich zumeist, auch wenn einige Ausnahmen vorhanden sind, um bildungserfolgreiche Mütter und Väter, die sich in der deutschen Sprache zu artikulieren vermochten. Auffällig häufig meldeten sich insbesondere Mütter mit pädagogischen Ausbildungen oder wurden Eltern, zwecks Interviewdurchführung, vermittelt. Als Expertinnen legten sie eine hohe Artikulationsbereitschaft an den Tag. Es wurde aber darauf geachtet, ihre Anzahl nicht so hoch zu halten, damit ein breites Spektrum an muslimischen Eltern in der Untersuchung vertreten ist. Die Gruppe, die sich über ihre Religion ausschließlich in türkischer Sprache äußern konnte, ist im Sample mit zwei Probandinnen und einem Probanden jedoch eher klein. Auch hier hätte eine höhere Anzahl an türkischsprachigen Eltern wahrscheinlich, neben vertiefenderen Aussagen zu ihrer Religion, nochmals eine höhere Binnendifferenzierung innerhalb der Typen ermöglicht. Auch fiel während des Samplings die Zahl derjenigen Eltern auf, die sich nicht dazu imstande sahen, sich in beiden Sprachen, sowohl auf Deutsch als auch auf Türkisch, zu äußern, was zum einen damit zusammenhängen könnte, dass sie sich nicht für kompetent genug hielten, sich über ihre Religion zu äußern, und zum anderen, dass eine gewisse Scheu gegenüber der Aufzeichnung des Interviewgesprächs vorhanden war. In diesen Fällen könnten andere Methoden, wie teilnehmende Beobachtungen oder anderweitige Methoden der Feldforschung, zu weiteren wichtigen Ergebnissen beitragen.

Nicht erfasst worden sind hier auch Eltern, die eher muslimischen Randgruppen angehören. Diese stellen innerhalb der türkischstämmigen Muslime wohl eine sehr kleine Minderheit dar. Aber auch stärker spirituell ausgerichtete oder alevitische Gruppen, die sich im Spektrum der muslimisch-türkischen Gemeinschaften befinden, sind in der Untersuchung nicht vertreten. Schließlich ist auch auf muslimische Eltern hinzuweisen, die sich zwar nicht zu einer explizit religiösen Erziehung bekennen und dadurch für diese Unter- 
suchung nicht gewonnen werden konnten, jedoch vielfach religiöse Elemente in einer unreflektierten Weise in ihren Familienalltag integrieren. Dies sind häufig traditionell gelebte Formen der Religiosität oder auch volksreligiöse Auffassungen, die mit einem geringeren Bewusstsein für die eigene Religion einhergehen. Hier finden sich auch häufig Vermischungen von religiösen und kulturellen Elementen, die es gerade Außenstehenden erschwert, zu erkennen, was hinter dem Attribut »muslimisch« steht.

Unabhängig davon, welchem Typ die Proband(inn)en angehören, spielen für sie alle die Befolgung von religiösen Geboten bzw. handlungs- und orientierungsleitende Prinzipien, die Verinnerlichung eines religiös-ethischen Leitbildes und sinnhaft spirituelle Momente in der religiösen Erziehung eine wichtige Rolle. Neben den die jeweiligen religiösen Erziehungstypen kennzeichnenden Unterschieden weisen die Gemeinsamkeiten auf die drei wesentlichen Grundkomponenten, wie die Glaubensgrundlagen ${ }^{103}$, die rituellen Handlungen bzw. die religiöse Praxis und die ethisch-moralischen Aspekte einer religiösen Erziehung (vgl. Kap. III. 3.3.1 d) hin. Diese sind für alle Eltern verbindliche normative Grundlagen, die jedoch mit einer unterschiedlichen Intensität und Prioritätensetzung und subjektiven Deutungsmustern verfolgt werden. Insgesamt äußern sich ihre Grundhaltungen demgemäß in der von ihnen gelebten Religiosität.

Das Streben nach Sinn und Orientierung, das insbesondere für alle idealistischen Eltern kennzeichnend ist, nimmt auch für Ritualisten, Identitätssucher und Ethiker eine zentrale Rolle ein. Jedoch weisen die letzteren Typen geringere Fallzahlen auf als die Idealisten selbst. Die Bedeutungszuweisungen bzw. Sinnbezüge, die nichtidealistische Eltern herstellen, haben zwar einen ähnlichen Charakter, unterscheiden sich jedoch in ihrem Ausmaß und zum Teil in der Zielrichtung, die durch sie gewählt werden.

Das Streben nach Sinn und übergeordneten Prinzipien, die eine Orientierung im diesseitigen Leben bieten sollen, stellt für Idealisten den Deutungsrahmen für ihre erzieherischen Vorstellungen und Handlungen dar. Da bei ihnen Begründungen auf religiös fundierte Begrifflichkeiten und Deutungsmuster stoßen, auch unter Bezugnahme auf islamische Quellen, könnte man hier von Erziehungskonzeptionen sprechen, denen idealistische Eltern folgen möchten. Auch innerhalb dieses Typs weist eine Binnendifferenzierung auf unterschiedliche Auffassungen einer Sinn- und Orientierungsfunktion der religiösen Erziehung hin. So wird mit »Orientierung« auf eine Kontingenzbe-

103 | Wie noch im nächsten Kapitel aufgezeigt wird, finden sich sehr starke Äquivalenzen zwischen den religiösen Erziehungszielen und den von den Eltern dargelegten Glaubensvorstellungen. Neben den Glaubensgrundlagen werden auch die Konsequenzen benannt, die sich aus diesem Glauben ergeben. Diese spiegeln die Grundauffassungen wider, die von den Eltern als Erziehungsziele benannt werden. 
wältigung im Alltag abgezielt, die Halt vor negativen Außeneinflüssen oder Zukunftsängsten bieten solle (vgl. auch Uslucan 2015: 753f.). Aber auch der Sinn und Zweck des irdischen Daseins und die Unterscheidung zwischen »Gutem und Schlechtem«, die der eigenen Wahrheit, d.h. der koranischen Auslegung in Form von Ideen, handlungsleitenden Regeln und Prinzipien bzw. ethischen Grundsätzen, entsprechen, sind für diese Eltern wesentlich.

Mit einer geringeren Intensität wünschen sich dies auch Eltern anderer Typen für ihre Kinder. Die Identitätssucher verwiesen, ähnlich wie idealistische Eltern, auf den Sinn des Daseins. Die Perspektiv- und Ziellosigkeit unter Jugendlichen, die als Folge der schnelllebigen Zeit, begleitet durch den rasanten Fortschritt der Technologie, eingetreten ist, soll durch Religion und religiöse Erziehung aufgehoben werden. Auch für einige Ethiker ermöglicht eine bewusst islamische Erziehung eine Wertevermittlung, die orientierungsgebend für den zukünftigen Weg der Kinder wirken soll. So wird dadurch persönliches Glück und auch beruflicher Erfolg erhofft. Auch unter ihnen wird auf die Kontingenzbewältigung im Alltag abgezielt: Geborgenheit, Sicherheit, ein Anker in schlechten Tagen und in Situationen der Verzweiflung sowie innere Ruhe und Frieden sollen durch eine bewusst religiöse Erziehung erreicht werden. Bei den Ritualisten spielt ebenfalls ein gewisses Schutz- und Haltbedürfnis eine wichtige Rolle. So solle die Religion Schutz, Sicherheit und Halt vor negativen Fremd- und Außeneinflüssen bieten und typischerweise eine Orientierungsfunktion (vgl. auch ebd.: 757) erfüllen, um gerade religiöse Vorschriften einzuhalten. Der Fokus liegt hier im Vergleich zu anderen Eltern bzw. Typen stark auf der Befolgung von Ritualen bzw. der religiösen Praxis.

Der Ritualismus ist, gerade wenn es um die Erfüllung der fünf Säulen des Islams geht, ein Wesenskern der islamischen Religion überhaupt. Ausnahmslos alle Eltern legen Wert auf die Erfüllung von Ritualen und implementieren diese mit einer unterschiedlichen Intensität in ihren Familienalltag. Auch werden durch die Eltern die gemeinschaftsfördernden Aspekte der Rituale mit einer unterschiedlichen Gewichtung betont bzw. gelebt. Allen voran sind es - wie es schon der Name andeutet - die Ritualisten, die auf die Einhaltung von religiösen Vorschriften ein ganz besonderes Augenmerk richten. Im Vergleich $\mathrm{zu}$ den anderen Eltern ist die Einhaltung von religiösen Geboten für ritualistische Eltern besonders charakteristisch. Sie legen viel Wert auf eine klassisch-islamische Basiserziehung, die die Glaubensgrundlagen und die fünf Säulen des Islams als katechetische Richtschnur für Handlungsanweisungen beinhaltet. Die Regelhaftigkeit besagt nicht zuletzt neben der Befolgung von religiösen Geboten, d.h. dem Gebotenen (arab. halal, türk. helal), auch das Verworfene (arab., türk. haram) zu umgehen. Insbesondere das Tragen des Kopftuchs findet als ein religiöses Gebot unter allen ritualistischen Eltern Erwähnung. Aber auch Eltern anderer Typen verweisen auf die Bedeutung dieses religiösen Gebots, ganz gleich ob es sich dabei um die eigene Sozialisation im 
ursprünglichen Elternhaus oder um die eigenen Kinder handelt. So spiegelt die Bedeutung des Kopftuchs für die Religiosität auch die öffentliche Diskussion rund um das Thema wider (vgl. z.B. Boos-Nünning 2007; Nökel 2002; Nökel 2007 u.a.).

Für idealistische Eltern, aber auch Identitätssucher und einen Elternteil, für den ethische Grundsätze im Vordergrund stehen, ist der Ausgangspunkt für die Befolgung von Ritualen bzw. religiösen Geboten ein anderer als für ritualistische Eltern, die von vornherein einen eindeutigen Regelbezug vermitteln möchten. Auch unter idealistischen Eltern wird, im Vergleich zu ritualistischen Eltern, z.B. der rituellen Befolgung der täglichen Gebete eine hohe Priorität beigemessen. Sie betrachten die Einhaltung dieses Gebots als eine »Selbstverständlichkeit«, der die Kinder vielmehr mit einer hohen Eigenverantwortung auf der Grundlage der von den Eltern vermittelten religiösen Deutungsmuster folgen sollen (vgl. oben).

Allen Eltern, gleich welchem Typ sie angehören, ist die Verinnerlichung eines ethisch-moralischen Leitbildes bzw. von Werthaltungen in ihrer religiösen Erziehung von besonderer Bedeutung. Auch dieser Aspekt der religiösen Erziehung, die eine wichtige Gemeinsamkeit zwischen allen Eltern bzw. Typen darstellt, wird mit graduellen Unterschieden an die Kinder herangetragen. Für Eltern, die sich vordergründig ethischen Grundsätzen verpflichten, den Ethikern, soll die Entwicklung zu einem "guten« Menschen und die Verinnerlichung von Charaktereigenschaften, die religiösen Normen entsprechen, ihre Kinder dazu befähigen, sich auf ihren Glauben zu beziehen, um religiöse Pflichten und Gebote gewissenhaft zu erfüllen. Dabei sollen sie sich selbst zunächst als Menschen wahrnehmen, die durch ihr vorbildlich (muslimisch geprägtes) Verhalten mit sich und ihrer Umwelt im Einklang stehen. Es liegt auch ein gewisser universeller Anspruch hinter dieser Forderung. Denn die Kinder sollen ethischen Grundsätzen, wie Gerechtigkeit, Geduld, Ehrlichkeit, Achtung und Verantwortungsbewusstsein, gegenüber ihren Mitmenschen u.a. genügen, ohne sich auf den Personenkreis ihrer eigenen Religionsgemeinschaft zu beschränken. Alle anderen Aspekte, wie Sinnorientierung oder religiöse Praxis, werden dieser Prämisse untergeordnet.

Bei Eltern anderer Typen spielt die ethische Komponente der religiösen Erziehung keine geringere Rolle, jedoch ist sie z.B. für die Idealisten stärker mit ihrer »Weltanschauung bzw. einem tieferen Gottesbewusstsein verbunden. Als religiös-muslimische Menschen sollen ihre Kinder die Welt aus »religiöser Perspektive « oder mit »einer religiösen Brille« wahrnehmen und bewerten, was auch heißt, dass sie offen den anderen Menschen und der Welt gegenüberstehen. Ein Gottesbewusstsein, das die Präsenz Gottes im alltäglichen Leben nahelegt, ist für idealistische Eltern der wesentlichste Antrieb für ein sozialethisch verantwortbares Verhalten gegenüber den Mitmenschen und der Umwelt. Auch unter Ritualisten und den Identitätssuchern werden ethische 
Grundsätze und Eigenschaften benannt, die als Resultat der religiösen Erziehung hervorgehen sollen. Dazu gehören Mitmenschlichkeit, Hilfsbereitschaft, Respekt, Ehrlichkeit, Geschwisterliebe und Toleranz. Gutes zu verrichten, diszipliniere nicht zuletzt auf eine besondere Art, die die Kinder dazu bringe, die »islamischen Vorschriften« einzuhalten. Bei den Identitätssuchern liegt der persönliche Schwerpunkt auf der Entwicklung einer Persönlichkeit, die sich in einer gereiften Form mit Eigenschaften wie Liebe, Vertrauen und Toleranz darbieten soll. An dieser Stelle wird unterstreichend angemerkt, dass die Liebe zu Gott zunächst die Liebe zu den Mitmenschen voraussetze.

Schließlich wird in der religiösen Erziehung auch auf die Entwicklung einer Persönlichkeit bzw. Identität rekurriert. So ging ein Typus hervor, der diesem Aspekt in der religiösen Erziehung besonderes Gewicht verleiht. Seine geringe Anzahl korrespondiert mit der Anzahl der Eltern, die sich darauf beziehen. Nur zwei Eltern, die dem idealistischen Typ angehören, verweisen eben auf den identitätsstiftenden Moment der religiösen Erziehung. Für die Identitätssucher stehen die Selbstverortung und die Selbstpositionierung als Muslim in der Gesellschaft stark im Vordergrund. Es verwundert nicht, dass gerade beide Probandinnen mit ihren pädagogischen Hochschulausbildungen sehr reflektierte Angaben über ihre eigene Sozialisation bzw. über ihre Suche nach einer möglichen Selbstverortung in dieser Gesellschaft gemacht haben. Diesen Eltern ist die Integration als Muslime in dieser Gesellschaft ein sehr wichtiges Anliegen und sie wünschen sich daher die Integration ihrer Kinder, besonders in den staatlich-institutionellen Einrichtungen. Sie engagieren sich daher stark, um dieses Ziel zu erreichen. Wie keine andere Gruppe bzw. kein anderer Typus setzen sie sich auch für den Dialog unter und die Vielfalt der Religionen ein. Der ausgeprägte Wunsch der Identitätssucher nach einem Dialog mit den Religionen bzw. dem Christentum deutet auf die Sehnsucht nach der Bewusstwerdung der eigenen muslimischen Identität in dieser Gesellschaft bzw. in der Diasporasituation, in der die Muslime eine kleine Minderheit darstellen, hin. Das Zugehörigkeitsgefühl, das dabei entstehen soll, zeigt nicht zuletzt das Bedürfnis der Eltern nach einer Anerkennung als Muslime in dieser Gesellschaft.

In diesem Zusammenhang spricht Schiffauer von einer »diasporischen Identität«, die sich unter den Migranten und Migrantinnen der zweiten und dritten Generation gebildet habe. Sie gehe aus der »Suche« nach der eigenen Identität hervor und habe auf Dauer »Wurzeln geschlagen, ohne die Bezüge zum Herkunftsland und zur islamischen Weltgemeinde aufzugeben« (Schiffauer 2010: 360).

Betrachtet man diejenigen idealistischen Eltern, die sich dem identitätsstiftenden Aspekt der religiösen Erziehung zuwenden, so sind deren Vorstellungen stärker auf der persönlichen Ebene (Mikroebene) zu verorten. Eine religiöse Erziehung soll Stärkung und Selbstvertrauen hervorbringen, damit 
die Kinder zu ihrer eigenen »Identität« stehen, die sie gemeinhin nach außen vertreten können.

Als letztes gemeinsames Merkmal konnte, trotz unterschiedlicher Nuancierungen, der intellektuelle bzw. wissensorientierte Zugang zur Religion vermerkt werden. Wie bereits dargelegt wurde, war eine gewisse Bildung die grundsätzliche Voraussetzung, um mit den Eltern überhaupt in Dialog treten zu können. Auch wenn die in der Untersuchung befragten Eltern einen Bildungsgrad vom Hauptschulabschluss bis zu akademischen Abschlüssen vorweisen konnten und sie einem hohen bis gar keinem Beschäftigungsgrad nachgingen, konnte hier kein eindeutiger Zusammenhang zwischen den Typen religiöser Erziehung und ihrem aktuellen Bildungsniveau ausgemacht werden. Jedoch setzt die Entwicklung von normativ begründeten Erziehungsvorstellungen ein »Mindestmaß « an Beschäftigung und Auseinandersetzung mit der eigenen Religion voraus (vgl. hierzu auch Karakaşoğlu/Öztürk 2007: 161), sodass auf einem unterschiedlichen (Bildungs-)Niveau und auf divergierenden Ebenen argumentiert wurde. Der Grad der Auseinandersetzung hängt stark von individuellen (religiösen) Bildungs- und Sozialisationsverläufen ab. Auch zeigte sich in vielen Fällen, dass ein hoher Gemeinschaftsbezug sowohl die intellektuelle als auch die rituelle Ausprägung der (Familien-)Religiosität beeinflusst.

\subsection{Religiöse Erziehung/Religiosität in den Familien}

Die Religiosität ist als Erziehungsziel ein Ausdruck der subjektiv vermittelten Erziehungsvorstellungen in den Familien. Ausgehend von den Glock'schen Dimensionen der Religiosität (vgl. Kap. II. 3.1.4 b) werden die erfahrenen (»affektiv«), gelebten (»handlungsorientiert«) bzw. auf die kognitive Ebene bezogen gedachten (»kognitiv«) Dimensionen der Religiosität innerhalb der Familien hinsichtlich der Gemeinsamkeiten und Unterschiede wiedergegeben. Hier können erstmals differente Muster familialer Religiosität, die in der Forschung bislang vernachlässigt wurden, aufgezeigt werden. Dabei werden auch die individuellen Schwerpunkte und Ausprägungen der Religiosität nach religiösen Erziehungstypen differenzierend berücksichtigt.

Es lassen sich allgemeine Kennzeichen und Merkmale der (Familien-)Religiosität wiedergeben, die bei einem Vergleich mit den zu Beginn vorgestellten Untersuchungen auf einige Ähnlichkeiten und Parallelen hinweisen. Sowohl die Analyse der Sozialisationsverläufe der Proband(inn)en in ihren Elternhäusern als auch die grundlegenden Charakteristika der vermittelten und gelebten Religiosität innerhalb der Familien deuten auf typspezifische Eigenheiten hin, die zusammenfassend zunächst in verallgemeinerter Form beschrieben werden. Die Entwicklung einer muslimischen Religiosität ist, wie schon Klinkhammer feststellt, infolge der »Thematisierung der familiären Herkunft und 
der biographischen Selbstverortung im Rahmen des Sozialisationshintergrunds« (Klinkhammer 2000: 284) zu verstehen.

Die Tatsache, dass die Migrationssituation die Religiosität der Muslime verstärkt, zeigen insbesondere die Sozialisationsverläufe von idealistischen Eltern. Ihr hoher Gemeinschaftsbezug und ihre, im Vergleich zur Elterngeneration, bewusste Suche nach der eigenen Wahrheit unter Rückbezug auf islamische Quellen, die den Orientierungsrahmen für die Entwicklung eines »authentisches Selbst« (Nökel 2002: 263) bieten, deuten auf einen sehr selbstbewussten Umgang mit der Religion und deren Grundlagen hin. Der hohe Gemeinschaftsbezug scheint bei diesen Eltern ein wichtiger Motor für ihr intellektuelles Selbstverständnis und infolgedessen für ihre religiöse Praxis bzw. Lebensweise zu sein, die sie an ihre Kinder herantragen.

Für die Ritualisten äußert sich ihre Religiosität vordergründig in ihren Handlungen und damit in ihrer religiösen Praxis. Dabei manifestiert sich ihre Religiosität insbesondere in den sozialen und gemeinschaftsfördernden Aspekten der Religion. Auch unter ihnen ist eine Abwendung vom traditionellen, religiös gelebten Islam der Elterngeneration hin zu einem »richtig« gelebten Islam zu beobachten. Die Aneignung von religiöser Bildung ist eine wichtige Voraussetzung, um diesem Anliegen zu genügen.

Alle (früheren) Untersuchungen belegen die identitätsstiftende Wirkung der Religion bzw. religiösen Erziehung auf ihre Angehörigen. Der identitätsstiftende Charakter der Religiosität wird, wie schon aufgezeigt, durch idealistische Eltern und Identitätssucher besonders unterstrichen. Die Religiosität fördert demnach das Selbstvertrauen, die Persönlichkeitsentwicklung und den selbstbewussten Umgang mit der Religion. Gemäß den Identitätssuchern trägt sie zur persönlichen Reifung bei und führt daher zum Wandel, sowohl in der Persönlichkeitsstruktur als auch in der gelebten (»reiferen«) Religiosität. Ihre Religiosität und deren Facetten werden stets unter dem Blickwinkel der Identitätsentwicklung betrachtet. Für Ritualisten dagegen ist beispielsweise einzig der Effekt, das Selbstvertrauen zu fördern, den die Religiosität auf ihre Kinder ausübe, von Bedeutung. Des Weiteren betonen die Identitätssucher und auch ein Elternteil bei den Ethikern, im Vergleich zu den anderen Eltern, dass die Religiosität ein selbstverständlicher Bestandteil des Alltags und des Familienlebens sei.

Bei den Ethikern fällt, trotz ähnlicher Zielsetzungen in der religiösen Erziehung und weiteren gemeinsamen Merkmalen, eine eher individuelle Religiosität auf. Alle Proband(inn)en wählen, neben dem gemeinsamen Anspruch, dass sich die Kinder zu »guten Menschen« entwickeln und ethische Grundsätze für sich beherzigen, einen individuellen Zugang zur Religion. Dabei spielen handlungsleitende Prinzipien ebenso wie sinnstiftende Momente der Religion eine wichtige Rolle. Auch unter ihnen ist eine Abwendung von volksreligiösen Auffassungen bzw. dem traditionellen religiösen Islam der Elterngeneration 
zu beobachten. Sie möchten, im Vergleich zu ihren Eltern, den eigenen Kindern einen »reflektierten« Islam vermitteln, was zunächst in der Hinterfragung des Gegebenen mündet und schließlich zur subjektiven bzw. individuellen Wahrheitsfindung führen soll (vgl. auch Kap. II. 2.1.2 »Untersuchungen zur Jugendreligiosität«).

Weiter nach den Glock'schen Dimensionen der Religiosität: -Dimension der religiösen Erfahrung, des religiösen Glaubens, der religiösen Praxis, des religiösen Wissens und der Dimension der Konsequenzen aus den religiösen Überzeugungen- differenziert (vgl. Kap. II. 3.1.4), zeigen sich bei den religiösen Erziehungstypen sowohl typspefizische Eigenschaften und Ausprägungen als auch Gemeinsamkeiten (der Religiosität) zwischen allen Typen.

Ein wichtiges Ergebnis dieser Untersuchung ist, dass die Dimension des Glaubens die theoretische Grundlage bzw. das normative Bezugssystem für elterliche religiöse Grundeinstellungen bildet. In den Vorstellungen über den Glauben spiegeln sich analog dazu die Ideen und Gedanken zur religiösen Erziehung wider und finden darin ihre äquivalenten Entsprechungen. Die Konsequenzen, die aus den Glaubensvorstellungen abgeleitet werden, beinhalten sowohl erzieherische Prinzipien, die sich auf die emotionale Ebene, d.h. auf die Dimension der Erfahrungen, als auch auf handlungsleitende Prinzipien (auch die rituelle Dimension) beziehen. Die handlungsleitenden Prinzipien beinhalten für alle Typen die Befolgung von religiösen Geboten bzw. die Einhaltung von religiösen Vorschriften und ethisch-moralischen Grundprinzipien. Diese entspringen bei den Idealisten im Vergleich zu den anderen Typen einem tiefen Pflichtbewusstsein und der Rechenschaftspflicht vor Gott. Auch die Weitergabe von religiösen Erfahrungen und spirituellen Bezügen, wie z.B. Gottvertrauen bzw. Bindung an Gott, Schutz, Sicherheit, innerer Frieden u.a., finden sich bei allen Typen in unterschiedlichem Ausmaß wieder.

Auf der Dimension des Glaubens wurden äquivalente Vorstellungen zu den Erziehungszielen dargelegt. So impliziert der Glaube an Gott für alle Eltern bzw. Typen zum einen das Wissen um seine Existenz und zum anderen hilft er, den Sinn des irdischen Daseins zu begreifen. Häufig wird auch mit dem Glauben auf die Bewältigung des Alltags, der bevorstehenden Aufgaben im Leben oder aber auch auf die Überwindung von Lebenskrisen, wie z.B. den Tod, angespielt (Glaube als Kontingenzbewältigung). Schließlich wird mit dem »Glauben« auch auf die Glaubensgrundlagen des Islams, wie den Glauben an die Existenz Gottes oder an das Jenseits u.a., Bezug genommen.

So verwundert es letztlich nicht, dass die Idealisten charakteristischerweise die (praktische) Umsetzung der koranischen Botschaft, als Wort Gottes, für sich als Rechtleitung und »Wegweiser« empfinden. Der Glaube an Gott dient für sie auch als Weg zur Selbsterkenntnis und erfüllt eine wesentliche Orientierungsfunktion. Auffällig stark betonen Ritualisten, im Verhältnis zu ihrem Glauben, die Weitergabe von spirituellen Erfahrungen, die »Ordnung« 
und Sicherheit in ihr eigenes Leben und das ihrer Kinder bringen soll. Die Identitätssucher streben mit dem Glauben an Gott und das Jenseits zur »Vollkommenheit« bzw. zur persönlichen Reifung, die der Mensch mit den Grundkomponenten seines Daseins (Seele, Körper, Verstand) wahrnimmt und sich entsprechend dahingehend entwickelt. Die Ethiker verbinden mit ihrem Glauben jeweils individuell unterschiedliche Aspekte, die oben bereits erwähnt wurden, d.h., es bestehen innerhalb ihres eigenen Typs im Vergleich zu allen anderen religiösen Erziehungstypen weniger Ähnlichkeiten und Gemeinsamkeiten. Bei den Ethikern fällt zudem als einzig wichtige Gemeinsamkeit auf, dass sie im Vergleich zu den anderen Eltern weniger die Rituale, sondern vielmehr die Aneignung von normativen (sozial-)ethischen Grundhaltungen als Konsequenz aus ihren individuellen Glaubensvorstellungen ziehen. Auch trifft man unter ihnen auf die geringsten emotionalen und spirituellen Bezüge, sodass auch hier ein intellektueller und erkenntnisbezogener Zugang zum Glauben deutlich wird.

Die Aussagen der Eltern über religiöse Erfahrungen beziehen sich sowohl auf den Glauben als auch auf Rituale, sodass bei der Darstellung der Ergebnisse Überschneidungen unumgänglich sind. Jedoch sollen diese nicht detailliert aufgeführt werden. Wichtig ist, dass alle drei religiösen Erziehungstypen (Idealisten, Ritualisten und Idenitätssucher) das Gottvertrauen und die Bindung an Gott als Folge ihres Glaubens hervorheben. Ein Vergleich zwischen diesen drei Typen zeigt, dass die Ritualisten die stärksten spirituellen und emotionalen Bezüge in ihrer religiösen Erziehung herstellen (möchten). Die Spiritualität, die sich in Form von Schutz, Sicherheit, Geborgenheit, tiefer innerer Ruhe und letztendlich in Gottvertrauen, Ehrfurcht und Liebe vor Gott äußert, soll einen halt-bietenden und schützenden Effekt hervorrufen. Der ordnungsbringende Ertrag der Religiosität liegt bei ihnen nicht nur in der Regelbefolgung, sondern äußert sich in einer eindrücklichen Weise auch im religiösen Erfahrungsbereich. Auch die etwas geringere Spiritualität idealistischer Eltern weist Ähnlichkeiten auf: Ein Gottvertrauen sowie eine tiefe innere Ruhe werden als Resultat des Glaubens von ihnen angestrebt. Mit Zufriedenheit im Leben, Glück und Vollkommenheit deuten sie jedoch auch auf weltliche Aspekte und Lebensbereiche hin, die sie zu aktiven Gestaltern ihrer Lebensbedingungen machen. Im Vergleich dazu treten ritualistische Eltern als »Ordnungshüter« auf, die sich sowohl auf ihr Innenleben als auch auf den äußerlichen Bereich (in Form von Regelbefolgung) der Religiosität bezieht. Die Identitätssucher bringen mit religiösen Erfahrungen insbesondere das Gemeindeleben, wo diese gemacht werden, in Verbindung. Dabei erlernen die Kinder ihren Glauben sowohl in der religiösen Gemeinde als auch in der Familie durch ein aktives Vorleben der Eltern. Am wenigsten stellen die Ethiker spirituelle Bezüge her, die aufgrund ihres Glaubens erfahrbar sind. Hierzu gehören Glückseligkeit, innere Ruhe, Friede und Sicherheit. Gemeinsame Bittgebete, in denen eine 
sehr persönliche Beziehung zu Gott hergestellt wird, bilden für Ethiker und ihre Kinder wichtige gemeinsame Erfahrungsmomente.

Die Dimension ritueller Praxis wurde im Interview durch Angaben, die sich auf verschiedene Rituale des Islams, wie die täglichen Gebete, das Fasten im Ramadan, das Koranlesen oder das Feiern von religiösen Feiertagen, beziehen, untermauert. Jedoch hatten die Eltern die Möglichkeit, vorab darzulegen, welche Rituale für sie im Alltag von Bedeutung sind. Auch im rituellen Bereich gibt es Gemeinsamkeiten und Unterschiede zwischen den religiösen Erziehungstypen.

Wie schon die Studien über die Religiosität der Muslime im Allgemeinen erörtern (vgl. Kap. II. 1.3), nimmt der Ramadan, als die dritte Säule des Islams, typübergreifend für alle Erziehungstypen eine ähnlich große Bedeutung im Familienalltag ein. Hier werden auch die wichtigsten gemeinsamen religiösen Erfahrungen gemacht. Die Befolgung der täglichen Gebete, die von Kindern und Jugendlichen eine hohe Disziplin erfordert, wird am regelmäßigsten in den Familien der Idealisten beachtet. Auch die Identitätssucher legen neben dem Moscheebezug, den sich die Kinder aneignen sollen, viel Wert auf das Verrichten der Gebete, stellt dies doch die zweite Säule des Islams dar. Überraschenderweise nimmt für Ritualisten die Befolgung der Pflichtgebete keinen hohen Stellenwert innerhalb der Familie ein. Aufgrund des Zeitmangels wird diese Aufgabe jedoch an die religiösen Bildungseinrichtungen bzw. Moscheegemeinden delegiert. Auch das Koranlesen wird durch die Ritualisten den Gemeinden übertragen. Bei allen anderen Typen (Idealisten, Identitätssucher, Ethiker) nimmt die Koranrezitation bzw. das Hören derselben eine mittlere Bedeutung ein. Das Bücherlesen bzw. die Beschäftigung mit religiöser Literatur in Form von Gesprächsrunden (türk. sohbet) wird in einigen Familien, gleich welchen Typs, verstärkt rituell wahrgenommen und in anderen weniger stark. Eine Ausnahme bilden hier die Identitätssucher, die dem Bücherlesen und dem Einsatz anderer Medien eine hohe Priorität zuweisen. Dies hat wohl zum einen mit ihrer pädagogischen Grundausbildung zu tun, die eine hohe Reflexionsbereitschaft nahelegt, und zum anderen mit der Bedeutung, die sie den Familien in Bezug auf die religiöse Erziehung zuweisen.

Ritualisten betonen besonders stark die gemeinschaftsfördernden Rituale, wie die Spendengabe (die vierte Säule des Islams), das Verrichten der Pflichtgebete in den Gemeinden und den Gemeinde- bzw. Moscheebezug im Ramadan. Aber auch der Besuch der heiligen Stätten (die fünfte Säule des Islams) bleibt durch sie nicht unerwähnt. So zeigen diese Ergebnisse, dass für Ritualisten ohne einen religiösen Gemeindebezug eine religiöse Erziehung nicht möglich ist. Eine Erklärung könnte, neben den hohen Anforderungen des Alltags, auch darin liegen, dass sie sich in religiösen Angelegenheiten nicht für kompetent genug halten. So brauchen sie die Unterstützung von religiösen Bildungseinrichtungen und Moscheen, nicht zuletzt, damit die Kinder dort eine entspre- 
chende religiöse Bildung erhalten, worauf sie sehr viel Wert legen (vgl. Ceylan 2014).

Die Ethiker messen im Vergleich zu den anderen Typen der Befolgung von Ritualen (ausgenommen den religiösen Feiertagen) eine etwas geringere Bedeutung bei. Die oben benannten Rituale wurden insbesondere durch Bittgebete oder zwischenmenschliche Beziehungen (als Ritual) ergänzt. Auffällig stark betonen sie die Bittgebete als einem wichtigsten Ritual, das sie mit ihren Kindern pflegen. Damit sprechen sie im Vergleich zu den anderen Typen eher den persönlichen, privaten Raum für religiöse Rituale und Erlebnisse an. Es wird eine intensiv persönliche Beziehung zu Gott/Allah gepflegt, die, anders als bei den zuvor anthematisierten religiösen Erziehungstypen, nicht an Orten wie den Moscheen (vgl. »Idealisten«, »Ritualisten«, »Identitätssucher«) bzw. an den heiligen Stätten des Islams (»Ritualisten«) zum Ausdruck kommt.

Die Dimension des religiösen Wissens erlaubt Aussagen über den Umgang mit islamischen Quellen, wie dem Koran und der Sunna des Propheten Muhammad (s). Hierbei ging es auch um den argumentativen Umgang mit den wesentlichen Grundlagen des Islams, die sich auf diese beiden Quellen stützen. Nach Glock ist es wichtig die Beziehungen zwischen Umfang und Art des individuellen religiösen Wissens einerseits und den Mustern religiösen Glaubens, religiöser Praxis, religiösen Erlebens andererseits zu ergründen, damit die Wissensart näher bestimmt werden könne (vgl. Glock 1967: 163). Auf die Frage, welches Wissen Eltern ihren Kindern in jedem Fall vermitteln möchten, konnten hohe Korrelationen zwischen den Dimensionen ermittelt werden. Daher erscheinen die Ergebnisse zum Teil als Wiederholungen dessen, was analog zu den Erziehungsvorstellungen bisher aufgezeigt wurde und stellen sozusagen den Ausgangspunkt bzw. die Basis ihrer gelebten Religiosität dar. Die Dimension des religiösen Wissens veranschaulicht letztendlich auch, welcher Zugang zur Religion gewählt wird.

So wählen die Idealisten einen abstrahierend intellektuellen Zugang zu ihrer Religion, was sehr stark auf normative Sinn- und Begründungszusammenhänge hinweist. Auch Ethikern und Identitätssuchern ist die intellektuelle Auseinandersetzung mit ihrer Religion gemeinsam. Differenzierter betrachtet, fällt unter den Ethikern insbesondere der individuelle Zugang zur eigenen Religion mit persönlichen Schwerpunktsetzungen auf. Hierbei greifen sie typische Elemente und Merkmale auf, die auch bei Ritualisten und Idealisten vorzufinden sind (Sinnorientierung oder die Befolgung von religiösen Vorschriften), ohne diese jedoch für sich als übergeordnet zu betrachten. Im Vergleich zu den anderen Typen legen die Ritualisten, die gerade mit Aussagen und Argumenten in der Interviewsituation eher spärlich umgingen, sehr viel Wert auf die (auch: katechismuszentrierte) religiöse Bildung, die sie als solche als erstrebenswert erachten. Sie soll insbesondere dazu dienen, handlungsleitende Prinzipien der Religion in die Praxis umzusetzen. Dies soll nicht 
heißen, dass die Aneignung von religiöser Bildung für alle anderen Typen von geringerer Bedeutung ist, sondern sie wird entweder durch die Idealisten und Identitätssucher als selbstverständlich vorausgesetzt oder sie dient im Falle der Ethiker für die individuelle Wahrheitsfindung, die sie bei ihren Kindern anregen möchten.

Für die Idealisten steht die Herstellung eines Sinnbezugs durch das religiöse Wissen so stark im Vordergrund, sodass sie folgerichtig der aktiven und z.T. intellektuellen Beschäftigung bzw. Auseinandersetzung mit den Inhalten des Korans, der Sunna und dem »Wissen « um Gott als dem Schöpfer einen sehr hohen Stellenwert beimessen. Auch unter den Identitätssuchern und Ethikern finden sich Elternteile, die ihre Kinder zur Beschäftigung mit dem Koran motivieren. Im Vergleich dazu nimmt dies für ritualistische Eltern, je nach Bildungsgrad, einen niedrigeren Stellenwert ein. Sie zielen mit religiöser Bildung stärker auf die klassisch-islamische Bildung ab, deren Aneignung vielmehr auf dem Auswendiglernen beruht als auf einer aktiven sinnbezogenen Vertiefung der Lerninhalte. Es muss jedoch darauf hingewiesen werden, dass das Auswendiglernen nicht zu einer schlechteren Qualität bzw. zu einer geringer ausgeprägten Religiosität beiträgt. Die Ergebnisse zeigen, dass ritualistische Eltern, im Vergleich zu allen anderen religiösen Erziehungstypen, die stärksten emotional-spirituellen Bezüge aufweisen. Offensichtlich übt gerade dies eine hohe Bindungskraft aus, die sich sowohl auf die Ausübung der (gemeinschaftsfördernden) Rituale bzw. Einhaltung religiöser Vorschriften als auch auf den hohen Gemeinschaftsbezug auswirkt. Nicht zuletzt ist auch zu erwähnen, dass sie die unreflektierte Weitergabe von religiösen Inhalten in ihren Elternhäusern kritisierten. Das Auswendiglernen beruht hier nicht auf einer sinnlosen Nachahmung, sondern hat einen stark handlungsweisenden Charakter. Das Wissen, das angeeignet wird, soll sich primär in der »gelebten « und nicht der »beredeten« Religiosität äußern.

Schließlich verweisen sowohl idealistische Eltern als auch Ethiker auf das Erlernen und Internalisieren ethisch-moralischer Grundhaltungen und allgemeiner Grundlagen der Religion, wie die Glaubensgrundlagen, das Leben des Propheten (s), das Auswendiglernen von Suren und die rituellen Pflichten u.a. Das Erlernen von Grundlagen wird insofern auch als eine Folge der aktiven Auseinandersetzung mit den Hauptquellen des Islams angesehen.

\section{Erziehungsmethoden und -stile}

Allen (Erziehungs-)Methoden voran, wurden vonseiten der Eltern zuerst die Vorbildfunktion und das Vor- bzw. Ausleben der Religion und das Nachahmen im Kleinkindalter als wichtigste Vermittlungsformen präsentiert. Neben der Regelbefolgung, der die religiösen Erziehungstypen einen unterschiedlichen Stellenwert einräumen, spielt in allen Familien die Kommunikation mit dem Kind eine wichtige Rolle. Hierbei werden differente Kommunikationsformen 
angewandt. Am meisten versuchen die Eltern, ihre Kinder durch Begründungen, Überzeugungen und das Erklären durch Beispiele an ihre Religion heranzuführen. Dabei wird sowohl auf eine altersgemäße als auch eine lebens- bzw. alltagsnahe Vermittlung von religiösen Inhalten geachtet. Je nach pädagogischer Versiertheit, die auf den Ausbildungen und Weiterbildungen der Eltern basiert, werden auch spielerisch-kreative Elemente in der religiösen Erziehung eingesetzt. Im Gegensatz zu den Ergebnissen, die Klinkhammer (2000), Tietze (2001), Frese (2002), Öztürk (2007) und Aygün (2010) gewonnen haben, zeigt die religiöse Erziehung von muslimischen Eltern in dieser Untersuchung eine erhöhte Sensibilisierung in Bezug auf die Wahrnehmung und Umsetzung ihres religiösen Erziehungsverständnisses. Es ist, im Vergleich zu früheren Ergebnissen über religiöse Erziehung in Familien, inzwischen von einer »Professionalisierung « der religiösen Erziehung auszugehen, die ihren Niederschlag auch im Familienalltag findet. Dies lässt sich sicherlich auch damit erklären, dass die Proband(inn)en dieser Untersuchung derjenigen Generation angehören, die im Vergleich zu ihrer Elterngeneration von einem neuen, bewussten Religiositätsverständnis ausgeht, bei dem sie sich auf den »wahren« Islam bezieht. Hierbei stünden die intellektuelle Auseinandersetzung mit islamischen Quellen und eine bewusste islamische Lebensführung im Vordergrund (vgl. Karakaşoğlu-Aydın 2000; vgl. Klinkhammer 2000; vgl. Nökel 2002; vgl. Tietze 2001; vgl. Frese 2002; vgl. Öztürk 2007).

Um die Erziehungsstile der Eltern zu ermitteln, wurde auf die Bezugnahme von theoretischen Konzeptionen verzichtet. Dies hat ihre Ursache zum einen darin, dass, bezogen auf »Erziehungsstile in Migrationsfamilien«, widersprüchliche Ergebnisse vorliegen, welche eine einfache Bezugnahme fragwürdig erscheinen lässt (vgl. Boos-Nünning 2011a: 33f.). Zum anderen handelt es sich hier um religiöse und nicht um allgemeine Erziehung, auf die sich die Erziehungsstilkonzepte vordergründig beziehen. Die Art und Weise, wie Eltern mit ihren Kindern umgehen bzw. wie diese charakterisiert sind, wurde in der vorliegenden Untersuchung daher induktiv, d.h. auf den Aussagen der Eltern basierend ermittelt. Um die Erziehungsstile bestimmen zu können, wurde neben der Regelbefolgung zudem die Konfliktlösungsstrategie der Eltern berücksichtigt. Gerade darin unterscheiden die Eltern vornehmlich zwischen allgemeiner und religiöser Erziehung. Es werden im Folgenden lediglich die prägnantesten Merkmale, die bei den jeweiligen religiösen Erziehungstypen auffallen, beschrieben. Ein wichtiges Ergebnis dieser Untersuchung ist, dass die Einhaltung der Gebetsvorschrift als ein Indikator zur Bestimmung der (religiösen) elterlichen Erziehungsstile gelten kann. Jedoch muss vorab auch deutlich gemacht werden, dass erst eine vertiefende Analyse der Erziehungsstile anhand weiterer Untersuchungskategorien notwendig ist, um die ermittelten Merkmale (hier in dieser Untersuchung: »Förderung der Selbstständigkeit«, die »Übernahme von Verantwortung« durch das Kind, »Disziplin«, »Liebe/ 
Geduld«, der Ausschluss von Zwang, d.h. »kein Zwang« und schließlich noch »Respekt vor Älteren«) zu stützen bzw. eine theoretisch genaue definitorische Beschreibung der Merkmale zu ermöglichen. Ein Analyseinstrument, das der religiösen Erziehung und den Erziehungsstilen in muslimischen Familien gerecht werden könnte, fehlt bislang.

Es konnten insbesondere anhand der Aussagen idealistischer Eltern und der Ethiker die »Förderung von Selbstständigkeit« und die »Übernahme von Verantwortung« als Merkmale elterlichen Erziehungsverhaltens herausgearbeitet werden. Bei der Übertragung von Verantwortung, die zu selbstständigem Handeln führen soll, unterscheiden sich die idealistischen Eltern von den Ethikern. Die Idealisten bringen die Selbstständigkeit und Verantwortungsübernahme mit der Befolgung von religiösen Geboten, hauptsächlich den täglich zu verrichtenden Gebeten, in Verbindung. Auch das Alter des Kindes spielt eine entscheidende Rolle. So werden von Jugendlichen eine höhere Selbstständigkeit und Verantwortungsübernahme bei der Verrichtung der Gebete oder beim Erfüllen der durch die islamische Sexualmoral auferlegten Gebote (wie z.B. das Ausgehverbot, das Verhältnis zum Gegengeschlecht, auch das Tragen des Kopftuchs) erwartet als von jüngeren Kindern. In einigen Familien herrscht auch ein disziplingeleitetes (»Disziplin«) Verhältnis zu den Kindern.

Die Ethiker hingegen legen mehr Wert auf die subjektiv-individuelle Wahrheitsfindung und Sinnfindung (zur Befolgung von Regeln) ihrer Kinder. Damit stellen sie bei Regelverletzungen bzw. der Nichteinhaltung von Geboten das Hinterfragen und Reflektieren, das bei ihren Kindern zu einer stärkeren persönlichen Autonomie führen soll, in den Vordergrund. Demnach überlässt ein großer Teil der Eltern die Verantwortung für die Befolgung von religiösen Regeln ihren Kindern. Da Rituale oder die Regelbefolgung nur für zwei Eltern innerhalb dieses Typs eine große Bedeutung haben, überrascht dieses Ergebnis nicht.

Die religiöse Erziehung der Identitätssucher ist primär durch »Liebe und Geduld« gekennzeichnet, da die Kinder noch im Kleinkindalter sind. Auch lassen sich ansatzweise, wie bei den anderen Eltern/Typen Erziehungsstile vorfinden, die auf die »Förderung der Selbstständigkeit« oder »Disziplin« verweisen.

Der Erziehungsstil von Ritualisten zeichnet sich primär durch »Liebe und Geduld « aus. Allen Eltern erscheint ein liebevoll-geduldiger Umgang mit ihren Kindern von herausragender Bedeutung. Auch ein disziplingeleitetes Verhalten (»Disziplin«), »Respekt vor Älteren« und die Vorgabe, keinen »Zwang« auszuüben sind als charakteristische Merkmale ihres Erziehungsverhaltens zu beschreiben. Die Verantwortungsübernahme durch das Kind und die Förderung der Selbstständigkeit werden von ritualistischen Eltern, im Vergleich zu allen anderen Typen, nur am Rande erwähnt. 
Zwang und Restriktionen werden in der religiösen Erziehung vonseiten aller religiöser Erziehungstypen abgelehnt. Dieses Ergebnis spiegelt auch die Antizipationen der Jugendlichen in den anfangs vorgestellten Studien (vgl. Kap. II. 2.1.2) wider. Bei Regelverstößen verhalten sich die Eltern unterschiedlich streng und disziplingeleitet. Von »Zwang« als einem möglichen Erziehungsmittel distanzieren sich typübergreifend alle Eltern, weil dessen Einsatz nicht zum gewünschten Ergebnis führe. Es berichten gerade diejenigen Eltern, die sich vorzugsweise von strafenden und unter Zwang eingeforderten Regeln distanzieren, gleichzeitig auch von einem liebevoll-fürsorglichen (»Liebe/Geduld«) Verhalten gegenüber ihren Kindern.

\subsection{Religiöse Sozialisation in anderen Kontexten}

Die religiöse Sozialisation erfolgt neben der Familie auch in anderen Kontexten bzw. Sozialisationsinstanzen, wie den außerschulischen und staatlich-institutionellen Bildungseinrichtungen. Untersucht wurde daneben auch der Einfluss der Peers, der Medien und der Gesellschaft bzw. der gesellschaftlichen Rahmenbedingungen, in der die religiöse Sozialisation stattfindet. Eltern messen dem Einfluss der verschiedenen Sozialisationsinstanzen und ihrem Beitrag für die religiöse Sozialisation einen unterschiedlichen Stellenwert bei.

\subsubsection{Religiöse Erziehung in außerschulischen Bildungseinrichtungen}

Den Moscheen und religiösen Bildungseinrichtungen, unabhängig davon, ob sie an Moscheegemeinden angegliedert sind oder nicht, und unabhängig davon, welches Bildungsangebot sie wahrnehmen, wird aufseiten aller Typen eine wichtige Bedeutung für die religiöse Sozialisation eingeräumt. Sie können als eine wichtige Säule einer islamisch begründeten religiösen Erziehung überhaupt angesehen werden. Wie schon die Untersuchungen und Expertisen belegen, kann dabei eindeutig (vgl. Kap. II. 1.4; Kap. II. 2.1 und II. 2.2.1) von einem unterstützenden und fördernden Effekt für die religiöse Sozialisation ausgegangen bzw. von einer wichtigen Sozialisationsleistung gesprochen werden. Das Verhältnis der einzelnen Typen zu den Einrichtungen und den jeweiligen Bildungsangeboten unterscheidet sich voneinander und es treten hier typspezifische Eigenheiten hervor.

Während die Idealisten die Moscheen und religiösen Bildungseinrichtungen für sich als Orte des muslimischen Lebens (ein Ort, an dem Bildungsangebote wahrgenommen werden, an dem tiefe Spiritualität erlebt wird, die ein Zugehörigkeitsgefühl vermittelt, die das Identifikationsbedürfnis stillt und die Heimatgefühle, Sicherheit und Geborgenheit vermittelt) schlechthin betrachten und diese folglich für sie eine tiefgreifende Stellung einnehmen, betrachten die anderen Typen diese in ihren unterschiedlichen Funktionen. 
Die Ritualisten kennzeichnen diese Einrichtungen typischerweise als Orte, an denen religiöse Bildung erlernt wird und die (gemeinschaftsfördernden) Rituale verrichtet werden. Betont wird ihre Leistung gerade im Zusammenhang mit den Pflichtgebeten und dem Erlernen der arabischen Schriftsprache bzw. der daraus folgenden Koranrezitation, deren Befolgung zu Hause nicht immer gewährleistet ist. Im Vergleich zu diesen beiden Typen streben die Identitätssucher nach einem ausgewogenen Verhältnis zwischen Familie, Moschee und den Schulen. Dabei heben sie die Familie als den wichtigsten religiösen Sozialisationsort sehr stark hervor. Die Aufgabe einer religiösen Erziehung dürfe demnach, trotz des hohen Stellenwerts, den sie ihr einräumen, nicht einfach an Moscheen delegiert werden. Für einen großen Teil der Ethiker nehmen Moscheen und religiöse Bildungseinrichtungen eine weniger wichtige Rolle ein als für alle anderen religiösen Erziehungstypen. Lediglich in der religiösen Erziehung möchten sie sich durch sie unterstützen lassen. Außerdem spielen diese, mit einigen Ausnahmen, für ihre gelebte Religiosität keine große Rolle.

Insgesamt zeigen die Ergebnisse bei einer differenzierteren Analyse, dass auch Kritik an der Bedeutung und dem Stellenwert von religiösen Bildungseinrichtungen geübt wird. Diese sollen vielmehr komplementär zur religiösen Erziehung innerhalb der Familie und, wenn dies auch weniger erwähnt wird, zur Schule wahrgenommen werden. Das einfache Delegieren der Kinder an religiöse Bildungseinrichtungen wird insbesondere vonseiten der Identitätssucher kritisiert. Gleichwohl unterstreicht fast die Hälfte der befragten Eltern die tiefergehende Bedeutung des religiösen Gemeindelebens für ihre Religiosität und ihre religiöse Erziehung.

Im Vergleich zu früher, als sich die Familien aufgrund geringer Bildungsvoraussetzungen und der Uninformiertheit über den Islam (vgl. Alacacığlu 1999; Ceylan 2008; Ceylan 2014; Karakaşoğlu/Öztürk 2007; und vgl. Kritik an Eltern in den vorgestellten Studien in Kap. II. 2.1 und II. 2.2.1) dazu veranlasst sahen, sich in der religiösen Erziehung durch die religiösen Bildungseinrichtungen unterstützen zu lassen, deuten die Ergebnisse dieser Untersuchung auf Veränderungen hin, die inzwischen eingetreten sind. Demnach zeigen alle Eltern, gleich, welchem Typ sie angehören, ein hohes Interesse bezüglich einer möglichst professionell und religionspädagogisch vermittelten religiösen Erziehung. Diese Tatsache verweist nicht nur auf die gestiegenen Ansprüche an eine religiöse Unterweisung außerhalb des familiären Rahmens, sondern auch auf eine bewusst vermittelte religiöse Erziehung innerhalb der Familien. Dieses Ergebnis gilt insbesondere für muslimische Eltern, die eine bewusste religiöse Erziehung an die nächste Generation weitergeben möchten. Betrachtet man diejenigen Eltern, die aufgrund einer geringen religiösen Bildung diese Aufgabe an die Moscheen delegieren (vgl. Ceylan 2014: 333f.), so ist möglicherweise auch unter ihnen eine Zunahme im Hinblick auf eine bewusst religiöse 
Erziehung zu erwarten. Jedoch fehlen bis dato weitere Forschungsergebnisse, die diese These stützen könnten.

Gerade die Aussagen über die Bildungsangebote religiöser Einrichtungen weisen (im Vergleich $\mathrm{zu}$ früher) auf eine zunehmende Professionalisierung und ein verstärkt differenzierteres Bildungsangebot hin. Auf das Bedürfnis einer altersgerechten Vermittlung von religiösen Inhalten (vgl. Kritik an Eltern in den vorgestellten Studien in Kap. II. 2.1 und II. 2.2.1) wurde reagiert, indem z.B. Frühfördergruppen (auch Krabbelgruppen) oder nach Klassen aufgeteilte Kurse eingerichtet wurden. Auch wird der Stellenwert der sog. sohbet-Gruppen, in denen ein informeller Austausch über religiöse Themen und Inhalte stattfindet, von den Eltern unterstrichen. Die Angaben über die religiöse Bildung wurden in drei Teile gegliedert wiedergegeben: a) Die Wissensvermittlung, der auch das Lernen des Koranlesens zugeordnet wurde; b) das Erlernen von Ritualen und c) die Wertevermittlung. Daneben wurden Angaben über die Methoden der religiösen Unterweisung und bezüglich der Freizeitgestaltung gemacht.

Im Antwortverhalten (unabhängig davon, welchem Erziehungskonzept die Einrichtungen folgen) der Eltern treten auch hier typspezifische Eigenheiten hervor. Idealistische Eltern stellen die Glaubensinhalte, die gemeinsam verrichteten Gebete, die Wertevermittlung sowie das muslimische Gemeindeleben (vgl. oben) in den Vordergrund. Auch verweist die Vielzahl der angewandten Methoden auf eine deutlich höhere Professionalisierung und die gestiegene Variabilität der Bildungsarbeit. Letztendlich drücken idealistische Eltern im Vergleich zu den anderen Elterntypen die höchste Zufriedenheit mit den religiösen Bildungsangeboten aus. Die Identitätssucher heben, ähnlich wie die Idealisten, das Erlernen der Glaubensgrundlagen hervor. Die angewandten Methoden in den Einrichtungen verweisen auf kreativ-künstlerische Elemente, die bei Kleinkindern eingesetzt werden. Auch die religiöse Atmosphäre und das soziale Umfeld in den Moscheen begünstigen gemäß diesen Elternteilen die religiöse Unterweisung in den Moscheen.

Ritualistische Eltern legen ihre Priorität auf die klassisch-islamische religiöse Bildung, womit schon im Wortgebrauch der Eltern auf die verschiedenen Disziplinen der islamischen Wissenschaften (Tafsir, Aquida, Hadith, Sira u.a.) angespielt wird. Einen besonderen Stellenwert genießen die rituell verrichteten Pflichtgebete und das Erlernen des Koranlesens. Darin ähneln ritualistische Eltern insbesondere den Ethikern. Jedoch fällt hier der unterschiedliche Wortgebrauch der Ethiker auf, die weniger auf eine klassische religiöse Bildung hinweist. Auch können sich Ethiker im Vergleich zu ritualistischen Eltern auf eine differenziertere methodische Umsetzung des religiösen Bildungsangebots berufen, was möglicherweise mit ihrer höheren Reflexionsbereitschaft zu tun hat. Gerade Methoden, wie das Auswendiglernen und der Frontalunterricht, die die Selbstständigkeit nicht fördern, werden von ihnen mit einem äußerst kritischen Unterton präsentiert. Im Bereich der Wertevermittlung sollen Ver- 
besserungen eintreten, die die Kinder und Jugendlichen durch das pädagogische Fachpersonal stärker als »Individuen« oder »Menschen « wahrnehmen lassen sollen. Dennoch drücken sie, alles in allem, auch ihre hohe Zufriedenheit mit den wahrgenommenen religiösen Bildungsangeboten aus.

Insgesamt zeugen die Erwartungen und Verbesserungsvorschläge, die alle Eltern bzw. Typen an außerschulischen religiösen Bildungseinrichtungen formulieren, von einem ausgeprägten Bedürfnis nach einer professionell vermittelten religiösen Unterweisung. Hierbei verweisen sie insbesondere auf die Qualifikation des Lehrpersonals, das neben der adäquaten Informationsvermittlung auch über (religions-)pädagogische Grundfertigkeiten (den Kindern ein Vorbildsein, alters- und kindgemäße Vermittlung, emotionale Fähigkeiten, Einsatz von kreativen Methoden) verfügen solle. Damit sollen insbesondere die Motivation und das Interesse der Kinder für den Besuch dieser Einrichtungen aufrechterhalten werden. Zudem wird der Wunsch an die religiösen Bildungseinrichtungen herangetragen, verstärkt auf die Eltern eingehen, indem Eltern-Kind-Konzepte unter Berücksichtigung spezifischer Anforderungen entwickelt werden (vgl. hierzu auch Ceylan 2014).

\subsubsection{Muslimische Kinder im Kontext von institutionellen Bildungseinrichtungen}

In dieser Untersuchung wurden erstmals Einstellungen, Wahrnehmungen und Bewertungen der Eltern hinsichtlich des Umgangs mit dem Islam in den staatlich-institutionellen Bildungseinrichtungen berücksichtigt. Dabei werden unterschiedliche Perspektiven und Blickwinkel der jeweiligen Typen deutlich. Ausgehend von der Fragestellung, ob Schulen und Kindertagesstätten einen fördernden oder hemmenden Effekt auf die religiöse Sozialisation ausüben, werden hier im Folgenden einige zentrale Ergebnisse zusammengefasst.

In einigen (wenigen) Fällen konnte aufgezeigt werden, dass die Schule einen hemmenden Effekt auf die religiöse Lebensweise von muslimischen Kindern ausübt, so z.B. das Tragen des Kopftuches behindert oder das Verrichten der täglichen Gebete erheblich einschränkt. Von einem hemmenden Effekt gehen am ehesten die Ritualisten aus. Aber auch die Idealisten wünschen sich einen toleranteren Umgang mit ihrer religiösen Lebensweise und Identität. In den meisten Fällen konnte nicht eindeutig nachgewiesen werden, ob ein fördernder oder hemmender Effekt auf die Religiosität der Kinder und Jugendlichen vorliegt. Zwar existieren erhebliche Benachteiligungen und Diskriminierungen, die sich auf die Religionszugehörigkeit und auf die religiöse Lebensweise zurückführen lassen. Jedoch konnte nicht eindeutig nachgezeichnet werden, ob diese Benachteiligungen auch zu einer geringeren Religiosität bei Kinder und Jugendlichen führen (bei den Idealisten, Ethikern und Ritualisten). Um dies eindeutig herausarbeiten zu können, sind diesbezüglich zukünftig noch 
wesentlich differenziertere Analysen unter Einbezug der betroffenen Kinder und Jugendlichen erforderlich.

Des Weiteren konnte in manchen Fällen nachgewiesen werden, dass insbesondere die Schule einen (nichtintendierten) religiösen Sozialisationseffekt begünstigt, indem Schüler/-innen aufgrund ihres Muslimseins zur Auseinandersetzung mit religiösen Themen angeregt werden. Dieses Ergebnis deckt sich weitgehend mit den Ergebnissen der Untersuchungen von Klinkhammer (2000) und Weniserski/Lübcke (2012). Es sind gerade die Identitätssucher, die sich eine fördernde Wirkung auf die religiöse Sozialisation im Zusammenhang von Identitätsbildungsprozessen erhoffen. Hier soll Religion als Ressource wahrgenommen werden, welche außerdem eine Orientierungsfunktion beim Aufbau eines entsprechenden Selbstbewusstseins einnehmen kann. Schließlich sind es auch die Identitätssucher, die im Vergleich zu allen anderen Typen der Schule als Sozialisationsort einen wichtigen Stellenwert bei der Vermittlung ihrer religiösen Werthaltungen zuweisen. Neben der Einführung des islamischen Religionsunterrichts wünschen sie sich, dass die Schule als ein Ort des Lernens Möglichkeiten für ein friedliches Zusammenleben zwischen Muslimen und Nichtnuslimen eröffnet. Insofern wird durch diesen Typ ein komplementäres und ausgewogenes Dreiecksverhältnis zwischen Familie/ Moschee/religiöser Gemeinde und Schule anvisiert.

Die Haltung der Lehrer/-innen und Erzieher/-innen gegenüber den Muslimen und dem Islam, die aus der Wahrnehmung der Eltern wiedergegeben wird, zeigt, wie viel Verständnis und Toleranz im Umgang mit der Religion existiert. Dabei ist insgesamt festzustellen, dass ein Teil der Pädagog(inn)en sich positiv und verständnisvoll verhält, wohingegen ein relativ großer Anteil Vorurteile gegenüber den Muslimen und dem Islam zeigt. Hier scheinen die Grundschulen und Kindertagesstätten etwas toleranter zu sein als weiterführende Schulen. Fast jedes Elternteil, gleich welchen Typs, berichtet von negativen Erfahrungen, die auf ihre religiöse Zugehörigkeit zurückzuführen sind. Besorgniserregend sind insbesondere Diskriminierungserfahrungen und Benachteiligungen, die sich sowohl auf das Muslimsein als auch auf die religiöse Lebensweise, wie z.B. das Tragen des Kopftuchs beziehen. Dabei nehmen Ritualisten die stärksten Benachteiligungen wahr und fühlen sich Vorurteilen durch Lehrpersonen am stärksten ausgesetzt.

Die meisten Eltern betonen das eigene Engagement und die Haltung zu den Problemen. Idealisten, Ethiker und die Identitätssucher zeigen sich im Umgang mit auftretenden Problemen besonders engagiert. Hierbei berufen sich die Identitätssucher am stärksten auf ein konstruktives Miteinander, was auf ihrem stark ausgeprägten Dialogverständnis beruht. Die Ethiker, welche Ritualen eine etwas geringere Bedeutung bemessen (folglich ihre Religiosität nicht unbedingt sichtbar ist) formulieren weniger (sozialisationsrelevante) Erwartungen an institutionelle Einrichtungen. Dies äußert sich nicht zuletzt 
auch darin, dass sie weniger Benachteiligungen und Vorurteile wahrnehmen. Die Ritualisten dagegen sind zwar darum bemüht, dass Aufklärungsarbeit stattfindet, allerdings fühlen sie sich mit ihrem Wunsch alleingelassen und nehmen z.T. eine defensive Haltung ein, da nicht noch mehr Probleme und Konflikte entstehen sollen.

Mit der Einführung des islamischen Religionsunterrichts (IRU) werden vonseiten aller Eltern bzw. Typen vordergründig integrationsfördernde und identitätsbestimmende Erwartungen verbunden. Ferner soll dadurch die Fähigkeit der Kinder, über ihre eigene Religion sprechen zu können, gefördert werden. Fast alle Eltern sind davon überzeugt, dass der IRU flächendeckend an allen Schulen eingeführt werden sollte. Jedoch werden kaum oder wenig sozialisationsrelevante Erwartungen damit verknüpft. Es treten auch hier typspezifische Merkmale auf. Die Erfahrungen der Idealisten mit dem IRU geben ein durwachsenes Bild ab. Auch wenn positive Effekte mit dem Besuch des IRU erzielt werden können, knüpfen sie diese an diverse Bedingungen und zeigen, im Vergleich zu den anderen Typen, die stärksten Vorbehalte gegenüber dessen Einführung. Die Ritualisten erwarten vom IRU typischerweise die Vermittlung von religiösen Grundinformationen. Dieser Wunsch korrespondiert auch mit ihren eigentlichen Erziehungszielen. Für die Identitätssucher und vereinzelt auch bei Eltern unter den Ritualisten und Ethikern spielen mit dessen Einführung der Dialog zwischen Muslimen und Andersgläubigen, die Anerkennung von Vielfalt, die Aufklärung über den Islam, der Wunsch des Respekts und der Wertschätzung gegenüber der eigenen Religion sowie die Integration von muslimischen Kindern in den Schulalltag eine besondere Rolle. Die Ethiker betonen mit der Einführung des IRU nicht zuletzt die Hoffnung einer intellektuellen Auseinandersetzung mit der Religion. Sie soll im Vergleich zu ihrem Alltagsverständnis die Kinder in die Lage versetzen, eine andere, wissenschaftlichere Zugangsform zu ihrer Religion zu wählen. Auch sollen wichtige Grundsätze der Religion und religiöse Begrifflichkeiten erlernt werden. Schließlich machen sie zudem auf die Qualifikation der zukünftigen Religionslehrer/-innen, die verschiedenen Anforderungen genügen sollen, aufmerksam.

\subsubsection{Die Peers, Freundschaften und deren Einfluss auf die religiöse Sozialisation}

Welchen Einfluss die Freundschaften und die Peers auf die religiöse Sozialisation haben, hängt jeweils von den Eltern ab, die ihre Kinder bei der Wahl ihrer Freundschaften in unterschiedlichem Maße beeinflussen. Im Vergleich zu den vorangegangenen Sozialisationskontexten bzw. -instanzen lassen sich hier weniger typspezifische Merkmale identifizieren. Einzig die Idealisten zeigen den höchsten Grad an Beeinflussung. Außerdem spielt in vielen Fällen die Anlage der Kinder eine Rolle, die innerhalb einer Familie aufgewachsen sind. 
Dies äußert sich im unterschiedlichen Umgang der Kinder mit Freundschaftsbeziehungen. Die Idealisten und einige Eltern bei den Ethikern, Ritualisten und Idenitätssuchern üben einen starken Einfluss auf die bewusste Freundschaftswahl ihrer Kinder aus, um einen positiven Einfluss auf die religiöse Sozialisation zu erzielen, so z.B. eine religiöse Atmosphäre zu gewährleisten, die Verrichtung der Gebete zu fördern, die islamische Sexualmoral und die muslimische Speisevorschrift einzuhalten oder den Kindern eine religiöse Perspektive zu bieten. Wiederum andere Eltern üben einen geringeren Einfluss aus und überlassen den Kindern die Wahl ihrer Freundschaften.

Alle Eltern betonen die Bedeutung der Peers und der Freundschaften, die in den religiösen Netzwerken (Moscheegemeinden, religiöse Bildungseinrichtungen) entstehen und durch die Kinder gepflegt werden. Die Eltern unterstützen bzw. beeinflussen ihre Kinder darin, um die soziale Seite der Religion erlebbar zu machen. In diesem Zusammenhang werden auch häufig sohbetGruppen erwähnt. Diese beinhalten Treffen von Jugendlichen, die sich informell über ihre Religion austauschen. Am stärksten betonen die Idealisten die Bedeutung der Peers in den Moscheen für die Entwicklung der Religiosität und damit für die religiöse Sozialisation. Aber auch die Ethiker, Ritualisten und Identitätssucher heben die Bedeutung der Zusammenkünfte zwischen Kindern und Jugendlichen in den religiösen Netzwerken hervor, sodass den Peers in diesem Rahmen insgesamt eine wichtige Rolle im religiösen Sozialisationsprozess zukommt.

Auch Freundschaften, die sich im institutionellen Rahmen, d.h. in Schulen und Kindertagesstätten u.a. ergeben, sind für die Eltern bedeutsam. Dabei haben die Kinder sowohl muslimische als auch nichtmuslimische Freunde, zu denen sie unterschiedlich intensive Beziehungen und Kontakte pflegen. Am offensten zeigen sich die Identitätssucher und einige Ethiker bei der Wahl von nichtmuslimischen Freundschaften. Eine Binnendifferenzierung innerhalb der Typen, zeigt, dass sich auch unter den Ethikern sowie unter den anderen Typen jeweils Eltern befinden, die wenig Offenheit gegenüber nichtmuslimischen Freundschaften zeigen.

Religiöse Themen werden von einigen Kindern aufgegriffen und mit ihren nichtmuslimischen Freunden thematisiert und für andere wiederum spielen sie in ihren Freundschaftsbeziehungen keine Rolle. Darin zeigen sich die Kinder der Idealisten am engagiertesten, was hier offensichtlich die intellektuelle Anregung bzw. Auseinandersetzung mit ihrer Religion im Elternhaus zu fördern vermag. Hier scheint auch der bewusste Einfluss der Eltern auf die Freundschaftswahl ihrer Kinder ausschlaggebend zu sein. Aber auch einige Kinder der Ethiker tauschen sich über ihren Glauben mittels Dialogen aus und Ritualisten über religiöse Gebote. Die Identitätssucher unterstreichen schon aufgrund ihrer hohen Dialogbereitschaft das selbstverständliche Zusammen- 
leben von Muslimen und Nichtmuslimen, sodass Religion und religiöse Themen nicht explizit thematisiert werden müssen.

Alles in allem lässt sich sagen, dass typübergreifend eine Gruppe von Eltern mit der Freundschaftswahl einen fördernden Effekt auf die religiöse Sozialisation erzielen möchte, wiederum typübergreifend eine andere Gruppe an Eltern dahingehend jedoch nur einen geringeren Einfluss ausübt.

\subsubsection{Der Einfluss der Medien auf die religiöse Sozialisation}

Zum Einfluss der Medien auf die religiöse Sozialisation wurden zu zwei unterschiedlichen Kernkategorien Aussagen getroffen. Die Eltern wurden zum einen befragt, welche a) Haltung sie zur Nutzung von Medien als didaktische Mittel einnehmen, und zum anderen ging es darum, welche b) Vorstellungen sie vom »Islambild« in den Medien haben und wie sie zu diesem stehen.

Den Medien als didaktische Mittel wird von den meisten Eltern ein fördernder Effekt auf die religiöse Sozialisation zugeschrieben. Dabei spielt auch die Form des Einsatzes, die im familiären Rahmen zur Geltung kommt, eine wichtige Rolle. Insgesamt stehen, im Vergleich zu allen anderen Medien, Bücher mit religiösen Inhalten im Vordergrund. Den Büchern folgen der Einsatz anderer Medien, wie Fernsehen, Internet, Zeitschriften, PCs, CDs, DVDs, iPod, MP3-Player, religiöse Lieder (türk. ilahi) u.a.

Im Großen und Ganzen ist wohl in unterschiedlichem Maße, je nach Nutzung, ein fördernder Effekt auf die religiöse Sozialisation festzustellen. Dabei kristallisieren sich, auch wie in anderen Sozialisationskontexten, typspezifische Eigenheiten der Mediennutzung heraus. Idealistische Eltern setzen neben den Büchern alle oben angesprochenen Medien ein, um ihren Kindern religiöse Inhalte zu vermitteln. Auch spielen rituell durchgeführte gemeinsame Lesungen, die zur Kommunikation innerhalb des familiären Rahmens führen, eine wichtige Rolle. In den Familien der Ritualisten werden ebenfalls Lesungen durchgeführt und Bücher gelesen. Gemäß einem Teil der Eltern üben die Medien jedoch keinen fördernden religiösen Sozialisationseffekt aus. Der andere Teil setzt, ähnlich wie die Idealisten, Medien ein, um gemeinsame Rituale im familiären Rahmen zu pflegen. Zudem werden den Kindern im Umgang mit den Medien Verhaltensregeln bzw. »Gebotenes und Verbotenes« (religiöse Vorschriften) nahegelegt. Beide Aspekte deuten auf einen Ritualismus hin, der hier nochmals zum Vorschein kommt. Die Identitätssucher nehmen unterschiedliche Positionen im Umgang mit den Medien ein. Während ein Elternteil betont, moderne mediale Interaktionsformen (Smartphone, Apps, Videoaufnahmen, Lernvideos, DVDs, vor allem religiöse Lieder) wählt, nimmt der andere Elternteil eine kritischere Haltung ein. So soll durch eine bewusste Auswahl der zu rezipierenden Literatur und Websites bewirkt werden, dass sich das Kind auf das Bücherlesen konzentriert. Zudem ist in der Wohnung kein Fernseher vorhanden. Ein Teil der Ethiker bringen vorzugswei- 
se Bücher in ihre religiöse Erziehung ein. Auch wenn neben Büchern andere Medienformen zum Einsatz kommen, spielen sie entweder eine sehr untergeordnete Rolle für die religiöse Sozialisation ihrer Kinder oder sie müssten stärker kindgemäß aufbereitet werden, damit die Wirkung nicht verfehlt werde. Sie erwarten daher eine Verbesserung der Medien als didaktische Mittel (CDs, Bücher, Spiele-DVDs), ähnlich, wie sie bereits ihre Erwartungen für eine höhere Professionalisierung der religiösen Erziehung in Moscheegemeinden usw. und auch im Rahmen des IRU (vgl. oben) formuliert haben.

Bezogen auf das von den Medien transportierte »Islambild «, das von allen Typen besonders stark negativ wahrgenommen wird, kann kein negativer Effekt auf die religiöse Sozialisation festgemacht werden. Allerdings wird durch manche Eltern ein hemmender Effekt auf die religiöse Sozialisation befürchtet. Die produzierten Feindbilder, die Muslime unter Generalverdacht bzw. Terrorismusverdacht usw. (vgl. Kap. III. 2.3d) stellen, führen zu Ausgrenzungs- und Diskriminierungserfahrungen bei Kindern und Jugendlichen. Vorurteile und die erlebte Ablehnung, die an die Kinder herangetragen werden, versuchen Eltern durch verschiedene Strategien und Lösungswege auszugleichen, indem sie sich auf religiöse Quellen bzw. auf religiöse Deutungsmuster berufen, die sie ihren Kindern vermitteln oder sie zur aktiven Auseinandersetzung mit dem Thema anregen.

Es wird vornehmlich vonseiten der Ritualisten und Ethiker ein hemmender religiöser Sozialisationseffekt befürchtet. Dabei legen insbesondere die Ethiker eine hohe Reflexionsbereitschaft an den Tag. Jedoch zeigen sie, auch wenn sie für die Zukunft Wünsche und Erwartungen äußern, ihren Kindern weniger Strategien im Umgang mit dem negativen Islambild in den Medien. Dies könnte damit zusammenhängen, dass die meisten Kinder jünger als zehn Jahre sind und davon »noch « unbeeinflusst bleiben. Bei älteren Kindern findet eine Reflexion statt, die es ihnen erlaubt, zu differenzieren und entsprechend $\mathrm{zu}$ verstehen, dass diese transportierten Bilder nichts mit dem von ihnen gelebten Islam zu tun hat.

Die Idealisten und die Identitätssucher fördern (oder möchten fördern, wenn die Kinder das entsprechende Alter erreicht haben), im Vergleich zu den anderen beiden Typen, eine aktive Auseinandersetzung mit dem Islambild in den Medien. Dabei haben sie diverse Strategien entwickelt, die den Kindern behilflich sein sollen, um mit Vorurteilen, Terrorismusverdacht und den daraus folgenden Ausgrenzungs- und Diskriminierungserfahrungen umzugehen. Hierzu zählen die (kritische) Auseinandersetzung mit den Themen, die zu einer Selbstverortung führen soll, eine positive Grundhaltung einzunehmen, einen sinnvollen Bezug zum Glauben und zum Koran zu entwickeln, ein vorbildhaftes Vorleben der eigenen religiösen Werthaltungen zu gewährleisten. Nicht zuletzt solle Aufklärungsarbeit über den Islam und Muslime dabei hel- 
fen, Ängste und »Feindbilder« abzubauen, damit ein friedliches Zusammenleben in dieser Gesellschaft ermöglicht werde.

\subsubsection{Die religiöse Sozialisation in einer pluralistischen Gesellschaft}

Es soll hier im Folgenden zusammenfassend wiedergegeben werden, welche Themen für muslimische Eltern im gesellschaftlichen Kontext besonders relevant sind. Diese geben die Rahmenbedingungen wieder, die die religiöse Sozialisation ihrer Kinder in dieser Gesellschaft betreffen. Aufgrund der Vielzahl der angesprochenen Themen wurden diese in der empirischen Analyse deskriptiv wiedergegeben. Gerade Themen wie Diskriminierung, Rassismus, Islamfeindlichkeit u.a. weisen auf komplexe Zusammenhänge, die allein für sich eigenständige Untersuchungsbereiche darstellen.

Im Bereich des Zusammenlebens werden die Nachbarschaftsbeziehungen und der Kontakt zu Andersgläubigen thematisiert, welche auf den Umgang mit der nichtmuslimischen Umwelt hindeuten. Auch hier sind unterschiedliche Verhaltensmuster und Umgangsformen feststellbar und decken sich zumeist mit ihren Vorstellungen zu den jeweiligen Sozialisationskontexten (z.B. Schule, interreligiöse Begegnungen, Peers, Medien). Auch die Wahrnehmung, wie Deutsche zum Islam stehen, betrifft das Zusammenleben (oder gar die Integration) der Muslime in dieser Gesellschaft. Die zumeist negative Wahrnehmung der Eltern ist eng verknüpft mit dem negativen Islambild, das über die Medien in die Gesellschaft transportiert wird (vgl. Kap. III. 5.5). Hier scheinen Mechanismen aufeinander zu wirken, die eine tiefergehende Untersuchung erforderlich machen.

Inwiefern die Familien und ihre Kinder ihre Religion in dieser Gesellschaft ausleben können, welchen Herausforderungen sie sich stellen müssen bzw. welche Chancen sich auftun, deuten auf Vor- und Nachteile der religiösen Sozialisation in dieser Gesellschaft hin. Die angesprochenen Aspekte (Vor-und Nachteile) stellen die »positiven « und »negativen« Rahmenbedingungen für die religiöse Sozialisation dar. Die Ergebnisse deuten auf Ähnlichkeiten zwischen allen Typen. Deshalb treten auch keine (oder weniger) typspezifische Merkmale auf, wie sie in allen anderen Sozialisationskontexten zu beobachten waren. Da sie keine Vorteile für die religiöse Sozialisation ihrer Kinder sehen, stellt die Wahrnehmung der Ritualisten hier eine Ausnahme dar. Lediglich bei den angesprochenen negativen Effekten bzw. Nachteilen für die religiöse Sozialisation in dieser Gesellschaft bestehen Ähnlichkeiten mit den anderen Eltern.

Als Vorteil wird durch die Eltern die individuelle Religionsfreiheit unterstrichen, womit ihnen die Möglichkeit geboten werde, ihre Religion frei auszuüben. Die Religionsfreiheit bezieht sich auf viele Aspekte, wie bspw. das Kopftuchtragen, die freie Auswahl von religiösen Bildungsangeboten (vgl. in Kap 
II.1.4; Schiffauer 2010: 55f.), das Erfüllen der religiösen Praxis u.a. Deutschland stellt für viele Muslime, trotz erlebter Diskriminierungen, ihre Heimat dar. Viele Aspekte der deutschen Kultur, wie das »Belesene« oder die »Ordnung«, werden positiv bewertet (Idealisten).

Die religiöse Vielfalt und das Zusammenleben von Menschen, die verschiedenen Religionen angehören, werden als weitere Vorteile für die religiöse Sozialisation der Kinder angesehen. Den Kindern wird durch die Eltern eine mögliche Erweiterung ihrer Perspektive geboten, was zu einem höheren Verantwortungsbewusstsein für ihre Mitmenschen führt und zudem den Blickwinkel für das »Eigene« erweitern soll (Identitätssucher und Ethiker).

Ein positiver Effekt der Minderheitensituation von Muslimen in Deutschland ist auch das Gemeindeleben, das im Vergleich zum Heimatland eine höhere Bedeutung hat und daher eine größere Bindung zwischen den Muslimen ermöglicht. Diese erlaubt ihnen und ihren Kindern einen höheren Rückbezug auf die religiösen Gemeinden und das Gemeindeleben. Diese Auffassung teilen vor allem die Idealisten und einige Eltern bei den Ethikern.

Trotz der benannten Vorteile überwiegen für alle Eltern die Nachteile als hemmende Faktoren der religiösen Erziehung und Sozialisation. Am häufigsten werden Islamfeindlichkeit, Diskriminierungen, Rassismus, Vorurteile gegenüber Muslimen, die Ablehnung durch die Mehrheitsgesellschaft und die geringe Anerkennung des Islams in diesem Land als hemmende Faktoren genannt bzw. beklagt. Da dadurch starke Einschränkungen bei der Befolgung der religiösen Praxis befürchtet bzw. hingenommen werden müssen, fühlen sich die meisten Eltern unter Druck gesetzt. Einigen Eltern bereiten die zunehmende Individualisierung und der Egoismus in der Gesellschaft Sorgen.

Zudem verstärke die Minderheitensituation nicht zuletzt Fremdheitsgefühle und die Heimatlosigkeit der Muslime in diesem Land.

Schließlich verweist der letzt genannte Aspekt, welche Leistung die religiöse Erziehung für die Gesellschaft erbringen kann, primär auf den Wunsch, ein möglichst reibungsfreies konstruktives Zusammenleben in dieser Gesellschaft zu erreichen. Hier wird auch die grundlegende Position der Eltern zur deutschen Gesellschaft deutlich. Ein friedliches Zusammenleben, die Bereitschaft, Verantwortung für die Gesellschaft (für Menschen, Tiere, Pflanzen, Gesundheit) zu übernehmen, gegenseitiger Respekt, Empathie und Wertschätzung für andere, sind Beispiele für die Absichten, die Eltern als Konsequenzen ihrer religiösen Erziehung betrachten. Des Weiteren können Werthaltungen, wie Toleranz, Akzeptanz, Solidarität, Ehrlichkeit, Offenheit, Hilfsbereitschaft und das Teilen mit anderen Menschen, durch das Engagement von religiösen Menschen aufleben. Zusätzlich werden ein gesetzestreues Leben, ein Sinn für Gerechtigkeit sowie eine positive Charakterbildung als Ertrag der religiösen Erziehung und Sozialisation betont (vornehmlich durch Ritualisten). Außerdem bietet die Religion, die allen Menschen vorgelebt und entsprechend um- 
gesetzt werden könne, für viele Eltern Orientierung und Halt im Leben und eine Ressource in Krisensituationen. Nicht zuletzt wird (insbesondere durch die Ethiker und Identitätssucher) ein bewusst positiver Umgang mit Andersgläubigen und Andersdenkenden auf der Basis einer gelungenen Dialogfähigkeit angestrebt. 



\section{Schlussfolgerungen}

1.) Es konnte mit dieser Untersuchung ein Beitrag zur Diskussion um die Operationalisierung des Begriffs »religiöse Erziehung« in muslimischen Familien geleistet werden. Bedeutsam war hierfür zunächst die Erschließung der Zieldimensionen einer religiösen Erziehung, die aus erziehungswissenschaftlicher Perspektive anhand der Aussagen muslimischer Eltern empirisch gewonnen wurde. Theoretisch liegt die begriffliche Definition der »Erziehungsziele« einem allgemeinen erziehungswissenschaftlichen Verständnis zugrunde (vgl. Miller-Kipp/Oelkers 2007). Wird Erziehung, die darauf abzielt, normativ begründete Einstellungs- und Verhaltensmuster auf Kinder und Jugendliche zu übertragen, im Verhältnis zur Religion und damit zu normativ-religiösen Begründungen gesetzt, so tritt sie für die empirische Sozialforschung in ihrer interdisziplinären Funktion hervor.

Die zunächst anhand der Aussagen und Ansichten über Erziehungsziele gewonnenen Daten verweisen auf verschiedene normative Sinnzusammenhänge, die auf die Grundlagen des Islams zurückzuführen sind. Diese wurden in einem Exkurs, in dem die normativen Grundüberlegungen einer religiösen Erziehung im Islam (vgl. Kap. II. 3.3.1 d) deskriptiv beschrieben wurden, ausgeführt. Die befragten muslimischen Eltern begründeten ihre religiöse Erziehung in unterschiedlichem Ausmaß und verschiedenen Ausprägungen mit Normen und Werthaltungen, die in diesen Grundüberlegungen wiederzufinden sind. Es konnte nachgewiesen werden, dass alle Proband(inn)en auf die drei wesentlichen Grundkomponenten, wie die Glaubensgrundlagen, die rituellen Handlungen bzw. die religiöse Praxis und die ethisch-moralischen Aspekte einer religiösen Erziehung, im Islam Bezug nehmen. Daneben spielen auch sinnhaft-spirituelle Momente in der religiösen Erziehung eine wichtige Rolle. Diese Aspekte werden durch sie mit unterschiedlicher Intensität und Prioritätensetzung sowie subjektiven Deutungsmustern verfolgt. So äußern sich auch die in ihren religiösen Erziehungszielen dargelegten Grundhaltungen gemäß der von ihnen gelebten Religiosität.

Um die Messbarkeit und Vertiefung der religiösen Erziehungsvorstellungen bzw. der daraus resultierenden religiösen Praxis und Handlungen in der 
empirischen Sozialforschung zu gewährleisten, wurde der mehrdimensionale Religiositätsbegriff nach Glock (1969) verwendet (vgl. auch Boos-Nünning 1972). Die Religiosität als Ausdruck einer subjektiv vermittelten religiösen Erziehung äußert sich gemäß diesem Ansatz bzw. Analyseinstrument in den wesentlichen drei Komponenten des Menschseins: der affektiven, der kognitiven und der handlungsorientierten Komponente (vgl. ebd.). So spiegeln sich in den von den Eltern zu Beginn dargelegten »Erziehungszielen« und damit Grundauffassungen die verschiedenen Dimensionen der Religiosität wider und trugen zur Vertiefung und Differenzierung ihres Religiositätsverständnisses bei. Neben einer differenzierten, gegenstandsbezogenen Kategorisierung der religiösen Erziehungsvorstellungen, die zur Typenbildung führte, konnten mithilfe dieses Analyseinstruments typspezifische Kennzeichen und Merkmale der (Familien-)Religiosität ermittelt werden. Insgesamt konnte auch aufgrund der hohen Korrelationen zwischen den Dimensionen der Religiosität und den religiösen Erziehungsvorstellungen ein zentraler Beitrag zur begriffsanalytischen Diskussion um die »religiöse Erziehung« geleistet werden. Allerdings ist zu berücksichtigen, dass in dieser Arbeit eine erziehungs- bzw. religionswissenschaftliche Annäherung an das Thema stattgefunden hat. Um eine stärker theoriegeleitete Vertiefung dieser Thematik vorzunehmen, erscheint eine interdisziplinäre Vorgehensweise, die einen Theologiebezug bzw. den Bezug zu den islamischen Wissenschaften im Blick hat, sinnvoll und notwendig.

2.) Die Analyse des empirisch gewonnenen Materials ermöglichte als Resultat die Bildung von vier verschiedenen religiösen Erziehungstypen, wie sie im Spektrum muslimisch-türkischer Familien mit sunnitischer Ausrichtung des Islams vorzufinden sind. Es ist jedoch nicht auszuschließen, dass durch weitere Untersuchungen noch andere Erziehungstypen ermittelbar sind.

Die Religiosität von muslimischen Familien, als Ausdruck und Folge einer subjektiv vermittelten religiösen Erziehung, ist sehr unterschiedlich charakterisiert und weist verschiedene Ausprägungen und typspezifische Merkmale auf. Für viele der befragten Proband(inn)en, spielt ihre Religion in der Migrationssituation aufgrund ihres Minderheitenstatus eine bedeutsamere Rolle als in ihrem Herkunftsland oder dem Herkunftsland der Eltern. Sie hat trotz des, im Vergleich zur Elterngeneration, eingetretenen Wandels unter Abwendung von traditionell-religiösen Auffassungen, ihre orientierungs- und handlungsleitende Funktion nicht eingebüßt, sondern verstärkt. Eine bewusst religiöse Lebensweise und eine bewusstere Auseinandersetzung mit ihrer Religion, auch unter Rückbezug auf die normativen Grundlagen des Islams, kennzeichnet für viele Proband(inn)en ihre Religiosität, die sie an ihre Kinder herantragen. Auch das religiöse Gemeindeleben und ein hoher Gemeinschaftsbezug nehmen für einen Großteil der befragten Eltern einen bedeutsamen Stellenwert ein. In Deutschland bieten sie muslimischen Familien einen wichtigen »Rahmen«, um Religiosität auszuleben und um die religiöse Sozialisation 
ihrer Kinder zu gewährleisten. So lässt sich auch die für manche Eltern tiefgreifende Bedeutung des Gemeindelebens erklären.

Die Religiosität ist für muslimische Eltern ferner identitätsbestimmend. Ein wesentliches Ergebnis dieser Untersuchung ist, dass für eine Gruppe intellektuell-reflektierender Eltern, die ihre religiöse Erziehung stets unter dem Aspekt der Persönlichkeitsentwicklung betrachtet, die Anerkennung als Muslime in der Gesellschaft ein sehr wichtiges Anliegen darstellt und ein hohes Dialogbewusstsein ihr Verhalten prägt. Der Wunsch nach einer möglichen Selbstverortung und Selbstpositionierung in der Gesellschaft zeigt ihr Engagement, als Mitglieder dieser Gesellschaft wahrgenommen zu werden. Damit sollen nicht zuletzt Wege für die Integration von Muslimen und ihren Kindern geebnet werden. Mit dem Begriff »diasporische Identität« verweist Schiffauer (2010) auf die (religiöse) Identitätsentwicklung, die sich den gegebenen Umständen in der Diasporasituation anpasst, ohne die eigenen Wurzeln zu den Herkunftstraditionen aufzugeben. Hier scheint gerade für die Theoriebildung bzw. die theoretische Rahmung der religiösen Sozialisation und daraus folgend für die Persönlichkeitsentwicklung ein Ansatz bzw. ein Gegenstand für Diskussionen angeboten zu werden, der durch weitere Forschung zu wichtigen Ergebnissen führen kann.

Als letztes charakteristisches Merkmal der Religiosität konnte in der Untersuchung eine stärker individualisierte Zugangsform zur Religiosität deutlich gemacht werden. Es handelt sich hierbei um eine Gruppe von Eltern, die ihren Kindern einen »reflektierten« Islam vermitteln möchte. Hierbei steht für diese Eltern die Hinterfragung des Gegebenen und daraus folgend die subjektive bzw. individuelle Wahrheitsfindung im Vordergrund. Dies deutet auf Individualisierungstendenzen hin, die sich in verschiedenen Lebensbereichen äußern. Deren Erforschung war dabei kein Gegenstand dieser Untersuchung.

3.) Metatheoretische Ansätze zur Erklärung der religiösen Sozialisation von muslimischen Kindern sind bisher kaum vorhanden und stellen ein noch weitgehend unerforschtes Gebiet dar. So brachte die theoretische Verortung bzw. die theoretische Rahmung des Forschungsgegenstandes einige Herausforderungen mit sich. Um die, neben der religiösen Erziehung in der Familie, als ein Ausschnitt bzw. Bestandteil des gesamten Sozialisationsprozesses zu betrachtenden weiteren Einflüsse auf den religiösen Sozialisationsprozess zu operationalisieren, wurde daher auf allgemeine Grundannahmen und Überlegungen zur »Sozialisation« und »religiösen Sozialisation« (vgl. Boos-Nünning/Golomb 1974 u.a.) zurückgegriffen. Hieraus ergaben sich folgende, für die Untersuchung relevanten Analysefelder: die Familie als primäre Sozialisationsinstanz, die nichtinstitutionellen religiösen Bildungseinrichtungen (auch Moscheen und Moscheegemeinden), die staatlich-institutionellen Bildungseinrichtungen (Schulen und Kindertagesstätten), die Peers, die Medien und die Gesellschaft. Aufgezeigt wurde, inwiefern diese einen Einfluss auf die re- 
ligiöse Sozialisation ausüben, d.h., ob diese jeweils fördernd oder hemmend auf die religiöse Entwicklung von Kindern und Jugendlichen einwirken. Das Erkenntnisinteresse galt hierbei Grundorientierungen bzw. Einstellungs- und Verhaltensmustern (vgl. ebd.), die Eltern zu den jeweiligen Untersuchungsbereichen bzw. Sozialisationsinstanzen vortrugen.

Als Ergebnis verweist die religiöse Sozialisation von muslimischen Kindern in der Minderheitensituation der Muslime in Deutschland auf diverse Spezifika und Bedingungen. Die Untersuchung bietet mit ihrem empirisch gewählten Zugang erste Überlegungen für eine Theoriebildung und für Diskurse rund um diese Thematik.

4.) Es konnte ein vielseitiges Bild des muslimischen Familienlebens aufgezeigt werden, worin sich auch die Pluralität von muslimischen Lebensweisen in der christlich-säkularen Mehrheitsgesellschaft äußert. Die Religionszugehörigkeit gibt noch keine Auskunft darüber, in welcher Intensität die Religion ausgelebt wird und was jeweils für muslimische Familien aktuell im Vordergrund steht. Mit der alleinigen Attribuierung »muslimisch« können folglich keine Aussagen über grundsätzliche religiöse Einstellungs- und Deutungsmuster gegeben werden. Die Ergebnisse der Untersuchung zeigen, dass allein schon unter den an der religiösen Erziehung interessierten sunnitisch geprägten muslimisch-türkischen Familien differente religiöse Erziehungsvorstellungen existieren. Die Bestimmung von religiösen Erziehungstypen ermöglichte einen Einblick in die Familienreligiosität, die sehr viele Facetten und typspezifische Merkmale aufweist. Die Berücksichtigung pluraler religiöser Einstellungs- und Lebensformen erlaubte einen differenzierten Zugang zum Religiositätsverständnis muslimischer Familien, die sich nicht selten mit Vorurteilen und Missverständnissen in der deutschen Mehrheitsgesellschaft auseinandersetzen müssen.

Es ergeben sich allgemeine pädagogische und religionspädagogische Konsequenzen, die jeweils bezogen auf die angesprochenen Themenbereiche formuliert und dargelegt wurden.

5.) Es zeigte sich, dass die religiöse Erziehung und Sozialisation von muslimischen Familien in empirischen Untersuchungen ein bislang kaum untersuchtes Feld darstellt und hier somit auch noch weiterhin Forschungsbedarf besteht. Gerade für die Entwicklung von religionspädagogischen Konzeptionen, die zukünftig insbesondere im Bereich der Familienbildung entstehen sollten, geben die empirischen Ergebnisse dieser Untersuchung wichtige Hinweise. Im Vordergrund steht die Berücksichtigung der spezifischen Bedürfnisse von muslimischen Familien, bei denen sowohl die Lebenswirklichkeit der Kinder als auch die wesentlichen Lebens- und Begleitumstände in Deutschland beachtet werden müssen. Diese betreffen alle in dieser Untersuchung angesprochenen Sozialisationsinstanzen bzw. -kontexte, woraus sich vielseitige Anforderungen an eine religionspädagogische Konzeptentwicklung ergeben. 
Auch eine islamische Religionspädagogik und Diskussionen über deren Fachprofil befinden sich in Deutschland aktuell noch in ihren Anfängen und beziehen sich in der wissenschaftlichen und öffentlichen Diskussion bisher zumeist auf den islamischen Religionsunterricht. $\mathrm{Zu}$ wünschen ist eine Erweiterung des Blickfeldes auf die Familien und auf in der Untersuchung angesprochene weitere sozial- und religionspädagogische Handlungsfelder. Vor dem Hintergrund, dass damit nicht zuletzt auf die Lebenswirklichkeit von muslimischen Kindern, d.h. damit auch von Schülerinnen und Schülern und ihren Familien abgezielt wird, ermöglicht eine Perspektiverweiterung eine zielgerichtete und adäquate Wahrnehmung der muslimischen Schülerschaft und muslimischer Kinder insgesamt ${ }^{1}$. Dabei sind nicht nur die muslimischen Religionslehrer/-innen angesprochen, auch das gesamte Lehrpersonal in Schulen und das pädagogische Fachpersonal in Kindertagesstätten können von einer differenzierteren Wahrnehmung bezüglich muslimischer Familien und ihrer Kinder profitieren.

6.) Für die Aus- und Weiterbildung des pädagogischen Personals und insbesondere des religionspädagogischen Personals, das täglich mit muslimischen Kindern zu tun hat, ergeben sich aus den oben genannten Punkten entsprechende Konsequenzen, deren Berücksichtigung zu einem vertiefenden Verständnis von religiösen Sozialisationsprozessen in muslimischen Familien führen kann. Die Typenbildung und die Charakterisierung des Erziehungsverständnisses bzw. der daraus abgeleiteten Religiositätsprofile ermöglichen, muslimische Kinder und Jugendliche jeweils aus ihrem eigenen (Sinn-)Kontext heraus $\mathrm{zu}$ verstehen. $\mathrm{Zu}$ beachten ist dabei, dass unterschiedliche Erziehungsvorstellungen auch differente Verhaltensweisen bedingen.

So können Reflexionsprozesse in der Ausbildung des (religions-)pädagogischen Personals angeregt werden, die diesem Anliegen dienen. Dies könnte z.B. bedeuten, idealisierte Vorstellungen, die normativ begründet sind, auf deren Umsetzbarkeit hin zu überprüfen. Hier ist durchaus vorstellbar, dass Anspruch und Wirklichkeit voneinander abweichen und möglicherweise Erwartungen in andere Sozialisationskontexte (wie z.B. in den islamischen Religionsunterricht oder den Unterricht in außerschulischen Bildungseinrichtungen usw.) hineingetragen werden, die nicht erfüllbar sind (Idealisten). Auch ist ein Ritualismus nicht per se mit sinnloser, unreflektierter Nachahmung gleichzusetzen. Eine Regelhaftigkeit bzw. die Betonung der Befolgung von religiösen Geboten drückt sich primär in Handlungen und weniger in einer Diskussionsbereitschaft über die Religion aus. Hier ist es wichtig, dass für diese

1 | Dies dient nicht zuletzt der Verbesserung der Qualität eines islamischen Religionsunterrichts (IRU). Gerade im Hinblick auf die Entwicklung von Lehrplänen des IRU erscheint hier nicht zuletzt eine große Notwendigkeit zu bestehen (vgl. Ceylan/Stein 2016: 5f.). 
Eltern der gelebte Islam im Vordergrund steht, der für sie ein gewisses Schutzund Orientierungsbedürfnis erfüllt. Folglich könnte z.B. die Anregung von Sinnzusammenhängen von Bedeutung sein, ohne dabei ihr Schutzbedürfnis zu verletzen (Ritualisten). Auch kommt z.B. bei Eltern, die sich ethischen Grundsätzen verpflichten, die Frage auf, inwiefern altruistisch-humanitäre Erziehungsvorstellungen, die durch sie religiös begründet werden, mit Individualisierungstendenzen vereinbar sind (Ethiker). Die Liste der möglichen Anregungsbeispiele für Diskurse, die den Reflexionen der Lehrpersonen bzw. des pädagogischen Personals, sowohl im Hinblick auf ihre eigene religiöse Sozialisation als auch bezüglich der Sozialisation der ihnen anvertrauten Kinder, dienen könnte, wäre hier beliebig erweiterbar. Die angeführten Ideen können und sollen somit als erste Beispiele für solche Reflexionsprozesse verstanden werden.

7.) Die religiöse Erziehung oder die Religiosität als Erziehungsziel wird in den Familien auf unterschiedliche Art und Weise vermittelt. Es konnte aufgezeigt werden, dass im Vergleich zu früher eine »Professionalisierung« bzw. eine Weiterentwicklung der religiösen Erziehung im Familienalltag stattgefunden hat. Die erhöhte Sensibilisierung im Hinblick auf die Wahrnehmung und Umsetzung ihres Erziehungsverständnisses veranlasst Eltern dazu, verschiedene Methoden und Kommunikationsformen anzuwenden. Dabei wird auch, im Vergleich zu früher, auf eine altersgemäße und lebens- bzw. alltagsnahe Vermittlung von religiösen Inhalten geachtet.

Die seit Beginn der Migration und der Migrationsforschung sich bis heute durchsetzende Auffassung, dass rigide und autoritäre Erziehungsmethoden den muslimischen Familienalltag bestimmen, kann somit nicht aufrechterhalten werden. Sowohl wissenschaftliche als auch in der gesellschaftlichen, öffentlichen Wahrnehmung existierende Vorstellungen über Erziehungsstile in Migrationsfamilien (vgl. z.B. Toprak 2012) bieten diesbezüglich widersprüchliche Ergebnisse, die oft zulasten der Familien in Form von Vorurteilen und Klischeebildungen gehen. Die Ergebnisse dieser Untersuchung zeigen, dass typübergreifend alle Eltern sich von Zwang und Restriktionen in der religiösen Erziehung distanzieren. Auch unterscheiden sie bei Regelverletzungen und Sanktionsmitteln vornehmlich zwischen allgemeiner und religiöser Erziehung, sodass Erziehungsstile bzw. -formen der religiösen Erziehung zukünftig gesondert untersucht werden müssen. Als eher kontraproduktiv erweist sich dabei die unkritische Übernahme von Erziehungsstilkonzeptionen, die sich auf die allgemeine Erziehung beziehen, und deren unreflektierte Übertragbarkeit nicht einmal für Migrationsfamilien (vgl. Boos-Nünning 2011a: 33f.), geschweige denn für muslimisch-religiöse Familien als geeignete Methode. Die Ergebnisse dieser Untersuchung liefern ferner Erkenntnisse, die zur Bestimmung von Untersuchungskategorien bzw. Indikatoren dienlich sein können. Hierbei erwies sich in der vorliegenden Untersuchung die Befolgung 
der Gebetsvorschrift als ein wichtiger Indikator zur Charakterisierung des elterlichen (religiösen) Erziehungsstils.

8.) Außerschulische Bildungseinrichtungen, in denen religiöse Bildung vermittelt wird, erfüllen eine wichtige religiöse Sozialisationsfunktion. Den religiösen Bildungseinrichtungen, die zumeist an die Moscheen angegliedert sind oder unabhängig von ihnen bestehen, wird vonseiten aller Eltern ein hoher Stellenwert mit unterschiedlichen Akzentsetzungen eingeräumt. So erscheint für die an religiöser Erziehung interessierten Eltern deren Bedeutung auch in Zukunft noch zuzunehmen. Es werden unterschiedliche Anforderungen und Erwartungen an außerschulische religiöse Bildungseinrichtungen formuliert, die besonders stark auf die Professionalisierung des Bildungsangebots und des (religions-)pädagogischen Personals abzielen. Nicht nur die Entwicklung von adäquatem Lehrmaterial, sondern auch die Unterrichtsgestaltung bzw. eine den Bedürfnissen der Kinder und Eltern angepasste Moscheedidaktik und -pädagogik heben muslimische Familien als eine wichtige Bedingung und Voraussetzung für die Aufrechterhaltung des Interesses ihrer Kinder am religiösen Bildungsangebot, hervor. Hierbei sind insbesondere bei der Qualifizierung des bestehenden Lehrpersonals, in Form von Fort- und Weiterbildungen und in der zukünftigen Imam-Ausbildung oder Religionslehrerausbildung, die Wünsche und Erwartungen muslimischer Familien unbedingt zu berücksichtigen. Da zudem in den meisten Fällen religiöse Gemeinden und religiöse Bildungseinrichtungen ihren eigenen (religionspädagogischen) Erziehungskonzeptionen folgen, ist in Zukunft eine wissenschaftlich fundierte Evaluierung und ggf. eine Verbesserung bzw. Weiterentwicklung dieser Konzepte wünschenswert.

Die Untersuchung zeigt, dass die Attraktivität der Moscheegemeinden auch durch anderweitige Angebote, wie bspw. durch Freizeit- und Sportangebote, die den Kindern und Jugendlichen Spiel- und Bewegungsmöglichkeiten bieten, gestärkt werden können. Dabei stellen die fehlenden Räumlichkeiten ein Defizit dar, das als Hindernis auf diesem Weg gesehen wird. Auch weitergehende Angebote, wie Frühfördergruppen, die als Alternativen zu den bestehenden Angeboten entstehen, ermöglichen einigen Elternteilen zufolge die Vermittlung von religiösen Werthaltungen und könnten einen Rahmen für die Entwicklung einer religiösen Atmosphäre bieten. Die Einführung von ElternKind-Konzepten, die die stärkere Beteiligung und Einbindung der Eltern vorsehen, kann hierbei die Effektivität der religiösen Erziehung fördern und sie somit sowohl an ihre Erziehungsverantwortung erinnern als auch eine stärkere Kooperation zwischen Elternhaus und den religiösen Bildungseinrichtungen ermöglichen.

9.) Diskriminierungen und Vorurteile sind in institutionellen Bildungseinrichtungen (Schulen und Kindertagesstätten) aufgrund der religiösen Zugehörigkeit und der religiösen Praxis, wie z.B. das Tragen des Kopftuches, sehr 
verbreitet. Fast jeder Elternteil berichtet über negative Erfahrungen mit Pädagog(inn)en und dem Lehrpersonal in Schulen und Kindertagesstätten. Dabei wünschen sich Eltern einen toleranten Umgang mit ihrer religiösen Lebensweise und möchten, dass Verunsicherungen und Benachteiligungen, die sich auf ihr Muslimsein zurückführen lassen, erst gar nicht entstehen. Hierbei könnte zum einen schon in der Ausbildung des zukünftigen pädagogischen Personals (Erzieher/-innen, Sozialpädagog(inn)en, allgemeine Pädagog(inn) en) bzw. in der Lehrerausbildung auf die Besonderheiten der muslimisch-familiären Sozialisation geachtet werden, um Vorurteilsbildungen entgegenzuwirken. Zum anderen sind grundlegende bildungspolitische Strategien gegen Diskriminierungen und Benachteiligungen vonnöten. Die von den Eltern vorgetragenen Verbesserungs- und Lösungsvorschläge beinhalten den Wunsch nach Kooperationen und der Erschließung von Partizipationsmöglichkeiten. Konkretisiert wird dieser Wunsch in Form von Aufklärungsarbeit über ihre Religion, die zum gegenseitigen Verständnis, Offenheit und Toleranz beitragen soll. Die Sensibilisierung des Lehrpersonals bzw. des pädagogischen Personals soll dieses dazu befähigen, zumindest Respekt vor ihren religiösen Überzeugungen und Handlungen zu zeigen. Wird die Präsenz von muslimischen Kindern als eine Selbstverständlichkeit wahrgenommen, trägt dies letztendlich auch zu ihrer Integration bei. Hierzu kann zudem die vermehrte Einstellung von Expert(inn)en mit Migrationshintergrund das Selbstvertrauen der muslimischen Kinder stärken und ihnen Identifikationsmöglichkeiten bieten. Positiv wird auch die Auseinandersetzung mit der eigenen Religion in verschiedenen Unterrichtsfächern bewertet. Gerade die Einführung des islamischen Religionsunterrichts (IRU) kann gemäß allen Elternteilen einen integrationsfördernden und identitätsbestimmenden Effekt hervorrufen und somit Vielfalt und Toleranz in Schulen fördern.

Schließlich ist noch darauf hinzuweisen, dass Diskriminierungen von muslimischen Kindern und Jugendlichen aufgrund ihrer religiösen Zugehörigkeit und Lebensweise in institutionellen Einrichtungen ein bislang noch weitgehend unerforschtes Gebiet darstellt. Hierbei ist es notwendig und sinnvoll, neben Eltern auch Kinder und Jugendliche aufgrund ihres höheren Betroffenheitsgrades in zukünftige Forschungsprojekte einzubeziehen.

10.) Interreligiöse Begegnungen und ein interreligiöser Dialog werden durch muslimische Eltern als Chancen für eine bessere Verständigung, Toleranz und ein friedliches Miteinander betrachtet. Mehr als die Hälfte der befragten Eltern wünschen sich interreligiöse Begegnungen im Kindertagesstätten- oder Schulalltag ihrer Kinder, da die Religion der anderen ein Teil des gemeinsamen Zusammenlebens in dieser Gesellschaft darstelle. Des Weiteren befinden sich unter ihnen, wenngleich zahlenmäßig deutlich geringer vertreten, auch muslimische Eltern, die sich bewusst für einen Dialog der Religionen engagieren. Dagegen fehlt vielen Eltern ein Gegenüber, das ihnen 
die notwendige Plattform für interreligiöse Begegnungen bietet. So könnte in institutionellen Bildungseinrichtungen die Herstellung einer solchen Basis zukünftig eine vermehrte Kommunikation und Kooperation ermöglichen. Gerade religiöse Feste werden durch muslimische Eltern als Gelegenheiten wahrgenommen, bei denen ein solcher Austausch stattfinden kann und z.T. auch bereits stattfindet. Auch wünschen sich muslimische Eltern, dass verstärkt Begegnungen und Dialoge zwischen ihnen und nichtmuslimischen Eltern erfolgen. Die Erweiterung von interreligiösen und interkulturellen Kompetenzen der pädagogischen Akteure sowie eine gezielte Elternarbeit könnten hierbei diesem Anliegen dienen.

11.) Das Islambild, das von den Medien in die deutsche Gesellschaft transportiert wird, gefährdet allen Eltern zufolge das friedliche Zusammenleben von Muslimen und der Mehrheitsbevölkerung in Deutschland. Muslime würden, als eine Folge medial produzierter Feindbilder, unter einen generellen Terrorismusverdacht gestellt, was zu Irritationen und Verunsicherungen bei den Jugendlichen führe. Die mittels negativer Berichterstattung forcierten negativen Vorurteile und Klischeebildungen über ihre Religion verstärken zudem das Gefühl der Ablehnung und Diskriminierung und stellen sie, nicht selten, unter einen Rechtfertigungsdruck gegenüber ihren Lehrern bzw. Lehrerinnen, Mitschülern und ihrer nichtmuslimischen Umgebung. Die Folgen sind Trauer und Unverständnis über die Situation, die einige Eltern durch unterschiedliche Bewältigungsstrategien auszugleichen versuchen. Wichtig erscheint daher die gezielte Aufarbeitung der in der öffentlichen Wahrnehmung vorherrschenden verzerrten »Bilder« über Muslime und den Islam, die in Zukunft einem differenzierten Blick weichen sollten (vgl. hierzu auch Uslucan 2015: 752f.). Respekt und Toleranz können zudem durch Aufklärungsarbeit in Schulen und anderen Einrichtungen erlernt und umgesetzt werden.

12.) Die religiöse Sozialisation erfolgt in der deutschen Mehrheitsgesellschaft unter Rahmenbedingungen, die zum einen als »positiv« bewertet werden. Hierzu gehört insbesondere die Religionsfreiheit, die Muslimen Gelegenheiten und Chancen bietet, ihre Religion frei auszuleben. Zum anderen überwiegen typübergreifend (über die gesellschaftliche Wahrnehmung existierte unter allen muslimischen Eltern ein breiter Konsens, sodass an dieser Stelle typspezifische Unterschiede am wenigsten nachzuzeichnen waren) »negativ« wahrgenommene (Sozialisations-)Bedingungen, die nicht förderlich auf die religiöse Entwicklung ihrer Kinder wirken und sie beim Ausleben ihrer Religiosität vor Herausforderungen und Erschwernisse stellen. Es wurde eine Vielzahl an erschwerenden Faktoren bzw. Themen, wie Rassismus, Islamfeindlichkeit, Diskriminierungen, Vorurteilsbildungen, Islamophobie u.a. benannt, die auf komplexe Zusammenhänge des gesellschaftlichen Miteinanders bzw. Zusammenlebens hinweisen. Gerade die zumeist negative Wahrnehmung, wie Deutsche letztlich zum Islam stehen, ist eng mit dem negativen Islambild, 
das über die Medien in die Gesellschaft transportiert wird, verknüpft. Hier wirken verschiedene Mechanismen aufeinander, die eigenständige Untersuchungsbereiche darstellen. Der Umfang und die Vielschichtigkeit dieser Themen ermöglichten in der vorliegenden Arbeit keine tiefergehenden Analysen. Dessen ungeachtet konnte aufgezeigt werden, welche Themen im gesellschaftlichen Kontext für muslimische Eltern im Vordergrund stehen.

13.) Nicht nur angesichts der oben erörterten Rahmenbedingungen des gesellschaftlichen Zusammenlebens erscheint die Religion bzw. die religiöse Erziehung als eine wichtige Ressource für muslimische Familien und den Einzelnen selbst, sondern auch für ein friedliches Zusammenleben zwischen Nichtmuslimen und Muslimen. Gerade für Letzteres eröffnen sie Perspektiven und Möglichkeiten, die den defizitären Blick auf Muslime als »intergrationsunwillige« Mitmenschen oder als »Problemgruppe« verändern sollten. Mit den von ihnen aufgeführten »positiven« Beispielen im Zusammenhang von Nachbarschaftsbeziehungen, ihres Engagements für Aufklärung und Kommunikation in verschiedenen weiteren sozialen Handlungsfeldern möchten sie Religion erlebbar machen und mit ihrer Präsenz eine »Normalität« vermitteln, die Vielfalt, Respekt und Toleranz gegenüber ihnen als Andersgläubige möglich macht.

Als Ziel einer religiösen Erziehung unterstreichen sie insbesondere die Herausbildung verantwortungsbewusster Menschen, die für sich und die Gesellschaft nützlich sind und als solche wirken. Sie streben damit ein konstruktives gesellschaftliches Miteinander an, das, jenseits von Egoismus und Individualismus, von Mitmenschlichkeit, gegenseitiger Fürsorge, Wertschätzung, Empathiefähigkeit, Solidarität und Toleranz gekennzeichnet ist. Die Charakter- und Gewissensbildung ermöglicht es für einige Eltern zudem, einen Sinn für Gerechtigkeit zu entwickeln, womit ein gesetzestreues Leben ohne Menschrechtsverletzungen erreichbar ist. Außerdem sind Umweltschutz und ein Herz für Notleidende zentrale Aspekte, die durch muslimische Eltern als Ressourcen für ein gelungenes Miteinander Erwähnung finden.

Gerade im Umgang mit Mitschülern kann sich muslimische Religiosität im schulischen Kontext als eine wichtige Ressource erweisen. Neben dem für das Selbstvertrauen förderlichen Effekt und der Erlangung persönlicher Stärke, die religiöse Erziehung bewirkt, kann durch Sensibilität und Hilfsbereitschaft das Mitgefühl für andere Mitschüler gefördert werden. Dies dient nicht zuletzt dazu, dass Aggressivität abgebaut und somit auch präventiv gegen Jugendkriminalität und Drogenmissbrauch vorgegangen werden kann.

Auch im persönlichen Leben stellt Religiosität eine wichtige Ressource dar, sodass sie als solche wahrgenommen und behandelt werden sollte. Die Religion erfüllt eine wichtige Orientierungs- und Stützfunktion, die den muslimischen Familien in schwierigen Zeiten und Lebenskrisen einen wichtigen Halt, Sicherheit und Schutz bietet. Die Erfordernisse und Schwierigkeiten des 
Alltags sowie kritische Phasen, wie die Pubertät, schulische Probleme u.a., werden durch sie anhand religiöser Deutungs- und Handlungsmuster, wie z.B. Optimismus oder Geduld, bewältigt. So tragen ihre religiösen Grundeinstellungen zur Bewältigung ihrer Probleme bei und sollen letztendlich Stärke und Selbstvertrauen hervorbringen. 



\section{Literatur}

Alacacioğlu, Hasan (1999): Außerschulischer Religionsunterricht für muslimische Kinder und Jugendliche türkischer Nationalität in NRW. Eine empirische Studie zu Koranschulen in türkisch-islamischen Gemeinden. Münster.

Alacacioğlu, Hasan (2000): Deutsche Heimat Islam. Münster.

Alamdar-Niemann, Monika (1992): Türkische Jugendliche im Eingliederungsprozess. Hamburg.

Asad, Muhammad (2009): Die Botschaft des Koran. Übersetzung und Kommentar. Düsseldorf.

Aygün, Adem (2010): Religiöse Sozialisation und Entwicklung bei muslimischen Jugendlichen in Deutschland und in der Türkei. Empirische Analysen und religionspädagogische Herausforderungen. Bielefeld. Abgerufen unter: www.bieson.ub.uni-bielefeld.de/volltexte/2010/1758/w [Abrufdatum: $01.10 .2010]$.

Badawia, Tarek (2002): »Der Dritte Stuhl«. Eine Grounded-Theory-Studie zum kreativen Umgang bildungserfolgreicher Immigrantenjugendlicher mit kultureller Differenz. Frankfurt a.M.

Bauer, Ullrich/Hurrelmann, Klaus (2007): Sozialisation. In: Tenorth, HeinzElmar/Tippelt, Rudolf (Hg.): Lexikon Pädagogik. Weinheim/Basel, S. 672675 .

Beer, Raphael/Bittlingmayer, Uwe H. (2008): Die normative Verwobenheit der Sozialisationsforschung. In: Grundmann, Matthias/Hurrelmann, Klaus/ Walper, Sabine (Hg.) (2008): Handbuch Sozialisationsforschung. Weinheim/Basel, S. 56-69.

Behr, Harry Harun (1995): Achlaq - Charakterbildung im Islam. München. Abgerufen unter: www. enfal.de/grund32.html [Abrufdatum: 01.09.2010]. Behr, Harry Harun (1998): Islamische Bildungslehre. Garching bei München.

Behr, Harry Harun (2005): Curriculum Islamunterricht. Analyse von Lehrplanentwürfen für islamischen Religionsunterricht in der Grundschule. Ein Beitrag zur Lehrplantheorie des Islamunterrichts im Kontext der praxeologischen Dimension islamisch theologischen Denkens.Universi- 
tät Bayreuth. Abgerufen unter: www.izir.uni-erlangen.de/ [Abrufdatum: 01.09.2010].

Behr, Harry Harun (2009): Koranschule. In: Blömeke, Sigrid et al. (Hg.) (2009): Handbuch Schule: Theorie, Organisation, Entwicklung. Regensburg, S. 406-410.

Bertelsmann Stiftung (Hg.) (2008a): Religionsmonitor. Woran glaubt die Welt? Analysen und Kommentare zum Religionsmonitor. Gütersloh.

Bertelsmann Stiftung (Hg.) (2008b): Religionsmonitor. Muslimische Religiosität in Deutschland. Überblick zu religiösen Einstellungen und Praktiken. Gütersloh. Abgerufen unter: www.bertelsmann-stiftung.de/bst/de/media/ xcms_bst_dms_25864_25865_2.pdf [Abrufdatum: 14.11.2010].

Biesinger, Albert/Edelbrock, Anke/Schweitzer, Friedrich (2009): Mein Gott Dein Gott. Interkulturelle und interreligiöse Bildung in Kindertagesstätten. Weinheim/Basel.

Biesinger, Albert/Edelbrock, Anke/Schweitzer, Friedrich (2009): Neue empirische Befunde. Ergebnisse des Forschungsprojekts »Interkulturelle und interreligiöse Bildung in Kindertagesstätten« im Überblick. In: dies. (Hg.) (2009): Mein Gott - Dein Gott. Interkulturelle und interreligiöse Bildung in Kindertagesstätten. Weinheim/Basel, S. 15-30.

Biesinger, Albert et al. (2009): Religion und Religionen in der Kindertagesstätte. Eine empirische Untersuchungzu interreligiöser Bildung in der Praxis. In: Biesinger, Albert/Edelbrock, Anke/Schweitzer, Friedrich (2009): Mein Gott - Dein Gott: Interkulturelle und interreligiöse Bildung in Kindertagesstätten. Weinheim/Basel, S. 149-229.

Bilmen, Ömer Nasuhi (2004): Feinheiten Islamischen Glaubens. Islamischer Katechismus. Bochum.

Blank, Reanate (2000): Qualitative Studie »Jugend 2000 - Fremde hier wie dort«. In: Jugend 2000 - 13. Shell Jugendstudie. Bd. 2. Opladen, S. 7-351.

BMFSJ (Bundesministerium für Familie, Senioren, Frauen und Jugend) (Hg.) (2009): Der Mikrozensus im Schnittpunkt von Geschlecht und Migration. Möglichkeiten und Grenzen einer sekundäranalytischen Auswertung des Mikrozensus 2005. Baden-Baden. Abgerufen unter: www.bmfsfj.de/Redak tionBMFSFJ/Broschuerenstelle/Pdf-Anlagen/mikrozensus-geschlechtmigration-pdf,property $=$ pdf,bereich $=$ bmfsfj, sprache $=$ de, $r w b=\operatorname{true}$.pdf $[\mathrm{Ab}$ rufdatum: 14.02.2014].

BMFSJ (Bundesministerium für Familie, Senioren, Frauen und Jugend) (Hg.) (2010): Ehe, Familie, Werte - Migrantinnen und Migranten in Deutschland. Monitor Familienforschung. Beiträge aus Forschung, Statistik und Familienpolitik. Berlin. Abgerufen unter: www.bmfsfj.de/RedaktionBM FSFJ/Broschuerenstelle/Pdf-Anlagen/Monitor-Familienforschung-Nr.24, property $=$ pdf,bereich $=$ bmfsfj, sprache $=$ de,rwb=true.pdf [Abrufdatum: $14.02 .2014]$. 
Bochinger, Christoph (2010): Religiöse Identität bei Migrantengruppen - eine vergleichende Perspektive. In: Behr, Harry Harun et al. (Hg.) (2010): Was soll ich hier? Lebensweltorientierung muslimischer Schülerinnen und Schüler als Herausforderung für den Islamischen Religionsunterricht. Berlin, S. 103-116.

Boehnke, Klaus et al. (2011): Lebenswelten junger Muslime in Deutschland. Ein sozial- und medienwissenschaftliches System zur Analyse, Bewertung und Prävention islamischer Radikalisierungsprozesse junger Menschen in Deutschland. Im Auftrag des Bundesministeriums des Innern. Berlin.

Boos-Nünning, Ursula (1972): Dimensionen der Religiosität. Zur Operationalisierung und Messung religiöser Einstellungen. München.

Boos-Nünning, Ursula (2007): Religiosität junger Musliminnen im Einwandererkontext. In: Wensierski, Hans-Jürgen von/Lübcke, Claudia (Hg.): Junge Muslime in Deutschland. Lebenslagen, Aufwachsprozesse und Jugendkulturen. Opladen/Farmington Hills, S. 117-134.

Boos-Nünning, Ursula (2011a): Migrationsfamilien als Partner von Erziehung und Bildung. Expertise im Auftrag der Abteilung Wirtschafts- und Sozialpolitik der Friedrich-Ebert-Stiftung. Bonn.

Boos-Nünning, Ursula (2011b): Die Bildungsarbeit von Migrantenorganisationen - dargestellt unter besonderer Berücksichtigung der Aktivitäten der Gülen-Bewegung. In: Boos-Nünning, Ursula/Bultmann Christoph/Ucar, Bülent (Hg.) (2011): Die Gülen-Bewegung. Zwischen Predigt und Praxis. Münster, S. 191-215.

Boos-Nünning, Ursula (2013): Aufstieg durch Bildung? Bildungsansprüche und deren Realisierung. Migrationsfamilien und einheimische Familien im Vergleich. In: Boos-Nünning, Ursula/Stein Margit (Hrsg): Familie als Ort von Erziehung, Bildung und Sozialisation. Münster, S. 217-245.

Boos-Nünning, Ursula (2015): Religionszugehörigkeiten in Deutschland. In: Engin, Havva et al. (Hg.) (2015): Handbuch Christentum und Islam in Deutschland. Grundlagen, Erfahrungen und Perspektiven des Zusammenlebens. Freiburg i.Br., S. 21-46.

Boos-Nünning, Ursula/Golomb, Egon (1974): Religiöses Verhalten im Wandel. Untersuchungen in einer Industriegesellschaft. Essen.

Boos-Nünning, Ursula et al. (1986): Zwischen Elternhaus und Arbeitsamt: Türkische Jugendliche suchen einen Beruf. Berlin.

Boos-Nünning, Ursula/Karakaşoğlu, Yasemin (2005): Muslimische Religiosität in der Migration. Nationale und konfessionelle Binnendifferenzierungen und die Bedeutung des Kopftuches bei muslimischen Mädchen mit Migrationshintergrund. Eine Sonderauswertung der Daten der Studie »Viele Welten leben«. Unveröffentlichtes Manuskript. 
Boos-Nünning, Ursula/Karakaşoğlu, Yasemin (2006): Viele Welten leben. Zur Lebenssituation von Mädchen und jungen Frauen mit Migrationshintergrund. Münster.

Böhm, Andreas (2003): Theoretisches Codieren: Textanalyse in der Grounded Theory. In: Flick, Uwe/Kardoff, Ernst von/Steinke, Ines (2003) (Hg.): Qualitative Forschung. Ein Handbuch. Reinbek bei Hamburg, S. 475-485.

Brettfeld, Katrin/Wetzels, Peter (2007): Muslime in Deutschland- Integration, Integrationsbarrieren, Religion sowie Einstellungen zu Demokratie, Rechtsstaat und politisch-religiös motivierter Gewalt - Ergebnisse von Befragungen im Rahmen einer multizentrischen Studie in städtischen Lebensräumen. Im Auftrag des Bundesministeriums des Innern. Hamburg.

Bukow, Wolf-Dietrich (1974): Religiöse Sozialisation in der Familie. Zu den Konstitutionsbedingungen des religiösen Bewusstseins in der Familie. Dissertation Heidelberg, Ruprecht-Karls-Universität.

Bukow, Wolf-Dietrich (2007): Junge Muslime in Schule und Bildung. In: Wensierski, Hans-Jürgen von/Lübcke, Claudia (Hg.) (2007): Junge Muslime in Deutschland. Lebenslagen, Aufwachsprozesse und Jugendkulturen. Opladen/Farmington Hills, S. 213-230.

Ceylan, Rauf (2008): Islamische Religionspädagogik in Moscheen und Schulen. Ein sozialwissenschaftlicher Vergleich der Ausgangslage, Lehre und Ziele unter besonderer Berücksichtigung der Auswirkungen auf den Integrationsprozess der muslimischen Kinder und Jugendlichen in Deutschland. Hamburg.

Ceylan, Rauf (2010a): Die Prediger des Islam. Imame wer sie sind und was sie wirklich wollen. Bonn.

Ceylan, Rauf (2010b): Imame in Deutschland.Religiöse Orientierungen und Erziehungsvorstellungen türkisch-muslimischer Autoritäten. In: Schneiders, Gerald Thorsten (Hg.) Islamverherrlichung. Wenn die Kritik zum Tabu wird. Wiesbaden, S. 295-314.

Ceylan, Rauf (2014): Cultural Time Lag. Moscheekatechese und islamischer Religionsunterricht im Kontext von Säkularisierung. Wiesbaden.

Ceylan, Rauf/Stein Margit(2016): Religiöse Erziehunginmuslimischen Familien und Anforderungen an einen guten >guten Islamunterricht<- Forschungsstand und Forschungsperspektiven. In: Zeitschrift für Schulpädagogik heute, H. 13 (2016), 7. Jahrgang »Was sind gute Schulen?«. Abgerufen unter: www.schulpaedagogik-heute.de/SHHeft13/04_Forum/04_12.pdf [Abrufdatum: 31.03.2016].

Darwisch, Kinan (2013): Islamischer Religionsunterricht. Darstellung und Analyse der islamischen Unterrichtsprojekte. Marburg.

Deutsche Islam Konferenz (Hg.) (2009): Drei Jahre Deutsche Islam Konferenz (DIK) 2006-2009. Muslime in Deutschland- deutsche Muslime. Gefördert vom Bundesministerium des Innern. Berlin. 
Deutsche Islam Konferenz (2011): Islamischer Religionsunterricht in Deutschland. Perspektiven und Herausforderungen. Dokumentation. Tagung der Deutschen Islam Konferenz 13. bis 14. Februar 2011. Nürnberg.

Dippelhofer-Stiem, Barbara (2008): Die Gestalt von Sozialisationsumwelten. In: Grundmann, Matthias/Hurrelmann, Klaus/Walper, Sabine (Hg.) (2008): Handbuch Sozialisationsforschung.Weinheim/Basel, S. 117-128.

Drehsen, Volker/Mette, Norbert (2001): Sozialisation (religiöse). In: Mette, Norbert/Rickers, Folkert (Hg.) (2001): Lexikon der Religionspädagogik. Bd. 2. Neukirchen, S. 2007-2015.

Drinck, Barbara (2008): Erziehung. In: Drinck, Barbara/Hörner, Wolfgang/ Jobst, Solvejg (2008): Bildung, Erziehung, Sozialisation. Opladen/Farmington Hills, S. 73-113.

El-Mafaalani, Aladin/Toprak, Ahmet (2011): Muslimische Kinder und Jugendliche in Deutschland. Lebenswelten - Denkmuster - Herausforderungen. Eine Veröffentlichung der Konrad-Adenauer-Stiftung e.V. Sankt Augustin/ Berlin.

Flick, Uwe (2007): Qualitative Sozialforschung. Eine Einführung. Reinbek bei Hamburg.

Flick, Uwe/Kardoff, Ernst von/Steinke, Ines (2003) (Hg.): Qualitative Forschung. Ein Handbuch. Reinbek bei Hamburg.

Fraas, Hans Jürgen (1987): Entwicklung und religiöse Sozialisation. In: Böcker, Werner/Heimbrock, Hans-Günter/Kerkhoff, Engelbert (1987) (Hg.): Handbuch religiöser Erziehung. Bd. 1: Lernbedingungen und Lerndimensionen. Düsseldorf, S. 106-119.

Fraas, Hans-Jürgen (1990): Die Religiosität des Menschen: Ein Grundriß der Religionspsychologie. Göttingen.

Frese, Hans-Ludwig (2002): »Den Islam ausleben«. Konzepte authentischer Lebensführungen junger türkischer Muslime in der Diaspora. Bielefeld.

Fuchs-Heinritz, Werner (2000): Religion. In: Jugend 2000-13. Shell Jugendstudie. Bd. 1. Opladen, S. 157-180.

Glock, Charles (1969): Über die Dimensionen der Religiosität. In: Matthes, Joachim (Hg.): Kirche und Gesellschaft. Einführung in die Religionssoziologie. Bd. 2. München.

Grundmann, Matthias/Hurrelmann, Klaus/Walper, Sabine (2008): Zum Stand der Sozialisationsforschung. In: Grundmann, Matthias/Hurrelmann, Klaus/Walper, Sabine (Hg.) (2008): Handbuch Sozialisationsforschung.Weinheim/Basel, S. 14-31.

Halm, Dirk/Sauer, Martina (2012): Angebote und Strukturen der islamischen Organisationen in Deutschland. In: Halm, Dirk et al. (2012): Islamisches Gemeindeleben in Deutschland. Im Auftrag der Deutschen Islam Konferenz (DIK). Forschungsbericht 13. Bundesamt für Migration und Flüchtlinge. Nürnberg, S. 21-154. 
Halm, Dirk et al. (2012): Islamisches Gemeindeleben in Deutschland. Im Auftrag der Deutschen Islam Konferenz (DIK). Forschungsbericht 13. Bundesamt für Migration und Flüchtlinge. Nürnberg.

Hamidullah, Muhammad (2003): Der Islam. Geschichte, Religion, Kultur. Hg. v. Kitab Kulübü. Köln. Originaltitel: Initiation à l'Islam, Paris 1963.

Haug, Sonja/Müssig, Stephanie/Stichs, Anja (2009): Muslimisches Leben in Deutschland. Im Auftrag der deutschen Islam Konferenz (DIK) und des BAMF. Forschungsbericht 6 . Nürnberg.

Hermanns, Harry (2009): Interviewen als Tätigkeit. In: Flick, Uwe/Kardoff, Ernst von/Steinke, Ines (2003) (Hg.): Qualitative Forschung. Ein Handbuch. Reinbek bei Hamburg, S. 360-368.

Hopf, Christel (2003): Qualitative Interviews - ein Überblick. In: Flick, Uwe/ Kardoff, Ernst von/Steinke, Ines (2003) (Hg.): Qualitative Forschung. Ein Handbuch. Reinbek bei Hamburg, S. 349-360.

Huber-Rudolf, Barbara (2002): Muslimische Kinder im Kindergarten: Eine Praxishilfe für alltägliche Begegnungen. München.

Hunner-Kreisel, Christine (2010): Respekt als generationales Muster? Aufwachsen im Kontext von Migration und familialen muslimischen Lebenswelten. In: Andresen, Sabine/Hunner-Kreisel, Christine (Hg.) (2010): Kindheit und Jugend in muslimischen Lebenswelten: Aufwachsen und Bildung in deutscher und internationaler Perspektive. Wiesbaden, S. 177-191.

Hurrelmann, Klaus (2002a): Einführung in die Sozialisationstheorien. Weinheim/Basel.

Hurrelmann, Klaus (2002b): Sozialisation. In: Endruweit,Günter/Trommsdorf, Gisela (Hg.): Wörterbuch der Soziologie. Stuttgart, S. 500-509.

Hurrelmann, Klaus (2012): Sozialisation. Weinheim/Basel.

Kanacher, Britta (2001): Religiöse Sozialisation und Individualisierung Zum religiösen Kultur- und Identitätskonflikt muslimischer Migranten. Bonn. Abgerufen unter: http://deposit.d-nb.de/cgi-bin/dokserv?idn= 968434908\&dok_var=d1\&dok_ext=pdf\&filename=968434908.pdf [Abrufdatum: 14.05.2011].

Kanacher, Britta (2003): Christliche und muslimische Identität. Anstöße für eine neue Verständigung. Münster.

Karakaşoğlu-Aydın, Yasemin (2000): Muslimische Religiosität und Erziehungsvorstellungen. Eine empirische Untersuchung zu Orientierungen bei türkischen Lehramts- und Pädagogik-Studentinnen in Deutschland. Frankfurt a.M.

Karakaşoğlu-Aydın, Yasemin (2001): Religiöse Orientierungen und Erziehungsvorstellungen. Eine Zusammenfassung der Dissertation von Dr. Yasemin Karakaşoğlu-Aydın. In: Religiosität und Modernität. Ansprachen und Materialien zur Verleihung des Augsburger Wissenschaftspreises für interkulturelle Studien 2000. Augsburg. 
Karakaş̧oğlu, Yasemin/Öztürk Halit (2007): Erziehung und Aufwachsen junger Muslime in Deutschland. Islamisches Erziehungsideal und empirische Wirklichkeit in der Migrationsgesellschaft. In: Wensierski, Hans-Jürgen von/Lübcke, Claudia (Hg.) (2007): Junge Muslime in Deutschland. Lebenslagen, Aufwachsprozesse und Jugendkulturen. Opladen/Farmington Hills, S. 157-172.

Khorchide, Mouhanad (2009): Der islamische Religionsunterricht zwischen Integration und Parallelgesellschaft. Einstellungen der islamischen ReligionslehrerInnen an öffentlichen Schulen. Wiesbaden.

Kiefer, Michael (2005): Islamkunde in deutscher Sprache in Nordrhein-Westfalen. Kontext, Geschichte, Verlauf und Akzeptanz eines Schulversuchs. Münster.

Klinkhammer, Gritt (2000): Moderne Formen islamischer Lebensführung. Eine qualitativ-empirische Untersuchung zur Religiosität sunnitisch geprägter Türkinnen der zweiten Generation in Deutschland. Marburg.

Lamnek, Siegfried (2005): Qualitative Sozialforschung. Ein Lehrbuch.Weinheim/Basel.

Lemmen, Thomas (2001): Muslime in Deutschland. Eine Herausforderung für Kirche und Gesellschaft.Baden-Baden.

Lukesch, Helmut (2008): Sozialisation durch Massenmedien. In: Grundmann, Matthias/Hurrelmann, Klaus/Walper, Sabine (Hg.) (2008): Handbuch Sozialisationsforschung.Weinheim/Basel, S. 384-397.

Mayring, Philipp (2010): Qualitative Inhaltsanalyse. Grundlagen und Techniken. Weinheim Basel.

Merkens, Hans/Schmidt, Folker (1997): Sozialisation und Erziehung in ausländischen Familien in Deutschland. Hohengehren.

Mette, Norbert (1986): Erziehung. In: Bitter, Gottfried/Miller, Gabriele (Hg.) (1986): Handbuch religionspädagogischer Grundbegriffe. Bd. 1. München, S. 52-60.

Miller-Kipp,Gisela/Oelkers, Jürgen (2007): Erziehung. In: Tenorth, Heinz-Elmar/Tippelt, Rudolf (Hg.) (2007): Lexikon Pädagogik. Weinheim/Basel, S. 204-211.

Ministerium für Arbeit, Integration und Soziales des Landes Nordrhein-Westfalen (Hg.) (2010): Muslimisches Leben in Nordrhein-Westfalen. Eine Zusatzstudie im Auftrag des Ministeriums für Arbeit, Integration und Soziales des Landes NRW. Düsseldorf. Abgerufen unter: www.mais.nrw. de/08_PDF/003_Integration/110115_studie_muslimisches_leben_nrw.pdf [Abrufdatum: 13.05.2011].

Mirbach, Ferdinand (2008): Islam in Deutschland. Islam in der Welt. In: Bertelsmann Stiftung (Hg.) (2008b): Religionsmonitor. Muslimische Religiosität in Deutschland. Überblick zu religiösen Einstellungen und Praktiken. Gütersloh, S. 76-84. 
Mohr, Irka-Christin (2006): Islamischer Religionsunterricht in Europa. Lehrtexte als Instrumente muslimischer Selbstverortung im Vergleich. Bielefeld.

Möllering, Anna/Schiefer, David (2011): Mehrgenerationenfallstudie. In: Boehnke, Klaus et al. (2011): Lebenswelten junger Muslime in Deutschland. Ein sozial- und medienwissenschaftliches System zur Analyse, Bewertung und Prävention islamischer Radikalisierungsprozesse junger Menschen in Deutschland. Im Auftrag des Bundesministeriums des Innern. Berlin, S. 44-102.

Nökel, Sigrid (2002): Die Töchter der Gastarbeiter. Zur Soziologie alltagsweltlicher Anerkennungspolitiken. Eine Fallstudie. Bielefeld.

Oswald, Hans (2008): Sozialisation in Netzwerken Gleichaltriger. In: Grundmann, Matthias/Hurrelmann, Klaus/Walper, Sabine (Hg.) (2008): Handbuch Sozialisationsforschung.Weinheim/Basel, S. 306-320.

Ott, Rudi (1986): Sozialisation. In: Böcker, Werner/Heimbrock, Hans-Günter/ Kerkhoff, Engelbert (1987) (Hg.): Handbuch religiöser Erziehung. Bd. 1: Lernbedingungen und Lerndimensionen. Düsseldorf, S. 61-67.

Öztürk, Halit (2007): Wege zur Integration. Lebenswelten muslimischer Jugendlicher in Deutschland. Bielefeld.

Prognos AG (2010): Familien mit Migrationshintergrund. Lebenssituation, Erwerbsbeteiligung und Vereinbarkeit von Familie und Beruf. Im Auftrag des BFMFSJ (Bundesministerium für Familie, Senioren, Frauen und Jugend). Berlin. Abgerufen unter: www.bmfsfj.de/RedaktionBMFSFJ/Broschue renstelle/Pdf-Anlagen/Familien-mit-Migrationshintergrund,property=pdf, bereich $=$ bmfsfj,sprache $=$ de, $r w b=$ true.pdf [Abrufdatum: 14.02.2014].

Pülz, Lars (2008): Jung - Gebildet - Radikal? Junge muslimische Akademiker in orthodoxen Religionsgemeinschaften. Marburg.

Rerrich, Maria S. (1995): Familie. In: Flick, Uwe et al. (Hg.) (1995). Handbuch Qualitative Sozialforschung. Grundlagen, Konzepte, Methoden und Anwendungen. Weinheim, S. 348-351.

Sarıkaya, Yaşar (2008): Grundlagen der traditionellen islamischen Kindererziehung und ihre Relevanz für den Islamunterricht in Deutschland. In:Gottwald, Eckart/Kiefer, Michael/Ucar, Bülent (2008): Auf dem Weg zum Islamischen Religionsunterricht. Sachstand und Perspektiven in Nordrhein-Westfalen. Berlin.

Sauter, Gerhard (2006): Religiöse Erziehung. In: Lenzen, Dieter (Hg.) Pädagogische Grundbegriffe. Bd. 1. Reinbek bei Hamburg, S. 456-464.

Schäfer, Franziska/Schwarz, Melissa (2007): Zwischen Tabu und Liberalisierung - Zur Sexualität junger Muslime. In: Wensierski, Hans-Jürgen von/ Lübcke, Claudia (Hg.) (2007): Junge Muslime in Deutschland. Lebenslagen, Aufwachsprozesse und Jugendkulturen. Opladen/Farmington Hills, S. 251-281. 
Scheuch, Erwin K. (1967): Das Interview in der Sozialforschung. In: König, René (1967): Handbuch der empirischen Sozialforschung. Bd. 1. Stuttgart, S. 136-157.

Schiffauer, Werner (1991): Die Migranten aus Subay. Türken in Deutschland. Eine Ethnographie. Stuttgart.

Schiffauer,Werner (2010): Nach dem Islamismus: die Islamische Gemeinschaft Milli Görüş. Eine Ethnographie. Berlin.

Schmitz, Bertram/Seibert, Leif (2007): Die religiöse Organisation im Islam. In: Wunn, Ina (2007): Muslimische Gruppierungen in Deutschland. Ein Handbuch. Stuttgart, S. 13-25.

Schneewind, KlausA. (1980): Erziehungsstilforschung: Theorien, Methoden und Anwendung der Psychologie elterlichen Erziehungsverhaltens. Bern.

Schneewind, Klaus A. (2010): Familienpsychologie. Stuttgart.

Schröter, Hiltrud (2002): Mohammeds deutsche Töchter. Bildungsprozesse, Hindernisse, Hintergründe. Königstein, Taunus.

Schweitzer, Friedrich (2003): Pädagogik und Religion. Eine Einführung. Stuttgart.

Seifert, Wolfgang (2012): Geschichte der Zuwanderung nach 1950. Abgerufen unter:www.bpb.de/politik/grundfragen/deutsche-verhaeltnisse-eine-sozial kunde/138012/geschichte-der-zuwanderung-nach-deutschland-nach-1950 [Abrufdatum: 31.01.2014].

Seiser, Kismet (2006): Konstanz und Wandel der Werthaltungen in türkischen Migrantenfamilien. Regensburg.

Şen, Faruk/Sauer, Martina (2006): Islam in Deutschland. Einstellungen der türkischstämmigen Muslime. Religiöse Praxis und organisatorische Vertretung türkischstämmiger Muslime in Deutschland. Ergebnisse einer bundesweiten Befragung. Zentrum für Türkeistudien. Essen.

Spielhaus, Riem (2013): Wer ist hier Muslim und wenn ja wie viele? Ein Gutachten im Auftrag des Mediendienst Integration. Abgerufen unter: http://me diendienst-integration.de/fileadmin/Dateien/Muslime_Spielhaus_MDI. pdf [Abrufdatum: 25.03.2014].

Spenlen, Jeanette (2012): Religiöse Erziehung im Islam: Gender-Perspektiven, Elternbilder und ethnischer Kontext in Deutschland und Ägypten.Abgerufen unter: www.remid.de/blog/2012/03/religioese-erziehung-im-islamgender-perspektiven-elternbilder-und-ethnischer-kontext-in-deutschlandund-aegypten/[Abrufdatum: 25.03.2014].

Stachel, Günter (1976): Probleme religiöser Erziehung heute. In: Bargher, Friedrich W. et al. (1976): Religiöse Erziehung im Elternhaus. Aufgaben Probleme - Schwerpunkte. Regensburg, S. 71-88.

Stöbe, Axel (1998): Islam - Sozialisation - Interkulturelle Erziehung: Die Bedeutung des Islam im Sozialisationsprozeß von Kindern türkischer Herkunft und für Konzepte interkultureller Erziehung. Hamburg. 
Thielmann, Jörn (2008): Vielfältige muslimische Religiosität in Deutschland. In: Bertelsmann Stiftung (Hg.) (2008b): Religionsmonitor. Muslimische Religiosität in Deutschland. Überblick zu religiösen Einstellungen und Praktiken. Gütersloh, S. 13-21.

Thiessen, Barbara (2008): Muslimische Familien in Deutschland - Alltagserfahrungen, Konflikte, Ressourcen. Im Auftrag des BMFSFJ. Deutsches Jugendinstitut München. Abgerufen unter: www.bmfsfj.de/Redaktion BMFSFJ/Abteilung2/Pdf-Anlagen/muslimische-familien-indeutschland, property=pdf,bereich=bmfsfj,sprache=de,rwb=true.pdf [Abrufdatum: 01.10 . 2011].

Thiersch, Renate (2009): Muslimische Kinder - Herausforderung und Chance für Kindertagesstätten. In: Biesinger, Albert/Edelbrock, Anke/Schweitzer, Friedrich (2009): Mein Gott - Dein Gott. Interkulturelle und interreligiöse Bildung in Kindertagesstätten. Weinheim/Basel, S. 48-66.

Tietze, Nikola (2001): Islamische Identitäten. Formen muslimischer Religiosität bei jungen Männern in Deutschland und Frankreich. Hamburger Institut für Sozialforschung. Hamburg.

Tillmann, Klaus-Jürgen (2010): Sozialisationstheorien. Eine Einführung in den Zusammenhang von Gesellschaft, Institution und Subjektwerdung. Hamburg.

Toprak, Ahmet (2012): »Unsere Ehre ist uns heilig«. Muslimische Familien in Deutschland. Freiburg i.Br..

Turhan, Canan/Turhan, Ibrahim (2011): Junge Muslime in der Schule. Probleme und Lösungsansätze im interkulturellen Dialog. Marburg.

Uslucan, Hac1 Halil (2008): Religiöse Werteerziehung in islamischen Familien. Expertise im Auftrag des Bundesministeriums für Familie, Senioren, Frauen und Jugend (BFSMJ). Abgerufen unter: www.bmfsfj.de/Redaktion BMFSFJ/Abteilung2/Pdf-Anlagen/expertise-religioese-werteerziehung,pro perty=pdf,bereich=bmfsfj,sprache=de,rwb=true.pdf\%20[Abrufdatum: 03.10. 2011].

Uslucan, Hac1 Halil (2009a): Religiöse Werteerziehung in muslimischen Familien, in: Drei Jahre Deutsche Islam Konferenz (DIK) 2006-2009. Berlin, S. $136-157$.

Uslucan, Hacı Halil (2009b): Erziehungsstile und Werte in muslimischen Familien. In: forum erwachsenenbildung, Heft 2 (2009). Münster, S. 9-14.

Uslucan, Hac1 Halil (2015): »Bildet euch - Im Namen Gottes, der Euch erschaffen hat.« Religiöse Erziehung im Spannungsfeld von Geborgenheit und Dogmatismus. In: Engin, Havva et al. (Hg.) (2015): Handbuch Christentum und Islam in Deutschland. Grundlagen, Erfahrungen und Perspektiven des Zusammenlebens. Freiburg i.Br., S. 752-768.

Uygun-Altunbas, Ayse (2010): Konzepte islamischer Religionspädagogik anhand von Experteninterviews. München. 
Veith, Hermann (2008): Sozialisation. München.

Wensierski, Hans-Jürgen von (2007): Die islamisch-selektive Modernisierung - Zur Struktur der Jugendphase junger Muslime in Deutschland. In: Wensierski, Hans-Jürgen von/Lübcke, Claudia (Hg.) (2007): Junge Muslime in Deutschland. Lebenslagen, Aufwachsprozesse und Jugendkulturen. Opladen/Farmington Hills, S. 55-84.

Wensierski, Hans-Jürgen von/Lübcke, Claudia (2012): »Als Muslim fühlt man sich hier auch zu Hause«. Biographien und Alltagskulturen junger Muslime in Deutschland. Opladen/Berlin/Toronto.

Wunn, Ina (2007): Muslimische Gruppierungen in Deutschland. Ein Handbuch. Stuttgart.

Yalçın-Heckmann, Lale (1998): »Growing up as a Muslimin Germany: Moral and Religious Socialization among the Turkish Migrant Families in Germany«. In: Vertovec, Steven/Rogers, Alisdair (Hg.): Muslim European Youth. Reproducing ethnicity, religion, culture. Aldershot, GB/Brookfield, USA, S. 164-185.

Yölek-Cantay, Hasiybe (2010): Islamische Bildung im säkularen Staat. Religionskenntnisse als Basis erfolgreicher Integration. Marburg.

Zaidan, Amir (1999): Al-Aqida. Einführung in die Iman-Inhalte. Offenbach.

\section{TÜRKISCHSPRACHIGE LITERATUR}

Ay, Mehmed Emin (2001a): İdeal din eğitimi.Istanbul.

Ay, Mehmed Emin (2001b): Çocuklarımıza Allah< 1 nasıl anlatalım. Istanbul. Bayraktar, Bayrakl1 (2002): İslam da Eğitim. İstanbul.

Bilgili, Fatih Menderes (2005): Çocuğun din eğitimi ve karşılaşılan güçlükler. Istanbul.

Bilgin, Beyza (2001): Din eğitimi ve eğitim bilimleri. Ankara.

Bilgiz, Musa (2006): Çocuk Eğitiminde Sevgi. Istanbul.

Çamdibi, Mahmut (2003): Din Eğitiminde İnsan ve Hayat. Istanbul.

Dodurgalı, Abdurrahman (1998): Ailede Çocuğun Din Eğitimi. Istanbul.

Hökelekli, Hayati (2003): Din psikolojisi. Ankara.

Karaman Hayreddin (2012): İslam > in Işığında Günün Meseleleri. Istanbul. Köse, Ali/Ayten, Ali (2012): Din psikolojisi. Istanbul.

Ibn Kayyım El-Cevziyye (1997): İslâmda çocuk. Çocuk hakları, terbiyesi ve ilahi hükümler. Istanbul. 



\section{Anhang}

\section{ANHANG 1: INTERVIEWLEITFADEN}

Ziel dieser Untersuchung ist es, herauszufinden, wie religiöses Aufwachsen von Kindern und Jugendlichen stattfindet. Die religiöse Erziehung ist dabei ein wichtiger Aspekt. Ich möchte mit diesem Interview herausfinden, wie neben ihrer Familie die Schule oder der Kindergarten, die Moscheen oder ähnliche Einrichtungen, der Freundeskreis der Kinder sowie Medien und Gesellschaft auf die religiöse Entwicklung ihrer Kinder wirken.

Ich möchte mich erst einmal bedanken, dass Sie an diesem Interview teilnehmen. Und ich hoffe auf einen gegenseitig bereichernden Austausch.

\section{Eröffnungsfrage (Erzählaufforderung)}

- Vielleicht (sensibel auf die Ausgangssituation achten)

Einiges vorab zur Familienstruktur (Lebenssituation in Deutschland/Familienstand/Zahl der Kinder/Migrationsgeschichte/Besonderes)

- Wie viele Kinder haben Sie?

- Wie war das denn bei Ihnen? War in Ihrer Kindheit und Jugend, Religion in Ihrer Familie ein Thema?

Ziel: Motivation zum Erzählen/Auflockerung, konkrete Hinführung zum dargestellten Thema

- War religiöse Erziehung in Ihrer (Ursprungs-)Familie ein Thema?

○ wenn nein: Darf ich fragen, warum nicht?

( $\rightarrow$ Bezug und Übergang zur nächsten Frage)

○ wenn ja: Welche Auswirkungen hatte diese Erziehung?

$(\rightarrow$ Bezug und Übergang zur nächsten Frage) 


\section{Religiöse Erziehung in der Familie Religiöse Erziehungsvorstellungen}

- Und wie ist es heute? Wie wichtig ist Ihnen die religiöse Erziehung?

- Was erwarten Sie von einer religiösen Erziehung? Was soll sie bringen/ bewirken?

Dimension des religiösen Glaubens

- Was ist Ihrer Meinung nach Glaube (=Iman)?

- Welchen Einfluss hat dies/haben diese (o.g. Vorstellungen) auf die Erziehung Ihres Kindes/Ihrer Kinder?

Oder: Was bringt der Glaube für die Erziehung?

Dimension der religiösen Erfahrungen

- In welchem Bereich haben Sie erste gemeinsame religiösen Erfahrungen gemacht? (evtl. Vorgaben: die täglichen Gebete, »Es gibt Allah!«, Bittgebete, Spende, Gemeinschaft)

\section{Rituelle Dimension}

- Welche rituellen Pflichten sind für Sie im Alltag besonders wichtig?

- Beten Sie mit Ihrem Kind/Ihren Kindern gemeinsam?

- Wie verbringen Sie den Monat Ramadan?

- (Wie) feiern Sie religiöse Feste?

- Lesen Sie gemeinsam den Koran?

\section{Dimension des religiösen Wissens}

- Welches Wissen wollen Sie Ihrem Kind/Ihren Kindern auf jeden Fall vermitteln?

- Stellt Ihr Kind/Stellen Ihre Kinder Fragen über religiöse Themen?

- Was sind die Fragen, die Ihr Kind/Ihre Kinder am meisten interessiert?

\section{Methode}

- Auf welche Weise versuchen Sie all das o. G. Ihrem Kind/Ihren Kindern zu vermitteln?

Welche Mittel wählen Sie?

\section{Erziehungsstile}

- Was tun Sie, wenn Ihr Kind/Ihre Kinder nicht folgen will/wollen? (Differenzierung nach Alter: Kleinkind, Schulkind, Jugend) Nachfrage:

- Bei positivem Verhalten: welche Belohnungen?

○ Bei Nichteinhaltung von Regeln: welche Strafen? 
- Hinsichtlich welcher Fragen gibt es häufiger/manchmal Konflikte? Nachfrage:

- Wie lösen Sie (gemeinsam) Konflikte?

- Wollen Sie noch etwas ergänzen?

- Welche Einrichtungen sind Ihnen mit Blick auf die religiöse Erziehung Ihrer Kinder wichtig?

\section{Außerschulische Bildungseinrichtungen}

(Moscheen, religiöse Vereinigungen, Gemeinden, auch religiöse Vorbilder)

- Geht Ihr Kind/gehen Ihre Kinder in die Moschee o. ä. Einrichtungen? z.B. Koranunterricht: Besucht Ihr Kind/Besuchen Ihre Kinder einen Koranunterricht?

- Was wird in der Moschee für die religiöse Erziehung geleistet? (oder: Was vermittelt die Moschee den Kindern?)

o Koranrezitation

○ Religiöse Unterweisung

- Lernen, Riten

○ Wertevermittlung

- Wie wird das gemacht?

(Koranlesen, Vorbild, Rituale, Auswendiglernen u.a.)

- Werden Freizeitangebote gemacht?

- Sprechen sie mit Ihrem Kind/Ihren Kindern über die Moschee oder den Moscheeunterricht?

- Haben sich Ihre Erwartungen erfüllt?

- Wie bewerten Sie die religiöse Unterweisung in der Moschee?

- nach Inhalt

- Methode

- Was ist Ihrer Meinung nach verbesserungswürdig? (evtl. Nachfrage: Was finden Sie gut? Was finden Sie nicht so gut?)

- Was wünschen Sie sich insgesamt (im Moscheeunterricht) für Ihr Kind/ Ihre Kinder?

\section{Religion in öffentlichen Bildungseinrichtungen}

(Schule, Kiga, Kita, Ganztageseinrichtungen)

- Welche Schule, welche Kita besucht Ihr Kind/besuchen Ihre Kinder?

- Haben Sie eine Vorstellung davon, wie der/die Erzieher/-in oder Lehrer/-in Ihrer Kinder zu Ihrer Religion steht?

- Haben religiöse oder kulturelle Elemente (z.B. Handlungen, Rituale, Kopftuch, religiöse Feste) im Schulalltag Platz? Wünschen Sie sich so etwas? 
- Bringen Sie Ihre religiöse Lebensweise konkret ein, z.B. bei...? (oder: Wie gestalten Sie mit?) Feiern Sie z.B. religiöse Feste?

- Gibt es Konfliktsituationen?

- Gibt es Benachteiligungen, die auf die Religion oder die religiöse Lebensweise zurückgeführt werden können?

Interreligiöse Begegnungen

- Besucht Ihr Kind/Besuchen Ihre Kinder eine konfessionelle Schule oder Kita?

- Sind Ihnen interreligiöse Begegnungen im Schul-/Kitaalltag Ihres Kind/ Ihrer Kinder wichtig?

Nachfrage: Welche Formen wählen Sie aus?

(z.B. religiöse Festtage/das Sprechen über die jeweils andere Religion)

- oder: Interessieren Sie sich für die Religion der anderen?

Nachfrage: Welche Formen der interreligiösen Begegnung sind Ihnen wichtig?

$\underline{\text { IRU }}$

- Besucht Ihr Kind/Besuchen Ihre Kinder den islamischen Religionsunterricht?

Wenn ja: Wie bewerten Sie den IRU?

○ nach Inhalt

- nach Methode

Nachfrage: Was soll der IRU für Ihr Kind/Ihre Kinder bringen?

Wenn nein: Wünschen Sie sich einen solchen Unterricht?

Nachfrage: Was soll der IRU für Ihr Kind/Ihre Kinder bringen?

- Was wünschen Sie sich insgesamt für Ihr Kind/Ihre Kinder?

- Was ist Ihrer Meinung nach verbesserungswürdig?

5. Peers

(Freunde, Kontakte zu Andersgläubigen)

- Welche Freundin/Freunde hat Ihr Kind/haben Ihre Kinder?

- Haben sie (die Freunde) einen Einfluss auf die religiöse Entwicklung Ihres Kindes/Ihrer Kinder?

Nachfrage: Hat Ihr Kind/haben Ihre Kinder auch nichtmuslimische Freunde? Unterhalten diese (die Kinder) sich gegenseitig über ihre Religionen? 


\section{Nachbarschaftsbeziehungen}

- Welchen Kontakt pflegen Sie zu Ihren Nachbarn?

- Gibt es unter ihnen (den Nachbarn) auch Nichtmuslime, zu denen Sie Kontakt pflegen?

- Tauschen Sie sich über Ihre Religion mit den anderen (den Nachbarn) aus?

\section{Medien}

- Nutzt Ihr Kind/Nutzen Ihre Kinder Medien im Bereich der Religion? (Bücher, Fernsehen, Radio, Internet, Telefon, Zeitschiften, E-Medien, PCProgramme, religiöse Sendungen)

- Welche Bedeutung hat es für die religiöse Erziehung? Nachfrage:

- Wie werden diese, d.h. auf welche Art und Weise, werden sie eingesetzt?

- Sprechen Sie (nach dem Einsatz der Medien) darüber?

- Welche Folgen hat das Bild über den Islam in den Medien oder die religiöse Erziehung auf Sie und Ihr Kind/Ihre Kinder?

\section{Gesellschaft}

Islam in der Diasporasituation

- Was glauben Sie, wie Deutsche zum Islam stehen oder über den Islam denken?

- Wie können Sie Ihre Religion in Deutschland insgesamt ausleben?

Nachfrage:

○ Wie ist es für Ihre Kinder?

- Welche Vorteile hat es für Sie, Ihre Kinder in Deutschland religiös zu erziehen?

- Und welche Nachteile gibt es?

- Was soll religiöse Erziehung in dieser Gesellschaft bewirken?

\section{Ergänzungen, fehlende Aspekte}

- Möchten Sie noch etwas ergänzen oder was wünschen Sie sich insgesamt?

\section{Rahmendaten}

- Daten zu den Kindern, Alter, Familienstand, Bildungsstand: Ausbildung/Beruf/Qualifikation, Staatsangehörigkeit/Migrationshinternd, gewünschter Deckname 


\section{ANHANG 2:}

\section{Die UntersuchungsgrupPe NACH TYPENZUORDNUNG/ ANGABEN ÜBER DIE KINDER DER INTERVIEWTEN}

\begin{tabular}{|c|c|c|}
\hline Typen & Namen* & \begin{tabular}{|l} 
Kinder** \\
(Geschlecht, Alter, besuchte Schulform zum Interviewzeitpunkt)
\end{tabular} \\
\hline Idealisten & $\begin{array}{l}\text { Ethem } \\
\text { Nermin } \\
\text { Lale } \\
\text { Dilek } \\
\text { Nisa }\end{array}$ & $\begin{array}{l}\text { W: } 11 \text { J. (Gym.)/M: } 9 \text { J. (G) } \\
\text { M: } 15 \text { J. (Gym.)/M: } 12 \text { J. (Gym.)/M: } 11 \text { J. (Gym.)/M: } 9 \text { J. (G)/W: } 6 \text { J. } \\
\text { M: } 21 \text { J. (Studium in TR)/M: } 17 \text { J. (Internat; Lise TR)/M: } 7 \text { J. (G) in D } \\
\text { W: } 17 \text { J. (Gym.)/W: } 10 \text { J. (G) } \\
\text { M: } 18 \text { J./M: } 15 \text { J.; beide (Gym.)/W: } 3 \text { Mon. }\end{array}$ \\
\hline Ritualisten & $\begin{array}{l}\text { Mecelle } \\
\text { Rabia } \\
\text { Selma } \\
\text { Ali }\end{array}$ & $\begin{array}{l}\text { M: } 9 \text { J. (kath. G)/W: } 9 \text { J. (kath.G) } \\
\text { M: } 12 \text { J. (Gym.)/W: } 10 \text { J. (Gesamtschule) } \\
\text { M: } 11 \text { J. (Gym.)/M: } 9 \text { J. (kath. G)/W: } 5 \text { J./W: } 5 \text { Mon. } \\
\text { M: ?? (G) }\end{array}$ \\
\hline $\begin{array}{l}\text { Identitäts- } \\
\text { sucher }\end{array}$ & $\begin{array}{l}\text { Hülya } \\
\text { Lema } \\
\end{array}$ & $\begin{array}{l}\text { W: } 5 \text { J./M: } 3 \text { J. } \\
\text { W: } 6 \text { Mon. }\end{array}$ \\
\hline Ethiker & $\begin{array}{l}\text { Belkis } \\
\text { Melek } \\
\text { Feride } \\
\text { Birol } \\
\text { Adem }\end{array}$ & $\begin{array}{l}\text { W: } 7 \text { J. (ev. G)/W: } 2 \text { J. } \\
\text { W: } 12 \text { J. (Gym. Dialog e. V.)/M: } 6 \text { J. (kath.G) } \\
\text { M: } 9 \text { J. (G)/W: } 3 \text { J. } \\
\text { W: } 12 \text { (Gym.)/M: 1, } 5 \text { J. } \\
\text { M: } 20 \text { J. (WiGym.)/W: } 19 \text { J. (Gesamtschule) }\end{array}$ \\
\hline
\end{tabular}

*Die Namen sind geändert. **ABKÜRZUNGEN: $\mathrm{W}=$ steht für ein weibliches und $\mathrm{M}$ $=$ für ein männliches Kind. J. $=$ Jahre $\rightarrow$ bezeichnet das Alter. Die in den Klammern $=$ (...) angegebenen Angaben beziehen sich auf die besuchte Schulform: $\mathrm{G}=$ Grundschule (kath. od. ev. bezieht sich hier auf die Konfession der Schule); Gym. = Gymnasium; wenn keine Angabe gemacht worden sind, besuchen die Kinder eine Kindertagesstätte. 


\section{Anhang 3: Tabelle (1) Religiöse Erziehungstypen} UND dIE EINFLÜSSE AUf DIE RELIGIÖSE SOZIALISATION

\begin{tabular}{|c|c|c|c|}
\hline 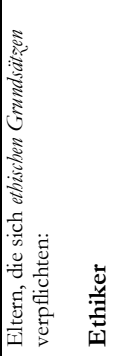 & 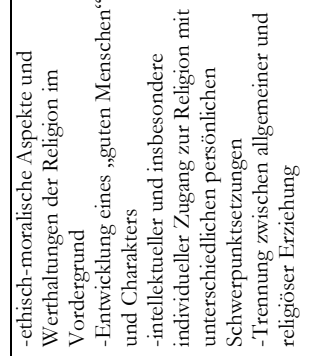 & 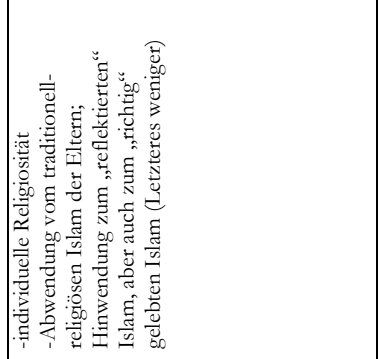 & 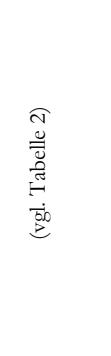 \\
\hline 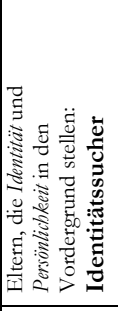 & 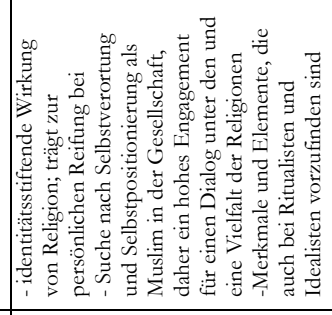 & 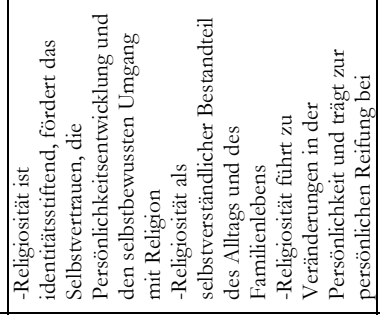 & 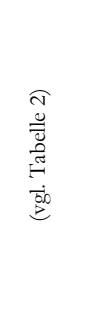 \\
\hline 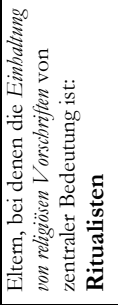 & 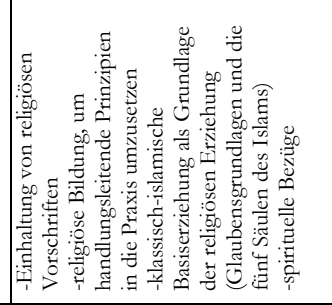 & 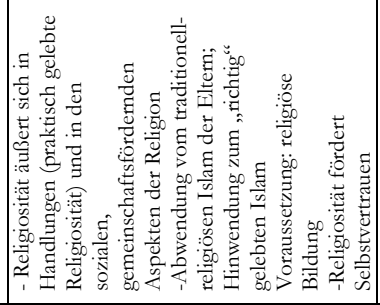 & 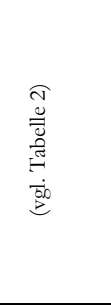 \\
\hline 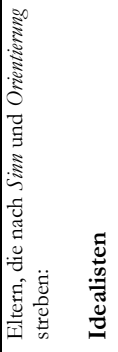 & 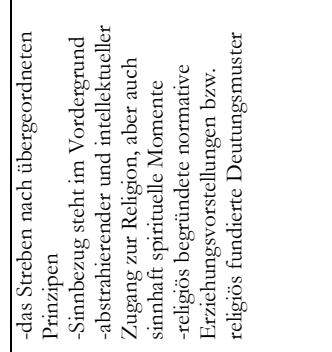 & 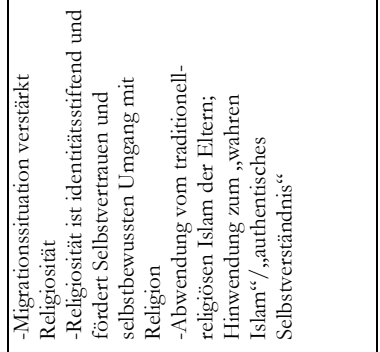 & 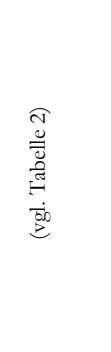 \\
\hline 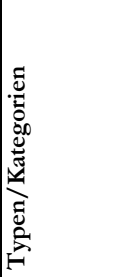 & 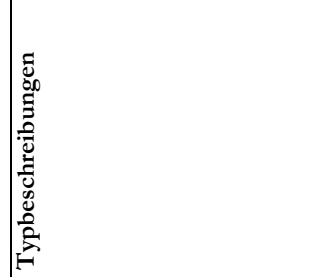 & 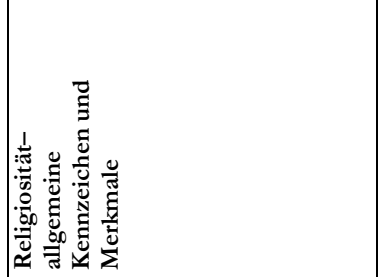 & 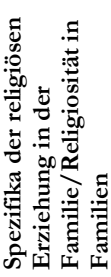 \\
\hline
\end{tabular}




\begin{tabular}{|c|c|c|c|c|}
\hline 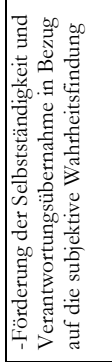 & 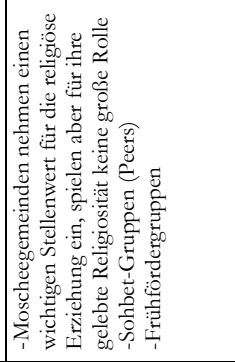 & 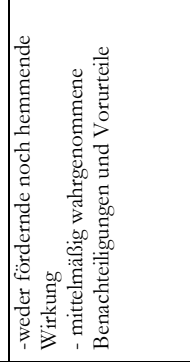 & 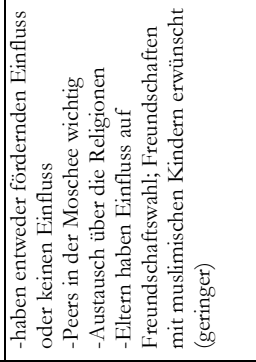 & 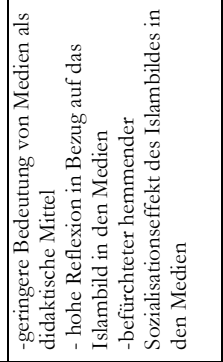 \\
\hline 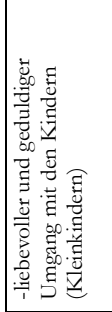 & 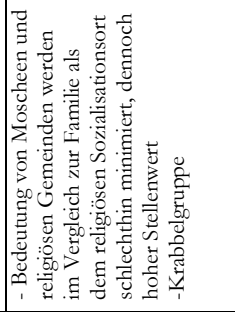 & 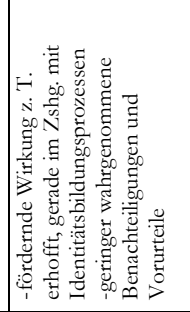 & 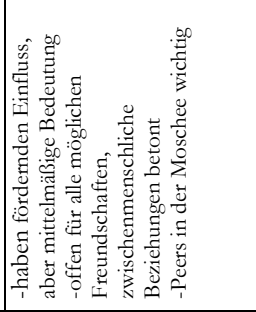 & 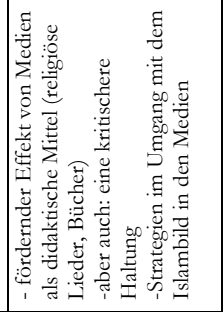 \\
\hline 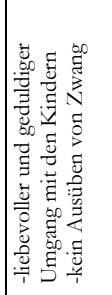 & 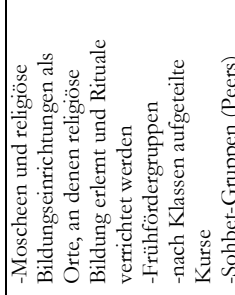 & 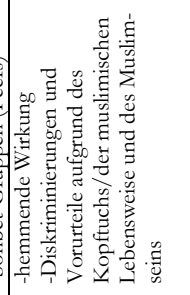 & 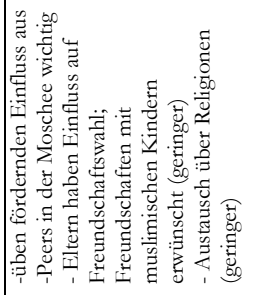 & 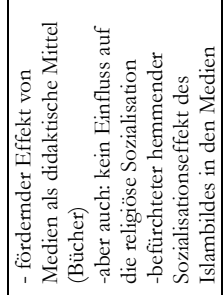 \\
\hline 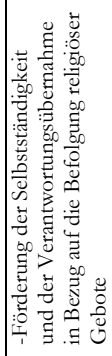 & 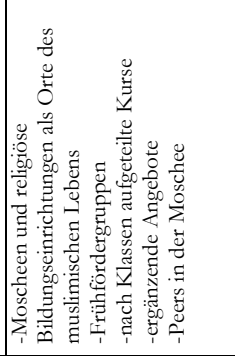 & 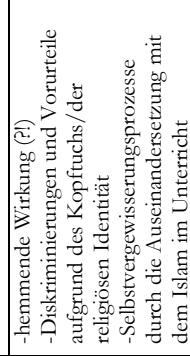 & 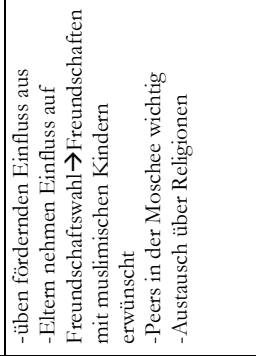 & 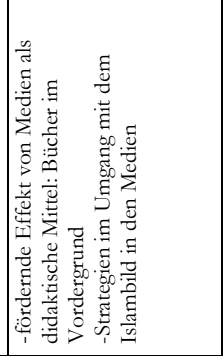 \\
\hline 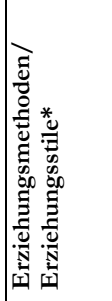 & 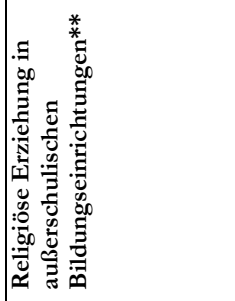 & 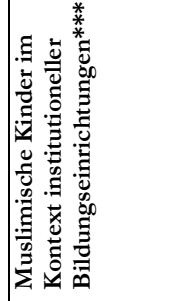 & ڤّ & \\
\hline
\end{tabular}




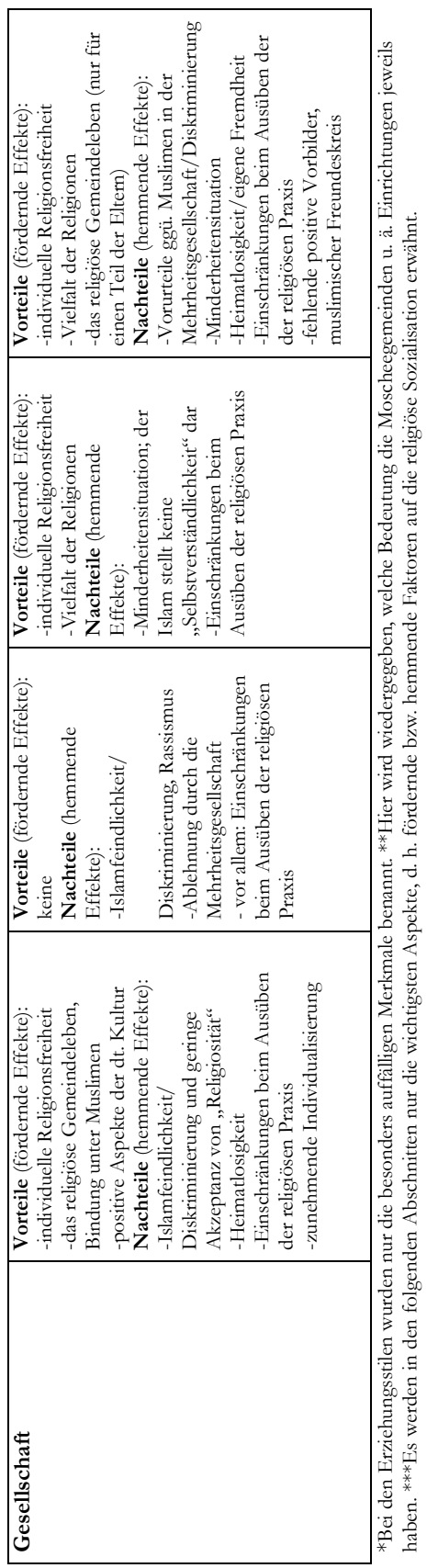


Tabelle (2) Spezifika der religiösen Erziehung IN DER FAMILIE/AUSPRÄGUNGEN DER ReLIGIOSITÄT IN DER FAMILIE NACH RELIGIÖSEN ERZIEHUNGSTYPEN

\begin{tabular}{|c|c|c|c|c|}
\hline & 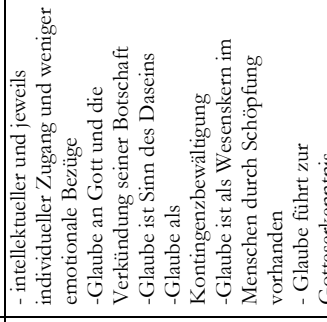 & 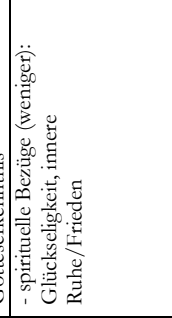 & 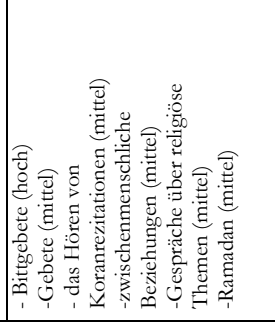 & 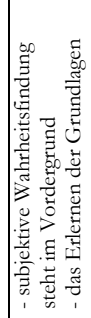 \\
\hline D. & 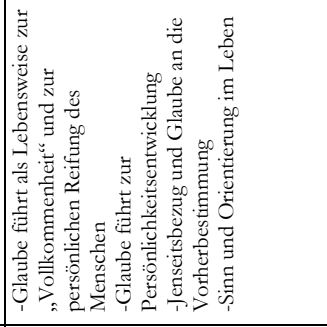 & 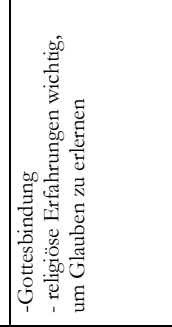 & 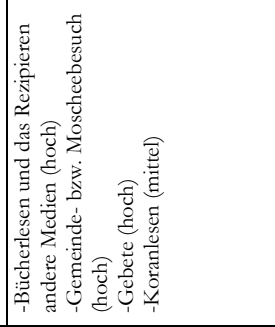 & 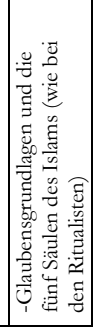 \\
\hline & 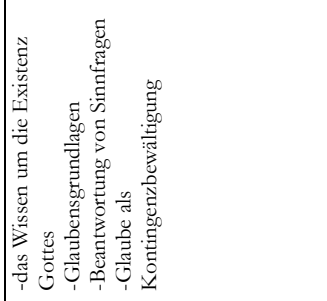 & 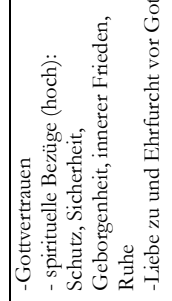 & 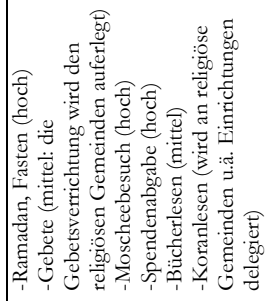 & 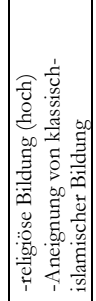 \\
\hline & 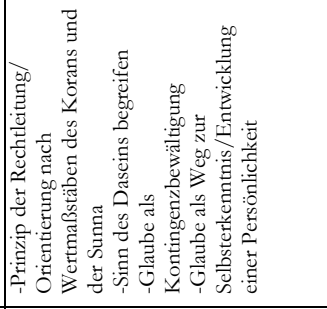 & 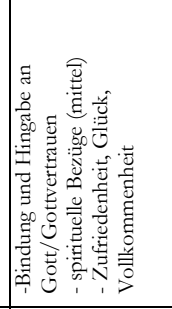 & 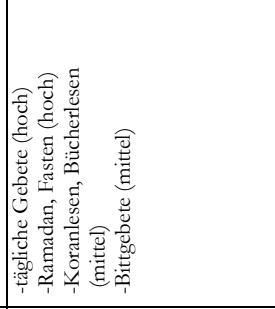 & 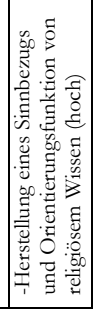 \\
\hline 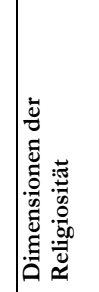 & 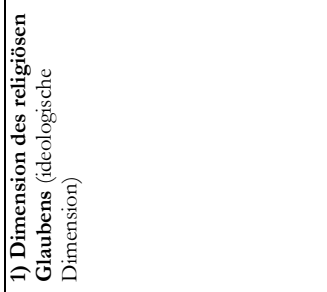 & 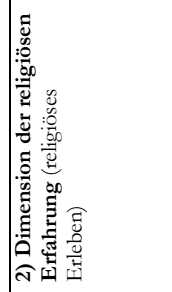 & 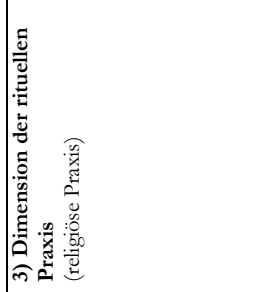 & 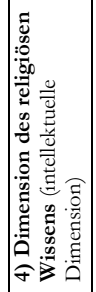 \\
\hline
\end{tabular}




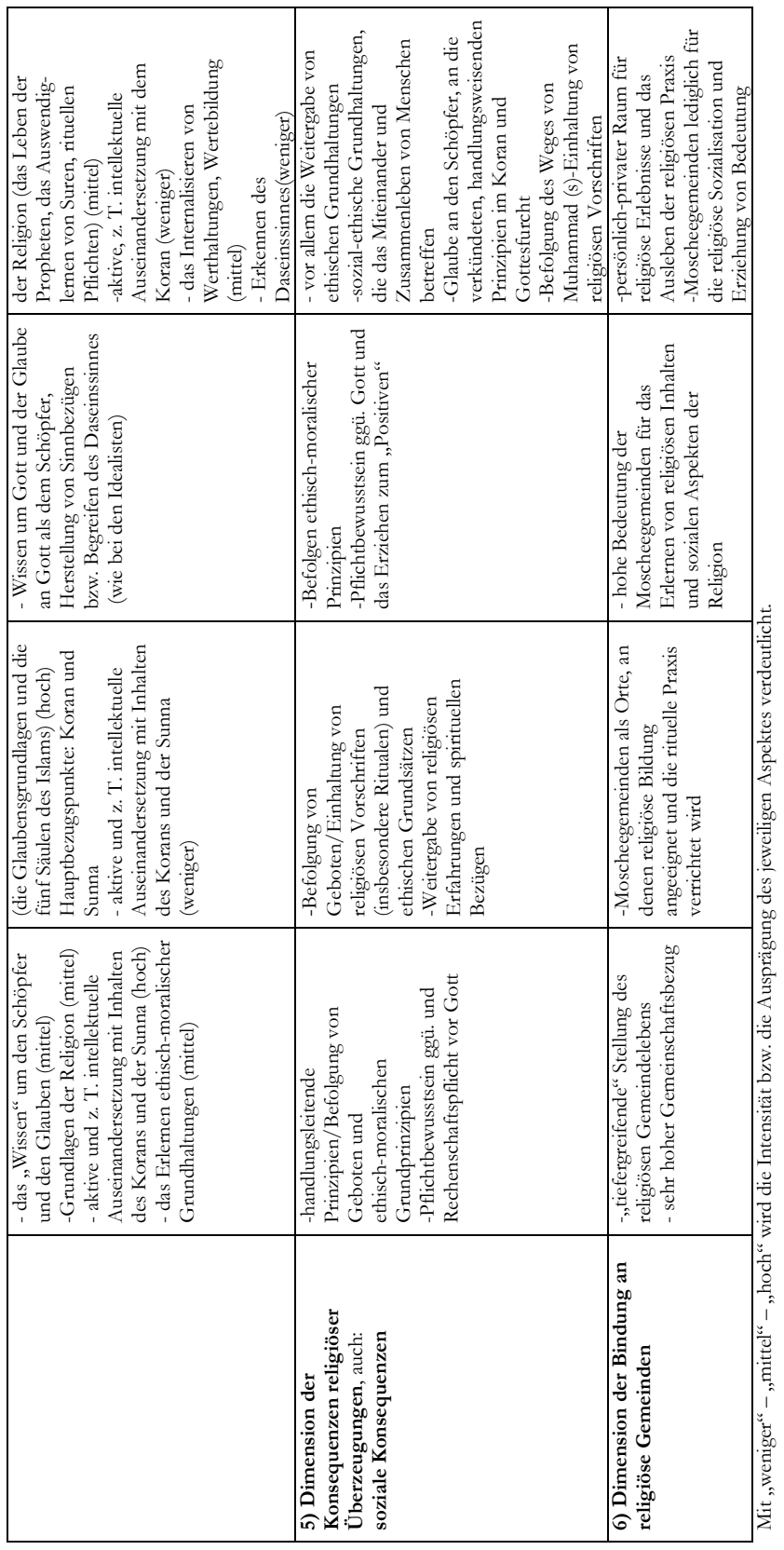




\section{Islamwissenschaft}

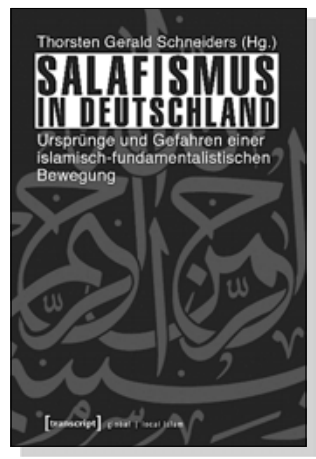

Thorsten Gerald Schneiders (Hg.)

Salafismus in Deutschland

Ursprünge und Gefahren

einer islamisch-fundamentalistischen Bewegung

2014, 464 S., kart., 27,99 $€(\mathrm{DE})$,

ISBN 978-3-8376-2711-4

E-Book: $24,99 €(\mathrm{DE})$, ISBN 978-3-8394-2711-8

EPUB: $24,99 €$ (DE), ISBN 978-3-8394-2711-8

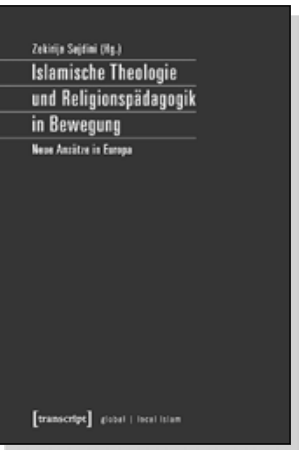

Zekirija Sejdini (Hg.)

Islamische Theologie und Religionspädagogik in Bewegung

Neue Ansätze in Europa

September 2016, 182 S., kart., 24,99 $€(D E)$,

ISBN 978-3-8376-3395-5

E-Book: $23,99 €(\mathrm{DE})$, ISBN 978-3-8394-3395-9

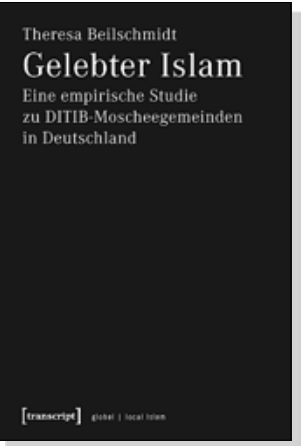

Theresa Beilschmidt

Gelebter Islam

Eine empirische Studie

zu DITIB-Moscheegemeinden in Deutschland

2015, 270 S., kart., 34,99 $€(\mathrm{DE})$,

ISBN 978-3-8376-3288-0

E-Book: $34,99 €(\mathrm{DE})$, ISBN 978-3-8394-3288-4 


\section{Islamwissenschaft}

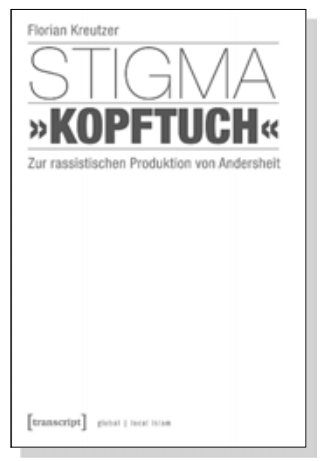

Florian Kreutzer

Stigma »Kopftuch $\ll$

Zur rassistischen Produktion von Andersheit (unter Mitarbeit von Sümeyye Demir)

2015, 236 S., kart., 29,99 $€(\mathrm{DE})$,

ISBN 978-3-8376-3094-7

E-Book: 26,99 € (DE), ISBN 978-3-8394-3094-1

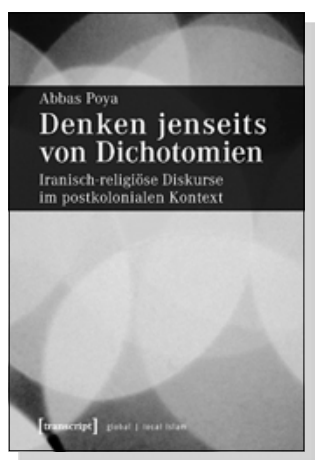

Abbas Poya

Denken jenseits von Dichotomien

Iranisch-religiöse Diskurse

im postkolonialen Kontext

2014, 270 S., kart., 29,99€ (DE),

ISBN 978-3-8376-2590-5

E-Book: $26,99 €$ (DE), ISBN 978-3-8394-2590-9

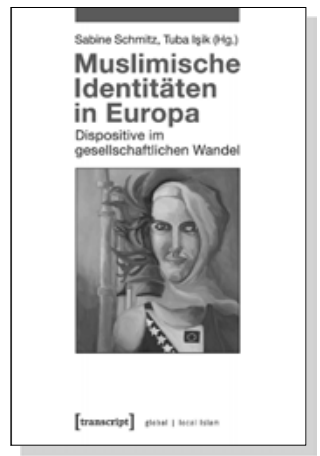

Sabine Schmitz, Tuba Isik (Hg.) Muslimische Identitäten in Europa

Dispositive im gesellschaftlichen Wandel

2015, 430 S., kart., 39,99€ (DE),

ISBN 978-3-8376-2561-5

E-Book: 39,99€ (DE), ISBN 978-3-8394-2561-9

Leseproben, weitere Informationen und Bestellmöglichkeiten finden Sie unter www.transcript-verlag.de 
